

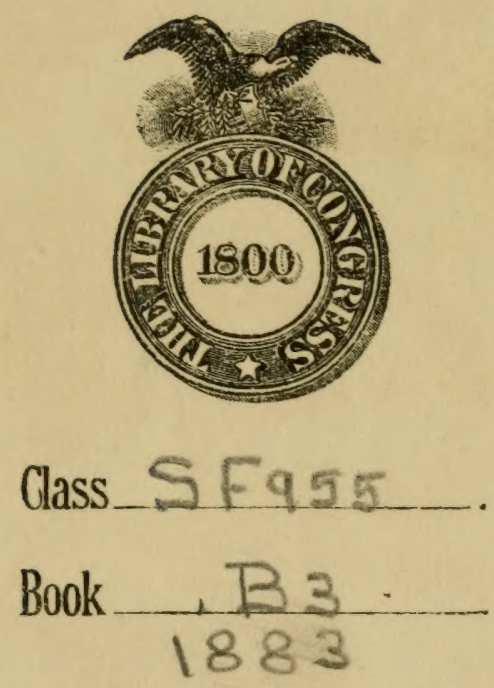

COPYRICHT DEPOSIT 



$$
2 \quad \frac{4071}{5879}
$$




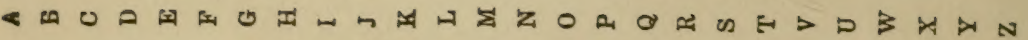

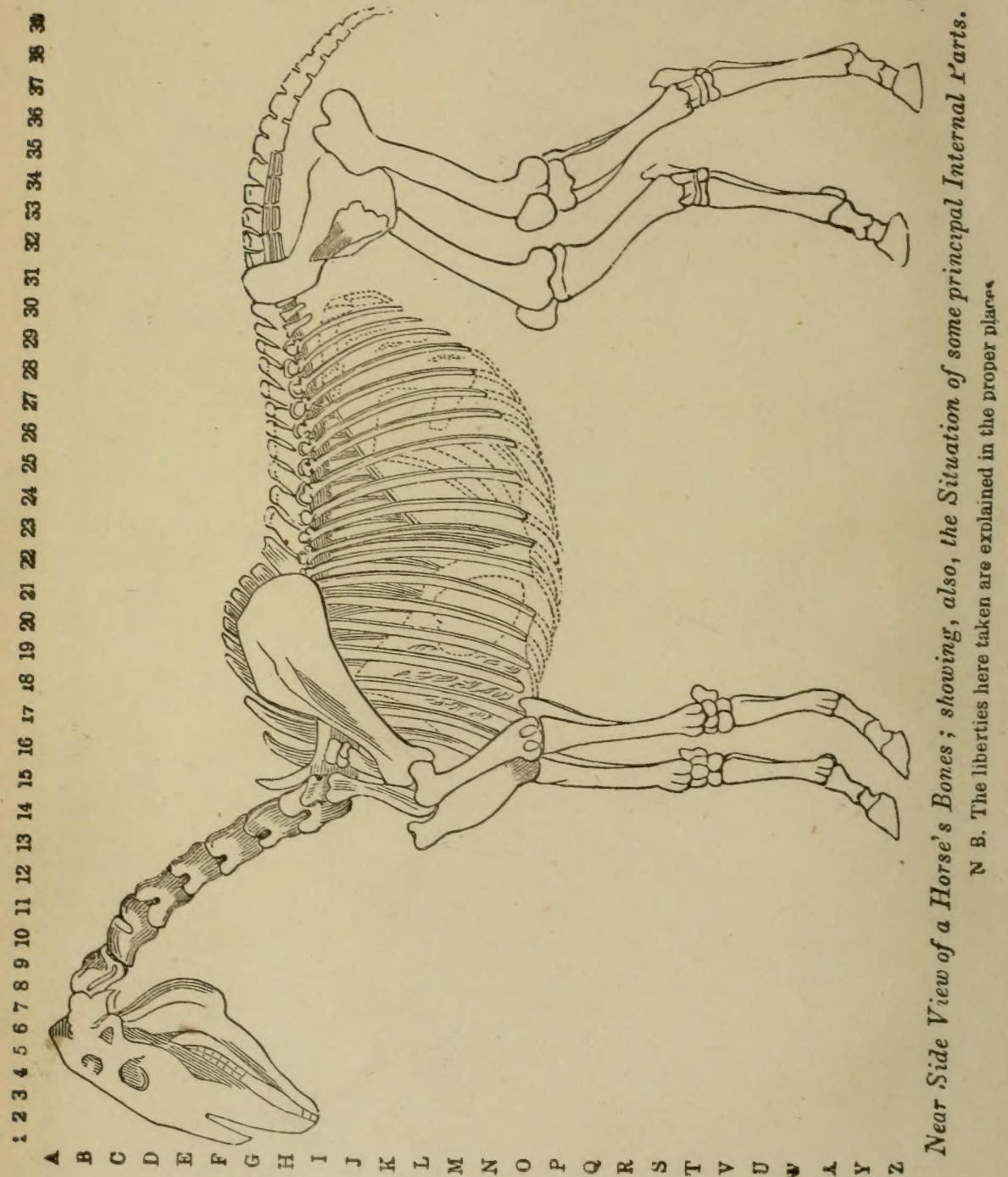


Hinds' Farriery and Stud Book-Nens Edition.

\section{F A R R I E R Y,}

TAUGHT ON A NEW AND EASY PLAN :

BEING A TREATISE ON THE

\section{DISEASES AND ACCIDENTS OF THE HORSE: WITH}

INSTRUCTIONS TO THE SHOEING-SMITH, FARRIER, AND GROOM.

PRECEDED BX

A POPULAR DESCRIP'TION OF TIIE ANIMAL FUNCTIONS IN HEALTH, AND HOW THESE ARE TO BE RESTORED WHEN DISORDERED.

$$
\text { BY JOHN } \text { JINTERINARY SURGEON. }
$$

WITH CONSIDERABLE ADDITIONS AND IMIPROVEMENTS, PAR= TICULARLY ADAPTED TO THIS COUNTRY.

BY THOMAS M. SMITH,

Veterinary Surgeon, and Member of the Londón Veterinary Medical Society.

\section{WITH A SUPPLEMENT:}

\section{COMPRISING}

AN ESSAY ON DOMESTIC ANIMALS, ESPECIALLY THE HORSE,

WITH REMARKS ON TREATMENT AND BREEDING;

TOGETHER WITH

TROTTING AND RAOING TABLES,

SHOWING

THE BEST TIME ON RECORD, AT ONE, TWO, THREE, AND FOUR MILE HEATS :

PEDIGREES OF WINNING HORSES, SINCE 1839; AND OF THE

MOST CELEBRATED STALLIONS AND MARES;

WITH

USEFUL CALVING AND LAMBING TABIES, \&c. \&c.

BY J. S. SKINNER,

Blitor now of the Farmers' Library, New York; Founder of the American Farmer, in 1818 and of the Turf Register and Sporting Magazine, in 1829: being the first Agricul-ONG/P

tural and the first Sporting Periodicals established in the United States.

PHILA DELPHIA:

E. CLAXTON \& COMPANY, WASHINGT

No. 930 Market Street.

1883 , 


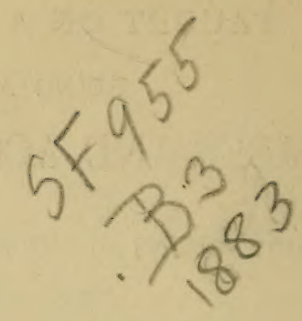

Entered according to Act of Congress, in the year 1883, by E. CLAXTON \& CO.,

In the Office of the Librarian of Congress, at Washington. 


\section{PREF A CE.}

Whatever person would consult these pages with profit s.sould previously read the first book with care; for in it he will find laid down the principles upon which all the subsequent details are founded, how the process of nature is carried on in health, and the cure is to be effected in every species of derangement. Indeed, he should stady it hard, if he would become proficient in "the Art of Farriery," and not rely implicitly upon other people's prescriptions for the cure of any alleged disorder, which have been composed for the most part without any such preparation.

From this neglect, also, symptoms of one disorder are contounded with those of another, when the proposed remedies can not possibly effect the cure. If he be imbued with the proper thirst after knowledge, be his station in life about the horse what it may, he had best to comply with the advice strenuously urged at the very outset, to examine the internal parts of dead horses, as often as opportunity preserrs itself, which, in the neighbourhood of large towns and hunts is frequent enough. For this is the manner in which I was myself mainly instructed; as well as by noting down wnatever then appears worthy of observation, connected with the previous disease of the deceased subject.

Such was my manner of proceeding for several years. And next about the present volume, how I came to write it, and what were my views in the manner of executing the task that was rather imposed upon me by the booksellers than sought after by me; and which was, in effect, occasioned by the nature and quantity of veterinary facts and observations I had a long time been in the habit of heaping together. But $\mathrm{I}$ had already been an author nearly a quarter of a century, having partly translated the manual of La 
Fosse, at the request of another bookseller, Mr. Badcock, of Paternoster-row. I claim no credit for that performance, and have already stated my present opinion of its degree of usefulness, at pages 133 and 135 . Proceeding with my " literary history," I may here add, that a few communications in the (old) Sporting Magazines, * to the Monthly Magazine, $†$ to the Weekly Dispatch newspaper, and other such publications, on topics connected with animal medicine, preceded the essays on the structure of the horse, which comprise the first book of this volume, and found place in a newer and much more brilliant publication. An accumulation of materials for these pages lay by me, with a satent hope of publication, when the mammon of a "ten pound prize," for their insertion in the Annals of Sporting, and some cheering commendations that attended the appearance of those essays, from time to time, induced me to finish the design of a complete pocket manual for owners, grooms and aspirants after the knowledge of horse-medicine, of every degree.

Like all other practitioners of the old school, or rather no school, my late father had long amassed together and preserved, in an immense and shapeless volume, entitled his "Receipts," all the alleged remedies recommended as eligible and found good in every variety of case: I believe he may have tried the efficacy of each, though I am now tolerably well convinced that some must have failed of com. plete success. Yet was the manuscript preserved like a family treasure; and destined to fill my pockets at some distant day, its contents were secluded from vulgar eyes, though it contained nothing but prescriptions. As usual with all similar accumulations, the proper remedies were therein stated, without a word as to symptoms or those anomalous cases that frequently baffle the utmost skill, for the practice of mediciue in any of its departments is but an imperfect science, even when we can ascertain the precise ailment under which the patient labours. This necessary preliminary is not always possible in veterinary practice we are more frequently baffled than assisted in our inquiries. Notwithstanding all this, my revered parent sus-

*For November and December, 1820, on "Fever in the foot," in refutatron of Mr. Cherry, in which was described the successful treatment of a nap trelonging to Mr. Bowley of Covent Garden.

t January, 1821, \&c. 
tained a high character for successful practice; his close observation of the symptoms and attention to the operation of his physic, supplying the want of a "regular education," which no one farrier could at that time boast of: indeed, few of them could even copy their own receipts, which they preferred to carry in their memory. At a very early period 1 endeavoured to repair this apparent defect by study; with what success the reader may judge, and I will endeavour in the next pages to make him comprehend how my task has been executed.

The reputation of our name induced the bookseller just named to ask my father's opinion and mine (among others), of a certain manuscript he held in his hand, which upon inspection turned out to be a treatise on the rationale of horsemedicine, with very plain directions for ascertaining the true symptoms of dieases before attempting to apply any remedy, however estimable. As the expositions of the writer agreed mainly with our own ideas, it was impossible to withhold approbation. Finally, Mr. Badcock also consulted with W. S. Rickword, of Moor-lane, and other veterinary surgeons of the college, and resolved upon the spirited publication of his new purchase, notwithstariding he had received the uncheering disapproval of Bracy Clark, of Smithfield, who gave for answer that "no one could learn the treatment of horses' diseases from printed books." Yet has Bracy Clark since then printed many books. The great success of the publication alluded to, which was James White's "Compendium of the Veterinary Art," justified our opinions of its merits, and gratified my vanity at the early share I took in its promulgation, and the revision of many passages with a view to simplifying the terms (in particular); in which commendable quality, by the way, MIr. White is not deficient, though, in other respects, a lapse or two which have since fallen out, come un ter notice in the course of the following pages (viz. pp. 39, 83,111 , and 154). No man can be perfect; how few among us know every thing that pertains to themselves.

Even at this moment preceding the birth of my volume, I am not certain but I may be found similarly tripping - to have expressed myself obscurely, when I fancied my lan guage most cornpletely understandable by the meanest capacity; and I doubt that my familiar style may frequently ap. merir vulgar to more polished eyes and ears than mus. But I 
take credit for having sedulously avoided the use of technical phrases, terms of science and learned dissertation, as wels as the crime of over-refinement with which I have rebuked two cotemporaries, whose laughable sublimations are idealIzed at page $\mathrm{i} 66$.

Candour ana ability for the task are not always found combined with willingness, even among our best friends, to amend certain slips of the pen, or to curtail such exuberances as the more animated writers are liable to fall into; and I am free to aver, that the friendly assistance I have obtained in this respect, the nature of which may be inferred from the note at bottom of page 50 , has not always se conded my plain meaning, nor adequately fulfilled my wish es, though I am grateful for these and every act of kindness After all my care, repetitions have crept in, and owing to the length of time occupied in the composition, or rather the mantier in which the various particles of information were collected together, and digested into form, great variety of style may be discovered, though unity of purpose, and the desire to instruct, pervades every page. The arrangement is at least obvious; the principles being taught in the first book, the details of practice follow in natural order in the second and third books, and seem to arise ont of the preceding " observations on the animal system of the horse, as regards the origin of constitutional disorders." 'The references from the latter chapters to the former, operate as exercises with those students who may have neglected to acquire and retain sufficient intimacy with the principles laid down in the pages so referred to.

The diseases of brute animals are few and simple, and easily cured when the symptoms can be distinctly traced up to their causes; for the remedy then consists in little more than putting the animal upon a direct contrary course to that which brought on the disorder (though not too rudely), and health follows. For example, heat, inflammation, fever, is the most general cause of constitutional derangement in the horse: in a state of nature, he seeks out and employs the remedy himself; when domesticated and pampered, or at least denied the use of green food, we judiciously set ahout reducing the heat by cooling medicines and factitious regimen, and the fever subsides. A gain, hard work occa sions lameness, rest restores the feet to their wonted state 
in incipient attacks, topical applications effect the remainder in bad cases.

For the same reasons few medicines are necessary in ve. terinary practice, but certain modifications of these add to their efficacy in particular cases; though the school in which I was first initiated, as well as the modern writers, White, and the Lawrences, quite overwhelm their readers with the quantity and apparent contrariety of their prescriptions, that frequently possess no essential variation from others that may be applicable to a whole series of disorders.

Under such circumstances, I have been extremely chary of puzzling the reader by merely altering the vehicle when the active material of the prescription had been already compounded for a similar disorder; therefore I have avoided repetition of such (mostly purgatives) by referring the reader to the page where these may be found. Notivithstanding the apparent difficulty of this mode, yet has it certain advantages that outiveigh the trouble, and compensate for the moments thus expended. During my noviciate, and long intercourse with persons employed about the horse, in almost every capacity, I noticed that all those who consulted the books respecting any actual disorder, did little more than turn to the prescription which was recommended in their particular case, and it was made up and given to the animal without once more reading over and comparing "the symptoms," and notwithstanding they already had the same medicine upon the shelf. By this blind manner of proceeding, they did but adhere more closely to the old system of their "book of receipts," to the entire neglect of the anomalous symptoms, and risked the mistaking of one disease for another, in many cases. To compel the inquirer to study his case before he applies the remedy, 1 at one time thought of adopting the method of La Fosse, and others, who have thrown their prescriptions all together, and referred to each numerically; but, after due consideration, I adopted the middle course, and simply avoided repetition in this respect, as that which best suited with my views of instruction. In some cases, the remedy is mentioned in general terms only; for example, at page 170, 1 said, "blistering ointment may be applied," \&c. The read er will of course, in this and all similar cases, consult the Index; and under "Blistering," he will find himself refor red to page 76 . 
Throughout the volume, though I naturally evaded all controversy, yet in a few instances it seemed necessary to advert to certain existing errors and authorized mistakes; to disabuse the public mind, to negative the mischiefs these were calculated to spread of themselves, and to assure the reader that I was not wholly unmindful of the dissonance of opinion betwixt the authors mentioned and myself. To the "Annals of Sporting," a monthly publication much devoted to the natural history of animals, I have frequently referred, and often quoted; because in the course of its earlier volumes many desirable facts, some good and useful hints, and valuable suggestions, appeared from time to time; some new opinions and statements were started, and met with repulse, or were more securely placed upon their proper bases. * In these respects a favourite project, first communicated to me by Mr. Badcock in 1802, and partially acted upon, $\uparrow$ was therein realized, viz. of collecting together the scattered opinions, remarkable cases, and fugitive suggestions that should occur to various isolated practitioners throughout the kingdom, in the same manner as had long effected so much progressive good for human medicine. He had engaged me and Mr. Rickword to assist him in this undertaking, and wrote to Mr. White and others for their contributions; but it failed at that period, like many other projects of a similar nature; and I observe that the lastnamed gentleman, in every successive edition of his "Compendium," constantly inserts his correspondents' letters on various topics at length, though it was clear to me that dis-

* In that useful publication ordinary passing events are recorded monthly, under the head of "Horse Intelligence," with brief comments, accompanied at intervals with exhortations to veterinarians to contribute their experiences to the same stock. In one instance, a vivid appeal, in the number for September, 1824, page 191, produced several valuable communications concerning hydrophobia, that are embodied in the present work, and acknowledged at page 162-3. The intelligent papers of Mr. Perry, of Swaftham, and others, also owe their origin to the same stimulus to publicity and the desire to establish a name for ingenuity in their profession to the writers.

+1 took occasion to advert to that project in my preface to La Fosse's Pockst Manual, and to lament that "the want of a more liberal practice is felt as an insuperable har to improvement in the art of farriery, which would be best served by communications of the discoveries made, and the mode of treatment most successfully followed by various practitioners. This it is which of late years has done, and is still doing, so much for other branches of medicine, and which, for the sake of humanity, it is devoutly to be wished could be extended io this branch also." Page vi. 
cussions like these rather belong to periodical publications, such as the "Annals" professes to be (where they admit of refutation), than to a "Compendium." For my part, I was early induced to enter into the spirit of those periodical investigations, and the inquiries set on foot in that work, and occasionally to furnish the materials for an article, or the argument in point for a controverted doctrine, or disputed "improvement." An offer of two premiums of ten and five pounds for the best and second best of an " Essay on the Structure of the Horse," had first induced me to labour in the pages of the Annals. The award of the highest premium to my paper* encouraged me to hearken to proposals for its enlargement, and the present volume is the result. $\dagger$

The volume has been a long time at press, and in October last was fully announced by advertisement. The author could not, therefore, satisfactorily account why his title was adopted by another in the month of April of the present year

* Divided into magazire-like portions, and inserted as convenience offered in many successive numbers of the Annals of Sporting, for the years 1822, $3,4,5$.

+ The second premium was followed by the like result: the writer of ith Mr. Percivall, (I presume) having since then published his volume on the Principles of the Veterinary Art." The utility of such periodical works that devote their pages to the promotion of useful arts, is thus manifest in the fact that to those premiums the public owe two volumes at least on animal unedicine.

London, July, 1827. 



\section{INTRODUCTION.}

As the value of the Horse is daily becoming more mani $\mathrm{fes}^{\mathrm{t}}$, it is presumed that any attempt to reduce into a sys. tem, the art of preserving it in health and of removing diseases will not be unacceptable.

It is certain that at no period in the history of this country, has the horse stood so high in general estimation, or by the display of his various powers, rendered himself an object more worthy of our consideration.

As greater attention is now paid to the breeding of horses :or the different purposes of the turf, the road, \&c.; so should our anxiety for their preservation increase.

The object of this publication, is to render as plain and familiar as possible, a subject that has for a length of tıme remained in obscurity; the want of a work possessing practical facts and illustrations, has long been severely felt and acknowledged.

Under this conviction I am induced to lend my aid, in bringing forth the present volume, with such alteration s and additions as an extensive practice in this eity may warrant.

To remove long standing prejudices, I am aware is a difficult task; still l venture to hope, that a careful perusal of these pages will excite in some degree, the feelings of humanity, in respect to the many sufferings to which the generous animal is frequently liable from unmerited crueliy and injudicious treatment, and that mankind may be inrluced to view his sufferings with an eye of sympathy and tenderness, and have recourse to a rational mode of practice, when accident or disease may require it.

I am not aware of any publication having issued from the 2 
press in this country, in which the Veterinary Science, or Art of Farriery, has been laid down in such a manner as to be clearly understood; the present work is so familiar in its composition, as to render it at once interesting and intelligible to every one who may think proper to peruse it.

To such persons who are removed at a distance from those. places where the assistance of a farrier can be had, in cases of emergency this work must prove highly useful, as such rules for the discovery of disease, and such a plan of treatment is recommended, as, if judiciously followed, will rescue from the danger of blind experiment, the noblest and most valuable quadruped in creation.

\section{THUMAS MOURE SMITH.}

Philadelphia February 11830.

VETERINARY SURGEON 


\section{CONTENTS.}

\section{-}

\section{BOOK I.}

The Origin and Seats of various Diseases in the Horse explained, with a viero to their Cure or Mitigation.

INTRODUCTION. The necessity and advantages of veterinary knowledge, and the means of acquiring it, as regards prevention and cure

Explanation and practical use of the skeleton - - . - -

Cinapter 1. External formation or structure of the hors, and the disorders originating therein - - - - - - - -

Chapter II. Concerning the horse's inside, of its conformation, the functions of the organs of life, and the diseases to which each is liable; together with outlines of the principles upon which the cure is to be effected - _ - - _ - - - - -

Chapter III. General observations on the animal system of the horse, with reference to the origin of cunstitutional diseases: recapitulation and further development of veterinary practice, upon the principles before laid down

\section{BOOK II.}

The Causes and Symptoms of various Bodily Diseascs incident to the Horse; with the most approved Remedics in every Case.

Chapter 1. Of internal diseases

CHapter II. Of external disorders-abscess and tumours - - I]

Cunpter IH. External disorders-purulent tumours, diseases of the glands

BOOK III.

(I) the Leg and Foot of the Horse; or, Shooing-smith's Guide.

CuApter I. Structure and physiology of the foot; mode of studying at advantageously 
Chapter 11. Disorders of the foot and leg - - . - . 170

Chapter IIl. Shueing - - - - - - - - 17\%:

Criapter iv. Diseases of the foot - - - - - 188

CHaPTER v. Of strains generally - - - + - - - 194

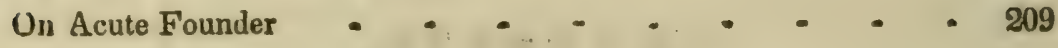

PLATES.

1. Skeleton of a horse

Frontispiece. 8 and 3. Anatomy of the fnot - . 169

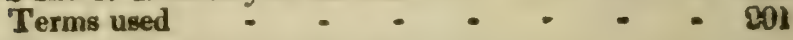




\section{FARRIERY}

TAUGHT

\section{ON AN IMPROVED PLAN}

\section{BOOK I.}

\section{MIE ORIGIN AND SEATS OF VARIOUS DISEASES IN THE HORSE EXPLAINED, WITII A VIEW TO THEIR CURE OR MITIGATION.}

\section{INTRODUCTIOX.- The necessity and advantages of veterinary knowledge, and the mearis of acquiring it, as regards prevention and,cure.}

Ar.thougn it can not be denied, that "tis better, in a humane point of view, to prevent diseases than to cure then ; "yet, looking at the fact as a veterina rian, without furgetting my feelings as a man, I do not hesitate to say, "this is a consummation we can not reasonably hope to arrive at, whilst the horse is comprlled to exert himself to the utmost of his power for our daily profit," whereby he acquires a constant disposition to create disorders. Nor would I be thought to maintain, that "preventives ought never to be employed:" the succeding fages fully disprove such a conclusion. I merely mean to inculcate, that, uncler existing circumstinces, they can not be resorted to generally : and this I say, notwithstanding it will be found I have here noted very many occasions, when rest, alteratives and regimen, might be often substituted for active medicines, more economically, (in my opinion,) both of rime and expense. The hour is not arrived, however, for me to insist too strenuously upon an entirely new mode of treatment of the horse in health and in disease, since that course would appear rather too theoretical for a Treatise designed to be wholly practical.

Those are the reasons which have induced me to keep in view the readiest way of enabling the sick animal to return to his work again, according to the long beaten track of my practice; whilst my main purpose is to show, by an examination of his powers and his parts (external and internal,) that a mode. rate mole of treatment, in sickness and in health, would be not only more humane hut more profitable, as preventive of many of those evils to which thousands of horses preniaturely fall victims every year. More conducive, also, to r profitable result to their labours would it be for the owners of horses, instead of studying how to "physic" their property, were they to put themselves in a condition, as near as may he, for rejecting, with some degree of certainty, not only such larses as are offered to them actually diseased, but such also as, by their awkward luilt or structure, and consequent ill-formation of the internal parts, can not fail to possess some inherent bad quality, and thereby a prone. turss to its curresponding affiction to the end of their days. This ought to 
constitute every horsernan's first step to horse knowledge, whether he undertake it as an owner or as a farrier, the latter most especially; of him I may justly add, that he can not be said to exercise his calling honestly as he ought, who sullenly neglects to learn those rudiments of art and practice that teach a knowledge of the animal economy and the functions of the horse in particular. I do not hesitate to insist upon the examination of the animal's internal parts, as constituting one main item of thuse rudiments; and I would not avoid giving this operation the proper name of dissection, but that I fear to alarm the general reader with an apparent difficulty where none exists in reality. How without that previous knowledge, durst he venture to pronounce what parti cular ailment, out of the numerous catalogue that pertain to the horse, his pa ient labours under? How can he ascertain the degree, or quantity and quality of the attack, so as to know when it may be increasing in malignity, or it: virulence is expended? Least of all can he succeed in the cure, when so much ancertainty hangs about his means of discriminating between one disorder and auther, - to say nothing of the usually attendant ignorance of the mode in which medicines operate upon those internal parts that lie concealed from his vicw, but upon one or the other of which they are, nevertheless, destined powerfully to act. If it be allowed, that no two horses are ever affected exactly alike w those disorders that depend upon the secretions, as I shall show at the end of this chapter, how is it possible that such neglectful men could ever reduce the symptoms of any disurder, without reducing, at the same moment, the power or functions of the part upon which their strange and ever-violent mix tures expend their force, and thus entail upon the animal a disposition to acquire some other disorder.

Every man who would make himself proficient in the knowledge of liseases should open his own dead horses, and as many more as he can obtain access to, and attentively examine the state of the stomach, the liver, the lungs, tho heart, kidneys, and bladder. If the animal be recently dead, this profitablo mquiry will be far from disagreeable, unless the cause of death has been of the putrid kind, spoken of in Book II. Chap. 1. as Typhous, but which rarely happens. In the pursuit of this necessary first step to veterinary knowledge, he will proceed in this manner. The horse being on its back, two legs on the same side are to be elevated by a cord passing round the fetlock of each, and fastened to a nail in the ceiling or elsewhere aloft. Then with a sharp knife, of the common shoemakers' kind, he will draw a straight cut all the way from the first rib or breast bone, at the intersection of $\mathrm{O}$ with 21 in the picture, to the sheath, or thereabouts. If the cut be not too deep, the skin will recede a little, and expose the membrane; cutting through this the intestines will protrude, and drive forth a thin expansive membranous sac, apparently unattach. ed, being designed for holding the guts, and preventing friction. This soon uursts, and the blind gut (or cacum), described at section 48, appears. He will slit open this pouch, and examine its contents before he quits the subject, [rrobably; but his first business is with the stomach, which is depicted in the annexed plate, as situated at the conjunction of $1 \mathrm{KL}$ with the figures $26-29$. Herein will be found the last drench that sent him out of life, or the last food, that gave hopes of a prolınged existence; and on its surface, vulgarly termed the coats of the stomach (when turned inside out), may be discovered the havou committed by the farrier's unskilfulness : according to the strength of the poions so administered, will the coats show the dilapidation, or at times a nole will have been perforated, that is the cause of instant death.

The young operator will keep in mind what is said of those parts at sectiuns 45,46 , \&c., if he do not turn to and read them over once more before he lakes up the knife. With the same precaution as to re-reading section 52 $\checkmark c_{\text {, he }}$ will proceed to examine the state and appearance of the liver and kit. 
neys. The description of these will be found at sections 52 and 53 respectively; and they are delineated as siluated in the yicture, the liver hetween the parallels of $\mathrm{J}-\mathrm{N}, 22-28$, and the kidneys at $\mathrm{H}, 29,30$. Returning forwards, the operator will find his way to the heart and lungs ohstructed by the midriff, (see plate at 22 to 28 , ascending slantwise from $\mathrm{L}$ to $\mathrm{H}$ ) that divides and keeps asunder these from the first-named parts, lest the guts and liver should ob. struct the action (functions) of the heart and lungs, and vice versa. Its ap. pearance has been described (sect. 35.) as resemhling a drum-head; and like it, if pricked with the knife, the cavity of the chest is instantly laid open-an immense vacuity, that proves to what a vast extent the lungs must fill at every inspiration of fresh air, to occupy so great a space, and further spread out the rils to the utmost extent of the intercostal muscle that holds them together. In the plate the lungs are depicted in a quiescent state, at $\mathrm{J}$ to $\mathrm{N}$, and 15 to 2.2; but when filled they occupy all the vacant space above, in addition to their lateral width. Hence, the importance of this viscus (as they call each of the vital parts ahove named), to which 1 have attached such high consideration in the sequel, will at once be seen and appreciated. See sections $31-36$.

Concerning the Heart, its structure and functions, - so much has heen said sin another place, and so minute is the description of each, that I shall add no more here, than refer to the sections, where the reader may find ample instructions for examining this main-spring of animal life. See sections 37 to 10. In the annexed picture, it is delineated as lying near the lungs [LMN, i9_-21], to the upper part wherenf it is attached, as described hercafter.

By pursuing this course of inquiry, the operator will discover what is, or - Ight to be, the healthful state and appearances of the main functions of the simal system, - he will perceive the auxiliaries and their uses, - he will have .nformed himself (it is hoped) of the treatment any horse has received previJusly to its death; and he may thus store up in his mind, or better still, upon paper, what drearl eflects may be produced by the drenches, cordials and diuretics that stimulate but to destroy the vitals of the animal. He will see and compare the animals that die in health (accidentally), or after a short illness, with those which die after protracted illuess; upon the healthy ones that are doomed, a few hours previously, he may try the experiment of some favoured farrier's celebrated mixture, and subsequently send him the stomach to prove its efficacy in "killing all disorders."

Happily, the cause of humanity may be served, and the interests of his owner promoted at the same time, by our (first) ascertaining the nature and amvunt of the horse's powers by his make, shape, or built; and, thereupon, demanding of him no more, in the way of scrvice, than is clearly proveathe to lie within his power, or putting him to those labours only to which his capabilities are best adapted. In the neglect of this plain rule lies the root of all error as regards preserving the health of horses. Some materials for making a tolerally good estimate as to this head of information, are arranged in the first chapter: the second being well pondered, and the facts and observations it contaius rightly stored up in the reader's mind, he will learn what functions belong to each prart of the animal in health; or, these being deranged or obstructed, he will know in how much the horse is affected : and the third chap ler being real with reference to both, I entertain the well founded hogre, that this course will enable the general reader to form tolerably accurate notions of the nature, origin, and tendency of the animal's internal and constitutional ciscases, upon which all the others depend, but which have hitherto received but litlle attention any where here, and, consequently, are but imperfectly known amongr us. Not only so, but the reader may, by these means, by study and close observition, enable himself to demonstrate nearly to a certainty, when s cure is hopeless; and further the cause of humanity. and the interests 
of its owner at the same time, by ordering the horse to be destroyed at once, rather than by fruitless delay, and at a heavy expense, prolonging the animal's sufterings to no worthy purpose.

I have not confined my researches to disease only: in the first chapter, the skoping-smith will find explained the principles upon which depend deformities of the hoof, and he may fashion his work accordingly; whilst the choice of a hurse mity be undertaken with some confilence, if the purchaser keejs in mind the practical advice and information here collected together from various sources, and added to my own observations, and long, extensive, and successful experience, in all matters of this nalure.

\section{Explanation and practical use of the Skeleton annexed.}

Tilv references that are maile to the annexed plate, and which will neces. sarily be found rather numerous in the chapter on conformation, are so made by imeans of letters and figures, corresponding with similar letters and figures nixm the plate. 'The letters direct the reader's eye across the picture, the figures from top w bottom; when he is referred both by letter, and figure, the flace of intersection is tlie point to which his attention vught to be directecu. Thus [C. 37.] which, by placing a flat ruler, or a piece of paper, across at "G." and ruming the finger downwards from the tigure " $3 \%$," would he found to intersect each other at the insertion or commencement of the horse's tail ; whilst [Y. 40.] would bring us to the hindermost pastern. Agaiu, [K. L. M. N. $1.1,15,16$.$] or [\overline{\mathrm{I}}-\mathrm{N} .14-16$.] directs the reader's attention to the shoulder-bone; at [M. 20.] is his heart, and at [H. 29.] his lidneys are placed.

'The reader will please to observe, that the Frontispiece is meant to be, less what is termed "a pretty picture" than a practically useful one, calculated to fircilitate his comprehension of what is sitid in this treatise about the living horse, his structure, and internal formation; of his capabilities, and all of the dismatse's arising from their misapplicatiun. To this end, a mere elevation of the skeleton was requisite; and, that this should be rendered more practically us:sful, it is diviled into squares, for more ready reference. The figure itself, is that of a rather long bodied loorse; the blade-bone having been lowered to show the continuity of the vertebrx, or backbone, hetween the shoulders, and the chow being bent forward for that purpose, so that the shoulder-hone is brougint to form its sharpest angle. 'This position of the limb, of cuurse, remlered the subject of the plate lower hefore than he would he were those homes more straight up and down than they are. See Section 8.

He will observe, too, that the situation only of some internal parts was required for the purpose of elucidation; thus, the heart seems unsuspended by its vessils, as its pericardium and part of the lunirs are removed; and it fol. luws, that whoever expected to find a delineation of everv viscus, perfect, has decrived himselt,-if any such there be. Respecting the poll, or bones of the head and neck, the reader will find some remarks in Section 16.

Further, the references my readers will meet with in the midst of the text are necessarily as brief as they are useful, and are made to the sections; or gart; into which the first two chanters are diviled after the manner of verses.

This mole of reference will be found highly serviceable in his inquiries by the attentive reader, who is unused to study things of this nature, hut who must som perecive the great pratical advantages to be derived from so inti mate an acquaintance with the smbject as this method of learning it wili for wast hin the means of acquiring. If, in the prosecution of his studies, he 
happen to forget what has been before said, lending to the same point of in. formation, or he be at a loss whereabout he should look to refresh his memory, these references supply him with the ready means of overcoming the difficulty. By adopting this method, 1 have likewise avoided the repetitions inseparable from a work of this nature, and have thus saved room.

\section{CHAPTER 1.}

\section{E.xternal formation or structure of the Horse, and the disorders originating therein.}

SECTION 1.-Scarcely any man who is in the habit of secing many horses perform their labour, and observing their capabilities of several kinds, but acquires, thereby, some insight of the properties conferred on the animal by such or such points of conformation. He can tell, at first sight, nearly from this habitude, "what a horse can do ;" but few men reduce their observations to writing, least of all to principles, upon which we may afterwards reason, or draw conclusions with any degree of certainty, as to what duties a horse can sot perform properly, when wanting those points of excellence, and which duties ought, therefore, never to be required of him; or, being so imposed upon him improperly, are productive of certain disorders that invariably attend such misapplication of his powers. No doubt it has happened, that a horse with a radical defect, -in the shape of his hind quarters, for example, - yet having a corresponding defect before, the one makes up for the other, and such horses may occasionally perform well for a short time, but then they are no lasters; all the while they may thus be at the full stretch of their physical powers, straining to the utmost the immediate coverings of the bones, some thing or other is going to wreck-of muscle or tendon, of ligature or sinew. Swoner or later so much excessive fatigue of the deformity runs along the solids, and reaching the vitals, occasions constitutional disease, or leave behind it an incurable malady of the limbs, mostly descending to the feet. Equally true is it, that we find out new properties, or hidden powers in a horse, which !ad never hitherto been known to his owners; but, then, as I shall particularize by and by, no such latent powers were ever discovered in any horse, without his possessing certain just proportions of the bones taken altogether.* What these proportions are, as well as what they are not, I come presently to lay down : the integuments (or coverings) ever adapting themselves thereto, in one case produce what is called symmetry; but if the limb be disproportioned, the coverings adapt themselves to that particular defect, and enlarged muscle ut these particular places becomes visible to the common observer.

The acquiring a ready mode of discovering when a horse of the one or the other formation is presented to our notice, forms the perfection of art in purchasing a horse.

2. But the horses's achievements, or "what he can do," under certain circumstances of shape and make, would ill employ my pen at the present moment-valuable as the investigation must always be in itself-were it not for the practical application I mean to make of it shortly, by way of illustrating the direct contrary, or defective shape $a^{\prime}+1$ make, as being the harbinger of

\footnotetext{
- Eclipse, a horse whose very name is used as synonymous for speed, had none of the pronortions crenerally deemed indispersstble to great speed, and he was cast, by the Duke of Cumberlard, for his apparent deformities when a colt; but his defects in one particular were amply supplied by excresses in another, and, tahen altogether, composed the very best bit of bone, slund, and inuscle ever produced. His lineage, lateral consang uinity, and the kind of cross ty which he was gor, demand the breeders' serious attention.
} 
several radical disorders of his frame. Nor is this all ; some are so evidently ill-formed in the chest and carcase, from the moment they are foaled, that no art of ours is equal to preventing the return of certain disorders which are sure to attend a horse of that particular formation all his life time. As the one is known and inevitable, so the effects of the other may be foreseen, and, in some degree, alleviated, if so much trouble and expense be not grenter than the value of the horse. This is all that can be done for such an animal; and since the resources of art are not equal to the obstacles of animated nature, so no man ought unreasonably to expect, least of all, to force his beast, to perform any species of labour or exercise for which nature or the accident of birth hath rendered him anywise unfit; although it must be allowed, as a general axiom, that it is only by pushing the animal to the extent of his jowers, that we can find out the most he is capable of performing at any given work. In this way it was the fast-trotting powers of the Phænomena mare (which was before then a butcher's hack) were discovered; for people of this trade generally try the utmost their nags can perform in the trot.

To be ahle to judge of a horse's defects as to what he can not do, undoubtedly it seems necessary to ascertain what constitutes a fine figure, or a perfect one, that can do every thing; but when it is considered that the exposure of those defects is intencied to apply wholly to the origin of disorders for which he will require medical treatment, if he does not deserve rejection in toto, I shall find less occasion for adverting to any known horse, entirely without error in his form or built. In most cases, however, good symmerry being accompanied not only by the power of achieving great feats, but a good portion of health also, or, at any rate, the absence of the diseases incident to a bad form, I may be allowed, while exposing his faults, to deviate a little, and to contemplate some few of his perfections also.

3. The most obvious physical truths are those which can be explained upon the principles of mechanics; upon such a basis, even the most abstract can bo securely grafted : that intelligence which is derived from experience, from ob. servation, experiment, and acute reasoning, is rendered more easily understood when conveyed with mechanical precision; and however strange it may appear to some, the gift of speed, if not of all progression, depends more upon mechanical principles than is commonly understood to be the case. See farther onward at Section 9, where the details are given. In all compound bodies, whether animate or inanimate, intended for our active use, it is above all other things requisite that they should stand well upon their bases or legs. A horse, or a joint stool, evidently defective in this particular quality, would be shunned as insecure; and the one is sometimes endued with movements as little suited to one's ideas of getting on safely as the other, both being indebted to their original bad built (or charpente, as Lafosse calls it) for the defect. Cover them both, the one with nuscle and skin, the other with drapery, how you will, the faulty legs are faulty still. A good stable aphorism has it thus - "a horse that does not stand well can do nothing well; and by natural inference, the horse that walks well can perform other paces well."

$\AA$ much better example, however, may be found

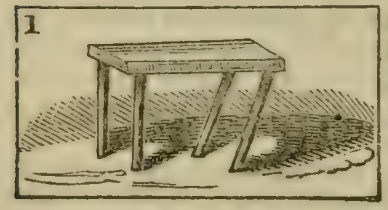
in a four legged table, of which every horseman knows there are many of different sizes and of various workmanship, some for heavy or rough usage, others more for show and to sustain light weights. But, if the fore and hind 'cgs bend towards each other upon the ground, any car penter may see that this first element of an ill-for. unation must sooner or later, produce a fall; he will know that more strength for sulpurting great weights would be found by making all four legs perjendicu 
'ar. But a horse not being like a table, immoveably fixed upon its legs, but being required not only to bear up but to proceed with his load, - which is sometimes eflected with difficulty on account of its weight; then must his powers of pressing onwards be estimated by the positions in which he can plare the bones of his hinder part, the legs particularly, since it is to these the propul sion of his body forwards is chiefly indebted. In his efforts to accomplish this duty, the position 2 of his hind legs will resemble those of the second table in the margin, stretched out constantly as these are, and each leg, alternately twice as much beyond his body; while his fore legs will bend under him alternately also, like those in the first table. In both movements his legs are stretched

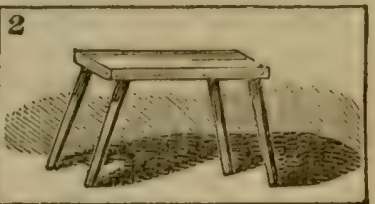
to their utmost when the Iracr is up hill, because the resistance to be overcome is then greatest, and we can thus form an opinion how much "he has the free use of his legs." When this is the case, all horses step short ; but, upon even ground, the hind leg, to be perfect, should come finely forward in the walk, and occupy the identical spot which the fore leg had just quitted. Sree further at Section 8. As the horse gets old, is tired, disordered, or over-much larlen, he ceases to do this as usual, in the exact ratio that he is affected the one way or the other.

4. Mares, occasionally, and skittish horses, frequently loring their legs together, much resembling the first figure, and are insecure roadsters as well as poor dratught horses. 'T he second sketch is the walking motion of an unladen cart-horse or a coach-horse standing still; these, as well as hunters, take the same position, which indicates that they have the free use of their limbs. In the drag, the former bring their fore legs under their bodies, the principle being applicable to any quailruped performing the like task; and such a horso would consequently fill down forward but for the resistance of the load he draws. But this accident seems provided for, by the power the horse has of contracting the muscles (see Section 10), and drawing up quickly the lower part of his limb, in time to get it out of the way of his hind lecr, both motions forming each a separate effort toward progression. I still have in view a walk ing pace, all other paces being no other than modifications of the walk; and, in fact, "a horse that walks well can do any thing else well," an aphorism that is a-twin with one equally well founded in the preceding section.

With some horses, the hind foot, instead of coming forward, as described at the bottom of the last section, "1pon the spot of ground marked by the fore one, falis short of the mark.- T'hese never turn out fast ones, although their fault does not alivays consist in the shape or disproportion of the bones, bat in the contraction of the muscle or tendon (see this tendon described under the head of "Foot"); at times it is owing to the relaxation of the immediate coverings of the bones, described at Section 16. Such horses may be well enough to look at, but can not perform properly. The extreme of this misfortune is termed stringhalt; but every approach towards it, however trivial, is gond cause tor rejecting the animal. In case of the hind foot coming too far forward (in thes walk still) and striking the fore one, the fault lies in want of sufficient strength (or quickness) in the fore lorg ; besides which see further at Section 10. If the hind foot comes down sometimes inside, at others outside, the just quitted situation of the fore fout, the animal has a disagreeable rolling in his gait from side to side, the fault heing as often in the fore leg as in the hinder one, sometimes in both. Such horses commence a journey with much apparent confdence, but tiring soon, they fall into their old error, and the security they have mspired is found to be deceptious:-many accidents are the consequence. This fault I hesitate whether to ascribe to the fore leg or the hind one lint : 
certainly originates in a disagreement between the fixing of the two upon the body, either as to the situation, or want of muscular strength at the place of joining. Such a horse is a stumbler, and when he trots away from us, wo can see nearly as much of his fore legs as of his hind ones; in the straightbuilt, well-set limbed horse, the fore legs are then concealed from our sight by the hind ones. I own this is with me a grand criterion for judging as to a horse's capability of going over the ground. In racing, or indeed any running, the fore legs are then brought closer together, the hind legs rather wider (so in leaping), as we see in greyhounds, hares, deer, and all other flect creatures.

Such as I have described is the act of progression with all horses, but in various degrees, according to their sizes (as with the coach-horse, saddle-horse, poney); four such efforts having called into action all the bones of the body, including more or less that of the head, tail, and neck, according to the pace or other circumstances.--See Section 11. Hence it must be clear, that to perform this duty of progression, or getting forward, properly, as regards either the length of time he sustains it, or the quickness of performance, weight, or velocity, the limbs must be adapted to the kind of work the horse has to perform and to each other, whether that be in harness, on the turf, the chase, or the road.

5. We do not find this adaptation of the limbs so much in the amount of covering the bones may have on them, as in the size and proportion of these, and the suitable manner in which they are fastened together; as may be seen in those horses (blood) where tendon supplies the place of muscle, and most strength resides in the smallest compass; and, as may be proved by the obstruction to his paces, which is always observable in the horse burthened with very muscular shoulders. Equally true is it, that, after we have approved of the proportions of a pair of horses in respect to bone and built, certain powers of going or lastingness are frequently discovered to be possessed by one so much beyond his match, that we are compelled to admit those powers do reside in something else than in his built. Superior health, sound wind, courage, give this strength, with speed, and lastingness; the bones being then well cased together and strongly supported by their immediate covering, have full and fair play.* But wherever they be fundamentally ill-adapted to each other, in whatever degree this escapes our observation, the muscles and tendinous parts adapt themselves in some measure to that lamentable kind of form, but which no filling up, or after-accommodation of the parts to each other, can completely eradicate, though it may he concealed from our view. The muscle that is so perverted rises up in the middle preturnaturally, as if some sprain or other had caused that appearance; the contiguous parts, consequently, undergo greater fatigue than, in the event of finer symmetry, would have fallen to their share: and the extraordinary friction or working thereof, occasions, at a day more or less remote, the exhacistion of its powers (see Section 21), and the lodgement of acrimonious matter in the cellular membrane, which ap. pears in tumour, abscess, \&c. This protuberant appearance of the muscle is most visible at the stifle [N. 30], and on the shoulder [M. 16], just above the elbow.

A more minute inquiry, however, on those points would lead me awaytoo far from my main purpose, at present; I therefore return to notice, in the first place, the structure of the legs of such horses as, by their untoward posi.

- Firing is suppeseu to restore derangement of the integuments, by causing inflammation and rentraction thereof upon the bone, so as to embrace it more tightly. This is effected ty much of the muscle being taken up into the system, or sloughing off in the curo; as well as the enniraction of the flexor tendon (back sinow] and its sheath. 
tion, entail on them the chances of producing some one or other of those evils that are known to afflict certain horses, incurably, to the end of their days. Thus, some are known to tread on the inner quarter of the hoof, others on the outside, without the real cause being evcr ascertained, and remedies are frequently applied that have not the remotest chance of achieving any good, on that very account. Some horses "cut" in consequence of treading on the outer quarter; on the contrary, by punishing the inner quarter in treading, others contract a disposition to "quittor and ringbone ;" both instances of nal-formation, or bad built (as I call it), produce splents, diseases of the frog, of the sensible sole, and of the coronet, as the case may be: how the various modes of wrong treading are brought on remain to be examined into hereafter. Meantime, it may not be amiss to ohserve that the right mode and make may be discovered by noticing the proportions of those horses, that, by the acknowledged just symmetry of their bones, the agreement in size of one limb with another, and the faultless manner in which these are attached to the body, go tolerably free from any such diseases, until old age, accident, or the misapplication of their powers, brings on disease.

6. There are, then, three kinds of mal-formation, or bad shape, attendant on the limbs of horses, which I consider original faults, those others to which they give rise being but secondary ones. 1st. That wherein the leg is ill-formad in itself. 2d. When it is badly joined to the body. 3d. When the fore legs disagree with the hind ones in length or quantity. Each, being attended by its respective defect in going, as to safety, speed, or strength, and liable to incur one or other of the ills enumerated, as appearing on the legs and feetis worthy of the reader's separate consideration; although it frequently happens that an individual horse is afflicted with all three faults at the same time, the two first being found together, sulsequently yroducing the other also. But 1 have generaliy noticed that one of those faults sometimes accommodates itself to the other, amending it considerably; as, when a limb that is too long is set higher up on the body than is esteemed right construction, in the same manner as a horse lame of a leg may be passed off for sound should the corresponding leg of his body atso fall lame.* Much the same is it with the third kind of disagreement, in the opinion of many people; because it has existed in some celebrated horses, and they would have us believe that this very disagreement was itself the cause of the celcbrity those individuals arrived at. This, however, was not the fact.

7. The Planomena mare, unquestionably the first trotter of her inches in our days, never did her work in style: nobody could account for her achievements upon the view, and I had always my doubts whether hers was a fair trot, though I won upon her. In the trot she bad an unaccountable shuffle. She was low before, hut had the gift of taking her fore feet out of the way of the hinder, which fell (in the walk) about half a shoe beyond that of the fore ones, the feet reaching the ground in succession.

Lacrles, a grey horse, hunted in Leicestershire, 1818, 1819, † of no particular powers any where, and confessedly clumsy in the forehand, without much fire, was yet in the halit of taking the ordinary six-feet leaps with ease, and clearing a ditch of twenty-five feet with pleasure, often exceeding those admensurements by nearly a fourth. Eclipse is known to all of us (as matter of history) for having had a low shoulder, which gave his fore quarters an awkward appearance: but this was compensated for hy the fine furm of his hind quarter, which, being particularly strong and muscular, threw his body

- Certain dealers are known to have inflicted lameness on the foot with 'his view. flmid ond disgusting as is the relation, 'tis no less true.

I At that time the property of Mr. Malxurly. 
forward at every leap, in despite of his low fore quarter,-for running is $\mathrm{mn}$ other than the leap reiterated. One leading characteristic, however, denoted all three horses to be of the right stamp in the main : they stood even on their leg-bones and the soles of their feet; that is to say, straight tip and down. nearly, from the elbow [N. 16] to the ground before, and from the stifle-join [N. 30] to the ground behind, respectively; both these parts, viewed sideways in the plate, being placed nearly horizontal, as regards each other, on the line [N]; at least, this was the relative position of the stifle and elbow, in the two first-mentioned animals, and of the third I do but presume that he was so, for "the history" of his form in this respect leaves us a little in doubt.

But "the shoulder of Eclipse was a low one," say the published accounts of him ; yet, as this defect, real or supposed, consisted in the inclination of the shoulder-bone [ $\mathrm{K}$ to $\mathrm{N}$ ] above the elbow, by reason of the great freedom of the muscles which held it and the shoulder-blade in position, he would, when stepping out with the fore leg, rise higher than when he stood still; a particularity that is reversed in horses whose shoulder-blades are set on more nearly upright than those of Eclipse were. This accounts for the vaulting manner he hail, as we read in the printed accounts of his exploits; and his running greyhound fashion, with his chest close to the ground, for he would thereby keep off the ground longer betwixt each leap, until the impetus received from his hind legs was nearer spent than it would have been but for thus holding up his fore feet. On referring to those parts in the annexed plate, they will ie found thus drawn.

8. Viewed in front, the fore legs, upon which the safety and ease of the animal's going chiefly depends, should, to be perfect, be widest next the chest, Fig. 3. approaching each other gradually, until the eye, hav-

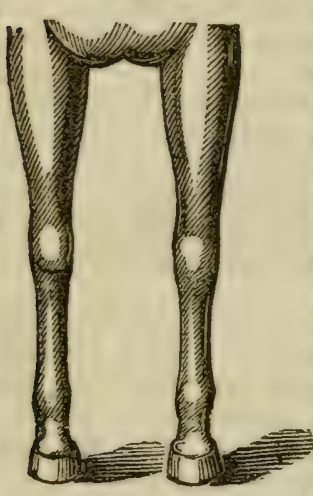
ing compared that part with the pastern, scarcely perceives the difference. Here, the leg, taken by itself, is smaller, though the interval between the knces and the feet does not differ, on account of the width and flatness which ought to exist in the well-formed knee, yet, taken on the outside, considerably more breadth will be found above than below. Such a knee, when flat and finely marked at the joint, is always well covered in a healthy horse, (see section 15), he then throws it out with great freedom, and takes a firm step fairly on the entire bottom of his hoof ; but, should the leg be ever so good a one in itself, yet placed too high upon the chest, where it is held, not by a socket or insertion of the bone, but by strong elastic muscle only, this throws the feet too near to. gether upon the ground; the horse then treads on the outer quarter of his hoof, and wears away the wall; and, when tired, is most commonly given to cut. Endeavours are used in shoeing to amend this fault, by paring away the inner crust; but it is one of those defects in the built which no art can completely eradicate, and has been termed "pigeon. toed."

Nor is the matter rendered any better when, by reason of the knees turn. 'ng i.., the toes turn out, and the horse then treads on the inner quarter; and, lowever those of the one or the other description may have the reputation of freat speed, it can be for a short distance only, because the action of such horses must be laboured and imperfect, particularly one of the latter kind of make. He must, consequently, fatigue himself more at every step, and tire gouner than one of the same size, and formed in every other respect similar iut having legs that come nearer in shape to those in the annexed sketch (fig: 
3]. That such knock-knee form is occasioned by weakness, is evident from the position of the knees, when the animal stands at rest. This he does ny supporting himself at times like a dancing-master, with one foot before the other; and, no doubt, the twist with which his pace is always attended when going, occasions certain disorders of the feet, which he seeks to ease by shifting the weight alternately from one, to the other foot. He will, moreover, sooner "knock up," and ultimately "get done for" earlier in life, by reason of the origin of this species of malformation being seated high up on the limb, thereby incommoding the action of the shoulder-muscles: the elbow, at N. 14, by heing pressed close to the ribs, having thrown in the knees, receives, at , very step the leg takes, a kind of double motion, which, of course, doully affects the action of those parts; and much fatigue, pain, and anguish succeril pach other, until it communicates to the cavity of the chest, or other interual parts. Such animals have frequently the shoulders unusually muscular, hiding, in a good measure, the original defect from the eye and touch of a common observer ; but it may, nevertheless, be ascertained to exist, by the symptoms just now mentioned, as well as by the appearance of the protruding muscle before noticed at Sect. 5. To knocked knees and inside tread, let me add the circumstance, that such horses have a broken pace, kicking lonse stones befure them, with a certain rolling from side to side, to the great annoyance of the rider. All this arises from awkwardness, by reason of the shoulder's bad position, whereby the leg being thrown sideways removes the fort in an increasing ratio from the centre of gravity, and, instead of its being thrown straight forward, describes part of a circle, more or less curved, ac-

Fig. 4.

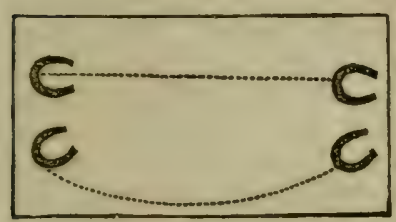

cording to the amount of the original defect. The straight dotted line shows the space a wellformed foot, such as belong to the leg in our preceding sketch (3), would take, being on papet just one inch; the curved line shows the course or nearly so, the foot is thrown which belongs to an il!-furmed shoulder, contracted at the elbow: as this line is an inch and an eighth ( 1 in. 1 ) in length, the horse so formed does an eighth more work than one with straight legs would do on going over the same ground.

In addition to his other evils, a horse with such a shoulder (being muscular) Is most liable to contract "fistula in the withers;" but, if not so muscular, "strain of the shoulder" is likely to attend his twisted manner of treading, when hard worked. With such a built horse, "splents" are usually more tedious than with a straight-limberl one; and strains of the sinews, i. e. of the tendon, as well as those of the coffin-joint, happen oftener, and appear with worse symptoms, in proportion as the limbs are more or less cross-built*.

9. Long and sloping pasterns [Y, 13-16, and Y, 34-39] partly denote the Arabian, are handsome to view, and make easy goers; but such horses sonn tire, and, I may say, are generally weak, having the flexor tendon, or back sinew, considerably relaxed. The small pastern, or bone inserted at the hoof, always rises in a direct line from the hoof, both being about 45 degrees for saddle-horses, as at $b$, (tig. 5.) and the large pastern is then several degrees nearer to upright. These hoofs stand of an oval shape, and have small frogs. But some, as draught horses, have large frogs, the hoof round, and more upright by nearly ten degrees in early life, as at $(c)$ in the annexed scale, in which case they are liable, if no change takes place, and they get older and weaker in the juints, to "knuckle over." But, getting aged, and the supply

- I reserve until a latter part of the volume what I shall have to say, respecting strain of ine back sinew and of the coffin-joint, which I have thus named in conformity with the gevergs vulgariam, in order to make mysell intelligible to the meanest capacity. - See $F$ Lot, a rection as 
of nutriment for repairing wear and waste falling short, the horse becomes -mmmice-footed. The wall or crust is then lower; and as the bottom of Fig. 5.

the foot grows convex, causing the ant-

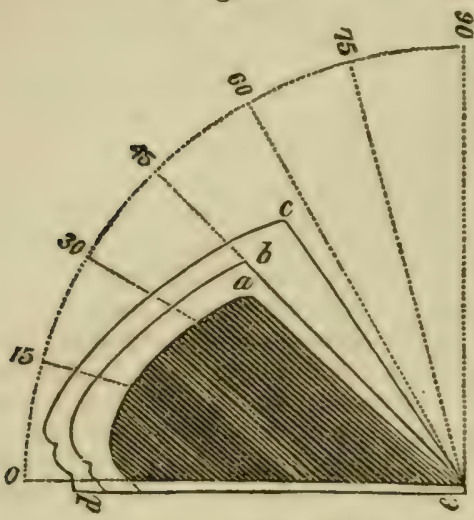

- mal to slip about, so the front of the hoof $(a-c)$ grows concave, the toe $(c)$ almost turning upwards. Horses kept for heavy draught have short pastern bones, the small one entering the hoof at the coronet $(c)$ in early life, but afte:wards changes, as I say, to $(a-d)$; and this new inclination, it will be seen, must depress the bone, as the animal acquires the sort of hoof called pommice-footed, and causes a constant straining upon the coronet; hence, the crippling, insecure gait, horses of this description acquire, even before they get old; and hence those numerous disorders to which the feet are liable from this one origin.

Contracted heels of this or any other species of horse, being destructive of h.s capability of going, should be guarded against as much as any other individual misfortune to which he is liahle: a disposition thereto constitutes sufficient ground for rejection. When this is the case, the interval or cleft between the heels, at $(d)$ in the annexed scale, is found to be more or less tender, according to the progress of the disease; the cleft will, in health, receive two fingers lain in, the part having in it nothing unusual in the feel. Soon, how. ever, the keat increases, the part hardens, and the cleft scarcely admits of a small finger; the horse flinches as if you touched a sore, and nothing but time and proper treatment can restore him, if any thing can. Nost commonly, however, the disease proceeds until the clefts of the heels meet and become rotten. Pressure upon the frog, is the certain preventive of contraction. See "Foot."

When the pastern-bones (great and small) rise one above the other too uprightly, the small one receives the whole concussion, and communicates the jar to every minute construction of the internal foot. See Foot, section of. The jarring of his pace is then very great, both to the horse and his rider. Such horses are very liable to go lame occasionally, but they recover by rest. The ass and wild herse (poney) are thus formed; but being hardy, and having less blood and less weight of body to carry about, suffer less by it than the horse.

The just form or elevation of the hoof in front, upon which mainly depends its form behind, has been discussed hy various writers, but remains yet awhile uncertain and unsettled. Mr. B. Clarke judges 33 degrees of elevation from the ground to be the best form of the hoof, and Mr. White quotes him with a portion of approbation, but most unaccountably refers to his "plate iv," on which an inscription tells us the fact is not so, but 45 degrees is the best possible elevation of the hoof: whilst those which are higher (lower he writes it, or "33"), "approach ton near the perpendicular;" the ligure on the plate itself differing with the diagram on the page of his book (305).

My ideas, however, on this subject are not so general; for I have found the best form of the haof differ, according to the shape of the two pasterns, as shey regard the hoof and each other; deeming that the best, in its particular ease, where the small one follows the same declination as the hoof, and the large pastern ascumls twenty degrees marer to the "pright, as befure statud. 
The preceling figure (No. 5) shows the outline of three feet of lifferent ilegrees of elevation : $b d$ describes the line of the coronet, or orifice, into which the thickest end of the small pastcrn-bone sinks, and rests upon tbe sprin.gy culstince attached to the inside of the hoof, and which bone, we naturally expect, should ascend out of, and take the same direction as, the hoof, whence tt springs. Any departure from this rule of nature is clearly an approach towards discase. In the paragraph above, I showed what mischief might he derived from an upright small pastern, such as would suit the outline hoof (c); of course, this elevation, or a greater, would be a mis-shapen hoof as well as pastern. In like manner, we knew that the pommice-foot is out of point and diseased, and it follows that the best possible elevation of the hoof nust necessarily lie in the niedium of those extremes, which we know to be diseases in themselves: this it is to determine a contest mechanically, withont once adverting to the well-known circumstance of the health and free use of its heels, which attends the horse whose hoof is, at any time of life, near $\mathbf{4 5}$ degrees of elevation or depression. Did we require more arguments to prove this to be the proper elevation, a conclusive one could be tound in the wellknown circumstance of those hoofs of horses which are very upright in early life becoming the lowest when the animals get old; whilst those hoofs which come near the standard of excellence in youth ( 45 degrees), retain the samo form, as nearly as the injuries of shoeing admit of, to an extreme old age.

10. So far as the foregoing observations on the fore-legs apply, they do belong, in every particular, and with equal reason, to the hind legs also; with the exception, however, of what is said concerning the elbow of the fore-leg, and its adhesion to the chest, for which we must now substitute the stifie of the hind-leg [N. 30]; and add, instead of the kind of defect described as heing occasioned by the contraction of the part, it is here owing to the expansion or spreading of the stifle from the sides. This throws the houghs together, and forms "cat-hammed horses," as they are termed; the mode of groing such animals are constrained to adopt, the circle their hind feet describe, at every step, the additional fatigue they undergo, the awkwardness of their tread, and the conseyuent diseases communicated to the sole, lately described (in sec. 6.) as pertaining to the fore-leg, - most unduubtedly afflict the hindleg also, with the additional fact, that this one is more liable to "grease." At rest, if an animal so built does not place one foot before the other, his houghs not unfrequently touch each other,-poney's and low horses more particularly so ; and it seems worthy of remark, that this species of malconformation seldom appears on the fore and hindlegs of the same animal. Indeed, I can not recolect having seen one instance, and I am thence led to conclude that this twist of the legs is a contrivance of Nature to accommodate itself to the disproportionate length of legs before or behind. But, when it so happens that the strength of the parts resists this bending of the hough or of the knee, such horses walk higher behind than before, and vice versa, $i$. $e$. when one pair of legs seem to have wutgrown the other pair; a defect which, though

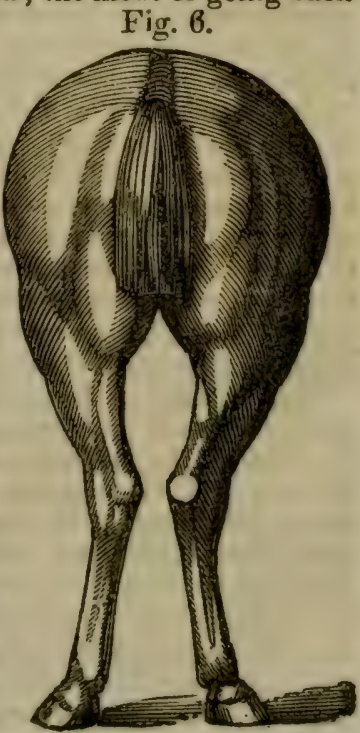


often overlool ed, is no less deserving of notice. The wound termed "overreach" is inflicted by the hind-leg of this formation upon the fore one. "Forging" is, likewise, occasioned by the hinder toes striking the shoe or shues of the fore-feet; and is sometimes brougnt on by injudicious shoeing on feet of the very best construction, and a loose rein; it is, therefore, to be corrected only by the contrary practice, keeping the hind-toes short, and the heel of the forefoot low, and driving with the reins borne up. By these means, the forehoof will spreail at the heel, and the animal be enabled to take it out of the way in time for the hind-foot to occupy the identical spot on the ground it had just quitted; for very few horses have the greyhound-tread of Eclipse beforonoticed, wherein the hind-feet tread much wider than the fore-feet. Neither is such a gift desirable to any but racers, perhaps: nor is it, indeed, compatible with the duties the generality of horses have to perform.

The great additional labour horses with houghs so formed undergo, added to the pain and anguish of continuing it, occasion irritation of the whole hind quarter, that communicates itself to the region of the kidneys and intestines, and superinduce inflammatory complaints, which frequently terminate unfavourably. Constitutional diseases appear on the leg and foot behind oftener than before; and those of the Coronet, with Curb, Thorough pin, spavin, strains, windgall, scarcely fill up the catalogue of evils caused by, or receiving aggravation from, too much expansion of the stifle, with its atterclant, the cat-hammed hough, and, consequently, a twisted tread of the hoof. No doubt exists in my mind that Eclipse would have been a cat-hammed horse had he been raced at two or three years old, as cur practice now is: both he and Flying Childers were five years old before they started on the turf. Heavy long-legged children of our species, in like manner, become knock kneed men, by being put on their legs too soon; this form of their knees deprives them of calves tu thin ill-formed legs, and the thigh, too, seems wasted, when the deformity is great.

11. When the fore-legs are shortest, the horse, whilst going, norls his head up and down a good deal, as he does when these are either weak, tired, or tender of foot: when they are very feeble, without any other ailment, he carries the head high constantly; but he works his head from side to side when the same subjects of complaint assail the hind legs and feet. Poneys being ever out of point in one or other of these respects, afford unerring proofs of those remarks. The value and advantage of the straight position of a horse's houghs are never more apparent than when he rises upon his haunches to take a leap, a service which never was perfurmed satisfactorily by a cat-hammed horse, because he seems to hesitate about what shall be the distance between his feet at the precise moment they are to leave the ground: a blunder which is inost visible in the standing leap, when the feet are seen first to stradule to their utmost; in an instant they are brought so close together as to lose all purchase, and he goes over from an intermediate spot, the whole transaction occupying as much time as does the counting of one, two, three, and away!

The motions of the head are always good indications of pleasure as well as pain. A horse will frequently thruw up his head, almost in his rider's face as if to rebuke his barbarity,) when he has been hit on the head or ears. (See Section 16.) He looks at his flanks dolorously when aftected by a dull pain in the intestines; if it be sharp pain, he turns about quicker: he thrusts his nose towards his chest, when pain assails his lungs generally; but when one lobe only is affected, he turns his head only to that side. If a horse be grthed too tight he will sometimes (justly) bite his tormentor, for this operation retards the action of the muscles between the ribs and of the ribs themselves, so that the lungs do not get room to play. (See Section 31, and Introduction, jage 4.; Old horses contrive to avoid this punish.nent by "loolding tbeir 
wınd" (keeping the lungs filled) during the girthing; a fine proof this of $\mathrm{Na}$. ture's dealings, for which they usuaily either get kicked under the belly, or hit about the head; but both kinds of punishment are the harbingers of further disease, viz. the first of the blind gut, as described at Section 48 and 49 ; and the other leads to poll evil, as descrilied in Brok 2.

A horse is frequently found to have contracted lameness in the fore-leg without showing any visible sign of its exact situation, and applications to the shoulder is the usual remedy in the hands of the grenerality of common farriers. Some of them imagine the strain is situated lower in the leg; hut they are no nearer the fact, though they are to the spot. A defect in the conformation of the limbs occasions the foot which leads to come upon the ground with more force than its fellow: the concussion of the hoof is greater, and is unequally placed when the leg is a-twist than in the upright form; the leading tires sooner, and the sensible sole hecomes inflamed when the horse is constantly urged to step out with it, the affliction barely showing itself between the frog and the tue, if any where. If a horse receives the impulse to proceed from the right hand or heel, he will step out with the fore-leg of that side, accompanied by the hind-leg of the near side; but his rider, or driver, should early teach him to change the leading-leg, by sometimes touching him upon the contrary side. It is worthy of note, ton, that the horse which executes this change with the least trouble, and oftenest, has most power and command of his limbs. [See Index-Fever in the feet.] When both legrs before are attacked, the horse exhibits a crippling uncertain gait, not urilike that of a drunken man, whence the term "groggy" has been applied, and, if he is not timely indulged in rest and a run at grass, he is a ruined horse, and becomes soon what is termed "foundered," of which disorder there are several kinds. The mistaking one kind of founder for another generally costs the animal his life, sooner or later, and the studious inquirer had better turn to the next Chapter (at sect. 21, paragraph 3), where he will find a few words on chest founder, many of the symptoms whereof are not unlike this of the feet.

Horses full of feed, and requiring purgative physic, stand with the legs stretched, more than our second cut, at page 7,-inordinately at times. Old Gibson attributed it to vice, and a disposition to kick, when a horse holds his toe scarcely resting on the ground; this is not always the case, for his foreleg is as frequently so held a-trip as his hind one; and I consider it the token alike of either sore feet; or of incipient founder.

12. Besides the disproportion the fore and hind legs bear to each other, another series of defects in construction exists between the length of the fore limbs and that of the trunk, being sometimes most apparent at the betly and flank, at others on the back, its tendency always depending on the turn taken by the latter. Although this is the old English way of judging of long carcased horses, Lafosse (an old French farrier) tonk the measure of proportions more properly from the breast-bone to the buttock, in the annexed plate being from the parallel line 11 to 38 ; then comparing this with his height, he tells us " a good horse, as we can learn from experience, should be a tenth longer from the breast to the buttock than he is high from the top of the shoulder to the ground." The latter admeasurement will be found upon the annexed plate to extend from the line [D to Z] and, with the former, will compose a Bquare rather wider than high, - the integuments being removed from the bones on all sides. My notions of just proportion, however, differ from the French standard, though they do not run into the contrary extreine; for I can not help thinking inordinate length of body, as compared to a hurse's height a very great defect as regards his health, that form being invariably attended wiks meagre, washy flanks, and a painful manner of going. But the Flan- 
ders and Norman breeds have all this tendency; and they are invariably of a sluggish nature, when the belly, also, hangs low.

i'lie major part of our horses of this built have their sides falling in, more or less, towards the hind quarter, some few of them to such a degree that the flank appears as if it were fastened to the loins. These are remarkably poor fecders, have a good deal of short-lived vigour, without the gift of keeping it up, at any kind of thing. Nutritious food, but less in quantity, does for horses which are out in the first-mentioned point all that can be done, and that is very little: those of the second species of bad form can not bear long journeys, nor long privation, or they contract ffatulencies and spasmodic cholic.

Another spiecies of disproportionate length, as compared to heiglit, consists in what is called "high mounted," the limbs having then much more length than the body; a defect that is rendered still more apparent when (as generally happens) the horse is also roach-backed, like the tirst sketch of back

Fig. 7.
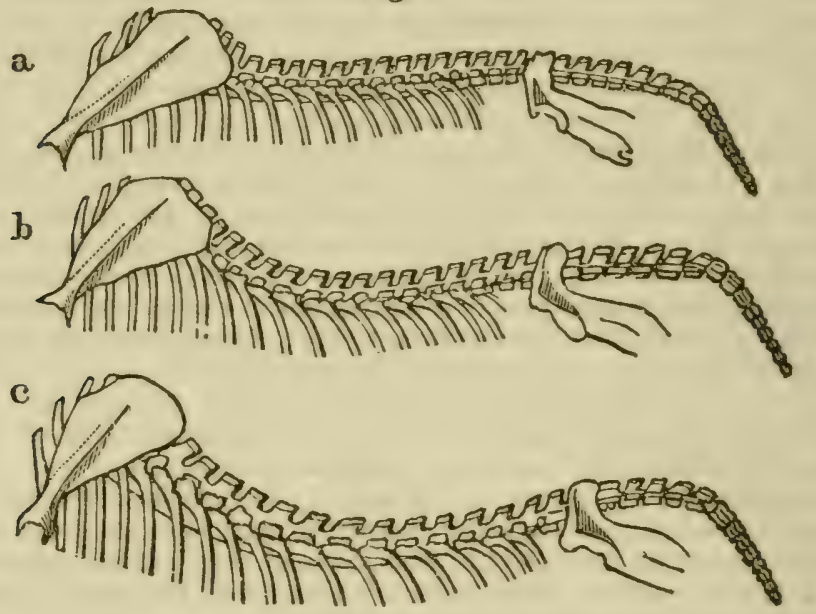

bone in figure 7; and it is still more striking when a little man is mounted apon it with a saddle that is ever sliding forward upon the withers. Such a form alwavs denotes weakness of limb, and want of freedom in the fore-hand; nor can a horse of this built take a long step, or trot well, or thrive in the field, by reason of the difficulty he has in reaching the grass, which induces him to bend one knee forward, whilst the other leg is drawn back under him. A ludicrous story is even told among horse-rleaiers of a horse so formed having starved itself in the fields, while the food lay within an inch of its nose; and though such stories are no argument, they, nevertheless, convey the general feeling of the narraturs, which is seldom completely wrong.

13. But a horse may be she rt in the carcase, which is not exactly "highmourited," in my view of the term; since much will depend upon the shape (or berd) of his back-bone, ts bring him under the one or the other description. We hive seen what sort of character a roach back bestows on a horse. the direct co itrary form, or hollow back-bone, [see the lowermost sketch in the last cut (c)] is no better, though built upon lone limbs, horses with this shaped back lreing in all cases weak in the loins; and, therefore, are they more liabie to contract inflammation of the kidneys, and to resist the cure longer than those of any other shaped back whatever. Yet are they prefeired hy 
timid horsemen, principally on account of the easy seat a hollow back affords Great caution in administering strong repeated diuretics should be impressed upon us at the sight of a very hollow-backed patient. See Sections 53-56

When the hend in the back-bone, or "hollow back," is restricted to the fore part of the animal, the loins being well filled up, his built in other respects is less material, to be "short in the carcase" being then an advantage; and it is much greater when the bend is confined to a gentle curve, scarcely distinguishable, just hehind the withers. [See middle sketch in the last cut (b)]. This is considered a straight back, belonging to a light made, compact horse; he is invariably ribbed home; and, as there then exists but a small space between the last rib and the hip-bone, as seen in the plate at 30 to 32 , so is it always accompanied by the deep chest, good hind quarters, and wide loins (i. e. not pinched together), and his ribs finely curved. Horses so formed are always healthy, and esteemed at first sight super-excellent, being supposed, with justice, capable of doing more work than those of any other built whatever. But the gift of leaping or of great speed do not always belong to horses of this form, however perfect in other respects, though health, vigour, strength, and lastingness do. Such horses always feed well and retain their condition. The inquiring reader would do right to turn back to what is said under Section 10 , and draw his conclusions from what is there stated.

14. Low-buttocks generally accompany roach backs [see sketch a.] and are always attended with another fault- "hind legs too straight," and incapable of stepping out. A horse so formed can execute no pace tolerably, and trotting worst of all. In the drag, such a horse steps short, and is always upon the bustle, as if his legs were tied. A large head, with short thick neck, denotes a sluggish horse, heavy in the hand, and usually "carrying low:" these are faults generally attending his entire breed. When the neck is longer, the case is not bettered, for then the animal is of the long-bellied kind, with thin flanks and washy. As a small light head, but wide at the forehead, with expanding nostrils, and bold prominent eyes, denotes (blood) strength of body, and vigour of constitution, so the contrary may be looked for in horses which have narrow foreheads, small or sunken eyes, and small arid nostrils. I never saw a fine well-turned head that did not belong to a gond set of legs, well fixed upon the body; the correspondence goes still further, inasmuch as the quantity of white in the face is commonly attended with a proportion of white upon the heels, thus: a star, one white foot; a blaze, two white feet; white face, four white legs, \&c. Horses with large jaws are given to keep open their mouths while at work; and, when aged, grind their teeth more than is necessary in feeding. The manner of breaking his food being, with the horse, different from that of other animals, viz. by rubbing his under teeth from right to left against the upper ones, - a motion to which the term "grinding his corn" has been applied, - an old horse will sometimes continue it when he has nothing to eat, thereby wearing away his teeth; a circumstance that occasions imperfect mastication and its consequences, ${ }^{*}$ besides subsequently leading us into error in examining his age. Hard-mouthed horses, and those which champ the bit much, fall into this idle habit.

Flat, or narrow-chested horses are sulject to those attacks which lead to consumption (see Section 36), and, consequently, are liable to show had con Jition; or, it may be, that disorders of the chest do contract its capacity. In some horses on the contrary, the cavity of the chest seems too great for its contents; they are short-winded horses of one description (there being several) 
that are aflicted with these kinds of mal-conformation, or disagreement in szze between the parts containing and those contained.

15. My purpose in making this exposition of the ill-effects produced by mis-shapen limbs, \&c. on the horse's health and usefulness, would be incomplete, were the original causes thercof left unnoticed. The most remote, or more general one, resides in the breed, or the manner of breeding the animal, whence we are sometimes led to say, "what is bred in the bone will never go out of the Hesh." As regards the kind of stock from which to raise a supply of young ones, breeders may undoubtedly suit their own fancies; but it must be seen that a brood mare which receives too much of the horse for her capacity, will produce a foal all father, as it is called, being at the same time larger than she can conveniently carry; it then lids fair from the beginning to be a mis-shapen animal. This happens oftener than is commonly imagined; but it is easily prevented hy adopting a horse for her whose strength comes tolerably near that of the mare. Disregard of this precaution is found to produce the first foal much smal!er, though more livcly, than the next and subsequent ones, especially if care be taken in the latter case to give her a horse more and more vigorous as she hecomes more roomy. For it must, be clear to any body [upon mechanical principles again] that if the foetus, growing too large for the cavity in which it is generated, originates too much bone, it must determine towards some particular part of the young animal; and the colt will be brought forth with that deformity, and carry it through life, after plaguing two or three of its owners with fruitless endeavours to physic off its ills.

I say nothing whatever of the cross to be adopted; that, being contrary to my plan, would carry me too far away from my main sulject. But I may observe, in passing on, that no breeder in his senses would think of employing a horse to raise stock that has served half a dozen or more mares in the course of the day ; and yet nothing is more common, nor more inevitable when the payment for covering is low (say a guinea or two), than that the smallness of the sum must be made up by the number of mares served, the price, keep, and attendance, upon stallions being expensive. This error must be so palpable to any man who calls himself a father, as to render any further argument upon that topic utterly unnecessary. Some twenty-five years back in to the last century, I recollect reading a well-attested account of a celebrated horse's dying in consequence of twelve or fourteen successive efforts in procreation; and if such be the deplorable case with the parent, what strength, bottom, or lastingness, can be hoped for in the progeny so begotten? Nevertheless, 1 am of opinion that a vigorous horse which may have been freely engaged (if early in the season) may be in a better condition for raising large and lively stock, than under any other circlimstances whatever, except recent exhaustion. Aged stallions produce hard-mouthed foals, and further proclaim the ill-adapted ages of sire and dam by extraordinary hollowness over the eyes.

Much depends on the country, the climate, or kind of land, in which the gestation or breeding may be carried on; and it may be presumed, that no one in his senses would chioose such a situation as is known to be disadvantageous to the particular kind of breeding he may have in contemplation to pursue; whilst those who may already be so placed, have no right to complain when they engage in a branch of business thus ill adapted to their plan of farming, and they get disappointed. As both oljections lie at the option of the parties toncerned, they require no further remark ; but another point of consideration well worthy our careful attention is, the treatment the mare ought to experience at our hands while she is breeding; this beingr a matter of some monenth and within every one's control, should not be neiglected. Thengh a brood mare in foal requires no pampering at any period, yet it is clear thet, from the 
third or fourth month, she should not be worked so hard as usual, and from this period to the day of her foaling, the duty to be required of her should be less and less every week. Nor, on the other hand, is complete idleness be. fitting her situation: in cases where she has not been used to hard labour, a run at grass, in a paddock, with access to an outhouse or stable, as it leaves to her option the quantity of exercise her strength is capable of sustaining, would be found most conducive to the best purposes of nature. Her foud should be of the first quality, and regular, and, though full enough, should not be too much. Occasionally, she may be off her feed, during the "time," but she does not therefore require "physicking," nor coaxing to eat. Great care should be taken that her body is einptied regularly, that no derangement takn place either way' : and that if opening physic is required at all, aloes is not in her case the best that can be prescribed for that purpose, since they act mostly upon the intestines lying immediately in the vicinity of the foal. An opening draught or drench should be substituted for the pill, as its operation begins sooner.

A very general cause of mis-shapen limbs is the placing unon younkers too great weights at first, whereby the houghs or the knees are thrown together particularly when the animal is constructed with the fore and hind leigs dispropurtioned to each other, as noticed at sections 9 and 10. Splents and sprains are the inevitable consequences of mounting colts, \&c. too early in life; and hollow back is oftener induced by this premature error than existing originally. As if all this were not enough, many breeders nearly starve their young ones until they are brought into use; whereloy they become deficient in solidity of bone and quantity of muscle, if they do not imbibe sume internal or constitutional malady, and the event of their limbs growing mis-shapen is no longer left to chance.

16. Notwithstanding all that has been said and done, little would avail the finest proportions of the bones towards the formation of fine-shaped limbs, least of ail to symmetry of the whole horse, but for the seemingly adventitious circumstance of the covering with which they are immediately invested; and which, embracing tightly several bones, and connecting them together, constitutes a limb. Some of these coverings are confined to the joints only, holding them in position as near as the Creator designed them, unless accident (of parentage, of birth, or misusage), as hefore described, should induce them to a perpetual strain, and they enlarge at these joints in spite of the next or universal covering of the bones: this is membrane (of which more shortly;) the uses whereof on the bone may be illustrated by taking a stocking of good length, and having filled it with pebbles of its own size, and tying the end tightly, a stick or club is produced of some degree of flexibility resembling a limb and its joints. If the tying be not performed well, by bracing the storking to its utmost, the flexibility of certain parts (or joints) of the limb will he greater: it will possess less strength at the joints when bent, and be liable $t_{3}$ give way or break unless supported by some other covering. It is easy to perceive that the horse which has those coverings in the highest perfection would move his limbs more correctly after the fashion they were designed for, than he which constantly strained them out of their places. He who was endowed with the first-mentioned quality in perfection would he considered a sinewy tight-built horse; the second kind I have already depicted in section 10, whert the houghs are described as kecping those integuments in a perpetual state of derangement, straining or twisting them in such a manner that constitutional enlargement at the joints is the consequence.

At the ends of all bones, a yielding substance, in appearance like bune it self, prevents friction, and by its elasticity fives a spring to the animal's steps. The ease of a horse's going mainly depends upon this substance, which ro 
ceives the name of cartilage, and is liable in some measure to be absorbed o: taken up into the system, or, in cases of diseased juint, to become stiff and bony. Consult sect. 23, \&c. on those points of information. We may notice this absorption in very young animals, whose bones are all substituted by cartilage; until the blood furnisheth the means of forming a more substantial frame, such as I have been describing; and teaches the validity of some remarks I made in a preceding section (15) on the kind of attention we ought to pay to our brood mares while the fatus, or unborn animal, is being formed in the womb.

Not only between bones, and embracing ever joint, but at the termination of the four legs in their horny feet, is this springy substance to be found, the whole being liable to wear cut, to contract or to harden with age or disease. Besides this casing of the joints in cartilage, the ligaments connect or tie the bones together. These ligaments are seldom troubled with any ailment but that of great lassitude when the animal is tired, and occasionally to sprain. This accident takes place when the horse steps aside upon uneven ground, and the ends of the bones press laterally upon the ligaments. It follows, of course, that mis-shapen horses whose feet are always constraired to take an uneven tread must be subject to a constant strain, and must be more liable than others to incur permanent accident, - every step forming a trivial one.

But the ligament demanding the student's most serious attention is that which suspends the neck bones, on the same principle as our old fashioned lamp-irons are suspended by a small one from above, only that the ligament lies closer, and covers the intervals of the upper side, as at $a-b$ of the annexed sketch.* So placed, and passing from the skull to the backbones, to both

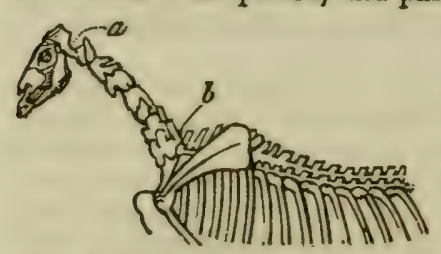
of which it is fastened, it has the power, at the will of the animal, of bending down or drawing up the head, which would, in fact, but for this support, fall to the ground. Horses in their last moments, when that will may be supposed to have left them, always cast back their heads considerably, by reason of the contraction of this strong ligament during the paroxysms of departing life. At $a$, however, where is the seat of poll-evil, it is usually thin, the cavity there found between the bones being mostly filled with muscle (s. 27); but this does not happen invariably, as some horses have little or no cavity to be filled with ligamentary sulstance, or with muscle. Our frontispiece is the portrait of a subject of this latter kind; but the reader is referred to some subsequent observations and cases on "poll-evil ". for more detail on this hitherto-neglected point of conformation.

17. At the joints formed by the bones and covered by cartilage, the whole are surrounded by a strong membrane, which wraps the bones tightly, and secretes an oil at the joints for its further defence from the effects of friction. Of this secretion, and of the membranes generally, some further notice is given in the second chapter at section 22 .

'I'his strong membrane is not, however, confined to any particular part, but continues its close attachment, or embracement of the bone, over the entire frame of the horse. Throughout its extended course it serves as an excellent holdfast for the sinewy ends of the muscles (see sect. 27), which are attached to it above and below joints, whereby they act as levers to raise the lower bones of the limbs, as described hereafter.

- Called by the learned "cervical ligament" and "the cervicular." In operationg for the poll-evil this ligament is frequently divided by the unskilful farrier cutcing it aerose rathar ttan lengthwise, which is the only right practice. 
According to the parts this membrane may cover, it has received from the marned in hard words and many, a separate name for each, as if that course wr Id further the cause of science; and whenever they speak of it as being found upon the joints, and skull, or the bones generally, they term it perichon. drium, pericranium, and periosteum, as the case may be: why, no one explains. It has been considered insensible, because in health it has not 1 10 sense of feeling so fine as other parts of the system, which are furnished wit! more nerves (s. 30); but, the very few of these fine organs with which the membrane of the bone is furnished, renders the pain occasioned by disease, whenever it may be attacked, the more acute; when flying from one nerve to another, those well-known shooting pains are felt (by us) that are universally mistaken for pains in the bones themselves. We do not go too far in inferring that the horse is similarly affected. This takes place in splents and spavin, when the bone enlarging forces its way through this tightly-braced membrane, and causes inflammation, temporary lameness, and, at length, those wellknown appearances 1 have just named. In the living horse this membrane is red, by reason of the fine blood-vessels with which it abounds; but in the dead subject, the supply of blood being withdrawn, it then turns white.

\section{CHAPTER II.}

Concerning the Horse's Inside, of its Conformation, the Functions of the Organs of Lifc, and the Diseases to which each is liable: together with Outlines of the Principles upon which the Cure is to be effected.

18. Such, as I have endeavoured to teach, being my view of the external frame or structure of the horse, which I have termed its built, I come, in the next place, to speak in a more particular manner of his inside; noticing, as I pass on from one part of him to another, the seats and causes of his diseases, with a view to their cure, but referring you to the second book for the separate treatment each requires. In the third chapter will be found my reasons for fol. - lowing up the principles herein laid down, by a line of practice, at variance, in some material points, with the present mode of treating the animal in health as well as in disease.

Organs.-But, before 1 proceed to describe those several part? of the horse's inside, there appears to me an absolute necessity for previously making the unlearned reader better acquainted with a few general topics: that we may proceed with the details sinoothly and more intelligibly together; viz. the names, uses or offices and powers, of that infinity of small organs which lie spread over most parts of the body, and belong in common to several of these parts in nearly equal degrees. 'The large organs, having the power of carrying on the animal system, first, as regards digestion, secondly, those employed in the circulation of the blood, and third, those of respiration, are too well known to the sight and touch to require explanation here; yet are they (the heart, kidneys, lungs, liver, \&c.) composed or made up entirely of those minor organs I mean first to describe. But the precise way in which these act in and upon the large ones, the great share they hold in further.ng the system of animal life, and the eminent rank their services maintain in restoring healsh when the system is any way disordered, has not received, in the practice of horse-medicine, that share of serious consideration the importance of the sulject imperiously demands. To these points, then, 1 shall shortly call the reader's undivided attention; meantime, as some cramp words and phrases ane 
applied by most people (writers and others) to those offices of the animal's organs, they stand in need of previous explanation.

19. Each kind of organ, whether small or large, was designed by the great maker of all things to perform some office towards the preservation of the animal in health. When such office is performed properly, as ordained, the organ is said to "perform its functions well." For example, the heart is given for the purpose of sending the blood through the arteries, all over the body; but when the pulse beats low or irregularly, that organ is said to "perform its function badly ;" when it ceases to beat, this function is lost or gone. So, certain of the organs are said to secrete something or other that is liquid; the doing this is their function; the power of doing so, that of secretion; and the article secreted or collected together, is called the secretion of this or that organ. Thus, the kidneys secrete urine, and it runs off (sect. 53): the glands, under the jaivs, secrete spittle (saliva), which passes off with the food by the intestines; therefore are they properly considered as excretory also, secing both the secretions aredrawn together for the express purpose of being so sent away, this last by the grand canal (or gut), as the first mentioned is by the hladder, and the perspiration is through the pores of the skin. But some secretions are found that have no outlet visible to us weak mortals, though they find their way through the skin, sensibly enough at times; and this then becomes the sensible perspiration or sweat, but when we do not see it, this third species of evacuation is termed the insensible perspiration; and in health, one of the two is always in action,-in disease not so.

When, however, it happens such functions are obstructed, or, on the other hand, too much of either secretion is furnished to the system, then disease begins; as does, also, our duty of finding out what part of the vast machine has ceased to perform its office properly. For, without this previous information, no man can possibly know how to apply the remedy in restoring the disordered organ to the proper exercise of its function; nor can any one loppe to arrive at this desirable point of veterinary knowledge, unless he has acquired the means of ascertaining where, when, and in what degree the mischief has taken place, by patiently examining the action of those organs while in health, and comparing their appearance, after death, with the particular symptoms which preceded that event.

20. SECRETION.-Although, as I say, the secretions just spoken of are im. portant in themselves, and of several sorts, as bile or gall by the liver, urine hy the kidney, \&c. yet the chief object of uur present notice is the secretion of a fluid, more or less watery, which pervades the whole system. It differs in quality a little, and very little any where, being adapted to the nature of the parts requiring its aid: 1st, In softening and enabling them to move freely over each other (as, between the ends of bones); 24 , Acting as a defence against injuries from extraneous bodies (as on the inner coat* of the inte'stines); and $3 \mathrm{~d}$, To prevert the parts from growing together (as the liver to the midriff), \&c. Misfortunes these which invariably happen when the supply of this fluid falls short of the quantity required for a long while together; and this is the case whenever the animal is worked until the fluid, at some part or other, is exhausted: a circumstance that strongly bespealis the propriety of allowing the worn-up poor creature more frequent supplies of water although this be done in smaller quantities. Inflammation, or fever, which is occasioned by suddenly checking the secretion, eventually exhausts this moisture by its great heat. Buth those disorders are therefore referred in the

The surgeons of human practice will observe, that $I$ here transgress the lontrine of the surfaces; but they will please to recollect that my object is to make my self unders on' I $\mathrm{v}$ a cercains chass of eadeis, of which they compose a very small are 
sequel to the same origin; the first being local, or pertaining to some particular organ or part, whilst fever pervades the whole system, and the solids in particular. The total absence of perspirable matter marlis both diseases

On the other hand, when too much of this fluid is secreted, and remains unabsorbed, disease ensues: vion the heart it forms "dropsy of the covering of the heart ;" on the covering of the lungs it becomes "dropsy of the chest ;" in the membrane of the helly it forms "ascites," or dropsy of that part, and usually falls into the scrotum. The powers of medicine have hitherto proved of no avail in the first description of ailments; and are but partially applicable to the last mentioned; the operation of tapping too frequently disappoints our hopes, to induce us to rely upon it as any other than a temporary relief, and it is, therefore, seldom or ever applied to the horse. Thus, in whichever way' we view this important secretion, its eminence must strike us as quite equal to any other. Whenever obstruction in this part of the system takes plave in the horse, the consequent adhesion of the parts being invisible, he gets worse used by his inexorable master for his inability to perform his usual work, and he soon falls a victim to the lash, the spur, and the bit. At the joints, this fluid is considered to be an oil (cynovia); at the heart it is confessedly nothing but water: whilst it partakes of a mucous, or slimy nature at some other parts of the body. This is the case with the membranes of the throat and gullet; on those of the nostrils, the heat of the horse's breath converts it into a "viscid mucus ;" when the secreted watery particles come off by sweating, it assumes a white or milky appearance, after a little time ap. pearing thicker and more slimy as the sweating continues, and the watery particles becoming less and less, its fluidity is also lessened. See membranes, sect. 26.

21. In all animals, the secretion of this watery fluid is carried on by the membranes, which are thin films placed between the various organs, over the bones and among the fleshy parts. These not only secrete, but sustain the fluid in its place, for the purposes above mentioned, and being of various texture or fineness, the fluid that is so secreted and held to its jurpose by each, partakes more or less of water, is more or less slimy, or consists more or less of an oily nature, according to the use it may be designed for. Each kind of membrane, and its proper secretion, has received a learned name,-the first being called serous, the second mucous, the third fibrous; but, having resoived to abandon learned words, whenever the thing can be understood as well without them, I find less occasion for introducing them here than is generally practised. For, the peculiar nature of the horse having assimulated together, by its action, the three kinds of secretion more so than is the case with other animals; and its habits contributing as much more to the hasty calling off of one kind of fluid from certain parts to the assistance of another part, which may have been exhausted of its kind; and as the treatment of the horse in all cases of a disordered sccretion of these fluids is the same throughout, the action oi medicine upon one always affording the assistance to anuther (as I shall prove shortly), there is no such necessity fur carrying the distinction farther in horse-medicine, although it may be so in the human practice.

Perspiration is always at a great height in the horse; it is one of the chief means of cure in most of his disorders, and consists in drawing the watery secretions from all parts of the body. These pass to the surface -eadily, coming through the membranes from the joints, the solids, the bowels, and their coverings; as may be noticed in the case of hide-bound, apon opening the animals that die in this state of exhausted nature; the mententery canal (hereafter described) is invariably discovered with yellowness, beng, at Limes, almost orange colour; but $l$ have as constantly found the lacteals of a 
fine coated hurse shine through as white as milk. Again, on over-working the horse, so much of the joint-oil is sometimes drawn off by perspiration, that lie becomes stiff in the knees, for want of that softening quality which kept the parts supple; we feel the same ourselves upon such occasions; and in taking off" the knee or the hough of a permanently "stiff-jointed" horse, I have invariably found the joint-oil affected; in very bad cases it no longer existed. During life, the escape of this oil, by reason of wounds (as bad broken knees), leave the joint stiff. Further comment on its uses is unnecessary; but those facts should teach his owners a practical lesson of moderation.

On the subject of absorption of these secretions, I noticed many years ago, a very ingeniuus reason assigned for "laıneness of the fore legs, of English horses particularly," in the great work of La Fosse, the elder, on what he calls "Hippo-pathology," or the diseases of horses. He says, "The fluids which did lubricate the parts (the shoulders) and keep them supple, oeing reduced in quantity, the food flying off by sweat, the remainder gets thicker in consequence, and the solids of his limbs become stiff and dry." It happens, mostly in the fore limbs, and he calls it a cold or chill, and says, page 267, it resembles a "stroke of the shoulder,"- "Citeval froid ct pris dans les epaules." A species of founder, that is clearly not to be cured by external applications, (as the oils, firing, \&c). but by restoring to the part the function of secreting a sufficient supply of the fluid which had been so exhausted. In these few words are included the whole secret of my method of cure in such attacks; and, in this case, gentle sweating is that remedy which is best calcu. lated for restoring the function.

22. When the skin does not permit evaporation, and sends forth the secretion by perspiration, disease has begun, the hair looks staring near the part uffected, and not a stable-boy exists, who, when he sees a horse with a rough coat, can not tell that "something or other is the matter with him." This arises from want of moisture within; the skin itself not having the power of secreting or drawing towards it, by effusion, the moisture which is necessary to keep it supple, it shrivels up, and this important evacuation, which is second only to the urinary, is then stopped, so that even the insensible perspiration ceases. Some idea respecting the amount of this insensible evacuation may be formed, by placing a horse, that has been exercised, between ourselves and a well white-washed wall upon which the sun shines: when the shadow of the insensible perspiration may be seen upon the wall ascending in tulerably thick volumes, something very like steam from a boiling pot. Indeed, the insensible perspiration is, when compared to sweating, the same as warm compared to boiling water.

Yet, although we do not know the exact workings by which this internal effusion (as it is called) of the watery particles from one part of the animal to another takes place, we do know, accurately enough for our purpose, that abundantly perspirable natter lies in and upon the intestines; as any affection of the heart, arising from the organs of sense (sect. 30 ), causis a sudden suffusion of blood in the slin, and induces heat and irritation there;* so do the intestines send forth their watery particles upon the slightest occasion, to the same place of exit, in order to moisten and render it more supple. Whether the very transparent membrane, called peritoneum, which sustains the bowels, or that other large part of it which covers these and all parts of

\footnotetext{
- rear, for instance, of the dealer's whip often occasions the skin to contract and expand, so ny $(1)$ cause the titil to shake with every alternate vibration of the heart; and I once rode with a Iow, a rightout journey of forty-tour miles, who whipped and spurred his horse to such a exrot, that the thairs actually fell off from his tail, exrept a few at the end, an occurrnce that is tually ascribed to scrophuta on the horse's hile; a disorJer tt night have also laboured unejcr, - aught I knesw w the contrary.
} 
: he inside, is most concerned in this secretion and effusion, is not worth the trouble of inquiry here. But, in addition to what is said in the last section respecting the colour of the lacteal duct, as it passes along the mesentery in vases of hide-bound. I may be allowed to observe, that we may daily witness the sensible perspiration from young and healthy horses to contain more of water than is found in feverish, old, or generally unhealthy animals; and that with these the siveat is more frothy, or becomes so much sooner, his mouth gets clammy, and his tongue dry and hot underneath, with less work than they; and that horses so affected are always found insatiably craving after water. Moreover, as regards the connexion that subsists between one part of the animal and another, 1 have many times found purging physic, given in the usual doses fail of the effect intended, and come off in the shape of profuse perspiration. Not only in those large and decided doses that are intended to produce much effect, hut even milder ones, as alterative-laxatives often turn out of their course, and, as well as diuretics, not unfrequently disappoint us in the same way, the latter also coming off by the skin instead of urine.* It follows, of course, that the less sweating a horse has got, the more he must stale, and accounts for the profusion of the latter kind of evacuation in winter, when he scarcely ever sweats, and perspires, but little, comparatively speaking. As a farther pronf of this connexion between the secretions and evacuations, let any one notice a horse when he first stales in consequence of taking a diuretic, and he will find a transparent water hanging in little globules at the enci of each particular hair of his coat all over his carcase.

23. We come now to speak of glands, nerves, membranes, absorbents, (being 1st, lymphatic, 2d, lacteal, ) and muscles, which are the names writers and practitioners of eminence have agreed upon to speak of those numerous minor organs that are employed throughout in carrying on the functions of animal life, and the uses whereof I shall come shortly to explain. The reader is already aware of the sinews, of three kinds, that more immediately cover the bones and keep them in their places (sect. 16, 17), to which if we add the bare mention of the muscular, or fleshy parts, and refer to the "circulation of the blood" (sect. 37-14), for a description of the veins and arteries, he will have before him the names of all the integuments of a horse's body beneath the skin. Detailed particulars respecting all these follow next in their order; the larger organs of the inside being reserved to the subsequent sections of this chapter. By this course of proceeding he will be better enabled to comprehend, as we study those things together, why and wherefore these were given to the animal, and what functions each has to perform in health; or these ceasing, or being obstructed, we shall be led to consider in the next place, what species of remedy is proper to be applied for removing such obstruction, and thereby of restoring health; for he may rest assured, that not the least atomy of matter has been conferred upon the anirnal form without intending that some gond and demonstrable end should he answered by its creation. In addition to all which, there are many causes, incessantly operating towards the simply grand purpose of prolonging life, and of providing for the waste which is constantly going on in the animal system, that are far removed from our sight, and others almost surpassing our comprehension, but which are nevertheless known to vxist by their effects; but, of all these several matters, more in their proper places; one instance of the insufficiency of human knowledge having been already adduced in the preceding section, as regards the unknown mide in which the watery secretions penetrate from one part of the body to another.

- Tears or any other evacuation of the water that moistens the animal system, are liable to tho eame kind of compatative remark. In man, when excessive salivary secrecion attends the wothach, the glands of the mouth and jaws carry off so much water as to affect the quantity of urine voided, and we may infer that a diuretic would reduce the inflammation of the jaws so mueh for the confurative practice: but not worthy of rejection on that as count alone 
21. All those important points of knowled ge in the first principles of our art lie within the compass of every man's capacity, who can read; they are cer tainly open to his inquiries; and he who is coustantly among horses can nor finil to learn (after studying the sulject in the manner I now propose) to makf himself as well acquainted with the symptoms or sigus of approaching diseasex as the generality of veterinarians. He certainly may render himself much superior to the old, ignorant set of farriers, who were bred up in the days of stupidity that are just gone by-never to return. Let such an inquirer after knowledge bring to tie task industry, patience, and good common sense, and he may soon acquire knowledge enough of the outlines of the art to be able to pronounce when a pretender is at work, or when it is that a man of judgment and real sound learning in his art has undertaken the treatment of this valunble animal in the distressful hour of sickness. On this head I am not ashamed, after the lapse of nearly half a century, to own that I once wept over the sufferings of a sick animal which died of the medicines administered by a stubhorn self-willed farrier, who could read, and write, and talk, give a drench, and drink himself-and nothing more: he could not think, of course could not cunpare one disease with another, nor mark the difference that exists between two or more that are frequently and fatally mistaken for each other. And here, once for all, J can not refrain from thus early insisting most strenuously on one point, which therefore $I$ shall not have to repeat when I come to notice certain barbarous practices perpetrated by some such men, and the not unguilty practice of other physic-giving horse-doctors; and this is, in short, whuever of them dares to undertake the administering of medicines to this incomparable animal without paying especial attention to the subject natter that is handled in this chapter, commits an umpardonable act of inhumanity on his sulfering patient, and of gross dishonesty towards its owner. The remedy for a disease is not always to be found in medicine; preventives never. Purgatives are not only the most obvious means of cure, but the best, the least dangerous, and those which promise in the readiest manuer to dispose th most vital function to resume its wonted action. Alteratives are the safest anc. most effectual remedy for valuable horses, and those which can not be spared from labour; they are indispensable in all cases of vitiated blood, and where found ineffectua! nothing else can be of service. Bleeding is the very best, or the very worst auxiliary we can employ; its efficacy and precise periods of utility may be learned in the sequel (see sect. 37 to 44 ), where "the circula. tion" comes under consicleration, also in the first pages of Book II, where the pulse is justly made a subject of primary consideration.

25. For the sake of making myself more clearly understood, I shall, when explaining the formation and functions of the horse's inside (i. e. as much of it as will answer my purpose), consider it under two distinct heads; namely:

1st. The fore part, or throat part, as it is called from its neighbourhood to the throat, or gullet; and,

- 2d. The hinder part of him, being his belly, properly speaking, \&c.

Both of these parts have obtained learned names; but that is no buslıess ef ours.

The fore part of a horse is that which lies between the rider's two knees, within the chest and true ribs. To the farthest of these is attached, as well as to the middle of the back bone, a natural division of the two parts, stretched tightly across his inside, like the head of a drum; and it is also fastened to his breast hone, but admits of the gullet to pass through, as it does of the great vein and great artery which carry on the circulation of the blood of the ninder part. With these exceptions it is air-tight, and it bears resemblance to the bead of a drum in another particular-it is membraneous, except round the 
edge next to the ribs, \&c. where it is found somewhat fleshy. From its situa. tion in the middle, this natural division is termed the midriff, or skirt, and ap pears to have been designed for keeping back the stomach and bowels of the hinder part, which as it is, when full, press it out of shape, not unlike that of a watch glass, and would, but for this barrier, interrupt the action of the heart and lungs. But by the present contrivance, as we shall see presently, this pressure from behind soon receles, the midriff returns to its level, and the ribs, no longer contracted towards each other by the aforesaid pressure, expand, thereby enabling the lungs to perform their function, of drawing in a fresh supply of air. Upon this principal agent in the function of respiration, see more in detail in the 35 th section of this chapter.

26. After this necessary preamble, let us proceed, as before proposed, to consider the construction of

The Membranes,

Muscles,

Glands,

Absorbents, (i. e, 1st lymphatics, and 2d lacteals, )

Nerves.*

Of these the most universally dispersed over the frame, those which occupy, defend, or embrace every part, are the membranes. As well behind as before the midriff, not only inside, but on the outside and every part of the animal are these skinny films placed, for the purpose, 1st, of keeping those parts which they encompass in a compact state; $2 \mathrm{~d}$, $\mathrm{t}_{1}$ ) secrete a fluid for protection (see sect. 21 ); and $3 \mathrm{l}$, to prevent those parts from rubbing against and injuring each other, or allhering together. The hetter to accomplish these purposes they are admirably calculated for the secretion of a fluid, as I observed before (sect 20 ); but whenever the property of secreting such fluid is suspended, then disease begins, and according as the secretion may prevail, being either too little or too much, will be the kind and quantity of disease. Hereupon may be calculated the importance they hold in the animal system: but of those matters I have already spolien higher up.

Membranis.-To appearance they are nearly transparent, web-like, and of a strong texture; some are simply film, having more or less of feeling according to their uses, and are those which, being interposed between one organ, or part, and another, prevent the interruption which would otherwise ensue; as the midriff, for instance, which I have just above adverted to (see sect. 31 and 35), which is the thickest of all, or the loose membrane that covers the lungs and divides them into two parts, so as each may act separately (see sect 32). The second species of meinbranes are finer, more transparent, and paler than the first mentioned, and possess the quality of containing in their cavities, resembling sponge, the matter deposited within them by the arteries for the purpose of repairing waste and adding new flesh; these we term cellular membranes, from their sponge-like texture, and they are, moreover, so infinitely thin as to pervade all over the solids, or fleshy parts, without being in every case visible to the eye. They are nevertheless proved so to exist, from the circumstance of those being greatly distended, when the subject dies of being "blown," as 1 have shown lower down (sect. 35). Then, not only the forehand, but the hinder quarter, even down to the hocks, become inflated with the wind, which, by reason of the animals being strangled, the lungs had no power to discharge, and the cellular membrane admits it into its cells er ravities. Any one may perceive this membrane and its numerous cells io advantage in a buttock of beef, or leg of mutton, after being dressed; upsn laking a slice between the fingers and straining it nearly asunder, tíc mem 
brane appears, but more evidently at the corners where two or more muscles meet; and in summer time, particularly with over-driven beasts, the membrane between the muscles will be found charged with a dull brown sort of matter, that may he, and frequently is, scraped away with the knife. Another familiar illustration of the uses of the cellular membrane, first mentioned by old Dr. Bartlett, of WVindsor, in 1764, is that of "the inside of a shoulder of veal, which hutchers blow up with a tobacco-pipe, or quill, to delude their customers." When the animal becomes adult (or full grown), the membrane that is so capable of being blown up is filled with meat, and shows the inpropriety of pushing young animals in their work before those solids have $\checkmark$ zached maturity.

When once divided, membrane of either species never again unites, but in case of a healed wound the granulations of new flesh hold the divided parts of membrane to their respective places; the obstruction thus occasioned in the deposite of blood causes pain upon change of weather, when the new flesh cither expands or contracts, as it may be effected by heat, cold, or humidity. In the human physiology, another lind of distinction is made between the kinds of membrane (as $\mathrm{I}$ said before), tending to show whether their respective secretion is more or less watery, slimy, or oily; but this view of the affair is not applicable to the physiology of the horse. My reason for abandoning that course was given at section 21 . I may, however, here aptly olserve, regarding that species (the slimy or mucous) which lines the nostrils, throat, and intestines, that its chief disorder is a cold, which shows itself in the cessation of the secretion; soon after this, the parts being inflamed, throw forth a thin acrid discharge, which is greatest when the inflammation arrives at its height, sometimes producing a little blood, either upwards or downwards; when the inflammation wears off; these appearances are also lowered by the mucus becoming more and more thick, until it reaches its usual consistency. The cure is to be effected by lowering the inflammation; but this is most frequently effected by the natural discharge of the mucous matter just spoken of.

2\%. Niscles are fleshy bodies of various sizes and shapes, according to their uses; reddish, of a fibrous texture, easily separated, but more stringy at some places than at others : the last-mentioned are termed "coarse parts," or pieces, in the animals sent for our sustenance, and are those where the greatest strength lies. These fibres formed into bundles, and surrounded by the cellular membrane, are visible to the eye, if there be not attached to each fibre a continuation of the same membrane that is not visible. Several of those bundles, heing further enclosed by a stronger membrane, form a muscle; each whereof is attached by its two farthest extremeties to some other, or, to two different bones, upon one or the other of which it acts as a lever. A muscle accomplishes this motion of the hone by expanding its belly or middle part, and contracting it towards the centre; whereupon the bones to which the muscles' ends are so attached are drawn towards each other, and that which is farthest from the trunk is drawn forwards or backwards, at will. Thus, if we wish to bend our elbow, the muscle which is situated just above that joint, inside, contracts in length, and expands in breadth, till the fore-arm is brought up to touch the muscle itself. Fighting men (boxers) exhibit this muscle, as indirative of their strength; and horses of good action show the same sign at every movement, whilst with those that are over-fed, the muscles are concealed in fat, that obstructs their movements; whilst, with those which are impoverish ed, the muscles dwindle away, hang slack, and ill support the wonted action of the bones. When much compulsory exertion, in liot weather, has cxhanst ed the secretione that keep these parts supple, aridity and stiffiess follow, and the action becomes impeded, difficult and uncertain.

All muscles of the limbs are long and narrow, when quiescent; those of 
the buxly are more wide than long; in a good measure, squarish, oval, or tr. angular, according to their uses. 'T'hey have been compared, with gond reason to the shape of flit fish, some beiner long and narrow, like the sole, others wide, like the plaice. At their ends, muscles often terminate in a much stronger substance, closer in texture, inelastic, bending with facility, and insensible, answering the same purposes, but oceupying much less room than muscle. 'These are tenlinous, and the horse which is well kept, having the tendons strong and vigorous, is bold, strong, and "sinewy," moves his limbs with agility, and gets over his work to admiration, by picking his feet off the ground well and replacing them (as you see while he is going) within a hair's brealth of the spot you may mark out for them to pitch upon. On the legs, tendon supplies the place of muscle, wholly so in blond-horses, less in the cart-horse breed. Muscle is constituted of blood deposited in the membrane, innu'nerable small arteries, some of which are scarcely visible, terminating within

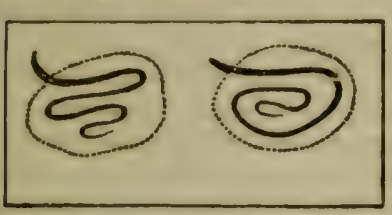
each muscle, by a kind of doubling up, or curl, as shown in the margin; within each of these a correspondent vein is twined, and the whole being covered with the finest membrane, constitutes a gland. Herein it is that the veins commence their share in the work of circulating the blood afresh, as we shall see in the sequel, and the lymphatics obtain the watery particles into which the morbid matter of those solids are converted : those figures receive the name of "glinds."

In blood-horses (natives of hut climates), as we have seen, tendon supplies the place of muscle, or flesh, upon the limbs particularly, which are always finer than those of other breeds; this accounts why our fleshy horses in sultry weather, or hot stables, feel the greatest lassitude, even to weakness, whilst those of full blood seem invigorated by the same circumstance. When, however, the atmosphere of the stable be moist as well as hot, both breeds suffer equally in one way or another; laxity of fibre and profuse perspiration, with weakness, fullow, and this producing an obnoxious effect upon the excrematory organs, occasions in stables those stinking ammoniacal vapours that destroy the lungs, by disposing them to contract inflammation.

28. Besides the GLANDs just alluded to, they are situated in and about tne solids and more secluded parts, and so small and concealed as to be scarcely exposed to the sight or touch, unless when inflamed and enlarged by disease, other larger and more evident ones occupy the hinder part of the animal, of which I shall speak in their place. They are, 1st the liver; $2 \mathrm{~d}$, the kidneys; anu $3 \mathrm{~d}$, the testicles; the functions of each being tolerably well known. See sections 52-55. All glands, of whatever size or shape, are employed in secretion, taking up and separating from other matters that quantity of watery particles which is constantly escaping out of one-part of the system into another, by means of the cellular membrane, as described at sections 21 and 22. The smaller glands, just now described, have each a small tube attached to it, which seems intended to hold the acrid, or otherwise noxious, matter which its lymphatic had refused to take up, as being at variance with its function; here it remains concealed, until the proper occasion arrives for carrying it off, which may be found by one of the three natural evacuations; but these failing, it is clear disease of one sort or other must ensue. Perspiration seems to be its most natural mode of passing off, unless the demand for that kind of evacuation happens to be low, and then it is drawn to the kidneys, (sect. 22). But, if the discharge by dung has been so copious as to afford too little of this acrid matter (essential probably in a certain degree) by mears of the absorbents of the intestines, then, and in that case, it is taken up once more. When the animal's spirits are low, the absorption imperfect, and this offensive mattar 
lies a long time in the tubes of these small glands, a general languishment of the beast takes place (called lentor by the old farriers); he perspires upon the least exertion, becomes unnerved, shows a rough hide, and refuses his meals. This constitutes "Iow fever," when the whole animal system is affected. This state of things, which is very common, points out the impropriety of now resorting to diaphoretics (sweating powders); for it has leen neglected so long, that tired nature, heing offended thereat, refuses to part with those particles which occasion the greatest injury. "By the urine," be it said. This way offers the same difficulty, and the answer resolves itself into my plan of opening the principal evacuations first. (See what I shall offer concerning bleeding and purging in a subsequent page.) So much, however, seemed necessary to lie advanced here, that the reader, who reads straight an end, should be at no loss as to what lately passed between us concerning secretion and effusion at sections 21 and 23 . Of all the smaller glands, the best recognised are those termed salivary, situated near the jaws for the secretion of spittle, wherewith to moisten the food while descending into the stumach, and thus assisting di gestion in its first stage. The strangles and vives are disorders of these glands: the swelling at this part is a corresponding symytom of glanders, and sometimes attends farcy. But the largest of these minor glands is situated in the solids, and lies within the buttock, concealed near its centre, into which passes an immense quantity of blood for its size, since it is found in the dead subject most disposed to putrify, especially when the animal has been driven hard, as is the case with all the cattle killed in London for food.

29. LYMPHatics are one of two species of absorbing vessels; the other species (the lacteals) being reserved for description under the head of "digestion," at sect. 44. They are small tubes, with mouth that suck up or absorb the thin watery particles of the solids, one or more being placed on each gland of these parts. Some idea of the important nature of this part of the animal system may be formed from the circumstance that mercury applied to a glandular part of the body undergoes immediate absorption by the lymphatics, and is conveyed by this means through the jugular vein to the blood. Persons who may be unfortunately ordered to rub in mercurial ointment on the thighs will feel a fulness under the left ear in the course of a few minutes, according to the previous state of their bodies. How mercury acts upon the second species of absorbents-the lacteals, remains to be seen hereafter. The tendency of both is towards the heart, or rather the left collar-bone; increasing in size and diminishing in number, until the lymphatic duct meeting with the milky juices of its co-absorbent in the thorax, the mixture soon becomes blood by the action of air in the lungs, as described at sect. 39. As the lacteals, it will be seen, absorb only nutritious juices, so the lymphatics absorb none but offensive ones, as the matter of diseases, wounds, spavins, broken bones, ulcers, and the useless part of the deposite made by the arteries as said at section 27 ; these being mixed, pass through the heart, there receive fresh vital powers, as hereafter is described, and thence to the liver, there to be purged of its bad qualities, which, passing incessantly into the intestines is soon eliminated with the dung. At least, such is the natural course in health; a change takes place when these organs do nut perform their functions aright, and we can perceive this misfortune in the dung; when the absorbents are at fault, particularly in the yellows The importance of stimulating the lymphatics in all disorders of the nuter surface, as mange, surfeit, farcy, \&c. must be evident: as it is, also, in cases of tumours, as poll-evil, fistula, \&c.

30. The NERVEs, like the glands, run in pairs, mostly, to all parts of the body; they are the organs of sense, communicate immediately with the brain, and are thus principally concerned in the function of voluntary motion. That the hurse entertains likes ant dislikes is certain; he has a memory too, botb 
for persons and places, as every one knows; he must, therefore, have perception, and he is kind and docile in his nature, which entitle him to a kinder return from his master than he usually receives. I have often lamented that he was not endowed with one more faculty, even in the smallest degree, that he might distinguish hetween those who really love him, and those empirics who make a profit of his sufferings; he would then be induced, probably, to kick some among them, as an example to all the rest; and I never hear of one of those fellows, or their employers, being unhorsed, but I think of retributive justice. So, when the horse is girthed up unmercifully, in such a manner as to obstruct his respiration, he frequently attempts to bite the operator-and, "serve him richt," I say. As the nerves of a horse are the seat of no distinct disease, I shall content myself with adding, that they consist of small cords, white and roundish, like thread; and are certainly the vehicles of pain, which vibrates from one to the other, pleasurable sensations being conveyed hy the same means to the sensorium, or brain.* The nerves are closely connected with the circulation, and with the brain, where they originate.

31. RESPIRATION is the act of drawing in the air by the expansion of the lungs, the cells whereof thereby become filled to their utmost, the ribs are distended, and the midriff pressed back upon the stomach, liver, \&c. This is inspiration; the expulsion of the air, forming the re-action, being termed expiration; both together constitute what we call breathing or respiration, and the matter was before introduced (in section 8,) when I noticed that powerful auxiliary of this function-the midriff. Now, as I have always attached much importance to the act of respiration, seeing its close connexion with the formation of blood, and the almost constant state of disease in which are found the organs that contribute to this great function of animal life, I shall enter into more minute particulars respecting these, than I have thought necessary for any of the preceding organs. By this course, the reader will be enabled to form more distinct notions respecting the forming and "circulation of the blood," and its concomitant, the formation of chyle, commonly called "the digestive powers"-both of them functions most essential to health; but unhappily, both together hecome, by contravention of those powers, the fruitful source of numberless ills, we thence call constitutional or hodily disease, as fever, abscess, farcy, \&c. To this point tends all that I have hitherto said concerning the inside of the horse; and the inquirer after veterinary knowledge will find his labour in studying this portion of it amply repaid, by the just principles upon which he will subsequently conduct his practice.

32. The LUNGS, or lights, are two well-known spongy bodies (called lobes), having at their conjunction a small lobe nearer to where the pipe enters that is to inflate them. At the same place is fastened the ends of a thin membrane, or rather two membranes, that enclose each one of the lobes: this membrane is termed the pleura, and seems designed to admit of one lobe performing its functions whenever the other may at any time be diseased Between the two

\footnotetext{
- Conscience (consciousness), which agitates the nerves by the faculty of thinking, when ao. plied to the evils that are in the world, does sometimes cause the accession of fever to those deit cate organs in human nature; but brute animals being denied thene powers (or of memory; except as regards the meitns of prolonging life) are little likely to contract " nervous fever;"; although that state of fretfulness some high-bred horses are prone to, partake of a good many, gymptoms of the human ailment, and may he cured by the same means. Sedatives, quiet, anc a cooling regimen are those mems. The lonse stable recommenderl by John Lawrence, and bow much adopted, contributes much to sonth the fretful horse. When the same fretfuliess ar despondency cumes over a horse, one of condition, or whose condition has been recerdly re. unced ho açuires slow fever. S'ee what is said under this head in Book II.
} 
lobes, the membrane (pleura) is double, and, from its situation in the miduls (ir: medio) is called mediastinum : it furms a passage for the great blood-vessels rumning near the spine, and it is very liable to contract disease, which shows itself in "thick wind," or rather short wind. Sect. 36 . In the pleura, then, are wrapped up, as in two silk handkerchiefs, the two lobes of the lungs, the upper part of that memhrane being fastened to the spine and rils; and on its surface is generated or socreted some of that fluid I before spoke of (sect. 20, 21 ), which is designed to keep the parts moist, and prevent their adhering together. His powers of secretion, however, and those of this urgan in particular, often fail in the horse, in consequence of his very great exertions, combined with the heat of his blood, exhausting more than the secretory power can supply; and we frequently find the pleura growing to the ribs, the lungs, or the rnidriff, by reason of its wanting a due portion of this fluid: from the same cause (a defect in the secretion), we sometimes find the upper orifice of the stomach partially attached to the midriff, evidently caused by inflammation of the parts. But whichsoever of those misfortunes attend the horse, he is invariably "hurt in his wind," suffers much pain at the commencement of a journey, and subsequently, if pushed hard, dies of a locked jaw, through excessive suffering. Disorders of this nature were hitherto unknown to fur. riers of any description, being mistaken for the worms by every one who has written a book upon horse diseases; and, by the most eminent veterinary author of modern times, the last stages of this mal-conformation are vaguely noticed by the erroneous term of "debility," and "general debility," which may mean anything amiss. Whenever the animals that are slain for our sustenance turn out to have beer so affected, their flesh is rejected by the Jews, under the denomination of trifler; for the whole animal system is entirely affected by the horrid circumstance; the secretory functions in general refuse to perform their share in the production of good and sufficient animal matter, and lentor, or slow fever, is the consequence, as mentioned higher up, in Section 28.

33. The WIND-PIPE, as its name imports, is the pipe or tube for conveying to the lungs the air which every act of inspiration draws through it. Extending from the throat to the lungs or lights, at their conjunction this tube divides into two branches, one penetrating to near the bottom of each lobe, and these again, having a dozen holes a-piece in their sides, inflate an infinite number of little tubes, or pipes, which compose the lungs much in the fashion of sponge. Except eight blood-vessels, which enter the horse's lungs, the intervals are filled with cellular membrane, and these being also connected with the same kind of membrane in all other parts of the body, accounts for a phenomenon, $\mathbf{l}$ shall take occasion to notice shortly (sect. 35 ), in the case of a blown horse. At his upper end, the wind-pipe is composed of strong cartilaginous plates, connected together by ligaments, and put in motion by small muscles for producing the sounds expressed by the animal. Next to the throat these cartilages, which are there strongest, form a curiuus kind of cham. ber, termed epiglottis, over which is a lid or valve, placed there to defend the passage into the air-tube, from the entrance of victuals, drink, \&c. For, upon the descent of any such substances, this valve shuts down like a trap-door, and they pass over it. No sooner, however, are they gone past, than up rises the valve again, lying back towards the mouth upon the palate, and being very large in the horse, accounts for the gulps with which he takes in water, and his peculiar mode of feeding. For the same reason it is, that the horse breathes only through his nostrils, between which and the wind-pipe there is close affinity in some diseases, and accounts for his incapacity for bellowing like the ox, or vomiting like man. At this spot it is, that certain savages in buman shape press the finger and thumb with brutal furce, in order, as it is 
called, "to cough him." No certainty, however, lies in this imagined test of his wind; for, although a thoroughly broken-winded horse will not ccugh, yet one which is partially affected will do so in most instances; whilst the soundest horses do most obstinately resist the coughing; and in a few, the cir cular cartilages so well defend the muscle, as to defy the inhuman effort, and seem to rebuke the ignorant attempt "to prove the goodness of his wind."

34. Farther towards its lower extremity, the wind-pipe becomes more membranous, but less sensible of injury, and the cartilaginous rings gradually lose their form: they no longer describe a circle, being composed almost wholly of strong elastic membrane, that it may bend out of the way when the gullet is distended with swallowing. Its internal surface is lined with a membrane, which incessantly secretes a quantity of the mucous fluid spoken of in sec. tions 20 and 21 , hereby defending its coats from the action of the air in pass. ing to and from the lungs. But this secretion being exhausted, sometimes by the very great exertions of the animal, he then coughs so as to shake his entire frame, as if to incite the membrane to make fresh secretions of fluid for its defence; or, in default thereof, the cold air still rushing in at each inspiration, he contracts a permanent cold, or catarrh, which, if suffered to continue, increases and runs along the membrane to the lower branches of the pipe, and ultimately communicates its baleful influence to one or both lobes of the lungs. If the attack be trivial, small green spots are found on the surface of the lungs, which afterwards form ulcers, increasing in size and number, according to the number of small tubes or cells that may be affected. These tubes lose their functions in consequence of the first attack, the animal's wind becomes worse every time he is hard pushed, and the cells burst into each other, until, perhaps, one lobe or half of his lungs is rendered useless. In process of time, it turns black as one's hat, infects the other lole, and mortification ensues, which is rather accelerated by the cordials with which the poor creature is usually punished, and it dies.

But when it so happens, that ton much of the fluid is secreted in the windpipe, the animal snorts or coughs it off by a sudden natural effort; wherein, the midriff being made to press forcilbly upon the lungs, by the sudden con. traction of the muscles of the lower ribs, out flies the wind through the nostrils, carrying with it whatever may have adhered by the way. Whenever this is the case, the membrane that lines the nose inside becomes irritated, and fresh accession of its own secretion, thickened a little, is the consequence; in flammation of the part, ulcers, and a rumning of foul matter ensue-and this, if the blood be not in a good state, soon becomes that obstinate malady-the glanders.

An instructive experiment may be made upon the pluck of a sheep-the relative situation and functions of these parts in all quadrupeds being the same, except that the sheep's lights, compared to those of the horse. are not so long in proportion to their thickness. Take a pair of bellows, and having introduced the nozzle tolerably well into the windpipe, tie it round with a colsbler's end; then, blowing hard with ne hand, while the other is employed in squeezing the pipe, to prevent the escape of the air back into the bellows, you may form an accurate notion of the effiet of inspiration. The lights or lungs at first give out the whole of the air which has been driven in, and may be inflated to an enormous size; but, if much force is used, the cells burst into each other, some appearing on the surface thin and transparent, and refuse to give back their wind; this forms "broken wind" of one description, and is that wherein the expirations are slower than the inspirations-the pleura being then affected in its thickest part, and the milrifl also Out of the first jart of this experiment may, likewise, be derived a more accurate knowledge of what is termed "second winl," among sportsnsen : when the animal (or man) 
has made great exertisins, so as to fill all the cells of his lungs to their ntmost, und then relaxes from the labour, he finds himself renovated, the cells being rendered more capabie of distention and expulsion, when each inspiration and expiration also occupies more time and less labour.

Sporting men, who are fond of our bear-baitings, Fecora-fights, and monkey scratches, may daily witness a practical natural illustration of the same doctrine, in the conduct of the bear towards his antagonist. Seizing the deg between his paws, he squeezes him up till he gasps for breath, when Bruin, bring muzzled, rams his nose tight into the dog's mouth, and, blowing with all his might, you may hear the wind whizzing : the dog swells all over, by reason of the air entering the cellular membrane, and he dies unless timcly pulled off. A dog which has "had a hurt" of this sort seldom regains his proper wind; he must be "a good one" to face the bear again, "as long as he crawls." Such is the polished language at those elegant places of town amusements.

35. The Midrifl has been already mentioned (ss. 25 and 31 ). It is termed diaphragm by the learned in hard words; and we have seen how materiali!y it is engaged in the business of respiration. But for the action of this drum: head-like membrane, neitlier the lungs on one side of it, nor the stoniach, bowels, and liver on the other, would obtain their full degree of motion, which is thus kept in tune, as it were, by those organs acting alternately upon each other; the action of the heart, too, is in unison with that motion; but when through agitation (occasioned by great exercise, affright, \&c.) it does not keep time, the temporary disorder, termed jalpitation, is the consequence. We may infer that, when the lungs have discharged their contents, the lower or thinnest end of that organ, falling upon the muscular border of the midriff, is by it repulsed and excited to action. Any man can feel, when he has expired all his wind, a kind of throbling internally, lower down than the heart, until he inspires a fresh portion of air. When the lungs are in such a state of supineness, those of the horse are about three or four inches thick at the conjunction with the windpipe, and ten to thirteen inches from thence to each extremity, according to the size of the subject; but, when fully inflated with air they together fill up the whole cavity of the chest, obstructing in a trivial degree the vibration of the heart: then do they reach to the enormous difference of twelve or thirteen inches in thickness, and somewhat more in length. At least such were the dimensions of this organ in a horse which was opened by me in May, 1820: he was of the cart-liorse breed, under sixteen hands, and healthy in other respects than having been blown by eating ton much corn; whereby nature was compelled to leave the lungs quite full at the moment of his death. The same subject is alluded to in the 26 th sect. where I intended to illustrate the formation and functions of the cellular membrane.

"No part of the animal has been formed in vain," as 1 before observed (s. 23): quadrupeds and bipeds both press the carth which gave them birtb and which affords them the means of prolonging life; accordingly this order of beings is furnished with a midriff, but fishes and insects, having no such necasion for this organ, are without it: neither have birds a midriff; but $\mathrm{Mr}$ Jolin Hunter was of opinion, that the want of it is supplied by the hollowness of the bones, which not only increase their buoyancy, but the air contamed in them re-acts upon the lungs in the same manner as a midriff would do.

36 In health, as in disease, the midriff is liable to be affected by its neigh. bours, both before and behind it, the stomach often communicating its state of feeling to the lungs through the midriff; for it is by this medium that me dicines impart their beneficial effects upon the lungs, as may be experienced upon our swallowing cold water at a time when our lungs are heatedthr relative situation of those organs heing much alske in man and in the 
norse. Immediately hereupon, a sensible difference takes place in the numher of respirations, and the quality thereof is also changed from a hot to a cooler temperature; well be it, if the suddenness of the check do not occasior inflammation of the lungs: again, whoever swallows spirituous liquors feels an immediate disposition of the lungs to repel the heated air of the cells which lie contiguous $t$, the midriff; the first breath which escapes the mouth being less heated than that which follows and finishes the expiration, and imparts a sensation wholly different from the vulgar belchings of an overcharged stomach. These come up by way of the gullet, and carry forth a nauseous effluvia; whereas air from the lungs is ever sweet, unless this organ be alreaily in an advancel state of decay. This state of the case leads me to make one practical observation, which shall not be set down, as more curious than useful; out of seventeen subjects, which successively fell to my lot to examine as to the immediate cause of death, only two, tolerably sound at the lungs, presented themselves; which I take to be the fair proportion of sound horses, as respects the lungs of all that live or dic. All those cases occurred from February to May, a season when such an affection might not be considered most prevalent. Hence, (my realer may smile!) I conclude from all that has been said, that a tolerably good guess at the state of a horse's lungs may be formed, by smelling at his breath after a canter, in like manner as our Smithfield dealers smell the animal's nostrils in order to detect the glanders.

From what has heen said, it follows, that a diseased stomach may be produced by diseased lungs and vice versa, and that the midriff suffers in either case: then does the midriff become livid, purplish and inflamed, with darkcoloured stripes, as if thickened at such places, the muscular border thereof assuming a putrid appearance, and sending forth a villanous stench. When this is the case, or any other ailment prevents the midriff from performing its proper function of inhaling and expelling the air from the lungs, that species of "broken wind" takes place which is known by the sort of breathing wherein the expirations are quicker than the inspirations; being thus contradistinguished from that other species of broken wind, which is occasioned by rupture of the air cells. A paralysis of the midriff, or the adhesion of the stomach to its lower side, is equally obstructive of its reaction upon the lungs: and I have this day (May, 1820), cut away an adhesion of this sort as wide as the palm of a man's hand.

Unfortunately for the horse which is affected, either in the midriff, the lungs, in the pleura, or covering thereof, his doctors heal the whole series in the same manner, not unfrequently including in their uniformly mistaken practice, the affections of the stomach, liver, pancreas, \&c. In all, the intlammatory symptoms are predominant, and a cooling regimen presses itself upon our notice as more proper than the best of medicines, although having the same tendency; whereas, the direct contrary is the practice mostly followed, and heating medicines, under the fascinating name of cordials, made of spices, ale, wine, \&c. are administered daily. Or, at most, if a sedative or opiate, by chance, finds its way (properly enough) into the anima!'s stomach, this organ is thereby only rendered more susceptible of the heating mixtures which are ayrain had recourse to immediately thereafter.

TIE ORgans of RESPIRATION are liable to seven or eight several kinds if disease, mostly origrinating in the horse's having caught cold; they are :lo. nominated accorling to the particular place where he may be affected, and is one respect, according to the degree of attack. A cold (simply) or cataris. produces that affection which denominales the patient "a roarer." Chrume cough brings on "broken wind," of which there are two sorts; and consump.tion usually follows the long continuance of either. When either hiss rou 
unued arwhile, and reduced the animal's strength, he is said to bn in a ron sumption; "worn out" is also a common phrase, as is "rotten;" "debilitated," and "done for," stand a little higher in gentlity; but all mean, that there is small chance of his recovery.

Pulmonary consumption is the only kind which may be attributed to constitutional defect; i. e. heated blond, with viscidity, causing over-much action of the parts (see section 32), when the pulse becomes powerful and quickened, and the horse scems anxious and fearful. Should it subside by judicious treatment, or the natural strength of the horse, he commonly retains so much of its effects, as to cause great danger whenever he may catch cold, or be worked too hard. This attack is too frequently neglected, or put off with the renark, "only a little touched in the wind," unless ly the addition of a cold, the disorder comes on rapidly, when it is termed "inflammation of the lungs," and the animal goes off in four or five days, if he be not promptly relieved. On dissection, the parts are found spotted with a livid colvur, and evident gant: grene; every variation indeed, is equally appalling to humanity, and I have: often wondered how the horse could have lived an hour under such horrid circumstances.

A cold, simply, or catarrh, commences by inflammation of the lining of the windpipe, which may be confined to some given part of it, or extends itself generally" from the nostrils to the lungs both inclusive, much resembling "a cold" in man; in either case, much matter is secreted, and thrown off by snorting: when the attack is confined to the upper part of the pipe, and lasts some time, the horse becomes a confirmed roarer, his groan bearing great resemblance to the roar of some wild animals, and he is equally incurable.

Chronic cough is that obstinate cough which remains and plagues the horse long after vain attempts at curing his cold ought to have taught his tormentors the inutility of their endeavours and the dishonesty of their prescriptions. Broken wind is of two sorts; the first is caused by the rupture of the air cells of the lungs by over exertion, in which the expiration being slower than the inspiration, he is, aptly enough, said to be "broken winded ", the second kind of broken wind is known by a breathing the direct contrary, and is occasioned by the cold having settled upon the perforations of the branches, and enlarged them, so that the air escapes ton readily. Thick wind, on the other hand, arises from the secretion of the pipe getting into the cells of the lungs, and affecting the orifices or perforations by thickening them, so that the air passes through with difficulty. Similar symptoms attend inflammation of the pleura (section 15), particularly when it reaches to the mediastinum, or double part; as they do when the muscular border of the midriff is affected. But these, though perhaps considered two different diseases at the commencement, in the horse, very shortly become one common affection, more or less, of all the organs of respiration; inflammation predominates over the whole series; and if the performance of his duties does not render them fatal, an injudicious treatment will fix upon him an incurable disorder, until the knife terninates his usefulness.

Lafosse, junior, olserves, that "flat-chested horses, are almost always subject to consumption, whilst (again) consumption narrows the capacity of the chest, and re-produces itself--there is no remedy for misconstruction." He further says, "Short wind is either produced by disorders of the chest, or it is a fault of construction, and both are irremediable. Such a horse is generally of less use than one that is thick-winded."

37. The circisation of the bronn is carried on through all parts of the hody, to which it affords the means of life and health; or, heing ill performed, Is the? fruitful source of lingering, olstinate and incurable diseases, somo whereof almost baffle our skill and care; and, while they induce us to admit shat the practice of veterinary fhysic never will reach perfection, inspire the 
hape that, by patient investigation, we may at least find out the means of allevating their evil tendency. These considerations should excite particular altention to the subject in hand, being that to which all other functions are iut subservient or conducive; respiration and digestion being more closely connected with it than any other, and requiring a corresponding degree of attention. The heart, jointly with the lungs, occupies the cavity of the chest, rather inclining towards the left side, against which its point may be felt bea' in.s, whenever the animal is agitated by exercise, or internally affected by anfiammatory complaints. Its figure is tou well known to render description necessary : in size it approaches that of an ox, and, like it, is cnclosed in a membraneous sac, but very thin, not unlike a tight purse. Another sac, called the heart-bag, less tight, surrounds the former, but is never so large, nor encumbered with fat like that of the bullock. On opening this sac there issues forth a fluid which turns to water, if it were not so already; in the ox it is confessedly water, and rather more in quantity than in the horse; - the reason for which difference I will show presently. So great is the stimulus of this organ, that its contractile power often exists long after the animal is dearl, and the arteries cease to flow: a phenomenon that occurs when the horse is killed in full health, by an accident, or otherwise, while in full possession of its functions. In animals of much mettle or courage the heart attains to a great size, that of the famous horse Eclipse weighing $181 \mathrm{bs}$. In some horses, the vessels that nourish this muscular organ lie exposed on tho surface; with others, they lie wholly concealed; a fact from which I have yet found no opportunity of making any sure deduction, but apprehend it may arise from the breed, and conclude it must have considerable effects on his disposition.

As the heart is the principal organ employed in converting into blood what is drawn from the finer particles of food sent into the system for that purpose, as well as in renovating that which has been exhausted of its vital principle in the circulation, it may well be supposed full of smal! blood. vessels. Four large ones meet at its thick end, and suspend it, by being attached to the bones of the back and ribs: two of them, bringing the dark vi. tiated blood from the extremities of the fore-part and of the hind-part, are veins; the other two large vessels are arteries, which, receiving the blood from the heart, just now refined by the process of nature, convey it with rapid con. tractions to every part of the system, there to give fresh vigour, and to impart health to the whole. These contractions constitute the pulsation, or pulse; a criterion of health as of disease, which we investigate with primal anxiety, as from it may be deduced the best prognostic of the state of disease, especially of inflammatory ones, to which this noble animal is more than any other subject, from eauses to be explained hereafter.

38. Two large chambers (as I call them) and two small ones, each of the latter appended to one of the former, mainly contribute to the process of circulation ; these, by their co-action, aid the contractile potver of the heart, compelling the contents of the larger chambers to issue with much force into the nrteries. But, hefore the blood can be thus again fit for circulation, nature has provided the means of rendering it so, by the action and re-action of these four chambers (or cavities) in the heart, contributing to refine it for that purpose; one large chamber, with its small one, being placed on the right side of the heart, and the like pair on the left side thereof. The blood from the veins flowing into the small chamber on the right side, irritates its inner coats, and they each contract upon its contents with nearly as murh strength and quickness as ive can open and shut the hand; - but certainiy not so much open, although there is a flap on the entrance of each small chamber, which therv liken to "a dog's ear," and call by the Greck word auricle, that being" 
an ear. At each of those closings or contractions, the blood is forced out of the snall chamber into its large chamber on the same (right) side, through a small door-way, or valve, which opens only inwards, the door being too large for the door-way. By the way, these valves are very numerous in the animal system, principally as regards the circulation of blood in the veins; and the reader will do well to recullect, when I speak of valves in future, the illustration just given by comparing the same to a door-way, which bears a near resemblance to the valve. In the performance of this office, the heart may bo said to have three several motions belonging to it: 1st, a quick one, by the contractions of the smaller chambers upon their contents: $2 \mathrm{~d}$, the contractions of each large chamber upon its contents, being just half the number of throbs made by the first mentioned: and, $3 \mathrm{~d}$, the vilbration or tremor of the whole heart in consequence of all those motions.

Well, on the right side still, the large chamber being filled with venous blood through the valve, or door-way, from the small one, becomes in like manner irritated so as to contract upon its contents, and to drive it out somewhere or other. Back to the small chamber it can not possibly go; the valve does not open the way, as I have just now said; and therefore it issues with much more force through another valve into a short artery, which soon opens into two, like the letter $\mathrm{Y}$, the heart being supposed at the bottom of the letter. $\mathrm{U}_{\mathrm{p}}$ rushes the blood to the top of the two branches-where it meets with - What? What do you think it meets with, gentle reader?

Here, however, let him stop a little, and consider awhile; for, upon his rightly understanding what now becomes of the blood (tlick, dark, and unservice. able as it is), and how, in a trice, it becomes healthy, of a bright scarlet colour, and invigorating, mainly depends his being able to comprehend, by-and-by, what I shall have to offer concerning the diseases to which a vitiated or corrupt state of the blood gives rise. He will not, otherwise, make out sufficiently clear in what manner the blood of an animal can contract and retain that morbid state which shall predispose it towards acquiring a constitutional disease that, however differertly named according to the parts whereon it may fix, has but this one common origin for the entire series. To this page, then, I shall frequently refer him when speaking to these points more in detail, hereafter; and he had best, also, keep the hook open at this place, whenever he may be endeavouring to comprehend what the learned veterinarians of the present day are striving to say respecting "the circulation," as they quaintly term it. Another of them, speaking upon the topic I have just lrought to a conclusion, says, "The heart is divided into two cavities, termed ventricles, each having an auricle, resembling a dog's ear. The blood-vessels proceed from these [those] cavities, the arteries from the ventricles, the veins from the auricles, \&c." All which is very true, but not very intelligible to the generality of readers; and yet is the author, who thus speaks, (Mr. White, in vol. i. p. 63) said to be the plainest spoken among the moderns; indeed, were he any thing else than a good one, I should not have deemed him worthy of this rebuke.

39. The Blood, as I have said, rushes out of the large chamber on the right side of the heart into an artery that soon divides into two branches; whereof one enters each lobe of the lungs, and there disperses, through certain cells, the blond with which it is constantly supplied. Here lies the the secret! At this point it is, that health or disease (at least a predisposition to one or the other) is imbibed and engendered in the blood. The lungs having receivea the thick discoloured blond from the right side of the heart, and being the receptacles of the air we all breathe, do, by means of that air, bestow upon tho blood afresh the principles of life, and health, and vigour. The cells, or tubes, thrnggh which the blool jasses in the lungs, termed pulmonary, are eight in 
number, being double the quantity given to man, and show, from that circum. stance, the immense circulation of which they are the agents. A cruel and almost incurable malady, that attends most horses at this part of the organs of respiration, with many and variable symptoms, was alluded to higher up, at sect. 36 ; and is what we term from those vessels, pulmonary consumption. But then, it is clear, that the air which is so brought to effect those beneficial changes upon the blood in the lungs, must be fit for the purpose:-that is to say, it should be vital or atmospheric air, uncontaminated by any noxious stench (as the ammoniacal smell of the stable, or the stench and snoke of cities); no poisonous vapours (as burning brimstone, the gaseous fluid, smelting of minerals*), nor infectious efluvia (as of cesspoisls or stagnant waters, producing fevers, glanders, \&c.) can give to the animal's blood that healthy vigour which was designed for his well-being; but, on the contrary, every departure from purity, in the air he breathes, must be an approach towards diseaset. Yet, how constantly is this simplest law of nature transgressed! And what; in such a state of things, can be expected, but that the blood will assimilate in character with the kind of air the creature is compelled to inhale? $F$ Accordingly, we find in the domesticated horse, that previous disposition tc certain diseases which we endeavour to ineet by correctives and repellants, but which by better treatment might have been prevented. Of these evils, bscess, or ulcer, is the most prolific, showing itself now on the head, at others on the heels, under the varied denominations of poll-evil, quittor, fistula, \&c.; but more frequently attacking, and making the greatest ravages on the in. ternal organs, where it is generally mistaken for the worms, and erroneously treated with hot and burning remedies, when evidently a direct contrary practice would best assist nature in casting off the evil.§ Ulcer upon the lungs, as it produces a staring coat, is too frequently mistaken for worms, and if the animal be not physicked and cordialled too much, a partial cure sometimes takes place, though in what way it is carried off is most inscrutable; but, upon opening the dead subject, I have often noticed spots which had been corrnded and gangrenous, where the cure had been effected in this spontaneous manner. As for ulcers upon the liver, also arising from the viscidity of the blood, if

\footnotetext{
- Scarcely any truth is easier provel than this: Horses that are constantly kept in close stables, in large numbers together, very soon hecome unserviceable, by the crnstitution throwing off some evil or other upon the surface; as one proof whereof, those which are occasionally placed in the under-ground stables, at the Swan with Two Necks, Lad-lane, show evident aigns of distress which subside upon being brought into the air. I hear from gool authority, that at New Orleans, in North America, where the atmusphere "exhibits a blue misty appearunce," nothing is more common than a disease which affects the knee, hock or pasiern joint with abscess, or near those parts with cancer, and the limb actually rets ofi: The like kind of attacks were found formerly most common in Cornwall and in Wales, and are atributed by all to the arsenical vapour of the copper mines being inhaled: they are, however, much less frequent at the present day, owing to the higher state of cultivation to which the land has been brought, and to the change of situation horses now enjoy. The free use of sweet oil is a good preventive of this poison in human as well as in cattle medicine.

$\dagger$ This is not the place for a finished dissereation on the communication of the glanders; but 1 must observe, in illustration of the text, that horses which have eaten glanderous matters without receiving the infection, no sooner smell it than they become diseased.

$\ddagger$ In cases of much sorrow or grief, our respiration is much increased; and the presentiment of death awaiting them, occasions all animals to take harmful substances into the lungs. Pirg, oxen, and even sheep, show signs of uneasiness, horror, or madness, at the effluvia of bloou of their own kind: and I have found in each kind of animal, upon slitting the trachea as far as the bronchia, dust, dirt, or other rubbish, which they had snorted up in the last paroxysms of despair.

$\$$ Four ounces of spirits of turpentine have been given with partial success: but such a dise must go near to destroy nut only worms, but the horse into the bargain, whilst it is not very t.ear to me that the small worms we sometimes meet with are hurtful to the animal, but aro designed to act as a stimulus to the intestines: and, if the loctor mistakes for wonns sume more corious disorder, the horse dies of this monstrous medicine, as sure as fato.
} 
they take place near its thin extremity, the common natural process is, that the part of the liver attaches itself to the gut, and the offensive matter will then slough off into the intestine, and come away by stool: a partial cure is the consequence: not produced by medicine acting upon the part, as is very clear, vut by a common natural effort, aided by a more vigorous and healthy state of the blood than when the disease was engendered. To assist the circulation in regaining this state is clearly the duty of the medical attendant, and is the only manner in which he can be of any service to the animal in restoring it to health.

40. In ihe lungs, then, does the blood receive from the air its invigorating principle, and no sooner does this take place, than it drops into another shor blood-vessel (a vein), and, by it, is conveyed again to the heart: not the same small chamber on the right side, of course, but to a similar one on the left side. Here the contractions go on as before mentioned, only that the blood differs in quality; this heing now properly fitted to promote the purposes of life, and for imparting the vital principle, occasions the heart to assume that twisted shape we see in some animals, while in others whose bodily exertions and arterial functions are less laboured than those of the horse (the sheep's for example) it is more round: and, indeed, the heart of this last mentioned animal is, from this circumstance, usually termed, in the London district, a "round heart." Out of the small chamber on the left side is the blond driven through a valve, as before, into the large chamber of the same side; which in its turn contracts, with much force, upon its contents, expelling the same into the great artery. This periodical rushing of the blood into the arteries, imparts to these vessels a motion we term pulsation, whereby the blood is propelled forwards, to the remotest parts of the body. Lessening in size, and increasing in number, the branch-arteries, which receive this blood, become more sensitive as they are farther removed from the heart, and afford us, at certain places, the means of ascertaining by the touch the clegree of heat at which may at any time be the state of the animal's blood; the contractions of the heart being regulated, in quickness and furce, by the degree of stimulation the heat of the blood may occasion it. This is termed the irritability of the heart, and the medical test of which I speak, is called "feeling his pulse." Even in the tail may this contractile power of the arteries, and its effects, be seen to advantage; when a colt is being docked, the blwod squirts forth with frequent gushes, answering in atolerable accurate manner to the state of his pulse, although the artery at that remote part is very small. But the blood that is so changed in the lungs, as 1 have just said, is still found to contain certain particles or properties, which would render it unfit for the purposes to which it is to be appliel, or those particles are required to effect certain purposes elsewhere in the system. Accordingly, the major part passes into the liver, there to be refined of its bitterness; whilst a portion is attracted to the kidneys, where it leaves its saline qualities, that pass off by staling, as the former is voided by dunging. See "Liver," farther onwards.

41. These purposes, however, are not always effected alike regularly, from several causes. Frequently, the blood comes to those organs in a state too vitiated for their utmost activity to clearise; sometimes a diseased state of the blund, at others, languis of the parts, indispose them to the performanre of their functions, and the blowd is suffered to circulate, filled with humours that war with the constitution, and form what is termed "constitutional disease," or predispose him to receive disorters of varied malignity, according to circumstances. I shall come to advert to this point when, shortly, the liver and kidneys claim our attention; but, the chictest cause of disorders incident to :he animal by reason of defective liver, is the great exertions he is put to, and the consequent rapidity of the circulation, wherehy the blood is propelled througt 
it with tremendous velocity : it then acquires inflammation, and becomes ul. cerated (see sect. 39); a disposition which must be increased whenever the blood has been formed imperfectly, either as regards the lungs or the lacteals So much is this the case, that the blood drawn from a very aged patient of mine lately, that was incapable of grinding his corn properly, showed evident proofs that particles of ill-digested food had entered into the circulation, and is an answer to those writers who aver that the lacteals reject the bile and suck up only the fine parts of the chyle; whereas, all inquiring persons must know, that they take up the lighter parts of all substances whatever that pass through the intestines. If this were not so, how is it that the slow poisons just spoken of enter the blood? or how would it come to pass that so much guod is performed by alterative medicines, that, in like manner, insersibly introduce themselves into the blood, and produce invisibly those permanently goed effects we so much admire? The opposition of a few is no obstacle to this commendation of an obscure but safe and certain class of medicines, - to say nothing of an alterative regimen, which is more safe still, and certainly more matural, though slower and less positive in its effects than active medicine. How much longer is the horse to be treated with nothing else but violence?

42. BLooD-vesseis, or tubes, I have already observed, pervade every part of the body, and are of two kinds, whose office is directly the reverse of each other. Arteries, it will be recollected, convey the vital fluid to all parts of the body, and the construction of these, it may easily be conceived, from what has been said, is simply that of a tube with great contractile powers: they are large near the heart, but soon branch out of a lesser size, until, entering the smaller organization of the solids, they become very minute, infinitely numerous, and more sensitive, thus affording the means of renovation, or growing to the flesh, bones, skin, hair, hoofs, \&c. The large artery corumunicates with minor branches, soon after leaving the heart, by two rows of openings, like perforations, in its lower sides, at two or three inches asunder. Some one has likened the arrangement of these vessels to the stem, branches, and twigs of a currant-bush, and so might the veins that run nearly parallel to the arteries, through every part of the animal, but are so constructed and arranged, as to take up and reconvey the blood (which the arteries constantly deposit) back again to the heart; and the similarity will still further hold good, if wo extend it to the leaves of the bush, and compare these to the glands (see Sectians 27,28 ), in every one of which an artery terminates, and deposits its nutritious contents, and where every small vein begins the absorption of what the artery has so left behind. This absorption, when obstructed, lax, or otherwise imperfect on the surface, may be restored by stimulating the parts with spirits; when it is too high, and labouring greatly in consequence of the viscidity of the blood, local inflammation is engendered, and one or other of those diseases I shall hereafter treat under "abscess," is the consequence of this constitutional derangement. Blood that is thick, heavy, or viscid-cali it which we like-causes heat, which being general, is fever; the rapidity of the circulation increases violently, and the blood becomes more fluid than when the animal was in good health. Arteries may be distinguished from veing in the dead subject, by the property they possess, of retaining their tubulat shape after the blood is discharged; whereas, the veins collapse, when empty.

43. If the arteries are plain tubes, lying for the most part concealed, the veins, on the contrary, are more frequently found exposed to the sight urder the skin, next to the muscle. But, more delicate and more numerous, the veins perform their part of the circulation by a totally different means than is found in the propulsion and contraction of the arteries. One of the means of effecting this purpose is by the obvious and simple movement of the body und limbs, as ivell as by the act of breathing, whereby the blood is pres.sed o'd 
of soine one part or other of the veins into the adjacent part; but these vessels being furnished with innumerable valves, within an inch, or less, of each other, the doors whereof open only towards the heart, the blood must necessarily force itself out that way, and no other. If we suppose that any given portion of the vein is hereby emptied; what follows from the circumstance, but that the next-door valve, which kept back the blood contained in the adjoining portion below, while it was pressed upon from above, being thus relieved from the pressure, will now open? Then, in rushes the blood, and the space is again filled, but only to be emptied in a similar manner. It is with a view to accelerate the circulation through the veins, and to keep the blood warm in winter, that mankind betake themselves to forced exercises, as hunting, running, or beating the arms athwart the chest, and that beasts with the same propensity gambol and frisk about, or rub thenselves : both promote the same ends, by brea hing short, so as not to cool the lungs too much, or by drawing in the same warm air over again, in sheltered situations.

44. By the process just described, the blood being once admitted into the minuter veins, finds its way to the larger ones, which convey it to the heart; near to which, as the quantity becomes great in the large vein, it receives a powerful auxiliary in the filling and emptying of the lungs, and the working forward and backward of the midriff, as described before. Passing through it near the back bone, and, consequently, as its more muscular part, the great vein must at every inspiration receive from the midriff considerable aid in pouring forth its contents-to say nothing additional of the pump-like action of the heart itself. At this part the vein acquires the appearance of a double tube, the outside thickened and muscular, the inner one membranous and collapsed, as if too big for the space in which it is placed. But the curious facthow the blood which had been sent into circulation through the arteries, gets into the veins at first, leserves consideration; as this must be effected laboriously, when the fluidity of the blood is lessened, or else accelerated with frightful rapidity, whenever it so happens that fever prevails : local inflanmation, by the same rule, must cause an unusual flow of blood to the part affected; and, as most of the impurities of the system will then be drawn towards it, at that place must they leave the occasion of the most direful effects. In proof of this doctrine, it happens frequently, that when an animal is attacked with inflammatory complaints at two places at once, the greater evil of the two increases, while the lesser one "runs off," as it is called, or gets cured of itself. So, on the contrary, when a diseased horse (glanderous, for example) is well fed and well kept, he not unfrequently overcomes his disorder without medicine, to the great wonder of the unknowing; the solution whereof is, that the constant supply of new blood has quite changed the nature of the animal, his disease has been "taken up," or absorbed, by the animal system, and ultimately carried off in the common evacuations. In short, absorption and effusion are the great internal secrets of animal life; although we can not say with certainty how they are carried on, it is no less a positive law of nature, that the veins at their commencement in the glands absorb or suck up, the blood that is deposited there by the arteries, and separated by the lymphatics; equally weil known is it, that effusion takes place, of arterial blood, into much larger veins, as well as from one part of the system into another, internally. 'These points are deducible from a multitude of fiets and well-known operations, some proofs of which the reader will find more in detail in the course of this treatise. In some parts, a positive connexion of the capillaries, or smallest blood-vesssels, is found to exist; in such a manner, that the sect:on of one or more of these, and the conseguent obstruction of the means of life to all the parts below it, which some would naturally expect, is herebs remedieu. 
45. Trie Prockss of Digestion, wherehy the food is preparcd to be con. verted into blood, is no less curious than "the circulation" itself, is equally conducive to the support of life, and being obstructed, is also the harbinger of disease. If, on the two other great functions of animal life, depend his immediate existence, no less does the horse's capabiiities, his present health, and? the engendering of future obstinate, incurable, and often mortal diseases reach his vitals by way of his stomach and intestines, that comprise the organs of digestion.

Every cue knows that outs and hay are the chief sustenance of the horse in a domesticated state, and these, togrether with one or two other similar fruduc. tions, and water, are given to him for nutriment alone; it therefore fullows, that whatever substances are taken into his stomach, which act not to the same end, must operate injuriously, even though containing nothing hurtful in themselves : these must obstruct, if they do no more. But, when matters obuoxious in their nature, and possessing strong powers and effects, are being adminis. tered to the horse, it seems but fair to examine whether such things are likely to agree with his common nutriment, with the blood that is made from it, or with his constitution, his habits, or the tasks he has to perform. Or whether, on the other hand, they do not prove destructive of the food itself, of the ves: sels that contain it, and of those which draw up its finer particles that are to be converted into blood.

Let him who practises by violent means consider a moment the natural structure, formation, and functions of the organs on which his medicines are destined to act, and compare their altered state, that has been brought about by reason of the treatment the animal has received at his hands. Some protection, doubtless, is afforded by nature in the secretion of the fluid so often mentioned, which defends the several organs against ordinary injuries; but these are often found insufficient in quantity (notwithstanding the supply which may be drawn by efiusion from other parts of the body), and the frequent repetition of the monstrous mixture of the doctor's skil-less art, ultimately effects its purpose in destroying the tone of the fine vessels just alluded to (the lacteals), and then the symptomatic disease of the skin, called hidebound, follows, as a natural consequence.

46. The Stomach is a bag, or pouch, with two holes in it; the one receiving the end of the gullet, the other opening into the small gut. See it; plate I-L, 26-29. It lies behind the nidriff, inclining a little to the left, having the lungs contiguous on the other side that membrane, and the liver next beaind or under it. This main organ of digestion is but small in the horse, as sompared to that of any other animal, being so designed to assist his fleetness, sut which would be impeded by his receiving large quantities of food at a tinc; and points out the reason why he requires to be fed and watered frequently : he larger and more distended the stomach of any animal may be, the more sluggish and vicious he is. As one proof of this position, I formerly obtained the stomach of a man which was larger than that of any other subject I ever saw or read of, and its possessor in life had a heavy, slow and sordid manner, together with one or two other bad qualities which brought him prematurely to his end.

At the upper orifice of the stomach, a membrane, nearly insensible, commg from the gullet, enters it loosely, and sprealing along its lewer part, lines about one half of it, thus defending it from acrimonious or poisonous substances, whilst the coat of the other parts thereof consisis of striated muscular fibres, very sensible and given to contraction, and ruaning transversely to those of the in. sensible coat, a circumstance which has given rise to the fanciful notion, that digestion proceeds in the horse's stomach by what is termed "trituration," os pounding; but, upon reference to the figure which illustrates another orgar. 
(at section $5 b^{\circ}$ ), the reader will be able to form a more accurate notion, neas enough for his purpose, how the stomach contracts its sensible part upon its contents. This sensible coat secretes a juice which, from its strong gastric nature, not only digests the food, but would also corrode the stomacn itself (insensible though it be), were it not supplied with another fluid for its pro. tection, in the saliva or spittle that descends the gullet along with the fond. This saliva is also secreted, in some measure, when the animal may not be feeding: but, whenever this supply fails, the gastric juice predominates so much as to cause a galling pain in the stomach, and occasion in the animal a ravenous desire for tilling it, if not with food, at least with some substance that may keep it distended, and perhaps carry off the painful superabundance. Horses so circumstanced, when in harness, gnaw the pole or shaft, or bite at each other, and soon learn to become crib-biters, gnawing any thing they can come near, as well as the manger; litter, bits of old wall, and dirt, at length, are found by them agreeable to their palate. See further at section 49 .

The insensible membrane I spoke of, by its loose folds, forms, at the entrance of the stomach, a kind of valve, which prevents regurgitation of the food, like that of ruminating animals; and a similar contrivance at its termination in the lower or right orifice occasions a shurt obstruction until the pulp is mixed; for, when the stomach is filled, the relative position of the two orifices alters in a great degree. From these premises it seems apparent that any substance entering an empty stomach dues not act upon the sensible part of it, but being soon mixed up with the gastric juice, it proceeds into the intestines, there to communicate its effects-iwhatever these may be. Whether nutritive or medicinal, poisonous or beneficial, the intestines receive all with but little alteration.* But when it so happens that the food does not pass readily out of the stomach, a fermentation commences, and the sensible part thereof being then distended, the ill effects ascend the gullet, reach the head, and cause vertigo, staggers, \&c. At times, a specific inflammation takes place, and communicates itself in four or five days to the whole of that surface, taking its course downwards or upwards, according to the orifice that may be most affected; this being all the way down through the intestines, blocking up the influx of gall (as described sect. 48), and causing yellowness of the eyes, until its appearance at the anus; or, in the other case, it ascends up to the nostrils, making its appearance first about the head, and communicates either way to the skin and its coat.

47. Of the intestines, guts as they are usually called, it is important to keep, in mind, that, notwithstanding the appearance of great tenacity they assume, they are, nevertheless, extremely irritable, being composed of two coats of fine muscular fibres that cross each other, the one circularly, the other lengthwise; and having a lining which secretes a fluid for its protection, they admit in their intervals an innumerable quantity of absorbent vessels, that are constantl: sucking up the finer particles of their contents. "This surt of conformation

- At this place, for the information of those who would practise the veterinary art by com. farison, it may be useful to observe, that in the human stomach is digestion principally performed, in the horse's very little; in both, the small intestines appear to mix the food with the bile and other digestive juices; but man having no cacum, or blind gut, like the horse, to re. ceive the heavier parts of the food as they escape from the small intestines, his lacteals begin kigher up than those of the horse, which lie wholly on the large intestines. It foliows that, whatever is received into the stomach of man is felt through the system inmediately; with the horse this does not take place until it has reached the intestines. One other dissimilarity in the mode of digestion is worthy of notice: in man, the work of digestion is nearly finished when the bile is mixed with the food-siny at an average of twelve hours from its being taken, whilst the horse passes his feed into the intestines in about two hours, before it has well assumed alı tomogeneous appearance, which the bile seems to effect for him. With us liquid remaina in the stomach; the horse passes water immediately into the cocum. 
renders the iutestinal canal obnoxious to repeated strong drastic farges, par. ticularly aloes of the Barbadoes kind, that heat and irritate the parts by their conarseness. Inflammation is most likely to succeed such irritation, in summer-time especially, and the animal is usually destroyed by the pretended $\mathrm{r}$; medies of the farriers; or, heing pressed forward in his work during the attack, goes until he drops down and dies. At the fundament may be seen the earliest indications of this species of over-physicking, in the disgusting protrusion of the inner coat whilst expelling the contents thereof; an ordinary effort of nature to get rid of what is offensive to it, which, considering the horizontal position of the horse, might appear wonderful to us bipeds, but for the wellknown double operation of the coats of the intestines. From the top to the bottom of the canal a spiral motion is kept up by the alternate contraction of the two coats thereof, the one in circumference, the other lengthwise, resem. bling that of a worm, and appearing as if a corkscrew agitated its inside. $\mathrm{By}$ this means the mass is pressed backwards, and as it increases in quantity and becomes less and less clearable, the oftended nerves excite the guts to renewed efforts for its expulsion, in which the lower part of the belly, with its cover ing, from the cœecum to the sphincter, concurs with all its powers of contrac. tion. Partial reterition of the breath, and consequent pressure upon the mid. riff, and parts behind it, contribute to lessen the longitude of the intestine at every effort. This kind of excitement, if repeated too often, it is plainly to be seen, must keep up the irritation of the parts concerned in it, and dispose them to contract infiammatory complaints.

48. In length about thirty yards, the intestinal canal has in its course two or three different offices to perform towards digestion, whereof the smallest gut nearest the stomach is for receiving the gall, or bile that has been formed in the liver for that purpose. At the termination of that small gut, at the end of twenty yards, an immensely large one occurs, called the sac (cœeum), or blind gut, where the contents are prevented from issuing too soon, by reason of the internal coat of the small gut getting into folds, as it were. We may as well consider this as another valve; and that it was provided by the Author of Nature to correct the animal's propensity for transgressing his laws against repletion, as well as to prevent the contents of the coecum from returning upwards, when this latter is compressing the large intestines backwards, in the act of dunging. But inflammation sometimes, obstructions oftenur, produce at this place more tedious affections than is generally imagined. When it so haprens that the stimulus of the bile is insufficient (as in diseased liver), and acrinonious particles are left hehind, or the half-masticated fond inflicts injuries on the very sensible surface of this passage, then the noisone effluvia reascends to the stomach; the bile, too, enters it soon after, by reason of the intestines having lost their power of compression and elongation, when the corkscrew motion downwards is changed to an upwards motion, and all becomes disorder in that region. Loss of appetite, fever and dullness, with drooping as if in pain, and a staring coat, follow each other in succession; for the secretion of bile, which I shall come presently to describe, as affecting the skin, is thereby vitiated. These appearances it has been a fashion to considel "symptoms of the worms," or of "debility" (another term for low fever); and the practice of administering bitter medicines, that are supposed to kill the worms, is only successful on account of their restoring the tone of the stomach, and by supplying to the intestines a congenial stimulus in the place of hiie This was the rase with Mr. White's statement, in vol. i. p. 170, where be say's, "I have sometimes succeeded in destroying worms by giving aloes, one drain and a half, every morning until purging was producet." That is to say, "the horse became well;" lut whether he had any worms to be destroyed is suther question; and then, if a dram and a half would succesl sumetimes, ! 


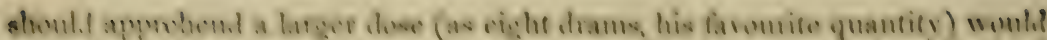

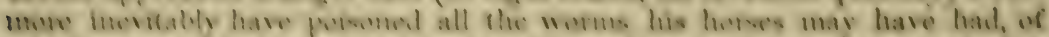

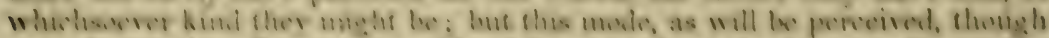

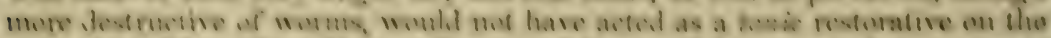

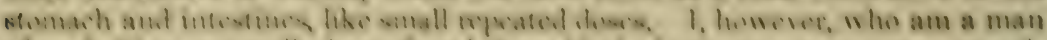

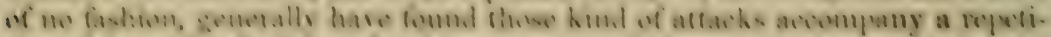

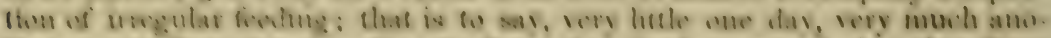

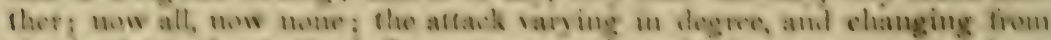

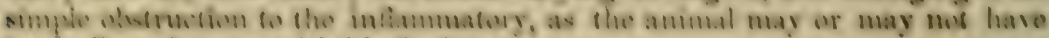
Exwe allowol water with his find.

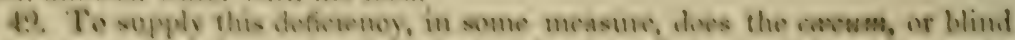

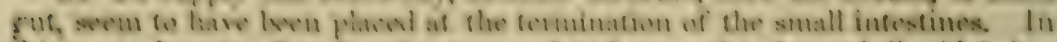

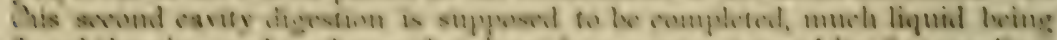

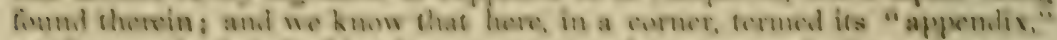

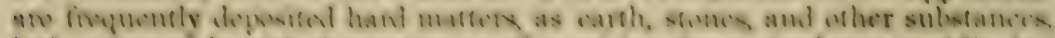

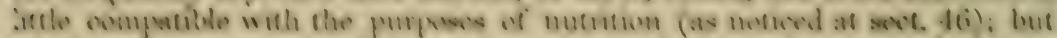

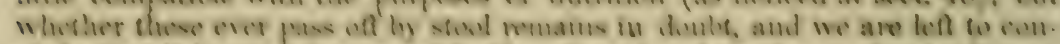

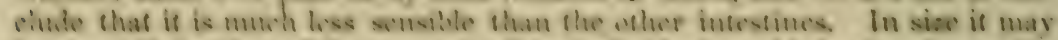

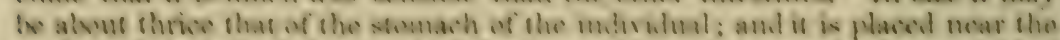

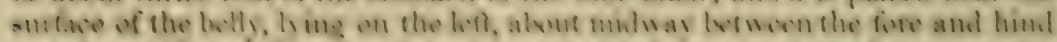

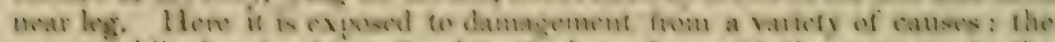

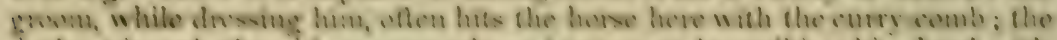

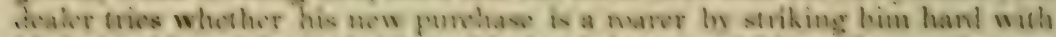

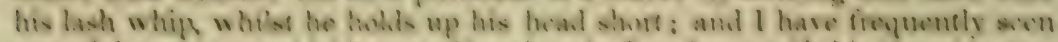

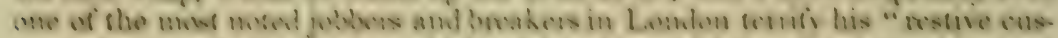

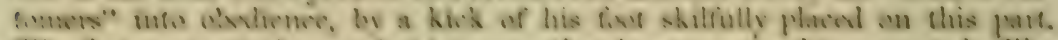

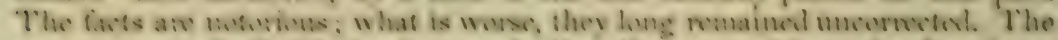

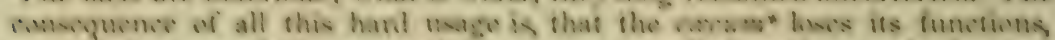

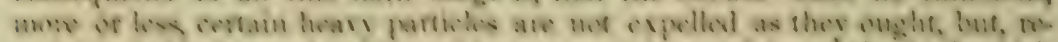

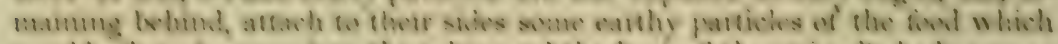

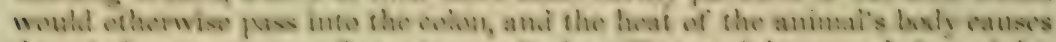

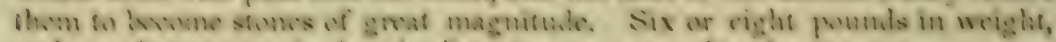

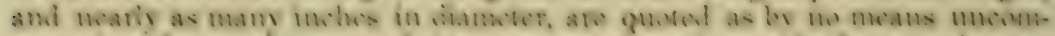

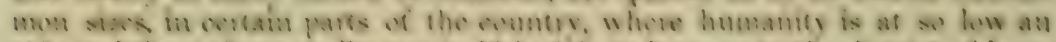

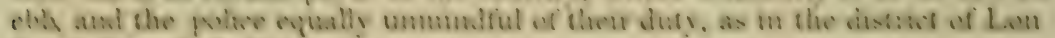
dion Letion allubleve

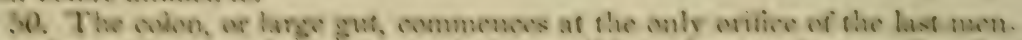

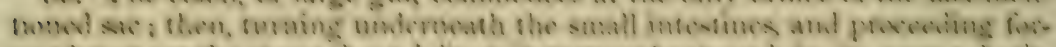

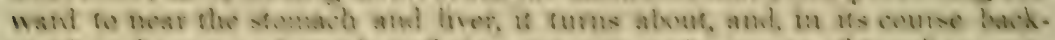

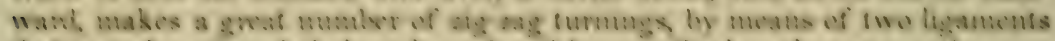

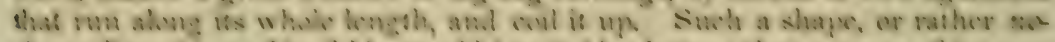

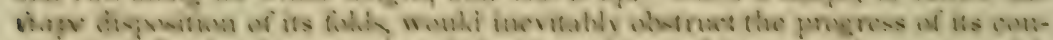

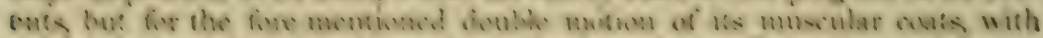

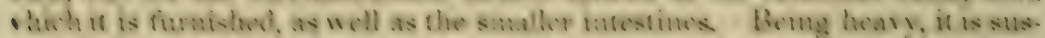

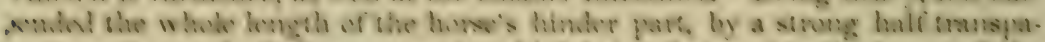

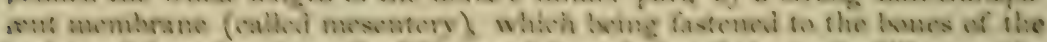

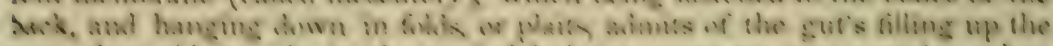

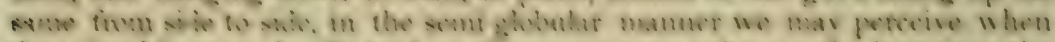

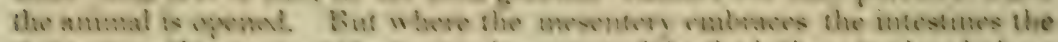

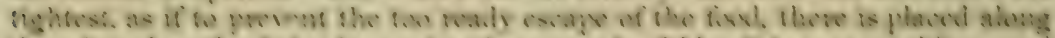

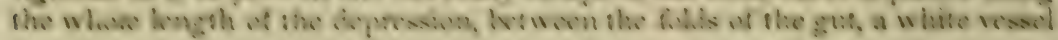

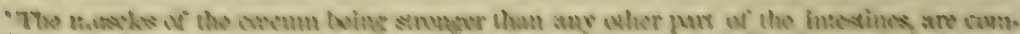

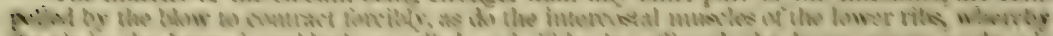

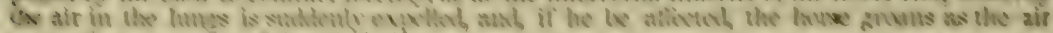

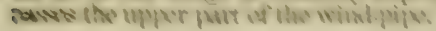


aorption (lake the lymphaties); the largest whereof lying along the nesentery

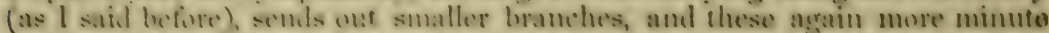

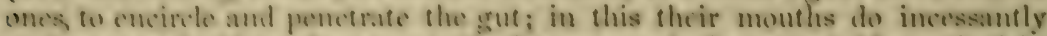

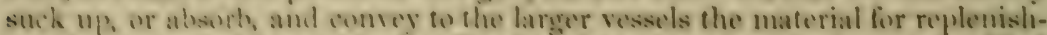

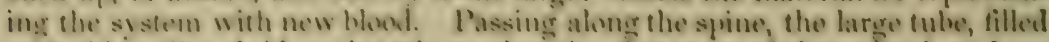
with this unlky thid, at length reaches the fore part of the animal, sud moquires the mane of the thowas atse? : here it mixes with a portion of lymph, and is convered immediately hy a large vein to the heart. Asocmeling tien pulmonary urtery, as described in a former section (37), the air entering the lungs changes is cohour to a fine healthy scarlep, and at the next pulsolfion at is friven info the cinoulation to mingle with the mass, to impart its newly ace quioud properties, and to return argin and again, wasting away, until at

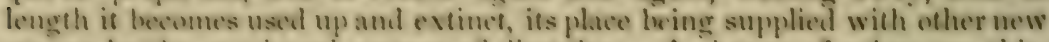
matter by the continued process of digntion. A change of substance this which is soid to take place with the whole boly of the horse in the conrse of every vear and a halt, or two years : so that at no time has he a particle of thesh,

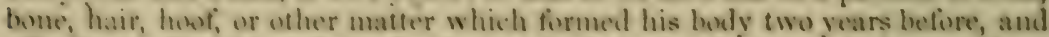
allowling a tit subject for rellection and almiration in us, as it imbites those who have the eare of providing for his healeh to take adrantage of the well

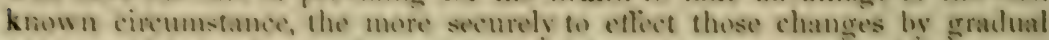
means, which ho frequenty are altempled by violeme, and fail. Nature will

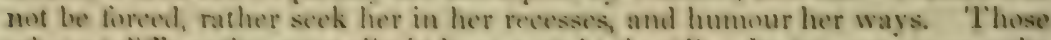
whe act dillerenty, generally indwo some hasting disorder to appear upon the surtine, which thy ireat as if lexal; when, alas! these are soufod in the rem vitals of the animil, sometimes in the most delicite parts of the mesenters. Healing, of condial medicines, as well as those ofher untowwarl mixtures which corroke, or blund, the mouths of the tiner lacteals, thereby dispose them to recive materials improper for the making of gonel howe; the eonsequence whereof is that cubercles frequently are foumd, which fill up the eavities of the lateal duet. 'The maller of these tubereles is ustally hardened, and resembes the yolk of a hand buled eng. 'The discase appears in a staring coat, is communly considered to be the worms, and treated as such, with more heating or drastie molieines, which but increase the enil. ()ther obstructions aro thereby formed, and if a solitary worm or two are foumd on dissection (as frequenty hapjens, they have treon generated in the obstructed part, but havo not caused any fisorier.

Of the mescutcric canal, it may lo useful, as woll as curious, to remark, that I have always found its state of health or disease fo correspond with the apyearame of his oont: when this is smooth, the former is full and free from obstrutions: when mugh, the contrary. In hihe-humb, thiscanal is yelhow; in faner, reil, as well as the buwcls: these appear bluish, when the horse dies in conseguence of being worn out, though at the same time, the flaced laceteals still preserwe their healthy white, if no other eause to the contrary prevails. Rut, upun such further particulars as are commected with the study of dizestion, as inflieming or influened liy respiration amd cireulation, 1 shall

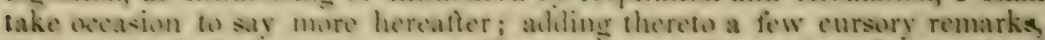
that were not alsolutely nevessury for the present illustration of the animal yystem, but will be find more in jowe in the suceerling soction.

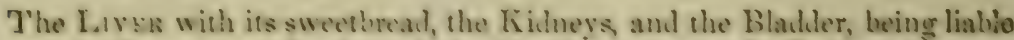

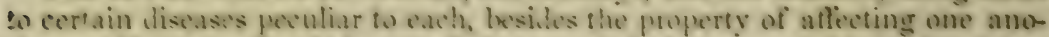
ther roblily, as woll as heing at all times mainiy instrimental in maintaining

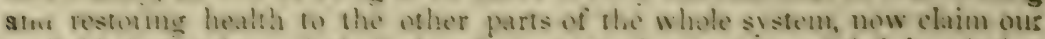

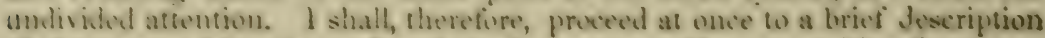

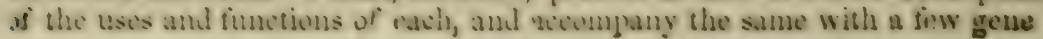


to carry it off, it may easily be forescen, would be the harbinger of jaundico; and its approach may he discerned by the yellowness of the eyes, hy the increased number and thimuss of the animal's dungings, and the constant emptiness of its belly, which both feels and looks loose and flabhy. On the contrary, too little bile, must leave the intestines without the requisite stimulus to expel their contents, which, som getling dry and hard, a constipation usually follows, that defies the remedy by purgatives : nor is the operation of hackraking with chsters always of effectual service. Whichever extreme af fects the liver, the patient becones weak: but in case of deficiency, though he may look more hrisk for a few days, stretching his hind legs out when unemployed, he afterwards becomes feverish, hot under the tongue, sluggish and dull in the eves. Schirrous liver-a corrosion or rustiness of its fine surfice, accompanies this deficiency of bile, and when it recurs often, the disease hecomes permanent; but whether caused by, or causing the same, I am unable to ascertain. Uleerated liver is occasioned by a toogreat heat in this organ: if eccurring upon its thin extremity, the disorder cures itself hy a natural operation, i. e. by alleesion to the grit, and passing of by stool; but when seated higher up, it terminates fatally; by wholly debilitating the system, and sooner or later destroys the patient.

The preparations of mereury, hefore alluded to, act variously upon the system, according to the mode of exhibition the practitioner may adopt: in the form of calomel it assists the liver to discharge its functions by lowering its tone; the blue pill (pilul. hyllorg.) is finely adapted to solve the crulities of stomach and bowels in carnivorous animals, but has never been extensively tried on the horse. For any disease of the whole system, or "lad habit of body," as Richard Lawrence properly calls that predisposed state of it which ultimately produceth tumours, grease, fistula, farey-mercury, in all its various shapes, is the only specitic.

Too great a secretion of the bile, although it pass off, produces a roughish meagre coat first ahuut the belly; the patient becomes languid, especially after being compelled to any great exertion, when he perspires too readily on the carcass, his manner is uneasy, and after a while, partial hide-bound commen ces under the chest. Should the bile be of a less acrimonious nature, thoso symptoms are then prerceptible lower down (i. e. farther back), and when his eves appear yellowish, it is then a confirmed jaundice; but in very bad cases, producing death, people vulgarly call it "broken hearted," because commonly brought atout by bad usage*.

Inflammation of the liver generally acempanies those appearances; but we can not be certain, though it is to be presumed, that inflammation is always consequent upon an over-quantity of secretion. After much procrastination, medicinal remedies are of little avail when tried on the most extensive scale, althourh no disorler to which the horse is liable is easier of cure, if it be taken in time: the patient requires only a treatment directly the reverse of that which brought on his ailments, and he gets well, almost of course. Regular work, molerate feeding, and tolerable behaviour comprise these na. tural remedies: they are usually found efficacious in the earlier stages of the disorder, and then only. But those natural remedies being neglected, and alteratives (the assistants of nature) never thought of, languor of the whole system prevails sooner or later, and the best of medicines fail to act by reason of that langurr. The absorbents are then accused of not performing their

\footnotetext{
- Stuce writing the abore, I have ascertained upon the vies, that a horse, rankling uncles firecffects of malirvament, aheolutely broke the cells of his hear thrutigh high-spirited cha. grin. The case is descrited much at large in the "Annals of sporing" for July 1s22, a papea which I was induced to draw up at the instasice of my friend John Bec, Ezc., who was presed at the deatb and the lissection
} 
finction properly ; or, if they doso, then the liver and the kidneys fail in refiniug the flowes sufficiently, sor that, at its getting to the extremities ornce more, those particles which ought to have beren carrisel off are there depositued. and form the ridus of those external maladies that are mistakerily considered local discases, and treated as such, instesul of correcting the foul habit of bredy which is thus plainly indicated. Of the whole series of tumours or alsoceses. grease is the only one whish penple in general think of taking up into the system; the matter that procoseds from the pustuless that form grease is oo pal[ably composed of urea, or the principle of urise, which ought to have been attractsol to the kidueys, that every luely whos would cure the grease, very properly, as if by instinct, aduinisters diuretios; and when this means of cure is adopted early, always with a proportionate degrece of succents. But of these things more in the following sections.

53. THF KInsere, although the seat of only one disorder (inflammation), yot are they so intimately comnected with the cure of other diseasen, which a re constitutional, that a right knowlenge of their functions can not but prove highly serviceable in the judicious administration of the uriversally approwed methorl of cure, hy the urinary prassage. Jiuretios, or urine betls, are so constantly in the hamels of gromms and others, that I would aslmorish them thus early to reflect a little on the conserquences of going on from day to day in urging these fine glands to over-exertion, whereliy they are kept in a constant state of irritation, are rendered incapable of acting their part, or literally beecome rotten. 'They are situatod, one on each side of the spine, close to the last two ribs (ace plate $(\dot{x}, \mathrm{H}$, as intersected hy figures $25-30)$, where they are attached as well by the blored.vessels which belong to thern, as by stout cellular memloranes which cover them underneath. With this exception the kidneys of horses seldom have the covering of fit, termed suet, which we find in other animals, owing, nodosbt, to the very great antion of the parts. Mr. Richard Lawrence must have bern thinking on the ox or sheep's kidneys, when he wrote his 28 sth page. For rry part, so little of this fat on the kid. neys has been noticed by me, that this bork was already at proses before I was convinced they were ever covered; arud yet I have assisted in opening and noting thestate of as many horsess, I believe, as any man in England who ever wrote a line on this subject: in France, I have reason to conclude, they are more industrious in this respect. 'The left kidney lies close to the ribs; the right one firther forward, is loose, and is connected with the right lobe of the liver; which heing much longer than its left lobe, seerns to extend itself backwarel for that purpose. Excitement, no doubt, is the rnutual intent of this connexion; and that deviation from her true systern, which natureallows in the effusion from one part to another, takes place, when either the one or the other inay he diseased, ohstructed, injured, or destroyed. On nis other grounds can we account how it is brute animals so long survive the total destruction of some vital part, as we frequently find.* Orie consequence of this lonse situation of the right kidney is, that inflammation generally makes its appearance upon it earlier than on the left, a circumstance which is party derived from its proximity to the liver; it also imparts some of its owr. feel. ing to that organ, when inflamed; two facts these which ought to be well kept in mind, when we wish to excite urusual secretion in either. In shape, the left kidney approaches the angular more than the right one; from which 1 infer that, although the functions of the two must be so nearly the same, in affecti.ms they differ; at least a gall or slight blow will affect the loft mucb sooner than the right kidney.

\footnotetext{
- Latcerly, Mr. Travers has given the public the issulis of many curious experlirentes en
} ais Exbject. 
Af 'The soction of a kiduey, which should be performed lengelowise, win show in the contre its polvis, in which the tube (or uroter) that carrics uft the water w the Habler ahes its riso: in this polvis stone is sometimes formed,

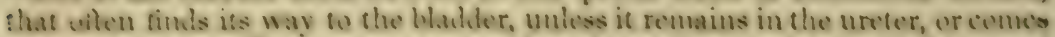
away entirely." The ureters communicate immediately with the Whalder, and the inater shey consey is formed by the outermust red jout of the organ inaw ing the Wuat into it, and thmugh which it is filsored by the vaseular or whitish

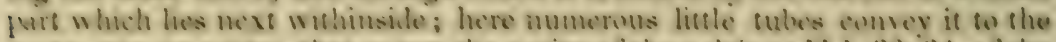
centre oute, or ureter, that chters the cavity of the pelvis at $111,33,31$, of the plate of a skeletom.

The blowl, which has bern so filered of its water, is alsorted by a vein,

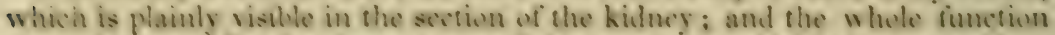
shows how raphily cinourous any meiticime most act, which being poured into

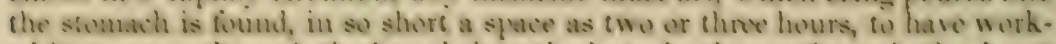

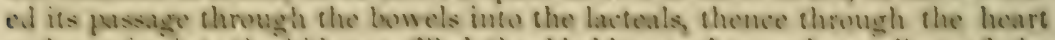

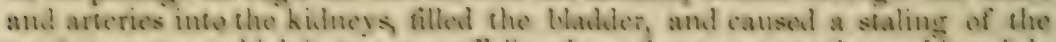
nowhes water, which is fo carry off disuriers of one sort or wher. Here it is

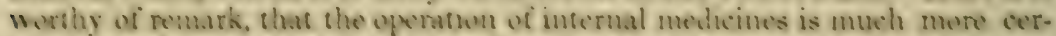
tam in the hurs, when diroted agaitst the alsorbing vessts and she hiluegs

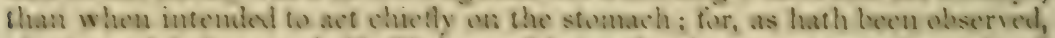
nis stomach being one hali of it insensible wo stimulants wo are mo cortain of frolwing upon it any chlive whatove. In all swollings of the legs the grow

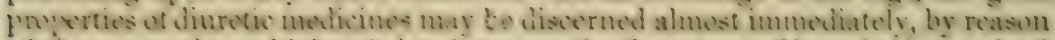

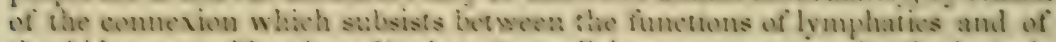

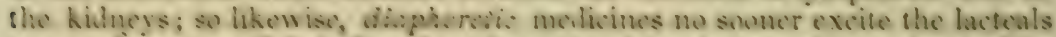
th a performance of their fumetion, than the shin shows ovident signs of $\mathrm{its}$

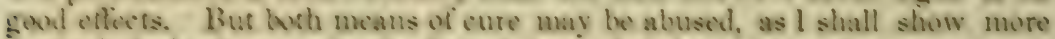
jarticularly in the sequel: the first, fring alministered tho often, wears out the functions of the knheys; the scront, lxing carriod on too long, at length refuseth to act upou the skin.

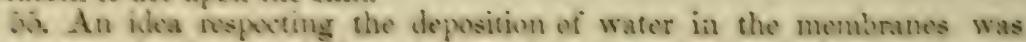
thown out in the twentich sevtion; sud suvther, as to varmation in the proportons of urime and perspiration in sumuer and winter, at the botom of

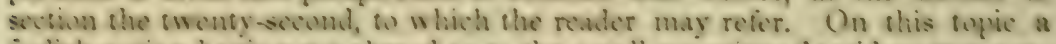
liwlish uovion having got abrood as fo the small quantity of actid matter onnhaimed in the urine of the horse, induod 1'r. 'Thomsunt to subenit a porthen

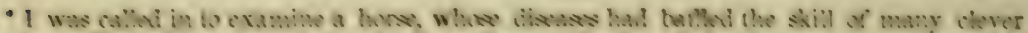

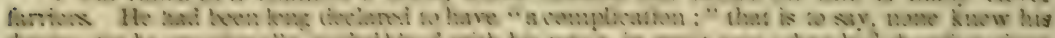

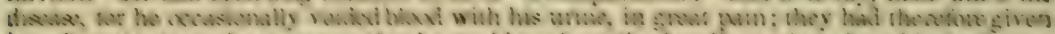

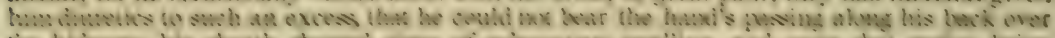

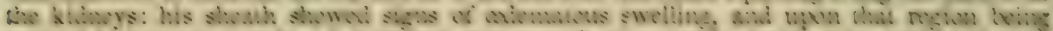

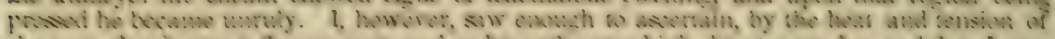

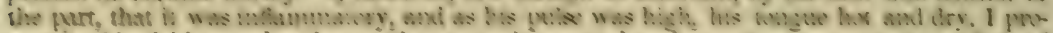

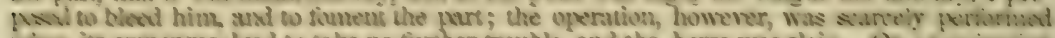

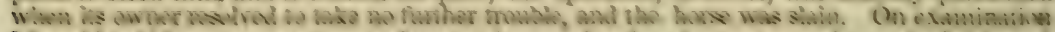

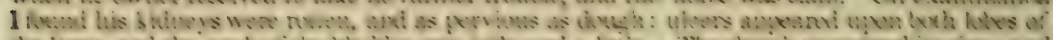

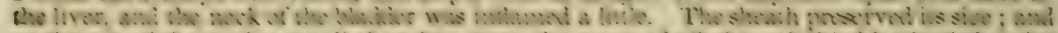

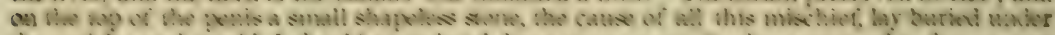

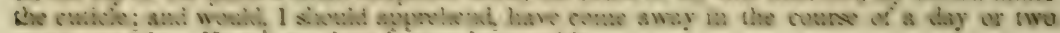

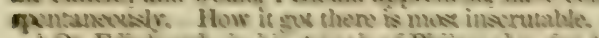

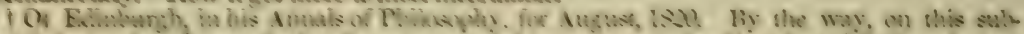

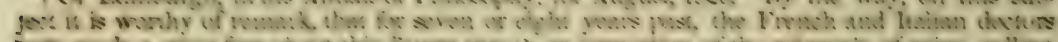

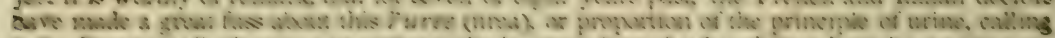

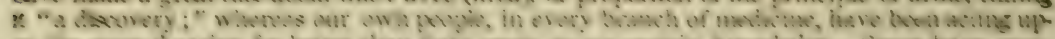

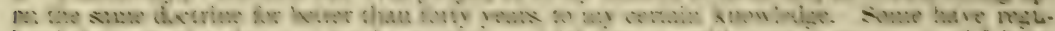

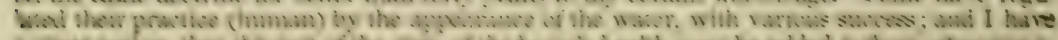

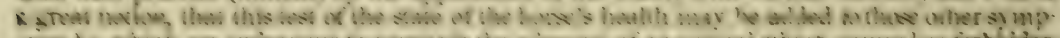

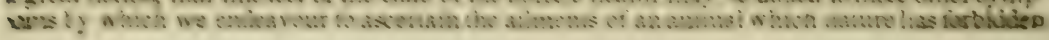


of it to chemical analysis in order to decide that proint. "The result wos, ihat

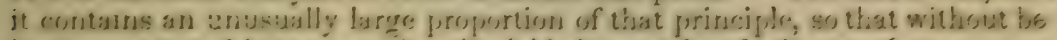
ing concentated by esaporation, it yislded cratals of nitrate of urea, wery readily on the ardlition of sitrie acid." "This faret being thus catiofartorily ass.

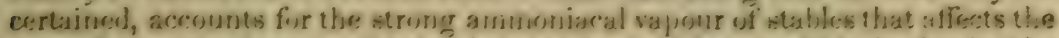
eyes of the altendants, and hring intualed (as said in sect. 39.) is clearly the harbinger of several disensess in the horsen confined in then-erlanders arnong the rest.

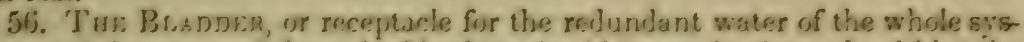

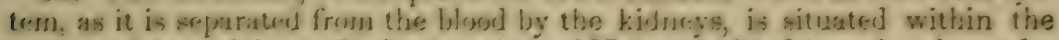
Lollow of the pelsis at the interserction of $\mathrm{H} \mathrm{I}$ with 33.34 on the plate of a

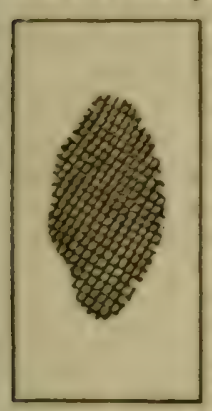
stuleton, with its outlet or neck turned towaris the plece of exit, sarving a litule according to the sex. It consists of three cnats or layers, the outer two being muscular, and having their fihres crowing each other-(as may be secon upon split ting asumer a stale blatder ), the better in ensalle it to constract upon and expel its contents. 'T'he inner coat is membraneous, scosithe on diatention, and secreting a murous fuid to protect itself againat the effocts of the urine. When. hrowever, the blasder beconses full, the secretion is insuffocient for its protrction, and irritation connuences in order to induce the muscular conts to concur in the expulsion of the urine. This drotre munt he wery great in the hrome, for the reasun asuigned at the chese of the precring section, and shows the nocesity of permitting him to vold his urine upon his first intimating an inclination thereto. 'The shape of some horsos' blachlers differs a good dieal from that of others, - particularly about the nock, those of the female being considerably wider, and shorter, than those of the male, a circumstance to be remenbered when I come to treat of the dierrders incident thereto; eince in inflammation of its neck, for exarm,le, in one sex we are obliged to have recourse to instruments, in the other the urine may be discharged by the fingers. But it so happens that horses are more liable to the disorder just named than mares. My reader will also please to note, that the thin rnesnbrane which defends the whole intestine against the friction of the surface, (terned preritongum, reaches backward to only half way over the bladder; so that it offers no obstruction to our operations upon its neck in cases of disease.

57. To recur once more to the subject of a preceding section (the 55th) the principle (of urea) that resides in any given quantity of urine evacuated by the horse, it may be here observed, that when the animal, on a journey, has been pushed onward, and thus preventod from staling for a considerable time, he at length produces it of a defper colrur and less in quantity than asual, a change which has been effected by the great heat of his brody having taken it up again, by the absorption and effusion which nature las provided, of aqueous particles from one part of the system to another. The principle. or urea, however, remains in the bladder, and proluces one of two evils; eithet the inner or sensible cuat becomes inflamed, and loses, after an attack of dia. bretes, some part of its function of secreting the rnucous fluid for its defenre, if it does not terminate fataily; or, being less severe, but often repeated, a de-

¿c complain Whatever practitioner atrowid undershe to julge of the horse's diseases by ix

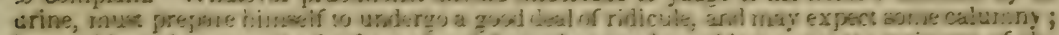

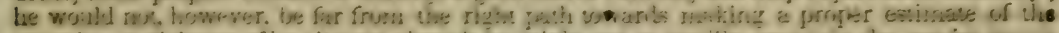

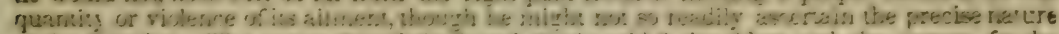

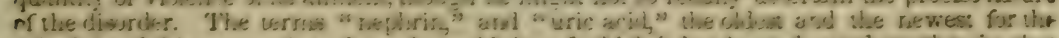

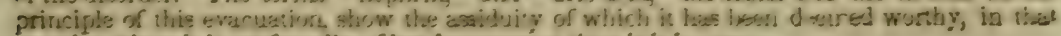
practice where it is confeaseally of less imporance than it is in urr. 
position of earthy particles takes plaee, which is generally converted into stone or gravel.

Palsy of the bladder is induced from frequent repetitions of thus neglect ing the calls of nature, as well as from injuries of the spine; in both which cases the nerves having lost their sensibility, the coats do not contract sufficiently, and some water is always left behind. In all diseases of the bladder, a disposition to fill specdily manifests itself: and in palsy, this is the leading symptom. When this evil takes place, the horse, while staling, seems unwilling, or is incapable of discharging the last drops of each voidance; and, if the usual practice of giving diuretics be adnpted, the animal is ruined, if he does not burst the fundus of the bladder and die immediately : rather, the contrary method of discharging, instead of filling t'ie bladder, should be sought, and the readiest way to effect this is to introduce the hand into the fundament, which having emptied, the bladder may be felt much distended. In this case, we are told, "too much pressure might terminate fatally; " but by smoothing the bladder gently with the tops of the fingers, from its neck forwards, is usually successful. In fact, I never should have thought of its failing, but for what is said in one of the books on diseases of horses (White, vol. i. $\%$. 121), where we find a good number of pages bestowed upon "suppression and retention of urine," which are not diseases in themselves, but the effects of disease; the first arising in defective secretion of the kidneys, the second in the bladder, or its neck. At all times a good deal of sympathy exists between this organ and the kidneys, and the kidneys with the liver; inflam. mation of either being soon communicated to all three, in a degree proportioned to the animal's general state of bodily health previously to the attack.

\section{CHAPTER III.}

General Obscrvations on the Animai System of the Horse, with Reference to the Origin of Constitutional Diseases; Recapituiution and further Development of Veterinary Practice, upon the principles before laid down.

SEEING that a recapitulation of the preceding chapters, and a few general observations arising therefrom, would be necessary, before we examine into the particular diseases to which they have reference, I shall here add the notice of such minor parts of the horse, as may seem to have been overlooked; and then draw such conclusions from the whole, as to the principles upon which veterinary medicine may be most successfully conducted, as appear to me best adapted to your acquiring those just notions of the theory as lead to favourable results in practice.

The animal system* (which has been so often mentioned) whereby life is continued and strength renewed, diseases are contracted, and the disposition to throw them off is constantly manifested, and by which the ordinary wear and waste of the various component parts of the body is unceasingly supplied with new and healthy matter, has been shown, in the foregoing lrief account of the separate parts that contribute, by their united actions, to make up this system. A system that, although apparently complex and infirm, is, in re. ality, simple, magnificent, and rubust. It is we (mankind) who derange the do $\because$ action of those parts, by our vanity, our wants, and self-will; or, by our

A system is a course of action, accorling :o some known rule or law of nature; and thy in has been applied to some of man's conivivances also, not very happily. 
our ignorance, put the whole system out of repair, when we endeavour to control nature, insteal of humbly following her track, and working after her fashion; and every mechanic knows, that a system, or a machine, being once put out of order in its minutest part, incurs the danger of complete disorganization in those that are more material to the performance of its functions as a whole : an ohservation that applies as well to a watch or steam-engine, as to a worm, to man, or the horse; but which, of course, I intend should be applied to the last mentioned animal particularly.

Our Creator, however, as if prescient of the barbarities his image would fall into, in the exercise and abuse of the power he gave us over the living things of the earth, hath, in his goodness, conferred on brutes the means of supplying from one part of the system the losses which accident may occa sion in another part: a subject well worthy our patient scrutiny, as furnish ing the means of effecting cures in desperate cases, and not to be disregarded in first attacks of malignant diseases.

But "the animal system," as a term, or in fact, may be taken to imply as well that of all animals as particular kind of animals-descending sometimes (not improperly) to individuals of those kinds. Some persons, however, descend still lower, and the term "system" has been sadly misapplied, and ban. died about from one thing to another, until it is brought to describe particular parts or portions only of the individual's system. The dog kind, the horse kind, and mankind, are good and proper distinctions, for the system of animal life differ in all three: they are not in every case moved in a similar manner by the same class of medicines; whereby we first perceive that their systems differ, and we examine the dead subject of either kind (as in the preceding chapter), to find out how this takes place, and in what degree, and we regulate our practice conformably to the discoveries so made. The several individuals, too, of the same kind, have particularities in their respective systems, arising from habit, from country or climate, or from crosscs, ${ }^{*}$ that demand our serious analytical reasoning, in the application of similar remedies, and adapting their proportions to the removal of similar symptoms. So, a sensible difference is known to exist between the constitution of a cart-horse and a blood-horse, between a galloway and a hunter; each requiring accurate discrimination in ascertaining the state of disease, $t$ and this consideration ought to inspire us with carefulness in applying the remedies, since that which restores the one miglit be injurious to the other. Ainong thuse four breeds, we frequently find individuals variously affected from the same causes according to their built, shape, or make (see pages 2,6 , and 18 ), according to the constitution and co-arlaptation of the dam and sire; as age may come on, accidents have taken place, or chiefly as the individual may have been mistreated by his unworthy master, the surilid farrier, or unfeeling ostler. "To all which important distinctions in the state of his patient's particularities, I beg to call the studious rrader's most serious attention, while examining his case, in order to apply the rimedy most appropriate to the degree of attack.

In the two preceding chapters of this treatise, more of the animal mignt undoubtedly have been described, or the same subjects considerably enlarged upon, and more parade of learning might have been displayed, but the reader would not have benefited one jot by that course of proceeding : he migl:t, probably, have bewildered himself (as many do) in the mazes which would lien surround him; whilst the description of those parts of the animal, which

-'Ihe eystem of the same individual, also, may undergo changes by time; so that a meüjcine may operate differently now from what it formerly did.

tThe surest barometer of health, the pulse, would indicate an approach towards fever in one individual, which might be the certain standard of neaith in another. sec The Pules," of page 60 . 
contislute but inferiorly to the system I had in view to illustrate and explain, might have led him to look upon these in a light, too imprortant for the func. tions they perform-as regards my purpose.

The eyes, the tongue, the ears, the skin and hair, the tail, the genitals, and the hoof, or foot, though each deserving our most sedate attention, for many good reasons, yet, as they do not originate disease, I then purposely avoided taking particular notice of them.* Nevertheless, I do not nean to deny, that they all, accorling to each its functions, accurately indicate the existence of disease, as they do of health, and the degree of both is marked on them with wonderful precision. Hence it was easy to conclude, even though we did not know the fact to a demonstration, that they are subject to some deplorable maladies that are peculiar to each, arising out of constitutional defectiveness, to say nothing of accidents, nor of the fancied improvenents man presumes to make upon the works of his Maker.

Under this last reproach lie all those farriers and others, who give pain unnecessarily to the animal in the indispensable operations. Among these, I class that of docking, notwithstanding the gibes of our continental neighbours (the French) conveyed to us in something like the following cuuplets, alonut the period of king James's abdication.

Proud Englishmen avaunt, barbarians as ye be,

Who cut your monarchs' heads off $\longrightarrow$ il horses take the queue!

We Frenchmen, better bred, who reverence the lasw,

Never meddle with our kings' heads, aric' let our hotse-tais grow.

Although of no moment in themselves, these verses show the then French ustoms, and mark the period when docking and nicking came up among us in Ergland, to be in the early part of the seventeenth century. But I put it to the reason of any, the most strenuous advocate for this custom, whether he ever contemplated the probability of a horse being subjected to this operation three or four several times; yet it is no less true, that at a market dinner-table, in the town of Watford, in May, 1820, I heard of a horse which had been so served five several times, from no other authority than that of the last owner of the unfortunate creature. I took occasion to show, in a precerling page, that in all great exertions of the animal powers, the tail and head had a share.

Firing is ancther of those barharous practices that are much oftener resorted to than is necessary or proper. In fact, we may observe that this and similar painful operations are adopted in an exact ratio that the operator's elucation may have been neglected.

Of the foot, I have already, in the first chapter, noticed some general faults, arising from constitutional defects in the form of the whole limb; and I shall thence be led to enter into further consideration thereof, with more particulars, under the article "Shoeing," as well as when I come to treat of the several .isorders incident to this important part of the frame. Meantime, I am induced thus early to reprobate one other species of that busy intermeduling in the affirirs of nature I took occasion to advert to higher up. This consists in the baneful practice of cutting away, unmercifully, the horny part of the sole, that lines and defends the sensible sole, whereby injuries upon the road become more frequent, and lameness from unknown causes is incurred; but if not so, canker, rottenness, corns, are sure to follow, or the hoof contracts, and fever of the feet and founder succeed each other.

The skin and coat received some attention under the article Secretions,

- The diseases of the foot, I consider as those of accident or infliction, and with a brief ano omiral necription, will form a separate chapter. 
and elsewhere, as the reader must recollect, or refer to; but he must never forget, that the first mentioned may be safely and powerfully stimulated as the outlet for many constitutional affections of the system, the proper time for their use being indicated (as I said before) by the appearance of the coat.

The tongue always partakes of the general state of the system: in the horse, it does not afford to the sight so sure a prognostic of the state of the stomach as in the human subject; but, to the feel, it communicates to us the state of the blood with so much accuracy as demands our assiduous attention, to the acquiring, by practice, the most intimate acquaintance with its monitions. This member of the body, in conjunction with the coat, I have always considered the health-gage of my patients. See observations on the "Pulse" at page 60.

The eye is a most material organ of sense, and is much studied by those who would render themselves good judges of the general soundness or un soundness of the horse's constitution. It beams bright and steadily in health, projects most fiery when the animal is most vigorous; in lassitude it sinks, it blears with a cold, and under extreme circumstances is extinguished. After a heat, horses full of blood, with foul stomachs, certainly alter in their vision, shy and become troublesome; and, so sure is the eye the barometer of vigour that horses got by old sires have the eye more sunken than others, with a hol. lowness over it.

The ears, by their movements, show the apprehensions of the horse, if nni his disposition. When he fears the lash, he turus their cavities backwards. Is he disposed to be resentful, they are laid flat on his poll. Following his companions, or the hounds, or going homewards, the cavity of the ear turns sharply forward : asleep, as well as under other circumstances of easy watchfulness, one ear turns forward, the other backward; but, when roused suddenly, they alternately change position. Who, then, would destroy these useful appendages of the horse's organ of hearing? Who would singe off the hairs, which, passing from side to side of the cavity, catch the sounds and convey to his rider the first notice of danger from wild beasts, as well as pleasure from the cry of the hounds? The Arab knows, by his horse's ears, of the approach of enemies; but the Englishman relies too securely upon his own comparatively imperfect hearing, and cuts off those better intelligencers of distant occurrences; or, he more assiduously abridges their utility, by clipping away the inside lining; or, worse still, by applying flame to the part, he renders the horse skittish ever after. Those are the only disorders of the ears of horses; if, for want of this hairy defence, prenature dulness of hearing, occasioned by rain, dust, and other substances entering these organs, be not another.

That the genitals draw off from the system and store up a noble secretion, for the purpose of continuing the kind, is certain; but 1 shall pursue the matler no further than to notice the change to which the coats of geldings are sulject as to colour, compared to those of perfect horses; and all the inference I nean to draw from that fact is, the still further corroboration of my previously maintained opinion, as to the seat of perspirable matter residing in the lacteal part of the system.

As it is the blood which by its deposite forms all those parts, so by means of the blood nust we endeavour to correct any derangement of the system of nnimal life, whether of quadrupede or bipede; for the working of the system in making of new blood and cleansing the old is the same in ail, though differing in degree, whilst mainly agreeing in the process. Would any one demand how it comes to pass, that quadrupeds draw so much substantial nourishment from herbaceous vegetables, whilst man can only extract a watery juice, dovoid of all nutritious qualities? let hin he answered, that all depends on the 
digestive powers, these being greater in the brute, than in man. It even appears plainly to me, that the animal food taken by man is the same as the herbaceous taken by quadrupeds, only that it has meantime undergone the process of digestion, sanguification and deposition in the solids, \&c. and hence arises the difference in the practice of the curative art as applied to the one animal and the other. Every disease is in fact a compound, varying in cifferent constitutions, and the composition of the remedy should be adapted to every variation thereof, even of the same attack. 


\section{BOOK II.}

THE CAUSES AND SYMPTOMS OF VARIOUS BODILY DISEASES INCTUENT TV THE HORSE; WITH THE MOST APPROVED REMEDIES IN EVERY CANA.

\section{CHAPTER I.}

\section{Of Internal Diseases.}

INFLAMMATORY DISORDERS, GENERALLY.-FEVER.-From all the infor mation the reader may have collected together in his mind, respecting the "circulation of the blood," as described with instructive minuteness at pages 33 to 42 , he will naturally conclude that the horse is ever most liable to contract one or the other of those disorders we term inflammatory. The great heat of his blood, combined with his bulk, and the amazing exertions he is compelled to make, all together constantly predispose him to incur fever of the whole system or inflammation of particular parts, according to concurring circumstances. Nor is the matter changed one whit, when we reflect that fever sometimes terminates in local inflammation, which we term "critical," as being the crisis and cure of the disorder; and that the inflammation of one part or organ (the liver in particular) frequently devolves into fever of the whole animal system, by means of the rapid circulation of the blood through the diseased organ.

Let us proceed to discuss the subject generally at first, and to pursue each in detail afterwards; simply premising, that all the disorders incurred by the horse are referable, more or less, to this over-heated or inflammatory state of his blood, and its consequent unfitness for the purposes of promoting animal life, health, and vigour. For, the more heat, the more viscidity or thickness there will be in the blood, and less will it be found capable of circulating the .onger such unnatural heat continues, up to a certain point of the disease: when the animal is so far affected as to lose its appetite, and consequently no fresh blood can be formed by the digestive powers, the blood then becomes thinner every day, because its more solid particles are constantly being deposited in the cellular membrane, to supply the waste that is unceasingly going on there. The reader would do well to read over again what is said concerning this process of the animal system at page 48 , with the references there made to page $3 \%$, to page 23 , and, in fact, to the whole tenor of the second chapter. But this supply soon fails, as necessarily it must, when it is not re. plenished at the source, and wasting of the solids succeeds of course, unless nature is assisted by our art judiciously; - the right application of this art is what we are now in search of.

One of the immediate consequences of the horse being hard worked, or high fed and physicked ivith stimulants, is the constant heating or feverish state of the blood. Increased action of the heart and arteries accompany and keep ap this state of irritation, which may be further accelerated by the animal's being allowed to take cold whilst in that state, whereby the perspiration is checked of a sudden, and the blood which may then fill the smaller vessels is detained there, to the further annoyance of the larger ones: he then contracte 
inflammation of wll the solids and organs of life, or, more properly, fecrer. But when only a certain part of the system, or a single organ is thus check. ed, we consider the affair under the name of inflammation of that part, as of the lungs, the kilneys, \&c. ; always keeping in mind, that, by continuance, these extend their baleful affections to other organs, with which a certaib. sympathy is known to exist. In like manner, when external muscular parts swell and secrete matter, this is in like manner an inflammation of that particular part, or tumour, or abscess, with a great variety of names, according to the place where it may be seated: poll-evil and fistula are among those external complaints to which I allude.

The latter, or local kind of inflammation, is the effect of the former or continued internal fever, and whenever such a tumour or abscess makes its appearance near the surface, the general inflammation or fever subsides; when it discharges offensive matter, the fever is cured. If such a tumour appear without previous general fever of the system, we repel it, so that it may disperse and pass off by stool. It may usually, however, he considered as an effort of nature to relieve itself of oflensive viscid matter that lurks in the system; and in this case only, when well ascertained, would that reduction of the system which I shall shortly insist upon as proper in all inflaminatory attacks, be least advisable, as nature would then require aid to assist her in her efforts, rather than subtraction from her powers, by the bleeding, purging, \&c. so recommended.

But whenever a cold is caught, whereby the trunk is affected, one of two evils is experienced, that are quite contrary in their eflects : 1st, Either the bowels lose the power of retaining their contents, and of contributing their aid to the purposes of digestion, chylification, and sanguification, i. e. the maling of fresh blood, and diarrhœa ensues; or, 2d, 'The extreme heat of the body causes the dung to harden, and if the obstruction be not speedily removed, the most distressing consequences usually happen. Either extreme may come on gradually and imperceptibly ; but as the latter (termed constipation) is of most frequent recurrence, is a disorder of over repletion, producing vertigo, staggers, apoplexy, megrims, or fits, I have considered it under a separate head, as "costiveness;" sceing that it sometimes supervenes without previous lever, though always accompanied by it. One or other species of affection of the bowels is also produced by catarrhal inflammation, or fever of the organs of respiration, when this is violent or of long continuance.

Respiration of confined or noxious air in close stables, as described at page 39 , also produces quicker circulation of the blood; with perspiration and temporary fever, which may be confirmed by sudden exposure to the open air, and the consequent detention of blood in the small vessels which we term capillary. Sudden immersion in cold water whilst sweating and respiring with difficulty after a run, wading through a river, or standing in a current of cold air, are all prolific sources of inflammatory disorders. Indeed fever and inflammation are so closely allied to each other, that we run little risk of creating confusion of terms by considering them as derived from the same origin, and none whatever in treating of both in the same chapter. For most stablemen and farriers, as well as many veterinary writers, do speak of the one and the other promiscuously, as if they were the same, when describing the symptorns of either; nor do I see any good cause for my deviating from this practice upon the present occasion, after the slight distinction just drawn.

One other general observation may be aptly male in this place, which may stand instead of much discussion hereafter. As fever is a vecessary consequence of any inflammation whatever, so without fever there would be no inflammation. Every run you give a horse heats or inflames his blored, quick. ous his pulse, and he sustains temporary fever. Whilst in this state. if any 
viscus, or organ, that constitutes a vital part of his system, receive such check or damiper as I have described, ohstruction of the finer blood-vessels ensues-as, of the lungs, by their drinking cold water, or mere affusion of it on the chest, and inflammation is the name: if the whole body of an animal cr its entire surface be so affected, the evil consequences are similar, and fever is the name by which we designate it. Horses out of condition, or already in a low state, though feverish, with quickened pulse, do not require further reduction; since this is evidently "low fever," which I have treated of under a separate head; as I have also "Typhus fever," or the affection of the whole system which arises from a vitiated or corrupt state of the blood. But, in all cases, the best guides to the practitioner for his prescriptions, and indeed all his operations, are the causes, the symptoms, general health and peculiarity of constitution of the animal; when it so happens that such particulars can be extracted from those about him; as will be the case in all studs of a superior cast. If the feverish affection arises from inactive kianeys, the diuretics recommended lower down will be all the treatment that is requisite in such a case; if a dull heavy pulse and the state of his dungings show that the bowels only are at fault, purgatives alone will restore health. So of any other vis. ceral obstruction, when these give pain fever ensues, and is best removed by the exhibition of mercury ; if the internal irritation continues, rowelling is the remedy most appropriate to such cases, and the state of the pulse will tell the doctor when and why he should bleed. This will bring us to an early consideration of "the pulse," its indications and general rules. In all cases of inflammation, whether of the whole system, or fever, or of particular organs, let bleeding be resorted to immediately, in quantity proportioned to the amount of heat, which is ascertained by the temper of the pulse. "Open the prima via," also, is a good maxim of a late respected lecturer on those subjects, meaning thereby-purge the bowels or chief canal, and keep them open. Co. pious clysters of warm water-gruel assist the latter materially, paiticularly if a solution of salts be added, according to the nature of the case; but rather than delay the clyster through want of the ingredient being at hand, use simple warm water only. Very often, in slight attacks, the animal requires no other treatment, if resorted to in time; but delay is dangerous, for with every hour the symptoms increase in a three-fold ratio, and the animal becomes weaker and weaker every moment, and therefore less able to bear up against the attack. In all cases, be quick, for ruin is going on with rapid strides, whenever the animal shows signs of great internal pain. Fresh air, diluting liquids, and clysters, in all cases of inflammation whatsoever, are found of as much service in the restoration of health, as the best active medicines that can be administered; the first mentioned most positively so, unless the animal perspire greatly at the time, or it suffers under a fit of shivering. Danger is to be apprenended in the latter case, and the fresh air need not then be admitted; but if shivering is succeeded by sweating, or even a small degree of moist heat, it may he considered as the crisis of the disorder, when something has taken place that is favourable to the cure-of which more particulars in the proper place. Continued shivering, by the way, denotes the termination of all inflammatory diseases-in death; cordials then may do good, but more frequently accelerate the catastrophe, whilst the diluting liquid -water-gruel, will afford relief in some measure, but can do no harm. But resh air, that issues not in streams, is of all other restoratives that upon which 1 piace the most reliance; even removal to a fresh stall, or up and Jown the stable, effects great changes in the animal's spirits, that can not fail to strike the eye of an attentive olsserv ${ }^{\circ} r$, and bespeak, more than words can sonvey, the vital necessity of a cool atmusphere.

The PuLSE-Being the chiefest criterion for judging of the state of the eir- 
sulation of the blood, and as I have sat down with the notion that my book will be read straight-an-end at first, let the reader attend a moment while I say a word or two on this preliminary topic. Without an accurate knowledge of this touch-stone of the main spring of life, no one can form a judgment fit to be acted upon as to when it is necessary to bleed or of the quantity to be taken: thus, in cases of fever, the groom begis: 3 very properly by bleeding; but he almost invariably takes too little, or in case of increased action of the pulse, through over exertion of the animal's powers, he bleeds when such a course is detrimental, and almost always administers cordials, thus reducing with one hand, and increasing the action with the other.-See pages 33 , et seq.

When in health, the pulsations or strokes are from thirty-six to forty in a minute; those of large heavy horses being slower than of the smaller; and of old ones, they are also slower than of young animals. When either may be just off a quick pace, the strokes increase in number; as they do if he be alarmed, or terrified, or hear the hounds' familiar cry. Fever, of the simple or common kind, usually increases the pulsations to double the healthy number; hence the propriety of ascertaining the state of this index of health, while the animal is still free from disease, goes to prove over again the propriety of my plan of teaching the curative art in animals by closely examinIng the indications of health, and setting down in one's mind every deviation therefrom as the approach of illness, that ought to be met and combated at the threshold.

In this view of its utility, why might not the attendant groom, or horsekeeper in more humble establishments, keep a register of the state of every horse's pulse, when it comes first under his care, and renew the same examination at intervals of a week or ten days? This practice alone would render him expert in all cases of imminent danger; to say nothing of those other indications, the dungings and the water voided. On this latter puint the reader will turn back to what is said of "Urine" in page 52, 53.

As the fever increases in violence, likewise, when the animal is in great pain from inflammation of the intestines, \&c., the pulse beats still higher, and reaches to 100 in a minute, or more. The danger is then great, and less than three or four quarts, drawn from a large orifice, would do harm rather than good, by increasing the action of the blood, and the hardness of the artery would also be increased. To ascertain either state, the attendant should apply the points of his fingers gently to the artery which lies nearest the sur. face. Some prefer consulting the temporal artery, which is situated about an inch and a half backward from the corner of the eye. Others again, and they are the greater number, think it best to feel it underneath the edge of the jaw-bone, where the facial artery passes on under the skin only to the side of the face. In either case, too great pressure would stop the pulsation altogether, though by so trying the artery against the jaw bone, will prove whether it be in such a rigid state of excitement as attends high fever; or elastic and springy, slipping readily from under the finger, as it does when health prevails and the strokes follow each other regularly.

The presence of high fever is further indicated by a kind of twang, or vipration, given by the pulse against the finger points, resembling much such as would be felt were we to take hold of a distended whipcord or wire between the fingers, and cause it to vibrate like a fiddle-string, sharply; whereas, in health, a swell is felt in the vibration, as if the string were made of soft maEerials, and less straightened;-facts these which owners would do well to ascertain by practising upon the pulse of their own horses. Languid or slow puise, and scarcely pcrceptible in some of the beats or strokes, indicate low. mess of spirits, debility, or being used up: if this languor s felt at interval* 
only, a few strokes being very quick, and then again a few very slow, this in. dicates low fever, in which bleeding would do harm. Quickness, however, is the chief indication of the whole class of inflammatory frvet and this being my principle olject at present, I shall postpone further consideration of the pulse until I come to treat of "blood-letting."

\section{FEVER.}

There are two kinds of well-marked fever, simply so called-first, that which arises from the pain an animal may be put to by the derangement of some main organ of life, by misusage, hard riding, wounds, \&c.; and second$\mathrm{ly}$, that which consists in a general inflammation of the blood arising from a cold, a chill, or sudden check, as before described. The ancient vulgar name given to this alarming disease conveys to the common observer a better idea of its force and danger, than those which are settled by consent of the faculty of horse medicine; and the phrase "inflammation of the blood" may be taken as more plainly indicative of the cause of fever than aught the moderns have substituted in its place. Had our plain-speaking ancestors termed it "inllammation of the blood-vessels," they would have been still more accurate, probably: but no mistake is more common throughout life, than to speak of the thing contained for the thing containing it, and vice versa. When the symptoms come on quick or acutely, the most prompt measures must be taken : a mild attack may be easily reduced if taken in time, but, if neglected, it assumes the most alarming symptoms. Evacuations and diluting drinks are the proper means of reducing the patient; but before purgatives are administered, see what is said a few pages onward respecting "Costiveness ;" for it not unfrequently happens, that this is all that ails the animal, except his being worked too hard while costiveness is upon him.

In either case of accelerated pulse from those causes, bleeding should presently be had recourse to, and let the quantity taken be regulated by the firce and quirkness of the circulation of the blood: for this is what constitutes the fever. If the pulsation advance to above 60 , two quarts should be drawn; if above 70 in a minute, three quarts of blood would not be too much to take away at once. If the number of beats be much more, ascending rapidly, with the rigid feel of the artery above described, four quarts at least must be drawn, and that from a large orifice. Should this rigidity, or hardness of the artery continue, notwithstanding the bleeding, a quantity that shall cause faintness or tottering might be taken, or rather a repetition take place of the same operation in lesser quantities, until that hardness of the artery is no longer felt. Some skill, derived from practice, is required in watching for this last mentioned symptom; but whatever is to be done, let there be no delay in the first operation : twelve hours should intervene between the two bleedings.

Immediately hereupon, let a mild purgative be administered, adapting this, as well as the amount of bleeding, to the size of the horse, if he belong to either extreme of exceeding large or very small. For one of the moderato coach-horse kind give the following

\section{Purgative Ball.}

Aloes, 7 drachms.

Castile soap, 4 drachms.

Uil of caraways, 6 drops.

With mucilage sufficient to form the ball for one cose.

In all cases of fever arising from accidents, hard runs, \&c. which may be con. sudered as temporary excitements only, the above treatment in its mildest formo 
will be found sufficient completely to reduce the symptoms; but in the fever simply so called (arising from inflammation of the solids as before described), a repetition of the purgative hecomes necessary, with mashes, a quiet stable, and an attentive groom. When the fever arises from indigestu.n, or any derangement of the stomach or bowels, its immediate cause will be found in hardened fæces; and in addition to the forementioned remedies, give a

\section{Purgative Clyster.}

Water gruel, 6 to 7 quarts.

Table salt, an ounce to each quart.

Let it be applied assiduously, and some assistance be given to bring away the firs hard fxces that appear: the remainder of the hardened dung will cume away, naturally, in good time. See further under the head "Costiveness."

Castor oil, in the quantity of a pint or more, will open the canal partially only, passing by the main evil in the coecum and great gut, ${ }^{*}$ and producing but a small quantity of the offensive cause of disease. But help must he afforded in this respect; and if the bowels yield not to the purgative ball, other means must be resorted to, though I should rever think of having recourse to oil in the first instances. Although the constipation or obstruction be obstinate, yet very strong diuretic purgatives are ineligible, as they might kill the animal, or at least injure the intestines materially, by reason of that very circumstance.

Distinctions have been drawn by some writers between "symptomatic and simple fever;" that is to say, whether the excitement, called fever, originate in a check of the circulation received externally or internally; but as the treatment in both cases is so nearly the same, I shall make no such distinction. The internal attacks alluded to, when confined to a single organ, and not extending to the whole frame, are more properly termed inflammation of that viscus or organ, and therefore will be treated of hereafter, under the following heads, viz.

Inflammation of the Lungs,

Inflammation of the Stomach and Intestines,

Diseases of the Liver-Inflammation, \&c.

Kidneys and Bladder.

All these produce fever throughout the whole system, when either exists but in a slight degree; for those parts are all of them vital, and communicate their feeling to the solids by means of the circulation. It is not, however, until these attacks are well marked, that they deserve separate consideration; for some horses suffer under the one or other during life, with more or less malignity according to exciting circumstances, the lungs being the most general sufferer, the howels the seldomest attacked of either, but usually prove the most fatal of this whole class.

The symptoms, in all cases, gre heat and acceleration of the pulse, as before described, and which in fact, brought me to the consideration of this portion of my sulject hefore the others. A hot mouth sonn comes on; shivering takes place early, and the animal c vinces signs of internal pain by iooking at his flanks or chest. The fever is then likely to fix on the lungs if not spreedily reduced. Loss of appetite follows; but too gradually to lie waited for, as a

\footnotetext{
- The practical reteder, whilst waiting the progress of the disease, will not waste his time by turning back to the first book, at p. 46 , and see what is said of the cunformation of thuse largo g'sw', and the difficulty of escape liat must attend their offensive contents at the turris or sinu wes (which I have there considered as so many valvas), when inflammation or fever has oeco begrun.
} 
a criterion for judging and acting promptly. He will evince langunr and dul. ness, with half closed eyes, and a small discharge from them, as if tears es raped; sometimes, this last will happen in cases of mere debility or starvation also, when it is not too much to suppose the animal may be deploring his hard fate. Consulting the pulse, however, will settle any doubt as to which ailment the animal labours under; for this main characteristic of health will, in the latter case, partake of his debility, and strike now hard and then soft, a few beats each : in this case a feed of corn or water gruel, would probably restore a more healthful even pulse, whereas bleeding would go to destroy the patient. It has heen termed low fever, though not very properly; and lentor or more justly lenteur (slowness, dulness, heaviness) by the French veterinarians; yet, having no better name for it than "low fever," under that head, I shall shortly bestow a few lines on this species of systematic debility.

The dung and urine are always good indications of the state of the body; if the former fail, fever is the causc, it subtracts also from the quantity of urine: and if he stale small quantities at short intervals, some internal inflammation has taken place. See Inflammation of the Kidneys. In fever, the mouth and tongue become drier than ordinary; and if any saliva be secreted, it is tnugh and ropy. If the animal be in condition, upon lifting the eyelid an uncommon redness appears; if he be out of condition, or in a low state, this does not always happen; so this indication may be reckened among the uncertain symptoms.

If the remedy and the symptoms of fever are thus pressed forward together upon the reader's notice, as exemplifying the assiduity he should display in repelling the attack, let him know that his work is but half completed when he finds the heat and acceleration of the pulse reduced by his endeavours to the ordinary standard. The tone of the patient's stomach and the whole digestive process require restoration, and this with a careful hand, that the bowels may not again get overloaded; because why, a second attack of this sort would be more difficult to surmount than at first; for the bowels have partly lost their function of expelling their contents, through the violence of the disease, if not by the harsh action of the remedies employed. Hardy working horses, of course, recover their appetite as soon as the fever abates; and no further care is required for such than an occasional laxative or purgative, according to the amount of obstruction. The ball prescribed at page 63 may bo given at intervals with the fever powders; and subsequently, the fever drink prescribed below for all other descriptions of the horse recovering from fever.

\section{Fever Powoder. No. 1.}

Powdered nitre, 1 ounce.

Mix for ono dose.

Emetic tartar, 2 drachms.

No. 2.

Powdered nitre, 6 drachms.

Camphor, 2 drachms.

Calx of antimony, $1 \frac{1}{2}$ drachms.

If either be deemed more desirable in the form of a ball, this may be effected by mixing the powder with mucilage and meal; but in the form of powder mixed with his corn is most eligible, as the medicine then acts earlier, where is the ball presently descends into the great gut.

Fever Drink.

Cream of tartar, I ounce.

Turmeric, 1 ounce.

Diapente, 1 ounca. 
Msx in pcivder, and add to a pint of warm gruel, to be given once or twice a day. This is a good cool stomachic, and restores the appetite, at the same time that the disposition to the return of fever is kept down: if found of marked tervice, the doses may be repeated to three or four times a day for a week.

\section{LOW FEVER.}

Together with TYpHus, or putrid fever, and RHEUMatic fever are diseases mcident to the horse, though attempts were long made to deny the application of these terms to any of his numerous afflictions, by those who dread, inordinately, the falling into analogies with the human practice; a fear that may be carried too far, notwithstanding all our care should be employed in separatIng this from the veterinary practice.

Cause. - Of low fever, under the idea of debility, a few words fell on the preceding pages: and truly, if "high fever" may be produced in a subject that is full of blood or condition, by over-exercise, and the other causes thereof set down above ( $\mu$ ages 59,60, see also Brok 1 . at page 42, \&c.), these same causes, operating upon a horse out of condition, or which has not sufficient blood in his frame to receive inflammation, necessarily occasion that languor whick attends debility of the el.iire system. The reader will, perhaps, oblige me by turning to book I. at page 40 , and reading over again what is there said as to some causes of low fever. But the respective terms we give to the various kinds of attack would signify much less than they deserve, were it not for the dinger we should otherwise fall into of treating one disurder for another, when the symptoms (some of them) so much resemble each other. This danger is more likely to come upon us in cattle medicine than in the other, since we are under the necessity of finding out what is the matter with our patients, whilst the human doctor receives the information at once, in words.

As inflammatory fever is more prevalent in the spring and summer, owing to the high condition of most horses when first attacked, so does low fever, or irritation of the animal system of a horse in low condition, mostly prevail in autumn and winter. We owe this latter in great measure to the debility or weakness brought on by the shedding of his summer coat, when the autumnal equinox setsin. Being then much exhausted by the heat of the season just gone by, he sweats profusely on the least exercise; then his conat becomes dry and husky when at rest, and his skin sticks tight to his ribs, slightly resembling hidebound. The animal having lost much of his natural covering and no care being taken to palliate this loss, he is more liable to catch cold if exposed and still pushed in his work. If not relieved from its severity, coachhorses in particular become unserviceable in great numbers, to an alarming degree, resembling much the distemper of the spring season. Too often it happens, such knocked-up horses are considered as done for, and the owner sells off; whereas experience tells us, that a nourishing regimen would restore them to their wonted vigour; for the serious or watery part of the blood (chap. 2, sect. 20,21) having been drained off by the violent perspiration they were exposed to by their summer work, the muscular fibres become too rigid, and the blood too thick for circulating in the finer vessels; it therefore remains rioting in the larger ones, distending their capacity and increasing the irritation. Working horses are then usually deprived of their corn, because they can not work; this only adds to the irritation of the vascular system and sulids which constitutes the low fever we are now considering.

Symptoms.-Parallels, or distinctive characteristics, of such discases as somewhat resemble each other, are therefore very proper, inasmuch as they prevent those dangerous mistakes in practice that happen oftener (even in th: human practice!) than suits me cven to hint at in this place. They are most 
particularly serviceable to veterinarians : for this reason it is I recommenil the reader to compare what is said of the symptoms of high fever, just above, with the present page, as regards the symptoms of low fever. They are placed near together for that purpose, as I then said (at page 64). The pulse in this case never mounts high Juring an entire minute, but beats quick a few strokes, and then slow, and so low as scarcely to be perceptible; this denctes, that though fever be present, there is not strength sufficient to bring it to a crisis. The artery feels rigid, at intervals only, and again becomes supple, if not elastic, to the touch; his flanks are agitated more than usual, and his hind quarters and ears become cool if not cold. As in high fever, his eyes are dull and heavy, and water will occasionally fall from them. Though in the former species of fever he evince considerable pain, in this no such symptom appears, but despondency assumes its place.

Remedy. - Unless his body be already too open, give the laxative draught, as under: and as he will still feed, diuretic powders may be mixed occasionally with his feed, consisting of nitre and rosin, of each about one ounce Should the urine appear turbid, or come off with difficulty, in small quantities, the diuretic ball is indispensable; and these, with good gruel and care, accompanied by tonics, will restore to the animal a comparative portion of bealth. Time and moderate usage will accomplish the remainder.

\section{Laxative Draught:}

Aloes and carbonate of potash, of each 2 drachms, Mint water, 4 ounces.

This will correct the urine also, and its laxative quality may be increasal by adding to the quantity of aloes.

\section{A Diuretic Ball.}

Turpentine and soap, of each 4 drachms, with mucilage to form the ball.

A good restorative for lowness, occasioned by the moulting fever of autumn, is recommended by J. Clark, of Edinburgh : he says, "the end of autumn proves very severe to those horses whose flesh and strength are exhausted by hard labour. In this low and spiritless state the moulting season comes on, and carries off numbers that good nursing and feeding, with rich boiled food, at this season might have preserved. Carrots and potatoes recover some horses surprisingly; it renews their flesh and the fluids generally, and promotes the secretions; it operates upon them nearly in the same manner as sping grass, and its effects are presently visible on their coats." Many stable men give oatneal mixed up into bergue, or crowdie, for horses that evince signs of languor and lowness of spirits, after fatiguing work in winter: if made into stiff gruel, i. e. boiled, the restorative effect is found still more desirable, and a smuller quantity of oats then sufficeti. A gradual return to hard food does ull for the horse's working condition which can be desired.

Fever is brought on, in some degree, whenever it comes to pass that either of the vital organs may be deranged in its functions. Not unfrequently it happens that a diuretic is all the patient requires, which may be judged of by the state of his pulse after the medicine has operated. When this is the case, the feverish symptoms owe their origin to suppression of urine, and the reabsorption of the contents of the bladder into the system. See Bladder and "Suppression of urine;" and, after treating the attack simply as such, a cor dial ball should then take place of all further treatment. as the immediate tall 
ing down of his pulse to a healthy standard will show. Too free use of urin balls, however, in the hands of horse-keepers, spoils the action of the bladder. See chap. ii. page 51. The French give a bottle of their routine wine made warm, and most of our farriers administer a quart of ale with the same view. Those are mostly wagon-horses, full of flesh, that so absorb the aqueous particles of the urine, and ultimately the principle thereof (termed urea), and light up the fever anew. Another cause of feverish attacks, generally of the slighter kind, but liable to prove fatal, if neglected, is the retention of his dung, or constipation, which means costiveness.

\section{COSTIVENESS}

May be considered an original disease, and as one producing as well as beng produced by fever. That is to say, hardness of the fæces generally attends a fever, and is frequently the chief cause of it : like the preceding ailment, we have only to remove the cause, and the effect ceases. See also "Diseases of the Liver."

Causes. - Want of the necessary or usual evacuation by stool, that is some. times occasioned by the bowels having lost the power of expelling their contents, as described in the second chapter, page 45. Simply speaking, the in. dividual having been a long time dosed with purgatives, any neglect hereof causes the dung to harden and obstruct the contractile functions of the intestines: heat ensues, and re-absorption takes place, as in case of retenti $n$ of urine, until the dung loses all moisture and becomes as hard as baked clay, forming in the rectum (or straight gut), small round lumps.

The same kind of big fleshy horses as are liable to suppression of urine, are also principal sufferers by constipation or costiveness. Hard food and hard work in warm weather is very productive of this malady, which is often mistaken for inflammation of the bowels, the means of prevention, therefore, are obviously the direct contrary mode of feeding, and also keeping a good watch on the dunging of each horse in the team.

Symptoms.- When constipation attends general fever, it is then but a corresponding symptom of that disorder, and the reader is referrel back a few pages to what is there said on this head. But, when the pulse is not so high as to warrant us in pronouncing it fever, and the dung is ascertained to be hard, there is no difficulty in treating it as simple costiveness. It may be dis. tinguished from colic and from inflammation of the intestines, by the quiet state of the animal when he is down, which is not the case with either of those disorders, in which pain of the bowels is most evident; whereas, these do not appear to suffer from the costiveness, though the brain and the whole of the nervous system, becoine more or less affected from sympathy with the stomach, and ultimately prolucing delirium and frenzy. His eyes offer the earliest symptoms by their duiness, contraction, and expansion, succeeded by sleepi. ness; he refuses his food, be will not work, the mouth becomes hot and dry, the ears cold, and the brenthing difficult or nearly imperceptible on account of the pressure of the stomach and bowels upon the midriff. See page 34 . The pulsation usually increases, if he be in a tolerably good condition; but this increase is ever inconsiderable until fever comes on, and marks the period when blood-letting would be necessary. A dull heavy pulse is more common, until the paroxysms of madness may render this symptom a little sharper and quicker for a short period. At length he tumbles down, regardless of the situation, and the action of the head shows how greatly this part is affected, intil stupor and death ensue, if the sufferer be not relieved.

Remedy. - Purgatives are not always the most eligible medicines even in thr iarliest stages of the disorder; for, if the constipation has lasted a con- 
siderable time, great injury would be done to the intestines by forcing a passage, wherely a commotion might be raised in the stomach, but would act in efficiently where the evil chiefly lies, viz. in the large intestines and rectum. As soon as it is ascertained that the animal has not dunged for some dayswhen he seems uneasy, a fulness is perceptible towards the flank, the fundament, \&c. and unusual dryness and tightness is discovered at this latter part, the oneration of back-raking should be resorted to. Castor oil, one pint, would indeed find a passage in the first stages of the attack, but good rart of the evil usually remains behind; in the more advanced stages, especially when the patient drops, nothing else will relieve him but back-raking. Let the operator strip his arm bare, and having well anointed it with soft soap, lard, or butter, (the first being the most eligible,) he will bring his fingers to a point, and gently introduce the hand and wrist, when he will feel and draw forth a portion of the indurated fæces he will there meet with, in lumps hard and dry. This he may repeat three or four (or more) times, and leave the animal to himself a little, whilst a drench is preparing. Trivial as the relief may seem which has been thus afforded to the patient, he will immediately evince proofs of its benefits, by a more sane conduct, by licking forth his tongue, opening the half shut eyes, by looking about him, and sometimes by getting upon his legs. In this latter case, plain water gruel, as warm as a person might take it without inconventence, may be administered in the quantity of two or three quarts, if he will take so much; but if the animal be ex hausted, and does not get up without difficulty, or without help, one half tho drench may be ale or porter. Although he will seem recovered, and may produce a stool, his bowels must next be emptied. In order to this, give a

\section{Laxative Draught or Drench.}

Castor oil, half a pint.

Aloes, 2 drachms,

Prepared kali, 2 drachms.

Water gruel, 1 pint.

Repeat this next day, leaving out the oil, and doubling the quantity of aloes; or, after an interval, give the usual purgative ball, containing seven or eight drachms of aloes, as prescribed at page 63 .

INFLAMMATORY DISEASES of every sort leave behind them a good share of weakness, which full feeding will not always amend. We must therefore restore the tone of the digestive powers by the aid of medicine, that may bo repeated according to circumstances, and the returning strength of the ec $n$. valescent animal.

Tonic Ball. No. 1.

Jesuit's bark, 7 drachms.

Prepared kali, 2 drachms.

Mucilage sufficient to form the ball for one dose.

In ordinary cases, one of these per day for a week will be found to have done as much for the animal as could be desired. But should tho cuat stiei appear rough and staring, give the following: 


\section{Ionic Ball. No. 2.}

Salt of steel, or sulphate of iron,

Columbo root, and

Bark, of each 3 drachms.

With mucilage to form the ball.

Great precaution is necessary to prevent a relapse, which would rencler the patient's case more dangerous than at first; the animal being less capable of bearing up against a fresh attack, by reason of the reductions he has been subjected to. Soft or sodden oats, fine hay, clover, a few vetches, carrots, gras? cut fresh from a sloping ground, may succeed each other in small quantities, until he may be returned to oats and hay as usual. If the heat return at intervals, as usually happens towards nightfall, give him

\section{A Cooling Decoction.}

Linseed, 2 quarts.

Coarse sugar, 2 ounces.

Water boiling hot, 6 quarts poured upon the seed.

Let it simmer three or four hours, and pour off the liquid for use when nearly sold. The linseed will bear another water, less in quantity; but some horses will take the seeds also, which may be permitted. Give the whole in the course of the day, at two or three intervals, and repeat the same decoction once or twice more.

\section{TYPHUS, OR PUTRID FEVER,}

Is caused by long-continued debility, or slow fever, as much as by the in. judicious use of medicines administered for the cure thereof. Of these, the most common error consists of cordial medicines, diapente, wines, \&c. ; which, as they give a short-lived vigour to the animal, are supposed to have done some good, and are therefore persisted in, until the digestive and secreting parts of the system are spoiled.-See chap. 2 , page $22, \& \mathrm{c}$.

Symptoms, the same as those in slow ferer, mark typhus fever, only the pulse is accelerated upon taking the medicines just alluded to: its irregularity is also greater, until, by continuance of the disease, it ceases to denote any particular state of the body long together. Hence, the supply of new blood carries with it similar effects : the vitals lose their tone, and the muscular part of the system wastes and becomes rotten on the bones, and if the same stimuating treatment has been kept up until the animal dies, its flesh will be found on dissection to have acquired an uncommonly bright purple colour, not oniy on the surface, but wherever incision is made. Putrescence, in a high degree, has already taken place ere that catastrophe seals the sufferer's fate!

I mention these munor circumstances to prove (so far as I can do so) the real existence of this main type of putrid fever. Another symptom of typhus goes to the same proof, namely, delirium, which follows a continuance of the stupidity discoverable in slow fever. A well-marked case is reported in the Annals of Sporting, for Nov. 1824, to which work I have since been some months attached; and, although I was prccluded by absence from examining the subject, I have reason to rely on the report afterwards made to me by $\mathrm{Mr}$. F.r. that its flesh was putrid in an extremely offensive degree, and wholly antit even to be cast to the dogs.

From the very unaflected and detailed account of the narrator, it anpears 
plain that unskilful persons might be led to apprehend such paryoxisms denoted hydrophobia; hut a short inquiry into the habits of the horse previous to its last delirium, would go a gond way to relieve the anxiety usually instilled into a neighbourhood by such events. None can say, however, until the experiment be tried, whether animals fed on such meat might not acquire rabies thereby.

The mad staggers, as the term is, which has never been satisiactorily accounted for, can be no other than this delirium of the typhus fever, brought on lyy pushing the animal in his work although labouring under slcw fever. None but common or ordinary cart-horses are lost in the staggers; whilst none but a very ordinary owner would so force his cattle to the last extremity during illness. As the above is all I shall find it necessary to say of staggers, I must here remark on the singular impropriety of Mr. Richard Laivrence's considering this as an attack of aproplexy! Since one pang alone denotes the death so to be named.

Rheumatic Fever is one of those disorders in the horse, upon the existence of which ductors disagree; but douttless the vicissitudes of heat and cold to which the horse is subjected, whereby the whole system is checked so as to occasion general fever, is equally likely to check the circulation in one or two limbs only. And the pain the animal would thus labour under in the performance of its duties would constitute one of the causes assigned higher up for simple fever. Little good, however, would ensue by my considering it separately; so I shall content myself with referring the reader to the head of sinple rheumatism.

\section{Epidemic fevers-Distemper.}

Cause.-When these appear, from time to time, they may fairly be ascribed to the season; for the kind of attack is not of a nature to become communicative, unless by continuance putridity follows : then, indeed, infection may begin, as it would also happen in any of the preceding species of fever. A rainy spring after a mild winter produces an epidemic catarrh, as well as sudden chill, among horses that are out at pasture whilst shedding their coats, and the most delicate receive this influence earliest. We may as well consider, that whatever may give one horse a cold, or affect his lungs, singly applied to him, would, if applied to many, in like manner affect the whole: this constitutes epidemy, or the distemper. Cloudy weather and cold easterly night winds, when the weather is warm or murky by day, is more likely to check the action of the lungs or of the whole system, than when a colder season has prepared the animals to withstand the influence thereof. An epidemic prevails sometimes in autumu; but, happen when it may, horses at grass acquire it less often than those which are kept in, upon hard food.

Symploms.-As just intimated, a cold, that harbinger of so many other evils, is what marks the epidemic in every case; in addition to this, the animal will labuur under the other symptoms of fever before described, according to is actual state of hody at the time of attack. Thus, if the horse be in ful! fesh and vigour, his veins quickly fill with the stream of life, inflammation of the blood wiil ensue, ur rather, to speak more accurately, of the vessels which contain it; hence, simple fever, or fever of the whole system follows, as before described, pp. 62, 63, but, be he poor, with little hlood to rereive inflamma tion, low fever is that particular affection which accompanies the original cold or catarrh.

Hence, I feet no hesitation in classing the epidemic-at last all those which have happened in my time, with one or the other of those diseases, and re. rommend treating it accordingly. At its carliest stage, of course, as it assumes 
the shape of a catarrh or cold (which in the more malignant cases becomes "Inflammation of the lungs,") I should treat it as such; but if not called in until this attark had extended to the animal's whole system, and catarrh had subsided into general inflammation, no reason exists why we should consider it a different disorder, merely because the patients may be more numerous chan ordinary! The reader had therefore best proceed on to the next head of information, for the details as to the sufferings and cure of a single animal, which I apprehend will instruct him how to treat the many; for, neither the name nor the character of the disorder can be changed by this circumstance, however alarming its extent.

\section{INFLAMMATION OF THE LUNGS.}

Causes.-Like all other of its class of disorders, inflammation of the lungs is nccasioned by a sudden check being given to the circulation, by cold when the animal is heated, either by exercise, food, or close stabling, as before de. scribed. How it happens that this organ of animal life is much more frequently deranged than any other, the reader who has well studied the second chapter, $p$ p. 3i, 32, will be at no loss to account for; adhesion of the pleura, or of the lungs, to the ribs, \&c. as described at section 32 , being very common: the labour of action, not to call it pain, is greatly increased thereby, and a certain degree of fever is thus engendered and kept up. The animal is in this manner always predisposed to acquire cold or catarrh; and ultimately inflammation of the lungs comes on, if the cold be neglected. Excessive ex posure to the rougher elements, added to the changes in our humid atmo. splieric temperature, accounts for the prevalence of affection of the lungs. Out of the same causes arise several minor evils, to be considered hereafter; as,

Simple cold, or catarrh.

Broken wind, of three kinds.

Roaring.

Chronic cough.

The symptoms of inflamed lungs rapidly follow each other; shivering, difficulty of breathing, loss of appetite and sluggishness, with drooping of the head, become visible in quick succession. In a few hours, if the animal be in gond keep, longer, if out of condition, those symptoms increase, with unusually quick action of the flanks, accompanied by hot mouth and hectic cough. Its ears and legs become cold, and he cares not to lie down, or being down, he rises languidly, as if mourning his fate. Sometimes the progress of this monstrous disease is accelerated by its previous habits, if the animal's constitution be predisposed towards inflammation.

The cure is sometimes mainly effected by the effusion of water in the chest, which frequently takes place upon bleeding the fatient; the practitioner has little more to do than place himself in the situation of the handmaid of nature, and all will go on well towards perfect restoration. How this effusion is perfurmed, none can know. Suffice it for our purpose, that such is the case, as I have shown in the second chapter, where l undertook to investigate the animal funcrions separately, and imagine I can not be misunderstuod: See sec. tions 19.20.21, in particular, at pages 22,23 . We may ascertain when nas eirtuston lais taken place, by an evident remission of the desponding symp. loms just set down: the flanks cease to heave so much as hitherto, the animal bckis up more cheerfully, he tries to eat a bit, the rough almost ceases, and the warnth of the ears returns, all in a partial legree: hut the roughness of 
hiscoat, which alway: accompanies inflammation, does not so soon return to its uriginal suppleness but assumes the first symptoms of hide-bound. When those favourable symptoms appear, much assiduity in the minor helps to ro covery should be kept up, though further bleeding will be evidently unnecessary.

I have presumed that the patient has been already blooded in this as in all other inflammatory attacks, and that to an amount commensurate to the virulence of the attack, even to the amount of five or six quarts, if the animal is of full habit. Of this proportionate deyree, or quantity, let the reader more precisely inform himself by turning back to what is said on this head and the pulse, uniler general inflammation, or fever, at pages 63 and 64 . The operator will of course follow up the bleeding with the purgative ball prescribed at page 63 , in the case of general inflammatory disorders. Were 1 to repeat over again such general instructions, however diversified in language, 1 should add no new information. In every case of bleeding a laxative should follow, as hefore directed, and clysters or water-gruel be administered in aid of both, at intervals of three or four hours. Neglect not tolerably warm clothing; and by good hand rubbing, beginning [gently, for 'tis sore] at the neck and chest, and so proceeding towards the hind quarters, endeavour to obtain external heat, if not perspiration. When these appear, it is a sign that effusion has taken place, in a greater or less degree, according to the quantity of perspiration. This may be assisted in some degree, after the laxative and clyster have well subsided, by administering a

\section{Sweating Ball.}

Take tarter emetic and asafoetida, of each ore drachm.

Liquorice powder and syrup, enough to form the ball for one duse.

Repeat the same in twelve hours, unless much perspiration has supervened in the meantime, when there will be no necessity for repetition. Thin watergruel will assist the expected perspiration; or, if the animal be a fleshy one, a bran mash may supply its place: either must be given blood-warm.

The heat of the lungs, which is the immediate cause of the disorder, is visibly reduced by every inspiration of fresh air the animal takes. Naturally, then, this air should he fit for its purpose, or pure; at least not the confined air of an over-filled stable, replete with noxious effluvia; nor, on the other hand, a current of air that issues by doors and windows to the right and to the left, particularly in cold weather, or even in warmer weather whilst the animal is yet sweating with the diaphoretics just now recommended. As in most other affairs of life, the best will be found the medium course; for the noxious stable air having irritated and so predisposed the lungs to receive the blighting influence of the cold air, it follows that either extreme of stimulating, or bracing overmuch, must do harm one way or the other. A tull and free inquiry into the best means of employing this main auxiliary in the resturation of health in inflammatory disorders would he well worth the labour of any veterinarian competent to the task ; but as regards myself at present, such a course would ill suit my views in writing this too brief treatsse. I shall, therefore, content myself with observing here, that since it is to this want of ventilation.in stables, and crowding many horses together, that we jwe all pulmonary complaints and most fevers, the subject is worthy considerairon as a preventive as well as a remedy.

Formerly, the general practice was to clothe the animal almost to suffucaiion, and to close up every aperture by which air might enter the stabie; the - visequence of which mistaken notion was a severe attack of the lungs that 
ustually proved fatal, wherever these addenda to stable management could be rmployed in supposed perfection. Not so the poor man's or the dealer's horses under inflammation of the lungs, or the more dreaded "epidenic distemper;" his stables being more or less pervious, and his horse clothing without the nap, it was no uncommon thing to find these had recovered, whilst the more pampered and more valuable animals fell victims to every species of inflammatory diseases. These results were known to many, in various circles, ahout the time of the establishment of the Veterinary College; and the mutual communications that thence resulted, proved the impolicy of the old plan of adding heat to heat, and increasing the disposition to acquire disease, of the lungs in particular. A revolution which had recently taken place in the human practice regarding the treatment of inflammatory and febrile disorders, also contributed to open the eyes of our veterinary practitioners in this respect, and they adopted the direct contrary practice in its greatest extremity. Mr. Colman advised turning the horse into a loose box, leaving open the apertures, without clothing or paying any regard to the seasons. Nought, however, could be more absurd than to suppose that a disease which is produced by cold should have the continuance of cold prescribed for its cure.

My practice has been to afford the animal as much fresh air to breathe as could possibly be allowed consistently with kecping out a draught or current; taking care also that none whatever should be directed towards his body, nor any enter the stable from the windward in stormy or cold seasons. With these precautions, in a loose box and well covered up about the chest, but not tighty, he would ever be foumd turning round to that side where the most air was .o be obtained, as if by instinct, knowing whence the readiest natural relief from his sufferings was to be found. In one case, of an aperture being made into an adjoining shed, the patient was frequently discovered inhaling the little air which was to be drawn thence, though the orifice was no other than a dis. placed knot of the wood partition.

In general, the disease bends before the remedies prescribed; the handrubbing must be continued, particularly of the legs, which in the worst period of the disease are uncommonly fine, but should it last him some time they swell, and in either case prove they are the barometer of the disorder, as well as the necessity of rubbing them. On the other hand, should the pulsation increase after bleeding, and no favourable symploms appear (as indeed they can not be then expected), this necessary operation must be repeated to the same amount as at first, or up to a state of tottering as recommended before, at page 63 : this necessity will occur but seldom, and that always with patients in previously high condition. Therefore, no danger can be apprehended from this copious discharge; for, at the end of twelve hours or less, which is the period at which 1 should again resort to the fleam, the blood would have returned tc: its former courses in every respect; the continuance of fever up to the same original height of the pulse, shows that the particular animal then under treatment, possessed an uncommon quantity of blood, and therefore that an unusual quantity should be taken away in order to alleviate the heat that is destroying it, and will destroy it, if the heat be not subdued at this second bleeding; for, should this fail, I expect little good from further attempts, though it is desirable to try what I always consider as the forlorn hope.

Should those remedies fail, suppuration takes place usually in six and thir. ty hours, and the animal is lnst. Occasionally, however, it happens with lowpriced animals, that the inflammation fixes itself and terminates with destruction of one lobe only of the lungs, generally that on the right sile, the sther performing all the functions, but how perfectly, or for how long time, $]$ had no means of ascertaining. At this point of his inquiries, the studious railer had better consult over again what 1 thought it necessary to say upon the 
Jissection of the lungs, in chap. 2 , pages 31 to 34 ; but he will please to re. member, I am not at present prepared to maintain, that the real cause of a destroyed lobe, which I have just suggested, is more correct than that ren tured by me at page 33 .

Bleediug, though highly beneficial at first, when the animal system is in full vigour, is extremely dangerous after the inflammation has continued some time. When (the fever continuing) weakness is indicated by swelling of the legs, or nature seeks to relieve itself by a running at the nose, then bleeding will be harmful; this latter was considered a most favourable indication of crisis in the epidemic fevers of my youth; but I sincerely hope that the groundless fears the rumour of such a plague engenders, never more will visit us with affright: the idea of infection, in such cases, is too ridiculous to admit of refutation.

Weskness follows, of course, every attack of so vital an organ as the lungs, and is a necessary consequence of the great evacuations of each sort his ex treme danger has rendered indispensable. But cordial balls, or indeed, stimu lants of any sort, are very improper, and might occasion a partial relapse, if given before the animal is quite recovered. Good grooming, diet, and exercise, constitute the means of restoring his strength. Let him be well rubbed down, daily, and his nostrils sponged out clean and often, when the discharge takes place, which most commonly attends the cure; the same offensive matter must be cleaned away froin the stall and manger, and he may be led forth daily whilst this business is going on. Hand-rubbing the legs should continue, so as to promote warmth, and they may be subsequently wrapped up, especially if the weather be chilly, with hay-bands, \&e. Exercise may be gradually increased as the patient gains strength and appetite. At first, good stuut oat-meal gruel, sweetened with coarse sugar or treacle, alternating this with wheat-meal, in order to coax his appetite; then oats which have been steeped in boiling water may be given, and next put him to hay of fine odour, in small quantities at a time. If grass or green vetches can be procured, a little, and not too much, may be cut for the now convalescent horse, in order to keep open his body; on the contrary, should he appear low spirited, a little malt occasionally will give him more vigour before leading him to the fiold every day, or leaving him there in clothing, whilst the sun may be out, if it shine at all.

BLISTERING and ROWELLING are recommended by most veterinarians, as tending to divert inflammatory heat from the more vital part of the surface. The theory is good; in the practice of human medicine I believe blistering is universally adopted; and this is one reason why I ever looked upon this means of cure with suspicion, even before I ascertained that the general heat or fever is always increased by the employment of either blister or rowel. Both are of the same nature; and the practitioner may learn how either operates on the system by ascertaining the state of the pulse previously to the application, and comparing it with the increased action of that barometer whilst the remedy is taking effect. Subsequently, however, it must be confessed, the agitation of the pulse will subside; and although I seldom find oo casion for employing either blister or rowel, yet I am free to allow, that the manner in which inflammation of these organs sometimes terminates (namely in abscess, or soft tumour under the skin), seems to invite an early adoption of artificial means to bring about the sarne ends. The hand-rubbing just recommended effects this tri a certain extent; and if it has been neglected, or lazily performed, then wili blistering become necessary to prevent suppuration within.

As this tumour usuaily makes its appearance and marks the crisis of acute sitacks, the practitioner may form an estimate of the probable beneficial of- 
fects of blistering in any case, by comparing and noting the earliest symptoms of any two cases, in one of which the crisis has been subsequently attended with such a superficial tumour, and in the other not so. He will then steploy blistering with more reliance on its efficacy than I have found neis sary after the hand-rubbing.

When this remedy is adopted for inflammation of the lungs, employ blistering ointment composed of cantharides and sweet oil, or hog's lard, or all three-or the following

\section{Blistering Ointment.}

Cantharides, powdered, 5 drachms.

Hog's lard, 4 ounces.

Oil of turpentine, 1 ounce.

Mix, for one extensive application over each side of the chest; which is a neater and more expeditious method of attaining the desired end than rowelling. When the latter method is adopted, let the tow used for the rowel bo dipped in a mixture of sweet oil and oil of turpentine; and the skin of the breast or belly, -if more than one such seton is employed,- - be separated only just sufficient to admit the rowel, in order to increase the irritation, but if the surrounding parts swell to an inordinate size, change the tow for some which has been sodden in digestive ointment.

Pleurisy, or inflammation of the pleura, a membrane covering the two lobes of the lungs (see chap, ii. p. 42)- has been described by Lawrence as a separate disease; but, as the treatment is the same as the preceding, I can see no propriety in making the distinction he does, especially as we can not know the difference until after death discloses all imperfections.

\section{A COLD OR CATARRH.}

Causes.-If I sought much nicety of arrangement, the disorder termed "a coll," would have preceded the similar but more malignant attack I have described under "Inflammation of the Lungs." Both are occasioned by cold applied to the animal's organs of respiration at a time that he is most susceptible of its influence, differing only in the part which may suffer. Thus, when the canal through which the air passes receives the check (before described), which is the immediate cause of inflammation, every one agrees in its being nerely "a cold," though in most cases no attack is more replete with danger if neglected.

But the origin and progress of such a check upon the functions of the membrane that lines this canal, having been already fully described in the second chapter, pages 33 , the studious reader must turn back to that part, if he would trace causes to their effects, and does not presently recollect all that is there said on this topic.

One prolific source of the disorder termed a cold, is found in the shedding of the coat in spring and in autumn, a process of nature always attended with a certain degree of debiiity or general weakness. Hence it is that the animal sweats profusely upon the least exertion; and being in this state sufiered to stand (harnessed perhaps) in the open air to cool, the sweating is ton suddenly stopped, and he gets a cold at least. 'That the lungs should suffer the soonest of any other organ is not at all astonishing : the very great exertions made by the lungs in the business of progression, is much increased by adhesions and other obstructions to the action of its several parts; and this, added to their exposure externally, and the constant inhalation of fresh, cold damp air. 
k.'tngether, the prevalence of pulmonary affections in every varied stage ought no longer to be matter of surprise to any person, however casually he may look at the matter.

The horse is sulject to cold or catarrh at every season of the year, and some animals retain chronic cough all the year round, and some during their natural lives. But the cold which is cuntracted in the spring differs materially from that of the autumn. 'The former attacks the animal when he is full of hard meat and gross feeding - "full of humours," according to a homely but intelligent phrase, and a malignant sore throat or an inllammation of the lungs is the ultimate consequence, however slight the cold unay have been at first. Sometines access of all those symptoms of diseased lungs, which I have already or may hereafter take occasion to describe, will be found in the same animal, and he usually bends before the complication of evils and dies, unless speedily relieved by bleeding, \&c. From its prevalence at some seasons, we then arree to call it "epidemic," and to recommend a treatment corresponding with the prevailing symptoms, if these be mild, as a simple cold; which form the epidenic fever or distemper always assumes in its earliest stages. On the other hand, the cold or catarrh which the moulting animal acquires in autumn, finds his system reduced by the heat and labour of summer; his blood, in quality or quantity, is scarcely capable of being excited to inflammation, and the first aftacks are more easily subdued. Neglect, however, increases the evil at all times, especially with the more valuable well-conditioned animals, some of which are so tenderly managed, that they scarcely can stand the opening of a door or shutter after dark, without catching cold. Neither autumn or winter is the season for remedying this defect in stable manage. ment,-if ever it can be got over at all.

Symptoms.-According to the precise part attacked, these vary not only as to appearances, but as to virulence or malignity, always increasing as the complaint descends lower and lower down towards the seat of vitality; the danger being also greatly augmented when the animal is pre-disposed to acquire catarrh in its worst forms by some previous misfurtune-as adhesion, \&c. A simple cold consists in slight inflammation of the membrane which lines the nose, windpipe, \&c. the functions of which membrane in health are described in the 3th section, chap. ii. together with the manner in which the disease is engendered. As we find in all other inflammatory disorders, variations in the symptoms occur, according to the previous constitution or evils of the individual, and its actual condition-much more than is attributable to an adverse season, or the immediate cause of disease. For example, if two equal animals be exposed to a chilly night air, that horse which had performed a journey previously to turning out, would catch a cold for certain, - the uther most probably would escape; but, if both had performed the same journey, let us surfose, and one of them laboured under the constitutional defect of "adheston of the pleura," (see page 32), he would acquire the more malignant cold, known as "inflammation of the lungs," - his less unhappy mate a simple cold. What horrid symptoms denote the former, I have attempted to describe; the simple cold, at its first appearance, is too well known to require minute description.

If the cold extend no farther than a check upon the mucous secretion of the membrane that lines the nose, a purulent discharge is first observed in the morning, its eyes become dull and a little bleared; and, in twenty-four hours, a short cough denotes that the inflammation is creeping onwards, and has reached the epiglottis. 'The attack upon this point of conjunction between the throat and mouth, will be greatly accelerated by the injury most horsta sustain which have been subjected to the brutal operation of beil.g "coughed" 
by the dealers; -an 1 .jury that thus produces latent effects, though the rrain were originally little, and that little long ago departed.

We hear this kind of first attack termed "a cold in the head," the secorid symptom is "a cough," and feel no disposition to quarrel with either term.

In propurtion as the attack may be more severe, the symptoms increase, as does the danger. Passing the hand down over the windpipe, at the epiglottis, the animal will shrink if it be sore within, and he will soon evince difficulty of swallowing, and refuse his food: inflammation has begun. When these are not preceded by a discharge from the nose, this symptom does not appear until the inflammation is lowered by bleeding and other remedies: the dis. charge is then an indication that the inflammation, or heat, has subsided and no linger demands the adjacent secretions. See page 33, for a more minuto description how this demand takes place.

With those symptoms of sore throat others hecome apparent, and the whole assume a malignant tendency proportioned to the severity of the attack and previous state of the suffering animal. As happens in all other inflammatory complaints, the pulse tells of the existence of fever, in its degree : accompanied by languid eyes, breathing quick and laboriously, and general heat of the skin without perspiration. In some cases the sore throat is substituted, in some measure, by enlargement of the glands underneath the jowl, which are also attended by soreness more or less; and as this suecies of attack is occasicned by the humidity of a cold spring or wet autumn acting upon moulting horses, great numbers feel its influence at once, and gives reason for veterinary writers to consider this general distemper as "the influenza," and an "epidemic." Enough has already been said under the latter head of information, therefore let us proceed to treat of the thing as it regards the individual patient.

Remedy. - When the glands swell, as just mentioned, and there is no reason to doubt, according to the corresponding symptoms, that it is the. effect of a cold-which may further be ascertained by their heat and tension, let some discutient application be used-as camphorated spirits of wine: but if the inflammation be to a great degree, bran poultice may be applied to advantage. If those enlarged glands already contain matter. the tendency to irritation will thus be reduced; if merely sordid tumours, either application will effect relief, by reducing the size and tenderness of the part, so as the animal may take his medicines with less difficulty. Steaming the head for an hour, or applying hot flannels that have heen steeped in boiling water, will be foutd serviceable, taking care to dry-rub the coat immediately after, which also assists to reduce the swelling. If this symptom does not give way before those applications, and the throat is ascertained to be sore, blistering may be resorted to, taking care to extend it over the whole of the parts affected. See page 76.

As in all other inflammatory diseases, bleeding to an amount proportioned to the violence of the attack, with purgatives and clysters, should accompany the foregoing external applications: and these, with plenty of bran mashes, sodden oats, and the fever powders prescribed at page 65 , will reduce the symptoms. Similarly to those also will be the precariuusness of his complete recovery, and so should be the care that the relapse, to which he is for a time daily liable, should not reach to a great height. I need not repeat the general precautions which are set down at page 70 .

Unwilling to leave the reader in a dilemma as to the mode of applying the bran poultice just recommended and upon the efficacy whereof I mainly rely, I love taken the paius to sketch a bandage proper fur that purpose, with its fastenings, the ingenious contrivance of some Frenchman, whose name I wo. Leve to have been Bourgelat. 


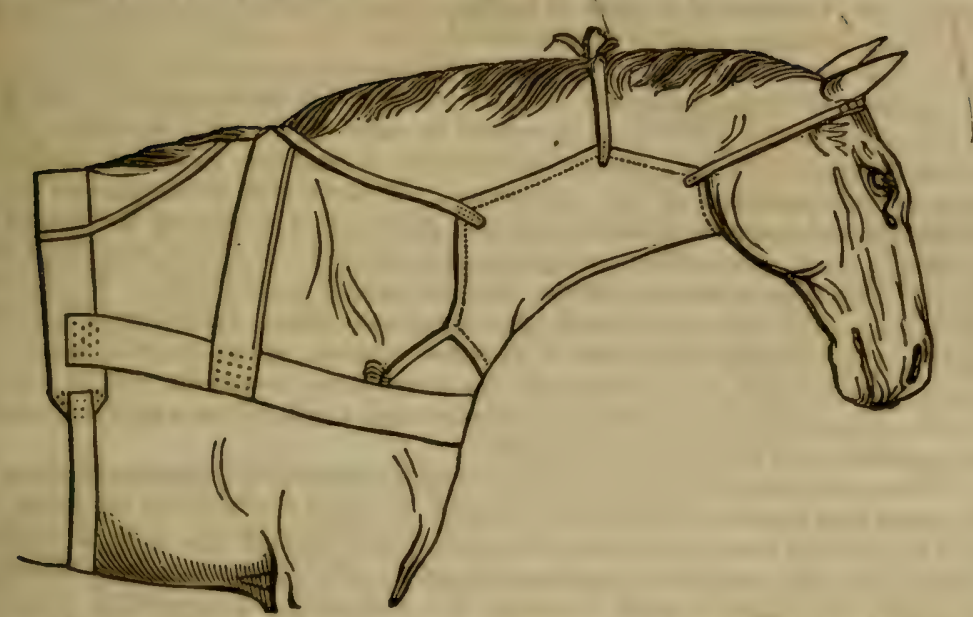

It will be seen, that unless the remedy proposed is practically applicaole, the rreparation thereof would he wholly unprofitable; therefore, when the poultice, the steaming, or the blistering, be found necessary, we should endeavour to secure it in the best possible manner ; and as most persons are utt poor horse milliners, I have undertaken in this instance, as well as in cases of Strangles, Poll-evil, and Vives, to exhibit the best means of retaining the remedies in their proper places.

The cloth to be employed should be of stout but supple linen, as Russia duck : or hempen sail-cloth; or in failure hereof, a fresh sheep-skin, or a piecc of Shamoy leather might be substituted.

Sorne recommend steeping the cloth in a solution of gummy substances, to render it water-tight; but such contrivances only add to its unconquerable stiffness, and I should prefer oiled silk, such as used for urnbrellas, if readily procurable, and not too dear for the pockets of those more immediately concerned.

When spread abroad, the cloth will be of an irregular octagon shape, at each corner whereof it is to be strongly sewed on a piece of broad tape for the pur. pose of fastening to the girth, or round the neck, or to a breasting of broat web, which is supported by another piece, that passes over the withers, and which two should be previously fastened together by stitching the cross-piece ends upon the breasting. The two extremes of the bandage will be the fillet across the forehead and the fastening at the girth; therefore measure should be previously taken of the whole length proper for the individual patient, lest the tie, which would otherwise be necessary at the ears, might discommode tho animal, and occasion skittishness; or on the other hand, the application would not be kept in its place properly. A single glance, however, at the cut will instruct a tolerably expert workman, or work-woman, how to manufacture such a bandage as would answer every purpose.

\section{THE COUGH}

Which accompanies this disorder will frequently remain after the other symptoms have abated; in some cases a cough is the only symptom of catarrhal in. flammation that the animal suffers under, and in both we should apply ourrelves to reduce the inflammation of the wind-pipe, \&c. which occasions the 
comerh; for f not chired at once, it baffles all our efforts for a long while, and ultimately becomes what is demominated (from the length of time it has last(ai) a curosic: coutin. But no absolute necessity exists for considering these as separate or distinct diseases, the one heing but a prolongation or fistening of the other on the system, as described at page 85 behow: therefore should our attention to the lirst attack be unremitted, and the remedies applied in turn to each variation of the symptoms. If these are accompanied hy the swellings and soreness of the throat and glands, just spoken of, the cough will generally cease, when these symptoms are removed; but if not, the cough must be considered as a simple disease, and be treated accordingly. By the way, sering that after all our care and anxious examination, we can but imperfectly distinguish hetween some case's of ill-cured catarrh, or the chronic cough, and the incipient cough, or a fresh cold, the practitioner would do well, in cases of doubt, when he finds one of those remedies fail to afford the expected relief, to try another, and another, for example.

When the courh continues, and there is reason to apprehend, from ine frequent and violent eflorts of the animal to expel the mucous secretion, that this is thick or viscid, and does not come away, though the animal evidently sneezes for that purpose, - the lungs must be relieved by softening the agglutination; otherwise termed "cutting the phlegm." Venesection always effects this end; but, when blool-letting is not rendered otherwise necessary, the drenches Nos. 1 and 2 will afford relief. As the cough always becomes more and more troublesome as the discharge lessens of itself, or ceases altogether, we may conclude some lurking virus that has fixed upon the lungs is the immediate cause of the cough. In order to enable the lungs to throw of this cause by a more copious discharge, give the

\section{Expectorant Ball.-No. 1.}

Sulphur, half an ounce.

Asafoetida, 1 ounce.

Liquorice powder, 1 ounce.

Venice turpentine, 1 ounce.

Mix for four doses, and give one on each of four succecling nights. See his exercise be moderate, and allow him the cooling regimen before referred to (page 67), as proper for convalescent horses after intlammatory attacks.

\section{Expectorant Ball.-No. 2.}

Powdered squills, 2 drachms.

Gum ammoriacum, 4 drachms.

Powdered ipecacuanha, 4 drachms.

Opium, 4 drachms.

Ginger and allspice, of each 1 ounce.

Balsam of sulphur, 4 ounces.

Mix, for six balls, with Castile soap, 2 ounces, beaten up with mucilage; treacle, or syrup: to be given once or twice a day.

If this regimen can not be followed by reason of want of attendants, his Bowels at least should be kept in a proper open state by mild laxatives; or, if costiveness prevailed when the cuugh first came on, simply opening the bowels will then procure ease, if it do not eflect a cure. This muy be astained by giving, for three or four days, 


\title{
The Laxative Ball.
}

\author{
Aloes, one and a half drachms. \\ Ipecacuanha, one and a half drachms.
}

$M_{1 *}$ ith liquorice powder and mucilage fir one dose.

Thuse medicines, and every modification of them, which the experienced chemict san suggest, it is desirable should be tried in succession, as the seat of the disorder is so very various and uncertain, that the partial good which one may effect, will frequently be aided by another. To this end the follow ing ball and drenches have been prescribed and used with success-

\section{Diuretic Ball.}

Yellow resin, 2 ounces.

Turpentine, 4 ounces.

Soap, 3 ounces.

Salad oil, 1 ounce.

Oil of aniseed, half an ounce.

Powdered ginger, 2 ounces.

Kub the two last together in a mortar, with a little linseed powder. Melt the Lest three articles over a slow fire, and then mix in the powders. Divide the mass into eight balls, and give one a day until the water is affected.

$$
\text { Drench.-No. } 1
$$

Vinegar, 8 ounces.

Squills, 2 ounces.

Trcacle, 6 ounces.

Bruise the squills and pour on the vinegar boiling hot; simmer these near the fire two or three hours, then strain off and add the treacle. Divide into threo or four parts, and give a portion two or three times in the course of the day.

$$
\text { Drench.-No. } 2 .
$$

Bruised garlic, 4 ounces.

Vinegar, 12 ounces.

Pour on the vinegar boiling hot; let it simmer fuur or five hours, strain off and add six ounces of honey. Divide into three parts or four, and give in the course of the day at intervals.

But no ultimate cure can be effected unless the diet and regimen is pro. perly followed up; nor, if the animal be pushed in his work whilst the disorder is virulent; and, after all our care, if the cough does not abate, but becomes worse by reason of a new cold, it fixes upon the lungs, and the arimal drags out a miserable existence. This has been usually treated of as consumption, by reason of its resenblance to the same disoriler in human medicine, from the wasting away, or consumption of the animal system, which accompanies a diseased state of the pulmonary arteries. Of the importance of this part of the system to animal life, to existence and health, the attentive reader can nut fail to be sufficiently aware who has well perused that part of the second chapter of this little manual, in which the functions of the organs of respiration are described with requisite care-page 31 to 35 . The hopelessness of bringing ahout a cure, after the ruin has proceeded so far as wa 
nave just contemplated, must likewise he most apparent to him : I will not therefore, pursue farther in detail the last wastings of this vitally essential organ of the animal system, but proceed shortly to notice some other effects of an ill-cured cold or protracted cough.

\section{BROKEN WIND}

Is already so minutely described, as to its causes and symptoms, in the second chapter, that I apprehend repetition in this place would prove worse than use less. The reader will therefore turn to page 31 , and the recapitulation of my treatise on the organs of respiration which immeliately follows, at page 35. Generally speaking, broken wind is hrought on by inflammation of the organs of respiration, and acquires a different name, though requiring but little variety of treatment, according to the part which may be the more in. mediate seat of disease ; for it must be clear, that although this may lie in the uppermost part or larynx, in the lowermost part or midriff, or more centrally -the communicable nature of inflammation is such, that the whole must partake in some degree of each and prery partial derangement. And this degree will be proportioned to the excitability of the individual's organs of respiration that may be the subject of attick : if the animal contract cold or cough in the vigour of age and bealth, he will experience its effects in the most frightful shapes; it proceeds to encroach on and obstruct the right functions of the lungs with rapid strieles, and if the symptoms do not abate, he dies. But, being partially removed, it becomes a chronic disorder* to the $\mathrm{rnd}$ of his days; and, agrecably to the part which may experience the attack, has it been the practice to denominate chronic cough either roaring-broken wind -thick in the wind-or asthma. Hereupon, however, the doctors disagree.

How this difference arises may be worth a moment's investigation here, although so large a portion of the second chapter has been already devoted to the subject, and the reader must absolutely turn back to it. At page 34 , the thickening of the midriff, in consequence of inflammation attacking the adjacent viscera, was minutely described: this thickening of the membrane also extends to every other part of the lungs, wind-pipe, Sc. whenever cold or inflammation prevails; and in the event of its continuance, the thickening of the membrane remains long after the virulence of the disorder may be sub. dued. If this state of the organs of respiration extend over them generally, the patient may very justly be said to be "broken winded;" when this extends to the thickening of the pleura only, he would then be thick winded, or short in the wind, as he would also in case of adhesions of the midriff, as described in page 34, already referred to. Neither affection, however, can fairly be set down for broken wind; though hoth those membranes being affected might properly enough be considered "a broken manner of draiving in and expelling the wind," for the inspirations and expirations are in this case extremely irregular, broken, or variable; whereas, when the air-cells are really broken, or burst into each other through great exertion, then the air escapes with difficulty, and the expirations are now slower than the inspirations (as before observed), and both together constitute irregular respiration, or true broken wind.

But of controversies there is no end. J. White and $\mathrm{R}$. Lawrence were fur some years at issue on these points; White having taken up Lawrence rather sharply, and somewhat unjustly, if he meant to impute error to the

- Chronic disorders are those which, having lasted a long time, become almost secand nature, and plague the organs of respiration more than any other viscus: thus, a tickling congh may etick br an animal for years, but it becomes worse upon any great exertion, or on cratsulus freath colus 
atter, as rerrards the symptom of respiration just spoken of, for each writer was right in his separate prosition: as they disagree as to what constitutes brol:en wind, so they could not of course agree as to the symptoms. See parres 159, 160, of White's first volume. This autlior also disorders his own positions at the same place, in two other instances, which I should not have noticed, but for his tart rebuke of $R$. Lawrence for attributing the term broken wind to the thickening of the membranes. In this view of the case, it will be seen, I certainly can not agree with this verv clear-headed veterinarian; hut I do not therefore, harshly refute a gentleman and scholar for not agreeing with me upon a simple term of science: it was this unamiable attachment to trifles that so long impeded the progress of chemical knowledge, until the plain-speaking Davy, Nicholson, Park, and Paris, came into vogue, and drove Lavoisier from his prostrate cuterie,-Dickson was put to silence, and Fourcroy's reveries were laid in the dust of oblivion.

White says, "The lungs of broken windexl horses that I have examined have generally been unusually large, with numerous air-bladklers on the surface." p. 160. Y et, in the next page, he opens a broken winded subject, and says, "The lungs were lighter [meaning less] than usual, and without the air-bladilers, contrary to the state Mr. Lawrence describes." What Lawrence had said was this: "The most common appearance of the lungs in broken windect horses is a general thickening of their substance, by which their elasticity is in a great measure destroyed, and their weight (i. e. size) specifically increased. On this account air is received into the lungs with difficulty, but its expulsion is not so difficult. Thus, in broken winded horses, inspiration is very sluw, expiration sudden and rapid, as may be seen by the flanks rcturning with a jerk." (p. 123, octavo edition.) And he is correct as to these two motions accompanying the thickened membrane or substance of the lungs; only I should have termed the disorder thick wind, and not broken wind, when all would have coincided with White's statement, barring his own self-contradiction as to the size of the lungs, which Lawrence had mistaken for weight, and which had met with the counter assertion of being "specifically lighter." On this point of their dispute, however, neither the one nor the other could possibly know aught with requisite certainty; and I, for my part, am inclined to believe, that the lungs of high-bred horses are specifically lighter than those of the cart breed, saving that the whole organs of respiration are much less muscular in the first kind than in those of the latter, the skirt or border of the midrift in particular. On the other hand, the hearts of blood horses invariably run of a larger size than those of the common English horse. Vide page $3 \%$. One cause of broken wind, or rather that mainly predisposes the animal to contract this disorder, is voracious feeding, which distends the stomach inordinately, and for a while gives to the animal a short-lived vigour arsh healthy appearance. This induces its proprietor to put him upon his mettle, and try the extent of his powers at progression; and as he will best prerform those feats upon a plentiful feed, the action of the midriff and lungs thereby becomes labuured, and the proper expansion of the lungs is impeded. Heat and tension are the irnmediate corrsequence, and broken wind of one or the other species is the remote consequence. Horses that eat their litter, and what other hard substances they can come near, are similarly predisposed io broken wind; namely, by the great distension of the stomach, and inability of inspiring a sufficient quantity of air to fill the lungs, whence the inert cells. or the purtion not distended, fill up, contract, and becom? useless, or, upon sudiden action and over distension, they burst at once.

Cure there is none for broken wind, and therefore all that can be done sv way of alleviating its symptoms must be effected by maragement, or as it is more generally termed, by 
Regimen. Of course, any person would avoid exposing the animal to fresb cold, and not push him too hard on a full stomach; nor indeed, give away a chance of increasing the malady by the same means as I have just said originally brought it on. He will, on the contrary, follow an opposite course of treatment, and as much as possible regulate his feeding and exercise upon moderate principles, for the stomach and bowels are always affected by broken wind. Hence it is, that flatulency accompranies broken wind of every kind, so that the animal in his endeavours to cough, usually breaks wind after an effort or two. Much medicine is not requisite, and, in slight cases, far from desirable; tonics, bracing air, and regular hard meat feeding, broken or sodden, and given in small quantities, will do more for the horse than physic of any sort. For the first, Peruvian bark, or cascarilla in small doses, may be given occasionally adapting the quantity to the bulk of the animal.

\section{Tonic Ball.}

\section{Cascarilla, $\} 1$ to 2 drachins of each, \\ Oil of Carraways, ten irops; with}

Mucilage enough to form the ball. If irritation of the bowels is indicated by a certain protrusion of the anus, add of opium 10 to 12 grains.

When the cough is particularly troublesome, or the animal seems to labour much in respiration, give the following

\section{Ball.}

Dried squills, powdered, 1 drachm.

Gum ammoniacum, 3 drachms.

Opium, 10 drachms;

With mucilage sufficient to form the ball.

If there is reason to apprehend the horse swallows his corn without grinding it, as commonly happens, bruised or sodden oats should be given, and the bowels discharged by purgatives, when alteratives may not be deemed equal to the urgency of the case. Those prescribed at pages 86,87 , are applicable in this case also; inasmuch as the two disorders bear very near resemblance to each other in this respect. Give green food, succulent roots, and bran-mashes, as there recommended. Let the water be soft, not too cold, and given in small quantities at a time, and frequently.

As broken wind produces disordered bowels, and is re-produeed by it, the connexion or sympathy between the two, thus plainly demonstratel, should be employed in the alleviation of the former in all its stages, when it has been of long standing. The means of attaining this object has been shown; and when the animal under treatment is equal to the care and expense, he frequently recovers so much of his former powers of free respiration, that his cure will seem for a short time fully effected. These appearances, however, aro completely illusive; upon the least extra work he relapses into his former dif ficulties of continuing it, and the cough, the roaring, wheezing, or labouring of the flanks and chest, return as bad as ever. If the work be very hard, as always happens when the horse has been sold deceptiously, and the new mas. ter would try his utmost powers, the reiapse is then worse than before; he hereupon becomes a confirmed roarer, by the wind and lymph being driven inside the membrane that lines the wind-pipe, anl causes inflammation of the very fine blood-vessels that traverse it. Hence the number of lawsuits that are instituted to recover the valuable consideration jaid for broben windus 
horses that are returned upon the hands of the sellers as roarers, that never were known to either groom or stable-hoy for roarers, before the day of action or trial. Hence, too, let us charitably suppose, the contradictory evidence often given, and the flat, downright cross-swearing that usually takes place on such occasions. For the horse having been partially made up for the purpose of sale, i. e. nursed, patched up, and to all appearance "right in all his parts," the fact of his gुoing in pain comes out by way of his skin at first, and the new purchaser being generally desirous of trying all he can do, the ruin is effected, by pushing him too much, of driving the wind inside the membrane. as before described.

Hereditary Roarers. Early in the present century, a question arose among breeders, whether the gift or the curse of roaring descended from parents to their progeny. The decision was looked for with unusual anxiety among the breeders of farm-horses in Norfolk and Suffolk, where a famous well-built horse in every other respect was much sought after, even subsequently to his being denounced a roarer prepense. Would his stock take after him? was a problem very desirable to be set at rest, when Mr. Wilson, of Bildestone, late Sir T. C. Bunbury's, propounded the question to Mr. Cline, an eminent surgeon and anatomist in London. In reply, Mr. Cline said, "The disorder in a horse which constituted a roarer, was caused by a membranous projection in a part of the wind-pipe, and was a consequence of that part having been inflamed from a cold,* and injudiciously treated. A roarer was not therefore a diseased horse, for his lungs and every other part might be perfectly sound; but when a horse was in strong action, his breathing becane proportionably quickened, and the air, in passing rapidly through the wind-pipe was in some degree interrupted in its course, and thus the roaring noise was produced. The existence of this in a stallion could not be of any consequence. It could not be propagated any more than a broken bone, or any other accident." $†$

Unfortunately, however, for this opinion, and not exactly in accordance with my wwn, several of that horse's get became roarers, but we are left to guess whether hereditarily or acquired. An accuunt of the horse in question appeared in the Anuals of Sporting for 1823 ; but the colouring given by an evident partisan of the stallion-master induces one to lament the absence of that cardour, from which alone useful truths are to be drawn; for, we are deterred from indulging in pathological investigation where the grounds of in. quiry are so impalpably sandy as were those adduced upon the occasion.

\section{CHRONIC COUGH}

Is already defined to be the remains of an ill-cured cold, which may or may not have been a cough originally. It bears close analogy to simple broken wind that is seated in the wind-pipe or its branches, of which it may be considered a continuation, or the natural consequence of neglect, with more inveteracy. How this effect would sn accrue was described at page 80 ; and the analigg is still further corroborated by the fact, that the treatment for cough of long continuance is precisely that which is found serviceable for broken wind, the situation of the two disorders making the only difference in either respect. Again, the symptoms of hoth may, by long and careful treatment, be so recluced as to seem cured, for a longer or shorter period, and bath will return in the shape of roaring, upon the animal being put to sudden hard

- Not always so, Mr. Cline.

l Our human anatomist is very nearly right as to an accident not being descendable; but oto. In that roaring did Jescend to the firs generation, we must infer that this was "an qucident of jirth, " add not a contracted nne which might possibly go no farther. 
work, as mentioned in the last pages. The corresponding symptoms of both are also so nearly alike, that I merely comply with custom while I recapitulate these for the use of readers who might not choose to consider that horse broken winded, which to all appearance is only affected with "an old cold in the wind-pipe." But, let the first term appear to an owner ever so formidable in sound, the latter is no less dangerous in effect, and both are alike liable to terminate in roaring.

The symptoms which indicate chronic cough are nevertheless so slight, that it is too often considered as but a small remains of the more alarming catarrh, which its owner vainly imagines will go off in time, as the other disagreeable symptoms have done. In this hope he is invariably disappointed, if the means of reducing it be deferred. After the more violent symptoms of catarrh have subsided, and the cure may reasonably be considered as complete, the horse returns to his usual feeding, and, as in the former case, eats voraciously; he is denied water oftener than twice a day, perhaps not so much; but, when at length he does drink, he gulps it up as if famished. This is commonly the cause, and the first indication of the cough which follows immediately after, but is often mistakenly attributed to his improving too fast after his long illness, and it is considered only fair that "he should be allowed to recover himself completely." Precaution is thus lul!ed in fancied security, and unless prompt relief be afforded before the damp season of autumn returns, the symptom in. creases to obstinate confirmation; until time renders cure hopeless, alleviation or abatement of the coughing being all that lies within the power of medicine or stable management to effect for it - the aid of the former being then of little avail. Very few small proprietors of horses use timely precautions in this respect, and the disorder goes on: large owners having more experience, adopt early measures, and if pursued with proper vigour, these usually prevail in lowering the symptoms.

An occasional cough is also brought on by high feeding, which, as it arises from the rapid production of fresh blood, is termed plethoric cough by way of distinction. Of this symptom it would be needless to tell the better informed, perhaps, at an interval of six days, that we have but to take away the cause, and the effect ceases of course. This, however, does not always follow; for the cough sometimes remains after the gross feeding has been reduced in quantity and quality. In this case, it must be considered as chronic cough, and treated as such, by emptying the bowels, \&c. as above directed.

Remedy. As in the case of broken wind of every other kind, the horse eats every substance he can come near, chronic cough being sometimes produced by over feeding, as well as always producing that symptom. Therefore, when a horse has a cough, occasionally, fur two or three days, his appetite being good, we had best conclude he is too full and must be emptied by an alterative or purgative, according to the emergency of the case: if he be of gross habit, or has failed in the proper evacuations; if his heels swell of a morning, or his coat stare like hide-bound, the cough will vanish before the following

\section{Purgative Ball.}

Barbadoes aloes, 8 drachms,

Castile soap, 2 drachms,

Ginger, 1 drachm,

With mucilage sufficient to form the ball.

Failing to stale properly, the patient's heels will swell, in addition to the cough, and both may be got rid of by a diuretic ball or two at farthert. If 
the evacuation by the skin be at fault, through cold or otherwise, accompani. ed by cough, the perspiration will he restored, and cough depart, by the exhibition of Enetic Tartar, one or two grains, every day twice in powder, untis its etfects are perceptible on the skin, and the cough then diminishes. This, however, is a very slow remedy, though sure, and is sometimes given in much larger quantities. The preparation is very simple when given in the form of a ball, being made up of liquorice powder and unucilage only, of a sufficient consistence to retain that form. If much heat of body is perceptible, though the pulse may not indicate inflammatory disorder, add to the foregoing ball, nitre, 4 or 5 drachms.

But whatever course is pursued, if symptoms of a bad habit of body are discoverable, it will be advisable to administer the foregoing pargative ball once or twice previous to adopting any other means of cure. If those symptoms of a bad habit of body do not appear, then the purgative should be of a milder nature and given at the same interval.

\title{
Mild Purgative.
}

Aloes, 4 or 5 drachms, Castile soap, 3 drachms,

Calomel, 1 drachm,

Ginger, 2 drachms,

Oil of Carroways, 10 drops ;

Mucilage enough to form the ball for one dose.

Some horses are more delicate than others, and heing then irritable about the throat and chest, are liable to contract a periodical cough, which becomes chronic without due care. Such animals should be exposed as little as possible to any violent weather, or sudden change of the temperature: these are the kind of animals that will benefit greatly, or suffer the most, by a summer run at grass, according to the heat, the dampness, or dryness of the season, and the precautions used previously to, and at the turning out. Neither should such tender animals, under circumstances of chronic cough, which generally affects their coats also, about the chest in particular, be treated with a purgative, even of the mildest form but with alteratives instead.

\section{Alterative Ball.}

\author{
Aloes, $\{12$ drachms each, \\ Emetic tartar, 1-2 drachm, \\ Ginger, 1-2 oz. \\ Oil of carraways, 1 drachm;
}

With mucilage enough to form the balls into six doses. Give one every morning until a loose stool is produced, which may happen on the third or fourth morning or longer, as the animal may be more or less relaxed.

Even with this moderate employment of laxative medicine, the kind of an: mal for which it is most desirable will be very unfit to turn out to grass of a sudden; as, on account of its delicacy, it will in that case be more likely to ac. quire a small hectic cough, which no one attends to because of its triviality, until time renders it chronic, with all its attendant consequences. Roaring, broken wind, are among these evils, and have already received as much attention here as they separately reguire.

Erequently it happens that a horse has a constitutional cough, ur une which 
comes on nnly upon high feeding, or a disposition to plethora will p-oduce the same kin? of cough, and, in either case, it seems but an effort of nature to relieve itself. In this case, the rapid repletion of blond drives it into the smaller vessels that line the windpipe, \&c. and there causes the titllation which after two or three efforts ends in cough, and so on repeatedly. None but those which are in some slight degree or other already afflicted with chronic cough are ever so attacked, I apprehend; indeed I have frequently remarked how excellent a test of "bad in the wind" was gond feed, or a large feed, with work upon it. In this case, the administering of nitre and resin will thin the blood, and give immediate relief.

\section{Drench.}

Yellow resin, $\}$ of each half an ounce, Oil of aniseed, 20 drops.

The vil should be first well mixed with the resin, and the whole given in a quart of water-gruel. Recurrence of the same affection may be prevented in some measure by giving the same in another form, which is in general reckoned more convenient-namely, as a cough powder, sulstituting aniseeds, 1 ounce, for the oil, and pounding the whole together; mix with the corn.

\section{INFLAMMATION CF THE STOMACH AND INTESTINES.}

Whenever one of these organs is affected, with inflammation particularly, the other soon feels the effects of the attack. This arises from the proximity of the two; or the continuity of the digestive faculty, which is mostly carried on in the intestines, as the reader of tolerahle recollection well knows was so described in Book 1. page 44, \&c. Corrosive poisons, indeed, carry on their work of destruction upon the internal or villous coat of the stomach until the ruin is complete; but, although horril inflammation accompranies its ravages, I wouid not class such a species of accident under any other head than "Poison:" to call it by its symptom would be delusive. N'either is the inflammation caused by worms, proper to be taken into consideration here, though in this case both organs are affected at the same time; but the bott question involves other considerations, besides the best means of destroying them, of preventing the access of this irritating insect, or of alleviating the effects of its bite and adhesion to the villous coat, alike of stomach and intestine.

With those exceptions, there is no greater difference in the causes, symptoms, or means of cure of inflammation in the stomach and intestines, than exists between those of the great and the small gut. Inflammatory pain in the smaller parts of the alimentary canal will ever be more acute than those which attack the larger ones; thus, when the stomach is the seat of disorder, the mins will be duller, the paroxysms less distinctly marked, ani the pulse but little altered; but, when by continuance it reaches the small gut at the luwer orifice of the stomach, then will the pain and anxiety of the amimal increase greatly, and the symptoms thereof, visible in his manner (to be described shortly), will become more distinct, rapid, and vohemeni. The pulse nureases in number, in sharpness of vituration, and irregularity. Such is the lifference also that is discernible between attacks upon the colon or great gut, and on the smaller guts. But all this rofers to the first attack; for after a while, if the means adopted are insufficient to chesk its career, the ruin goes on to affect the whole abiomen, and the aumal dies in cxcruciaung tormente. 
Causes.-Much the same as those which occasion fever in all orüinary cases; that is to say, a sudden check given by cold to the action of the parts, while these may be in a state of excitement, or through over action, hard work, excessive heat of the weather, the operation of cordials, \&c. By this latter means stallions and brond mares are sometimes destroyed prematurely, even without catching any cold, or this part of the system receiving any check whatever; in these cases, excitement has been carried to the utmost pitch by high feeding, and stimulating the male, until nature gives way, or rather, I might say, catches fire almost, and if not speedily arrested, the heat soon de. stroys the functions of all the abdominal organs of life.

To stage-horses, inflammatory complaints usually prove fatal, from the same immediate cause; the animal being fed high, and pressed forward to the accomplishment of his daily task, regardless of the first indication of this disease; and in summer time, we witness numbers of such dropping down in harness, sometimes whilst going along, seldom giving warning of approaching dissolution. But, whatever be the previous state of the animal's bodily health, he can rarely stand the maltreatment he receives from his driver:-viz. that of being driven through ponds and large rivulets, while he is yet perspiring greatly through fatigue and the heat of the weather. Long rests in currents of air, or unsaddling horses under similar circumstances, are alike productive of inflammation of those or some other part of the animal's inside, if it do not bring on fever of the whole system - as before observed, p. 59. The kidneys or the liver are sometimes alone affected by this species of culpable neglect; but in either case the effects are not immediately perceptible, and the disorder creeps on unheeded, or seizes the animal violently, so that it dies at the next going out.

Neglect of the necessary evacuations, or the discontinuance of those which have been customary, even though injudicious, will occasion an accumulation of dung in the intestines when they are least capable of bearing it: upon this, pressing the horse in his work will bring on inflammation, as it will sometimes after a heavy feed and water, which some injudiciously give on account of a hard day's work lying before him. The same happens to horses that are inordinately fat, when hard worked; the dung that is then eliminated bears with it a portion of the slime or mucus that lines the intestines, and this appearance has obtained for this species of inflammation the term molten grease. I postpone, for a few pages, the consideration hereof, in compliance with custom rather than in obedience to propriety.

Adhesion of the gut sometimes takes place, so as to cause partial obstruction to the passage of aliment; at others, tubercles are formed on the mesentery that holds the bowels in position; and in either case the secret is disclosed by a staring coat, which some mistake for the worms. Both those affections are the effect rather than the first cause of inflammation of the part, and may be distinguished from "the worms" by the state of the pulse, by the heat, tension, and soreness evinced by the patient on passing the hand over the belly. See page 46, book $I$. The reader will also perceive, upon turning back to page 22-21, in what manner this adhesion is effected, by the exnaustion of the moisture that is designed ly nature to lubricate the parts.

Colic of long continuance, if the animal is worked while this is on him, is another prolific source of inflammation of the intestines; as is the drinking cold water copiously, while in a state of perspiration, or after a trying jour ney, which is al ways attended with spasmodic colic of the stomach and bowels. at first, and of inflammation sooner or later, according to the temperature of the individual. The necessity of getting rid of the lesser attack before it ac quires a permanent and dangerous aspect must be obvious; and as the treatment prover for either, is at total variance with the other, the one requiring 
wor mth and stimulation, the other a cooling and reducing treatment, our first duty is to ascertain precisely the exact nature of the attack; for a mistake on this wint wonld, and does frequently, prove fatal-ay, in human as well as in horse medicine. Therefore it is, that 1 have judged it expedient to set down here a tahle of the syn:ptoms that will enable the practitioner to distinguish between the two kinds of attack.

For this mode of setting before the eye in parallel columns the discriminating symptoms of two such apparently similar disorders, 1 am indebted to $\mathrm{Mr}$. Ryding, who inserted it in lis "Veterinary Pathology," 1801, pages 86, 87; and it was copied by Thite inio his "Compendium," 1803 , with a few alterations, by no means for the betie:; I have adhered chiefly to Ryding, with but one slight alteration.

SYMPTOMS.

A table for distinguishing betue' $n$ tie Colic or Gripes, and Inflammation of the Bowels, by the symptoms ticut mark the character of each.

Spasmodic or Flatulent Colic.

1. Pulse natural, though sometimes a little lower.

2. The horse lies down, and rolls upon his back.

\section{The legs and ears generally} warm.

4. Attacks suddenly, is never preceded, and seldom accompanied by any symptoms of fever.

5 . There are frequently short intermissions.
Inflammation of the Boroels.

1. Paise very quick and small.

2. He lies down and suddenly rises up again, seldom rolling upon his back.

3. Legs and ears generally cold.

4. In general, attacks gradually, is commonly preceded, and always accompanied by symptoms of fever. ed.

5. No intermissions can be observ-

Whilst marking these distinctions, which ought to be kept in mind while prescribing for disorders so nearly alike at first view, but differing so widely in effect, the reader is earnestly requested to turn to the Indcx, and there find the page at which I have thought proper to treat pretty much at large of "Inflammation of the Kilneys," "Diseases of the Urinary Organs," \&c. He will there perceive how fatally these affections have been mistaken for "Colic ;" he will learn that this unhappy error is likely to happen more frequently than would at the first glance be imagined; and he will observe that the symptoms correspond in many respects with those in the second column above-therefore require an equal correspondent course of treatment, but that the deposite of the stone in the kin'ney is an incurable disorder that admits of no remedy. Furthermore, the reader will obscrve, that the whole of the article alluded to, on "Calculus, or Stone," requires his strict attention: and also hear in mind what is there said as to calculous substances which are deposited in the coecum or blind gut, producing symptoms so much like spasmodic wlic, that much care is necessary in applying the appropriate remedy in each case, lest he hastens the patient's end.

Of those symptoms the state of the pulse is the surest inclication of the ap proach of an inflammatory attack of the lowels, or any other viscus; and the particular part which is then suffering must he gathered from other circumstances. If he has long suffered colic without relief, doubtless inflammation has taken place, and gangrene is likely to follow: this is the harbunger of death. Adhesion of the gut sometimes baffles the best treatment for tolic 
and soon devolves into inflammation. In either case, the remedies proper for colic must be alaridoned, and others more adapted to the change of circumstances be employed instead.

Whenever the cause of inflammation of the bowels may fairly be ascriled to the quantity or quality of their contents-without adding thereto by any extraordinary exertion, its approach will be very slow, and denoted by sluggishness and the refusal of food at first. As they are mostly working cattle that are thus attacked, the evacuations are not sufficiently minded, or the attendant neglects to make mention how these have discontinued in a great de gree, or changed their appearance-the dung being then hard and the urine high coloured; hereupon the pulse increases, and the outragenus symptomis described in the second column of the table of symptoms go on to a frightful degree, endangering the lives of bystanders. Even in this stage, the progress of the disease may be arrested by prompt and vigorous measures, adapted to the kind of animal that may be the sulject of attack, and the circumstances under which the present alarming symptoms may have lieen brought on. If a heavy lumbering wagon-horse, that owes his disease to alimentary indulgence, we shall find no higher operation necessary than emptying the overcharged canal by force of arms, i. e. back-raking; but the high-couraged stagecoach horse, which falls under the exercise of the lash, and the influence of a vertical sun, has seldom aught within him of that kind to part with, and requires the introduction of some substance or liquid that shall cherish the afflicted stomach and bowels, and alleviate the burning heat that, ascending tr, the head, causes his delirium. Presence of mind, however, or the adroitness which much practice teaches, is frequen $\mathrm{y}$ wanting for the first mentioned remedy ; ard the means of applying the second is so seldom at hand, that the animals are too often left to their fate and are lost. But I anticipate the remedies. See also pages $62,68$.

Remedy.-From the rapid progress made by this disorder, when left to it. self, and its usually disastrous termination, the duty of attending to the pulse of his animals as before insisted upon (at page 62), will strike every intelligent horse proprietor, as the very best means of guarding against the fatal consequences of inflammatory attacks. He will by this means be apprised of the earliest approach of the disease, and thus enable himself to meet it in its mildest form: he will compare this certain indication of heal-whether fever of the whole system, or inflammation of a particular part, with the state of the patient's urine, which will then be high coloured, and the dunging defective. The rectum will be dry, hard, and hot; the belly, on passing the hand over it towards the sheath, will have the same feel; the animal will shrink from the touch, his eyes appear languid, or partly shut; as the disorder proceeds they assume unusual redness, or what has been termed blondshot.

Up to this stage of the disorder, the first remedy will be clystering and bleed. ing the animal freely, if he be not very aged or of spare habit, inmediatcly after giving the following

\section{Laxative Drench.}

Powdered aloes, 2 drachms,

Sulxearbonate of potass, 2 drachms.

Water gruel, 1 pint,

Castor oil, half a pint. Mix.

If culay is to be apprehended in procuring the above drench, give castor cal one pint, or in default hereof, salad oil, two pints, whilst the drench is pro paring. 
In ordinary cases, a voluntary stuol will be produced at or soon after bleed ing, oecasioned by relaxation of the tenesmus that constitutes the disease. If the dung comes forth in small quantity and small hard knobs, the anus must be cleared by the hand, aceording to the directions given at a preceding page, 69. And, when the constipation has endured for a long time, the hardened dung will not come away at all without this manual operation of back-raking, which must be performed the more assiduously as the difficulty may be greater and the dung harder. Let a warm clyster be thrown up that is copious enough to fill the emptied gut, at the least.

\section{Clyster.}

Water gruel, from four to six quarts, Epsom salts, 4 or 5 ounces,

Inject warm, with a large syringe, or ox-bladler and long pipe : perform this operation effectually.

A second and third should follow, a little warmer than the first, and after an evacuation has taken place, the next clyster may be made without salt, and a small degree thicker than at first. Its effect will be to remain and nourish the parts nearly in the same manner as a poultice does an external inflamed wound.

Too often, however, those early indications are entirely neglected; the animal is harnessed in to his day's work, and the consequences are both dreadful and dangerous to behold. If he be a stage-coach horse, or destined to take his turn at a posting-house, his sluggishness and refusal of food is usually attributed to "a little overwork;" and the much abused cordial is commonly ad. ministered; which brightens him up for the renewal of his daily task, and ac. celerates his fate, unless rescued as by a miracle that is very seldom wrought. In these cases, the first symptom perceptible to the driver is the horse's leaning against its next horse; but, upon being touched up, it makes fresh exertions according to its quantity of courage, until it falls down with closed eyes, in excruciating torments, lashes out behind, and beats about on the ground, seldom having the strength to get upon its legs again. Bundles of straw should be placed for the aflicted animal to roll upon, and his head pressed down with the hand whilst the severest paroxysms expend their force. When at length he gets up-which may be considered a favourable sign, that proves his strength is not wholly sublued - he may be supported into a stable. Meantime, however, an examination of the rectum must take place, and the manual operation of emptying it be employed-if need be; that is to say, if hardened dung should be accumulated there. At any rate, water gruel in large quantities must be prepared, as well for administering by way of clyster as of drench; in both, giving it now without the addition of salt, and in the latter inanner nearly cold. By these means, the alarming symptoms will diminish greatly; but if there is still reason to apprehend that obstruction may prevail in the larger intestines this must be got rid of by means of the vily laxative prescribed at page 91 , and the repetition of clysters in quantities, and admin. istered with a vigour sufticient to reach the evil.

Bleeding, of course, would be adopted to the amount of four, five, or six quarts, according to the exigency of the case and the size of the animal. If the blood become buffed, as it is called by some, or sizy on the surface, a second blood-letting is necessary to complete the curc. Low, but nourishing ditel should follow; as bran-mashes, stiff gruel, and afterwards sodden eats; the return to hay provenuer being made gradually, and then of good quxiity.

In very bad cases, the return to full health and vigour will be slow, and a 
relapse is to be ?'readed, as a fresh attack would prove much more obstiuate than the first. The dung, by its quantity, consistence, regularity, and genoril appearance, will afford the best means of judging when the buscls are completely cleared of their offensive contents; for it not unfrequently happrar.s that several tolerable stools may be procured by the help of medicine, and jot some lumps, replete with danger, remain behind. The pulse, that great c iterion of health or disease, by dint of low living, may have regained its natur $\mathrm{l}$ state, and so remain steadily for a tolerably long period: but watching the lung for a day or two will corroborate that main indication of health, or by its irregularity dispel an ill-founded reliance on the completeness of the cure. Yet will the administering of purgatives, or even alteratives, of aloes in particular, be found full of danger, as tending to irritate the bowels anew. 'The same may be said of all stimulants whatever, whether applied externally or given in the form of cordials, notwithstanding the animal may evince signs of returning pain, and these be ascertained by the corresponding symptoms of low pulse, warm legs and ears, to arise from spasmodic or flatulent collic only. For these returning pains are usually occasioned by the soft kind of regimen just recommended; to which the patient may have been subjected during this illness for the first time since it was a foal. I have known a sinall feed of corn or two effect relief from lowness, in the case of horses which had been long time previously used to hard food: if these be devoured voraciously, this will tend to prove 1st, that the change is desirable, and 2 lly, that the next feed should consist of broken oats—or a new disease will be engendered. A dopt the tonic system, recommended generally, at page 69 .

\section{MOLTEN GREASE}

Is but a variety of inflammation of the intestines when the subject of attack happens to be very fat, and little accustomed to exercise; when marked by costiveness, it may be treated as such; or, if attended by a luoseness, may rather be considered as a spasmodic effort of nature to relieve itself of an unnatural load. The vulgar name given to this affection of the intestines is farther supported by the popular notion that the fat, or grease, which the individual possessed in a superlative degree, had melted (or was molten) and passed into the guts, whence it was expelled with the fæces. This, however, is physiologically impossible, notwithstanding the support such a notion has received from some revered authors; the appearance of slimy unctuous matter along with the dung, more particularly when this is much hardened, being no other than the mucous secretion described at pages $22,23,24$ designed by nature to defend the surface of the intestines from the injurious action of hard substances that might be taken into the stomach. Indeed, this intention of nature in providing such a defence is demonstrable in the fact, that the harder the knols of dung may be that the animal presseth forth, the greater is the quantity of this greasy, unctuous, or mucous secretion that is eliminated along with it, and which gives name to the disorder. Probably, the secretion of thiz grease may then proceed with more celerity; its access may be greater, the more it is thus required by nature to deferid the alimentarv passage. 'This supposition is drawn from the fact just stated; but, whether the well-founded conjecture be too hastily hazarded, is fur the more minute inquirer to conclude upon, or investigate farther, as may seem good to him.

At any rate, the ductrine of effusion, or the passing of those secretions, whether mucous or aquenus, from one part of the system to another, as nature or accident may require the supply, is tolerably evident from another circum. stance that is often recurring in cases of molten grease. [The subject is mure fully treated of at the parge just rrferred to.] The perspiration of the two so? 
cretions in succession, here referred to, is pretty well recognised, and is easly proveable, in the manner there set down; the unctuous, mucous, or greasy secretion (call it which we like) of the external surfaces following that of the more liquid, or watery kind, after any great exertion. Horses that contract molten grease are ever those which have been highly fed, without exercise sufficient to excite visible perspiration thereby; and the feverish heat of the body occasioned by high living and indolence, in time exhausts the whole supply of the aqueous secretion. So much is this the case, that the animal's dis charge of urine becomes less and less as its seclusion is continued, until the decided access of fever takes place, and we notice its colour is higher and ingher as its quantity decreases. [Look again at sec. 55, page 52.] As before explained, the secretion of mucous matter takes place within the guts, \& $\&$, or that surface which is next to the food; on the other side, and every other part of the animal system, the watery secretion destined to lubricate the parts, ti keep them supple and to prevent adhesion, takes place. On that side (which is popularly considered the outer surface!) good quantities of fat accrue, all along the whole length of the intestines, which is usually scraped from slain beasts, and preserved as tallow. From this source is derived that access of grease, which, as I have said, is greatest as the inflammatory symptoms may be higher. When this has long been the case, and stools are at length procured, a long thin wormlike portion of this fat comes away with the dung; which would be of itself a sufficiently alarming appearance, though wanting animation, but for the well known, but inexplicable, doctrine of effusion, or communication through the gut: this appearance, then, of a long tenacious fatty portion of thin membrane, which usually accompanies molten grease, should be considered as little more than denoting the crisis of the disorder.

Let the system be reduced according as the state of the pulse may dictate -for which consult again page 62 , as to bleeding, and page 68,69 , as to treating him for "costiveness" simply. If heat and irritation be perceivable to the touch and sight about the anus, without high pulse, the first symptom may be reduced by administering

\section{The Sedative Clyster.}

Camphor, 4 drachms,

Spirits of wine, 3 or 4 drops,

to promote the solution, and add

Sweet oil, 2 ounces.

Mix well, and then add thin warm water gruel, 2 or 3 quarts.

As before intimated, molten grease is rather an effect than a cause of disease, and partakes of colic in one of its forms and of inflammation in the other; the symptoms that enable us to distinguish when the one or the other prevails being precisely those set down at page 90 . Allowing somewhat for the feverish symptoms that always prevail with such fat and hloated animals as are subject to this disorder, the prastitioner can not commit himself to the guidance of a better test than that just referred to, nor more safely adopt a treatment that is more likely to reinstate his patient in health. For the treatment which is proper in case of spasmodic colic affecting fat animals, the reader is refurred to the next head of information.

\section{THE COLIC, GRIPES, or FRET.}

This disorder has been frequently referred to, under the preceding head of Inflammation of the Intestines, to which it hears urreat affinity in some of its 
puints-as already stated, the cause of both being nearly the same in most cases, and long continued colic always ending in inflammation, if not effectually checked in time. Much of the difference that exists between the two kinils of attack depends on the previous state of the animal attacked: if it be a high fed and hard-worked animal whose digestive organs receive a suduen check, lue contracts inflammation in the first instance; but one that is lower kept, and therefore not so irritable in any part of its system, is soon troubled with spasmodic affection of the intestines, which receives the name of gripes, or fret in different counties, as it does that of flatulent colic in most of the books that treat of animal medicine. Colic, however, is the general name given by most stable people to every pain of the inside (of man and horse) that occasions writhing, or other demonstrations of that pain, which few can discriminate in their own persons; much less in their horses. To this undiscriminating manner of naming disorders that require such very lifferent treatment at our hands, is to he attributed the loss of many lives anıually. Into this anomalous manner of treating those disorders it is painful to notice one of the most scientific veterinary writers of our time has fallen. We do not find in Mr. Richard Lawrence's "Complete Farrier" any reference whatever to inflammation of the intestines: though under the head of "Colic or Gripes," he proceeds to describe the symptoms of inflammation in such a manner as might mislead ignorant or half-taught persons to treat both alike, and thus destroy their horses.

A violent cold, or a slight one, will also determine the disorder one way or the other, when the individual's system may be of no decisive character at the time of contracting it. That a low state of the animal system is favourable to engendering spasms of the intestines, is inferred from the circumstance, that subsequently to a horse afflicted with inflammation undergoing the copious evacuations recommended in the preceding pages for the cure of that disorder, he is frequently visited with spasmodic affections that require sedatives and tonics to restore the patient to complete health.

Causes. Next to drinking cold water, and catching cold by exposure to air or water whilst heated, the eating of bad, ill-got, or rank hay, is a prolific source of spasmodic cholic. If it lie in the intestines chilly and comfortless, and thus predispose the animal to acquire cold, the cause of epidemical colic is plainly attributable to such bad hay; for it then prevails usually over certain districts, and mostly among courtry cattle. Pushing a horse in his work when large lumps of undigested matters distend parts of the gut, will bring on spasms, torpor, and inflammation in succession. Horses that gormandize much, being worked hard, and the stomach lecoming empty, occasions the fret, and inordinate action of the intestines expels the mucous secretion that is designed for their defence. This constitutes molten grease, of which I have treated largely just above, and am decidedly of opinion that the expulsion of offensive matters in all cases where the animal evinceth but small sensaions of pain, is but an effort of nature to relieve itself, and ought rather to be assisted than abated by hot or "cordial medicines."

Strong astringent purgatives, oft repeated, or neglect during the operation, are frequently succeeded by flatulent colic, that soon becomes inflammatory if the internal commotion be not judiciously arrested by sedatives. Cordial balls and drenches, as they impart a short-lived vigour, so when their stimulating effects die away, they leave behind a debility that is more excessive as those factitious effects have been most intense; in this respect, the cause and its consequences assimilate closely with those which succeed the disease of in. dammation, and the debility which follows the cure thereof, with spasmodic colic. Diajente, and other provocatives, that are given to stallions in tho season, leave behind them the same species of debilitating effects after rover- 
घng, and would dewive into colic first, and inflammation afterwards, hut that :hose horse's evacuations are well lenked after, and the system of stimulants is kept up by repetition. 'This treatment, however, ean not always succeed, so we frequenty find that stallions die sudienly of intlammation in the intestines, in the spermatic conds, or other parts of generation. Cases of death, in actus coridu, from the same causes, are upon record. I mentioned this hefore, at ?age 18.

All horses that have been pampered in the above manner, or oy being kept in close stables, or having their water chilled, when they come to be subjected to common usage, are most likely to suffir by colic in its worst forms. Horses that are made up for sale by dealers and cumning breeders, in order to give their coats a sleck appearance, upon passing into the hands of new owners, commonly untergo attacks, more or less acute, of spasmoxlic colic, if they do not at chee fali ill of intlammation of howels, kidneys, or bladder. With animals so circumstamed, mere flatulency or lonseness may be considered a favourable termination of the making-up system before alluded to.

Symptoms. These, as contra-distunguished from those which denote inflammation of the intestines, will be found in the table of comparative symp(wons at page ?). In addition thereto, other symptoms, that mark the degreo of spasmovic attack, require equal discrimination, secing that treatment which may be hishly proper in the more virulent attacks, would be injurious if employed upon every slight accasion. Neither is it every horse which shows signs of pain in the inside that has the colic, even though the symptoms set down in the second column of the "table," at page 90, do not appear; for, he may be aftlicted with pain in the kidneys, or intlammation of the bladder, which the attendant should ascertain before giving the stimulants that may be very proper in most stages of colic, but would accelerate the diseases incident w ilose "urinary organs." "lhe careful reader should therefore turn to the subjects "Kidueys," and "Bladder," lrefore he proceeds to treat the animal simply for colic pains.

In its millest state, flatulent colic first appears in the form of violent purging, which is in fact no positive disease, as before observed, but an eftirt of nature to rid itself of a collection of offensive matter, either indigestible, cond, or irritating. Of what precise kind this may be at any time is ascertainablo upon the view, and requires only to be assisted in coming off, provided but little pain is evined by the animal. If he be a crib-biter, preces of extraneus matter are usually found among the dung, as hits of wall, of woxd, litter, \&c.; if an aged horse, or one that has been kept on bad hay, his food comes off undigested; if a very fat horse, the mucous secretion comes away as described under "molten grease," just above-and all these require at most sone of the mikler purinatives that are least likely to irritate the howels.

Whenever the ears berome eoll, after gripes have continued some hours, it is a certain indication that inflammation has taken place of some one or more organs, mustly of the intestines. This is sometime's discovered when two late, to attend a rupture of the distemled bowels throngh the peritonaum (Vhle Book 1. page 46 ) when the protruded gut mortifies (as is found after denth) in consequence of strangulation. After this, the pain seems to subside, ant the animal dies quietly. The ruin that has taken place is only told on dissection. Fet do most ignorant persons pronounce horses still alive to have a "twist in the guts," and stranger still, they preseritue a remedy for it, although it is incarahle. The ears act also as a gand harometer, when inflammation of the kudneys may be anprebended, or inflammation of the hladher is more than sus. pected, on diesunt of the ditheulty evinced by the patient in passing tta urine. if the water come off high-colloured, it is a sure sign of intlammation, which is further corrobrated by cold ears; if of its natural colour, the ears will be 
warm, and the difficulty in staling is occasioned by the hard distenderl gut pressing upun the ureters and neck of the bladder : proxuring a good stosol or iwo, or a clyster, then restores the functions of the bladder.

The earliest symptom observable in his manner, is when the horse haska rouml at his flarnks occasionally, whisking his tail at intervals; he Irxises at the attendant, if there be any breed in him, seeming to implore help. Hes stampo with his himd foet alternately on the ground, sometimes striking at his belly. As the pain increases, these symptons are oftener repeated, and with more vethenence; he gathers his legs under him, as if preparing to lie down; which he at length effects, rolling about in the stall and getting up again re: peatedly. It may here be remarked, that ehis rolling on the back is well cal. culated for affording temporary case to the bowels; but should inflammation have already attacked these, or at the kidneys, this rolling on his back would isut increases the pain of the animal, and his jumping up instantly upon his legs, as if the spur or whip had been applied, goes to prove the existence of inilammation at one or the other viscus.

Cure. 'Too much care can not be exercised in ascertaining the precise na. ture and amount of the discase; for, in error in this respect resides extremes danger of life, which is too often sacrificed to precipitancy, to ignorarice, and presumption. As soon as a horse is pronounced "ill of the collic," the atterdants, without investigation, proceed to give "sornething to do ham gors];" which is ever of the stimulating class of domestic renedies. Warm ale, with ginger, peppermint water, gin and water, whiskey and pepper, are the common propular remedies usually applied in this case; and, provided the disorder be really flatulent colic, relief from the pain must follow the exhitition of either one or the other. Frequently, however, it hapgens, that the doing good is sarried too far, and inflammation is thus superinduced, if it do not already prevail. By such persons every internal pain is pronounced " the colic ;" and they all conclude that what has removed it once will remove it again, without being certain that it is the same disorder - as they do, that whatever is good in suall quantities must needs be more so in larger ones. Put I have already olserved, that the removal of urnbilical affections, whether flatulent or inflammatury, by rough, harsh, or protracted means, scarcely ever fails to produce the other concomitant disease, and the inflammatory symptoms no sooner subside, than the jaded vessels contract spasmodic affections, as do also the continuance of flatulency, and sorne of the means of curing it superinduce inflarnmatory symptoins.

In whatever shape the horse is attacked with those disorders, the first and mosit obvious duty is the employment of clysters, to be repeated at short intervals, with this single variation; viz. in cases of relaxation, where the anirnal is already purged, the clyster is to consist of simple water-gruel only; but when the patient's bowels are overloaded with hardened dung, the addition of salts, as prescribed at page 92, will be found most effectual. In the absence of Epsom salts (for no time must be lost), a hardful of comrnon cultnary salt may be employed, in the quantity of four or five ounces. Backraking, wo, should be assiduously applied, when the body is in this state, as recummended in the case of inflammation at p. 31, with the laxative drench prescribed at the sarne page, or the simple salad or castor oil in default thereot.

In oultnary cases, when the attack is not, of the most violent kind of either description of colic, that is to say, when neither purging nor constipation prevail extremely, let the following be given. 


\section{Colic Drench.-No. 1.}

Epsom Salts, 4 or 5 ounces,

Castile soap, sliced, 2 ounces.

Dissolve inese in a pint of warm ale, and add

Oil of juniper, 2 drachms,

Venice turyentine, 2 ounces.

Mix well togrether, and give it warm ; repeating the same in four or five huurs, and if the symptoms do not visibly ahate. repeat once more. Tincture of opium is sometimes substituted for the turpentine to the amount of 4 drachms; hut the drench is thereby rendered exceedingly nauseous, and should be given deliberately. Opium is, moreover, least proper when a tendency to costiveness is discovered to exist.

Colic Drench.-No. 2.

Tincture of opium, 2 drachms,

Oil of juniper, 2 drachms,

Spirit of nitrous ether, 1 ounce,

Tincture of benzoin, 4 drachms,

A romatic spirit of ammonia, 3 drachms.

Mix together, and preserve the same in a bottle, and give in a pint of warm peppermint water. Repeat in three or four hours.

When the case is not very alarming, a neater manner of giving opium, in the form of a ball, is recommended:-

\section{Sedative Ball.}

Asafoctida, 4 drachms,

Opium, 4 drachms.

Make into four balls with liquorice powder and syrup, and give one every two hours. The balls may be given along with the oily laxative at page 91: immediately preceding it, or before the laxative has operated. These balls are very serviceable to travellers on their journeys, and may be given to horses that are liable to contract spasmodic colic, which is the case with heavy, fleshy draught cattle, with post horses and the like.

Colic is not often fatal, unless it terminate in inflammation; whilst it should be kept in mind, that colic always ends in inflammation if not removed in time. A day, or at most two, may pass away withuut danger and without relief, in ordinary attacks of spasmodic colic; and where a looseness takes place, a short time longer of neglectfil carelessness might not terminate the life of the animal; but, when inflammation commences, a shaking or undulation of the tail is observable, with evident shivering of the whole frame. The danger is then great; especially when each tit of shuvering is not succeeded by perspiration.

If the costiveness is not well removed when those symptoms, with cold cars and legs, come on, let the belly be fomented with warm water by means of woolen cloths steeped therein. A horse rug may be used to advantage in this way by two men, one standing on each side the hors and foment. ing the belly by bringing it nearly together across the back and supplying with warm water. After half an hour's application, or more, let the coal be well rubbed with dry cloths, and the animal wrapped in borly clothing 
The clystering, and other remedies recommended in cases of inflammation, should then be employed with assiduity. Lastly, employ the tonic system recommended, generally, in all inflarnmatory cases, at page 69.

\section{DISEASES OF THE LIVER.}

\section{INFLAMMATION. 2. THE YELLOW\&, OR JAUNDICE.}

WIrEN we consider the vast active functions the liver has to perform, in cleansing the blond which takes its passage through it, and the secretion of bile, that becomes more obnoxious as this organ is more diseased, we ought to feel surprise that so large an animal as the horse has so few ailments springing out of that source, rather than lament the frequent existence of this one. For, the two names set down at the head of this article, agreeable to the general practice, have only one origin, viz. inflammation; but differing as to the amount of heat, and situation of the evil, which is scarcely distinguishable until after death. The symptoms of both are the same, and the first attack ever becomes the most lasting, if the remedies be delaved, or wholly neglected.

Having been led to enter somewhat at large into the causes and remedies for certain affections of the liver, while describing its structure and functions in the first book, p. 49, I shall find less occasion to add much more at this place. The reader will of course turn to that page.

Cause of inflamed liver. - Inflammation of the liver does not very often take place as a primary affection, but more frequently participates in the disease of some of the adjacent organs, as the stomach, bowels, \&c. and according to the acuteness of the inflammation, an increased or diminished secretion of bile is the immediate consequence. The blood, in passing through the liver, acquires a portion of this extra heat, which reproduceth more at ils next passage through it, more at the next, and so on, until the inflammation of the whole liver is completely effected. Increase of the bile or gall proceeds in the same ratio, until the gall duct, that communicates with the small gut, is closed by the uncommon heat of the inflammation, or by the thickening of the gall, or by both operations united, no matter which. At any rate, the bile which ought to be conveyed away by stool, is returned into the system, and occasions yellow skin-whence the vulgar name. When this occurs, I apprehend the inflammation lessens, but the communication with the bowels does not always return to a healthy state, though $I$ believe it to be partially the case. Indeed constipation in the first instance often obstructs the passage of bile into the bowels, and thus increases the evil. Over-feeding has the same effect, and both produce slight temporary yellowness, which goes off upon the removal of the cause; generally followed by diarrhœa. The feverish symptoms also which accompany the commencement, also pass off, leaving a low, irregular pulse, until the bowels resume their wonted course, either naturally, or by the aid of medicine.

Symptoms of inflammation before yellowness comes on.-As this last and surest indication of diseased liver only appears when the evil is a confirmed one, and is extremely difficult of cure, particularly in old animals, we should assiduously set about ascertaining its commencement, so that the remedy may be promptly employed, and a further procrastinated mischief be timely pre. vented. And the more so, seeing that what constitutes a remedy in $1 t$ earliest stages is no longer so after a time has ber $n$ spent in delay.

Whenever inflarnmation, or extraordinary action of the kidneys, or of the diaphragm, has lasted some time, in ever so small a degree, in that degree will heat or inflammation attend the liver. It enlarges upon the accession of this heat, visibly so when this has continued a while, but may be previously ascer 
tained by the feel. As will be seen,* the liver extends much farther back than the last rib, and a little beyond the false one. Here a considerable protuberance appears when the liver is enlarged, and disease may be ascertained that is attersded by the presence of pain only. Old horses, which have been well bred, retain chronic affections of the liver to a very great age; and this is frequently the main disease under which they suffer for many of the last years of their lives: great numbers of such animals die with a liver of so small a size, that nought but its situation could assure us it ever had any functions to perform. Hurses so visited with a trifling undetected affection of the liver lose their courage, and gradually sink into lethargy the longer it lasts: we often hear such animals accused of being " used up, done for, or 'tis all up with him," and yet driven about to the last moment of a painful existence.

When the attack is rapid, and acute inflammation, arising from the causes just set down (page 99), the pulse is the sure indication of the ruin that is going on, by its irregularity, quickness, and uncertain vibration. See page 62. One lobe only suffers in this case, and then the animal turns its head round sharply to that side from time to time. Cunstipation always accompanies acute inflammation of the liver.

Remedy. - Acute inflammation, which comes on with dangerous strides, when the subject of attack is of vigorous habits, must be met by a bleeding proportioned to the state of its pulse, and that without delay. For, it speedily communicates to the intestines, and death ensues; or, being suffered to expend its virulence (provided the animal possesses strength sufficient) by stool, the bleeding will then be unnecessary; or being persisted in, will confirm the slighter affection just spoken of probably to the end of his days. A purgativo ball should accompany the bleeding, as in all other cases is prescribed generally at page 63 ; but, if the animal produce a stool voluntarily, the disorder has taken a turn, and neither the operation nor the physic is required.

After bleeding, let the sides be rubbed with the blistering ointment (vide page 76), and apply a rowel to the chest. These latter, however, are doubtfully eligible, though always employed by the regular collegians. The patient will require the same treatment; as to diet and regimen, as for inflammetion of the organs of respiration and general fever, hefore ireated of at page 60 , in the course of which his pulse and frecs should be watched, and a relapse provided against. Calomel is that medicament which more immediately acts upon the liver, and unless the horse scours, should be administered in the form of

\section{Alterative Balls.-No. 1.}

$$
\begin{aligned}
& \text { Aloes, } 9 \text { drachms, } \\
& \text { Calomel, } 1 \text { drachm, } \\
& \text { Hard soap, half an ounce. }
\end{aligned}
$$

Mix with mucilage sufficient, and divide into three balls; to be given $\mathrm{cn}$ three successive nights, unless a thin stool comes off with the second ball. But in case of scouring, give

\footnotetext{
- In the plate of skeleton, at the parallel lines H, 30, is placed the kidney of the ncar side; wnilst the off-side kidney in the sane subject would be intersected by the line 29. With this latter, the right lobe of the liver lies in contact, and when an enlargement of it takes place, it may here be seen and telt; when the access of inflammation and tension render it painful only, the doctor should press the points of his fingers (of the left hand) gentty behind the last or false rih several times, whereby he will ascertain whether any and what degree of pain the patient endures. If seated high up on the liver, he will not, of course, flinch at the first slight touch

$\because$ To prevent error, I would here mention, 'hat in the picture of a skeleton now referred to. it is the left lobe of the liver that is there represented. and this was reduced in size, ir, order w show a clear profile of the stomach.
} 
No. 2.

Oil of turpentine,

$\left.\begin{array}{l}\text { Hard Soap, } \\ \text { Ginger, powdered, }\end{array}\right\}$ of each 1 ounce.

Mix with flour and mucilage to form three balls; and give one on each of three successive nights.

\section{THE JAUNDICE, OR YELLOWS.}

Canse.-Inflammation of the liver, or any other obstruction of this organ, which, preventing the escape of the bile into the duodœenum, or smallest gut, through the gall duct, by reason of this duct being inflamed, or choked up with the thickened bile, whereby it is sent again into circulation, and thus pervades the whole svstem. When the inflammation is very great, the disorder quickly carries off the patient; the inference therefore is, that poor animals alone acquire the yellowness which gives name to this disorder, though it must be allowed that the same effect may be produced by over-feeding and constipation, by swallowing hard substances, or otherwise offending the said gut, or the pylorus orifice of the stomach, as described at pages 44,45 . Its situation may also be seen depicted in the plate of a skeleton at the intersecticn of $\bar{K}$ 26. At that place I did not choose to speak of negatives, and therefore omitied to notice the fact, that the bile or gall secreted in the liver of this animal proceeds at once, as soon as it is forned, into the gut, without being detained in a sac, or gall bladder, as is the case with all other animals, except deer; so that, upon any revulsion or hindrance to its free entry to the bowels, the gall must at once return to the numerous cavities that pervade the whole liver, and its re-absorption by the blood is no longer problematical.

Symploms.-A dusky yello:vness of the eyes, bars of the mouth, and tongue, The dung scanty and pale, generally hard, and covered with slime; but in some few cases the horse scours; that is, when slight inflammation of the bowels also attacks an ill-conditioned horse. The pulse is that of low fever, and the same kind of dronping inactivity, with loss of appetite, noticed under that head at page 64 ; differing from it only in respect to the seat of disorder, the low fever being general, or of the whole system, jaundice of the circulation only. Sometimes, however, yellowness comes on without the other symptoms, after an inflammatory fever; an occurrence that can not fail to be foreknown. Genuine jaundice may further be discriminated by the yellow lips, yellow saliva, and dark urine. From this latter appearance we may draw these curious inferences-viz. that the colouring of the bile which has ceased to impart its property to the dung, having gone with the blood to the kidneys, there leaves its darkest or more earthly particles-the lighter or brighter ascending to the heart, and passing through the vascular system, there imparts its yellowness. By this providency of nature we see how it is that malevolent particles in the blood are cleansed at the kidneys, and pass off by urine. Thus it is that grease and other tumours are cured by judiciously stimulating the kidneyణ. The urine voided, as above described, which is ever done with evident pain and difficulty, leaves on the ground an appearance $\mathrm{rf}$ blood.

Cure.-Young horses and fat ones, are easily cured: they have indulged too freely in good living, on hard meat, and require no more treatment than a good physicking. Give the purgative ball (page 63), or the alterative hall, No. 1, prescribed in page 100 Give bran mashes, green food, and succuls nts, according to the season. Bleeding is seldom necessary, or proper, whicl the state of the pulse will show. 
The Livfr is also frequently affected with tumours on its fine surfuce, as will as with ulcers or schirrus, which are all the effects of an evil state of the bhend, of over action, and probably of accidents from external injuries, communicated by the kidneys.

We can easily conceive that the thin parts of this large viscus may be dis. oased, and even inflamed, without causing derangement of the biliary function, further than increasing its action, and by thinning the blood over much, it obtains more bile. The animal then waxeth thin, though devouring his food as usual for a while; and we may ascertain when this evil has begun by the state of his dung, principally as to colour, which will then be of a much deeper hue. As pale dung is a symptom of suppressed bile, so is deep colour an indication of a superabundance, that is caused by over action, which is itself occasioned by the heat of the liver, from some cause or other. One of these may be "inflammation of the kidneys," or it may be occasioned by ulcer, and we set about ascertaining which, according to the instructions set down at page 100: and in the latter case give the alterative balls, the same as for inllamed liver, at page 100,101 according to the circumstances there discriminated; but it never happens that a scouring is of a dark colour, and No. 2 would in this case seldom be required, a strong purgative never, though the bowed. should be kept moderately open. When there is reason to apprehend that the adhesion of the ulcer to the intestines has taken place, as described at page 50 , the animal should not be worked hard, though moderate exercise is de. sirable, and so is change of $p$ hysic, as in all cases that require alteratives. The following balls may take place of the preceding, particularly when the coat is staring.

\section{Altcrative Balls.}

Emetic tartar, 3 drachms,

Aloes, 9 drachms, Hard soap, 1 ounce, Ginger, 1 scruple.

Mix, and divide into three balls, one to be given on successive nights, unless two havc sperated.

\section{INFLAMMATION OF THE IIIDNEYS.}

This being one of those diseases which hears resemblance to another, and as the mistaking and treating the one for the other generally proves fatal, reference should be had to what is said under the head "Inflammation of the neck of the bladder." Such a mistake of the disorder in the present instance is very likely to be made by the common observer, inasmuch as the kidneys, as soon as they becone inflamed, secrete much more urine than in a state of health, and any one noticing this, and sulsequently its defalcation, as the disease goes on, may easily imagine the bladder itself is affected at the neck. It is worthy of remark, that mares are more liable to aflections of the kidneys than horses, particularly brood mares: while, on the contrary, they are less liable than the male to inflammation of the neek of the bladder, in consequence of its shortness . its straightness, too, affiords easy proof of the real seat of the disorder,that esseritial frelude to effecting a cure. See page 53.

Couses. - Too constant use of the diuretic powders ant halls, commonly lorings on inflammation of the kidneys, by the irritation and over-action of the glands which are thereby occasioned. When one kidney only is aflected 
(hough in a mild degree, if suffered to continue, it soon communicates to the other, and sometimes proceeds with such rapid strides as to affect the intes tines, when mortification and death ensue; but we have no means of ascer taining when this last incurable mischief has taken place until after the animal is dead-nor would the knowledge be made available tor any present purpose; though finely instructive as to future cases; then it is the kiuneys present an enlarged and rotten appearance and feel, their texture yielding to the slight. est impression of the finger-nails, which shows in what degree and how long they have been affected.

$A$ hard blow across the loins will injure the kidney on the side so struck, and, as is said before, soon affect the other also. Sudden transition from an open airy situation to a stable that is close and hot; violent riding or driving, or an ill-cured affection of the bowels, whether inflammatory or spasmodic, will affect the kidneys in more or less degree. Those causes all together combine to affect these parts more frequently than is generally supposed, the reason for which misconceit is nevertheless most apparent to me: it is owing to the neglect of a'l the milder symptoms; some persons imagining that unless bloody urine be produced, the defective staling is caused by something less remote than the kidneys, though in all obstructions of the liver, as we have seen above (page 101), the quantity of blood these send to the kidneys leaves some of its colouring property to the water. This class of unreflecting people generally fix upon the bladder as the seat of disorders that so affect the quantity of water. They almost invariably give stimulating medicines, that do but in. crease the disorder and confirm the ruin it is their duty to prevent.

Symptoms.-The most evident of these has heen just now alluded to, and was formerly treated as a distinct disease, under the coarse title of "BLOODY URINE:" it is, however, considered as happening more frequently to horned cattle than horses, and to the female rather than the male.

When this symptom appears, it is accompanied by a corresponding symp. tom, viz. great tension and soreness of the part; which may be ascertained by passing your hand along the small of the hack, over the kidneys, when the animal shrinks from the touch. No doubt can then exist that this bloody urine indicates genuine inflammation of the kidneys; and of course that we should treat it as such, and nothing else-nor by any other name. If the pain and tension can not thus be ascertained, then "bloody urine" is caused by obstruc. tion in the liver. Another symptom that may be relied upon is a stiffness of the hind leg on that side which may be attacked first; afterwards, when both kidneys are affected, the animal becomes stiff of both legs. This symptom does not occur in "inflammation of the bladder," and is a good distinctive mark te go by, when we may be labouring under doubt in somie other point of resemblance between the two diseases. In all stages of this disorder, the horse stands as if he wanted to stale; straddling, and making the most exertion when he voids the least urine (then generally bluody), which shows the destructive tendency of these efforts on the gland itself. The consequences are, that the kidneys waste away, and the disease communicates to the bladder, until the final ruin-mortification, ensues. The practitioner, in this case, will not fail to look at what I have thought proper to say respectind "stone and other calculus," a few pages farther onward.

"Suppression of urine" is also a sure indication of the genuine inflamma tion of the kidneys; that is to say, the capacity of secreting it is nearly extinct, or it is performed with exceeding great difficulty, pain, and danger. Whereas, in affections of the bladder, the secretory function is not lost by the kidneys (or suppressed); but, when the urine has been sent into the bladder ins latter has not the posver to expel its contents. How this hafpena, sen page 53, \&c. 
But the most prolific source of diseased affections of the kidneys, and the least perceptible of any are ill-cured pains of the intestines and of the liver. These leave behind them certain morbid effects that are not imrnediately felt nor easily discoverable, but nevertheless work their ruin imperceptibly; for, as previously observed, when the kidneys lose their function of secreting urine, they enlarge, and after death scarcely bear the pressure of a finger point.

Cure.-Seeing that strong diuretics are reckoned with truth, among the causes of diseased kidneys, no man in his senses would think of administering any such, after he has ascertained that this organ is disordered in any way whatever. Such, however, is too often the practice of unskilful persons, who, after noticing the defective quantity of urine produced, think of restoring the animals capacity for producing more by medicines that stimulate the parts, which already labour under a disease of too much stimulation. "As in all other cases of inflammation or fever [how often have I not repeated the same words!] when the pulse is high, let the animal be bled according to the amount of attack." See general observations at the head of this chapter, pages 5.9 to 63. Give warm clysters frequently as there prescribed; and with a similar view give him a loose stall, if the paroxysms are so acute as to cause him to lie down and get up again. Immediately after bleeding, give castor oil 18 ounces, provided the animal has not dunged during the last twenty-four hours, as commonly happens; less may suffice in general; but a horse that has been much addicted to diuretics, thongh his bowels may be in a tolerable state, will not suffer aught from a small proportion of aloes:

\title{
Mild Purgative Ball.
}

Aloes, 4 drachms, Castile soap, 4 drachms, Mix, with mucilage enough for one ball.

Should the symptoms abate nothing in consequence of this treatment, the bleeding must be repeated and the purgative too. Rub over his loins with a stimulant

\section{Embrocation.}

\author{
Spirits of wine, 2 ounces, \\ Suap, 2 ounces, \\ Camphor, 1 ounce.
}

Mix and apply it with the palm of the hand to the loins; cover the animal up well, and be careful how it is subsequently exposed to the air. The mustard embrocation is equally efficacious: being rubbed on soft sheep-skin, cover the loins therewith. Give the cooling decoction in large quantities, as at page 70 ; and if the animal is disposed to eat the sodden seeds, it may be permitted to indulge: they are little nutritious when the saccharine has been drawn out by the hot water.

The food should consist of bran mashes, green food, and the cooling regimen already iecommended in all cases of inflammation at pages 61,69 , to which the reader is respectfully referred for some general directions for bis rule and conduct, equally applicable in all such cases.

\section{DISEASES OF THE BLADDER.}

These are really much fewer than are commonly ascribed to it, the bladder being but the vehicle or outlet for several evils that take their rise higher up; 
and amomg there: I lave al ready demounced the alarming apporance of "hiloxily urine" as a disorder of the kidneys and liver, pase 10\%. "Neither is the "13upp pression of urine," mor its olwerse "diabetes," asceribable to the bladder, but to the kidneys; for if these secrete uone or inperfoe:tly, little or mone can be sent into or escape out of the bladler ; but retention of urine may be a fault of the bladder, or collapsion of its neck; and the means of procuring its escape was before recommended at page 53, \&ce.

INFIAMMATION OF TUE BI.AJDFR, and consrequent "incontinence of urine," are the same disorder; the latter leing the irritating effects of the inflarnmation only, and this I slatl comsiler separately, referring those other fiforders that are commonly ascribed to the blarhler, to consideration under the houd of "Diseases of the urinary organs, generally."

Cause. Heat amd inflammation of the kidneys conmonicate this effect to the ureters and bladder. It may be infiamerl also by the irritation of stones or gravel concreted within it; or the excessive labour imposed upon it by the great access of diabetes, after these have ceased.

Symptoms. Frequent desire to stalc. the bladder contracting upon every drop of water, almost, that finds its way into it. A quick, sharp pulse, and small, accompanies, if it has sot precriled inflanmation of the bladder; yot blecding would not he propoer in this casse, ans it is the poorness of the horod which brought on the diabetes that catesed the inflammation. When, however, this symptom lass ant preceoded inflamumation, the pulse will be more full, and beeding to an anount proportimed us the state of the pulse (see page 62 ), would then lie necessary.

Remerly. - $\Lambda$ slightly purgatise ball stould of course follow the bleding, but employ neither in the extrens. Give the cooling decoction recommended in general fever, at page 70 ; achminister clysters of the same, two or three times in the day. Should great beat of the hladeler continue, notwithstarnding these renediess, give the fever powder, No 2 , at page 65, and ufterwards No. 2, made into a bull, dxily.

\section{DISEASES OF THE URINARY ORYAXS, GFNERALLY.}

Besides the forespoing main dismases of the kidneys and bladder, there are several other conjuint affections of the same oreans, or parts dependent thereon, which require notice, and donanul attention, while we exarrine the distirctions that ought to be drawu between the one sot arul the other. Mistakes as to the actual seat of disorilers are more danerorous than the unskilful ad. ininistering of medicines, for thosse might do grond by accident, the former never can he applied properly : the lucture the "recxeipt" nay be, the worse for the lorse. Few of these lrsiser discises are original, hut arise frotn some de. fect or ill-cured disorder in the other partisof the animal's systern. 'They rraty be considered under the herals-1. Dialetes, or excessive discharege of urine. 2. Blocely urine. 3. Calcouli, or stone. 4. Strangury. 5. Suppression of urine. I am aware that the ingenuity of some howetors has subdivided these, atul added to the number of cliseases imedilent to the kilneys, ureters, and bladder; but, onitting those which attach to the orgatss of generation in breeding ani(nals, and also theses seated higher up-the connumication of acute pains to the more vital parts, by means of the ernulgent and sema cava, to the hoart itself. This last, however, is so inmediately the precursor of dissolution, that no other benefic can arise from the durctor's skill in this respect, than bidding him to cease his coffirts, to forlwear to torture the expiring patient, ard to pres acre his ruedicines for a leses forlorn purpose: the pulse, hy its extreme lar. guox, tells when hope itself must rexign its place. 


\section{DIABETES, OR EXCESSIVE STALIXG.}

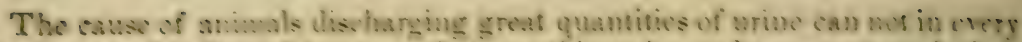

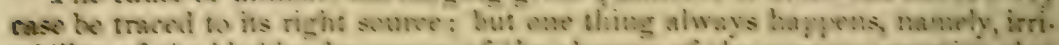

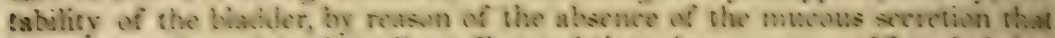

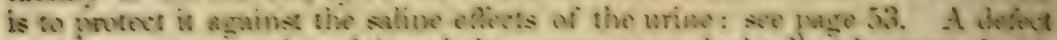

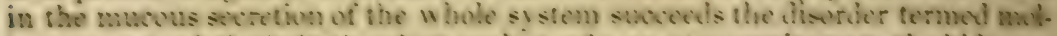

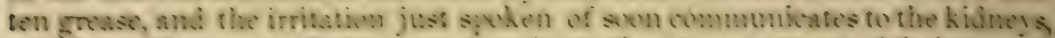

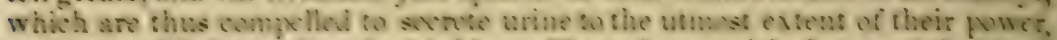

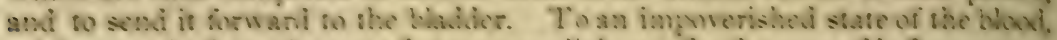
arising uwetly frow the use of strong modicines- Cor the cure of inflamumatory

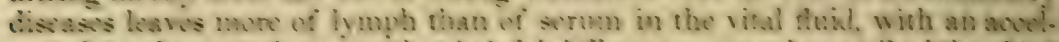

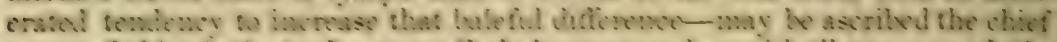

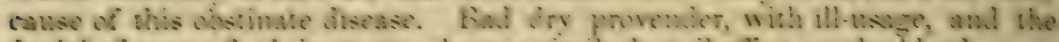

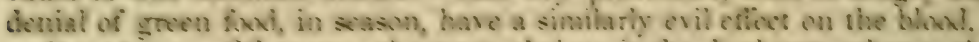

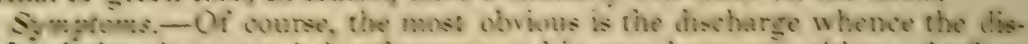

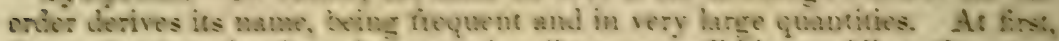

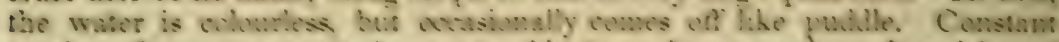

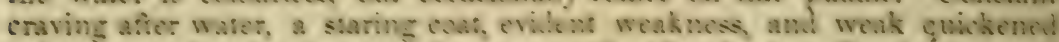
pulse, stwoed ewh wher, and incrase os the disenker is sulfired wo procen? uncherked.

Owre-Change in the arcimal's diet, whateverthey may have kera. If the

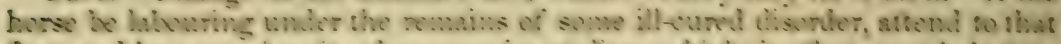
tiost, and by rombing in, the exessive staliug. whath in that case is but an

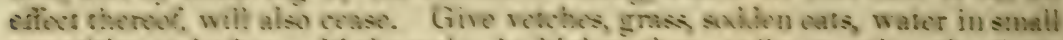
geantitics and offen. If the pulse te hifber than onlinary, give the ferc:

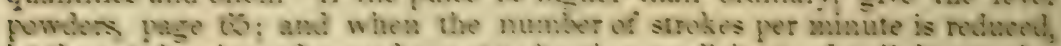

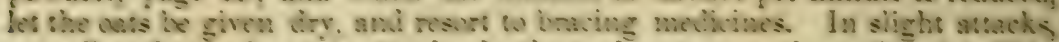
as well as for the les ribust animals the various preparations of tark will te found sutticiently toric:

These Bail.-Xis 1.

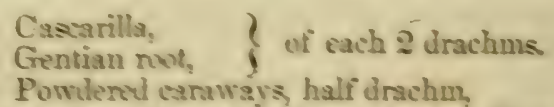

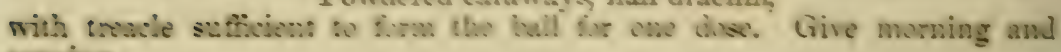
evening.

In the more furcuidable cas:s where grouter strength or more telious symp toms require to be combated, give the

$$
\text { Tumie Ball-Yo. } 2
$$

Vimke curpencios, I scrughe, Sulyhate of uyger, $\}$ of each 1 dnachm
Ginger.

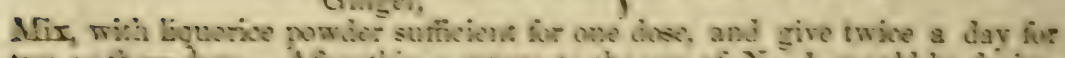
two of three days. Affer this, a return whe use of 10.1 , wivald be desirahe, until the disonier is subuiced. Should wotiveness ensue, give a elyster. which will also relieve the irritation of the prats: castor cil, owe pint must elso he aiministered, it the costiveness appeat distinate.

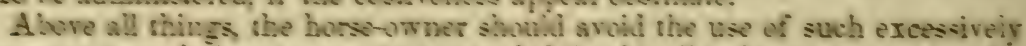
gnomant prescriycions as are rovomuewded, in this disonder nust pariculariy, Ey every village quack : they are mostly the bunss of hen!-morking perple 
that are attacked with this disorder, and those people more than any other lie open to this kind of advice.

Incontinence of urine is of the marne nature as the last-rnentioned, only differing ir: the discharge being involuntary, and the amount, or quantity pros duced. The disposition to stale frequently, or the urine coming away with scarcely an effort, proves that great irritabulity of the bladder is the proximate cause, and we may infer that the quantity woukd be greater if the animal had more in his system. For this feature of the diabetess altacks only old worn up horses, in whom the quantity of blowd is small, and its course slow. Diabetes of the younget animals sometimes terninates in this mode of producing water by driblets and in small quantitios, but ts which the moderns have given a distinct term, though both are the same disease; a sroalt degree of inflammation prevails when the animal is greatly affected with incontinence. See page 106.

The treatment should be the sarne, nearly, as directed at page 106. Give occasionally the wonic ball, No. 2, page 70, frit two or three dayn. A run at grass for a week, and generous feeding afterwards, generailly crsmplete the cure, no other obstacle intervening.

\section{BLOODY URINE,}

I have already said, is but one feature among many other symptorns of infamed kidneys; and the only reason why I deen it worthy of separate notice is, that real "inflamrnation of the kidneys" is not always present when bloxdy urine appears, especially when no other symptom thereof accompanies this eingle dernonstration of disorder. Its causes may be traced to excewive labour, as drawing in a cart or wagon, whilst a slight cold of the kidneys may ohntruct their proper action: the office of separating the blood from the water is in this event performed with much difficulty, and of course inperfectly; and small portions of the former, instead of ascending towards the heart, descend to the bladder with the urine, while the animal is straining ewery nerve and vein.

Rest and a cooling diet are the best remedies for this apparent affliction. Should tendernews of the kidneys be evinced upon the touch, or other wymptoms of augmented pais appear, give the tonic ball, No. 2, patge 70 , orcasionally employing No. I instead : the alteration will be found berieficial. If theme symptoms increase (which I should not apprehend), then of courae the attack must be met with strong appropriate remediss. But I have never known one case of bloody urine out of several score, where the aprearance thereof ceases with the day of rest, and cornes on again with hard labrour, that did ever terminate in genuine inflammation of the kidneys: it will return at interval (ujwin hard work) during the animal's whole life probably, without any further ailment attending it.

\section{CALCULUS; OR STONE IN THE CECUM, KIDNEYS, URETER, AND BLADDER.}

When we consider for a mornent the vast circulation that passes the (live? axd) kidneys, there to undergo separation, as before fully described in the firet book; and recollect, that hard extraneous substances pass through theec orgars, and fird their way even into the blood, our astonishmerit ought to ceaso it discovering earthy particles, often hardened into stme, in some one or other of those parts.

Cause. - The first particle that is deprosited or loft behund is no doubt vers tr:vial, as the bisecti un of many such stones trost amrily proves. Want of 
vigour at the time of its access, and the consequent inability to expel the intru sion, appear to be the immediate cause of this otherwise inscrutable disorder Sulsequently, other congenial materials reach the original evil, mostly in the liquid form, and thus add to its size, increase the number of striata, and heighten the danger. The water that is drank by quadrupeds is abundantly impreg. nated with fit materials for generating calculi : soft river water, and that of turbid pnols, convey the softer or earthy particles into the animal's system, whilst that drawn from springs contains the elements for forming stone, as perfect as any geologists find in the strata of our earth. The softer kind of these concretions are found in the blind gut, or cocum; the harder, or stony kind, in the other viscera above named.

Heat is the power that separates these elements, and hardens each additional lamina that has accrued, or grown over the preceling, from time to time, as the animal may have heen exposed to drink so impregnated. This is visible on the section of those stones which have been found in horses and other animals, and preserred by the curious, and cut in two hy the lapidary. Every such concretion so found, of whatever nature it may he, exhibits in the centre the nucleus or commencement of the evil, which proves itself to have been either originally stone, or some soft substance, as a bit of chaff hardened by the heat; but much oftener it presents a perfect peblile, that must have been Dorne along by force of the current, and in the cleansing function of the kidneys got detained and deposited there. If not entangled, as it were, in the cellular membrane of this gland, such a pebble will detach itself occasionally and descend through one of the ureters into the bladder. For full information as to the structure and functions of these several viscera, the reader is again referred to the second chapter of book the first, which treats alone of such matters; as regards the cœecum, at page 46 ; the kidneys at page 51 ; the bladder at page 53 .

One original cause of such concretions has been ascertained beyond contradiction, and as the information may prevent its recurrence among a numerous slass of horse proprietors, 1 quote my authority much at large, by way of pre ventive advice, seeing that a cure is at present beyond the reach of art; remedies worse than useless. Let us hope, notwithstanding, that the mite which .$s$ here contributed may not be thrown away, but incite some future close observer of nature and her ways to add hereto the result of his own inquiries, ard so increase the sphere of his utility in one respect, since imperious circumstances have contracted it in another and more obvious line of his profession-the desire of gain.

Millers' horses are most liable to contract this disorder, and for obvious reasons; being large heavy animals for the most part, their owners opulent if not rich, and grain and pulse ever at hand, dry food is invariably given to them with a liberal hand. To render these substances more agreeable, to hasten digestion, and thus produce a fine coat with a well-filled carcass, their corn is passed through the mill, the beans also are usually broken; and, thus pampered, they eagerly devour the ready feed, and with it whatever extraneous substances it may have acquired in the process of grinding. These are not few in quantity, it seems; for such articles are invariably ground between stones $\checkmark$ a soft nature, that ensily part with their rough surface, and these stony particles all find their way into the stomach and intestines; some, here and ihere, pass on through the circulation, by means that are neither uncertain nor inscrutable in the minds of those who have studied such suhjects, and will refresh their memory by turning to what I have said thereon in the second chapter of the first book.

Dr. Withers, of Newbury, Berks, having many years before given to Dr. Hunter a large intestinal stono, which proved fatal to the horse whence it hail 
been taken, communicates to the Medical Society of Crane Court, London, a similar circumstance which had come under his observation-both being cases of millers' horses. He then clescribes "the case of a very valuable horse be longing to Mr. Andrews, another miller, which lay ill of the colic," as the owner supposed. " 1 told him (says Dr. Withers) that if he would examine the intestines after death, he would most probably find a large stone, which was the cause of the horse's illness." This, the miller, of course, neglected to do; but his dogs made the discovery for him; it was a large round stone, broken, from which circumstance $I$ infer that it had been at first a soft or earthy concretion, and proceeded from the cœecum. Four such instances all together were remembered at the same mill, besides many others elsewhere; but, with -haracteristic negligence, the millers in no case thought proper to furnish the woctor with the when and the where found, nor does the doctor say why.

The symptoms of calculous deposite throughout apparently resemble colic to the view of common observers, as in the case of Mr. Andrews' horse, just quoted; the animal looking at his flanks, straddling when a kidney is affected, as if he would stale, which he does with great difficulty, and sometimes a little blondy. This last appearance also occurs when the bladder has been affected for any length of time, so that the anguish of acute pain had communicated to the kidneys by means of the ureters, in which manner alone blood could possibly have been produced in the celebrated case cited by two contemporary writers from M. La Fusse, the elder. When stone resides in a kidney, it may be ascertained by pressure of the hand thereon: I will not exactly say you can feel the stone, for it lodgeth underneath, but the greater tension and enlargement of one kidney beyond the other, leaves that notion on the inind; besides which, the animal will shrink, or rather start, a little quicker that in case of "inflammation of the kidneys"- the symptoms whereof, as set down in a preceding page (103), the reader should consult in order to shape his practice accordingly.

Calculous, or earthy deposits of substances in the cœcum may he ascertained and distinguished from simple colic or gripes, by passing the hand along the lower part of the belly, as described in the first book, at page 46 . While such an uhstruction remains deposited near the blind part of that gut, no immediate danger or inconvenience is to be apprehended; but when the lump, hy any means whatever, moves to the urifice, and obstructs its only passage, the most distressing consequences ensue. One of the causes hereof is the exhilition of hot, strong, or drastic medicines, which are usually given in cases of genuine spasmodic colic; and as the symptoms that attend both are alike almost throughuut, with the exception just made, no mistake is more general, probably, than people treating this disorder as they would colic, which course endangers life.

The ureters, it will be seen, are but. of small capacity, and in its descent from the kidney, whence it has been detached, the stone sometimes meets with un insurmountable obstacle; the irritation it thus occasions communicates to the adjacent parts; entire suppression of the urinary secretion is the immediate consequence, and mortification of the intestines and death ensues, witliout the possibility of relief. Indeed the remedies that seem most proper do but accelerate the catastrophe.*

Much perspiration attends the first hours of the suppression, and it affords evident relief; but painful efforts to void urne, which comes off in very small quantity, and ultimately ceases altogether; and then cold ears, cold legs, tremor and an alarming irregularity of pulse, preceue but a short time the

- I say seem, for none can say preciscly what is taking place. He whose judyment teinge him nearest the real cause of pain being most likely to apply the proper remedy. 
dissolution of the functions of animal life. 'This is the most dangerous species of disorder, arising from calculous deposit, that I know of.

In the kidney, however, little danger to life is to be apprehended from the stone, unless the animal is put to severe work, so as to produce the symptom of bloody urine before described. They are mostly fat horses that die with stone in the kidney; in fact, all that I have ever seen or heard of, and these have been numerous; for I have long made a point of inquiring after such cases of calculus, where they seldom escape notice, viz. the horse-slaughterers' yards, of which it is proverbially and truly said, that not a hair enters but is turned to profit. The probability is, that when the stoue detaches itself and descends into the ureter, the fat which partly enveloped it and the residue of the kidney had been withdrawn, through disease or poor living, and the membrane which supported both had divided. I once thought thad made some observations on this part of my subject which would be worthy of public perusal; but these are not sufficiently mature to find place in this little volume, devoted as its pages are to matter of fact, and fair deductions therfrom, and wholly cxclusive of theoretic speculation. Nevertheless, in aid of what others may think fit to say in any other place (out of a spirit of controversy), I would just add, that only one kidney is affected at a time, or one ureter; that the calculi found in either of these are invariably of the hardest kind, whilst those of the bladder are softer, and those of the intestines softer still, or little more than cuncrete earth. Lastly, that none of those horses which I have found troubled with either kind of calculous disorders suffered under a second at orie and tho same time.

\title{
CHAPTER II.
}

\author{
EXTERNAI, UISORDERS
}

\section{Abscess and Tumours.}

Swerting, with inflammation of the solids, the glands, or simply pustules on the skin, are all tumours, have been divided into eight classes, and accord ing to their situation, are termed superficial, or deep seated abscess. Superficial are those which appear on the skin, as farcy, \&c.-Deep seated are those which more generally are hidden amongst the muscles, ligaments, \&c. as pollevil, fistula, \&c.-A few general coservations on the remote causes thereof seem necessary to a right understanding of each particular complaint.

All those disorders in common, together with several others, I have no hesitation in attributing their remote cause to constitutional defectiveness at least, or incapacity in the function of circulation, better known by the homely expression, "a bad state of the humours," as before insisted upon, principally at pages $53-61$. Both series are referable to the same predisposing cause. That species of inflammation of the whole system which we have agreed to term fever, frequently terminates by concentrating its latent humours, and deposit ing the same critically in some fleshy part of the carcass or limbs, producing matter (or pus,) which, with heat, constitutes the disease. Whether abscess or tumour supervene, both have immediate connexion with blood-vessels of no small consideration, though the disorder may have commenced with the finer rossels (capillaries), as insisted upon at the pages above referred to; and hath 
been repratedly proved. First, as regards tumours, these bring probed, the patients have bled to death, with arterial blocol. A um secondly, in every case of alscess, in proportion as they increase in size, so does the patient's strength invariably diminish. When mature makes an opening to the surface, after iong-protracted illness, the patient is usually si) exhausted, and the parts ad jacent rendered so unfit to re-unite, that the strength of the constitution apjears to run off at the orifice: life is seldom yreserved, health never com. pletely restored.

Tumours sometimes appear of tolerably large size, that become indolent, without feeling, and are movealle under the skin. 'These are caused hy the same evil state of the blood, or its vessels, and the inflammation or irritation having ceased at some tirne or other, the enlargement remains, though the sonnexion with the system of animal life has long ceased. Although very unsightly, the animal feels little inconvenience from those protuberances: they receive the name of wen, and might be taken off by dividing the skin, and pressing out the wen: it is then to be drawn forth with the forceps, and the healing of the wound is effected loy strapping down the skin with alliresive plaster; the cure is thus said to be effected by the first intention. The usual precautions of taking away the hair, and afterwards keeping the patient's had up for a few days, would of course be adopted.

The genuine tumour is soft and tender, and is contained in a membranous case, or coestus, that has been likened to the finger of a glove, or to many of thern, when it acquires the distinctive name of fistula. T'he case, or cosstus, having been formed by tie disorder, and matured by heat, acquires strength the longer it is suffered to continue unopposed, seeking its way inwarls, until the knife alone can afford relief. At the shoulder the fibrous and membranous construction is exceedingly strong. Look at page 11. Generally speaking, all swellings of a circumscribed nature are tumours.

Sorne objections which have heen raised acrainst the view I have taken of the origin of this whole series of diseases must not go quite urnoticed here, though I dislike controversy as much as any writer who has gone before rno on either side the question. At the very commencement of this book (page 5!), and without adverting to either set, or indeed thinking at all of the con. troversy, I assigned a reason why the apparently triumphant proof of $\mathrm{Mr}$. Whice, at page 29 , is no proof at all, but the contrary, as to the thickness or viscidity of the blood increasing with the continuance of inflammatory fever. Every writer on this subject allows that the swelling and discharge of matter that frequently occurs after a fever, or inflarnmation of the whole system, denotes the crisis or termination of that disorder; and insists that it must bo considered as but an effort of nature to throw of something that is offensive to the well-being of the anirnal. The same happens often after "inflammation of the liver" has been reduced ; but this kind of occurrence, though it adds nothing material by way of argument, leads us directly to the point at issue. General inflammation (fever), it is allowed on all hands, begets something offensive, and so does partial or Incal inflammation of any organ through which the blood passes, particularly of the liver and kidneys, through which the whole mass gets filtered, as it were: and nature's efforts to get rid of this offence against her rules are evinced in swelling of the external parts, in the inflammation thereof, and subsequent escape of the offensive something, where by a cure is effected.

All this is acreed upon by those who deny the necessary pre-existence of a general ill state of health, as well as by those who already know, or have yec to learn, that the liver, that acknowledged cleanser, permits much grosser ma perials to pass through it than those offensive matters, or gross humours, which wo conteud reside in the bloor], and constitute disorder of one isind or other on? 
the surfice, or at least predispose the animal to ac'quire such, according as cir. cumstances may determine whe way or ile uther. Seving that such gross sub. stances as bits of straw, chatl, $d i$, have issued from a vein on blenel-etting, it is too much to concede the ultimate print that the feculent humours, which constitute tumours, fitrey, $\mathrm{N}$. may int in like manner escape into the circulaiim, and be detained at that particular part which is rendered by some accident le'ss capable of eontinuing the harmtul matter in a tuid state? A blow, a gall, a ligature, or bruise, are known to metasion this disability and bring on disease in one of its varied shate's. So doe's "a cold" produce fever in some animals somer than in ofhers; moording as the circulation may be more langruid, or more predisfosed to intlammation, or otherwise unfitted for its pur. phose; whilst some agrin acyute inllammatton without any such accidents or cold, the fever being lighted up ocoasimally by warm stabling alone, though the air they breathe may be perfectly innoxious.

How it is that those external discases, enumerated at the head of this chapter, are generated, I shall nut here repeat: the reader may consult the principles upon which my opinions are houmled in the wenty-ninth section of brok the first, pase 30 : to which I will here merely add, that the tumours we perceive on the body that are not of a nature to break and discharge their contents-as farey, irease, efe. - are usually, if not always, acemplanied by corresponding tumurs on some vital orean, as the lumes, liver, fe. But single tumours, containing matter, as the whole tribe of fistula, de. are designed to counterat and carry off ohstrutions and all baleful aflections inchlent to the orums just mentioned, and of all others : an owner ought therefore to deem biunself fortunate, when some inserutable hung illness of the inside terminates in this manuer. The appearance of these latter on the surface may be taken as a gond assurance that none then exist internally; nor, inded, any other disoriter whatever, the natural strength of the animal system enabling it thus to cleanse itself. Again, we may remark in general, that as it is the hetter bred animals that are mist lialile (n affertions of these organs, so is it the "country-bed cattle," withut any breding in them, that mustly suffer those extermal attacks. Fo the reflection of every man of experience I refer this material print if dissontmee between the iwi varieties of hurse, which serves to prove that those having erreat lumps of muscle at the parts liable to such attacks are most dispused to contract lixeal indlammation, and that putling up of grand or lymphatic which we call tumour of various kinds. Local inflammation alome, however, could not eflect the evil, without some corresponding esuse; else, how comes it to pass that none but aned horse's, that are heavy in the hand and low in blowd, coutract fistula or abseess; young and li:ely borses, and those with some brewding in them, never? Once more, - if the disurder reside not in the blool, how does it come to pass, that a horse having contracted one species of tumour, he is never known to undergo an attack of any other species-and there are a dozen at the least? For example, give a horse the poll-evil, and see how little he will be disposed to contract the glanders.

Fleshy horses, those of the cart breed and of indolent habit of body, aro most liable to contract poll-evil, tistula, fe.; indeed I might say, the ready dis. position thereto is contined to that breed, though either could be inflicted upun higher bred cattle, which might mot he so predisposed by a bad habit of budy. or by the gross humours before noticed. When the animals are young, and leed ravenusly, the strangles carry off those humours; when youth leaves them and more dolish halits come's on, these humburs appear in some other varied shapes: lesile's thuse dicases just mumed, the farey, grease, \&ec all eome on from the same inchlent halit of boly. They are always ravenums eaters, gross feeders, and conseyquenty lethargic in their movements, tlat ac- 
guiro prill-evil ; for they dernand harwh treatrnent to keep them at their wopk

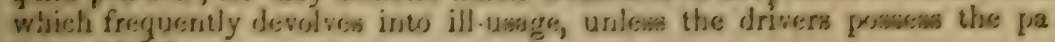
lience of Job.

Hence the duty of attending to the health of surch hrorsens, as much as may we conviatent with the avocations of the owner; of avoiding the infliction that in often the irsmediate cause of cither aprecins of ailment; and, these being diecowered of applying the neceseary rensedies for their instant diefersionif the symptoms are mild, and thus promine succeses, a low rogirsen followis of courne. But delay wog often confirms the diecase; it approachios towarde ma. turity, and will not be repremed : then does the duty of "bringing it forward" 4) suppouration present itself as the only means of obtaining a radical cure; and I may add, that this is always the safest, the beot, and the most certain means, when the discase yieldes not to the firmt effiorte at dispersion. In cordinary cassos of sadsle gall, theswelling and herat will berul before an ascidurous and early application of the repellent lotion; not an easily, however in case of "fintula in the withers," which liew deeper and is more of htinate. Leant of all will confirmed poll-evil give way before the strongent repellents ; or, if the resolution be apparently effected, the least extrrnal injury, or nore whateser, will euts. socyurntly reprexluce the disorder with more than its original virulences. PerShaps, in no yart of the farrier's art has he the opportunity of evineing his julgrowent more, than in chowsing the precise preriest when he will quit all attempls at suppreming the abscess or turnur, and set about bringing it forward (1) suppuration and a radical cure; when he will alos quit the low regimsen which was proper in the first atcernpt, and adopt a more generous diet, that is better adapted to the painful discharge his patient will now be compelled to undergo, either by dint of medicinal applications or the knife.

Abscoss in the more fleshy parts of the body, or under the belly, are far lows dangerous or troublesome situations than on the parts just named; they alson prive in be symptomatic of the actual state of the bloxist, of which they then form the crisis or proint of cure, and therefore the represweion of such (as reo cornmended in other cases) should not be attempted, neither whould the animal systen be lowered, but the contrary. If, however, the turnour appears near a joint or just abreve it, as the hock, so as to irnpede its action, in which case it would sorn ascume an ulcorous appearance, by reason of the movernent of the rauscles of the limb in going, repression should then be resorted to with assiduity and skill. Artificial inflamination, excited upon the skin and cellular merntrane, nocar the part, by means of blistering, or rowelling higher up, has the grool effect of drawing off the heat and tension from the rnore inryort. ant joint, nor does the anirnal by this application undergo som much pain as he would were the tendon affected, wherelyy the lirsb would becorne irremediably stiff and useless.

\section{CRITICAL ABSCESS}

Is that swelling or tumour which is occasionally thrown out on the body or limbs from no apprarent accident, but what may be traced to that derangement of the systern we call fever, and is sometirnes attendant upen frotracted inflammation of the liver, when the discase appears on the fascia of the mus cles of the belly, on the jowl, or other glandular parts.

The cause and the effect thus become manifest together; and when great tenderness is evinced upon touching the parts in ordinary cases, nothing morre is required than to make an opening in the lowest edige of the swelling, and expremsing the contelits; the cure is effectexl by means of the comanon "digeative ointrnent," which is prescrised under the article "Poll-evil," farther down. But the proper time at which the opening is to be thus coade requires 
cluse observation. In general, this may be ascertained by a change in the anmal's manner : he wil eat more heartily as the matter increases: which proves that the disease of his habit has accumulated at this precise spot. $\mathrm{He}$ should not be allowed long to remain in this state, lest the offensive matter should penetrate inwardly or laterally. If the disease is thus distinctly known to proceed from the remains of ill-cured fever or inflammation, poultices should be applied to bring it forward to the surface, and the animal receive increased feeds of dry oats, of beans, or sodden oats, according to his former habits, in order to encourage the access of matter ; for nature, exhausted by the violence or the continuance of the disorder, is incapable of expelling this last remains of the enemy, and stands in need of support. Should the horse have been lately laid up with fever, or for some time past shown languor in his gait, and heaviness about the eyes, or it may be concluded from his recent hard labour and hard mode of living, that he has been long ailing inwardly : in this case the abscess being evidently a critical symptom of the general evil state of his blood, nature must be assisted in getting rid of the offensive matter; and for that purpose bring the tumour to a head by means of a poultice. The head is most commonly the seat of swelled glands.

\section{Draving Poultice.}

White bread, the crum of a $4 \mathrm{lb}$. loaf. Onions chopped, $2 \mathrm{lb}$.

Boil the onions in water, and pour the whole on the bread: mix to a tolerable consistency, and whilst blood-warm apply copiously to the parts in a cloth. Support the application by means of a bandage of stout linen cloth, with ligatures tying over the forehead and across the poll thrice, as described in the annexed sketch. Some persons have recommended the use of a solution of gum to render the cloth impervious to liquids. See page 79.

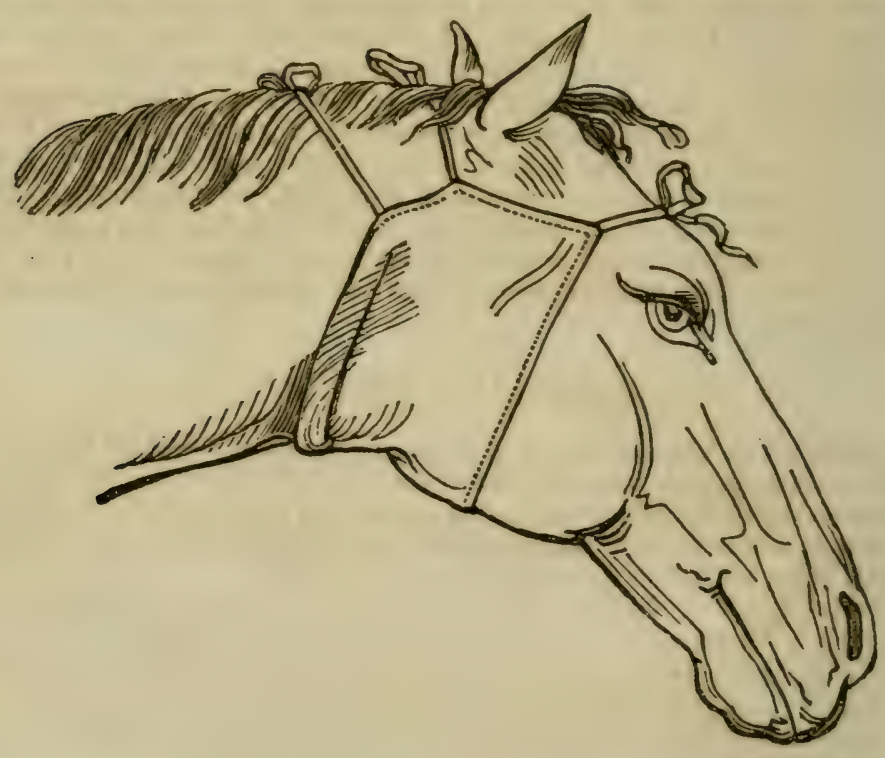


Should circumstances require a more extended application, or that the patientsestlessness might rub off the bandage, let a more extended bandage be em. ployed. For such a one, and as to further particulars, the reader may consult page 79, where a bandage for sore throat is depicted.

By those means the swelling will come to a head, and give signs of being about to burst, but which I have reason to believe seldom happens spontanenusly by reason of the thickness of the skin. Apply the knife, or bistoury, as directed much at large in the case of poll-evil; give a mild laxative the same day, and lower his diet. When it so happens that the opening has been made too soon, before it has accumulated sufficiently, the orifice may be kept open by means of a seton passing through it to the lowest or must depending side, ard the running continued for several days, until it assume a healthy appearance and the swelling subsides. This plan must be always adopted with the slow or sordid tumour, which will not come forward, though heated with the onion poultice, and even with a biister: then let the seton be applied, changing it daily and soaking the tape in the irritating mixture, as in case of pollevil, page 119. That other critical abscess, called strangles, comes under a distinct head, farther down.

Deep-seated abscess, under the fascia of the muscles of the belly, is scarcely ever curable, being seldom discovered to the eye until too late to render assistance in bringing it to the surface by means of strong drawing poultices, as in case of obstinate poll-evil. On passing the hand over the part, the animal may be observed to flinch from the touch; but this rymptom is seldom attended to, and it makes its way inwards, bursts in the ravity of the abdomen, and kills the patient.

\section{POLL-EVIL.}

Causes. - Next to a diseased habit of body, as just above noticed, which predisposes a certain description of horses to contract tum ours in various parts of the bociy, the poll-evil is frequently occasioned by a blow; or gall, of a very trivial nature, if it do not come on without this kind of excitement. The action of the head is very great with some horses, arising probably from an itching in the upper part of the cervical ligament, where it is attached to the vertebræ of the neck; and this causing irritation, we need not hesitate long in accounting for the inflammation that affects the nuscle which interposes between it and the poll-bone, in a cavity that is greater with some breeds of horses than others. This variance ir conformation is exemplified in the whole length portrait of a skeleton which is prefixed to chapter i. wherein the cavity that should form the seat of this disease is scarcely perceptible; whilst the small fivure, inserted at section 16 of that chapter, to illustrate the uses of the cervical ligament, has this cavity of the usual extent. Of course, this latter would be still more predispnsed to contract poll-evil than the former, which was a peculiarly formed horse in another respect also; and it is more than probable, that, if the two were to fall into an equally bad habit of body, whilst the latter might acquire poll-evil thereby, the constitution of the former might throw off any offensive matters that might accrue by some other meals.* The reader will do well to turn back to the section referred to (p.20), as well as to the skeleton [at A 5].

The wheelers, in a set of horses, will frequently throw back the head in

- These might appear in shape of grease and farcy ; but it has been generally obser red tnat a disposition to farcy abates, if it do not subside entirely, upon the appearance of poll-evil. Again, horses that are most liable to contract the grease, are precisely of the same disposition Rs those which are afflicted with tumours, sec. viz. of indolent habit, heavy in the hand, and slow of blood, fleshy and dull. 
warm weather, or after hrisk work, at feeling the reins that run through then head-harness to the leaters: this action is performed, as the reader will have learnt, by the action of the cervicular ligament, the upper end whereof terminates where the ear-band rests, and perhaps pinches the part. Horses that are given to shy are likely to contract poll-evil when hanging back, and throwing up the head with a jerk.

But the most prolific cause of poll-evil I am inclined to attribute to the low stable door-way, whereby the animal gets many a trivial hit at going in and coiming out; next in point of frequency is that brutal mode of attacking restive horses about the head with the butt end of the whip. Education of the lower classes has effected the abatement of this as well as many other unfeeling practices. Oftimes, the edges of the ear-band, being sharp, create a painful itching, then soreness and irritation about the part, as does also the showy tip, or "cutting at a fly," practised by our flashy four-in-hand men, who may have discovered that touching up the animal in such a vulnerable part is "sure to make him go along." "Stage-coach horses, however, do not now acquire poll-evil, so far as I can learn, like what they did formerly; for the great expedition these vehicles are constrained to, compels the proprietors to use better bred cattle than their predecessors- those that are less indolent, not so heavy in the hand, nor sluggish, consequently not so liable to contract diseases incident to a bad habit of body, or vitiated state of the blood, like pollevil and its nauseous train of co-existent evils, that we shall proceed to take into consideration one after another.

Symptoms.- At first the animal appears restless, throwing his head back and returning it to the former position, as if the efforts had occasioned pain. Soon after, it droops the head, holding it now on one side, now on the other; appears dull about the eyes, and becomes sluggish in its movements. In this state it continues a longer or shorter time (even weeks) as the violence may have been greater or less that brought about the evil; the time depending alsc in some measure on the height of the pulse: a languid system making of course the slowest advances towards bringing the abscess to maturity. This uneasiness of manner is accompanied by heat, swelling, and shortly by ten. sion of the part, and increase in the pulsation. As it goes on, a disposition to flinch from the touch is evinced whenever the part is approached with the hand; if the evil be deep-seated, the swelling is wide, but not so high; but when nearer the surface, it presents a point, is circumscribed within a wellmarked circle, and ultimately tells how necessary it is that the contents should escape, by a throbbing which may be felt at this point. Again, to ascertain that the matter is near the surface, apply two fingers alternately on the sides of the tumour, and the matter will recede from side to side. Let it out.

Cure.-At first, this may be attempted, in the earliest stages of the disorder, by repression or dispersion, provided the disorder be not deep-sented near the bone; which will be the case if it has been brought on by violent means, or it be a second attack, when endeavours to repress it would be vain indeed. On the contrary, if we can trace the cause to a hurt of no long standing, or of trivial import, and we know the horse was in good health before the swelling took place, then ous duty is to carry off the evil through the animal system, by means of active physic. Foment the part well with bran and water, warm; rub it dry with cloths, and apply the

\section{Embrocation.}

Spirits of wine, half a pint

Camphor, 2 drachms,

Goulard's extract of lead, I drachm 
Mix, and apply the same two or three times a day, gently rubbing the part $2 . s$ much as the animal can bear. Give also at the same time the

\section{Alterative Ball.}

Aloes, 4 drachms, Castile soap, 2 drachms,

Calomel, half a drachm.

Mix with mucilage, and give one every third day, provided the embrocation is applied so long.

During these applications, a cooling regimen should be observed, the feeds being reduced to half the usual quantity of oats, and ultimately discontinued altogether. There will be no propriety in cluthing up the patient, nor need he be exposed to the cold air, if it prevails. When the disorder has been bruught on by simple compression of the ear-band, and is recent, I have never known the foregoing treatment to fail ; and in cases of vigorous constitutions, the swelling, heat, and tension have been reduced so quickly (i. e. in four or five days) as to leave certain careless observers in doubt whether the animal had really laboured under a genuine attack of poll-evil.

Remove the halter, and if the animal be put to work, contrive to keep back the ear-band. A good and valuable embrocation will be found in simple vine. gar three or four times a day, or the sediment of very stale beer. Old verjuice answers the same end; and all this kind of embrocation must be laid on warm, by means of cloths soaked and applied repeatedly.

*** The same treatment and observations will apply to all the other species $^{*}$ of abscess in its milder state, fistula, warbles, quittor; but of these I shall speak more particularly under their respective heads of information.

Second method of curc.-Very few cases present themselves to recollection of even recent poll-evil, that would admit of being completely dispersed, and a radical cure effected, by any means whatever; and it is due to candour to acknowledge, that some of the most stubborn attacks were found to have re. lapsed after a while, which proved that the cure so effected to all appearance was not radically good, but had left a violent preelisposition to renew its ravages afresh. Probably, the time of inflicting the injury had not been accurately marked, nor its degree ingenuously reported to the owners in those cases of relapse.

However this be, when the disorder is found to baffle the endeavours employed to disperse it, the whole course of proceedings must be changed, as befure hinted in the concluding sentence of my general observations on this topic. Instead of putting back the swelling by those means, let us pursue a direct contrary course, in order to bring it forward: the mode of feeding must ye changed along with the medicines that now become proper to procure sup. puration, or a discharge of the offensive matter; a full habit being mainly conducive thereto, and proving how closely connected is this disease with a gross habit of body, which in all fleshy animals superinduces a diseased habit, vulgarly but accurately termed "full of humours." After having found useless your efforts to disperse the tumour, or, mayhap, finding at the first view of it, or by the first touch, certain symptoms that prove it ought never to be dispersed, the practitioner will of course seriously set about permitting, or forcing, the offensive matter to escape. Every hour's delay in putting this resolve into practice serves but to render the ultimate cure still more difficul and hazardous; for the evil is all this while extending its baleful effects inwards and sidewise, and forming around it, in every direction, the fistulous : ihse or cæstus before spoken of, which is a film, ur skin-like substance formad 
of the cellular membrane, thickened by the disorder. (See Book I. Sect. 27. page 28.) In this event, the tumour has become decidedly fistulous, and is to be treated as such, when the great length of time it may have been suffered to make head, and its now extended surface, warrant that conclusion. The knife is almost the only remedy, notwithstanding the superficial tumour will in some cases break and discharge matter of itself; this, however, never happens with the deep-seated abscess, which lies close to the bone, and destroys not only it, but the muscular substance of the poll, and the end of the cervica. ligament also. In these series of abscess or fistulous tumour, nothing but the knife can ever reach the disorder, and it must be employed fearlessly, but with a commensurate share of skill, after the skin has been prepared with fomentations, \&c. Let the parts be softened and drawn with poultice of oatmeal, put on lukervarm, twice a day; and if the effect be not visible to the eye and toush, as before described, increase the powers of the poultice by the addition of onion chopped and mixed with the poultice whilst warm. Or, a mere change may be adopted, and a bread pcultice applied instead; for, notwithstanding oatmeal is stronger, yet 1 have occasionally found the milder have more effect when the former had not succeeded entirely according to my wish. The poultice should be provided in sufficient quantity to cover the whole swelling two inches thick at least, having a small quantity of sweet, oil, hog's lard, or oil of turpentine mixed therewith. Fix it on by means of a contrivance that is sufficiently explained by the annexed cut, in which it will bo seen that the girth is to have a web breasting, to which the lateral corners of the clnth are to be attached by broad tapes, as was explained in another simi. lar case at pages 79 and 114 .

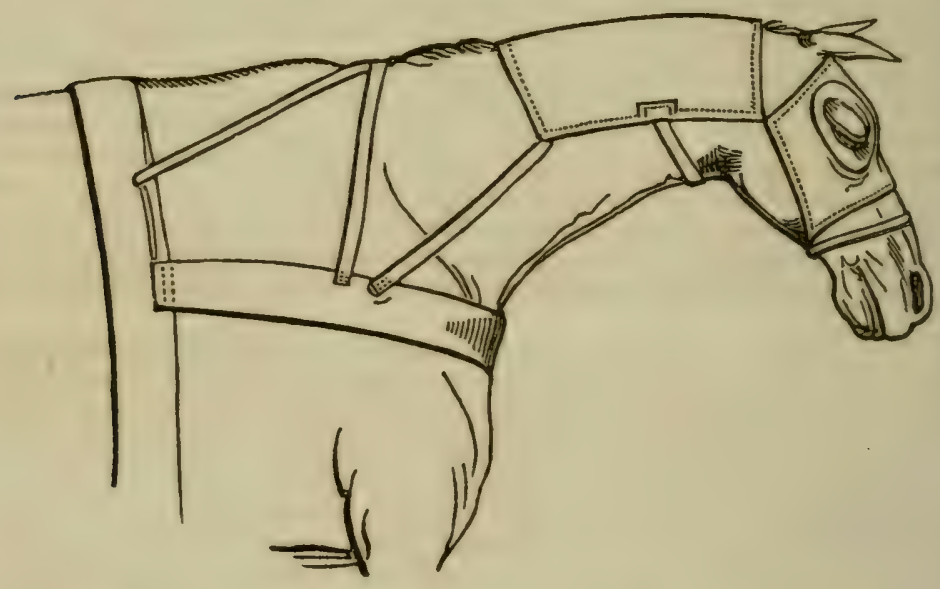

I have here represented the bandage rather longer than requisite, under tlse presumption that it may occasionally be applied to other affections farther back; a prolongation of the bandage may be affixed at either enç, either plain or plaited, according to the amount of the sivelling.

When the symptoms above stated inform our senses that the matter ought to be so "let out," an opening is to be made the whole length of the abscess, a little below its cenire; taking especial care that the knife do not pass crosswise, lest the attachment of the cervicular ligament to the first (vertebræ) bone ohould be severed; in which case the animal would droop its head ever after 
as may be learnt by consulting its construction at p. 20, of Book I. On the escape of the matter, after ascertaining by a probe whether it runs in pipes, ut sinuses, this way and that, or with small bits of diseased fibre or memlirane stretchng across the cavity, so as nearly to divide it into unequal parts-let each be just touched with the knife or scalpel. There is no propriety in the old practice of squeezing out all the offensive matter from this kind of abscess, although it be very proper in that decp-seated sort where no pipes, nor the small cavities just spoken of, are to be felt or seen, for the following reasuns : the first mentioned kind have the case or cœstus before described, which con tains the matter, and if laid open before the evil be sufficiently ripe, it doe not come away freely. This, however, the operation effects in two or three days, if kept running by means of a seton, or other contrivance placed at the orifice; but the application of tow, or any othar sulstance, that ohstructs the escape of this matter, is ever to he avoided. On the contrary, when the abscess is very deep, reaching to the bone, which may be felt, and presenting but one large cavity, then the matter should be expelled by pressing gently on two sides of it at once. Let the lips of the opening be dressed the first time, and as long as it may be found necessary to keep open the wound, with any ointment hereafter mentioned, on which has been strewed sulphate of copper, powdered. Should the lips adhere together, or appear much diseased, wash with muriate of ammonia, taking care it does not run upon the sound parts, nor into the cavity. In either case, was! off the dead parts with warm water, before each new dressing is laid, sponge it well and dry, after inserting the probe on every side into the fistulous sinuses, and continue this mode of treatment until the parts assume a healthy appearance.

The seton should never be neglected in bad cases of either description, but be introduced at the lowest or most depending side of the abscess, after being wetted with the following

\section{Irritating Mixture.}

\section{Spirits of wine, 2 ounces,} Corrosive sublimate, 1 scruple;

Mix and saturate the tape therewith daily. This will keep open the orifice until the offensive matter has run off, and is succeeded by the more healthy sssue of a thicker consistency, and nearly white. On this appearance the seton is to be withdrawn, and the parts dressed with the digestive ointment, the animal physicked once or twice with a moderate purging ball of six or seven drachms of aloes, and the cure will complete itself with the usual dress. ings, viz.

\section{Digestive Ointment.-No. 1.}

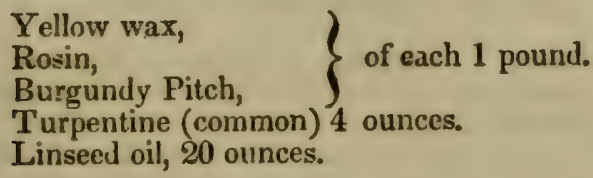

Dissolve over a slow fire, and spread upon leather or stout linen cloth, suffi cieritly large to come over the undiseased region of the evil, after the wound has been well cleansed. Fresh dressings hereof should go on daily, bui in no case until the matter assume a healthy appearance, which it never ean be brought to, unless the whole recess has been reached with the knife ur by tho 
nperation of the "scalding mixture" of the old school of farriery. This reme. $\mathrm{dy}$, so applied, though at variance with our modern notions of pathology, has been adopted by the collegians of St. Pancras, and with good reason, for it r.ever fails to effect a cure, by effectually cleansing away the diseased parts. Three several mixtures are adopted in different parts of the country-the Hertfordshire and midland county farriers employing No. 1.; No. 2 is that recommended by Gibson; and No. 3 is Ryding's.

\section{Scalding Mixturc.-No. I.}

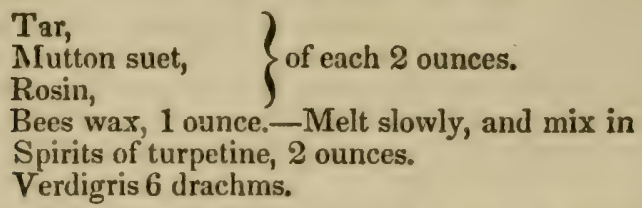

Mix and pour into the orifice hot, and close it with stitches. The next two have the recommendation of being more scientitic, and are withal better adzpted for penetrating into the sinuses.

\section{Scalding Mixture.-No.2.}

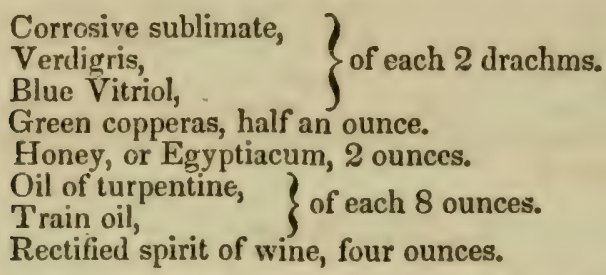

Mix, and apply as before directed. The difficulty of retaining this last in its proper place, is its only defect; but Gibson appears to have prescribed a quantity sufficient to allow for spilling a good portion. Since writing the above, however, I have inserted the sketch of bandaging for poll-evil remedies at page 118 , to which the reader will refer, when requisite, and introduce such modifications as the nature of the applications may demand to prevent the loss of any part.

\section{Scalding Mixture.-No. 3.}

Oil of turpentine, 2 ounces.

Verdigris, 1 ounce,

Ointment of yellow resin, 6 ounces.

Mix and apply as above. In using any of those hot mixtures, a pisce of tow should be so placed as to surround the orifice and prevent its running over the sound parts-ivhich would he injured thereliv, as would the operators fingers, \&c. if he neglect the proper precautions. These he shuuld not fail to take as regards the acrimonious discharge from the abscess, as absorption thereof rnight take place at the root of his nails; so, if the discharge be allowed to rest apon the sound parts of the horse, it will be found to corrode and produce ulcers.

Frequently it happens-and I belicve the old farriers always "repeated the dose," that a second application of the "sculding mixture becomes neckssary, 
for thirir cases were aiways very bad ones. In this event, opportunity is afforded of employing both prescriptions in succession; but whichsoever is first adopted, let it remain undisturbed from sixty to seventy hours, if the stitching do not sooner hurst. Sponge out the parts with warm water; cleanse away the adjacent filth, and either repeat the same or proceed at once to the curea determination the dictor will come to, according as the rottenness may have sloughed off, and the inside of the abscess may present a healthy appearance, or otherwise. If it be quite clean, the adhesion of the parts will follow with very little further care than applying the digestive ointment according to the receipt in page 119, - or the following

\section{Digcstive Ointment.-No. 2.}

Common turpentine, 4 ounces,

The yolks of two eggs.-Mix these well, and add

Myrrh, in powder, 4 drachms,

Mastich, 2 dractims,

Tincture of myrrh sufficient to hring the whole to a proper consistence.

Should the cure of the wound proceed too fast, the over luxuriant granulations of new or proud flesh must be touched with caustic.

But notwithstanding all that has been said above, it sometimes happens that a totally different course becomes necessary, when abscess in the poll is connected with another disease arising from the same vitiated state of the animal's system, and the remedy for one of these will cure the other. Farcy is the correspondent disease to which I allude, or rather I should say a tendency to farcy, visible in certain scanty lumps or tumours on the body and leus: these will run off sometimes by means of a copious discharge at the poll. More frequently, however, the farcy is of too inveterate a description, and proves that the whole mass of the animal's system requires correction, and that it must be treated with medicines proper for the farcy, as well as the local affection of the poll.

People in general like to be borne out in their most novel opinions by those of lunger standing in society, and I confess myself one of those sort of people as regards the doctrine of a vitiated or a corrupted state of the animal's system, which it is absolutely necessary to correct by medicine before the cure of some disorders can be effected. I strongly touched upon this topic in the first book, and at page 59, to which probably the inquiring reader will turn, and become convinced with me that poll-evil may be no other than the critical abscess of farcy; which farcy is a disease of the system, and is correspondent with glanders, as poll-evil is with quittor, \&c. The writer I shall quote as agreeing with me, mainly, in this view of the subject, is Richard Lawrence. He says, "the poll-evil is sometimes connected with a disposition in the habit of body to farcy; this may be known by the animal appearing universally [i. e. generally] unhealthy in his coat, the tightness of his skin, and also by small tumps or stvellings in different parts of his body, and particularly on the insides of his legs. When it is ascertained, therefore, that the poll-evil arises chietly 'rom a disposition to farcy, the mere operation of opening the anscess, and using the dressings usually recommended, will not prove sufficient, without the aid of medicine given internally; because the abscess, not being then a 
local affection arising simply from partial injury, it will he necessary to correct the general hathit of body, before a cure can be effected. The medicines best adapted for this purpose will of course be found under the head of "Farcy," a few pages farther down.

\section{FIS'TULA IN THE WITHERS.}

Cause.-Although closely resembling poll-evil in so many respects as to $8 \mathrm{sem}$ the self-same disorder arising from precisely the same causes, but differing in situation only, I must here premse that some other distinctions aro proper to be talien, which it will be necessary to keep in mind. We have seen, a few pages higher up, that poll-evil may be produced without external violence; this never happens with fistula in the withers, which is always brought on by external injury-namely, the galling of the saddle: in the first case the tumour frcquently turns out a simple aliscess, in the present caso never, but hecomes fistulous at its very carliest stages. This arises from the quantity of the membrane which is found in the shoulder and whole forchand of the horse, in the cellular structure whereof the offensive matter finds an easy receptacle, and spreads its ravages from side to side; and accumulating in yuantity, by its own specific oravity, finds its way, eventually, amongst tho muscles, and forms sinuses. How this operation of nature is performed, the reader is instructed in the first book, at sections 26,27 . I have also descantcil somewhat at large, in the general introductory observations on this wholo serie's of disorders, as to the distinctions proper to be kept in mind between ono kind of tumour and another, how they are formed, and what description of horses are mostly liable to this or that species of the disorder. At page 112 will this information be found, and which the reader would do well to consult once more before he sets about treating his horse for fistula in the withers The symptoms are most obvious to the touch, as in all inflammatory tumours, the animal shrinking when the hand is passed over the shoulder from tho mane downwards. But the ill-formel sadlle, or one that fits the particular animal like nothing, or one that is so liadly girthed on, that the poor beast may be perceived going in great pain, shall be set down as the symptom of all symptoms, that the animal is destined to contract this particular disorder of tho parts so injured. Sometimes he tumbles down, or seems to trip frequently, which should admonish its inconsiderate rider or driver, that his carelessness is very likely to cost him a broken neck.

Cure.-As soon as the journey can be brought to a close, which has been thus improperly pursued, remove the cause and bathe the part well with the cold saturnine lotion, and when the saddle has undergone the proper alterations, the journey may be pursued, if necessity demand such an exertion.

\section{Cold Lotion.}

Subacetate of lead (goulard), 2 ounces,

White vinegar, 4 ounces,

Water, 3 quarts.-Mix, and apply with a sponge.

Should not this prevail, and the horse evince pain at the touch, with in. creased heat and tension, and swelling of the part commence, the disorder is canfirmed; and if not repelled in its very earliest stagges, suppuration must ensue. Let it be taken in time however-that is to say, in the course of a day or two, or a week, with healthy active horses, is not too long-and the heat and inflammation will be reduced by employing the embrexation, recommend al in incipient attack of poll-evil, at page 116 , and grving at the same iime tho 
alterative lall there set down. Success more generally attends this first mo thod in the present kind of tumour than in that to which I have just referred vi\%. poll-evil; but this method of curing both is so exactly similar, that it would he a waste of words to go over the same grounds again, or make the same ob. servations which I thought proper to set down under that head of information. At page 116, the reader will perceive, that whon he is attempting to repell the tumour and allay the inflammation in its earliest stages, he is to empioy a cooling regimen; that when the disorder has been brought on by a trivial cause, this methor of cure seldorn fails, if taken in time; and also that fistula is easier prevented herehy than is poll-evil. "However this be, when the disorder is fouml to bafle the cudeavours employed to disperse it, (as I before olsserved), the whole course of proceedings must be altered ; the regirnen, or feeding must be higher, the parts encouraged to collect matter and come to the surfise, instead of making inroads upon the adjacent muscle and bone, which it will effect more hideously as the animal may be afflicted with a gross habit of boily.

After having found all efforts useless, the practitioner will change his plan; and force the matter to escape as soon as may be; for the disorder is every hour extending its baleful influenee. For this purpose the knife, or common bistoury, is to be employed when the tumour is sufficiently ripe, which is a state it may be brought to, by means of the application of a poultice. Of these, I preseribed two or three kinds, with the method of fastening them on, but in this latter respect, a material difference arises in consequence of the different shaye of the parts. The bandare in this case must be allowed to come farther back, and be there detained by tying the tapes short behind and lengthening the front ones. See figure at page 118.

Fomentations of warm water, in which cloths have been steeved, slightly wrung out and applied to the parts, will be found highly serviceable, and may precede the application of poultice. When by these means the tumour appears ripe and rearly, open the most prominent part with lancet or bistoury, and insert a whalehone prohe to ascertain the direction that the fistulous sinuses or pipes extend, in order that these may be laid open, and the whole matter suffered to escape. In some cases a stifler and larger probe may be employed, and when a sinus lies favourable, introduce the probe, and cut down upon it. But as to the lowermost sinus, when it temls towards the shoulder, so as to interfere with the action thereof, the knife is not to pass through it, but a seton is to be inserted in its lowest or most depending part, so that the matter may escape through.

As directed in the previous case of poll-evil at page 119 , the knife should be fearlessly applied in severing any small bits of muscle that may apjear to grow across the cavity; a touch of the knife will he sufficient for any purpose, as by kecping open the lips of the wound, all that belongs to this diseased part will slough off, and should he wiped away as before directed, every time new dressings are applied. Let the seton be soaked in the mixture of corrosive sublimate and alcohol as directed at the pagre just referred to; and in the worst cases apply either of the scaldiug mixtures in the manner mentioned at page 120, and repeat the same if the first does not accomplish all that is desired

The operator in this case will not fail to use the proper precautions as regards the application of those scalding hot remedies, nor neglect to remove the matter that is discharged from the wound, in the manner set forth at page 121. Mrost frequently the lips or ederes of the sore are thickened, and assume a very inflamed and ulcerous apperance; this should be reduced lyy the knife or caustic or it, becomess so luxuriant at times as to close the orifice, and to cause a renewal of the fistula, ia which case you have all your trouble to go sver angain. At Alfort, they have a very neat method of cieaning out fistulwue 
ulcers, by rolling up pledgets of linen cluth, the edges whereof have been scriped out thin, so that when introduced dry to the bottom of each sinus or pipe, and being twisted round, it brings forth the offensive matter and any residue of blood which may have got into them during the operation. They also employ gentian root to keep down the swelling or thickening of the ips of the sore. The healing is not to be suffered to go on too fast, nor until all the offensive matter has been expulsed, and a more healthy discharge, whilst it manifests the change that has taken place, and warrants your closing the sore. Blue stone spread on any plaster of digestive ointment will effect this; or takc

\section{Ointment of nitrated quicksilver, 3 ounces, Oil of turpencine, half an ounce.}

Mix, and apply as long as may be found proper to keep the orifice from closing, to which it will be ever too much disposed.

Something was formerly said about scraping the bone when the long continuance of the disorder, its virulence, or the bad state of the horse's general nealth, hath been such as to affect its surface; but this part of the operation is rather showy than useful, as the rottenness so occasioned will come away as the discharge is kept up, there being a constant disposition throughout the whole system to throw off all such offensive matters.

\section{SADDLE GALLS; VIz. WARBLES, SITFASTS.}

The first of these partake $i_{i}$ the nature of the disorder just above treated of, viz. fistula, and are caused by the same means, bruise of the saddle; but being situated farther back, less scope is allowed for the spreading of the original tumour. Consequently, the smallness of the affliction renders it much less formidable, though, if suffered to suppurate, they become most troublesome sores. The means to be adopted for the cure of warbles are similar to those recommended for other tumours, viz. at first try to prevent the accumulation of matter by repellants, such as the embrocation prescribed at page 116, the domestic remedies in the next page, as verjuice, made hot and applied by means of cloths soaked therein, and repeatedly changed. Or apply, in the same man ner, the following

\section{Cold Lotion.}

White vinegar,

Spirits of wine, of each 3 ounces.

Super-acetate of lead, 2 ounces,

Water, 6 ounces. Mix.

Should not these succeed, change your treatment, adopt the direct contrary mode, and bring the tumour forward to suppuration by means of poultices, \&c. as before recommended; and finally, when ripe, open the tumour with a lancet, promote the escape of the offensive master, and then proceed to healing the sore, as in the former case of poll-evil and fistula in the withers.

Sitfast is an indurated tumour, one that has neither matter nor motion in it, and may arise from either of two causes. The first is simply a gall or bruise, which has produced no inflammation, and consequently no matter has been eugendered; the second comes of an ill-cured warble, that has closed, leaving a hard insensible swelling behind. Blistering is the favourite remedy with most farriers, though fomentations and poultices will frequently achaeve as 
much good in very little more time. When suppuration has taken place, the cure is to be completed by dressings of detergent ointment, taking care that the sore does not hea! too fast. Should this be the case, put blue stone powdered, upon the plaister once or twive, or merely touch it with lunar caus tic as often. Sometimes the callosity does not come off of itself, though the efleres rise up; it is then to be taken away by force, separating it from the living parts with the knife. The small portion of blood that comes away does no harm, but the contrary. If, however, any one objects to the use of the knife, or doubts his skill in this operation, mercurial ointment will effect the same end, as follows:

\section{Ointment for Sitfast.}

Oil of turpentine, 10 ounces,

Blue ointment, 8 ounces,

Gum ammoniacum, 4 ounces;

Mix and apply to these and all hard tumours.

\section{QUITTOR}

Is a disease of the foot, at the coronet, but is so decidedly fistulous, that 1 choose to treat of it in this place, rather than in the chapter devoted to the foot in general, that the student may more readily remember the general observations I thought necessary to prefix to this whole class of diseases, at page 110; \&c.

Cause.-A tread which the horse inflicts on itself, for the most part, seeing that it generally occurs on the inside of the foot. This tread or bruise may either be inflicted upon the coronet, or lower down, by over-reaching, or even at the sole; by taking up a stone or other hard substance; also by a prick or blow in shoeing. A quittor is also sometimes occasioned by gravel working up into an aperture left by an old nail, acting upon the sensible laminated substance, separating it from the insensible, leaving a cavity from the aperture quite up to the coronet, where it lodges, inflames, and produces abscess, which is frequently very difficult and troublesome to cure; if not early attended to, sinuses form, sometimes reaching to the coffin bone. The blood vessels at the coronet cease to perform their proper function of secreting new horn and the consequence is frequently the loss of the inner quarter of the hoof.

Cure.-The sore is always very small, but admits of a probe being intro. duced, by which the extent of the evil may be ascertained, and this is generally very extensive and ruinous, according to the time it may have been allowed to make head. The probe will pass readily forward and backward to the whole course of the disease, and sometimes it will be found to have penetrated to the coffin bone, every where forming sinuses or pipes, as in fistula of the withers before described. But in this case situation makes considerable difference: unlike the former, poultices are rendered inapplicable, whilst the employment of the knife or lancet is dangerous in the extreme. Besides which, the diseased part is already open, and seems to invite the only species of remedy yet known, in the shapie of escharotics, that by irritating the case or castus, which forms the sinuses, shall cause it to slough off. In slight cases, those which are found not to have penetrated deep, the simple application of a wash will prove sufficient, and may be employed in this manner. Dissolve blue vitriol in water, and charge a syringe therewith; this is to be discharged into the orifice, aud suffered to remain, as much as can be retained. A poultice of bread or oatmeal is to cover the part, and the cure will be com. pleted after two or three days. But unfortunately tor the owner and the an. 
mal, the disease is seldom taken in hand thus early, but is suffered to proceed until much stronger means become necessary. For this purpose take a long norrow slip of thin paper, and moisten it with muriate of antimony; over this strew powdered corrosive sublimate, and roll up the paper, so that it may not be too big for the pipe which it is intended for. Generally it happens that the opening requires to be enlarged before this pledget so charged with the escharotic can be fairly introduced. Take especial care that the pledget reach tho bottom of the pipe, cut it off close, and pass a similar one into as many sinuses as may have been ascertained forms the disease. As considerable irritation of the part will quickly ensue, a poultice sufficient to cover the foot should be previously got ready, and applied inmediately.

In three or four days, the bandage being removed, the diseased parts will slough off, a considerable opening presents itself, leaving a healthy looking sore. Let this be sponged off with warm water, and when dry apply tincture of Benjamin, which will effect a cure. A solution of white vitriol is used with advantage, especially when a disposition to secrete unhealthy matter is at any time perceptible. Physic, the patient after the operation, according to the actual state of his bowels, the motion whereof will alleviate the pain necessarily attending the escharotic quality of the pledgets applied to the foot. If the horse's bowels be found in the ordinary state, give two balls on successive days, thus:

\section{First Alterative Bad.}

Aloes,
Hard soap, $\}$ of each 2 to 3 drachms,
Oil of cloves, 6 drops,
Calomel, 1 drachm;

Mix, with mucilage sufficient to form the ball for the dose.

\section{Second Alterative Ball.}

\section{Aloes, 4 to 5 drachms,}

Soap, 6 drachms,

Oil of anise-seed, 10 drops;

Mix, and give one dose the day following the first ball.

\section{VIVES.*}

This is the term given to swellings of the glands just under the ear, towards the angle of the jaw, that mostly attack young animals. The tumour is easily repressed or driven back into the system, and by more simple means than those employed in more inveterate complaints of a similar nature, show ing themselves in other parts of the body. In some respects this disurdes bears near affinity to the strangles.

The cause of Vives may be distinctly pronounced "a cold," that prolific suurce of so many other disorders incident to man and horse. The vives usually comes on after hard work and sweating, by being then exposed to a current of air, or cold rain.

The season of shedding the teeth, when the contiguous parts are unusually tender, is that in which swellings similar to vives pervade animals of any speries. Nevertheless it sometimes attacks horses at an advanced age, notwith. standing they may have previously got over the most healthful form of stran-

\footnotetext{
-From the French "avives," and the verb aviver, to be brisk and lively as if it were con
} arred ironically upon the animal in its dullest statc. 
gles, when we might reasonably suppose nature had ridded itself of a disposition to secrete any more such pestilent matter. Want of the usual head clething is then the immediate cause of vives. The violence deemed neces sary in breaking colts also causes the vives, when the pressure on the parotid glands, at reining up the animal, irritates the parts.

Symptoms.- Swellings under both ears, generally, that occasion manifest pain when touched: the animal coughs more than one which has the strangles, and a difficulty of swallowing soon hecomes evident. Stiffness or aridity of the neck follows, and the patient makes frequent efforts to swallow the saliva, which it is the proper function of these glands to secrete, but which they are soon disabled from performing, by reason of the cold checking or chilling those functions. Of glands generally, their construction and uses, the reader will find many instructive particulars in the first book, at page 29; these of which we now speak being called "the parotid glands," from their situation; and as they now refuse to perform the office of secretion, the watery humours flow from out the animal's eyes, which it partly closes, as if he were about to sleep. For want of the same supply of saliva, inflammation of the mouth and gums takes place, producing what is vulgarly called "the lampers," or swelling of the roof of the mouth near the front teeth, which I shall speak of separately a little further down. Sometimes the swelling of these glands, if not assiduously subdued, continues a fortnight or longer, becoming more troublesome every day, and evidently occasioning very much pain; all this while the horse loses condition, is feverish, and at length so weak as to totter when he moves even in his stall. Spreading downwards under the throat, they at length terminate in strangles, and are then to be treated as such.

The cure of the vives that arises from simple cold is very easy, but not so that which is connected with a general bad habit of boly; for then the swelling and subsequent suppuration of the abscess must be considered as an effort of nature to relieve itself from something that is offensive to it, and must be treated as a disease of the whole system, nature having adopted this or that particular spot for demonstrating its offence. But I have already explained my opinion on this interesting point of veterinary pathology, much at large, when treating of other tumours and abscesses. Vide page 110, \&c. Oftentimes it happens that the vives depend upon glanders or farcy, of which they are then a correspondent symptom, and will only subside when the virulence of these are reduced. However, no harm can come of fomenting the part with warm water at least; and after it has been well dried, clothe the head so as to keep off the air, upon the principle of "remove the cause, and the effect ceases of course." The application of the bandage described at page 114, will sufficiently clothe the part.

Much of the pain and tension of the tumour will be alleviated even by this treatment, and a slight attack will be removed by following it up with fomentations of marshmallows; or, anoint the parts with ointment of n:arshmallows, and cover the head as before. A bread poultice affords relief, and bleeding in stublorn cases of simple vives is often necessary, with purgatives. Indeed, the body should be opened, whether we bleed or no: always leave open the main road for such humours to escape by. This alone will carry off a recent attack, provided the head clothing be kept on at the same time, nature performirg the remainder by absorption. To assist nature towever, employ the fuilowing

\section{Lotion.}

Sal ammoniac, half an ounce,

White vinegar, 6 ounces,

Goulard's extract 1 ounce;

Mix and rub the part well twice a day. 
Low diet, a plentiful supply of water urmel, and bran mashes, to which an ounce of nitre may be adled daily, will reduce that thickened state of the blood which ever attends this species of tumour. But, as in the proceding cases of tumour (poll-evil and fistula), it is sometimes found improssilule to remove the vives hy those means or any other; matter is formed, the tension and inflammation continue upon the inerease, and plainly indicate that suppuration must ensue, and all our labour is rendered vain, if it ought never to have been so employed. In this event, apply a meal poultice, restore the animal $t$ his ordinary diet, and promote suppuration, which eflects the cure in the same mammer as all other abscess mentioned before. See page 114, se.

lialse vives, or imperfect ones, that are hard and insensible, sometimes cause a good deal of needless trouble. They neither come forward nor recele, do not seem to cause any particular pain, but still continue an cye-sore; and give reason to apprehend disigreeable consequences, and always prevent an advantageous sale of the animal. Stimulating embrocations are well calculated for roducing these hard tumours, and the blistering liniment, made of cantharides and oil, never fails.

\section{LAMPERS, OR LAMPAS.}

Cause.-As just said, lanipas is oceasioned by mflammation th the mouth. This is bronght on by inatility in the parotid glands to secrete the saliva necessary for lubricating the throat and gums. I'hese glands though liable to the disorder we term vives, yet the derangement of their secretury function does not always show itself by the vives: it may continue to flow, though not in sufficient quantity to meet the increased heat of the animal. Idle or illworked young horses are most liable to lampas.

Symploms.-A swelling of the bars of the mouth follows the rising vigorur and heat of the animal; they then project below the surface of the teeth, and interfie between them while feeding. The pain is necessarily very great on feeding: and the animal ceases to chew of a sudden; it afterwards commences anew, with greater caution; but as the disorder becomes worse, it refuses find entirely, and starvation would be the consequence if something did not intervene which is always sure to happen.

The cure would be effected of itself, if the horse lived in a state of naturi, or more probably in that state he never would have contracted the disease. Over-gorging and consequent fulness of habit having occasioned the blookl to flow lixuriantly towards the region of the head and throat, so that the disorder is thereby produced, the reduction of that full habit follows this compulsory abstemiousne'ss which the afflicted animal practises much against his will, and might teach man himself a monitory lesson he is usually slow in attending (1), until too late. Reducing the system is the neatest method of removing iampas, and purgatives should be employed; bran mashes, in which an ounce of nitre daily has been introduced, may also be given until the pulse becomes nore natural. If the lampas be not lessened, by these means, the projecting part is to be cut with a lancet, but some people commence operations with the bearing iron, as the readiest way, and give physic afterwarus. This applica won never fails. 


\section{CHAP'TER III.}

\section{EXTRIRNAI, DI:SOTHIJIRS.}

\section{Purulent Tumours: Discases of the Gilandz.}

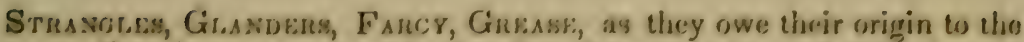
watne predisposing cause so evidently, that the appearance of ejihor is goon! assurance that no other disorder is then to be appretuended-neither of thes above nor thome treated of in the preceding chapuer, a few preliminary observations should occupy atterstion, lwefore we treat of any one in detiil. Both sories of diseasses are in like suanner constitutional, or residing in the filond; and the whole class agree tosgrether so nearly in canse, symptoms, and efiect, that the situation of cach on the various parts of the busly constitutes the main distinction between then; as this does also affect the appearance and consis. tency of the matter produced.

What I most strenuously maintain is, that the laterit cause of all tumourn, inflamed glands, and spontaneous discharge of matter loy skin or membrane, is entirely attributable to the actual state of hloos of the individual animal. Whence 1 infer, that sone horses are more liable to incur contagrious diseases than others, and this in a degree proportioned tos the state of the blosed at the lime of communication; so that some might escape: with impunity, whilst others meet with certain death from the self-sane cause. This arcounts for the greater virulence with which eome horses incur glamers, for example, comsuared h) what others suffer, which cateh the disoriler at the same mornent of time; as was proved on a largish sort of a soale, asul that protty well known arrorog practitioners, during the linte war on the continent. 'The case was briefly this:- A transport with cavalry horsos on logard, on its way to the Low Countries, met with bad weather, so that the hatehess were hatcened down, and in this manuer were part of the horses sufliocated. Of those which survived, amounting to some twenty-two or more, sascorly one resajmed the glanders, but, notwithstanding we may conchule that they infected and reinfected each other at the same moment, sond under precisely the sarne circumstances as to heat, respiration, and privations, yet the symptoms varied greatly, and some few resovered so readily an to leave great doust whether they really had re. ceived the glandersor owt, whilst others exhibited roal glanders in the highest degree of virulence. Between these extremes, we are informed, the remainder were variously affereted : all which circumstances prove incontestibly how unch deperuled upon the previous luealth of each individual, the vitiation of its blored aud its co-fituess or arlaption to recrive the infection. I imagine this to be conclusive of the doctrine I have all along lail down. But I wil! adduce another authority -a veterinary writer of France, who carries the principle even farther than I have alwentured to push it.

With that specious ingenuity which attends all aflairs of research in that country, an author named Dupuy, who also quotes the rapport of another called Gilbert, derluces the dispresition to contract such disorilers from the pro genitors of the afflicted, ur, as I should have said, from the hloced or toresed, and he recommends a corrective kind of reginuen for horos mares and stallions; that is to say, in other workls, an airy gituation for the breceling stur!. witt. 
pastures rather elevitel, where they will have sufficient norriture during the period of gestation, and can find occasional shelter from the weather. "By these means (says M. Dupuy) the disorder may be prevented in great measure." The disurder he here speaks of he calls "scrophulous tubercle ;" to which "all cattle whatever, bred in marshy situations with scanty allowance to the parents, are very liable." This disorder of the blood or breed, accord. ing to M. Dupuy, "predisposes the horse to contract those diseases that are known to us under the terms strangles, bastard strangles, farcy, and defluxions from the eyes ;" which latter, it will be scen, at page 127 , is a corresponding symptom and never failing attendant upon the vives, as it is of all other glandular swellings ahout the jaws. The Frenchman thus converts a single symptom into a disorder!

In England, moreover, we do not talk or write of scrophula in horses, or a disposition thereto, this being a symptom of a vitiated system in carnivorous animals. For, the mange in dogs, scurvical or scrophulous eruptions in mankind, and the farey or grease in the horse, although appearing very similar to the eye of a common observer, and all originating in a depraved state of the system; yet the immedrate cause of each of these differs greatly, by reason of the manifest difference in the structure of the capillary vessels or tubes that deposit the offensive matter of either kind, demand a very different treatment at our hands, and we reject the anomaly of M. Dupuy as inapulicable to horse-medicine. But when this gentleman represents the general predisposing cause as a "tuberculous or fistulous affection, that is capable of being al. leviated, prevented, and in some cases cured," he brings his arguments quite within the range of our conceptions; and I, for my part, take all that he sub. sequently adduces, as being in perfect consonance with my own doctrine respecting the predisposing cause of diseases. As to ancestry, and breeding from a good stock, in favourable situations, of which this writer appears to entertain correct notions, I had already anticipated him, as the reader may perceive at pages 18,19 , which is a part of ny book that appeared in the Annals of Sporting for 1822 .

\section{THE STRANGLES.}

The Strangles, as the name imports, is first indicated by a coughing, and difficulty of swallowing, as if the animal would die of strangulation. It is a disorder of youth (like our hoojing cough), is inherent to the nature of the animal (as is our small pox) once only, and its virulence may be abated by inoculation, whereby we choose a favourable period for meeting the inevitable attack, after duly preparing the patient.

Cause.-Repletion of the system of life, and the deposite of blood in the glands under the jaw; which failing to be taken up and reconveyed back again into the system (called absorption-see book the first, p. 21), the glands become inflamed, swell, and burst, the discharge of the offensive matter being the cure. I have always considered it a critical disease, and treated it as such, encouraging the formation of matter, and assisting nature in throwing off a something that is evidently obnoxious to the cunstitution. Indeed, 1 have never heard of any other practice; the impertinent attempts at repression, so frequently adopted at the request of proprietors in other cases of tumour, never having extended itself to this. Strangles, strictly speaking, are incident to the young animal only-that is, from two years old, until five or nen six; when the circulution (as the blood is called) has attained its fulness, and, perhaps, slight cold has first detained any portion thereof in the glanis, where: oy the inflammation is engendered that constitutes the disease. "When these Rlands siyell and discharge at a more mature age, the strangles must then ba 
sonsi kered as the effect of constitutional depravation, and would as properly come under the general description of critical abscess, treated of at a former page, 113.

S'ymptoms. - A swelling commences between the upper part of the two jaw-hones, or a little lower down towards the chin, and directly underneath the tongue. A cough, and the discharge of a white thick matter from the nostrils, follow ; with great heat, pain, and tension of the tumours, and of all the adjacent mentbranes, to such a degree that the animal can scarcely swallow. 'The eyes send forth a watery humour, and the animal nearly closes the lid: this is mostly the case when it happens that the two larger glands under the ear are affected also, which frequently happens; but when these latter are disurdered without the animal having the strangles, we then say he has the vives. The swelling increases and usually bursts of itself, sometimes without any medical aid whatever, and even without being perceived by any one. This last happens to colts and fillies at grass, when their wants are little attended to, and they seldom fail of doing well. Consequently, it follows, that those attacks which take place in the open air are of a milder nature than those more obstinate cases we so frequently meet with among in-dnor cattle. which serves to prove, once more, my ductrine as to the cause of all tumours or "tuberculous affections," as M. Dupuy has it. The horses that are kept in doors accumulate gross humours, by this mode of living on dry food and lying on soft beds, the exercise they take not being sufficient to carry of the effects of either. Enervation generally accompanies this mode of treatment; the glands and membrane suffer relaxation, the pampered animal is not exposed to the air sufficiently to occasion that check, or slight cold, which is generally the immediate cause of strangles, and the accumulation of these humours proceeds, until they overcome the capacity of these organs, and the strangles then become a formidable disease.

When this is the case, the feverish symptoms run high, loss of appetite follows with constipation of the bowels, the horse can neither drink nor eat, and the pulse increases. The tumours in these bad cases will be found to have risen nearer the jaw-bone than they do in a mild attack, and are longer in coming to maturity than those which begin more towards the middle. The disorder is seldom fatal; but when this does happen, the animal dies of suffocation, in which case it stands with the nose thrust out, the nostrils distended. the breathing is then exceedingly laborious and difficult, and accompanied by rattling in the throat.

Curc.-For this last mentioned extreme case, no other remedy is found than making an opening in the windpipe, through which the animal may breathe. For this spirited operation, I must refer to $\mathrm{Mr}$. Field, the veterinary surgeon, who has performed it frequently, and says his practice was to cut an aperture the size of a guinea, which nature afterwards supplies in due time. With this exception, perhaps, I might be justified in saying that we have little or no business to meddle with the strangles; unless, indeed, unfavourable symptoms arise, and the previous habits of the horse, his present fleshy or gross habit of body, with the unfavourable situation of the tumours near the bone, give good reason for believing that the disease will turn out a tedious or dangerous case. And $\mathrm{ye}^{t} \mathrm{I}$ should be very loth to recommend purging or bleeding for stran. gles, as I have seen done with no good effect; for, although the symptoms are thereby lowered, yet tise continuance of the disorder is protracted to an unmeasurable length, and I have heard of the strangles devolving into glanderg by this course of procecding - the subject of this case being a five year old nare.

On the contrary, the disorder being constitutional, that is to say, an effort of nature to relieve isself of some noxious matt'rs, the strength of the animal 
system should be sustained in some degree proportioned to what it may obviously require. Therefore, horses that ma he in good condition at the timo of the attack, and withal highly feverish and full of corn, will only require opening medicine, whilst a brisk purgative might do harm by lessening the access of matter to the tumour, and the system would still retain a portion of the offensive cause of disease, which would break forth at a future period in sume one or other of the correspondent diseases dependent on tubercular af. fections. In this case give the fullowing

\section{Laxative Ball.}

Aloes,
Castile soap,
Ginger, 1 seruple. Mix for one dose.

If difficulty of swallowing is already perceivalule, a drench would be found the more desirable form of arriving at the same end. Then give the

\section{Laxalive Drench.}

Caivior oil, 6 ounces,

Water gruel, 1 quart,

Salts, 6 ounces. Mix.

Meantime, at the first appearance of the disorder, let the hair he clipped off close at the part affected, and a little way round, to a!low of greater effect from any application that may be deemed necessary. The head being clothed, will restore as much warmil as hath hereby been abrilged. Mild cases will require no more than this, probally, and the assistance of a poultice and fomentation of marsh-mallows daily to the throat, to bring the swelling to a proper state for opening. This will be shown by its pointing, or becoming soft and peaked in the middle. But a premature employment of the lancet is to be avoided, fur the reason before assigned, viz. to give time for the whole matter to collect; when this period arrives, the whole swelling will be soft and yielding to pressure, unless the animal be a very thick-skinned one, with a great chuckle-head. In these cases, the part should be rubbed with a stimulating liniment, and if the tumour is working its way inwards so as to threaten suffocation, blistering ointment may be applied. After each and either of these applications, the poultice is to be again put on with care; and as mtheh of its efficacy depends upon its remaining in contact with the throat, the adjusting of it properly requires great pains and some adroitness for the thing.

Much difliculty being experienced in making serviceable bandages, I have unnexed a descriptive sketch of such a one as would be proper to keep on tho applications. It needs no further explanation than is given in cases of sore hroat at page 78, and of alscess, at page 114.

\section{Stimulating Liniment.}

Mustard, poivdered, 1 ounce, Liquid Ammonia, 3 d́rachms

Mer and apply assiivussly to the part. 


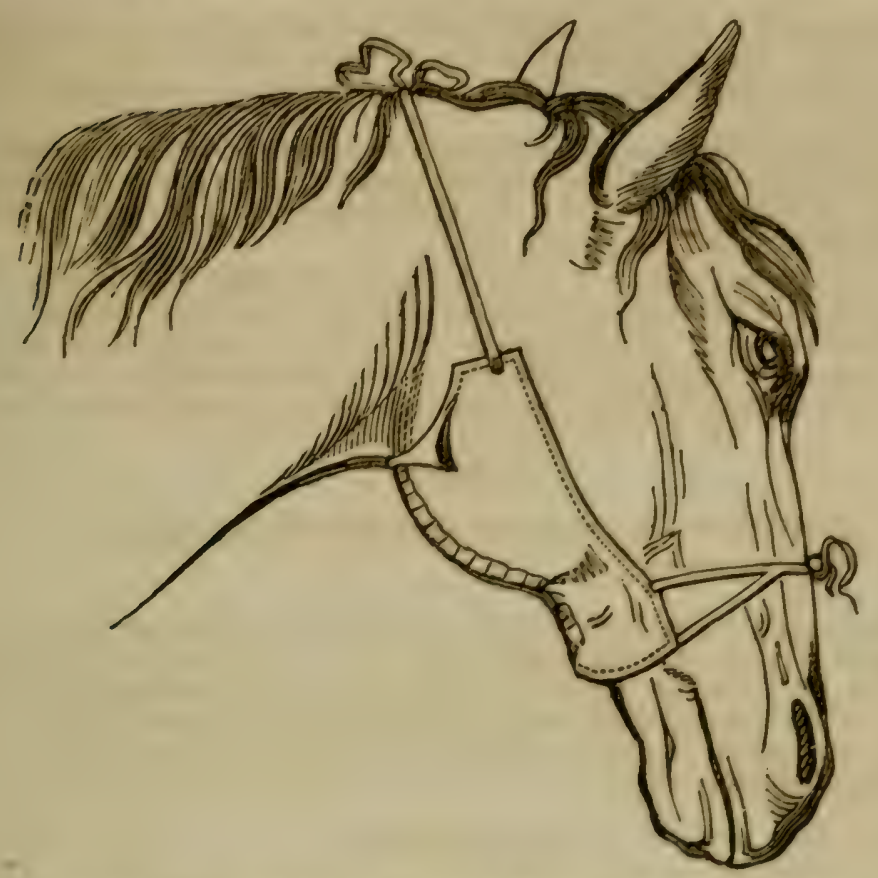

The suppuration may he further promoted by steaming the head over warm water, or fumigating it as follows: give him bran mashes frequently, placing the vessel that contains this, well securred, in another vessel larger than the first, into which much hotter water can be introduced, so that the vapour may rise up all round the mash, and constantly envelop the head. When the tumour is ascertained to be ripe, and not before, an opening is made at its most depending part, and the matter expressed gently; wash it off clean with warm water, and if the sore appear healihy, it will heal spontaneously, or witn the application of adhesive plaster.

Inoculation for the strangles has been recommended above and was partially practised. Alout 1802, M. La Fosse, the younger, mentioned the affair in his Manuel d' Hippiatrique, which book I translated into English the following year, and we hear that two or three country practitioners in England afterwards adopted the suggestion. The method was merely to scratch the inside of the nostril, and then smearing the sore with matter from the abscess of a diseased horse-it never failed. In careful hands the practice was feasille enough ; but great dangrer would accompany this imitation of variolous insculation, inasmuch as the matter might likewise convey a disposition to farcy or glanders.

Stranilas of tire gurtert. Sometimes we find those symptoms of strangles reduced to one only, viz. an obstinate running at the nose, which isually lasts a long while, and occasionally ends fatally, hy the animal wast. ing away in pulmunary consumption, as I am informed from good authority, ?ut never witnessed such a termination of this species of strangles, which La Fosse calls "strangles of the gullet." Many people mistake this disorcier for glanders, but it may be distinguished from that contagion by a rattling in tho gullet, whence its French narne; also hy the quality of the running, whici 
is neilher so white nor of so much consistency as the true sort; lut wate . and curdled. The animal goarcely ever is troubled with a cough, and then I is very feeble, but to make up for this exhibits frequent contractions of th larynx.

After the tumour is opened, give gentle physic, for which purpose the laxa tive ball recommended in page 132 will angwer every desirable purpose; a you may add thereto one drachm of emetic tartar, and give another ball aftes an interval of one day, unless the pulse is low.

BASTARD STRaciles is a favourite term with some persons, who would soften down the real fact of their horses having the glanders, which it really is, and not strangles. But bastard or not bastard, it is always infectious, and the animal either dies of strangulation, or the disorder becomes the glanders, producing a sanious discharge from the nose when the cough ceuses. Apply a

\section{Fumigation.}

Take the leaves and root of marsh-mallows, an arm-full. Water, 6 quarts.

Boil them, and fat the whole into a nose hag, and hang it round the head of the animal to make him inhale the steam. 'The bag may be made of stout cloth, but hung with the upper part quite open, to avoid suffocation. Leave the bag at the animal's nose until no more steam will arise. 'l'his will be found a very proper remedy in all cases of strangles, the lirst stage of glan. ders, and obstinate colds.

\section{GLANDERS.}

For about twenty years I apprehended that we had arrived within a short space of finding the true cause of glanders, and that we should then soon as certain the means of preventing vur hurses from engendering the malady, if we could not avoid their catching it, nor discover a specific remedy. But, lo! we were not yet agreed even as to the symptoms of true grlanders; as to that which was communicuble and dangerous, compared with another affection of the glands and pituitary membrane, which was but a tempurary disease, not easily communicated, and was asserted to come within the reach of the curative art. Most small proprietors, unwilling to destroy their afflicted horses, maintained that they belonged to the latter deseriftion, and in this they were frequently supported by the cupidity of practising farriers, who administered medicines and performed operations with a conficlence which never could belong to any department of science-and least of all to that of medicine, ${ }^{*}$ which is, alas! ever uncertain.

During this state of the question, we turned to the French veterinarians, who up to a certain periol enjoyed the reputation of being superior to all Europe besides in this and a few other pursuits [war and chemistry, videlicet],

\footnotetext{
- Much inhumanity was siown by the country practitioners in their mode of treatment. they scraped the bone after slitting the nosril; and also seared the swelled gland with a ho tron. A late writer applauls the practice of searing ulcers and abscesses, generally, "where. by (aclds he triumphantly) they are retuced to common scalds:" he was then speaking of the doctors in Moroceu I mere Turks. The gentleman, probably, did not distinguish between ab. sress and indolent tumour.

It is related by La Fosse, that in 1801, several recriments in Alsace and Loraine employed the actual cautery as a cure for g'andered horses. Some "applied tire to the jugular gland in threo lines; o.hers camterized the bones uf the lorehend and lose; but the inost ridictilous aftair of al! was, w see fory hoses cogecher which had fire applied round their cyelide io iure the run. oing," :inat is rommon to all glandular affections about the heal!
} 


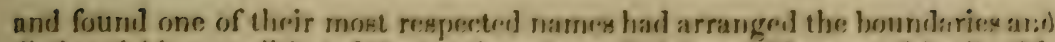
distinguishing gualities of the two into three divisions. "Nor was this all. $M$. La F"omes, the younger, who enjoyed the pout of "principal farrer to the Feneh army," and was withal a unesuler of the Institule, iusiated with much energy

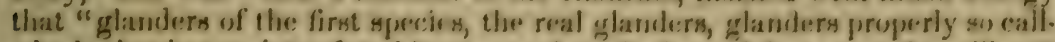
col, absolutely consints of mothing more than the less of the aense of monellinge," and is "a curable disorder, if triatod carly, tut incurable when confirmed." llie treatuent was very simple, and worthy of calu consideration, as are also the mears he propones for ascertaining hy the rympenss when it is a lumed is afflicted with communicable glanders, and oughit to be destroyed. It is in this latter respect that I reprint here the sulistanes of La Fosse's researches on this highly interesting sulject ; for, sisce none of us can offer a remedy that ought to be reliod upon-urnlese the animal be submitted to our neasures carlier than is usual* - I think a useful particle may los adelent to the ne.w stuty of mediral jurisprudence, by showing the line of demarcation that divides health amd contagion-the point at which destruction onght to commonce, by authority, or, in commen tumarity, to prevent the throghteses from imumolating the pros. perty of others, who are usually little proprietors.

I am the more determined in this course of proceeding, leceaues all my in. quiries on the subject are alreasly in print, and these coincile so noarly with the speculations and reasonings of two or there respectable writers now hefore the public, that 1 could add but a small portion of novelty to what has been su elaborately discussed by others. On all those points on which I differ from them, I shall offer a few practical observations, in the horpe of heing gerviceable, whilst I shall sedulousily avoil the "debateable land," which sorne contend for a little unamiably.

"So great has been the destruction of horaes which have either really leen, or reputed to be glandered, through the prejudice of ignorant persons, that it has been said, whoever can point out the distinction between the contriurica. ble disease and those which hrar some affinity to it, will confer a benefit on socicty, and serve the cause of humanity. Much labour had been bestowed on this subject by the elder La Fosse, who threw a great deal of light on a disease, which, of all others that attack the horse, is least known, ard there. fore most misrepresented."

What M. La foose groposes to show is, 1. "That it is ceasy to confound this disorder with others that resemble it, in some particulars. 2. That among the different sorts of glanders (so reputed), some are infectious, whilst there are others that are not 80 ; and 3 . 'That some of these are curable, and others incurable.

"There are few veterinary practitioners who do not know that strangles, bastard strangles, pursiveness, or asthma, and other pulmonary complaints, exhibit the same external appearance as the glanders, properly so called; con. sequently it is easy to be deceived on the subject, and the farrier will fat in his endeavours at a cure if he has not previously ascertained the distinguishing symptoms of the disorder. What then ought he to do in order not to be led into error, and to ascertain with precision that species of the disorde: with which the animal is affected?

"After much experience on the sulject of the diseases of horses, we are convinced that it is necessary to distinguish threes sorts of glanders, viz. The tirst sort, which is the glanders, the real glanders, the glanders properly so called; the second is nothing more than some disorder circulating in the rnass of blood; and the third may be denominated the farcy glanders. Gilanders

- From the nurotser of experiments which have lately beon mule at the Veterinary College

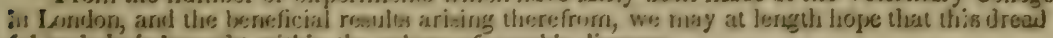
is malady is breught within the sphere of curable diseares 
of the first kind is not infectious, except it be complicated with other disorders 1 but thrs is seldom the case, though we may daily witness horses thus attacked abandoned as incurable, or with little more humanity put to death. On the contrary, glanclers of the second species is communicable, because the horse, besides rumning at the nose, and becoming glanderous, has likewise ulcers, and these ulcers appear to be the only proximate cause of contagion.

"The third species of glanders is in like manner contagious, because it not only occasions a running of the nose, but the tumefied glands and the cartilage of the nose are ulcerated, and likewise certain parts of the body are covered with lumps and ulcers, which latter characterise the farcy glanders, the most dangrerous disorder of the three, but not the most common. These two latter species of glanders are infectious, because the disease resides principally in the blood; but the glanders of the first species, the real glanders, the glanders properly so called, is not in anywise contagious, although it most frequently occurs.

"The second and third species are incurable, lut the last only is mortal. But as to grlanders of the first sort, it is neither incurable nor mortal. In the first place, we repeat, this disease is not mortal in any case, and a horse attacked by it is iu the same situation as a man who has lost the sense of smelling ; it is the loss of a sense, and the loss of a sense prevents neither the man nor the horse from fulfilling all the animal functions; for, as we daily observe men affected with ulcerated noses preserve an otherwise sound constitution, and even look jolly; so we may olserve a glandered horse preserve his strength and health.

"Secondly; it is incurable only when inveterately confirmed; but when taken in an early stage, its progress may be stopped with very little trouble.

"Thus we find that glanders of the first suecies, the real glanders, glanders properly so called, absolutely consists of nothing more than the loss of the sense of smelling. Its cure may be readily effected by frequent hleedings and fumigations. Hence may be estimated the little necessity there is for killing horses attacked by this disorder; and what important services may be rendered to society or to a regiment, for instance, by an intelligent farrier making a proper distinction between this species of glanders and all other affections and diseases resembling it."

So far M. La Fosse: his table, prefixed to the translation, "Veterinarian's Pocket Manual," is sold separately by the booksellers, and may be consulted with profit by those who would push further their inquiries respecting "true glanders."

Cause.-The glanders is a contagious disease only when it lias lasted for some time. Original glanders may be acyuired by horses being shut up close together, in hot, dampstables, in swampy situations-as in the case of the twenty-two cavalry horses adduced higher up (page 129), which were confined damp, under hatches, but were variously affected, according to the predisposing cause in the constitution of each individual. Those animals were improperly condemned, because the disorder had not continued long enough to render it contagious, and they might have recovered if treated as for a simple cold.

A sudden transition from cold air to a hot stable, as well as from heat to enld, will occasion a running at the nose; or a blow there, as well as a drench slumsily administered : either of those causes being foreknown, should render us chary of pronouncing the running contagious, and thus subject the proper. ty to itestruction, as propuscel. Almust any running, from whatever cause proreeding, or however healthy the previous state of the animal's system, causes ihe glands to enlarge and inflame: after a while, remaining un'ured, they ksually adhere to the bone, when alone we should pronounce the glanders cou 
firmed and incurable. This is "the second species" of La Fosse, which may be communicated by contact, or by respiring the same air, in the stable; though it does not appear until eight or ten days after the infection, in the enlargement of the gland, accompanied by running. The third species is caused by farcy being in the system, or loy inoculation, in which way the glanders is often communicated by experimentalists: the running at the nose and swelling of the glands are then symptomatic of farcy, and must be treated as such. What inference is to be drawn from all those premises, but that we should endeavour to ascertain the length of time the patient has been afflicted; whether he has received any external injury to cause it, or, has he been brought in contact with infected horses, and when? and out of the answers hereto we form the resolution of condemning the animal to solitary keeping, at the least; and setting about the remedies that are likely to restore him to health. Crowcled towns, posting stables and barracks, are most subject to contain glandered horses, on account of their closeness, and the frequent succession of inmates to which they are liable; for some horses will hear it for a good number of years, the discharge almost subsiding (though the swelling of the glands remains) upon changing to country quarters, or to a succession of regular living and regular work.

Symptoms. - No cough accompanies real glanders in any of its stages; and this though a negative piece of information, shall be taken as a good and positive criterion that must not be neglected: a running may make its appear ance, as it does at the left nostril usually, in the glanders, and the glands under the jaw may adhere to the bone, as they do in real glanders, but no cough accompanies these symptoms of glanders. When cough supervenes, the disease may be a catarrh, or a consumption, the asthma, or strangles, but these are not contagious, unless they last a long time, and adhesion of the glands takes place: in these last mentioned disorders the discharge commonly proceeds from both nostrils alike; whereas, the running in incipient glanders is chiefly confined to the left,* and the gland of one side only is then affected.

As the disorder proceeds, it affects both sides alike; ulcers appear all over the pituitary membrane, occasioned by the corrosive nature of the discharge. This assumes a different appearance as the constitution of the individual may have been more or less gross or vitiated; the appearance or quality of the discharge differs also, according to the manner in whicn the disease may have been acquired; i. e. whether it has been engendered or caught by infection. If it come of the first mentioned, through a depraved system, the glands are harder, often smaller, and always adhere closer, than in those cases which an derived from infection, at a time when the animal is otherwise in comparatively gond health. Again, with the infected horse, the matter comes off copiously; $i t$ is curdled, and may be rubbed to powder between the fingers when dried. It subsequently hardens, and becomes chalky when submitted to acids; whereas the animal that engenders the disease without receiving infection sends forth matter that is party-coloured, less in quantity, blackish, watery; and mixed with bloody and white mucus. Finally, if the animal that receives the disorder by infection be previously in a bad state of health, those symptoms are complicated and more intense, the ulcers are more numerous, the cartilages of the nuse become rotten, and the bones likewise in a short time: the creature seerns to have combined together the evils of its own system with that of the sufferer from whom he had received it. In both cases the swelled glands are simply hard tumours without any matter in them.

In addition to the preceding tokens for discovering at an early period the truo

- 1) eight hundred cases of glanders that come under the notice of M. Dupuy on'y one hor was affec'ed in the right nostril. 
glanders from another disorler, having some of the same symptoms, let the nostrils of the animal be examined, and the left or running nostril will be found of a deeper colour than ordinary, whilst the other or dry nostril is of a paler colour than ordinary, or almost white. At this period the discharge is a white glary fluid, and the maxillary gland of that side is hut just perceptible to the touch; but these being sympitoms that belong equally to a catarrh, it is best to be guided by the varied coluur of the two nostrils, remembering that in catarrh, or cold, both nostrils run.

It has been remarked by some, that when horses in a tolerable state of health first receive infection, they show mettle, and are full of freaks theretofore not experienced; as the disorider proceeds in its ravages, this mettlesomeness goes off; other acquired diseases have the same effects on all animals-the venereal, for example, on man.

The remedies that have been applied to the affleted aninal in this forlorn disease are found of no avail, unless taken at an early periou. As hath heen snid higher up, infection is not to he apprebended at first, and therefore the precaution some use to prevent its spreading, by bleeding and purging all the rest of the horses in that stable, is unnecessary, unless the animals require that process in other respects; but some practitioners must he doing sorne. thing, and some owners will not rest satisfied unless preventive measures be undertaken.

As soon as a horse is suspected of glanders, it should he kept separate from all others, and the fumigation of marsh-mallows applied, as prescribed at page 131, repeatedly; a purgative or an alterative ball may be given, according to the state of his body, and the usual remedies as for a catarrh, continued for a week or ten days. If the disorder does not lessen in this time, but the symptoms increase in virulence, the horse should be destroyed; but unfortunately for healthy animals, this measure is not compulsory, no statute existing upon the subject.* Besides which, disputes might arise as to the precise nature of the symptoms, and the executioner subject himself to heavy damages for his temerity. Something of this sort happened near Woburn, in Bedfordshire, early in the present century, to a lately deceased statesman. A neighbouring farmer having a horse in a state of confirmed glanders (in my opinion), persisted in keeping it in an old shed on the roadside : his obstinacy was highly provoking, and Mr. WV. the gentleman alluded to, went with his sørvant and shot the animal; at which the venal part of the periodical press set up a great clamour, from which none defended him, for the transaction was at variance with his public professions.

Stables that have been occupied by glandered horses retain a long time the taint, and the mears of communicating the disorder, which nothing will remove but washing with soap and sand, and scraping with sharp instruments, every part of the rack, manger, and all other parts that may have come in contact with the diseased horses. After examining the cases reported by various writers, particularly St. Bel, I have come to the conclusion that there is no analogy between glanders and the venereal disease, but the inoculation of sound animals; and that the exhibition of mercury in any form is utterly falla vious. One case, in which this mineral was employed with asserted success, at the Pancras Coilege, is proved unworthy of credit, by the failure of the same medicine in every succeeding attempt.

\footnotetext{
- The common law, however, s fully sufficient tu prevent improjer exposure of animals af. uic:od with a contagious disease in horse-matkets, fiairs, and other assembiages of cattle. $\Delta$ rase of this sort wiss $a^{-1}$ judged at Guildhall, Ioluibn, the fiuts whereof were detailed in she $A n$ nils of Sporting for March, 1526.
} 


\section{FARCY.}

Causcs.-General ill state of the blond, vulgarly, but most appropriately, termed "corruption of all the humours of the hody ;" and, by prevalence of he farcy buds in the course that the veins run, all over thesurface of the bidy, an doulit can exist that it resides in the blood. In fine, the original cause has been already defined at the head of this class of diseases, to which the reader who is fond of research would do well to turn back for a few minutes, at pages 129), \&c. However, infection is frequently the imnediate cause and (as olrserved of the glanders) the animal will be anlicted more or less severely, as his constitutional health nay he sound or otherwise at the time of receiving the infection. When this disease is engendered or created-which is easily supposed to have happened at first, and capable of being so produced at the present day, the blood being overcharged with offensive matters untit for its proper purpose, it hecomes stagnated at the lymphatics which follow the course of the veins (see Book I. page 30 ), and these corrole the parts, inflame, and appear on the surface in the form of "louds." And I should feel surprise if they do not also pervade the large glands of the viscera, though I have had no opportunity of examining: such tumours on the skin of mankind have heen foumd similarly seated on the inner surfaces, on dissection. "I foel all over as if pins were running into me, observed a patient; and so, poor fillow, he might, for on dissection I found the same sort of tumours even on the heart," said Mr. Abernethy in one of his lectures. As regards the horse, I take this upon credit, and by analogy for a while, purposing to satisfy myself more closely upon the first favourable opportunity that offers.

A predisposition to farcy must exist in the system, for it is cured by means of currectives of the blood; and its commexion with glanders has been proved, for the one will produce the other by inoculation : and without it running at the nose is one of the symptoms of farcy. $A$ certain inability to perform its office, termed "debility," that leaves the fincr vessets filled with the vital fluid, which exercise might have carried of -is one main cause of farcy; and a sudden check by cold after exercise stops at once the perspiration, and the blood that would stherwise be taken up, or absorded into the circulation, remains in lluse fine vessels, as aforesaid. Hot and crowded stables relax the vessels, and indeed the whole system, when sudden exposure to the air inflicts the same evil I have just now contemplated. The reader may recollect, that I refirred the cause of fever to the same want of ventilation, to the same exposure - 0 cold air, and made the r'mark, that the state of the animal's bodily health at the period of the atlack would deternine whether it should acquire this or that particular disease; the quantity and kind of cold, or chill, would also delermine whether the horse should be aflicted with inflammation of a certain part of his inside, or of his whole system, which we term fever.

Symptoms. - Though too well known to be nistaken, we yet may describe them, as, in the first place - skin tight and dry, for want of perspiration, as just said, when some swelling is perceivable about the hind legs, and on the insides particularly. This symptom increases to an extrenely large size in the course of a night, when the genial heat of the animal's system, and of the stable, appear to have matured the disease. The lymphatic vessels, and the more perfect glands, that run in the same direction as the veins, rise above the surface; and it is easy to be seen that they are sore when touched, the glands in particular, which feel hot, liglit, and hard at first, similarly to the glands of the throat, as described in the glanders. A few hours cunfirm the exact na turest the mischief: the inflammation of those glands proceeds, they herome sotter, and each throws out an ichorous, unbealthy discharge. 'They are then atrued furcy buds. The edges have a chancronts apuearance which it is 
fommd umpessible to heal with ointments. As the disease advances, a glanderous runing at the unse takes flace, with swelling about the nose, lips, and all over the body nearly.

According to the eonstifution of the horse at the time of receiving the infeetion, so will the procress of the disease be rapid and disastrous, or unacenutuhly slow and uncertain as to the result. In this latter case it retains its appetite, and bears up its strength for a considerable time.

Cure.- Three stages of the disorder present as many methods of cure: first, when the eflicts are slight or partial; secombl, when it resolves itself into large tumours, and a more conjous discharge from a smaller number of ulerers carrics ofl the disease: third, when it is contirmed, general, and diffused over the whole system.

In the first instance, when the glands only are aflected, it may le treated as a heal disorder, which has not yet found its way into the animal's system; and if appearing on one limb only, the natural inference is, that the system is indisposed to carry on the threatemed evil. 'l'his happens mostly to animals in erond condition, that are strome and vigorous, and of good habit of hody ; with such the farey is not brought on spontaneously, or by being engenderid in the animal, but has been acquired hy infecton. 'The limb atlected is generally so fo a goud extent, and the conded veins scareoly visilile; this happens mostly to a fore-leg (not always), and has heen considered of a dropsical natture, in a slight degree, or rather, lymphatic, the glands still continuing their functions. In this case give a purgative ball, and repeat it in three days after; but should the animal be a very theshy one, and full of condition, with full pulse, this may be preceled by blecding to the amount of three quarts, or four.

\section{Purgative Ball.}

Aloes, 8 drachms,

Castile soap, 1 drachm,

Liguorice powder sufficient to form tho hall for ono dose.

L'repare the animal with hran-mashes; let his drink be chilled, and he may be moved about, under shelter, with body clothing on that covers the affected limb. 'The linbl should he fomented with warm water, or the chamomile decovetion, taking care to rub the part dry, and wrap it up warm. 'This course ustally prevails against an ordinary attack of tirey, and the cure is aided when it afliets the fore-leg only, by a rowel inserted under the chest. But the absorption or taking up of the disorder into the system, and carrying it ofl hy stool, is by tar the neate'st manner of managing the cure; for this purpose give the following hall, after the animal has leeen reduced by the fore. going treatment.

\section{Alterative Ball.}

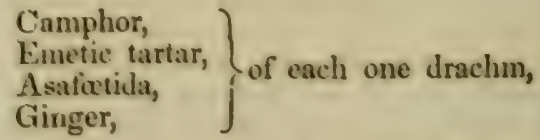

With mucilarge sufficient to form the ball for one dose. Give one of thesedor thee sucecssive nights; then stop one night between each dose, until the dos cuse is removed. 


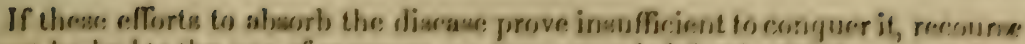

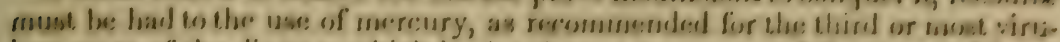

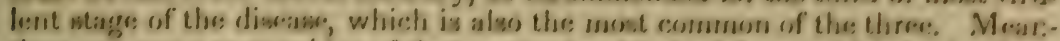
time, we conse to combider of that particular kiml of farry which is the leas comomon of all thres; and this is wherein thes cumoum are larger than usualiy happens, and smailer in number. 'The diasase then partakes sery much of

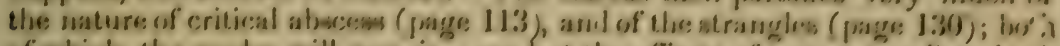
of whish, the reader will pereseive, are but the eflorts of nature tio relieve ito.jt of an accumulation of offensive matter; and, this recaping the cure is efficet.

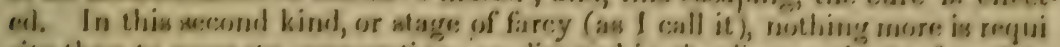
wite than to promote suppouration, as directed in the diasases just referred to, and follew it with the phasis: preserribed for the strangles.

'T'he third, most economon and virulent kind of farrey, that which cones on quickest, lants the longes, and requires the mont powerful moans for its re-

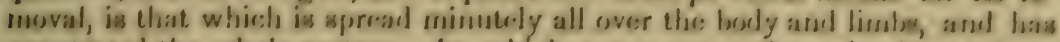
penetrated the whole system. In whichever manner the anional may lave ur.juired the disorder, wo may safely presune that the mases of humenro is lidesonaly depraves, and mercury, in one or other of its varied formo, is thos only antidute to be relied upon for ins extinetion. Previonsly, however, the farey buds and ulesers ment be reslured to the state of common acores, ling means of the actual cautery fresty appolied to each. When these slosugh off. am thes cores assume a healthy appearance, lowe of the mercurial preparation will be required; but if theae retain a livid and therefore unhealthy hue, accompariod by a proisonous dimeharge that ulcerates the acljacent parts, a tiverough courase of mereury is the only cortain remedy, and this muat be managed with caution.

\section{Mcrcurial Ballo-No. 1.}

Rethiop's mincral, 2 drachms,

Opium, 10 grainis,

Liquorice powder and mucilage to form the ball for ones dises:

Give twice a day, until the patient's breath srnells very offermive, arnd then disontinue the unedicine a day or two, as you shoukd also when the arrional is found to stale isordinately, or the buwels be very much disordered. But, when the bowels are only slighily affected, increase the quantity of opium to twernty or thirty grains.

\section{Mercurinl Ball-No. 2.}

Corrosive sublimate, 10 grains, Einetic tartis, half a drachm, Opium, half a drachm.

Mix, will liquorice powder and mucilage sufficient to form the ball for one dose. Give as hefore, at night and morning.

Feed the patient generously during the operation of this strong medicion, wath its progreses closely, and lewasen the quantity, or discontinue it altogeth $r$ " day or two when he is agitated greatly within, jarticularly if a kind of sick. ueses or gurgling he discernible, and the hore is of his appretite. Let him be clothed completely. Malt mashes, sodden corn, and conarne sugar mixed witl, his corn, dry, are good assiatants to the properer operation of mereury. Thint

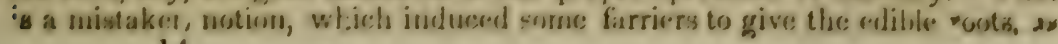


turnips, carrots, \&t. to the horse under a course of mercury. They war with its operation, and cause that very commotion in the bowels we should mosi sedulously avoid.

In recommending the free application of the actual cautery to the farcy huds, in the last page, I do but follow the common practice, being altogether the safest means in ordinary hands, who apply fire in many other cases, with much less reason than is done in that of farcy. Butter of antimony, or sulphate of copper, effects the same end, and has the recommendation of being used exclusively by the French veterinarians. What La Fosse says on this point is emphatic, and shows his opinion of the predisposing cause of farcy: "Do not apply fire in any manner to lumps produced by farcy, under an idea of stopping the disorder. The disease being in the blood, treat it accordingly, and as for the lumps, cut them off: apply lue stone, dissolved in water." When he forefends the "idea of stopping the disorder," doubtless in saying this he only allows that to be the true farcy, which I have considered as the third stage, or confirmed kind. But the earlier or milder stages, which would ultimately end in the third or most virulent kind, if not stopped, being occasioned by the cessation of the lymphatic function - when the attendant glands refuse to communicate with the system (the blood, ) can not have yet carried the consequence of that stoppage into the blond. In making this remark, I have not overlooked what was said of the practice in Morocco at a preceding page, 135, note.

\section{ANTICOR}

Is more prevalent in France than in this country, and is so named from its position, anti against, and cor the heart. The French words ante-cocur have the same meaning, and are derived from the same origin. It consists in an inflamed swelling of the breast near the heart, and the name is extended to any other swelling from this part back under the belly, even unto the sheath, which also swells: in this event anticor is decidedly dropsical.

Cause.-Full feeding without sufficient exercise, similarly to this whole train of disorders which I have been just above considering. Hard riding or iriving, and subsequent exposure to the elements, or giving cold water to ani mals that are very fleshy in the forehand, as is the case with the greater part of French horses; these, combined with a vitiated state of the blood, which is then sizy, produce those extended swellings that partake somewhat of the nature of swelled limb in grease, and yet terminate in abscess when the case is a bud one.

Symptoms.-An enlargement of the breast, which sometimes extemls upwards to the throat, and threatens suffocation. The animal appears stiff about the neck, looks dull and drnoping, refuses his food, and trembles or shivers with the inflammation, which may be felt. Pulse dull and uneven. By pressing two or more fingers alternately, the existence of matter, or a disposition to suppurate, may be ascertained (as in poll-evil) by its receding from side to side as the pressure is withdrawn. On the other hand, if the disease owes it: origin to dropsy, each pressure of the finger will remain pitted a few seconds after the finger is withdrawn. Consult "Poll-evil" in its two stages.

Cure. - As in other cases of timour, that do not partake of critical abscess ufter fever, \&c., this disorder admits of being repressed, readily, by the means before prescribed, or of heing otherwise cured, as it may be allied to some disoruer of the constitution. To repress the swelling, bleed the patient copiously; give purgatives and clyster him; give bran mashes, and let the chill be taken off his water. Foment the throat and breast with bran mash or marshmallows. every four or five hours; and when these have reduced the sympicm, give as 


\section{Allerative Ball.}

Emetic tartar, 2 drachms,

Venice turpentine, half an ounce.

Mix with liquorice powder enough to make the ball for one dose. Give one every eight-and-forty hours. On the contrary, if the swelling depend upon dropsy, as aforesaid, let a fleam or horse lancet he struck into the skin at four or five places distant from each other, and in the lowest or most depending part of the sivelling. From these punctures a watery discharge will take place, that relieves the patient of his affliction hourly, and the issue of matter is to be prometed by keeping open the sores as directed in the case of fistula, \&c. at page 119: again, when the swelling indicates the collection of morbid matter, let it lo fomentel, poulticed, and opened as directed in cases of critical alscess, in poll-evil, fistula, \&c.: the whole scries of these diseases are of the same nature, but differing principally as to situation, which sometimes affects the disease mainly. In this case, for example, the swelling sometimes ascends along the throat, and goes nigh to chuke the patient: receurse must be harl immediately to poultices, and let these be changed twice a day. 'T'he modes of bandaging may be learned by consulting those I have given sketches of, in other cases, at page $79,8 \mathrm{c}$.

\section{GREASE。}

Causes. - This is another of the diseases that take their rise in a tardy circulation of the blood, and consequent indisposition to take up and carry back again to the heart that which has been sent into the extremities for their nourishment and renovation. In Book I. at bottom of section 44, this process of taking up, or absorption, is spoken of, whilst the few pages that are there bestowed on the manner in which the circulation is carried on, show the importance of this function, and point out the principles that should guide us in promoting it, when aught has occurred to retard its action. When great age and consequent lethargic habils cause the blood to circulate slowly, our art can but ill supply the remedy, though the evil may certainly be alleviated by stimulants. A small portion of beans given to aged horses admirably assists the circulation of the blood, especially towards the heels, whilst this very species of food given to young horses will promote humours of the hind legs in particular, where grease is mostly situate. 'That is to say, at the part of the animal that is rennotest from the heart is the effect of a slow circulation most frequently recurring, and to heavy fleshy cart horses oftener than to those that are lighter and freer from flesh about the hecls.

Trimming the heels of the hair, which was intended to keep them warm in winter, is a very prolific source of grease. Thorough-bred horses never incur this disorder, so far as I can learn; and the chances in favour of those which are produced by crosses from blood stock, is in proportion to the amount of their breeding,

A cold in the heels is caught by walking the horses through water whilst they are hot: or beir,g put into the stable with wet feet at nights; or lying in a stable that imperfectly keeps out the wind; all conduce to that stagnation of the blood, or tardy performance of its function, that causes the animal to generate this disease. They term it debility, but I think we had hetter say "want of ability," or of vigour to drive on the circulation of the bloud; so that if the bhod thit is left behind in the fine capillary vessels be ever so good and proper fur its purpose at first, yet the very circumstance of its remaining idle sanses an inflammatory heat, that attracts towards itself all such congenia' 
farticles of the blood which may have been sent through the arteries to the part for the propagation of new horn, or the supply of marrow- of the nnture whereof the matter partakes. Indeed, I have very little doubt that the marrow is concerned in the production of grease; for I have successively examined twenty legs which were affected with grease at the time life was exting ished, and the marrow was invariably confined to the lower part only, as if it were fallen down there for want of vigour, whilst the upper part of the bone was hollow, in every instance : healthy leg bones are alivays full to the top of each. and I have reason for thinking that this is the case with all debilitated horses. Again, the glutinous substance that pervades the surface of the coffin-bone, and to which 1 have attributed the formation of new horny matter of the hoof, is always found scanty in greasy-healed subjects. See my observations on the foot in the next chapter.

One of those legs parted from the knee, having the skin removed, but otherwise untouched, was hung up in the yard whilst the sun was at 70 degrees (July, 1825). In three or four days the grease might be seen to give a colour to the lewer part at the fetlock joint, and every day the greasy nature of the colour was evident to touch and smell, whilst the articulation of the large mastern and sesamoid bones remained unaffected in either way. Upon lreaking the bones nine months afterwards, the marrow had all escaped without a puncture, i. e. through the bone.

The following ingenious suggestion I find among much voluminous Veterinary Memoranda, but whether it he my own, or I owe it to some friend, I have no means at hand for ascertaining, nor does my recollection serve me sufficiently to say who. "Horses with one or two white feet are more liable to the grease in the feet that are white than in the others; and if the pr-position be true that white feet are weak ones, we come to the same conclusion, that the want of colour having occurred through want of vigour in the part: then weakness and grease have the same cause."

Symptoms. - First perceptible by a swelling at the heels, mostly of the hind legs. This is occasioned by local inflammation, and is soon followed by a slight issue of greasy matter, whence the name; but it is sometimes more watery, ichorous, and offensive, which will depend principally on the constitutional health of the patient. The swelling sometimes extends much higher than the fetlock joint, even towards the hough, and occasions stiffiess of the limb and indisposition to move. He can not lie down, by reason of the unbending nature of his joints, and therefore stands to sleep, which renders the disorder more virulent by the accession of fresh matter to the part; the skin cracks at various places, and ulceration ensues. The hair sticks out like furze, the discharge is darker than originally, is thin, acrid, corroding, and stinking.

Remedy. - The grease is one of those disorders about which we should employ our ingenuity in prevention rather than the cure; and this indeed is the case with nearly all the diseases that depend upon constitutional defectiveness, or rather inability of some of the organs of life to perform aright the functions of nature. How these ought to act I have spoken at large in the second chapter of hook the first; and pointed out the free circulation of the blowd as the principal cause of healthi, as would also the want of a (rin) circulation prowe the harbinger of disease. Now this affair of grease lwing pro. duced entirely by such inactivity, it seems clear that exercise would be the best preventive of it; and the horse-keeper should also keep the heels dry after work is over, and hand-rub him \& little with as much industry as he can afford. HIe should also let the hair remain on the heels of his heavy horses, and give to the large ones suficient depth of stall and bed, so as to prevent such from hrowing their long ags half way out in the stable (as too often happens) upois stoc cold thuor, of winter nights. 
In slight attacks, a wash made of a solution of alum, as under, will correct the disposition to grease, and a dose of physic set all to rights in a short time; both, however, regulated according to circumstances. When considering these, we should inquire into the preceding habits of the patient, as to his usual evacuations, and whether these have been stopped; for it frequently happens that grease is caused ly the suspension of the urine balls, to which. many proprietors are so very much addicted, that they give them without reason, or suspend the giving through the same whimsicality. In this latter case give the diuretic powder, and the horse will require very little more physic. Again, if the animal require opening physic, give him the purging ball as uniler, and in-door exercise; but should his debility be then very great, the commotion this would occasion might reduce him too much, and therefore, the alterative ball will do better, with the same attention to in-door exercises if he can hear it. Sometimes, however, the heels are so cracked and chapped, that every step the animal takes only makes the matter worse; we should then assiduously apply ourselves to keeping the heels clean, with water of which the chill has been taken off, and with a hrush get rid of as much of the running as possible; and after drying it well with cloths, use the alum wash of the stronger preparation; provided always the inflammation be not too high at the time, but which the warm water without the alum wash has a tendency to alleviate.

I will now set down the several articles just recommended above, premising this much as an apology for the numerous recipes here prescribed, that the grease requires we should be always doing a something for the animal, either of topical application, or in devising the means of carrying off the cause of the disorder by stool, by urine, or by perspiration. For, by keeping one or other of these evacuations a-going, we enable the animal system, to take up, or atr. sorb (as before described) the watery particles of the lymphatics, which re maining indolent constitute the disease.

\title{
Alum Wash.-No. 1.*
}

Alum, 2 ounces,

Biue stone, 2 drachms,

Water, 1 pint.

Mix and wash the part two or three times a day.

\author{
Strong Alum Wash.-No.2. \\ Alum \\ Sugar of lead, $\{$ of each 2 ounces,
Vinerar, \\ Water, 1 pint. Mix and use as before. \\ Strongest, or Mercurial Wush.-No. 3.
}

Corrosive sublimate, 2 drachms,

Muriatic acid, 4 arachms,

Water, 1 pint.

Mix and apply in inveterate cases.

- Inscoari of this, the following is preferred by some persone, and those good judgat we 
Diuretic Altcrativc Porter.

Nitre,
Powdered resin, of each 2 ounces.

Mix, and give in four doses, of mornings. To be contsaned until its effects are visible.

$$
\text { Purging Balls. }
$$

Alves, 9 drachms,

Hard soap, 3 drachms,

Ginger, 1 drachm.

Mix with mucilage sufficient to form the ball for one dose.

\section{The Alterative Bal!.}

Aloes, 6 drachms,

Hard soap, 8 drachms,

Ginger, 3 drachms.

Mix with mucilage sufficient to form the mass, and divide it into four balls.

Give one every morning until the bowels are opened sufficiently.

The perspiration must be promoted by the following

\section{Diuphoretic Ball.}

Einetic tartar, 2 drachms,

Venice turpentine, 4 drachms.

Mix well, with liquorice powder sufficient to form the ball into one dose; ani give every other night for a week or ten days, taking care to clothe the patient, or put a rug on his body at least, regulating his sweats according to the weather. Some persons do not think it too much trouble to divide the foregoing lall into two parts, and give one every night for the periods just mentioned, which would bring the whole quantity of einetic tartar to the same amount in the end. Becarcful to buy it genuine; and if the horse be taken care of while in his sweats, it will mainly contribute to his getting well. The patient is not to have this sweating ball whilst he has other physic in him; but it may be given alternately with the foregoing powder of nitre and resin ; and is better administered thus, when it happens that the individual requires to be set a staling, and we thirk best to sweat him at the same time. If the medicine makes his bowels grumble, add to the ball

\section{Opium, half a drachm,}

which some do pur into the prescription, whether or no. But then the opium having a tendency to bind the body, it counteracts our labour in this respect, and is not desirablc in case the animal requires opening physic.

Regimen.-A good generous feeding should be allowed, with a few beans for the elder patients only; and in all cases where the disorder has lasted a long wiale and the cure is effected with difficulty, a rur at grass is greatly conducive to compilete recovery; especially if the convalescent can be allowed the othion of a field, or covered shed, lying high and dry, or the advantages of the nomestead, with an allowance of corn and hay. This change of regi men is greatly assistant of absorption when the physicking has ceased, espe 
cially where the disorder has terminated with a tedious ulceration which causes lameness, on which event he should not be exercised; hut let the parts be poulticed with a turnip poultice, or it may be made of oatmeal and the grounds of stale beer, or both may be employed alternately ; and then the parts, if luxuriant or thick, may be washed with a solution of blue vitriol in water, or the wash, No. 3. Dress the cracks with the following

\section{Ointment.}

Oil of turpentine, 3 drachms, Hog's lard, 6 ounces,

Litharge water, half an ounce. Mix.

This may be varied by substituting Venice turpentine, half the quantity of the oil. In these inveterate cases we have now under consideration, a change of medicine is desirable, if but for the change which it occasions in the animal's digestive powers; for this purpose the blue pill has heen given as an alterative, as well as that other preparation of mercury, the well-known crilomel. Both act upon the kidneys, and set them in motion for the production of urine; $₹$ nd calomel chiefly effects this, by previously stimulating the liver, which again is very desirable by way of change.

\section{Alterative Balls.}

Calomel, 1 1-2 drachms,

Aloes, 3 drachms,

Castile soap, 6 drachms,

Oil of juniper, 40 drops.

Mix ; make into three balls and give one daily for a week; but should it gripe the animal, discontinue it, or add upium from half a drachm to a drachm.

\section{SURFEIT-MANGE.}

Both of these diseases of the animal's system, and the first-mentioned proves its connexion with the second by sometimes ending in the mange. Overfeeding, or too much of it, or gross feeding, as it is the cause of these twin diseases, so are the two appeliations it receives in the different stages of the attack descriptive of the cause : both are of French origin, as I apprehend; surfait or overdone, being tantamount to mange, in its imperfect tenses, the effect of eating too much, which has brought on the disease. A surfeit, or sur-fait, is not an uncommon disease with reasonable man, and is alike caused hy eating improperly, if not too much, and scmetimes from the preparation of viands that are over-luxurious for the stomach that is to receive it, and is in fact incapable of digesting it. This is a state of the stomach that is by no means uncommon, and up to a certain extent happens every day to the full feeders of every genus of created beings. If, during this full and over-replen ished state of the alimentary canal, and its then active state of lactification (o making of new blood), a sudden check be put upon the said process, by dririk ing cold water for example, what happens but the rapid propulsion of some part of the blood through the arteries, whilst the mouths of the offended lar teals close up for a period, and the blood, already filling the capillary vessels ot the surface, becomes extremely irritable? Perspiration ceases; the lympha tics refuse to yerform their oflice of absorption, and the blood so deposited iri a due course of nature, forms innumerable small tumours under the skin, or hecome scaloby, and throw off a dry scurf. The first has received the appro 
priate name of surfeit, the secord is the more hathed riange, both having im one common origin. They are of the class of tuhercular diseases, spoken of by M. Dupuy yuoted higher up (as partaking of glanders, $f(c)$ ), are akin te grease, and to other accessions of matter on the surface, dibtering only as $f^{\prime}$ situation, and like the grease, require that we should promote ahsorption am. the application of repellants.

The cause of surfeit is thus distinctly met by the means of cure. The symptoms, however, frequently announce the disorder that has taken place within but a few minutes ere they subside again, to the utter surprise of all theholers. On such occasions mischief is supposed to lie in wait, and it is generally understood that the pustules, or tumours, only retreat from the skin w) infest some more vital internal organ; but I always considered that such an attack had subsided through its own weakness, for nothing ever came of it after thus retreating spontaneously. Like surfeit in man, these tumours aro attended with a pricking pain, the animal appearing restless, flinching from the touch, and looking round sharp at his legs and sides as if he were spurred trivially. Whenever he can bring the parts to bear against the stall, the bail, or the wall, the animal will rub violently, until the hair comes off, and the skin is raw. Instead of tumours that emit a sharp, acrid, and stinking humour, like grease, a dry seurf appears, resembling scabs, and this is mange in some animals: whilst other suljects exhibit no eruption whaterer, thougherery hair is affected in a small degree, the skin hecomes dry, and he is then hidebound.

Cure.-Surfeit is easily removed by a cooling purgative ; but if the pulse be high, he should be bled also. Promote perspiration by means of the diaphoretie ball recommended at page 146 , with the same precautions as are there set down. If the animal be lat, he must be reduced; give bran mashes, sodden oats, and good exercise; and should moisture be found to discharge from the skin, wash it with the

\section{Surfeit Wash.}

Blue vitriol, 1 ounce,

Camphor, half an ounce,

Spirits of wine, 2 ounces.

Mix in a quart bottle, and fill it with water. Wash with soapy water warm (as in grease), rub dry, and apply the alove wash once a day, and at the sams time give one of the diaphoretic balls, as above. Let the diet be cool and opening, as scalded bran, sodden oats, or barley : and if the horse is low in flesh, mix an ounce of fenugreek seeds with his corn daily for a fortnight at leasi.

\section{THE MANGE}

Sometimes succeds an ill-cured surfeit ; and is morcover an original disease, arising from filthiness, hard living, ill-usage, and the concequent depraved state of the system. It partakes of the nature of itch in ma, is communica. ble by means of the touch, by using the same harness, cloth Ig, \&c. and probably by standing in the same stall as a diseased horse may have left.

The symptoms are stated in the preceling pages, and from its cause we may rest assured never attacks horses in condition. As in surfeit, the horse is constantly rubbing and biting himself: great patches of the coat are thus rubbed away, and ulceration frequentiy supplies the places. Scabs appear at the roots of the hair of mane and tail; large portions whereof fall away. When eruptions appear, they form a scurf, which peels off, and it is sacceeded by fresh eruptions. 
The cure is to be effected hy topical applications of sulphur, and giving the aarne internally as an alterative; lout mercurials are mostly preferred hy cour moderns; and there is not such a variety of opinions and prescriptions at this

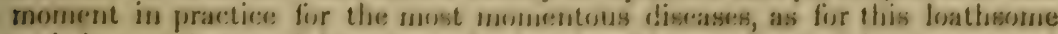
malady: negleet and innorance having lirought on the evil, ignorance and stupidity engage to efliert the cure. I shall suljoin a few forms of those which are in most repute, and have been found effectual: even alteration is frequently foumd hencficial, though it may not at first secen to nave been for the best.

\section{Mange Oinlment.}

Prepared hog's lard, 2 pounds,

Sulphur vivum, 1 pound,

White hellebore, in powder, 6 ounces.

Mix with vil of turpentine sufficient to make a soft vintment, rub the animal wherever the eruption and scurf appear, with hair clotlis, or a new beson, so as to get rid of the loose filth hefore applying the sintment. Rub it in well every other day, and give the following

\section{Alterative for the Mange.-No. 1.}

'Tartarized antimony, 1 ounce, Muriate of quicksilver, 2 drachms, Aringer and Arise seeds, $\{$ prowdered, of each 3 ounces.

Mix, with mucilage sufficiont to form the mass ; divide it into six balls, and give ore every morning until the eruption disajprears.

$$
\text { Alterative for Mange.-No. } 2 .
$$

Antimony in fine powder, 8 ounces, Grains of Paradise, 3 ounces.

Mix, and add Venice turpentine to form the mase which divide into twelve balls. Give one daily whilst the rubbing is contin ad.

\section{HIDE-BOUND.}

The cause of hide-bound is commonly the same as that which produced the ast-mentioned disease, viz. poverty, only that the prorticular animals may not both be in the same state of general health, and the more depraved would incur mange, whilst anotlier would breome simply hide-fround. This is lems of an original dissase than the effect of some other, and of bad digestion and cons. serquent defective perspiration beyond all others, as may he inferred from what I have sail concerning the irtimacy that exists between those two operations of the anirmal systron in my srecond chapter of hook 1, at pages $23-25$. The justne-s of this view of the cause of hide-hound was further proved by a series of dissertions of this particular unalady undertaken by me in May 1820). I invariably found tumours had formed upon the larger lacteal vesir:ls of the peritrnasum, on the gut, or the like kind of attack in the volsura that covere the lungss. The formation of those tumours was no joubt the rnediate cause of hide-hound, and had been brought on (I have evezy seagon for believing) by 
the inordinate use of diaphoretics, the stimulating nature whereof, as is usual in all such cases, had thus defeated itself.

Horses that are so affected with tumours, are they which become distressed ensily, though in good apparent health, upon being pushed on a journey, or at a heavy drag, particularly when the helly is distended. Thus the cause of hirle-bound exists long before we can perceive it, and is the reason why I recomm 2 d the arsenical preparation hereafter prescribed, as a tonic, previous to administering the sweating remedies. The appearance of hide-bound is frequently ascribed to the worms, botts, \&c.; but in all those sulyjects examin. ed by me, amounting to half a score or more (for I kept no notes), no worms were to be found of any consequence, for it would be ridiculous to talk of two or three such stray insects occasioning such an extensive disorder, so remote rom the seat of their supposed ravages. What is very well worth remarking though such a thing is not very singular) is, that the writer who has most ustily cried out "Worms, worms!" upon every occasion of disordered skin and staring coat, has recently suggested that after all, worms are necessary to the horse's digestion: and the gentleman seems to think that these insects act upon the horse's stomach much in the same manner as pepper on that of mankind! Thus he hlows hot and cold with the same breath, or rather worms and pepper with the same pen; for, whilst the worms are so laucled in one volume of his works, the malediction remains uncorrected in the other.

Symptoms.-As the word implies, the hide or skin seems bound or glued to the bones; the animal is always very low in flesh, or we might aver that the skin adhered to the flesh. The pulse is low, and great weakness is mani fest in every step the patient takes. As the tightness is first observable at the sides of the animal's body, before it reaches the limbs, and every hide-bound sulject examined by me proves the fact, I have no hesitation in ascribing hide bound to disordered digestion, which includes the negation of wherewithal to digest, or starvation and hard work. Again, one of two extremes attends the howels: they are either relaxed greatly, or much constipated-usually the former; which may be the effect of a long fit of illness from inflammation or fever, and the use of strong medicine, or much of it.

Cure the animal by the direct contrary conduct to that which brought on the illness. If its stomach be empty, as commonly happens, fill it nearly with food that is easy of digestion; if it be too full, empty it; give alterative laxatives and tonic alteratives afterwards; restore the perspiration by the diaphoretic ball recommended at page 146 , and let the curry-comb and brush be assiduously applied to his coat. He may then be exercised, but not before, as it is nearly impossible without inflicting great pain. Besides which, forced exerrise, or sweating, as hath been strongly recommended, would in this case only aggravate the disease; for if the animal did sweat, it would be caused by internal pain; probably the tubercles which had formed upon the membrane would suppurate and burst, and thus confirm the disorder internally by the inflammation of the particular viscus where the disorder began.

\section{Alterative Laxative.}

Aloes, 8 drachms, Hard suap, 7 drachms, Anise sceds, powdered, 1 oz.

Mix with mucilage sufficient to form the mass into four balls. Give day after day until they effect the purpose of bringing away a good stool. Then zive the arsenical tonic alterative, thus proportioned for a large horse, witt care. 
T'onic.-No. 1.

Prepared arsenic, 10 grains, Ginger powdered, 1 drachm, Anise seeds, powdered, 4 drachms, Compound powder of tragacarth, $2 \mathrm{dr}$.

Mix with mucilage sufficient for one dose. Give daily for a week, preceded and followed by mashes, and then give the bark, thus:

Tonic.-No. 2.

Cascarilla, potvdered, 4 ounces.

Ginger, 8 drachms,

Salt of tartar, 10 grains.

Mix with mucilage sufficient to form the mass into four balls; give them daily. If the preparation of arsenic in No. 1 is disliked, substitute the alterative ball at page 147 , and follow it up with the bark as above (No. 2).

The following ball is calculated to improve the coat, and will be found beneficial when the animal is recovering, if given in these proportions fur ten days or a fortnight.

\section{Alterative Balls.}

Tartarized antirnony, 3 ounces,

Powdered ginger, 2 ounces,

Opium, 5 drachns.

Mix with mucilage sufficient to form the mass, to be divided into ten balls.

\section{WORMS.}

As remarked in a preceding page, 150 , so many other disorders, exterual as well as internal, have been charged to the existence of worms in the intes. tinal canal by veterinary writers, that we find much diffieulty in persuading ourselves that this is not the precise ailment which aftlicts the animal when his coat becomes staring, and his skin sticks to his ribs. Most frequently, however, that ugly appearance which denotes hide-bound, and other similat symptoms that depend upon suspended perspiration, arise from tubercular diseases of the mesenteric canal (see page 46), and not within the gut or stomach; for the excess or the suspension of perspirable matter must alike depend upon Eomewhat of a more general affection than worms, that fasten on this or that part of the stomach or intestine (as we are told), and can only influence the part they immediately occupy. Unfortunately, we know of no specific cure for worms, the remedies that are usually prescribed being of a hot, burning. and destructive nature, that are as likely to injure the intestine as the worna, it becomes our primary duty, therefore, to ascertain when the disorder be really the worms, so as to prescribe the proper remedy when we have ascertained that the fact is so. It is very easy to say a horse "has the worins," and to give him worm medicine; but much more difficult to ascertain the real fact, than to remove it when well authenticated. Our inquiries, then, shouid be directed towards this pont as much as to any other unsettled question-the pxistence and quality of true glanders, for example; and vet more fine learn 


\section{CALELS AKI DININGUISHING SLMITOMS. NATURAL REMENES.}

ingr has been hestuwed 1 hon the uncertain linowledge of hotts and other werms than has altrated the atlention of our veterinatry writers to any other portion of their labours.

Concses.- Imbigestion and consequent stoppage of the alment in the stomach and coetum; which again may be oncasioned by bad corn, musty hay, or hay male from rank grasses, - if all hay whatever does not contain the means of gremerating inseits, when used without suflecient water; also, when either substance be swallowed, as often happens, without being properly mas tieated, through woaring away of the treth (see pare 17), the lampera, No. Much pampering of the appetite, by dealers and others, to produce fine coats by means of stimulants, as egres, wine, ale, hread, diapente, linsed, dee; when the eflects thereof are worn away, these leave the lacteals (see pagre 4\%), impaired or offended at heing deprived of a short-lived energy. The articles just enumerated form indigestible crmblities that become the appropriate nidus or generating worms in the canal so deprived of its matural functions by artifitial means. Consult anain what is satil at the conclusion of the first book, at page $\$ 1$, sc. Irregular fioding also tends to the lodgment of erulities in the caecum, or second stomach.

Symptoms. - A staring evat, with emaciatlon and weakness, were formerly derened sufficient indications of the existence of worms to warrant the doctor in pouring into the animal his monstrous mixtures; for a worm eatse was esteemed by the professor like a little anmuity, pro tem. 'Those symptems, however, are at first rather the presage than the concomitants of worms ; since they are also symptomatic of several other internal diseases, some of them produeing worms in the sequel, whilst other some are found still more rapidly destructive of life than worms are, and therefore demand more immediate con. sideration. Slight aflection of the lungs, as well as of the liver, heing of long continuance, oceasion partial roughness of the hair, and slight hide-hound of the interuments nearest the se:at of disorder, that spreads progressively all over. The cough which accomplanies severe attacks of the worms differs from cold in the organs of respiration; the first being more deep and cavernous, leaving a shake or vibrating heave of the thanks, whilst the former comes off vith a wheeze, as if not fiched from so deep a recess.

As the disorder proceeds, and the worms may be supposed to extend thei, ravages, the patient's appetite is suljeet toextrime variation; he heing some times ravenous after fond, at others not caring to eat at all; which show's that the stomach is affected, and is frequently succeeded by vertigo, or statergers. A horse with worms that give him uneasiness in the bowels will leave ofl eating sometimes for two or three minutes, when a cavernous rattle may be heard coming from his inside, and he resumes his feeding. If he condeavours to kick his belly, it has been construed by the worm adrocates into the pain occasioned ly worms gnawing his howels; but neither symptom is an invarialule indieation of worms, for he doe's the same when attacked by any other pain of the belly-whether colic, tight girth, injury of the sheath, fe. When the worms appear coming away spontaneously, with successive stools, no matter of which kind, it aflords prouf that the animal has taken grass or hay that cone tains grasses of an anthelmintic property, and points out the propriety of conlinumg him on the same food.

A yellowish ordure appearing about the fundament something like flour of sulphur, shows the death of a good number of small worms (ascarides) has tren oceasioned by some such natural means as the preceding. Some iverms come away as soin as grenerated in the aliment, but if no other sign of their existence is manifest, the solitary fact should excie no uneasiness. WV hen botts, having been detached by similar natural means, leave the stomach-where they do not always cause inconvenience, we find them adhering to the large intes- 
snes and rectum, to which they adliere and cause the animal to rub his breech against the wall or upright of the stall. Should those symptorns continue, and the generating of worms remain urschecked, the horse falls into profuse sweats on the least exertion, and when these cease, lee exhibits a weak and languishing condition, scarcely notices a brisk application of the whip, his skin adheres to his ribs and flanks-hide-bound has commenced. Cough more or less hecLic according to his remaining strength, accompanies hin to his end; for, as to a cure being practicable when hide-bound arising from such a cause has fairly laid hold of him, 'tis clean out of the question.

Regimen.- As the commencement of this disoriler is mainly attributalile to the coarseness of che animal's fond and consequent incapacity of its guts to cxpel the hardened materials, so will an entire change in the mode of feedug him (o) more towards effecting a cure than all the medicine we can prescritie, and all that the most liberal band would iestow. I thisk it would be ton much to expect that generous treatment alone should effect a cure of itself, but 1 certainly have known worms voided after a fe-w days' casual good keep; and in these cases I apprehend we may attribute the corning away to the change or alteration that was so effected in the state of the patient's bowels. Hence the propriety of any change of his usual diet. as well as the advantages of alterative medicines. In the first ylace, try a run at grass, or give green food in-donrs, or succulent and agreeable vegetables. If poor living has not been the original cause, some defect in confurmation has; and the above change, with plenty of water-gruel, bran mashes, briled protatres, bruised corn, and the like, by 'ubricating the parts, may detach the worm, or at least assist the medicine, which ought to have the same tendency.

Cure. - Since the worms are not always to be killed even by strong poisons, nor brought away by hrisk purgatives, for a certainty, but are frequently discharged in a few days by an alteratise regimen, reason dictates and nature beckons us to follow her course, in affirding to the horse which can not be spared from work, or a run at grass the olitained, to adopt the means nearest thereto that lie within our reach. Laxative alterative nedicines then obtrude themselves upon our notice, and in all cases are found to do good, more or less as they may he adiressed to the actual seat of the disorder: in pills, if the worms lie in the intestines; in puwilers or liquid, if they occupy the stomach -in all forms alternately when we are uncertain. The various preparations of mercury and of antimony, with Barbaloes aloes, as being more drastic in operation; also common salt, box, sulphur, savin (a vegetable poison), and sal Indicus, offer a sufficient varivty for tlie bases of as many varied prescriptions; and variation here is most desirable, inasmuch as some kind of worms which resist the effects of one sulwance nay be defached and hurried off by another.

Water-gruel, as it relaxes the parts, and prepares them and the worm for receiving the antidote, should precerte every other remedy, particularly the nercurials; a course of which should be followed by a jurgative, but not be given together, as is cornmonly practised. For ascarides, which usually irfest the large guts, I have found great service in calonel to the amount of a drachm or more, given over night twice, followed by a purgative next morning after thi: secorsd.

\section{No. 1.-Mercurial Bolus.}

Calomel, 1 1.2 drachms,

Anise seeds, 5 drachms.

Mix with treacle for two dloses. 
No. 3.-Purgative Ball.

Barbadoes aloes, 4 drachms,

Gamboge, 11.2 drachms,

Prepared kali, 2 drachms,

Ginger, 1 drachm,

Oil of amber, a tea-spoon full,

Syrup of buckthorn suflicient to form the ball for ine duse.

Tarticular care should be taken of the horse, but he should not take any gruel for the two days that the mercury is in him, as directed by White, but give him bruised corn or other dry food with little water, the calomel not having entered the system. Neither does he require any of the exercises usually forced upon patients "in physic." Let a week elayse ere the same bolus and purge are repeated as before, when they seldom fail to bring away whatever worms he may have in him. Instead of the foregroing, some persist in the foliowing old method, by way of laxative mercurial, which, however, 1 must premise, seems much tou strong, notwithstanding the high character some bestow on it.

No. 3.-Laxative Altcrative Balls.

Quicksilver, 1 ounce, and

Venice turpentine, 2 ounces.

These being well rubbed together in a mortar, add

Aloes in powiler, 2 ounces,

Ginger, 1 ounce.

Mix with syrup of buckthorm, and form the compost into four balls, one to be given with intervals of five or six days. Water-gruel or a bran mash to precede each ball, as before, and give the same when the physic may be working off.

Some horses, however, can not bear the bolus No. 1, calomel having a tendency to gripe; in that case the quantity should be divided into three balls and given on three successive nights, followed by No. 2 , on the fou:th morn. ing. In like manner, if the horse be not a very strong one, the above quant: ty of No. 3, may be divided juto six or cight balls, and given at intervals of two days each until purging is produced. Indeed, neither of these medicines should be given, least of all continued, when the animal dungs loosely. From those precautions, it is manifest that my opinion, so often expressed regarding the misuse of strong medicines, remains unaltered; and if I have been successful in impressing the reader with the same wholesome and humane truths, be will at once perceive the absolute necessity of attending to the symptoms, to assure himself that the patient really has the worms, and not some other affection of the liver, kidneys, cœeum, \&c. as remarked by me at the head of this article. Mistakes in these respects often prove fatal, or at least affect the animal's future health.

If worms do actually exist, they can not fail to come away with the foreguing course of medicine; and the patient, though a little weak at first, will come out of hand with a good appetite, hrisk in his manner, and bright as a ruly. These considerations, however, shiuld not influence us to neglect a trial of the milder medicines, before enumerated, as containing anthelmintic proper. ties, less powerful indeed than the foregroing, lut not tharefore less likely is 
prove servicenble in ordinary cases. Of these, the Indian salt (sal Indicus) deserve's the first consideration, though denounced as differing very little from common salt, with a small portion of sulphur, both of which are known to he goodly anthelmintice. Pe its virtues what it may, the following substitute will be fusual to contain all the properties of the genuine salt, and may bo employed swhen this can not be readily procured.

\section{Laxalive Poivder. - No. 1.}

Sublimated sulphur, 4 ounces,

Emetic tartar, 4 drachms,

Liver of sulphur, 1 ounce,

Bay Salt, 4 ounces.

Mix for six duses, one to be given daily in the corn, which should be previously moistened with water-gruel. $\Lambda$ s soon as the bowels are tolerably opened, desist for a week at least, but should it fail to produce this effect, give the following

\section{Laxative Balls.}

Barbadoes alues, 4 drachms,

Gamboge, 1 drachm,

Hard soap, 3 drachms,

Anise seeds powdered, 4 drachms,

Oil of cloves, 6 drops.

Mix with syrup of buckthorn enough to form the mass, and rivide into two balls. Give them on two successive mornings, unless the first prove effectual. I have found these balls, without any other aid, produce worms, a few, by repeating as often as five or six times. Arother preparation of antimony may be substituted for the first mentioned powder, viz.

\section{Laxative Powoder.-No. 2.}

\section{Liver of antimony, 3 ounces, \\ Cream of tartar, 4 ounces.}

Mix for six doses, one to be given daily until the boly is opened. But should not this happen, the laxative ball just advised should be given.

Savin (the leaves pounded, and a spoonful given twice a day in the horse's oats for ten days, and then laxative balls above, bring away slimy matter with the dung, and worms alive.

Arsenic has fieen tried, to the amount of ten grains a day, for a week, but its powers are tonic only: it is a dangerous remedy in unskilful hands. All bitters are anthelmintic and tonic; thus worm wood, rue, and chamomile flowers, have been attributed the faculty of killing the worms, but the fact is not exact!y so; those effects are prolluced by bracing the stomach, and restoring its tone, and thus disposing the parts to throw off the intruders.

\section{STAGGERS, APOPLEXY, MEGRIMS, VERTIGO, FITS.}

STAcigens is the common or vulgar name given to all those disorders of the head, which consist in vertigo, or "swimming of the head." Drowsiness attessding this symptom confers the distinction of slecpy staggers upon this kind 
of attack, whilst mad stagerers is that atiection of the brain which causes the nnimal to kick, to tumble, and plumge alrout: both are oceasioned hy diseased stomach, brought on hy inflammation of that organ, or simply by the retention of a great mass of indigestible foud there and in the intestines: constipation attends every species of stacrerers, and in some cases the hardened dung may be folt or observed hy applyiser the senses to the proper parts. The breath is oflensive, the respiration injeded, and the pulse high and sharp in mad stagrers, whilst in the slecpy it is slow, heavy, and full, without vibration [seo page 63 . When these latter symptoms contiome a horg time, the blood determines fowards the head, and the pulse incteases, if the animal be one in good condition: amd unless bleding and purging be employed eflectually, somer or later ends in apojlexy, or ine paroxysu only, which terminates fatalls. High-bret calthe, stallions, amd brond mares, which are pampered in their food with stimulants, frepuently fill vietins to this kind of attack, as do their promeny wlylst unler tainiag, sometimes. In some cases the animal makes one efliort, in oflers if dmpis instantaneously; so the reader may perceive that he does not starerer at all: and I infer that a manifest diflerence exists betweon the two, although hoth arising from the same cause; for, the one we may aflionl some assistanee to, and usually stceed in performing a cure; in case of apoplexy, the only symptom is remediless-death. 'To prescribe for stch an event would be utterly useless.

Under the head of "costiveness" I have already considered the orierin of stugrers, and prescribed the remely at page bis; because that is the disease, whilst stagrers, Sc, are but the accompanying symptoms.

'Tut: Mbiands is an occasional attack on the sens, rium or brain, in which the animal drops down as if shot, lies motionless awhile, recovers slowly, and Is next day fit fo gro aml to the same thing again, if pushed in his work. This disorder originated in a foul stomach, in one case that came under my care, and was at first a fit of the slecpy kind, which afterwards degenerated into megrims; the morbid state of the head, I apprehend, continued in a trivial degree, which any great exertion brought into activity. Sometimes theso merrims are preceded by a short warning, when the animal rears up before it falls, or rambles like a drunkard; it then tumbles and plunges about with considerable danger to those who may collect around it. The muscles of the eye are usually affected, much in the way of horses in locked jaw, or the human subject in afilling fit " lut all those symptoms disapjear upon em. ploying the proper remedies, some of them so quickly and by such means as to appear the eflect of a simple mechanical operation.

The cause of staggers, and the symploms that distinguish the one kind from the others, being thus settled, without distracting the inquirer with needless distinctions of agricultursts or the fanciful reveries of the doetors, let us proceed to the

Remedies.-Farm horses that live much in the straw-yarl, and work hard on bad hay, Sce. will sometimes stand still at mee, as if struck motionless in the midst of their work, which is a sure sign that some great leading function has been suspended for the mement by reason of the great exertion. The driver has nothing more $t, h_{1}$ in this case than let the tired creature rest for the space of a minute or two, and then proced in his work a little more leisurely. Prevention is better than cure.

In all ortinary cases of stagrers, simply opening the lrowels will effect a eure nine times out of ten; and when the animal shows symptoms of a disorAered stomach, the coming disorler may be warded off by a close of pbysic. In violent attacks, let a clyster le tirst empluyed, of warm water, in which common salt has been disinlwed, and the hardened dung brought away by manual assistance-as more fully chtailed elsewhere-see the mude of roing 
this effectually, at prage 6.9. I have known violent cases of staggers ceasn by this remedy alone, and the cure was completed with a purgative ball, as prescribed at page 63 .

T'lie fits that constitute megrim, or the more genuine stagerers, will require the lancest, and let the quartity of blood taken be commersurate with the violesces of the animal, his bulk and fleshiness. From four to six quarts will thus reduce his powers, and ided by the back-raking and purgative just recommended, a cure is soon effected.

\section{LOCKED JAW}

Is rather the effect of other diseases, of the acute kind, than an original attack, and is symptomatic of approashing death. A prick in the foot and docking the tail, are fruitful causes of lorked jaw. Ifot weather is mont conducive to this mammer of dissolution, which is lorought about by great excitation of the nerves, and accompanied hy imperfect digestion. The remedy would of course he found in restoring the tone of the former, and opening the main outlet of nature. I have seen a case of locked jaw proceding from inflarnmation of the intestines, of a very aggravated nature.

Symptome.-The case io which I allude was that of an old horse, from twelve to fourteen years of age, just off from hard work, which seemed to have lived badly and sufferesd severely the ills of a protracted life. Date, May 14, 18:20, when the weather was prematurely hot. As usual, it began hy the animal thrusting out its nose and eating with some difficulty, which increased as the stifrness of the neck becarne worsc. The ears stuck up, and the sufferer could scarcely move a fort, and this with the greatest pain. Thus, every hour the malady is found to extend itself towards the more vital parts, until reachmg the heart, life is then extinguished. 'The brain appears to be affected at the very earliest perioxl of the attark, when the animal evinces unusual apprehension, and will neigh aud prick up its ears at the approach of any one, as the last effort of nature to cobain the notice of man. The pulse is then increased to ahout 70) but in the future stages of the disorder it falls again below 40, and lower still until its final extinction.

In a few hours, the balls of the eyes of the animal just alluded to were turned hack, showing the nerve which retained the ball in position in a very disgusting manner; he appeared to suffer much pain, respiration had ceased, tho abdomen was drawn togother, and immediate dissolution was exprected momentarily. When the subject was opened, I was struck with the inflamed state of the mesentery, and all the lacteals assumed a bloody appearance. Previously to this catastrophe, I hit the anirnal haril on the furehead with my fist, once: the blow shook his whole frame, which before was as stiff as if made of wood; its syes immediately returned full one-half way back again towards the proper situation, and I was not mistaken when I imagined that its jaws, which had been knit together, seemed to relax somewhat, and the rigidity of the neck gave way.

Remedies have been prescribed, and Mr. Wilkinson of New-castle reports several cases of successful practice upon young horses which had acquired bocked jaw by bring nicked, or docked, or pricked in shoeing. The chief obstacle tin the alministering of any medicine being the closeness of the teeth, which defies the introduction of a horn, it may not be amiss to observe, that profiting by the forcegoing experisnent, I have in several cases caused a little relaxation in this resprect, hy placings a piece of wood upon the forebead and striking a smart blow upon it with another piece or a small mallet. Somo substarice might then be plared between the teeth to prevent their return to the originsl closeness, whereby the remedies recommended by Mr. Wilkinson 
may be employed with much prospect of success, for he only failed in fou cases in which the jaws were immoveable by any means which he then knev. of; and as he has treated this particular sulject more happily than any veto rinarian of our time, I think 1 can not do better than follow the example o. copring his accomat of a well-marlied case successfully treated.

When called in, he ohserves, "I fumbl the symptoms were a spasmodic af fection of the muscles of the jaws, head, neck, lack, hinder extremities, and abdomen, which ereasioned them to become rigidly contracted, and the abdomen was much drawn in; the pulse was about tifty, with some irregularity, the breathing a little quickened, the jaws were considerably shut, but not eo close but medicine might be alministered as a drench with a small horn: tho appetite not diminished, but she could not masticate hay; the head somewhat raised, and on clevating it a little more, the haws covered great part of the ball of the eye, the nose was thrown out from the chest, the nostrilsexpanded, the cars ereet or perched up, a grent stilliness of the neck and lack, the tail a little elevated, and, upon a little fatigue, a shaking of it, a strabdling of the himder exfremities: the animal was very costive, and the urine was somewhat diminished. 'The mare had been shoed about three weeks before, and the farrier had driven a nail into the sensible part of the foot while shoeing her. The lameness thus produced was sen removed; and the disease came on after performing a journey: that is, about three weeks atter the injury in the fout had been indieterl. "Two quarts of blood were taken off; a purgativo drench and an emollient elyster were given; considerable friction was used over the muscles of the jairs, head, neck, and back, particularly where they were found most rigid; a stimulating liniment of turpentine, hartshorn, mus. tard and oil, was well rubbed over those parts, which were afterwards covered with sheep skins, as recently taken off the sheep as they could be procured, which soon brought on sensible perspiration. The diet was principally thin bran-mashes and vatmeal-gruel, of which she frequently took a little. Tho next day, pulse the same, hreathing a linle quicker, jaws not more locked; a constant perspiration bad been kept up by the sheep-skins; the purgativo drench not operating, another clyster was administered, which promoted its action; the liniment was repeated. Next day (the ninth), symptoms nearly the same, perspiration copious : the purging having subsided, the anti-spasmodic medicine, compused of opium, camphor, and asafortida, was given with a small horn morning and evening, and a similar mixture, with the addition of thren pints of a decertion of rue, was administered as a clyster, morning and cvening. The drench and clysters were repeated morning and evening till the 1.th day; and during this, the quantity of opium, viz. 1 drachm, was increased or diminished according to the violence of the spasms, which at times were very severe. It was always administered in such a manner as to have its effects constantly in the system, without producing much restlessness; during this time, there was also a most copious perspiration going on under the sheep-skins. The bowels becoming costive again, another purgative drench and an emollient clyster were administered. Oin the 15th, the drench not operating, a clyster was given which produced the desired effect. Pulse and breathing a little hur ried and irregular, jaws not more locked, still perspires under the sheep-skins, appetite goon; but can not masticate hay. 16 th, Pulse more regular, breathing more calm, perşires freely under the skins: the purging having subsided, the opium, ․e. were administered as before, and continued until the 21st, when another purgative drench and emollient clyster were given. The jaws were now more oyen, and the mare could masticate hay; the muscles of the head, neck, back, and himder extremities hecame considerably relared, and on raisung the head, the haws did not cover much of the eye. On the $23 d$ day, the rurging having subsided, the anti-spasmodic medicino was again empluynd 
entil the ICth of April, when another gurge was administered. On the 12th,

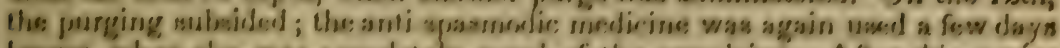

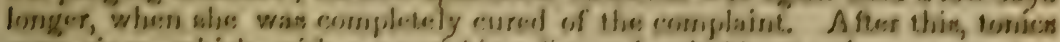

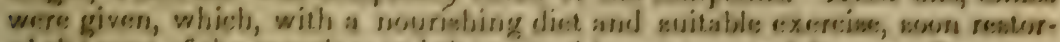

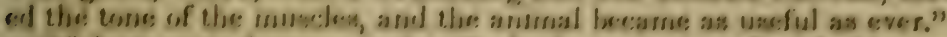

Of the twenty-four cases deweribed, nime come on afest docking os cutting off the tail, from ten daye to a month afier the opweration. In such cases, thes

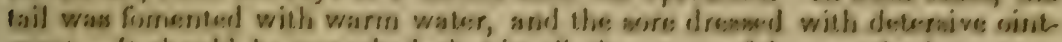

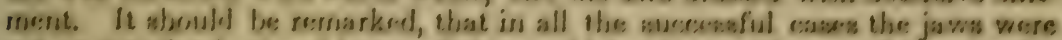

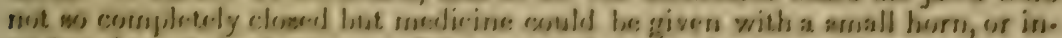

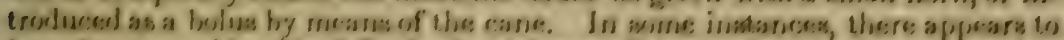

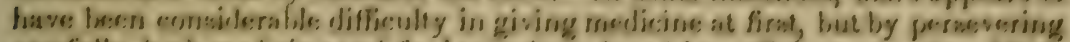

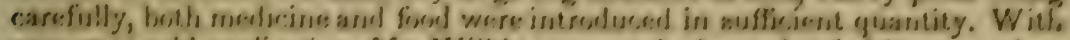

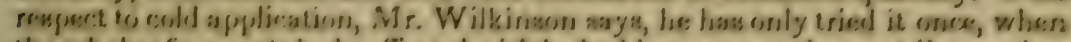

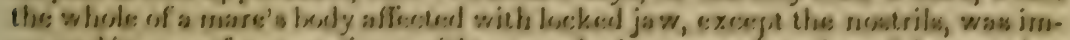

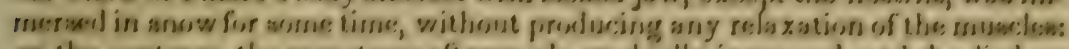

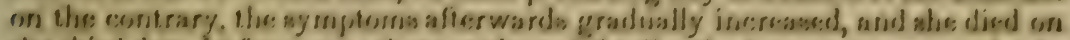

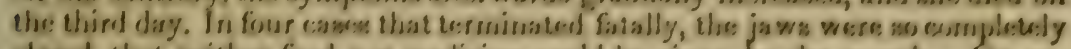

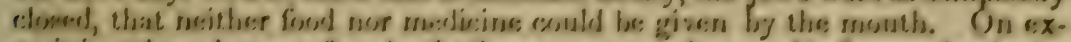

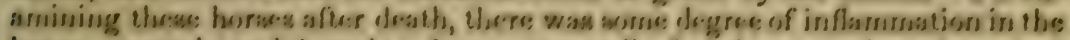

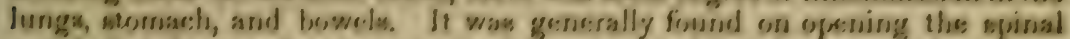

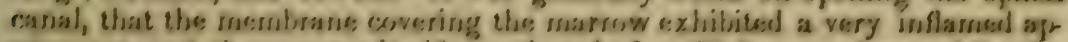

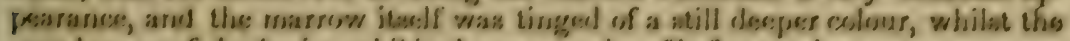

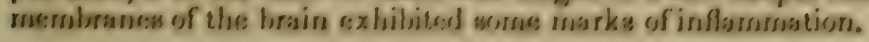

\section{HYDROPHOHIA.}

is notice whatever would bave been taken of this droadful malarly, but fore

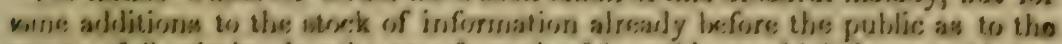

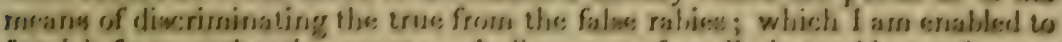

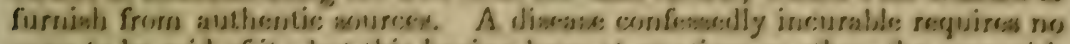
roore $t$ b be said of it; but this bas, ing been at one time or other, the case with several other eubjects treatod of in thim volume, I most mot, consiesently with

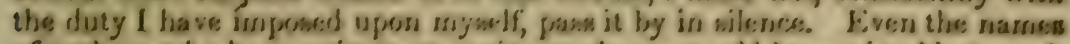
of authern who have writuen on casine madruses would be servicsable wo such

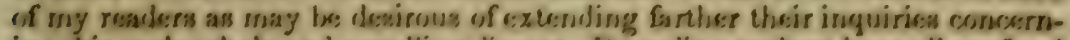

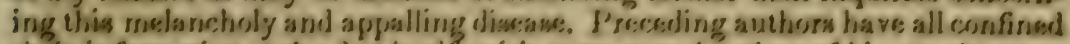
their information ts the deg itw:lf, with mere casual notirses of ties altariks upon

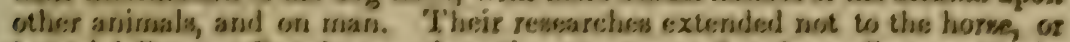
but trivially ass. Put, inasmuch as the aymptomos of mashoses diacsserable in

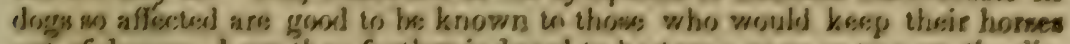
out of Janger, I am thes further induced in bentow a page cor two on the dire

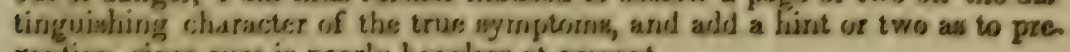
verition, since cure is nearly horpeless at present.

Camese. - The bite of a rahiid arimal, urivernally of the dog, and in every cane that I hear of, on the lip. The bull-doge, the lurcher, the mongrel, the Dariah dog, ard the shephrerel degg, are the kinds mont dispomed to run at horees, eapeciafly when so aflicted (the fint-rneritioned, on other occasions usually fighting at the (hroat), jumping repreatedly at the hores until they get hold, and the two firat pertinaciously holding fast a long time, even until killo ed sff, as we hear ard believe." "This will fiapgen rnowtly with buresen tight

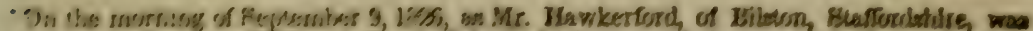

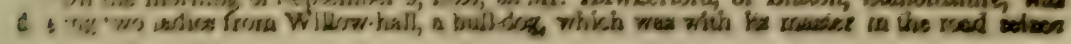


reined, or which we lear up in harness, whilst those having the head looge rear and paw off the offender, or being at large, evade or trample upon him; int however slight the bite, the inischief is alrealy committed, so that avoudance by thiegt is the only preventive of an irremediable evil, unless we are prepared to shoot the caitift; or to rum him through. We hear the free use of loorseflesh for keeping doess in England, churged as one main cause for engemdering rabies, or at least guarrelsomeness; add to this, the denial of water to which some of them are subjected at a season when dilution is most required-" what timo the deg-star reigns," and we think the sugerestion is not very far removed from the fact. At least, we are infermed that this appalling disorder is comparatively small in other parts of the werld, where horsedlesh is less plentiful, or water, the antidure, is found in abmolance, and Listron is adduced in proof, where dogs perform the oflice of scivengers, and further are supplied whls water by indivilunl houselieepers.* ()ur own towns, foo, in which water is easily obtained, are much selfomer subject fo ephidemic visitations of rabies than others more arid, yet lying open to an acoess of earron in nbundance. 1)ors invariably take water with much eagerness in every stage of the disoreler, so far as I have seen, or heard of, orally; some printed accounts difler. Man dreads it; but when lee can get it down, which has been done within a day or two of his dissulution, he limis the raging heat of his stomach alleviated by the effort.

Sumptoms of hydrophohia. In the dor, its approach may be known by a marked deviation from the greneral habits of his kind, amounting to dislike of former friends, a symptom which ought to be particularly regarded. 'They have been seen to eat their own excrement, and lap their own urine, besides other marks of depraved appetite; though at this early stage of the complaint they are less likely to attack a horse than to resent an aftront, or he guilty of trachery towarts friends. But as the disorder increases, he shows an inordinate desire to gnaw any substance whatever, and evinces nugmented antipathy to cats. Even the :long called 1)anish, though mostly kept with, and very fond of hurses, would, as som as aflected, be the most likely to snap at his old companions' moses. As the malady increases, his cyes become inflamed, and are aflected with a blearing from the lids. He howls horribly when the throat is inflamed at the laryox, or part where the voice (barking) proceeds from; the sound of which whower has once heard, he can never aflerwards forcet or mistake, unless he limself be bit, or become deaf. The confirmed mad dog now usually sits upon his rump to howl his obstructed bark, throngl very pain from apparent intestinal inflammation. If suflered (o) range about as the last stares approach, he seems bewildered and devoid of sight, and should be cither avoided or nttacked with clubs and other weapons fo extirpation f fechle opposition is obviously dangerous.

The symptoms of hydrophobia enung on upon the horse are direct and positive; bloo! on the lip, and other marks of violence, convey the first intelligence that the mischief has been inflicted; for neither horses, sheep, nor neat eattle incur rabies without inoculation. We are further told, by M. Huzart, that they do not posse'ss the fower of communicating the disease by bite to other animals, even thomgh lahouring under the highest degree of hydronbobia at the time; a fact 1 do not further vouch for, hut which, when proven by well-marlied cases, would go fur towards inspiring confidence and certainty in applying any of the allered remedics. What man is bold enough to ad. minister a ball, for example, whose own life is at stake, ingloriously, by the

the horse hy the nose, and retained its hold, though the hotse ran away, overturnet the gig, and llorew the pary into a hedge. Sill the ferocious brute retained its hohl, until its throat was cut n! the spot. Vide Anmals of sporting, No. 58 , page 238

"Ir "Annais of Sporting," No.46, pago 217, signed J. 13. 
feat? Increased puleation, influmed throat, and evident thickening of the

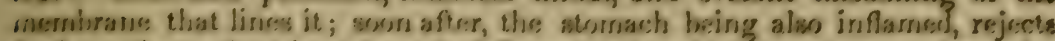
firal, or the pationt is at lease indifferent to it, which may oxcur about the eighteresth doy afier the inoculation; four or five earlier if thes arimal be in

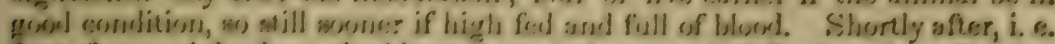
from five us right days, the bitten farta conlarge, and differulty of swallewing

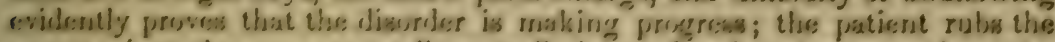
jart againat the manger, stall, or wall, increasing in wehernence from the iwentieth or twenty-third day. Ife diry soot drink water fresely, as usual, though this is by mos mans a certain criterion, for his power of owallowing is

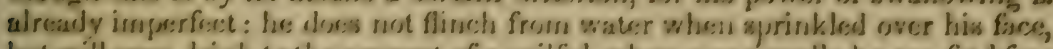
but will ewen drink to the awount of a pailful, when coccasonotily he can find frose

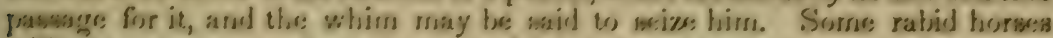
will take to water, and one in a wery high state of excitsmont was known to have run into a river. Sujpresenion of urine suext prowes that the inflammation has reaches the region of the kidrey w, which is effrocted by way of the

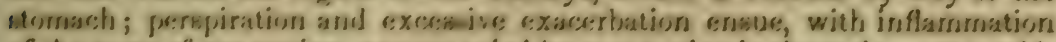
of the parte of generation, arcempanied by contraction in the rnale-yet a gelding was fiund is lave protruded its sheath, and otalexd with rouch pain to the amount of half a pint, alkout the twenty-fourth day.

Weaknew of the lark and lons monctimess is ohmervable at any period of the diacues; some guastrupeeds being thus attacked, and falling down mad without previous indication of aldios.

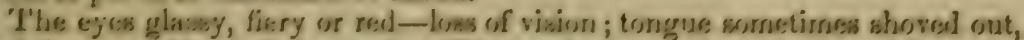
and then gnashing of the teeth. The raging nymptoms increase from the twenty-tecond or iwenty-fiurth day to the iwenty erigbth or thirtieth day after being litten, when the animal will besat itos: If to drath, unleses the owner more humaruely puts it out of yain with a muaket; for 'tis dargersus to approach within reach : the interposition of a strong gate acrowe the mtable, and the application of a etring rope well fastened, are grood preventives of accident during this final operation, or a cart that will bear sorne kicking might be enriployed.

Regimen. - Yone will afford any yerrnanent relief, though it has been usual to place before it water as a cent of its rnadnews-though risw known to be a fiallacisos one in any ntate of the disorder with any animal whatever. All horseses continue to feed up to a cortain perives - untif the stomach is attackedand some eat voraciously in the intervals of the fits, and drink tor, but no good can be expected from either, urilem rnade the velicles for the introduction of some numstruxn. If a cure be attempted, certainly nutritious forol, easy of digeotion, and cooling, must aswist it. 'The stomach being sery much inflamed in this disorder, poinits out the propuriety of bran mashew, manhmallows, and of water grusl, given colld, which will afford the rnearis of alleviating the anguish of that organ, to the corats whereof the last foxd taken by the expiring pationt has lxen finurad to adhere after desath; that is to say, the fitorous coat of the stomach of the suljoset alluded to identified itself with the forckl an inti unatoly, that it stripped off, whilst the insernsilhe coat atill aulhered.

Remedy. - Ewwry prosible remedy, wome of them of opposite tendency, has been tried on the doge, and on man. Sea-brathing, the Ormakirk meedicine, coppious bleating, excinion of the part, the actual caukery, and cupping the parts, have been each empleyed - succemsully, we are told; but no reliance can be placed on either, since they oftener fail, though there is no reason why the horme should not undergo blowding and cutting off the laceration as soon ofter the arcident as prosible. When we conkider that the part bitten is ever otherved to enlarge previsus to the borwe chowing other signs of confirmed i. jolroghobia, it aserus clear that the custing of the immediate cause of ircup: 
ent rahes presates itself upou our notice as the most efleacious measure for warding ofl the disouse. Six months is mo unusual time for dons fo concend rabid infereton, a quarrelsme dispesition heing for a loner time tue only inciication perceptithe; but the herse sehtom groes begond the Iwentieth day in de. veloping all the symptoms before emumerated; which shows that the pecoliarly rapid circulations of the hlood, noticed clsewhere (page 59) as the harbingere of inflammatory complaints of every kind in the horse, naturally demands early and eopious blecding as a cond accessary remedy for this particular one. In this ease alone we should not be solely guided as to the quantity of blond proper to be taken by the quickness of the julse, or actual inflammatory indication, but its fulness, and habit of the parient's boly: empty his hody sulp. seguently, as directed in cases of fever, with a brisk jurgative, as follows:

\title{
Purgative Ball.
}

\author{
Aloes, 7 drachms, \\ Calomel, half a drachm, \\ Hard Soap, 3 drachms, \\ Oil of caraways, 12 drops.
}

Mix with mucilage suflicient for one desse. If the animal secm not otherwse to require purging physic, onit the calomel, and onit it also if the bleching has been trivial on accoum of the pretions low state of the animal's system.

'The application of the plant seutellerio laterifolia is lately reported from North Ameriea to have succeded in several eases; but the symploms do sut accompany the report male to us, and we rest in doubt as to its eflicacy. However, let it be tried. So we say of "any mineral acid," which a certain medical gentleman recommends may he applied-a few drops on tow to the wound whilst fresh. 'This may be iried in the form of oxygenated muriatic acid, which has the property of being destructively detersive; it decomposes the virus, and acts as a styptic. Salt water hathing has been employed upon a large scale, and has been loudly commended; then, let common salt be also tried to the amount of two or three omeces a day mixed with the patient's corn. It is but fair to add, that sea-bathing failed of effecting any grood, when tried upon the canine under the best anspiecs. The king's staig-lonunds, in 18023 , being more than susbected of rabies, were taken to brighton, and the ablution well performed under the directions of Mr. Sharpe, the huntsman, lut to no good eflect; they were all destroyed. Dr. Faycrman, of Norwich, published a case in the spring of 1805 , of the cure of hyilrophotia in a man of fort $y-1$ wo years, by giving him supreracetate of lead (Goulard's extract) in doses of from fifty to tendrops on lumps of sugar. He also bled the pratient, who was at one time raging mad. Strong soap boilers' lye, or solution of potash, in either of its varieties, has been used frequently as chficacously defersive of the virus left by the bite or bites intlicted by a rahide enemy; thesides which, the seat of all the wounds may thas be discovered, as they usually lie conceated by the hair; and thus, if excision be deemed necessary, every injored part mity bo similarly treated: let the eyes be cruarded against the lye, ame the wounds should be quiclily pressed and assiduously washed. An eschar forms and completes the cure. 'The once celehrated "Ormskirk Medicine" is unworthv of reliance.

'The sulject of eanine madness has feen well handled hy Mr. Gilman, in his "Dissertation on the Bite of Rathid Animals," Bvo. Mr. Maniel, in his "liural Sperts," has made some cood, sensible, practical observations on this subject. Mr. 'Thomas, in his. "Shlowter's Guide," is more pithy than commu. nirative ; be recommends immediate: death being visited upon tho victins of 
the desease; a very effectusal mode of preventing commonication, truly, but he

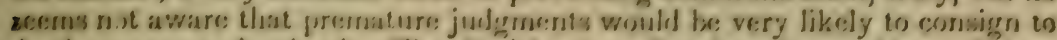

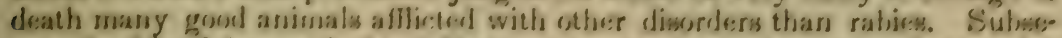
quently, Mr. Johnesn, in hins "Shornter's courupanion," hase printed wome in terosting details of excurrencess within his own propeer sphere. Dr. John P'inackard's "Casos of persons who have fallen victirnus wo the hite," are well marked. Siut the labrurs of nome are so moch in peint, as resgarlas the horme, as the regearches of my frieml, Mr. John Surr, Surgeon, communicated to

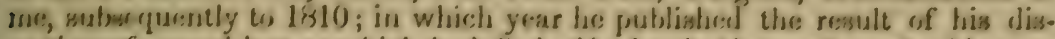
section of weverial horwas which had died of hydeopholdia, martly under his own

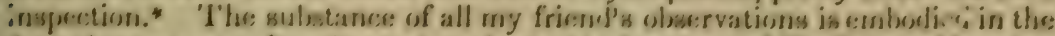

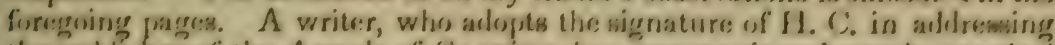

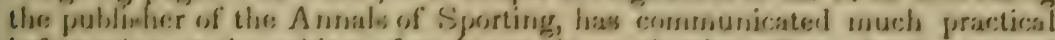
information on the suliject of cantre madneses, that is well worthy thes peruabl of all persons interesteil in this order of crosted besings.

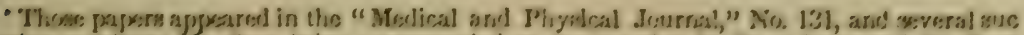

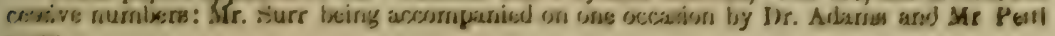
grew. 


\section{BOOK III.}

\section{OF TIE LEG AND FOUT OF THE HOHSE; UR SHOEING-SMITH'S GUUE.}

\section{CHAPTER I.}

\section{Structure and Physiology of the Foot ; Mode of studying it advantageousıy}

CEnтA:x disorders of the foot owe their origin to bad structure of the limb, and the manuer it is aftached to the hody, which influences the tread, or bearing, that the foot has upon a plane surfaced ground; others arise from accident or hard work, and a good number from the errors shoeing-smiths fall into when they neglect to adapt their work to the circumstances peculiar to each kind of horse. Furthermore, almost every individual horse has its peculiar tread, and the scientilic workman should place himself in a situation to ascertain whether this be owing to such original defectiveness, or to the evil accumulations of age and hard ustuage : he must not pretend to counteract, but te fillow the first mentioned; the second he may endenvour to correct, to amend, and prevent its evil effects. In order to effect these objects, he should study the form and structure of well-formed limbs, learn the uses of each bone, liga. ment, and tendon, and ascertain how it happens that deviations from symmetry un the limb always aflect the sole of the foot, sooner or later.

But so much space has leeen already occupied in the anatomical description of the leg, that it might properly be considered a waste of time to enter into new details to the same purpose. The reader will therefore turn back to the early sections of the first book (page 5 , se.) and he will readily perceive in what manuer an originally defective limb, or the ill-adaptation of the parts to each other, or its awkward attachment to the body, may become the harbinger of one or other of the many diseases of the foot, which we come shortly to take into ennsideration. He will know, also, that hesides this error of birth, as I call it, there are ofhers of mismanagement: as, the employment of horses in work that is heyond their powers, or of that kind for which nature never designed them; cither of which is as likely to bring on distortion of the foot, and its train of disorders, as any accident of birth to which I before alluded. Natural defects go much farther than shape or make, and the distinction between the'se and the inflicted, or acquired, may be aptly illustrated by the fact, that white-legrged horses, whatever be tneir shape, are more disposed to contract "Erease" than those" of any other colour. This is therefore a natural predisposition to that disease; whilst the animal which is suffered to contract the "grease" entirely through mismanagement suflers an infliction as much as another, which, being put upon hard services, throws out splents, spavin, curb, dec. in consequence.

Furthermore, the shoeing-smith who should inform himself of the primary causes of badly formed feet would carry on his business with the greatest emolument to himself, and with the most satusfaction to his employers; for he would alayt his shoes to the natural defects, whilst the acquired ones he would mend by derrees until be could contrul the horses' heels to a I wealthy shaje, 
and thus promote the regeneration of healthy horn. IJe should also accuresons himself to reflect on the various hreeds of boroes that are brougle under his care, their limbs and howen, produced in certain nituations, climatem, or conn tries, as we hear them denominated, eachs of which requiress some preculint contrivance or adaptation. 'Thus, horses fored in swampy situations have lorg Dahby limbs and large flat hoofr, in say mothing more of their long washy carcases, that predispeme: them en contract certain ills which come shortly to 'se enumerated. All those "countries" where ague prevails aroong roarakind are unfit for breseling gesed horses, as is proved by the thick rporigy hesel and enoft fort. It was to this pecouliar climate I oljected souses yours ago, when I firat printed the advice given at page 18 , which has since leen corroborated by the opinion of M. Dupuve as quoted before at page 130. Brittle hoof ias produced by a hot, samily breeding country, as much as by the heat and drynesen of the anional's cernstitution. Bout, to whichever extrene the individual be:onge that may come under comsideration, mis-shapen foof is visible frots the earliest yours. Tris increases as the animal is worked, and disease of one descripsion or another follows, which requiress the care of the shoxing-smith to mosify, or of the doctor to eure. 'I'hus the combination of ferrier (or iron-work er) and veterinary surgeon in the same peran is not so very incongruous as at first sight may lo imagined.

In the anatomical treatise that sccupins the first chapter in this volume, the roader will ohserve (at jage 11) how etrenuously I insisted on the proper shape or e.evation of the beof; and he will not overlook the great service our shocingstrith, or ferrier proper, may derive from duly considering this shape and exlernal form, and of anlapting his shoe on each deviation from the true form, as I shall show preseretly in Jretail. For that attendant upon and assistant to nature, who is rorglectul of her deviations, or ignorarot of the causes which produce them, is ill calculated for his office, whether that be forrier or doctor; in fact, he is ever the most prizable workman of either class who is best ac quainted with throse deviatione, accillente, or errom that, for the most jart, are inflicted we know rot how. 'The loot and shoe maker, for example, whos can hest suit the bumble-fortud man, is a more ingernious mecharic than he who is wholly miployed in making his cordovans for perfect-footed persons only. But then, the "shoe maker" of either gersus should not be ignorant of wellturned feet, and the symmetry of the horese's forot should form an especial part in the cilucation of an intelligent shoeing-srnith; else, how is he to work for the preservation of the propere shape, of its restoration when time or circumstaneas may have efferterl those alterations we deplore, and strive to amend if we can not fully. restore?

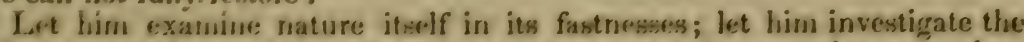
minute parts that constitute the whole foot, to which his operations are calculated to afford support, or to seffert alterations in its form. To aid him in his inguiries, I have annexcel hereto the section of a foot of nearly perfect shape. prepared by myself, and pullished sorne time before these shects, in order to fuert and correct the blumbers intelligent shocing-smiths were every day led into by relying upon the misrepresentation of the sulject contained in certain piblications of the jursent day. I lamented this the more, because it is inpossibic to withhold approbation from the lealing jarts of the work in which the ill-conceived pirture appeared, and therefore it is very likely to have diffe. serl crrom more extersively than a loss jopular author could powsibly infict. As an artishote to all mistakes on this interesting topic, I would recommend cvery une who has occasion to meddle with horse's' feet, as owner, gromon, of 
shoeirus-smith, to obtain a fresh hoof of a horse which has died in comprative health, and having softened it in warm water, proceed to make a section there of, in the same manner as $\mathbf{I}$ have here done.

\section{Fig. 1. Section of the Foot.}

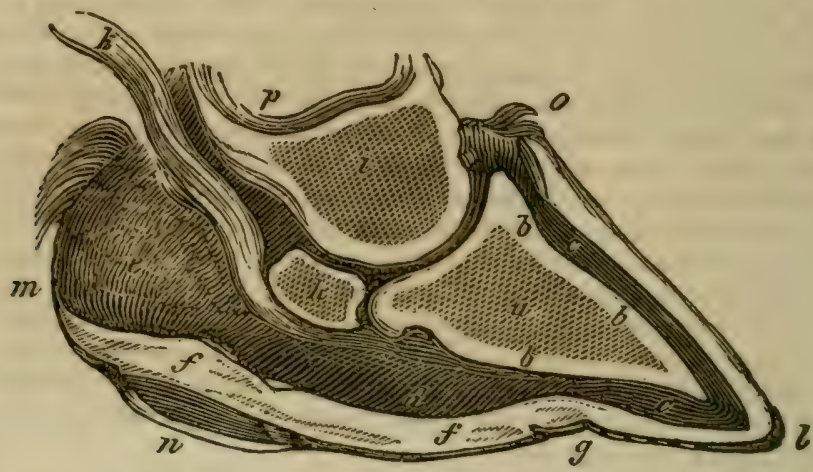

This portrait of a section of the healthy hoof was taken from a freshly severed foot of a five year old horse, recently killed in full health. This latter remark veterinary readers will know how to appreciate, when comparing this with their own preparations, which may have been derived (as generally happens) from the anatomy of diseased suljects, after the "blood" which should have supplied fresh secretory matter has been long turned aside, or converted to increase deformity.

To the general observer, the foot of a horse inclosed in its hoof would, indeed, seem like a corpse shut up in its conin : and there is, certainly, no mode of arriving at a knowledge how these act upon, and with, each other, than by dissecting the hoof. By this means the whole arcana of its construction are laid open, but in no manner so intelligibly as by the section straight up and down from the toe up to the coronet, and throughout between the clefts of the frog and hee!. This being done, the vessels which supply the juices for renovating the wear and tear of the whole exterior are plainly bared to the view : the ligaments, bones, and tendons, show their mears and manner of action; and, above all, the back sinew laid flat behind the smaller pastern-bone, and quite so at passing underneath the navicula, and at its insertion in the lottom of the coffin-bone. On entering the hoof it acquires the term tendo palnaris among the learnel, but this course only serves to puzzle the general reader.

At $(a)$ on the colfin-bone, the general prorosity thereof is much greater than at any other part, being the avenue or receptacle for the blood which is diffused throughout it, except on the surfice, or border, at $(b b b)$. 'The shaje of this bone at the toe $(l)$ is worthy of note, as leing that which is best calculated to give lirmness of tread, fitting with the greatest nicety to the shape of the hoof; on rather, perhaps, we should say, that the shape of the hoof of a healthy animal should ever partake of that which we have before us, and is evidently instructive to the shoeing-smith in his final raspings, to keep clear at the toe. Deviations from this rule, bring the coffin-bone nearer the surface of the hoof, as is shown in fig. 3 , plate 3 , where the coffin-bone $(c)$ and the wall of the hoof $(g)$ are in contact; and even this representation, the picture of the Coliege, shows tnat the toe of the bone is much sharper than the horn, which they rasp away sc inuch at $(l)$, that the new shod animals go a little groggy fi- a short time. 
Between the hoof and the coffin-bone interpose an aggregation of secretory vessels, forming a juicy elastic substance, that prevents concussion, as would necessarily happen at every step but for this providence of nature. I have marked it (cc); but this sulistance, in like manner, pervades the concurrence of all other hones of the foot, only differing much in quality, and in structure a little: between the shuttle and coffin-bones it is more vascular, and the blood is still deciledly arterial. Underneath the coffin-bone at $(d)$, it hecomes more elastic, thicker, and striated, resembling pale India rubber, which qualities in. crease towards the heel at $(c)$. These latter rest upon the frog $(f f)$, which is horny, or perforable with a point-knife, so far as $(g)$, where it joins the toe of the hoof, more abruptly as the horse is most worked, or ntherwise.

The navicula $(h$,$) or shuttle-lone, as it has been called, moves in the midst$ of much elastic substance, resting upon and pressing the back sinew flat upon the strongrest part of that substance, above the centre of the frog. This little bone, it will be seen, is well adapted, by its shape, to traverse the lower surface of the small pastern $(i$,$) and the lateral eilge of the coffin-lone (a$,$) when-$ ever the back sinew $\left(k_{1}\right)$ is drawn up to lift the foot, as it dues from off the ground, always returning into its place as the foot comes down. At $(l)$ is the toc, $(m)$ is the heel of the fiot, and at $(n)$ is the near side cleft of the insensible frogr. At $(0)$ is the coronet, or coronary ring, as at $\left(p_{1}\right)$ the lowest end of the large pastern bone.

At $(a)$ when the hone is recently cut through, no difference of structure is perceivable, though upon stricter examination, it will be found at the central part more porous, than that which is adjacent to the other bones; the hardness increases towards the whole surface $(b b b)$, where the cutting presents a perfect enanel. But the contents of the receptacle at $(a)$, I have proved by experiment to be unequivocally the same glutinous substance (in a state of preparation) as the hoof itself. This process of nature is well explained by the old aphorism that, "arteries entering bone engender bene, those of mus. cle create muscle," and so on; and the blood deposited in the coffin-bone, and being dispersed over the internal part of the foot, partakes of all the qualities of hone, nembrane, muscle, and skin-the whole combined becomes horn.

If my advice be worth any thing-if my earnest exhortations to investigate the subject effect their object, every man who reads these pages, whatever may be his station in or about the stable or the smithy, will not fail to make a section, or cut down the middle of a hoof at the earliest opportunity. T'o effect this purpose, the now industrious operator needs little more preparation than to furnish himself with a cordwainer's knife, and a butcher's saw with fine teeth : if he can ald to these the use of a carpenter's vice, in which to fix his sulject, he will much accelerate his labour. Having secured the foot upside (iownwards, he will cut down between the cleft at the heel until he comes to the bone at (b), and the wall, or horny part of the hoof (at $g$ ), where the lahour of sawing is to begin. The shuttle bone $(h)$ he will feel and hear rattle forward and backward at every stroke-the horn yields easily. As he pro. reeds, he will find his trouble lessened and his views of the matter ir hand much enlargea by driving into the chasm his exertions have made, some rwo or three wedges of wood, whereby he will ascertain that the stiffest part of the hurn is elastic, even though he should not have adopted the precantion of soaking his preparation, as recommended. He will thus he convinced, that the apjulicatiun of Bracy Clark's jointed shoe is not without its uses. But if our inquirer has sonked his horn as directed, he will find that the warm water renders it more clastic; and lo: will conclude that the practice of permitting their horses to stiml in the linuncls during the issue of hot water from brew fries, die-houses, retiliers' promise's, \&.., must soften the hoofs, and indispose then for jmucdiate concusinen uver the rough stones of jur paved streets. 
He will also thus distern why I advise, in certain cases, the enveloping the whole fint whenerer the application of a poultice becomes necessary to any phart of it.

On completing the section, he will disonver two branches of arteries which desiend into the fint at the coronet near the quarters and supplied the colling. bone (a), that mecupies the cavity of the horuy hoof, with fine blond for its ne production. In other words, the formation of new horn is derived from the What, which is sent hicher in grod quantity, and pervades the internal part of the coflin hone in particular. In this tone the operator will perecive a cavity, or rather there hollows communisating with each other, in which the horny matter is generated. Or, probalily, this is the reservoir for such particles of blowed as are suifed to the formation of heof, as it may be required and called for he the provess of nature, and the demathls of wear and tear, of nasping und drawing inndinatels, all which must subract fom its quantity, and leave the bone comprovatively hollow, and less fit fir resisting the lard comeussions to which it is liable at ewery step. 'This fire may be aseertaimed by leeping a bisected font fir a few months, when the moditure having left it in great measure, in the cavity of the collin-thone will he finud a vellowish glutinous substame precisoly of the same mature and colour as that which fills the space

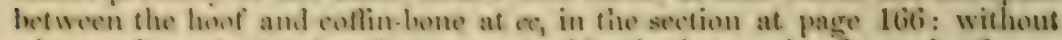
ondour and mearly tasteless, its uses are evidenty the supply of new henf.

Secing this curions construction of the foot, we are conpelled to allow that numerous accilents may also vecur to prevent the supply of blood to the parts, to say mothing of its mifitness at times to carry on its proper purposes. 'Tho two iesseds betire netied that hring this supply of new hlowd desoend into the fint behind the stmall pastern bone, and pass with the back sinew $(k)$ undermeath the shuttle thone (h), as may be noticed in the section, at page lobi. Here it enters the coftin-bone at the sole, by an indentation of the bene de signed for the protection of the resserls passing in and out. From the recep tacke in the collin-hone, after concoction, the bood isstes forth-part of it to lubricate and nourish the shuttle-bone and its adjacent ligaments, the remainder to effert similar purposes elsewhere, but the greater part is destined to supply the horny material of the hoot.

Those "concussious" at ewry step, lefore spoken of, as aflecting the action of the shutle-bone upon the postering point of the cotlin-bone, occasion trivial injury at every step in quick motion: more harm arises as the animal is much pushed in his work; then heat and fever of the fint strpervene, controctions follow, with a train of evils that have acquired different names, thirty in number, but which I have reduced by three-fourths, with a view to simplitying the sulviect: mest of these diffir only in situation. Very hand concussions, or a single injury of sutticient magnitude, preduce lameiness at nuee, which most unaceountably received the name of "strain of the collin-joint," and under which general inisenception I shall shortly give it a moment's considera tion.

'The stulent who would push his inquiries farther will next turn his atten. bon for the mustes, ligaments, and tendens, that guide the fort; that lift it up, and sulfir it angain to meet the ground; that may perform these offices firm and eflectively. or heing relaxed, disensed, or ill-formed, they and their functions agree mot with the well-being of the fent. I'robably he will find it consenient to lay open shis part of the areana of progression by the horse's meg (the hower part of it) previnus to severing the foot itself, secing that the anhjot will then be quite fresh. and that one part may intelligibly illistrate 

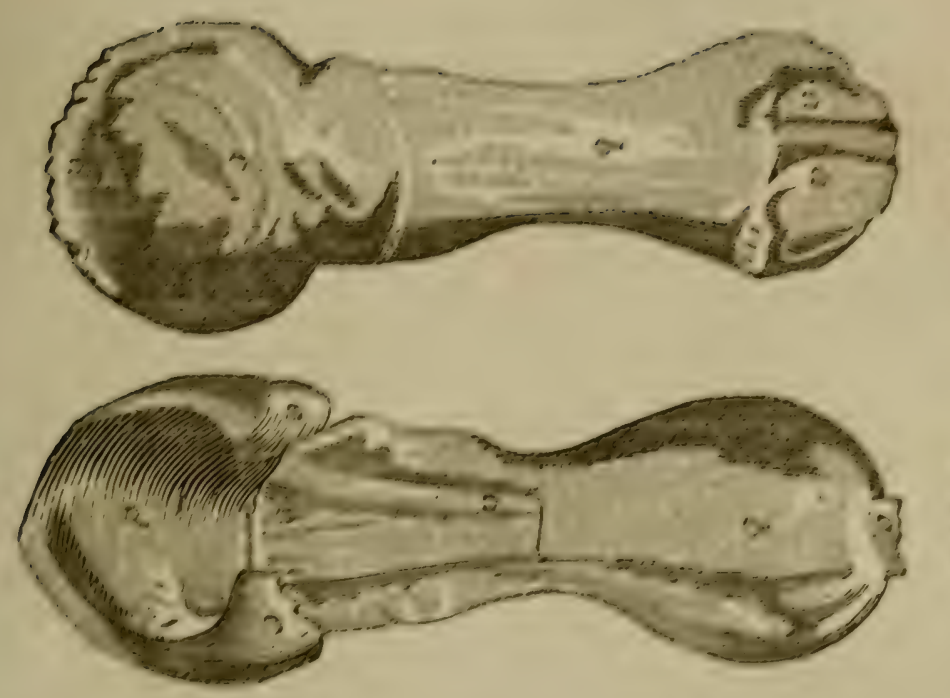

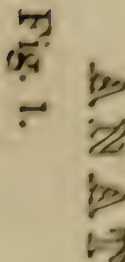

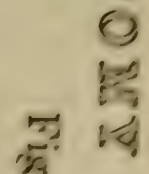

is 9 대] iy

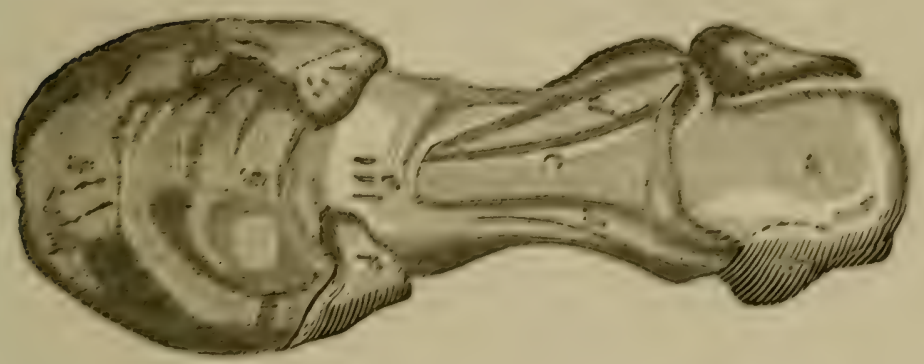
ing

ry

ज

Q :3 is स्टौ

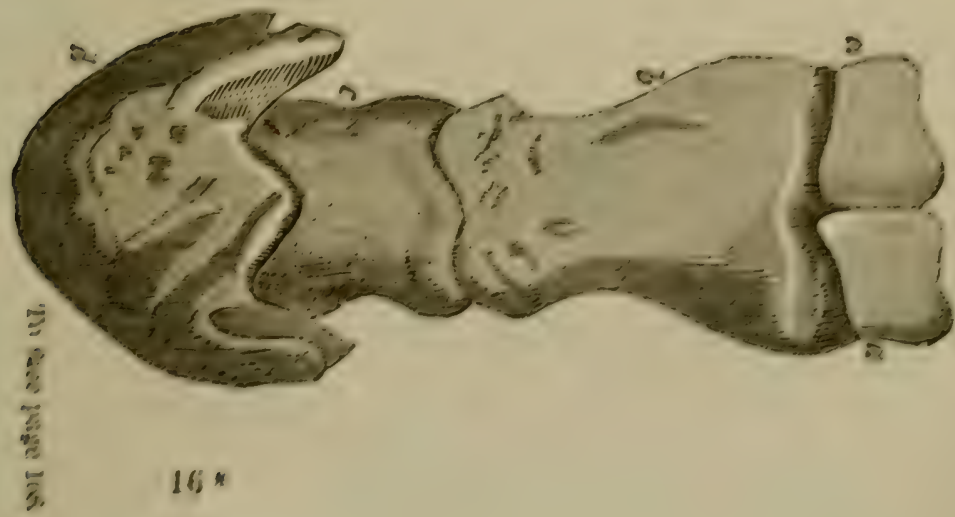

ㅍ. 9

ज 9 $+\frac{7}{8}$ $1-1$
$\vdots$
$i$
0 


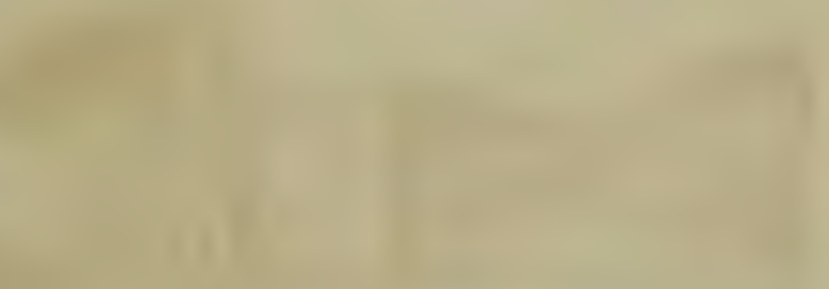



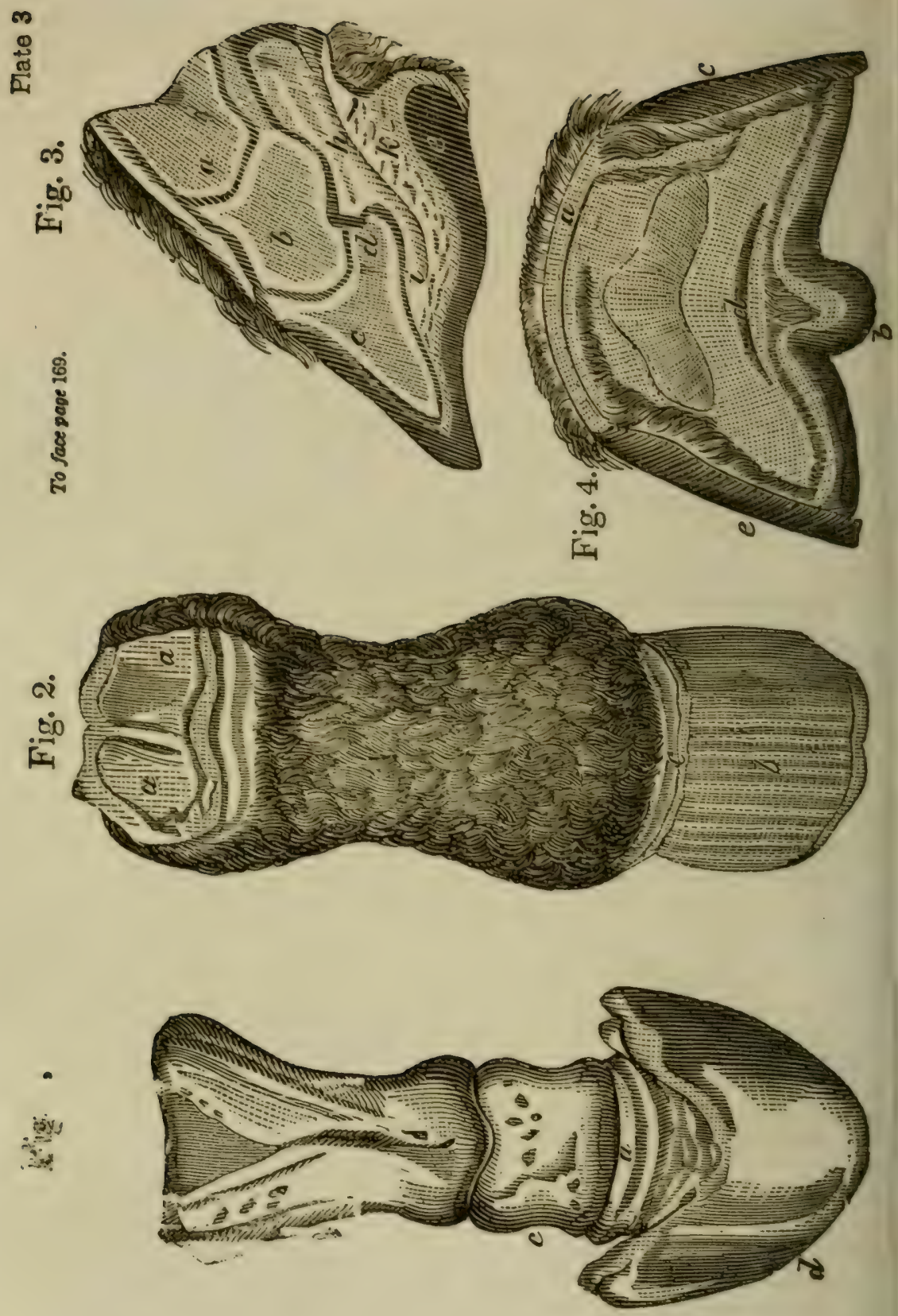
the other. This is more particularly the case with the flexor tendon, or back sinew; which he will ascertain is of great length, descending all the way from the hock, or back of the knce, behind both pastern bones, under the shuttlebone, and is fastened to the bottom of the coffin-bone.

With the following "description" before him, he will study the figures 2 and 3 of plate 3 ; and aftur romoving the remainder of the integuments, and cleansing the bones, he will then perceive the articulation of these, the manreer of their working in and upon each other; and as he proceeds to repeat the investigation, be will note the difference that exists in the shape of a leg taken from a thorough-bred horse and that of a cart-horse; the one small and llat-sided, or sharp before, as hest calculated for speed, the other round and heavy, as heing made for heavy draught, and to support a large, muscular, and lrony frame. In giving this advice, I presume he has already examined the superior part of the limb, though the lower bones and their covering come more immediately under notice in this place.

\section{Description of Plates 2 and 3, of Analomy of the IIorse's Foot.}

These figures were not designed or corrected liy me, with one exception, viz. fig. 2 , of wate 3 ; they are, however, very fair representations of the subjects studied, and depicted by members of the College. I have here a small objection to make to their mode of enlarging the colfin-bone. which they invariably draw much two big in proportion; why, I never could learn. In fig. 4 of plate 2, for example, where the whole of the integuments are supposed to be removed, the coffin-lone projects inordinately beyond the small jastern, which is not the case at all when viewed in front, or at the back. In other respects these figures speak intelligibly without further explanation.

Plate 2, fig. 1. Front view of a cult's font, hoof, skin rernoved, and $(a)$ the sesamoid bone, (b) the large pastern, $(c)$ the coffin-bone, $(d)$ the toe.

Fig. 2. Back view of the same- $-a$ a the back sinew, or flexor tendon, as it appears above its ligarnentary sheath and below it, descending flat into the foot underneath the coffin-bone at $(c) ; d$ the coffin-bone, having the sensible sole still adhering to it, $c c$, the lateral cartilage; $b$ is the sheath in which the back sinew is enclosed, and moves at every step, but part of the sheath has been removed in order to show the course of the sinew.

Fig 3. 'The whole of the ligaments is here laid open by the removal of the flexor tendon, whereby is seen (at $a$ ) the smooth surface of the sesamoid bones over which the tendon is ordained to pass; at $b b$, part of the sheath is turned back, at $c$ is the tollow part of the sheath; at dd the ligament that connects the small pastern to the bone above is shown, with its insertion below at $e$, whereby the large pastern is kept in position; ff the lateral cartilages; $g$ tho fottom of the coflin-bone, $h$ the toe.

Fig. 4 is a front view of the same, but with all the integuments removed; $a a$ the sesarnoids; $b$ the large pastern; $c$ the small pastern; $d$ the coffin-bone, but represented rather wider than ordinary.

Plate 3, fig. 1, back view of the bones, in which $a$ the shuttle-bone, is secr that works loosely hehind the conjunction of the small pastern, $c$, and coffinbone, $d$; but the small pastern $(c)$ has been lifted or strained upwards inordllately, as the lower part of it lies concealed, as far as the mark (c) in the nealthy subject, behind the shuttle-bone. The shuttle bone may be seen at its middle or thickest part, in the "section of a healthy font," at page 166; and by turning the cut sideways, the perspective will be found sacrificed to no useful purpose.

Fig. 2. View of the foot, with the hoof only removed, showing the front of ar,e coffin-bone at $b$, and the coronary ring just above it at $c$, in which the sur 
stance is treasured up that constantly supplies the material for new horn to tn. font bclow. At aa the sesamoid bones, freshly severed at the fetlock joint.

Fig. 3. A section of a foot, agreeing essentially with my suloject, at pago 166 , hut evidently drawn from a diseased foot, the elastic process marked $c c$ in that picture being wanting in this, and the shuttle-bone, $d$, having lost its finction; neither do we perceive the descent of the back sinew ( $k$ in the preceding) to its insertion at the coffin-bone. At $a$ is the lower end of the large pastern, $b$ is the small pastern, $c$ the coffin, $d$ the shuttle-bone, $c$ the cleft of the frog, $g$ the wall or hoof, $h$ the situation of the sinew, $i$ the sensible sole.

Fig. 4. Transwerse section of the foot, from the coronet $a$ to the point 0. the frog $b$, having the wall ce on each side, and showing the divided edge of the sensible sole $d$.

\section{CHAPTER II.}

\section{Disorders of the Foot and Leg.}

Introductory Obscriation.-ALt, those derangements of the limbs which we come next to consider, I shall divide, for the reader's more ready comprehonsion, into-1st, those of the leg, and $2 \mathrm{~d}$, diseases of the foot: for it does not always happen that affections of the leg alone can be properly denominated diseases, whilst those of the foot are invariably so. 1 before observed, that both, or either, may be occasioned by accident, derived from ancestry, or bg the fault of misconstruction and consequent misapplication of the individual', powers. They may be also considered as, 1st, those of the bones, $2 \mathrm{~d}$, of the ligaments, tendons, and muscles. But I shall not so subdivide the heads of my treatises on the several diseases, since each will appear under the respective heads of information, hesides which (as will be seen further down), whenever the bones suffer derangement, original or acyuired, the integuments follow the same evil course. Enough, however, has been said on these points in the tirst chapter of this volume.

Rest is the primal remedy for all acquired disorders of the limbs, whether those of hard work or of accident; but employing the animal whilst yet too young, is an universal error, which is but seldom remedied by allowing it rest when lameness once lays hold of him, much less is it capable of being cured. The impolicy of this practice, the fruitful source of so many evils, is demonstrable ny the custom of the Arabs, who never mount a lame horse, even in the desert, nor prupagate from horse or mare which is permanently marked with the effects of overwork. One remote consequence whereof is, that the foal is not entaled with a predisposition to contract readily such disorders as I come shortly to treat of; whence the superiority of the Arab breed in this respect. At least, the fact is to he dejlured, that most of our stallions of the wagonhorse breed are worked at plough and in the team at two and three years old, too much for their tencler years, and permitted to cover mares at this very carly age; the result of this lancutalule cupidity of ownership is, that their get nre impregnated with one or other of the maladies that I come shortly to enu merate, ere they reach maturity; hut the causes and symptoms whereof I have shown are so similar, or proceed so naturally out of each other, that they differ but in name for situation, in treatment nothing. Higher bred cattle are subjected to the same disadrantages in most breeding studs, in which the breders prefer to derive their stuck from parents which may have beon successtul at winning three year old stakes, or probably strained e very mus cle bone, and tendon whilst yet yearlings. We owe to the late Sir T 
Bunoury, of Bildeston, the introduction of this practice on a large scate, which is so evidently harmful to the rising generation - of horses.

Lameness is universally the symptom that denotes disordered limb; it is the only one perceptille for some time, until its continuance throws out some appearance on the surface; and that inquirer who can ascertain its true seal is most likely to find the cause, and to effect a cure. For instance, lameness occasioned by disordered bone, as in ring-bone and tone-spavin, is almost unlversally ascribed by the stable-men and humble practitioners to strain in the stifle, in the shoulder, or the whirlbone; whereby so much valuable time is lost in applying the proposed remedies at the wrong place, that those two disorders in particular make head almost irremediably before the true seat of ailment is ascertained. The same species of bluncler is propagated when a disease happens to the foot, and the precise cause thereof, even when well known to those employed about the stable, is kept a secret from the owner and the doctor. "Let them find it out" is sometimes heard muttered in the distance; and in order to comply with the unfeeling permission, we pass the hand down the whole leg and foot from the top to the sole, compare the size of the lame limb with the corresponding sound one, and move the animal about. For withuut this examination it would be next to impossible to ascertain the presise seat of the disorder, and quite so to apply even the right remedy at the proper place. As an illustration of this position by its reverse, I may adduce the coming on of bone-spavin as that kind of attack which we can ascertain with the greatest precision of all those which lie concealed from our view and touch. It happens, too, that this is one of the few disorders of the leg that admits of cure by early applications, as it is also that which, being neglected, enders the animal wholly useless. When a horse becomes lame of a hind leg occasionally, and that after rest only, the complaint going off on taking a short exercise, we may be quite sure he labours under incipient bone-spavin, provided no other distinct cause can be adduced for his lameness; but should the lameness increase with exercise, then it does not depend upon bone-spavin, but some other malady. Further consideration of the causes, symptoms, and cure of this disorder ivill be found a few pages lower down.

*** Then lameness occurs to his horse unaccountably, and the inquiring reader turns to these pages for information, he had better run over once more the whole of the next six or seven heads of information; their great similarity in many respects dictates the propriety of this additional trouble, as most of the series will be found referrible to the same causes, and require much the same treatment, though differently situated.

Throughout the whole of this chapter, the reader will find great help to unterstanding the details, wy carefully consulting the delineations of the leg and foot in plates 2 sud 3 , and the cut at page 166, with the description of pach. References are not always made in words at length, it being presumpd that he is already acquainted with the preceling pages, to which he is now referred.

\section{QUITTOR.}

Under the class of fistulous affections, I spoke of this disease at page 125 I) wnat is there said I may here add, that as quittor is caused by sand-crark. 
in a tread, or the prick of a nail, so will its situation be determined by ihe precise cause, on the inside of the coronet, or the outside, near the heel, or otherwise, as the cause may have heen inflicted; and also, that the cure being eflected by harsh means, of hurning remedies, these leave the foot disposed to contract other disorders at this region, as ringhone, \&c. Hence it follows, that the more moderate the means employed to get rid of this disorder, the less probability is there of the patient's contracting some other. Therefore it is udvisable to try the milder remedies first, unless the quittor is of long standung and of very had sort. The extent of each sinus, and the course it pursues, is denoted by the coluur of the soft parts of the foot, heing black or livid, or else searcely tinged, aceording to its virulence. In order to pursue this examination more accurately, it will be necessary to stop the circulation of the bood above, by twing a ligature tight round the fetlock joint, whereby the skin of the healthy parts helow will apperar white, and thus inore distinctly expose the nature of the simuses. The pledgets that are to be introduced for the destruction of the pipes may thus lee selected of a larger or smaller size, as the calibre of the sinus is greater or less; as also may the quality of the caustic application be made stronger or weaker, as the virulence may require.

Some hastily use the knife, and lay open the pipes freely along their whole cuurse; and if it approach near the bottom of the foot, the coflin-bone is usually affected with rottenmess (caries). This they hesitate not to scrape off, though, if the patient be of strong and vigorous constitution, exfoliation will take place without extending the operation so far. Indeed, it seldom happens that more is required than to give the disorder free vent at the coronet, whereby the necessity of operating underneath is superseded; for it will be seen that the ascent of the hoof-making particles from the sole will bring away to the orifice of the ulcer any oflensive matters from below; and this process of nature effects the cure. Whenever a simus leads towards the hack tondon, or the joint, much care should be taken not to injure either with knife or caustic, for a had-looking seam is then left behind, with lameness that terninates in anchylusis, or stiflening of the tendon, or growing together of the small pastern and the coftin joint $(a)$ and the shuttle-bone $(h)$, in the cut at pagre 166.

\section{RINGBONE.}

Causes.-At times a badly cured quittor, at others ill-shapen fout; which nccasions that concussion of the hoof and small pastern bone at their conjunction, which causes the latter to swell at the coronet. Cart and wagon horses with short upright hoofs, that do not sufliciently secure the articulation of the roflin and pastern tomes agrainst injury, are most liable to this disease.

Siymploms. - Lameness is sometimes the first intimation we have of the existence of ringhone, which is at first neglected, and only ascertained by passlour the hand clown over the part. As usual with most diseases of the font, :he attendant commonly ascribes the lameness to a strain higher up-of the shoulder generally, as ringhones afflict the fore foot oftener than the hinder wne. It consists in the ossifieation of the cartilage in front of the foot, which extends in time to the lateral parts also.

Remedies.-These may be applied to relieve, but no cure is to be found for rmghone. As high-heel usually accompanies the short upright hoof, the concussions of tne foot may be lessened by lowering the heels. Apply blistering outment to the seat of the disease, and firing may also be employed with arf"antage. 
WINDGALLS.

These appear a little above the fetlock, on each side of the back sinews, and consist of small puffy swellings, that occasion no immediate inconvenience but prove that the animal has been strained in his work, unless it has beer. occasioned by his having been put to it too early in life. They might be oc. casioned by the sinus of a tumour, pointing towards the pastern joint, having been cured too harshly, whereby the joint oil issues forth upon their being pricked.

Blistering, and a run in the straw-yard, are the only remelies, though experiments are often tried (when it is found necessary to sell the animal) with preparations of muriatic acid, and muriate of ammonia diluted in water. Saturate a roller bandage herewith frequently, and partial alsorption takes place.

\section{THOROUGIPIN}

Is of the same nature as the furegoing, arises from the same cause, and is eyually devoid of immediate consequence to the animal's going. It consists of a soft flexible swelling on the inside of the hock joint, as well as the outside, immediately opposite each other; whence it obtains the name of thoroughpin, heing supposed to go through the joint. When one of those tumours is pressed it yields, and the fuid it contains is thereby forced into that on the wher side; when the pressure is removed it immediately returns to the gamo state as befiore.

'This disorder has no other effect upon the animal's going, or value, than its appearance amounts to, as it conveys the information of its having ber $n$ workm too hard, and too rarly in life, as do all these minor evils we are now considering. How this is effected, I have shown in the 15 th and 16 th sections of the first book, at pages 18-20. Like unto the other disorders of thie alass, lilisters and rest are the only remedies: apply the blistering liniment composed of cantharides and spirits of wine.

\section{SPAVIN.}

Bong spavin is the more common, bloor spavin but rare. Both varieties, as well as hone spavin, owe their origin to hard work in early life, in the same manner as just adduced in cas:'s of windgall, and thoroughpin. Bog spavin s caused by the joint sil of the hough issting into the inembrane that surrounds it, and stagnating under the vein causes this to swell. The old reme. dy of taking up the vein hy ligature should be abandoned as a long and tedious mode of cure: the circulation has then to force a rew channel, in doing which irritation of the parts adjacent is the means of cure, by promoting als. sorption; whereas the same rffect night be procluced by blistering, as in the two correspondent disorders just named above.

\section{BONE SPAVIN.}

T'his disorder consists in a bony enlargement at the upper end of the shankIone, inside of the hock-joint, or a little below it. It belongs to the hind leg soly; and if not undertaken in time becomes incurable.

Aithe seat of this disuriler the leg is composed of three brones, which fit to. gether into one common cavity at the hock; and notwithstanding they appear us close together as one lone, yet possess separate motion to give elasticity to the animal's tread. and assist him in the act of progression, as may be observed in the working of his latanclies when the lorse is going at full speed, or mak.ing a standing leipl. !y mounting the colt whilst tor yourg to hear the 
superineumbent weight, by pushing him hard in his work, as well as by work ing young eattle at plough, a practice some breeders of heavy horses injudiciously adopt, these bones get strained asunder, as it were, and inflammation takes place.

As almost every one knows, by misusing young colts in the manner just dicscribed, they become cat-hammed, if they do not derive that particular mal-conformation from parentage, as before hinted (p. 161,) and is more scientifically accounted for in the first chapter of Book I. Generally it happens that horses so formed are good, easy groers, brisk and active; but though well allapteif for light weights, are utterly incapacitated from undertaking horseman's weight at speed, until they are full mouthed. If heavily mounted, or hard driven earlier in life, they invariably throw out a curb or spavin. 'The shoeing-smith frequently contributes to the contraction of bone-spavin without knowing it, by turning $\mathrm{u}^{\prime}$ the heels of his shoes in frosty weather unevenly. In the same manner, when the inside heel preserves its roughness longer than the outer heel, it is clear that this last must bear lowest, and further contribute to the evil strain that eat-hammed horses are ever liable to, about the hock. Cow-hourhed is but another name for the same mal-conformation.

Symptoms.- Intlammation is scarcely perceptible at first, or any other symptom; and as it is ritally necessary that we should apply the remedy thus carly, we must employ the discriminating test described at page 171. If the existence of adhesion, which constitutes bone-spavin, be not discovered in the manner proposed, the disorder proceeds until it may be perceived upon comparing the hocks together. At first, the inflammation is but trivial, when the horse is also lamest; but when time has heen allowed to unite the bone, the heat and enlargement increase, and the spavin is incurable, but the lameness is less.

Cure.-At the commencement only it may be eflected easily, by simply blistering the part all round the hough, in such a manner as to raise the blister to a good extent. Generally, in bad cases it would be adrisable to repeat the blister; in which event let the former nne be first well cleansed away with Goulard's extract, diluted with water. But should the duration of lameness and degree of swelling give reason for apprehending that the adhesion is un commonly extensive, let the part he fired previously to blistering. Be careful to keep the horse's head up whilst the blister is operating, and subsequently dress with hog's lard; but do not use any greasy applications previously to blistering, as these only tend to harden the skin, and so obstruct the perspiration and absorption which promote the cure.

Making the shoe thin on the outside at the heel relioves the pressure when the horse is worked : the contrary form of shoe is conducive to all diseases of the leg bones.

\section{CURB.}

Cause.-Inflammation in the sheath of the back sinew ( $b$, fig. 2 , plate 2, ) a little below the point of the hock, where the sheath is attached to the muscle. Like sparin, curb mostly affects young horses of the cew-hocked built, whoso legs stand too much under the body, and which have been worked premafurely hard, as in cases of bone-spavin. Indeed, the two diseases bear so much resemblance to each other, in cause and symptoms, except only as to situation, that I foel no difficulty in referring the reader to the preceding page for my description of these, only premising that he can not discover the eoming f a curb, by any other means than lameness, and comparing the two legs to each other sidewise, when a diffused stwelling may be seen, but very littlo heat fielt, by reasor of the disorder being deep-scated 
Co e. - It may be effectually removed at first, by blistering, as in cases of sone-ispavin; hut when the disease has lasted a long time, firing must be re. Bontel tin with the same precautions as those before recommended. Ease may be aflini.d liy adding to the thickness of the heels of the shoe.

\section{SPLENT}

May be tooked upon as a disomler of the foretegs, though occurring on the hind one., at times.

Causc.-Working of young horses before they have acquired sutficient stamina, or on lahour which is much heyond their strength, as in case of Fipavill, curl, \&ec. to which the reader is referred, and the concussion which the leg receives at every step, upon hard ground, stones, \&ec.

Symploms.- - Irerguent lameness, that goes off and returns without apparent cause for either, before the splent shows itself upon the shank-bonc, which it does above the knee, inside. Similarly hereto, it affects the bone of the hind legr, and then acquires the name of bone-spavin. Inflammation of the skin is suron felt, and the horse goes lame until the splent is completely thrown, and afterwarls he does as well as ever, except retaining the splent mark, perhapss ; liut severe cases occur, that do not terminate so favourably. Such happens when the shank bone has recrived the concussion, that causes the enlargenient and rupture, which constitutes the disease, at the hinder part of the leg, whre it meets with tenduns or the suspensor ligament-(See back view, plate 2 , fig. 2, 3.) The lameness and the inflammation are then greatest, and the splent requires our careful attention.

Remedy.- But should not the horse throw out the sprlent on this last mentioned dangerous part, and become lame, he will yet suffer much in all ordinary cases; for the culargement of the bone strains the membrane which covers it tightly, as described in Book 1. sect. 17. p. 20. For this purpose apply a warm stimulating embrocation, which affords relief in the more favourable cases; but when the splent rises under the ligament or tendon, blistering or firing must be resorterl to. The latter, however, is proper only in extreme cases, and only to be adopted when blistering is found inadequate to the purpose; if the swelling is hot and tender, firing would have the effect of enlarging the whole bone of the leg, and even the blistering liquid is improper when this symptom is highly prevalent. Rather let the heat subside, or assist it in doing so by means of Goulard's extract, diluted with water, frequently applied. When this has reduced the heat, employ the following

\section{Liquid Blister.}

\section{Cantharides pulverised, 4 drachms.}

Mix with sweet oil to the consistence of treacle, and apply the same twice during the day; thus, - Let the hair be clipped off close from the part, and all round the $\mathrm{k}(\mathrm{g}$, and the blister well rubbed with the hand for five or ten ninutes If this does not cause further swelling and a discharge of a clammy nature, a third application of the liquid blister becomes necessary. After a day has elapsed, dress (wo or three days with hog's lard, and the patient may ire walked about, to get rid of the stiffness. It may be proper, after this, farther to reduce the heat by more applications of the Goulard's extract, as alone.

Shoeing is supposed to nccasion splents sometimes, it being the practice with 'nost smithe to make the inner lueel of their shoes thinner than the outer; and rle inner hecl being also lower than the outer, occasions the splent bone to re. 
ceive the concussion more sharply than the outer one; for, as I before observed splents oftener occur on the inside of the leg than on any other part of it.

\section{MALLENDERS AND SALLENDERS.}

Scurvy eruptions on the bend of the knee-joints, or un the corresponding bend in the hock joint; the first mentioned term being applied to those eruptions that appear upon the fure leg, the second, sallender, is confined to those of the hinder leg. A crack, with much soreness, accompanies both.-The cause may be found in the gross halit of body, attended by suppression of some evacuation, as stool, urine, or perspiration; therefore, to

Cure the patient, restore the defective evacuation by giving one of the two purging-balls prescribed at pages $86,8 \%$, accorling to circumstances; or a urineball, or the emetic tartar, at page 65 , or 113 , in smaller doses, and the scurf decreases until it wholly disappears.

Let the hair be cut off cluse from the part affected, and the scurf well washal with strong suap-suds, and then rub over it daily, of the

\section{Ointment for Scurvy Eiruption.}

Red precipitate powder, half an ounce.

Hog's lard, 2 ounces. Mixed well together.

Sometimes, a poultice, in which is introduced acetated litharge, becomes ne cessary when the eruption is divided by a gaping crack, which the ointment may have occasioned. The blue ointment is employed by some instead of the above ointment.

\section{STRAINS.-LAMENESS.}

These are the most deceptious class of ailments attributed to the foot of the horse; for many such are spoken of in the most confident manner which do not exist in reality, whilst others could not possibly happen to the parts indicated by the names they commonly bear; yet shall I fall into this old method of titling the various affections of the limbs, in order to make myself more generally understood. Our neighbours, and rival veterinarians, the French, in the instructions issued to their smiths of the army, went a little farther in their cumplaisance to error: "All swellings of the tendons from the knee to the coronet or from the hock to the heel, show an extension or strain of the integument. Take off the shoe and pare the foot." In fact, their practice of giving rest in all cases of strain, which often effects a cure with very little further assistance, could not be more assuredly complied with than by thus taking off the shoes; for the Marechallerie were ill able to retain their sick horses in quarters upon urgent occasions of active service, unless they could demonstrate the fact upon the view to their superiors. By this general mode of forming their judgment as to the cause of all swellings before or behind, we may perceive they included all "extensions" of the bone in their notions of a strain, and treated spavin, splent, curb, strain of the tendons and ligaments, all in the same manner at first. Of these latter-mentioned we come next to consider the distinguishing symptoms and most appropriate metheds of cure; and I will here candidly allow, at setting out, that our neighbours took a correct rinw of the general cause of all lameness: those strains which occasion inflammation of the ligaments, tendons, and muscles, always communicate fever in the foot, whence arise thrush, canker, sand crack, \&c. \&c. We very improperly, as far as precision is concerned, term all lameness of thrs tendona 
Ke. a strain, though it may arise from any other cause, as frequently happens. viz. a blow given by the toe of the hind fost, in hunting over heavy lands, whon the fore foot is detaincd too long in the ground, coming in contact with rulling stones in leaping, the kick of another horse, \&ec.

\section{STRAIN OF THE BACK SINEW AND LIGAMENTS.}

Cause.-Pack sinew is the vulgar name for the tendon, which the reader will find depicted in a section of the foot at page 166 , and marked $(k)$. It ascends behind the small pastern ( $i$ ) and large pastern, up to the knee-bend of the fore legr or the hock joint of the hind one, respectively. In plate 2, fig. 2. at $(a)$, this sinew is acrain shown, where it emerges out of the heel, and enters its sheath (b), to which it is attached in a certain degree, by means of very finc metnhine, adluering from side to side, and capable of distention or relisation. The sheath itself is attached to the two pasterns, of which it thus becomes the tendon or support; whence the back sinew and its sheath, or flexor, togrether obtain the plural-tendons. Within the sheath is secreted a fuid, intended for lubricating and defending the parts during the very great action to which they are liable in every effort of progression. As happens in all wther secretions, this one sometimes fails to produce enough for the intended purpose, when the sinew and its sheath adbere together, or at least do not act with freedım; the consequence whereof is lameriess in a greater or less degree, which may be temporary only, or become permanent, according to crscumstances. If the dryness and adhesion be trivial, as happens after hard work and a night's rest, the horse upon getting warm, loses the lameness this deficiency has occasioned, for the secretion has been thereby renewed, and the lubrication is now supplied in sufficient quantity ; but the horse falls lame again next day, probably, and if he can not be allowed rest, 'tis 7 to 1 that he becomes yermanently lame. In this respect the French beat us hollow (as just before remarked), though they do not profess humanity so sensitively as the English; and even the Arabs, though robbers hy profession, by habit, and inclination, are too sensible of what is due to a faithful animal in distress, tc travel on lame horses. The same fact was before adverted to at page 170 .

Symptoms. - That sort of strain which consists of relaxation of the back sinews shows itself by the horse going low upon his pasterns, in consequence of his "carrying high," or heing trotted constantly in harness. Occasional lameness sometimes ensues in that fore foot which beats, or has the lead at setting out-generally the off one; inflammation of the whole foot may be felt by comparison with the heat of its follow, which is aptly enough termed "lever of the foot" by the old farriers. This is a very puzzling kind of lameness, no other symptom than those presenting itself for us to ascertain the exact cause; and of course the less observant persons are very likely to apply the wrong medicine, and render the horse a disservice instead of doing him good. The lameness sometimes goes off without any treatment whatever but rest; it is, however, more frequently accompanied, or followed, by some disease of the sole, in consequence of the secretion of horn in the foot being obstructed. Sard-crack, thrush, corns, are among these evils, arising from supernatural heat.

Whenever it so happens, that the secretion does not restore to the entico tendons their original motion, it follows that some prart adheres to another inflammation is the consequence, and the horse becomes worse and worse every day he is put to work, the lameness never leaving him altogether. When the adhesion begins extensively, the inflammation and sweiling are equally $\varepsilon_{0}$; the pain is the! very great, and the lameness complete and pernament. "This denotes the disorder called "strain of the back sinew8." In 
very bad cases, or where a slight attack has continued some time, the ligament that passes between the back sinew and the pastern bones becomes greatly diseased, and conducts the inflammation to the foot, affecting alike the sole, the coffin-bone, and the hoof, with heat.

"Fever in the foot" is that low state of the symptoms which arises from a slight attack which has been neglected; the more virulent attack must como under separate notice.

Cure.-Rest is indispensable; foment the entire foot with warm branwater, or make the whole into a poultice sufficient to envelope the foot all over, as high as the inflammation may extend, which is sometimes as far up as the fetlock. When the heat is greatest at the sole, and the fever extenus no higher than the coronet, a stuffing of cow-dung will reduce the heat considerably; it may be secured by thin splinters of wood, and changed twice the first day or two-once a day afterwards. Introduce a strong solution of nitre, and let it be strong, as you can not employ much of it. Both legss should be stuffed at the sole, though the sound one (if one only be affected) does not require changing. Let the animal have a loose stall during any stage of strain, or disorder of the limbs. Look after his evacuations, and cause them to be regular: a simple fever (or inflammation) of the foot depending very often upon nothing more than one or the other of these being stopped, which affects the whole animal system sometimes, to say nothing of a single limb.

Violent strains*, and swelling above the fetlock joint, when the lameness is very great, require strong physic; and the inflammatory symptorns, when running very high, with a quick and irregular pulse, should be lowered by bleeding. Apply fumentations of bran, or a poultice of the same, or of oatmeal in which saturnine lotion has been introduced, as much as it will bear. When the great heat of the part has caused dryness of the poultice, saturate it externally with the saturnine lotion, either by soaking cloths in it, and spreading these all over the part affected, or in a poultice as above.

After this treatment has reduced the inflammatory symptoms, but not the swelling and lameness, apply opodeldoc, which may be made as uniler, viz. No. 1. Embrocations. If this does not fully succeed in the course of three or four days, recourse must be had to No.2: and if this does not prove suficiently stimulating, apply the mild blister No. 3 .

\section{Embrocations for Strains.-No. 1.}

Spirits of wine, 6 ounces,

Camphor, half an ounce,

Soap, 2 ounces.

Dissolve the camphor in half the spirits; mix the remainder with the soap, and then put both together. Rub the parts assiduously twice or three times during the day.

$$
\text { No. 2. }
$$

Crude sal ammoniac, 2 ounces, Vinegar, 1 quart.

\footnotetext{
- The word strain, as here cmployed, is evidently used in the wrong sense: $n$ shouid bo prain, i. e. bent or twisted out of its proper position. To strain or stretch any thing long to a greater length, as when the back sinew is strained or elongated so as to permit the pasterns to alope or bend down, as in mild cases of "breaking down," would be more accurate.
} 
Mix in a bottle. and rub the parts twice daily. Let a long bandage, dipped ip the embrocation just prescribed, be passed tightly round the parts, beginning at the bottom and making it fast above the knee, or the hock, as the case may be. Moisten the bandage after it is on.

No. 3.

Cantharides, in powder, 1 drachm, Spirits of wine, 2 ouncer.

Mix, and rub it on the part. Although this acts as a vcry mild blister, the horse's head must be tied up for a few hours while it is operating.

A course of treatment that has been followed in this manner steadily, and with duc caution, seldom fails to restore the animal to a comparative soundness, if nut completely so : though the swelling may remain after the lameness has ceased, it generally subsides when the convalescent animal can he permitted to walk out for a little exercise, which should take place gradually, and the use of a loose stall allowed, than which there is not in the whole catalogue of remedies a more certain adjunct to be found. Going out too early after apparent recovery is very likely to bring on a relapse, and a relapse, as every one knows, is always more difficult to remove than the original disorder. Time is required for the injured parts to recover their former posture and strength, if that event ever arrive. Firing may be employed after a while, but is very often resorted to prematurely, before the tendons and ligaments have recovered position, or absorption has reduced the muscular parts to their former size, and restored their action. When three, or four, or five months of moderate labour give reason for believing that these events have taken place, firing is likely to prove highly serviceable by bracing the whole together in a tight skin, much resembling, and greatly excelling the long bandage prescribed with embrocation No. 2, in p. 178. The reader of discernment will please to note, that if the said artificial bracing be found to lessen the lameness in that early stage of the disorder, no less will the bracing of the natural skin by firing be found beneficial when healthy action is restored, but not perhaps the former strength.

\section{CHAPTER III.}

\section{SHOEING.}

Terms and phrases, in all matters connected with the arts of life should convey a good and most distinct notion of the thing spoken of. This does not always happen in our day, formerly never, ard proved a vast stumbling-block to the advance of science; but whoever termed the horse-shoe an "irun-defence, was a happy fellow, and deserves well at our hands, inasmuch as his appellation is goodly descriptive of the thing intended, and tells plainly what a shoe ought to be in reality. If not made of sufficient quantity, and of a proper material, it proves inadequate to defend the hoof from injury: if made too heavy, or ill-shaped, the shoe becomes the cause of grievous offence, of pain, heat and contraction of the horn, with its train of evils. Any workman may learn by practice, and therefore every one ought to know, at least, when too much or too little is applied. Sôme feet have the wall very thick, and the shoe will require a good bearing; if very thin, it can not carry a heavy 
slive though it stand most in meed of defence. Again, the horn of some horses' feet is so well-tempered and stout, that they might be permitted to go without shoes without dancer, if not worked upon stony roads. Time, however, and hard work, occasion brittle hoof, and distortions, with numerous gisorders that attach to the foot generally, or belong to the sole only.

When these ailments berin to show their eflects, the shoeing-smith must adapt his work according to the new pattern thus cut out for him, and here begins his ingenuity : in some cases he will even have to adopt a different shaped defence for the same set of feet; but in all cases, and under every circumstance, he must fixten them on firmly to the horny wall of the foot by nailing and clenching. By paring the sole inordinately, the bones within are pressed out of position, and the wall haviug now no resistance in the horny sole to keep it expanded, it contracts and becomes shapeless and diseased. Parial parings overmuch proluce partial accidents from without, and engender diseases within, which have received a great number of names according to the situation, but all having their orierin in this or some such injury, and all producing contracted hoof and sole. 'The importance of avoiding this baleful practice may be dediand from the areat anxiety of our ancestors to particuLarize, by so nany diflerent names, this single disease of the sole arising from contracted hoof. For whenever constitutional diseases fall into the foot, they never aflect the sole, or any part of the bottom, unless attracted thither by accidents or contraction of the hoof, by reason of this paring and rasping avay of the natural defence.

Under each of these heads of information, I shall presently place before the operative reader a few plain and intelligent precepts, accompanied by some admonitions; for most assuredly, that teacher who contents himself with telling the learner what is necessary to be dome has hut half performed his duty, if he leave uncorrected certain long standing errors, which he knows to exist, and to have received the sanction of ages that were confessedly working in the dark, as regards horse-shoeing above all other operations. But the method of performing this operation is avowedly not to be taught in its rudiments, upon paper. Practice is indispensable, manual labour requisite; and much of it, conducted by an intelligent mind well versed in books, is necessary towards forming the proficient shoeing smith. Hitherto, however, from the nature of the black-smith's trade, its laboriousne'ss, and the deficiency of general education down to a late periol, most of the operatives in this branch of mechanical labour were precluded from nequiring the additional information that books contain, after they had once adopted their future calling. Error and prejudice lad fist hold of our ancestors, for ages; hut the prevailing national desire of acquiring the minor school endowmints promises a different result at the present day, and on this oceasion, when Science has been disrobed of her cloak aml the niceties of $A$ rt are sought in language that all can comprehend.

'T'he shoes anixed to the feet of their horses by the continental farriers differ materially from our own and from each other; which proves that no fixed principle is acknowledged by either of them; though the English and the French assimilate together the nearest of any, and are those, I apprehend, that approach nearest to perfection; notwithstanding the controversies and bold assumptions of superior wislom, and the "patents" that enabled a few persons here to give themselves airs, and to set up pretensions they have miserably failed to substantiate. The jointed shoe, for instance, of Goldfinch, ani of B. Clark, which is the best modification of the old semi-oval defence f:r healthy feet, was preceded a whole century by the French author of "Lo Thu sat" a folio French work, noticed by Mr. Bee in the Annals of Sporting, for 1823. 
Practical Precepts.

The Shoe. In quantity or size, the common defence of the full-grown norse's foot is made nearly half an inch thick at the toe, but near the heel no fivurth less; here, also, it must be made narrower by the half than at the toe, where it is an inch wide, and so continues round to the quarters, lessening away towards the heel, where it is but half an inch wide. Very near the outer edge a groove is made, not too deep, but sloping from the side next the rim, in order to throw the heads of the nails slanting, when the final hammering down takes place. A practice prevails of making this groove, called ful lering, much ton close to the edge; and to so great an extent does this mista. ken notion prevail, that he who could so make it nearest to the edge without cracking the rim was long considered the best workman. This, however, is not the most approved method of our times; for the nail-holes that are to be punctured in this groove are thus brought too near the edge of the horn, so that the nails do not hold fast, unless driven and clenched high up on the hoof, which also is an exploded part of practice. Neither should the fullering be continued round the toe, nor to the quarters, lest you weaken the defence where its protection is most required.

Iron is the only material proper, and the toughest is the best defence, as it affords a small degree of elasticity in action, is least likely to crack, and is cafrable of being hardened at the wearing points at will. 'The toe alone is usually hardened at the time of making, unless in winter, when it may be found necessary to turn down the heels, termed frosting, when these may also be hardened, or steeled.

Some persons frost all their shoes in winter, by fullering them all over the ground surface; but this rough soon wears away, or is of little service from the first. On turning the heel down, a crippling gait is produced if the rough be long, especially with heavy horses, having low hoofs, which may be counteracted, so long as the roughing lasts, by turning down the toe also, and steeling both. But then the necessity of frequently removing the shoe, and thus impairing the wall or crust, may be remedied by making screw-holes in the ground surface of the heels, and proviling a suitable supply of screws with steel heads, that may be applied and screwed on fresh every day if nced be. Sizes of course would vary according to that of the horse and shoe.

Shape. For sound fect, buth surfaces of the English shoe are made perfectly flat, the inner rim being thinner than the outer. The shoe extends all round the edge of the wall or crust, which it is desirable to defend, and termi. nates where the bar and crust join at the heel. A curve upwards, at the toe, to prevent tripping, though sanctioned by authority, and carried to an extreme by Goodwin, and others, is seldom desirable, even with heavy horses, or those which go close to the ground, and is well met by a modification of the German and French method, of forming the shoe wider than ours, and consequently less pointed at the toe. The toe being then rasped close to the shoe, no tripping takes place on that account.

The French form, or shape, differs from our English shne, in being made wider and approaching nearer to a semicircle, and instead of being flat next tu the hoof, is hammered hollow, which renders the ground surface convex; 2 mode of proceeding that suits admirably with their coarse footed horses, and comparatively harmless roads Imeaning neir petit chemin, ard the sides of their grand chemins], but is inarlmissible in England, excepting perhaps with sur agriculturist owners of the like ordinary cattle. They also make their shoes as thick at the heel as at tho toe, which is a transcression against the general precept, at page 180 , that 1 can not reconcile with propriety: what is more against the French, they take little heed of hardening either toe or heol 
An adjustinef curve upwards, which they give to the toe, could add nothing to the security of at horst's going aloug safe on our roads, whatever it might do on theirs; but their system of punching and nailing is altogether so excellent as to deserve imitation more extensively than it has hitherto been honoured with, and is deseribed with due diserimination lower down. The horn at the twe would of course be made of a fit shape to receive such a form of shoe as the French; and 1 have reasin to believe that it aflects the toe of the coffin-bone in process of time, which also becomes curved upwards, precisely after the form thus factitionsly given to the horn, and doubtless gave rise to the discrepant representations adverted to at page 166.

On finishing off fine work, let the inside of the edge or rim of the hinder shoes be well hevelled ofl towards the grouml, and rounded, to prevent the pussibility of coming in contant with the fore foot: with horses that are apt to forge, the necessity of kereping the fore-she heel short, so that it may not project beyond the natural heel, should never lee lost sight of. So, of the inside of the fore shoes to prevent cutting : let these also be filed ufl, sloping, towards the ground, though not so far as the heels.

An inproved form of shoe, preferable to both the foregoing, has been rerently introduced, which is an assimiation of the French and English shoes. Instead of adhering to the old practice of fullering the ground surface of the common English shore, to admit of punching the nail holes therein, it is the improved practive to huilow that surfice, and leave a shoulder towards tho outer rim as a protection to the nail heads. 'This is performed by a tool resembling the incad of a hammer, one face whereof is well represented by the annexed figure; the lower part at (a) lheing placed on the work, as is $b$ usual in fullering, hut nearly a quarter of an inch from the edge; the hammer is applied at (b), which leaves at (a) the desired shoulder, and along that surface so far as nailing is necessary, a hollowness equal to the inner stope of the tool. This hollow is not in fact any more than a wider fuller, extending the width of the shoe, excepting the wilth of the rim left at the outer edge; though some do further prolong the hollowing all round the toe, and to within hali an inch of the heel, whereby they leave a slight caulking that never incommoles the animal, but which may he increased in quan. tity and hardness towards winter. 'I'he operation of hollowing the ground surfice just described, produces a slight convexity upon the foot surface threefourths of the shoe's wilth, leaving the outer fuurth still flat to receive the bearing of the horn. Hereby the distance between the sole and the inner rim is increased, and is moreover less likely to retain stones, gravel, or filth, than is the usual flat surfaced shoe, and possesses all the advantages of the seated shoe of old Osmer, that has been claimed by some of our moderns. Moorcroft took great pains to recommend the seated shoe, but finding some ditficulty in getting them manufxetured, he set up a machine for puncturing out the hollows, that quite failed of success, because the power employed was only equal to cutting solt iron, and this was found inadequate to the requireci wear, we are told. "Why he did not subsequently harden, or "steel" the toe and heels, seem surprising.

Healtiy feet are those alone which 1 have kept in view hitherto; the barshoe, concave and seated shoes being contrivances for ill-formed and diseased feet, require separate notice.

Ohjec.ins lave certainly lsen raised against this mode of forming shoes, that seem platusilie emough at first erlance: not so fast, however; for upon cool examination they vanish. The oljectors aver, that because we can not impart the desired frectom of expansion to the whole of the foot, forstoth, we are not to allow it at any part : if we can not get all we want, we are to reject what is within our reach. One if these. who is likewise the last, tells us, 
- In order to aduit of expansion and relaxation of the hoof by a joint, it woule] be necessary to make the nail holes wice enough zo allow suffirient play between the shoe and the nails [!], thus promlucing an eflect similar to the enul play of" carriago springs. But even suppusing (says he) this provision wero inale, the shoe would soon tear out the nails."

The jointed shose- A form of stsex: was proproumbel for cutting the slooe

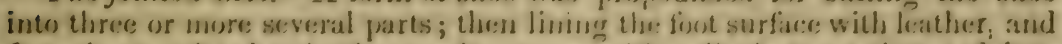
fastening on the shoe in the usual manur, wilh nails that were inserted into

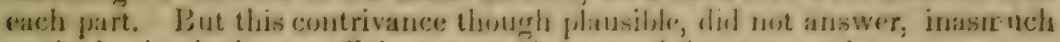
as the leather fard not sufficient strengih to stand the wear and trar.

Mr. Bracey Clark may have been the real insoutor of the jointed shose that bears his name, for aught $1 \mathrm{know}$, but he lalomers umber the disadvantage of lwing precented hy about a century, by at Frotels author; so that his battered saying that his great discovery ! forns "a hasis for the repose of the profession," however celegant in expression, lecenturs monsense ti) our rars, who concede mothing to sirsple gerstility, ambless than that to se If -complacent eogotism. "Clark's shoe," in its various moulifications, diffi-rs mothing from the grencerality of stoes, except in lweing disibed at the tew, asul fastencel acrain by means

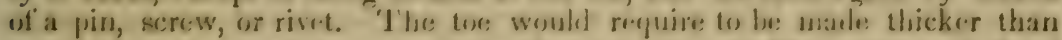
usual, let we sugerest, to prevent the rivet's partioge, and to secure reach head of it in a counter sink; one half the thirelowess of the toe is to be cut aswa on one side at the groumd surficer, and from the feot surface of the wher hatf, resembling what is termed in carpmutey; a mitre; and these fweing brought close

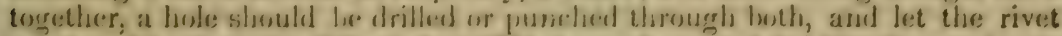
employed be the size of the hule. WV hateser drgree of rigidity the workman might restore to the entire slowe, it is plain that the groat weight of the horse would very sun strain the rivet, so as to (ause it to walax therefrom, and allow the heels to expand by so much. 'I'hat this night extend over a larger part of the front of the hosf, Mr. Clark preferred nailing the shoe pretty far back towards the quarters, which I reckon among the mistaken notions of the whole class of improvers. But, mark the dissomance of our teachers! the next inventor or inpurover ran into the other extreme, erroneously punching and nailing up intolerably near to his rivtes or pins, for he has two of them, as per marginal cut.

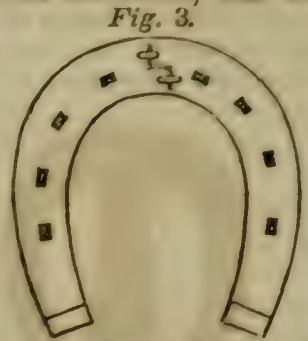

This representation of the shoe inwented by Licutenant Colonel Goldfinch exhibits a modification of "Clark's patent." Like it, the recessity of making the shoe thicker at the toe than usual with the ordinary shoes is evident. The fatesst was conrolled in October 1821, granting to Lientenant Colonel Henry Cislifinch, of Jythe in Kent, an exclusive right for fourteen years; and his spreification of its advantages and novelty, and the manner of making it, ap. porars to be as follows: "The separation is to be made in any indented form, and the two parts fastened turgether with pins. It is further proposed to at. tach the shor to the horse's husef by driving the nails obliquely, as in the French marner of shoeiner. With this view, the nail-holes are to be puriched about one-third to half the wilth of the s!oe distant from the outer edere, and tend. ing in a slanting direction sutwards." In this laterer reconmendation 1 corp. dially join the culonel : he was the first writer who noticed it, and is the mode rif punching and nailing hefore alluded to, and hereafter described as the only nise conrse. Since 1 fiel it was arlopted hy the more intelligent smiths of tino metropolis, and is hereafter minutely described. One main lilunder whien the colonel commits is evidently intended to correet the visible insecurity or ni 
shoe at the joint: his holes are punched so near his patent joint as to restore the rigid inmobility the patont pretends to amend.

Coleman's patent shove for giving pressure to the frog continues in use (though in a very limited degree), notwithstanding the demonstralility of ita inapplieation to frugs alrealy diseased. Bint, in the hands of the professcr himself, and any practitioner tolerably habile in his profession, 1 was free to allow, from the very first, it might be remlered available-but not in ordinary hamls; * with these it has failed of suecess-in sone cases from the want of an assortment sulapted to the various kinds of feet; a defect that may to now romedied in some measure.

Under these new circunstances, and sieeing that Mr. Coleman's opinions as to pressure, and the distases consequent upon the absence of it, are emboxiced in his specification, drawn up to obtain this patent (for the professor has several), he may be allowed to speak for himself on this ever interesting sulyjot. He says, "the improvement proposed in this patent is to provent contraction, mad to relieve contracted leet, contracted frogs, flat soles, corns, sand-cracks, thrushes, canker, and quittors, and also to prevent cutting."

'The patenter observes, that the "fore feet of horses in their natural state nre nearly cireular, but from the ordinary shoe worn in this comntry, which keeps the trogs from oft the ground, the hoofs of horses with light fore-quarters are generally found to he more or less contracted, and this in proportion as the frugs are inore elevated, and support little weight:" whence the cause of those diseases. To remedy this defeet, and to afford the necessary expansion to the hoof the patentee proposed the annexed forms, observing that no specitic firm of shoe can be suited to all horses under all circunstances, and toevery sort of road; it being necessary to alter the shoes of the same horse at diflient periols.

'The construction of the professur's shee will be seen in figures 4, 5, 6 .

Fig. 4.

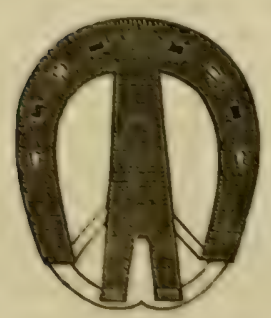

Fig. 5.

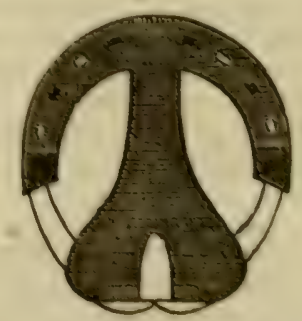

Fig. 6.

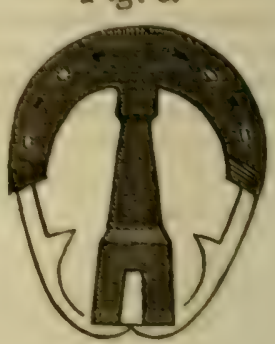

" The bar of iron down the middle of the shoe, called the frog-bar, is made broader than the frogr, and welded to the shee. This bar, when the cleft of te frug is diseased, is slit open in the middle." But all that 1 have seen in the are without the slit represented in the margin; and the welding on of the Lar is greatly objectionable, inasmuch as the chief sirain is at the junction of the har with the shoe or tip, and I have often seen the bar break off here, of else draw the nails, and throw the patent shoe altogether.

Of preparing the heof- - The general principle of all shoeing is to support she fint of the ground by means of the wall or erust, so that the fing shall not eome in contact with the hard plain road, whilst it may be allowed to receive pressure from soft ground : the first prevents injuries and resists wear and tear,

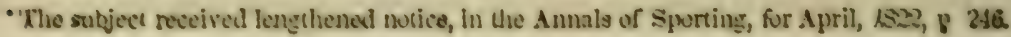


ne latter promotes the secretion of healthy horn; the proper degree of jrea ure being received by the heel, frog, and hars. Whatever is here eaid, the "re foot is still kept in view, unless the hinder foot is particularly mentioned, and occasion will present itself for the distinction, as there is great difference oetween the two, as regards heavy draught cattle. Greater hicat, fever, and affections of the lungs also cause the fore feet to contract disorders unknown at the hind foet; whilst a tardy circulation of the blood, and the conseque it relaxation of the animal system, to say nothing of the evils incurred by heavy dracrs agrainst the collar, produce affections peculiar to the hind feet. Some thing more is said of this kind of variation at page 12 , Book $I$.

When very much flaky or rotten horn presents itself, the sole should then be pared the least, for this is a proof that great heat, or inflarnornation, affects the whole sensible foot, and that the hoof is then too brittle. When the flakiness is trivial, run over the whole surface with the butteris, or knife, but go no deeper than the removal of the lonse flakes. La Fusse and Moorcroft were both in the right when they told us that paring the sole inconsiderately is "the chief cause of contraction," for the sole is thus rendered less capable of resisting the pressure of the wall on all sides, and of the coffin-bone within, inso much, that were the paring carried to an extreme, this bone would protrude at the sole and come upon the ground for want of sufficient resistance. Whenever a sanith applies his thumb to the sole, and then cuts again until ho causes it to bend under the pressure, let hirn be admonished that he coritributes his aid towards contraction of the fort, and some one or other disease of the sole. He has hut to cut away a little more to arrive at the sensible sote, which would produce blood, and ruin the horse by a quicker mode than thumbing and cutting.

The frog selitom requires the knife; never after the removal of a show which has allowed it to come upon unpaved ground; for then the wearing away is carried on naturally; but if not so, the rough and rotten outside must he taken away, which sorne smiths eflect by first tearing away the slips, or exfoliation, and then paring the mealy-looking part underneath. Hereupon the well recognised healthy horny frog rnakes its appearance, but is by no means to be mediled with. 'T'he cleft is to be cleared out by means of a knife having a sharp return at the extrenity; but it must be evident that if the cleft has incurred no foulness, nor the frogg grown luxuriantly, neither the one nor the other will require the least reduction. I will not say a word on the necessity of removing the rotten overgrown horn at the toe, and round to the guarters, so as to obiain a proper seat or bearing upon the shoe, this being an affair within every one's compass; but the rasping should al ways proceed with the shoe before the workman's eyes, unless when he may find it necessary to take it to the fire for the purpose of making alterations. The habit of doing this to a nicety with a single heat may be acquired without going to the fire half a dozen times, as I have seen dine; least of all should the shoe be tried on hot, that the most ignorant of workmen may see where it bears most, or the least industrious lessen his labour by softening the horn. Ruinous consequences attend the application of fire to the feet, and yet I remember the period when it was the common practice to place a shovel of hot coals on brittle hoofs to easo the workman's lainur!

When a foot is fitted to receive the shoe, the bottom resemblas somewhat the hollow and rim of an oval dish. On being placed on a plane surface, the frogg and heels bear equally; but when the shoe is applied, the frog is raised by as much as the thickness of the shoe may he at the heel. At the heels, for nbrut an inch of its length, the rim of the shoe is to project beyond the nut wide of the hoof. 
Take good liced that the inner edge of the shoe-heel bear not on the ground more than the outer, but the contrary.

Nailing, a very important operation, requires much previous study of the formation and functions of the internal sensible parts of the foot, many inju. ries being inflicted by penetrating those parts to the quick, and thereby oceasioning them to fester, as we shall see presently, when treating of the diseases incident to the sole. A good aphorism has it thus-"If it were possible to keep the shoe in position without nailing, we should then have arrived at perfection in the art of shoeing; it follows that the less number of nails that are driven consistent with safety, is the most commendable practice." I believo it was Mr. Bracy Clark, in the plentitude of his many inventions, who once proposed to fasten on the shoe hy enveloping the whole hoof in an iron delence, and fastening it by screws; but the scheme failed for a must obvious reasun-its weight increased the offence adverted to elsewhere (page 179). But I will not speculate on novelties, nor further olject, simply contenting myself with taking the evil or puncturation as one that is inevitable, though capable of alleviation. All hands agree that the less nailing we could suffice witl: the less chance there would be of driving into the quick-hence the firmer each mail is driven, the less liable is the shoe of loosening, and this good never can be effected unless the nails fit the holes so nearly as to prevent shifting, and also pass through a good portion of the horn. Doubiless, a couple of nails on each side would be sufficient to retain a light shoe for a short time, if the work be not heary, and allow that desirable expansion of the heel which all agree promotes the secretion of new horn, and the health of the foot; but we employ double the number in common work, and seven altogether in the "improved shoe,"

As before remarked, the fullering usually practised upon the common shoe is so near the edge, that the rim sometimes breaks off of high-tempered iron: whilst, if it be soft, the punching inevitalyly drives out a bulge that the smith seeks to reduce by hammering, which agrain contracts the size of the nail. holes; the latter error occasious the nails to break off in driving; the former leaves the heads exposed to be knocked off, or readily worn away; and by either the security of the shoe is diminished greatly and dangerously. Besides which objection to the old method of fullering, there is a corresponding necessity imposed upon the workman, of clenching high up on the hoof, which increases the danger of puncturing the sensible internal parts of the foot. This entire objection to the narrow fuller, or groove, is fully remedied by adopting the proposed manner of punching the nail-holes farther in from the edge, thus taking firm hold of the whole thickness of the horn, and driving out sooner and clenching lower than is ordinarily practised-say, within 3 quarters of an inch of the shoe in all cases.

The nail commonly used is much ton long in the shank for any kund of shoe, and too thin near the heal; but should be of the same thickness throughout from the head so far as the pointing takes place. The material must be of the tougrhest quality, equal to Sivedish, insumuch as the nail may bear hending forward and backward half a score times without breaking; it should have a counter-sink head to match with the second punch-holes, and the hammering which the head receives before, at, and after driving, sutliciently hardens it to resist the immediate effects of wear. Do not joint the nails too much, lest they spiinter in the driving, nor make two or three punctures before you drive home each nail : both these practices proclaim the clumsy workman.

Punching.-As before inimated, the nail-holes should ie punched as tan from the ou.ar elge of the shoe as the $w^{*}$ " is thick. A small punch of tao size of the nail's shank is to be first driven smartly and visibly through, but not su deep as to raise a burr on the hoof side. 'Then, open the Lole with s 
pritchel; and a large counter-sink punch, the size of the nail-head, is then ir be employed, but not driven so deep as the small punch; the first being of the size of the nail-shank, the second is to receive a small part of the head. This morle is, of course, best adapted to the "improved shoe" recomrnended at page $18 \%$, where a shoulder and grosve supply the place of fullering. But in every form of shoe, and every molification of nailing, the manifest advantage of admitting the nail-heal to a rest or protection from rude concussions agazat the ground, must he evident, when the counter-sink part of the head is allowed to lie deep in the shoe.

The number of nail-holes has hitherto been eight, but a better practice prerails in siome furges of driving seven nails only, three on the inside, four outsicle; wherehy the fourth nail outside is thrown so much farther back than the third nail inside. More play is thus allowed for expansion at the quarters: arsd if the pusching and driving be performed effectively, the hold thus obtained will be found fully adequate to any service to which the greater number of nails is applied. The safety of the shoe depends more upon the nails' passing through grood sound horn, and filling up the punch-holes in the shoe, than ujun their number. A good workman can hear when the nails thus tell, by the sourn of driving. After punching, the smith must not apply heat or a hammer to the shoe, with a view to reluce any bulge, or burr, which the punch may have occasioned; for this exploded practice spoils the shape and size of the holes, upon the fitness whereof wholly depends the security of the shoe. Indeed, good and proper iron does not readily incur either of those objectionable forms, nor will it break or chip off at the fuller-edge (when such a plan is adopted) like ordinary metal.

Driving the rails home properly includes no small share of skill. Formerly, he who could drive highest into the crust without uccasioning lameness ivas reckoned the hest workman, whilst the French method of driving both into sole and crust is an error in the contrary extreme, and argues no little sloveriliness and disregard of the construction of the sensible part of the foot. As may be seen and accounted for by reference to the section at page 166 , immediate lameness is not always likely to succeed the pricking of the sensible part at $c c$, but matter may form underneath, and lameness ensue at a future day, unless upon removal of the shoe it issue forth at once in the shape of blood. The hoof, which may have lost the elastic substance of this sensible part through age or infirmities, as represented at $(g)$ fig. 3 , plate 3 , is usually "pricked to the quick" at once, and flinches, or goes crippling away from the smithy.

According to the most improved modern mode of punching and nailing, the nail should enter at the conjunction, nearly, of the sole and crust, so as to penetrate almost the whole thickness of the crust, * and be driven slanting outwards, so that the clinch be little more than half the usual distance above the shoe. If the nail-holes be punched too near each other, and the driving be perfurmed by a workman who drives and draws his nails, and then peers into the punch foles, then points his nail and drives again-however well his work may aprear when put out of hand, he will but have prepared the hoof for fresh injuries at the next shoeing: after this treatinent portions of the hoof are apt to come away, and the smith is thus compelled to fasten on his defence by the toc or at the quarters, and so produce fresh offence and incurable lameness.

Di not nick the hoof, as is ton commonly practised, previous to turning the clenches; as most feet can not affiord to lose so much of their natural supporn, and even the stoutest foot ought not to be suljectrd to the loss of so much of its main strength. Feither rasp off the clincli, by way of finish, for the same reason, but hammer it down like the head of a rivet.

- As shown in the figure of Golufincli's shxe, at page 183. 
Mi R. B. Teast recommends a construction of the foot surface, that seems pery well calculated to attain his object, the preventing contraction and amend. ing the several evils arising therefrom, by raising a ridge along the wisole ex tent of the shoe so far as the heels, exclusively, thus making an inclined plane outwards of the thickness of the wall or crust of the hoof. The punching and nailing takes place at this ridge, thus affording secure driving for the nails, and a safe hold upon the iron. Withinside, the shoe is convex on both surfaces, but admits of modification, at will, on the ground surface. The hoof must be prepared to receive this form by paring away the horn lower on the inner part than on the outer side, or external eilge of the wall; in fine, so as to correspond with the form of the shoe. At least, this is what I understand in the course of reading a series of very obscurely written "Practical Observations" on the subject; for, although the plan seems admirable, none of my connexions have seen it in actual use, notwithstanding I called at his forge for that purpose. This was in 1821 , soon after the promulgation of Mr. Teast's plan.

By the means proposed, the hoof is spread outwards at every step, so as to afford expansion to the heels, and avoid pressure upon the sole; an advantage for such horses as are weak or thin-soled that is at once obvious and gratifying. His idea of giving pressure to the convex sole, by making his shoe with the whole foot surface inclining outwards, is more vague, since all that is requisite is attained by the first method.

Notwithstanding the French method of punching has been spoken of in terms of approbation, and their mode of driving and clenching low is recommended to imitation, let it not be supposed that in other respects they make the best shoeing-sniths in the world, but the contrary. Their finest shoeing is sad, slovenly work to look at; and this very excellence of theirs is more attributable to laziness than to design or plan. As one instance of this undesirable quality, they assign two men to placing the shoe, a lacquey holding the foot and bringing the tools, whilst le marechal himself hammers it on with much pomp. In Portugal they employ three, which includes the gallegos, or porter.

\section{CHAPTER IV.}

\section{DISEASES OF THE FOOT.}

WHEN these can not he traced distinctly to any specific cause, they are fairly attributable to ailment of the whole system dropping into the legs, and "fever in the feet" decidedly so, in my opinion, when both are so afficted. Therefore it was that I noticed this disease along with "strain of the tendons," to which 1 attribute its origin, as much as to other causes of general heat of the fort. Indeed the whole structure of the foot of the horse is so peculiarly curious that it almost deserves a separate study, but we must always keep in mind, whilst considering its ailments, that the great irritation kept up by its extreme action is readily communicable from the one to the other, so that we can not intelligibly separate the leg from the foot, when speaking of the ailments of either, notwithstanding I have thought proper to begin this chapter with the disorders that are situated higher up, and mean to close it with such us un'y make their appearance below.

But there remains still another distinction that may as well be drawn here, 
nefore I entes into other particulars, as to fore foot and hind foot. In all the little dissertations which I have ventured upon in this book, and elsewhere, as to the structure of the foot, and all the dissections I have made, from time to time, I have taker the fore leg and foot only, with one unimportant exception. I know not why this preference was first made; I believe it to be general, but is of very little importance. For the hind foot, though a little smaller, and somewhat more upright in form, corresponds exactly in all its parts with the fore one, until age and deformity comes on; the back sinew descending from the lough behind the pastern bones, until its insertion underneath the coffin bone of the hind leg, in the same manner as before described, as pertaining in the knee and bones of the fore leg. Further, I believe the name given by the learned to this sinew in the hind leg differs from that given to it in the foreleg, that being tendo plantaris, this one the tendo palmaris; a distinction that lecame necessary, perhaps, that they might be enabled to make themselves understood by each other, when speaking of this important tendon as belonging to the one or the other leg.

When we reflect upon this strict accordance between the structure of the fore font and the hind, and then look over and lament the numerous disorders that the first is liable to, whilst the hinder one is comparatively free, it gives us reason to pause. But without entering upon an elaborate investigation of this difference as to health, I come to the conclusion that we ought to attribute discases of the feet, as I have already those of the body, to excessive heat of the vascular system, promoted by the great exertions the animal is put to, and the ruile concussions the fore feet in particular cndure at every step; thus creating heat and attracting hither any evil humours that may afflict the boly generally

\section{FRUSH, OR THRUSH.}

A running of matter at the cleft of the frog was furmerly called " a running trush;" the moderns, however, write it "thrush." But, to frush, being old English for, to break, or crack, or crush, like the cracking of walnuts, 1 pre. fer that term before thrush.

Cause.-Depraved habit of body and disordered pulse always accompanyIng the appearance of a frush, I have no hesitation in ascribing its origin to that remote cause, especially as it is proved to be a deep-seated morbid accumulation; aided more immediately, perhaps, by an injury received whilst travelling, either by the bruise of a stone, or the insertion of gravel at the parts. This latter, however, is not a necessary cause of frush, though the gravel and Jirt work into the ulcer as soon as it opens; for the lurking approach of the Jisease towards this consummate symptom may be ascertained by turning up the hoof and pressing the cleft, which will give pain and occasion the animal to flinch : inflammation has already begun at the insertion of the back sinew in the bottom of the coffin-bone, where the branches of crural artery also enter the bone, at the bottom whereof is the sensible sole which separates it from the horny sole. See this structure of the foot described at page 166, \&c. Filthy stables promote frush, and, when the cure may be nearly effected, cause relapse in nine cases out of ten.

Symptoms. - The earliest, as just said, is denoteu by tenderness at the cleft, accompanied by sharp, quickened and irregular pulse, as usual in all cases of local inflammation, being at the same time both cause and effect. Of courso it follows, that as the disorder in the sensible frog proceeds towards maturity, the bloud feels and tells of that fact by increased disorder of the pulsation. These timely indications being neglected, as usually happens, if the animal be then put along over stony or newly-dressed roads, the first discovered symp 
tom will then be ns tumbling down through acute pain. The clen openes and an issue of a most oflensive kind presents itself.

Cure.- If not speedily taken in hand, canker will be the consequence of s nenglected frush. But, dis scarcely one in ten will take the precaution to ascertain, from the state of his pulse, when the horse is likely to ncquire this or aly other 'nflammatory disease, it may be deemed impertinent in me to say, taat the preventive of frush in its worse state may be found in purging physie and a cooling regimen, as preseribed for general inflammatory and febrilo complaints, set down at the commencement of book 2 , pages 59,63 , \&cc. fcr this disease frequently depends on some untimely suppressed evacuation, as the urine, stool, or perspiration; then let these be restored by giving the diaphoretic powders, purging or urine balls, according to circunstances. A very much hurried pulse ivould of course point out the necessity of immediato bleeding; for the animal so suffering in the vital function must necessarily contract disease of some kind or other; and that particular organ or member which may be least able to bear it is sure to feel its effects soonest. 'This is as likely to happen to a horse with defeetive frog, as to its size, texture, or shape, as to any other part of him. Then, let the eareful owner examine and find out the least perfect part of his horse, let him watch it closely in all its weakness, and endeavour to deted the first symptoms of illness, that he may aid nature and restore her functions, before these run riot beyond the help of art.

When the frog has been paresl away, and the filth of the sore removed, wash it with a solution of vitriolated copper, and apply a pledget dipped in tar or turpentine at the opening. If the case he a bad one, the wash may be made stronger by the addition of a few drops of vitriolic acid to the solu. tion; and the tar may be poured into the opening whilst warm. Place dry low, and keep it in position by means of splints. Repeat this tar dressing every other day, until the injured parts slough off. Purging physic will be necessary to complete the cure.

\section{CANKER.}

Evidently a corruption of the word cancer, as applied to a running sore in human ailments, it is yet well silently to permit the innovation, the better to heep the two practices separate, in small as well as more extended affairs.

Causes. - Precisely the same as those which produce the frush, only making its appearance at various parts of the sole, frog, dec. Sometimes the canker is hut an agrgravated frush a very bad or neglected cure becoming in my estimation a canker, and next to incurable; whereas a frush, taken in time, is easily cured. Our French neightours write of the two under the same head, of cancer, let them be seated wheresoever they may.

The symptoms are those of frush, extended also to the bars of the frog, the heel, the sole, Sc.; and so is the

Cure; with this aldition, that the paring must be carried on to the extremity, laring all the diseased parts, though these extend over the whole bottom of the foot Cut away the proud flesh to the quick, and when it has bled a little, apply

\section{The Poroder.}

Sulphate of copper, 1 ounce, Corr. sublimate, 4 drachms, Prepared chalk, 1 ounce.

Mix and sprinkle it over the exposed surface. If the disease makes a hollow 
between the hoof and the coffin-bone, the powder must be introduced there by means of a spatula, or flat pieces of woorl, with a bit of tow on it ; but do not leave the tow behind, as that might produce a fresh disorder. Butter of antimony is preferred by some to the foregoing powder, because it is a liquid and acts more generally; but it operates only for a short time before its effects cense, being killed by the moisture of the disease it was meant to destroy. Bind up the forot until the following day, when the application rnust be repeated, after wiping away roughly as much as possible of the diseased parts.

$\Lambda$ s it is foumd of mone importance to the cure, that the foot should be kept as much as possible from wet and filth, and seeing that the moule of tying on a great bundle of tow in cloth, in the manner now in vogue, often fails, a light shoe, adapted to the present shape of the fisot, should be put on, for the purpose of sustaining the dressings, \&ec. which may be found necessary to put on. The shoe has another advantage over the tying fiashion, inasmuch as it allows of the animal to place his foot fairly on the ground, a prosition that mainly conduces to the cure by promoting the secretions, especially when at length he can move about. Let the shoe be narrow-webled, with a groove on the inside edge, so an to admit of a tin sluder bring shoved in and drawn out, when you dessire to examine the under surface of the foot to change the Iressings, \&ec. Such a shoe will obviate the complaints usually raised ly our stable attendants, that they can not keep on the dressings, nor preserve the foot from damp, which always retards the cure; for they are most of them bunglers at bandaging, owing to the very little practice which falls to the share of any one prerson among the whole fraternity. Splents of wood may supply the place of tin, when this latter may not be at hand.

Whenever the cankered parts slough off, and leave a more bealthy apyearance, the powder need no longer be apyolied at those particular places. Upon these lay on a dressing of tar, in which has been introduced about a tenth part of blue stone, powdered. Let as much pressure be given to the sole as can be contrived, to prevent the granulation of new flesh coming on too luxuriantly, which is otherwise very likely to happen, on the edges of the wound particularly. In this respect, the grooved shoe will be found effectually serviceable. If, notwithstanding all your care, the edges will grow too fast, touch that part with lunar caustic; and in case the horny substance grows over the still cankered parts, it must be again pared away and laid bare. Perhapss the animal is young ared vigorous in other respects, and his system probably would jromote the secretion of new horn quicker than an older, or less healthy horse ; this differcnce should teach us to employ some digestive for the dressings, which has less tendency to promote the growth of new horn than tar has, which would be found more proper for old horses. For the younger animals, let turpentine be substituted, into which has been mixed a small portion of vitriolated copper.

From what has been said, the reader will perceive the dressings require changing with sorne degree of judgment and discrimination, and that they should not be prassed over or delayed, as he values the horse; for, upon this marked attention alone depends the cure, and such a cure as shall prevent a relapse. Of course he will not fail to take care of the evacuations, as in case of frush; nor that the earliest exercise the animal takes be proportioned to the anount of disease he has undergone in an inverse ratio.

Prcoention. - As we have seen that inflanmation is the immediate cause of all disorders of this class, and seeing that the irritation which produces this bas been brought on by distress of the parts for the want of due pressure on the frog, any one whose eyes are open may see the necessity of paring down the her:ls so that the frogr may have a bearing, when the horse is walked over ficld or turf for example. For hereby it will be seen, on turning to the bries 
deseription I thought proper to grive at the beginning of this book, puges 167 L(i). de. of the infermal conformation of the feot, that the healthy action of the parts upon each other is only to be kejt up ly the pressure of tho semsiblo tring.

"When the frog is not sulliciently pressed upon, (says Mr. Coleman) it becomes soft fiom the aceumulation of the fludel which it inturally secretes in great ahundance from the fally [elastic] substance, which lies immediately under the temlon." "This view of the process tallies tolerably well with my 20 cxamination of the subject, at the pages just referted to, and elsewhere.

\section{SANI)-CRACK.}

When sutlered to comeinue, the coure is attemded with great ditheulty, and the disorder may therefore be divided into two stiges or degrees, like many other atlections of the horse. 'The name of samd-crack is cherived from the worst of these states, whe'u sand, gravel, or dirt, has got into the crack, which constitutes the disease.

Cause.- brittle hoof will oecasion sand-erack of a very bad sort, but the acecomplanying cause is the cessation of the function of supplying matter for forming new horn in the vessels leading from the coronet. This may ane? from an external injury at the coromet, or severe treatment for some other disoriler of the finot, as a rumbing frush. As the hoof is always hot, one main cause of samelerack is referred to heated roads, to travelling in deepe, hot, sandy countries; seantiness of water, and removal out of a cold to a very hot climate, as from kngland to India (bitst and West), are all known to causo the heat and britleness which accompany sand-crack.

Symptoms. - A split or crack in the hoof, on the insick quarter of the fore foot, for the mest part, but often on the front of it, down towarels the toe, and occasionally on the outside, and also mor the hed. Sometimes it appears on the hind fiot, on the front of it, and prevails with us generally in hot weather. Same-rack is either superficial and easily remedied, or deej and extensive, reyuiring much attention, and an operation or two in its diflerent stages.

Cure.-It will be seen that a slight erack may, by working the animal, become one of the worst speedies. L'are away the roteon parts, if such be found, and make a transwerse mcision across the upper part of the crack ; wash out the sand or dirt, apply daily tincture of tar, with a pledget of tow, and give the horse rest. Bind round the hoof tight with listing, and stop up the solo with cow-dung, and this treatment will suttice in ordinary cases. But when the crack extends so high, that there is no rom left for making this incision across, to stop the progress of the erack, the disorder has assumed its worst aspect: the edges of the crack interually mow press upon the sensible part, or laminated substance that holds the cottin-bone and hoof torgether, and inflammation succeeds, if blood does not issue forth. If the crack aflects the coronet, you may draw one sile of it down to the quick about an inch with good eflect, but no farther, as that would oceasion the hoof to divide more readily. Rest, however, will restore athesion to the upper part of the crack, and when this has taken place extensively, the opreration of cutting across, or of firing it across with one line only, may be perfomed with every prospect of suecess; for as the hoof grows down, which it does from the coronet, this transwerse ardificid crack you have male intercepts the material for forming horn, on its insile, and thus contributes greatly to fill up the chasm below. To increase this supply of the horny material, let the coronet be anointed with a solution of tar and tallow and hog's lard daily, which should be extended to the horny part of the loot:

Stopying has neen mentioned as necessary to be adopted on the first or 


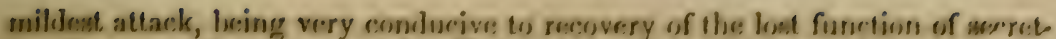

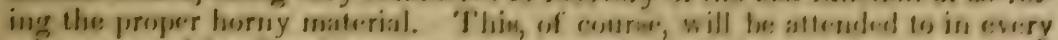

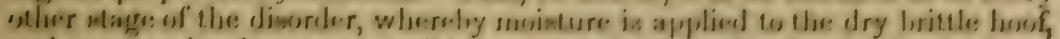

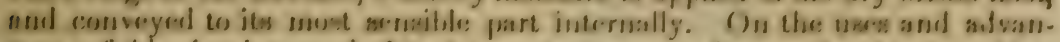

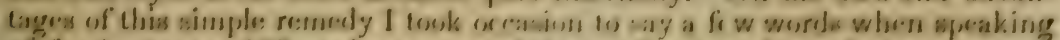

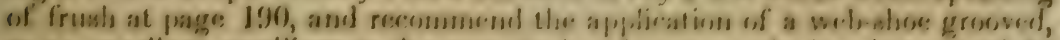

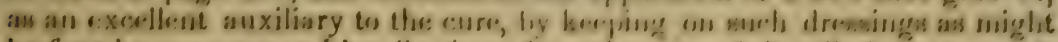

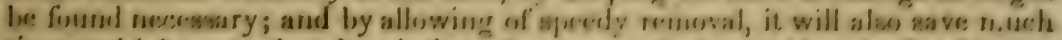

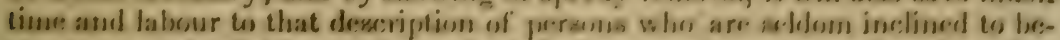

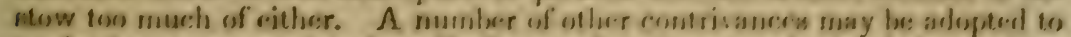

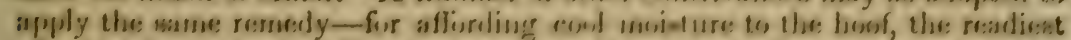
of which is the loading him forth to a shaded place, and there tethering him up, where he might stand upon the natural asel, grase, clay, or aoft groumel,

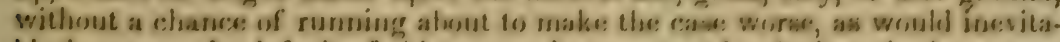

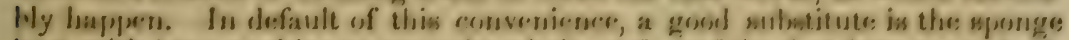

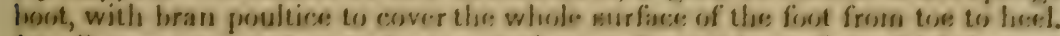

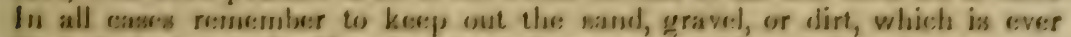
likely to insinuate icalf and protract the cure, and, if not otherwise come at. able, an oprening must be mate for that purjose by cutting down one: side

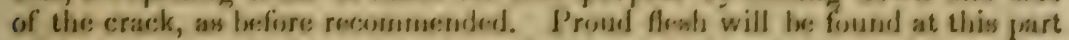

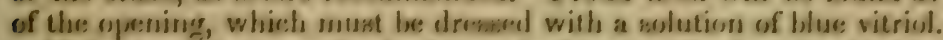

If the crar:k toe near the hes:l, merely thinning the horn and taking off that part which losars upon the whor, will asoist the cure; arsl whatever shoe may

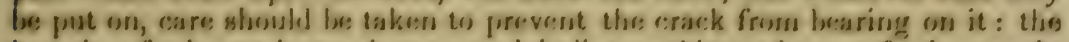

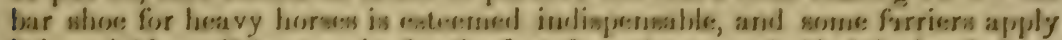
it invariably. Oehers angin fire the fort, from the upperer half of the hoof, alwo:e the crack, to the fretorik joint. 'This in sertainly derrisive practios, an the

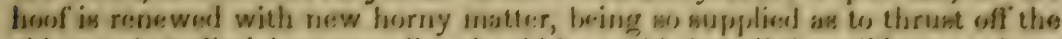
old orse; but all virleut remsedies should be avoided until the milder oross bave been tried and failed, which will not be the casce with thome means I have ree commenuled shove.

'The bearing of our English shore lwing commonly on the outer surfaces of the hoof, protsotess the crackling and chipping off of the wall. Mr. Teast's

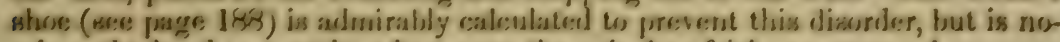
wime calculated to cure it, when once the ruin has fairly comsnenced.

\section{THE CORN.}

Causca.-I shall not repreat what is already waid on the two first-mentioned

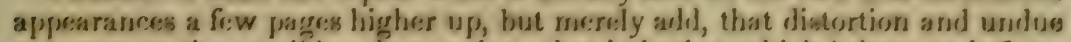
presesure on the enernible woles oresasions that irritation which bringes on inflammation of its edge, where the shuttle-fone, or her:-bone, preases sown uporn it at every step, and causers the utmot bending that the mimule elasticity of the

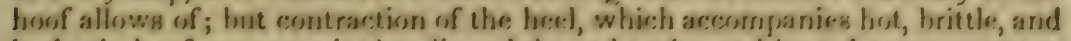
im-lastice horf, prevents its bording duly and truly, ard lateral proweres upon the quarters follows. 'The ofole bring thus unduly pent up, the cirrulation is otvetructed in its pasessege to and from the casity of the coffin-bone, and a der

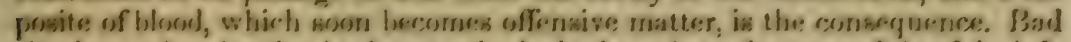

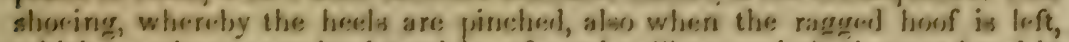
which inay have contained [rartireles of saru], will caume irritation, and end in corn, or figg.

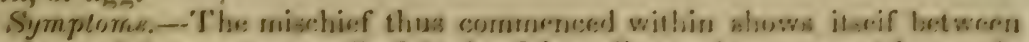
the lar wod the crumt, or wall of the hoof, in a dirty-red teusour, wist egroatly

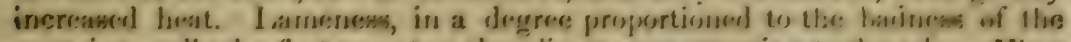
corn, is usually the first symporn that directus our altention to the sole fogk 
is but anuther name for the same kind of corn when situated close to the har of the fruer, a little firther back in the hollow of the sole. Pain, very acute on the touch; or, when the horse treads on a hard substance, he issues a moan, or grunt: it is that sound in which his voice is aptly likened to the complaint of the human sufferer.

Cure. - Although oftentimes very troublesome, returning again and again when the farrier apprehends he has cured it radically, yet no affection is easier of a partial remedy, or effected by more ordinary means. Deceived by the name, perhaps, resembling the hard excrescence called a corn, on the humar foot, they proceed at once to "pare the corn out to the quick, till the blood starts;" but they heellessly put on the same shoe upon the same thick heel and hard hoof which first lirought about the malady, and the lameness returns. Let the heel of the shoe be cut off on the side that is afflicted, or if both sides have corns, a bar shoe is recommended as giving pressure to the frog. The heels are then to be rasped away free from any contact with the shoe; if they are thick and hard, this will give them play-if thin and tender, they will thus be freed from pressure. The thick heel is most commonly aflected, and should be softened by an extensive poultice that is to cover the whole foot, after the corn has been pared and treated with butter of antimony. Tar is then a very desirable application, or Friar's balsam; and if inflammation is again discovercil, poultice the foot once more. Fire is applied by some, but theherof is permanently injured by the actual cantery; and whatever good is achieved is thus comnterbalancel by the evil. Vitriolic acid mixed, carefully, with tar, in the proportion of one-tenth of the former to nine-tenths of the latter, will promote the absorption upon which the cure depends.

But in some desperate bad case's, the matter has already formed within, most offensively, and discharges at the coronet by means of that curious process of nature which I described at a preceding pase, as affording the coronet the material for forming new horn to supply the wear and tear of the hoof. Upon paring away the horny sole, which now becomes necessary, the offensive matter will be found to have spread itself underneath the sensible so!e, which will ooze forth and give immediate relief to the coronet. Let so much of the horny sole as lies lonse from the sensible sole be pared away, and a dressing of tar, or of Friar's lalsam, be applied as before directed ; and if inflammation is again discovered, apply a poultice; should the growth of horn be found too luxuriant, discontinue the tar.

\section{CHAPTER V.}

\section{Of Strains Generally.}

\section{STRAIN OF THE COFFIN-JOINT.}

Cause. - As previously observed, lameness of the foot does not consist in a strain of the joint within the hoof, but is referrible to general concussion of all the parts, and is rather a strain of the back sinew at its conjunction with the bottom of the coffin-bone. Inflammation and accelerated circulation follow, and numbers of the fout succeds: these, if not remedied betimes, are followed by ossification of the tendon, of the ligament of the small pastern, and he cartilaginous pucess at $(f)$, fig. 3 , phate 2 , also becomes bone. 'I'hat the joint of the coftin-bone with the pastern-bone may he strained, is very probable; but no injury, blow, or concussion, ('an affect it, which does nit at the 
same lime affect all the component parts of the font. Thin honf and sule aro most liable to this injury.

Symptoms.-Dudden lameness, that is always increasing, and has scarcely an intermission, without any appearance to account for it on the limb; and the persons who permit the horse to incur this disorder ly their carelessnes; celdom have the candour to acknowledge that they know the cause to he a tread, a rolling stone, or a stumble, and the doctor is left to "find it out." A, most every one imagrines the lameness to reside higher up, as in the shoulder or the hip joint. Great heat and tenderness of the part soon come on; the latter symptom may be ascertained by striking the hoof in front with a key or small stone, when the animal will flinch considerably more than when the corresponding foot is struck in the same manner. When the horse would stand at ease, he usually does so with his toe pointing forwards, so as to keep the pastern in a straight line with the leg, and therely take off the tension or pressure upon the back sinew and ligaments: the inflarnmation shortly after reaches the upper part of the sinew, as may be ascertained by passing the hand down over it when the patient flinches.

Cure.-Blistering at the coronet and fellock repeatedly will reduce the inflanmation within. A poultice covering the whole foot also tends to the same effect, which will be further assisted by paring the sole, if it be not alreaciy too thin: reduce the frog also, and do the same for the corresponding foot.

Formerly they pared the toe tulerably close, and bled it there, by making a longitudinal incision: the usual application of tar, \&c. then completed the cure. But this is an operation that is seldom jerformed with sufficient exactness, the incision leing ton often made unwisely deep, so that other diseases were thus generated at some future day. Others, agrain, passed a seton through the heel to the hollow of the frog, taking care not to touch the sensible sole. A third set apply the actual cautery, whic! comes least recommended of either of the remedies just deseribed; especially when we consider that the actual disease is very often mistaken for some other; a remark that implies how much caution should be used in first ascertaining the exact seat of the lameness, its cause and symptoms, ere we set about the cure by such violent means.

\section{STRAIN OF THE SHOULDER.}

Horses that are weak before, and low footed, with an unsteady tread, are most liable to contract this disoreler, which consists in a twist or sprain of the strong muscles that attach the shoulder to the body. I think the horse is very hable to incur this disaster, in a petty degree, whenever his progression is accelerated to the utmost of his jowers; but we must guard ourselves against placing entire reliance upon the hastily-deliverod opinious of empiries, who holdly promounce when they hope to deceive, and expect belief from the credulous.

Cause.-Much the same as those which occasion concussions, blows, and numbuess of the fiot, with their consequences, which we consent to call "strain of the coffin-joint," without the most distant possibility of knowing whether this misfortune ever has happened. When the horse is subjected to any rule accident, as a kick, or beirg thrown down, or slipping on javernent, ice, \&e., or treading on a loose stone, he is very likely to incur strain of the muscles of the shoulder. Sce conformation of the shoulder, in chapter $1, \mathrm{p}$. 10.

Symptoms. - Decided by swelling upon the chest, or at the top of the shoti: der; but we think it desirable to ascertain whether the accident has taken place before this symptom becomes apparent. Lameness immediately suc ceeding any or either of those accidents, which may te distinguished from a 
strum hwer down he the animal's drawing his twe along the ground, from in aliity in the part to lift it off the egroumd; lut when he throws ont the foot in a semicirche, described hy the segnent at page 11, this shows that the hurt is chiclly confind to the lower part of the showher near the eliow. 'l'aking up the fint and benling the limb will further prove the existence of strain in the shoulde; if the animal evince pain; whereas, if it lie in the ferot, and sust in :he shoulder, the lame leg can be moved as supple as the souml one. The dilliculty of ascertaning the real seat of lameness is sometimes so very great, being entirely invisible, as to putt us upon all sorts of expedients to find out the real seat of the disorder. For this purpose, hold up his head high, and after emparing and finding no diflerenee in the shape of his fwo shoulders, let enc the head, when he will be observed to flinch upon bringing it towards the afticted side. Let a person rattle some eorn in a sieve at a distanee hehind, now on this side, mow on that, mol he will be observed to evenee pain at turniner the neck so as to strain the aflected side; not so it the pain he in the lout, of course. As the horse will step short, and also throw out his leg somewhat in a semicircle, when he has received a prick in shoeing, this latter s"in is not to be talien as finally indieative of "strain in the shoulder," until the fort has been examined, and the shering smith questioned as to his skill and carefuluess.

C'ure.-If the injury be considerable, as when the horse has been thrown down, he should be bleil at once, in the plate rein when it is local, but in the neck when the injury has been more general. A laxative ball, or a purgative, must follow as a malter of course, proportioned to the actual state of his holy nt the time. A fomentation of eamomile thewers, or of sealded bran, should be applied largely and assiluously at the ehe'st and inside the ellow, and theso remedies, with rest from all labour and exercise, grenerally perfect the cure.

When the swelling is great, hut not extensive, as in the case of a kick, spirits of wine, in which a fourth of its weight of eamphor has heen dissolved, should be rubled in. This will supersede the necessity of walking the horse toe early, with the hope of recovering the "use of his limb," by promoting the lymphatie absorption. A rowel is sometimes employed, when the heat and swelling are very high, with gond eflect; but the obl system of previously horing and blowing, and laving on "a charge," is exploded as barbarous and inutile. (On the symptoms afotingr, let the convalesecent horse have a looso stall, and in iroportion as his action may be free from lameness, so should bo regulated his refurn to walking, to exercise, and to work. Before he can te: tit for his former oceupation, it generally is foumd best to give the horse a run at grass; but previously he may try his powers in a contractod plot of ground? in the homestead, to prevent his induging $t(x)$ freely in exercise, secing that he is very liahle to a relapse, which is generally more difficult to overeome than the original attack.

Norimming the horse "for strain in the shoulder joint," was a favourite remedy fiomerly, but is deservedly exploded, although we could be certan that the joint inteided to be cured were the ellow. This accident, however, does not happen often: I never saw a marked ease, and merely deem it $p$ ssible; yet has the practice still its advocates. And it may be serviceable in owher re spects, as the muscles are thus brought into play, and the whole limb employ ed in quite different kind of action fo that of walking on terra firma. Some persons submit their horses to hathing, by entire submersion; an operation liat was performed most adroilly, about thirty-five years ago, by a stableman named Denis Lawler, in the bay of Dublin. His manner was to rile his horse to a convenient depth of water, and then jumping forward suddenly on the animal's head, thus souse it head foremost to the bottom. The feat caused great marvel at the time; but not so the total disapyearance, upos one ocea 
sion of the performer: poor Denis is suppowed to have reccived a kick to the

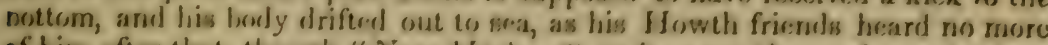
of him after that, thengh "New Larbour" underwent. thorsugh repair sinco Lawler's last kick.

\section{S'TRAIN OF' 'THE: WIIIRL-BONE: (IIIP-JOIN'T').}

A suppositituos disorder, that is more frequently foumd to to a tardy attack of bore spavin, that is slow in coming forward, and upron which $\mathrm{M}$. la Foms: n.ss thought proper to be very faceticiss: "a horse has the opavin, or he has it not," says he: "fior it is ure like a jark-in-a-hox, that waits to make his sppearance when you pull the stringe." leither spavin or strain of the whirl-

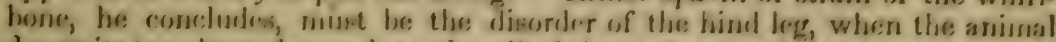
draws its toe aloug the road, as described juat above as being a symptom of strain in the fore fog. When the animal has received injury in the region of the hip, the camplioraled spirits reconumenuled in a preceding page (196;), should he applied; hut if the locat, swelling, and trosion, do not abate by this treatment, listur the parts with the mild blister, No. 3, at page 179. This application, with rest, is adequate tu any ordinary cass of hip-joint accident.

\section{STRAIN OF 'THE S'T'HLE.}

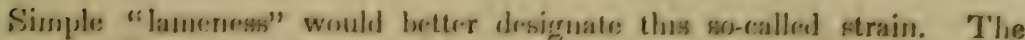
same remedies as those proseribed for whirl-bomestran will apply to thos part ; also fomentations, physic, and if the case be inweterate, a rowel, Sec. \&ec. orr: after another. Camphorated spirits, or ulimately a miled blister, are useful and proper, according to the circumstances just set down.

\section{S'IPING-UALT'}

A catching upof the hind log at revery sep the horat taker, constitutes what s.termed string-balt. It is orse of the incurables; hat this corsideration shali not deter une from cober rving, that this over-action of the himd Ieg may be brought abrout by art, or rather the ingenuity of man operating upon a known function of sature.

The cause, naturally arisiog, is wry obscure; iut the horese-exhibitionere, having occasion for much show at their angphi-theat ric coureses, soughe to bring on this "Jigh slows" ly puncturation. "T'o them let the secret belong; it is barlarous and unsecmly.

\section{S'I'RAIN OF' 'THE' BICK}

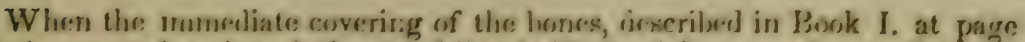
19, become relaxcol, and therely fail to hold the joints together sufficiently firm, the conscquence saturally arizing from this circumstance is, that they berul a little out of place, at every movemont the ar:ional makes, and the least accilent confirms the strain, or simrain. Merely straining of stretehing will effect this evil at times, though that le: no greatrer than an effort to relieve ra. ture by a motion.

Cause.-Mostly affecting draught cattle of the leasy kiml, and prineipally incident to cities and towns, where dray and rart-hurses are obliged to turn short upon slippery stones, we may ascribe llis disoriler to what is called a wrench, or twist in the human practice. The stealy pull, unattrided iny a

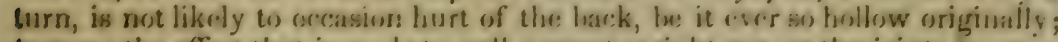

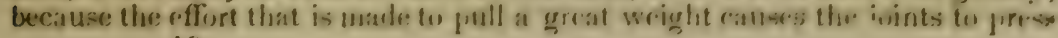


straght against cach other, every capsule heing than filled with uts mext ex $\mathrm{r}$ responding convex hone.

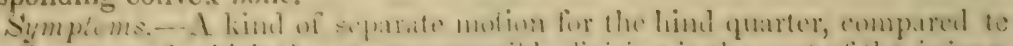

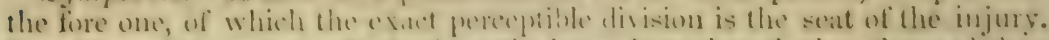
Sometimes it appears at lar back ats the homs, hut when forther forward than

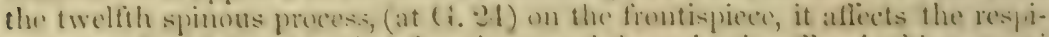
ration, and with it other vital fumctions, and the anmal sullers in his generai lesalth. It may he muscular or ligamentary, or componomed of both, in which cases the parts adapt themselves for the derangement that has taken place, hy thickening their substance, and the first lameness decreases gavally: in this erent the horse's comdition is not at all allected. While staliner his ellints are somewhat ludierous; as are also all attempts to make a trot of it when out

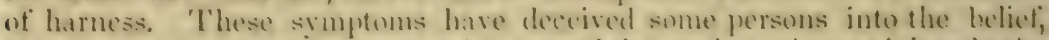
that the one or the oflere cxertion has caused the strain; whereas it is only the earliest demonstrution of it to the observer.

Remedics applied early may assist nature, hut the lameness never cam be cured complotely. If the wrench ur sprain has been of a violent sort, as in case of "strain in the shomkler," let the animal lie hided to a gond extent, i. e.

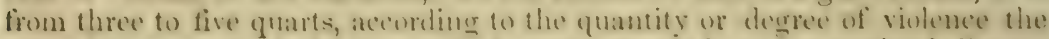
animal has sustamed; for it ustally happens that it has heen straimed all orer, in various parts. 'T'wo dray-horses, which were employed in pulling beer

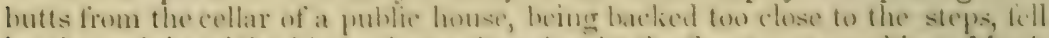

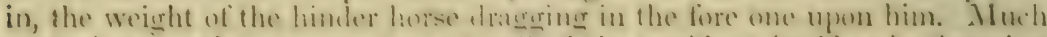

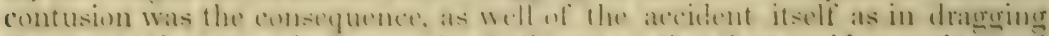
them ont : they were in thet stratued all were, so that they could scarcely stami firr a while. Bleeding copiously, however, to the amount of six quarts, re-

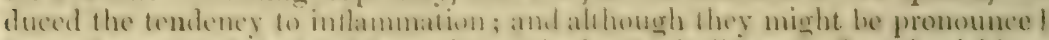
hurt all ower, and the hamb horse in paticular, hoth dit well after physicking: and a few days of light work.

I have found a fomentation of hot vincuar of very great service, in a well marked case of recent string; the plan recommended by White, of administer Eng it hy means of a woollen choth or roes, steeped and hosely wrung out, be. ing followed. A fresh sheep-skin, josit thyed, was applied immediately, and the lameness semsibly lessoned, atter (wo digs, apylying the fomentation four or tive times.

\section{EOUNDER}

Is a disurder, or rather a complication of disurdelis, of the fore feet. Some controversy has crept inte our herlis of larriery latterly, as to what really is lomm. er: and whilst some would ennfiue their consideration of the sulject to the fout only, others follow the fishion of gromens, and ascribe the incurable lanee. ne'ss that has no visible specilie eatuse, to an allection of the chest. Hence "chest founder" of the stables, and the "horly femmler" of TVhite. "Shouldershook" is a provincialism of the smilly, when the farrier ean pereeive "no thing amiss" with the feet-so far as he call see, feel, or understand. Sur. bating was ancher name griven to the symptom we now recogrise as founder, at a time when it was the pratice to divide and sublivide every disorder maler many, useless, and ummeaning appellations.

Ciause.-Hard work, bad shoemg, are and ill-usarge, cither of which produce so many other disorders pertaining to the horse in his demesticated state, precede fomblex; for, we never met with it muless the animal has been so sreated or kept, and 1 look upon it rather as a complication or eflect of serverai diserases of the fout. Somme of these, we have seen, are liable to be mistake?

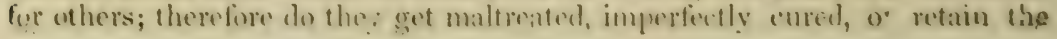




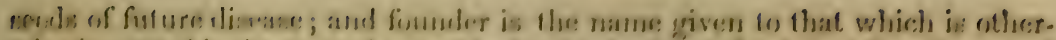

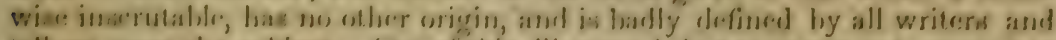
lalleres

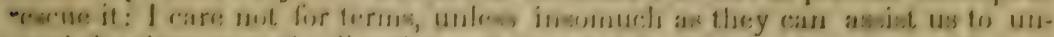

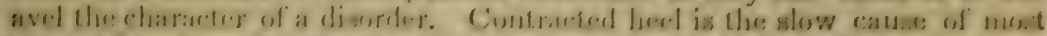

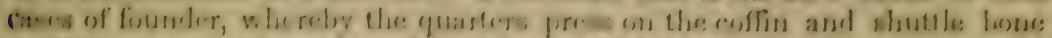

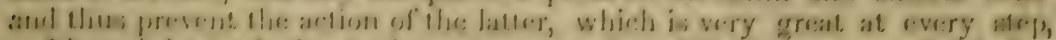

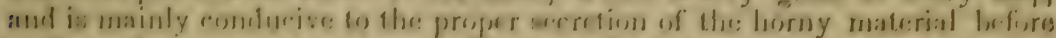

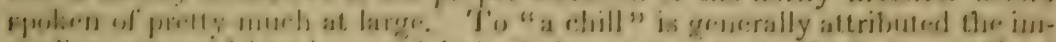

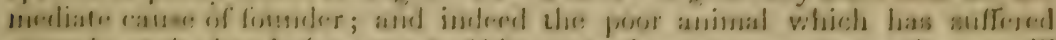

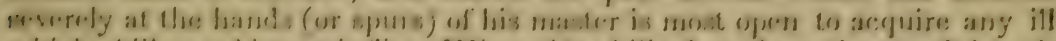

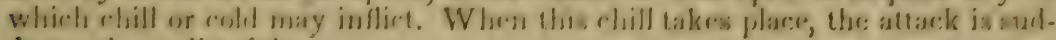
den and usually violent.

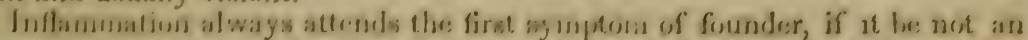

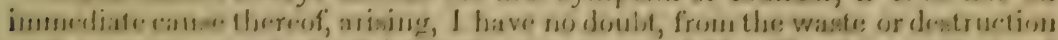

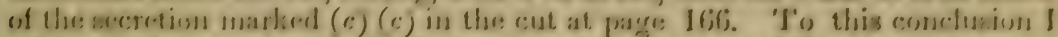

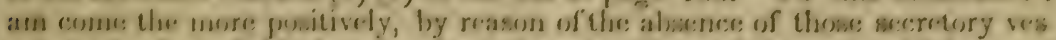

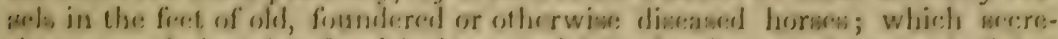

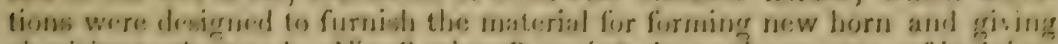

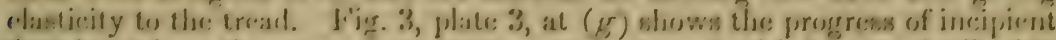

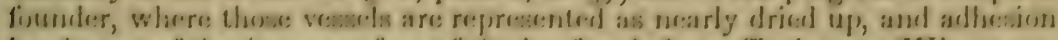

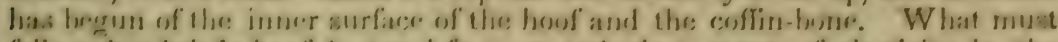
follow, but britle heof lattered feret, or surbating, wast of elasticity in thes

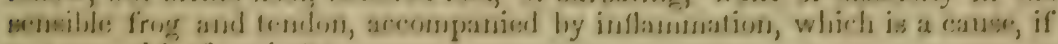
not caused by founder'?

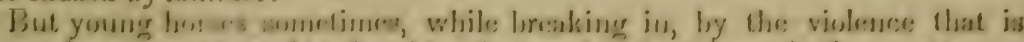

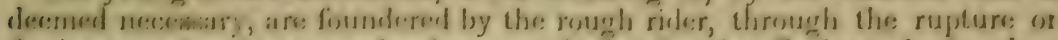

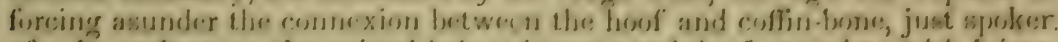

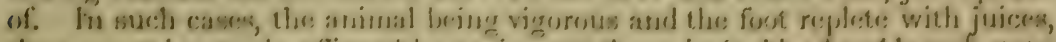

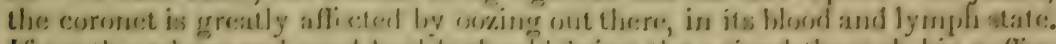

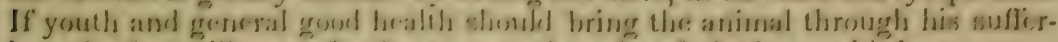
inses, its feret will reser after luat rexlernal markes of the internal injury.

Sigmplesms.-Curved, wrinklerl, or striated hoofis, ever attsend those animals

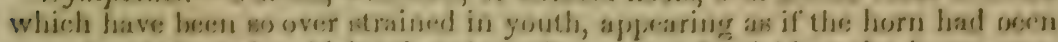

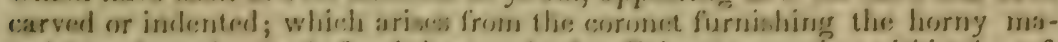

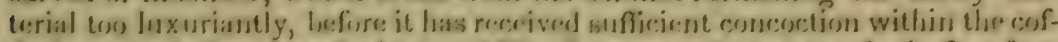

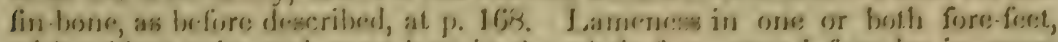
with evident pain, and grent beat in the whone foch, attend foumder in every

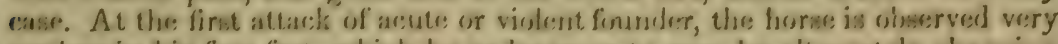

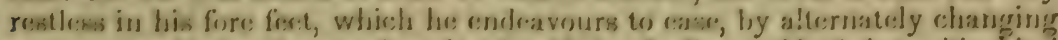
pocition, and lying down when he shondd be foscling. He lorings his himb

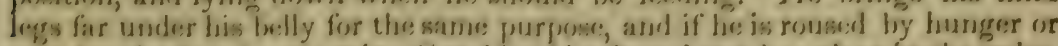
moudate he liess down agrain. Considerables alteration talses place in the pulases which indicates fever, and the patient breathes shest with prain. 'T'hes prove

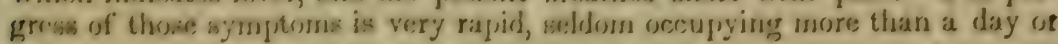
two.

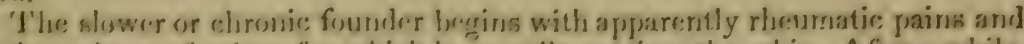

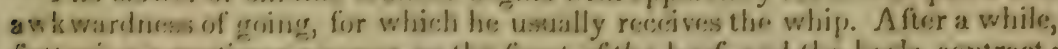

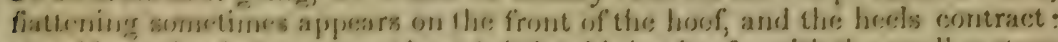
the older animals hase now short, brithe, shinires horfs, with the sruall prastern

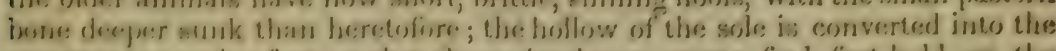
consex, or pusnice: fout, so that thre animal can warce find foret-fold on the ground, Inct will slip, and slide alnout. He is then considered grogery, that is to eay, "like a drumbari," and may last many years, thas is chest founder, and tedeed the whine liubl, is usially affocted up to the very cluest. 
Whether the attack be of the acute or the chron.c kind, it dies if not ro lieved; for the coffin-bone becomes rotten, and the hoof is cast off without the possibility of ever being renovated. In some constitutions, nature lends its aid in critically raising a tumour at the coronet, the breaking whereof and the discharge of offensive natter eflects a cure. The same sort of critical tumour as denoting the crisis of general fever, or inflammation, was noticed at page 114, "Critical Abscess."

Remedy.-As soon as discovered take off the shoe, note well the condition of the sole, the heat, and other symptoms, for according as these vary, so must. the remedies be changed. Draw the soles a little with the buttress if foun 3 too thick, not otherwise; rasp the heels and quarters, which will ease the pain occasioned by the binding of the hoof, and give room for the action of the foot ; a fact that may he ascertained hy hending it at the pastern, forwards and backwards, hefore the operation, and trying the same experiment afterwards. Apply a bran poultice warm to the whole font daily, but do not add to it any greasy or oily substances as is too often practised. The sponge boot may be enployed with advantage, made large. After three or four days, that the horn has recovered its former consistency, put on the sloe gently, and walk the patient, to try in how much he is now lame; and if the attack has been a slight one, he may recover with very little more treatment than a turn out in a meadow will afford. Otherwise the feet must be stopped, and kept moist and cool, as directed in case of Canker, at page 191.

In all cases, (except where the foot is pumiced, or the sole is very thin), tho jointed shoe of B. Clark, or of $\mathrm{H}$. Goldfinch (page 183), will be found serviceable, as being well calculated for giving play or action to the parts of the foot, which produce the secretion that is so salutary to the renovation of new hoof; but which the disorder we call "binding of the hoof" has sadly perverted into an offensive and harmful matter.

The proper secretion of the juicy elastic substance, for the formation of new hoof, being essential to the restoration of the horse, and as the lameness will not wholly subside unless this process goes on healthily, resort must be had to blistering, provided he still goes lame any. This should extend from the coronet and quarters to the knee, and be repeated, taking care to keep the heels open and the sole stopped. The good effects to the sole that will be found to result from blistering, shows the connexion or companionship that exists be tween the legs and feet, as I took occasion to observe at a former page.

$\mathrm{But}$, as to drawing the sole, as before recommended generally, there is one exception : if the lameness and other symptoms come on after an inflammatory fever of the whole system, then we ought to look upon it as an effect of the fever sceking to throw off its dregs thus critically; and a swelling and discharge at the coronet may be expected soon to take place that should be encouraged, and treated as simple abscess, not fistulous. When this is the case the bar-shoe is better adapted to keep the parts in position, that the dischargo may proceed temperately.

In default of sending the sick horse to a meadow, he may be allowed to stand on a clay-made floor in an outhouse by day, or any slip of snft ground. but by no means adopt the plan of putting the patient upon litter that is damp, and is therefore half rotten and heating. A number of contrivauces for af. fording coolness and natural pressure to the sole and frog, besides the forego ing, have been resorted to, and among these the admixture of vinegar, alegar, verjuice, or solution of nitre with the clay, with the stopping, \&c. are well ialculated to answer the purposes intended. Rubbing the knees with turpentine is also serviceable.

Physic would not of course be neglected at the earliest stages of lameness, alapted to the previous state of the yatient's bedily health, and calrulated to 
lower the access of inflammation, which so much pain must naturally produce. Lither of the three evacuations being suppressed, or imperfectly perfurmed, must be restored, and a purgative, a urine-ball, or a diaphoretic fowder be administered as occasion requires, and opportunity presents itself: of course, neither of those will be given while the animal is out of doors.

\section{PRECAUTIOAS NECESSARY TO BF, OBSERVED ON BUY ING A HORSE.}

Much as hath been said of the make, shape, and proportion of the various breeds of horses in Book I., some few precautionary hints, still more farniliar, erem desirable in this place. Of the several points of inquiry to which purchasers apply themselves, the age of the animal is ever considered the most deserving of attention; the state of its legs, bodily health, and eye sight, coming next in order, if gencral appearance dues not precede every other. On eace? of those heads I offer a few words of advice, most of which are tolerally well recognised, though seldom in print, as most of those who deal in horse-flesh: acquire their knowledge from experience rather than books. Before all things, the new horse-dealer should guard agrainst imposition, and not "look at a horse" where he has grot to withstand two or three masked advisers. To be sure, no one desirous of a nag would submit to the imposition of a cart-horse instead; but, next to this kind of gross attemint, the thorough-paced dealers practise deccit of every species, and throw obstacles in the way of cool exainination, especially when we come to investigate the seat of any actual defect.

General appearance: an idea of a grood horse.-And first, that we may make no blunders, and the younger portion of readers be thinking of one part of him, whilst I am talking of another, let the annexed plate of "Terms cornnonly made use of to denote the external parts of the horse," be kept constantly in sight, so that there be no mistake of that sort.

Previous to stating our own old English notions, it may not tee useless to quote the instructions with which the purchasers of cavalry for the French military service travelled (as I believe) over that country. Its coincidence with our own opinions and practices is at least curious, though on such a topic no Englishman whatever requires instructions from a foreigner, if his own assertions are to be taken for grenuine. "The persons sent to purchase horses should not only keep in mind the colour, height, and price of tiurses for which he is to treat; but also the usual defects of the country, that he may guard against them; these are, faulty sight, flat hoof, too brittle, or too soft, and affections of the lungs.

"Those things being well thought on, the purchaser will look at the horse sideways at a tolerable distance: he will choose him as nearly as possible one tenth longer than he is high, measuring from the breast to the quarter, and froin the withers to the ground, so that if the horse be five feet high, his length should be five feet and a half.

"Preserving the same situation, he will see 1st, If the horse has a small head, not too ileshy, perfectly free from tumours, and well placed, neither cal rying it too low nor too high; 2 nd, If he has not an ill-shaped neck, with his windpipe hanging ton low, or bending; $3 \mathrm{rd}$, Whether his withers be either too sharp or too large, with fieshy shoulders; 4th, Whether he is not hollow back. ed; 5th, Whether his chest he well formed, neither too round nor too flat, Gth, Whether he be low-bellied, with a small sheath; 7th, Whether he be touched in the wind; 8th, If his fore legs are not too slender, or his hock do not bend forwards too much; $9 \mathrm{t} \mathrm{J}$, If the tendons or back sinews be not ailing, i. e. either sure to the tuuch, or else stiff-jointed; 10th, Whether the animal se not either long-jointed, or short-jointed; 11th, Whother he be strained in 
tne pastern joint, going low; 12th, Whether flat-hoofed, with low heels; 13 th, Whether he be not narrow at the hind quarters; 14th, Whether he has not spavin, windgall, or curb, ring-bone, or thorough-pin, or is likely to cut. Examine his sole and heel for thrush, canker, or corn, and if contraction has taken place."

Having thus before us the Frenchman's precautions, we come to the Englishman's long accepted description of a good horse, and nothing clse. His head ought to be lean, of good size, and long; his jowls thin and open; his ears small and pricked; or, if they be somewhat long, provided they stand upright like those of the fox, it is usually a sign of mettle and toughness. His forehead long and broad: not marefaced, but rising in the middle like that or a hare, the feather being placed above the top of his eye, the contrary being thought by some to betoken approaching blindness. His eye full, large, and bright; his nostrils wide, and red within; for an open nostril betokens good wind. His mouth large, deep in the wykes, and hairy. His windpipe big, unconfined, and straight when he is reined in by the bridle, for, if it bends like a bow (or cock-throttled), it very much hinders the passage of his wind. His head must be so set upon his neck, that there should he a space felt between the neck and the jowl; for, to bo bull-necked is uncomely to sight and prejudicial to the horse's wind. His crest should be firm, thin, and well-risen; his neck long and straight, yet not loose and pliant, which our north countrymen term withy cragged; his breast strong and hroad; his chest deep at the girth, his body of good size and close ribbed up to the stifle; his ribs round like a barrel, his fillets large, his quarters rather oval than broad, reaching well down to the gaskins. His hock bone upright, not bending; which some do terı sickle-hougl.ed, and think it denotes fastness and a laster. His legs should be clean, fat, and straight; his joints short, well knit, and upright, especially at the pastern and hoofs, with but little hair at his fetlock; his hoofs black, strong, and hollow, and rather long and narrow than big and flat. His mane and tail should be long and thin rather than very thick, which some think a mark of dullness.

Some do affect a small head at all hazards, thinking none other belongs to a good horse, but much will depend upon how it is set on; if that be upon a crane-neck, as usually happens when very small, he will carry unsteady, with tail up as a counterbalance; and if large head arise from thickness of the jowl, this will also be a real deformity and interfere with his safe going : hard nouthed usually accompanies the great hig head at the jowl. Expanded forehead is quite a different thing, and belongs to neither of those objections, but on the contrary is a redeeming sign of good breeding for any kind of faulty head, or long or short, or thick or thin. The crest being slightly curved is always accompanied by distinctly marked windpipe. No horse with a bal shoulder can carry his rider with ease and pleasure on the road, though a large one be requisite for harness, or a very oblique one belong to a speedy hors?; because it is the hind legs that send the animal along, as was eminently the case with

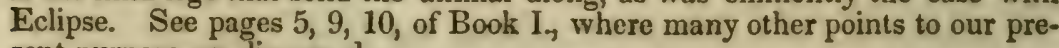
sent purpose are discussed.

As to bodily health, also, the reader will not have far to lonk to enable himself to julge how any animal is affected which he may desire to purchase. The whole volume now in his hands is devoted to a description of the func tions of animal life, and of their derangement.

\section{AGE.}

General appearance bespeaks the age of every animal, to thuse who havo wuch practice in ascertaining that pnint, and whose interest may be said ro 


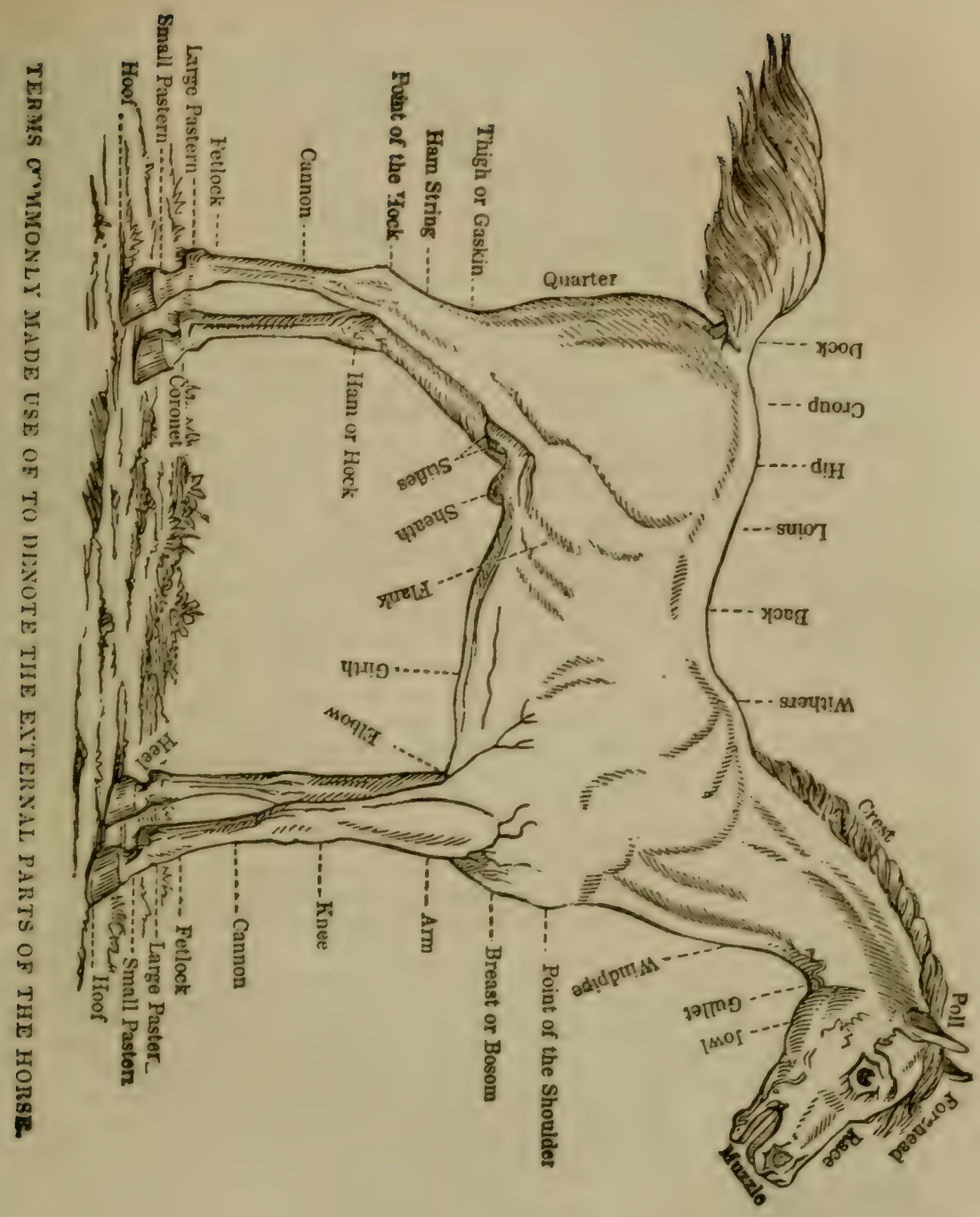


sharpen their judgment: in the horse we are enabled to make a fair eatumate of his years from the birth, to ten or twelve, by means of its teeth, but then we should guard ourselves against a number of deceptious tricks that are practised on the unwary.

A certain juvenility of countenance and springiness of action, legs long compared to the carcass, or filling up, large at the knees and other joints, wide jowl, rough coat, and intractability, denote the foal and colt in succession; all which indications vanish gradually as it advances towards maturity, and becomes full mouthed. Heavy cattle assume premature age and sometimes deceive us upon the first view; nor do such decay when agred so fast as the more spirited, fretful, and lighter breeds; and as no one would purchase a horse for use before it be fit for his purpose, nor take to one that is worn out, the vendor hesitates not to stretch a year or so, one way or the other, as may best suit his own interest and his custumer's wants. To aid their nefarious designs, they are said to file the marks of age in colts' teeth, and to bishop the agged, for confirmation of their falsehoods. But we never rely wholly upon those marks, but turn our attention to the curve of the tushes in the horse's rnouth, and the sloping forward of the corner teeth in both sexes, to detect the imposture.

When we open the mouth of a full grown, or four year old horse, we perceive twelve nipper teeth in front and twenty-four grinders behind: between the two sets, alsove and below, a space is seen on the gum, designed by nature to receive the bit, and termed the bars of the upper or lower jaw, as the case may be. A bout an inch behind the last of the front teeth, the male has tushes at this age, which seldom occurs with mares. The tushes coming up in the lower jaw sometimes occasion soreness at the bars, when these are tu te lan. ced and the tushes appear: this the dealers effect prematurely at times; and having also drawn out the two front sucking teeth, this causes the "korse teeth" to come up soon, so that the animal may appear four years old befure its time. Pursuing the same species of deception, they proceed to draw the remaining sucking teeth, that the animal may assume the appearance of a five year old. Jockies have then a pass word for this operation, which they term "all up!"

In examining the mouth to ascertain the age, we leave entirely out of consideration the grinding teeth, and chiefly rely upon the under jaw; though when deception may be suspected, the buyer should refer to the upper teeth aiso, as these follow the same course of nature as the lower, but do not decay so fast in old age.

At fifteen days old the fore teeth (two above and two below), appear above tho gums, the outside shell first, having muscular stibstance in the middle of the two shells, which fills gradually up, till about the end of the first year, when the surface becomes smooth, and a small ring is observable towards the root of each.

Meantime, when the fual is a month old, the next two teeth (one on each side) above and below, appear in like manner; and at thirteen months tho fleshy cavities of these fill up, and a ring is observable as in the former.

At four months old the corner teeth come up, and the filling up is similarly effected at sixteen or seventeen months old. After this periud the whole six teeth wear even, and so continue smooth and unmarked until two years and a half, the corner teeth being still the least perfect, the front ones largest.

During this state of the mouth, if the unprincipled dealer would give his animal's teeth Ite mark of three or fuur years old, he is said is "file" two or four front teeth hollow in the middle; though in fact it is

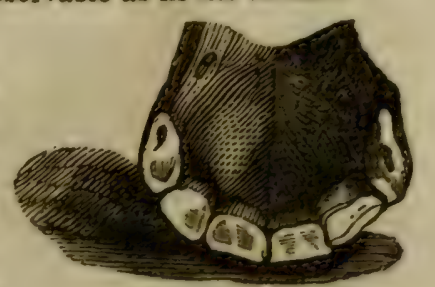

21-2 yeurs old 
burnt in wilh an acil that is eapable of destroving the hardest substances fint this talsidication may be deferted, lst, by comparing the upper with the lower jaw which thes imit "to tile;" "d, ly notwing whether the marked

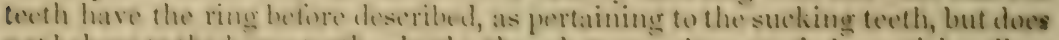
not behme to the horse teeth-lastly, these latter are larger, of a hownish yollow tunge, and swn acyute tartar, very unlike the fine whenessof the sucking teeth

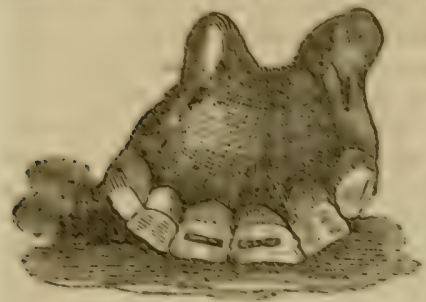

lising 3 years.

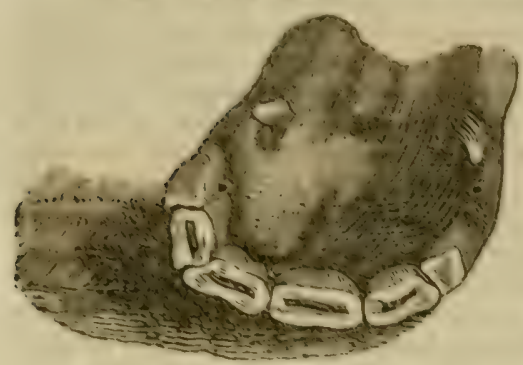

4 gions oll?

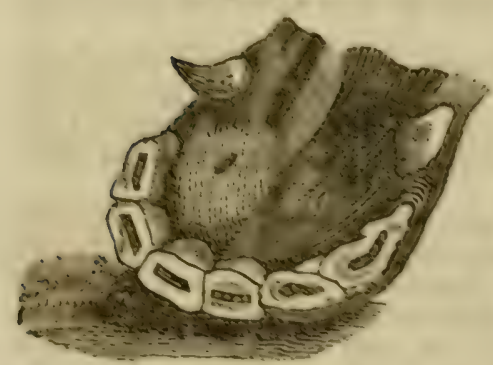

5 ycars.

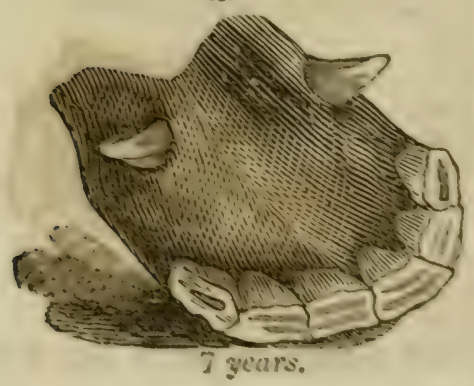

On rising three years old, the two fore tecth (below, and two above) full out, and are ro placed lyy two horse teeth, having the hollow mark in the middle, as shown in the amored cut. As just said, they are also larger and of a darker colour than the sucking teeth. But hetween the third and fourth years, two further colt's teeth (as well ahove as below) shed, and are replaced ly "horse feeth," i. e. harger and browner than the sucking weth, with the black mark; the tushes also jush forth, and the horse is now fully mouthed, as represented by the cut in the margin.

Ouly the corners now remain unchanged from colts' to horses' teeth. 'I'hese difler from the others in being shorter, smaller, and of a shcll-like ap. pearance, until the middle of the firth year, when these also are displaced by horse teeth, in shape much like the former, and their marks but just prerceptible within the upper surface. But. toward the completion of five years of age, they become larger, are more strongly marked, and are grooved on the inside, which groove denotes the age to be five with precision; no deception can he practised on this point, nor as regards the tushes, which are now curved, having grroves inside, that may be felt with the tinger, and seen as represented in the figure annexed. At this age the two front teeth give proof of being worn, principally on the outer elge : the wearing away goes on, and at six years the surfice is level, or as they say, "the mark is grone," whilst the next two teeth also begin to wear. Now, also, the grooves just spoken of in the corner tecth fill up; the curve in the tushes is diminished, I at seven years their grooves fill up in like manner, and become convex in another vear or two. Up to this age only the two corner teeth retain the mark, and that but slightly; when the horse acquires the term "ared," and these two likewiso soon after become smooth.

'I his is the state of the lower jaw at seven years old, but the teeth of the uplos 


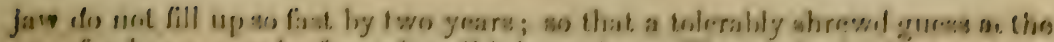

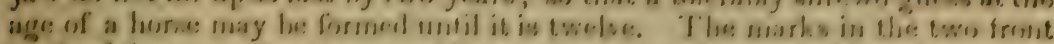

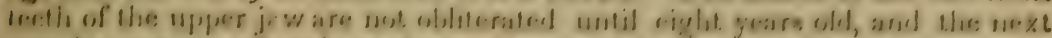

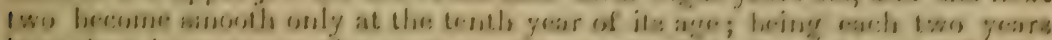

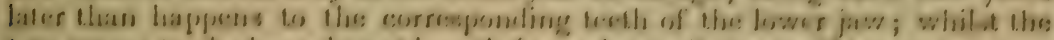

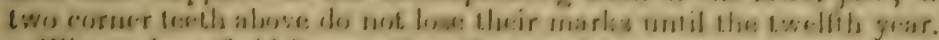

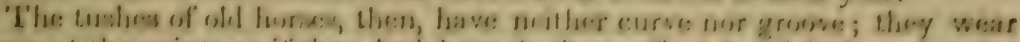

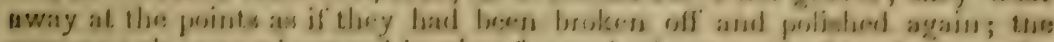

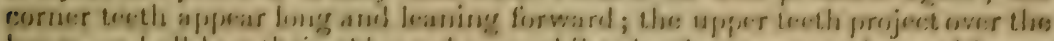

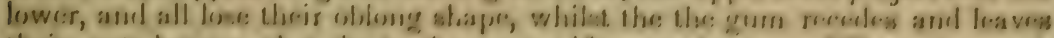

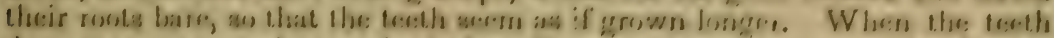

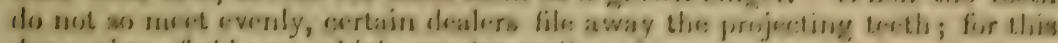

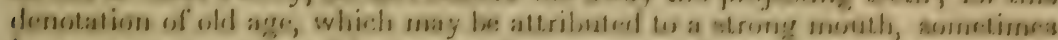

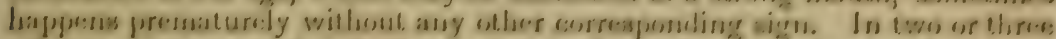

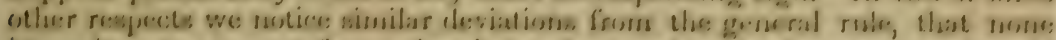

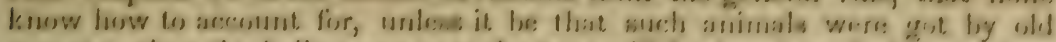

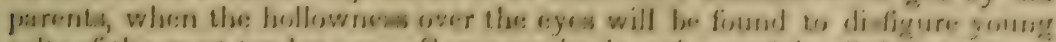

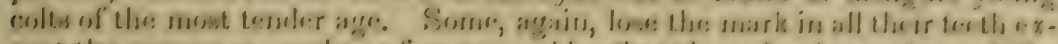

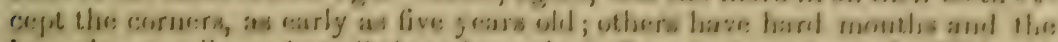

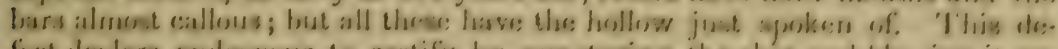

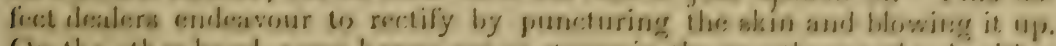

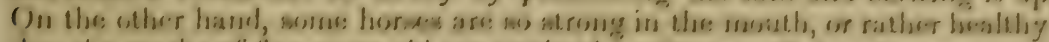

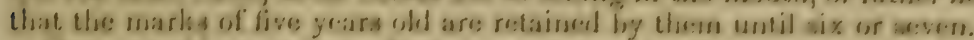

fixtrence old age: way he further ascertained by the mosilh, with moderates

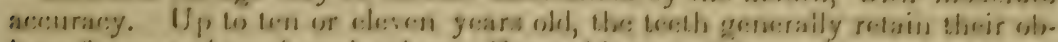

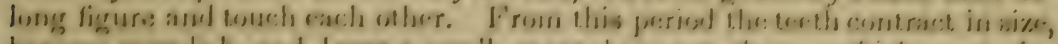

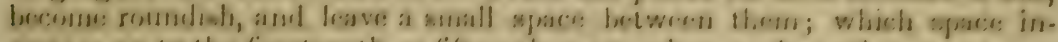

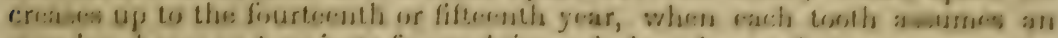

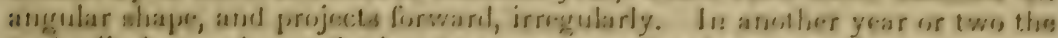

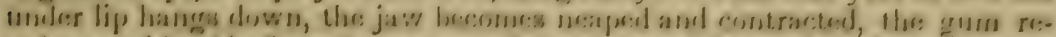

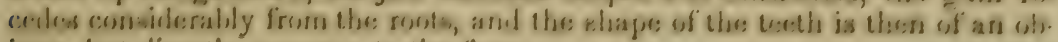
long, lut direclly constrary to the lirst.

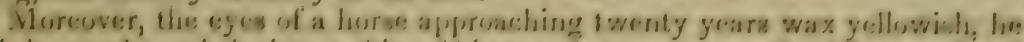

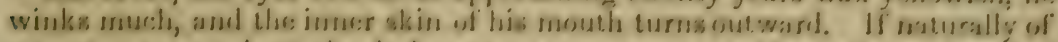

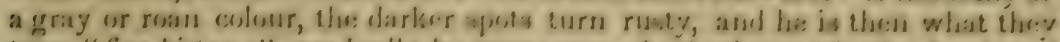

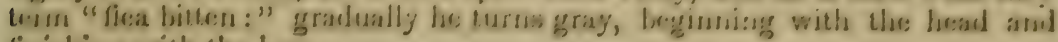
finishing with the legs".

\section{MMENESS}

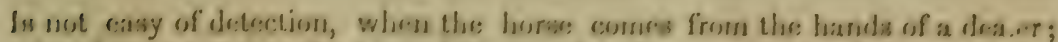

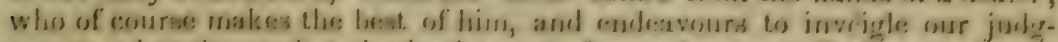
ment, and to thow obsackes in the way of exarnination. J'erhapes when a

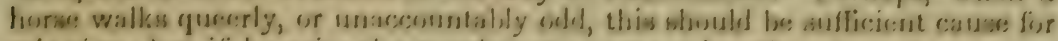

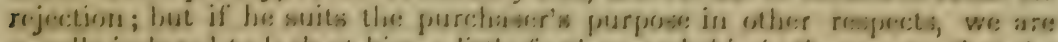

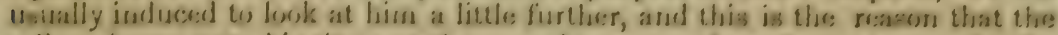

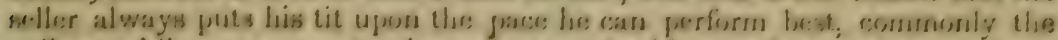

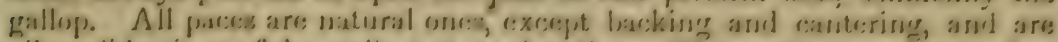
all modifications of the walle, trot, and gallop. 'I hes walk is maile in four

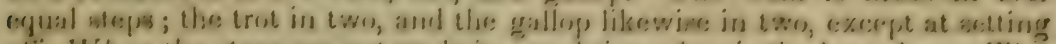

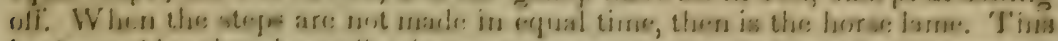

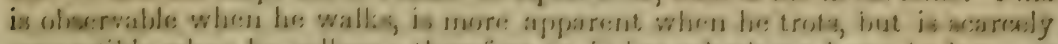

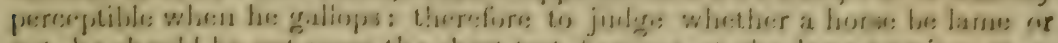

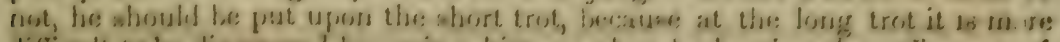

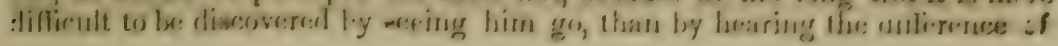


sound in each alternate step. Hence, it will be seen, we must examine whether a horse be lame by a grentle trot. To juilge whether the lameness be before, let him come towards you, then the fore leg which falls to grourad the quickest is the sound lear, and the contrary one is faulty; but to find oun whether the inequality of his paces proceeds from defect in the hind leg, make him trot from you, and that leg which is longest in coming to the ground is affected in some manner or other; and in either case the faulty leg is to be elosely examined, according to the instructions before set down, page 17i Even then, unless the persion has great experience, he is liable to be imposed on, as the poor animal is often lamed of a fore and a hind leg, at the same time : an oceurrence that may have been inflicted on one leg in order to counteract the first appearance of actual lameness in the other. To detect his cruel impnsition, it becomes necessary to examine every leg, to turn up all the soles, and to ascertain whether the horse has not been pegged between the shoe and the sole, or his "heels opened," by the shoeing-smith for the purpose of sale.

\section{BLOOD-LET'TING.}

Every one, almost, can bleed a horse in some way or other, and it is often found extremely desinable that the operation should be performed without delay. But, like many other excellent remedies in the hands of unretlecting persons, this one is frequently employed imperfectly, as well as too often. Each has its peculiar notions, either as to the fit part whence the blood should be taken, the time when it becomes necessary, or the quantity proper to be taken; the latter being the more common error, as it is also the more excusable, inasmuch as they can plead "authority" either way for what they do, is nevertheless demenstrably ruled by wrong principles. The practice of bleeding at given perions, be the quantity taken ever so small, is most injudicions, to say no worse of it ; for, why should we employ a curative when there is nothing to cure? especially when we thereby sulstract from vitality itself.

"Only bleed in cases of inflammation," say the French farriers, and then they take a large quantity, under the impression that taking a quart, or a little more, frim a mass of two hundred and twenty quarts, which is fairly calculated to reside in a middling-sized horse, "is but trilling with the disorder." The existence of intlammation, or fever, is to be ascertained by the state of the pulse, upou which I was tolerally minute whilst speaking of fever, dec. (pages $61-(14)$ the number of beats, and the kind of vibrations, being well considered, previously to taking the fleam in hand, when the quantity drawn should be commensurate to the extent of the disorder. Keep in mind, however, the exceeding danger of mistaking one series of febrile symptoms for another, as may be judged of by turning to those of "low fever," at page $6 \%$ when bleeding would destroy the horse. See also pages 68,69 . Without question, if the operator entertains a doubt about the symptems as indicated by the pulse, the least quantity he takes is likely to perpetrate the smallest amount of harm; whilst, if he be correct in his otiservations, and has witnessed the grood effiets of bleeding in strictly similar cases, its inadequacy can effeet no grond whatever, nor repetition amend the matter one tittle, but ihe contrary. So that he must be wrong either way.

For, as 1 proved at the pages before referred to, the disorders for which bleeding is found serviceable depend less upon the quantity of blood that may be in the system at the time of the attack, than upon the construction or "state of the blood,"* and the degree of irritation that may exist in the ves-

That is to ay, the propurtiun of its then component parta, which ir mainly affected by tho 


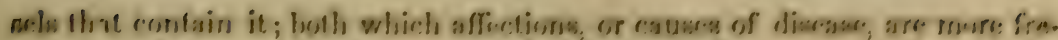

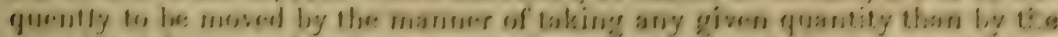

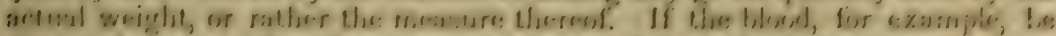

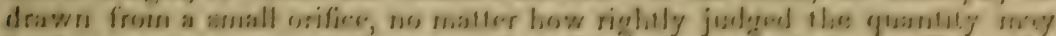

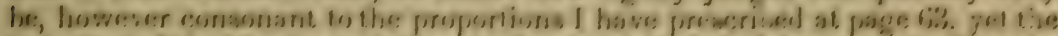

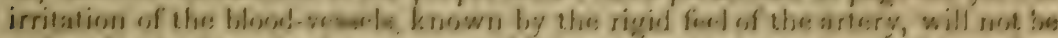

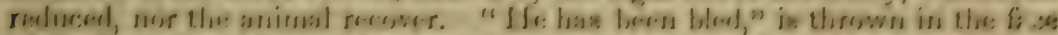

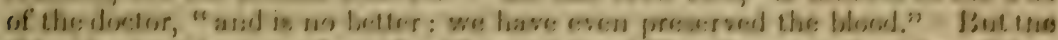

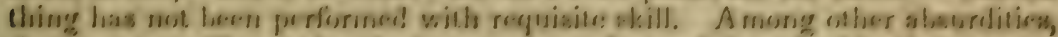

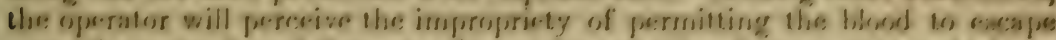

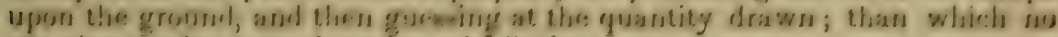
practice can be mores slovenoly and fallaceious.

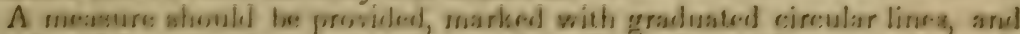

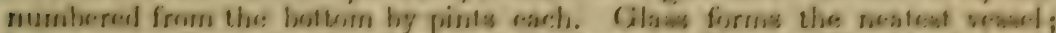

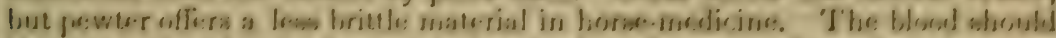

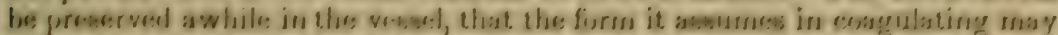

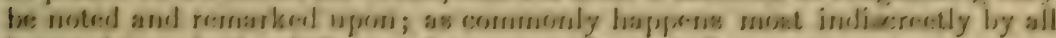

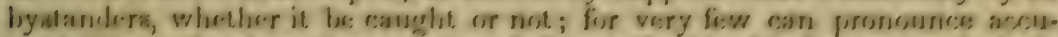

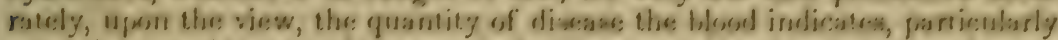

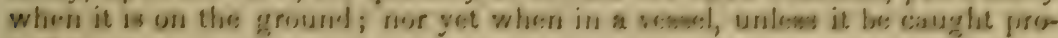
pmrly.

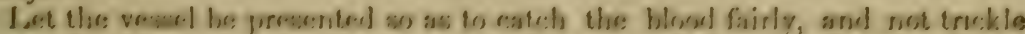

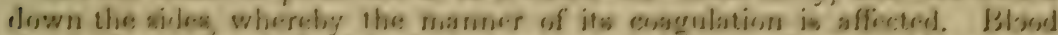

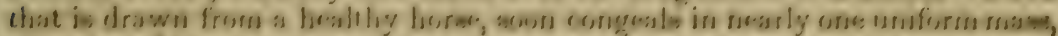

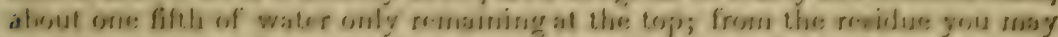

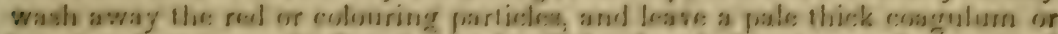

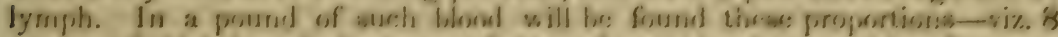

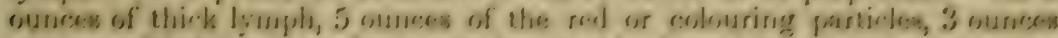

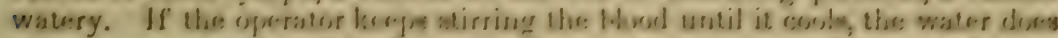

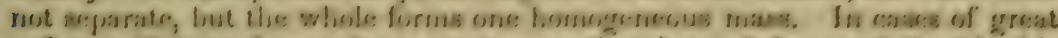

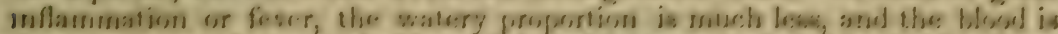

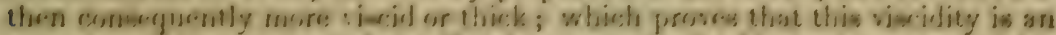

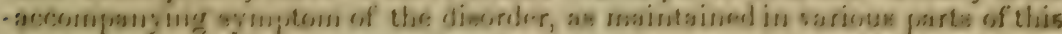

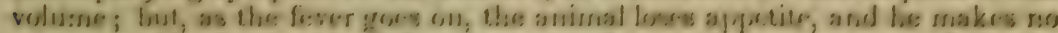

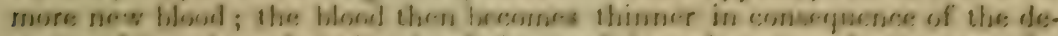

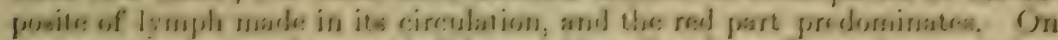

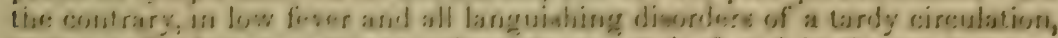

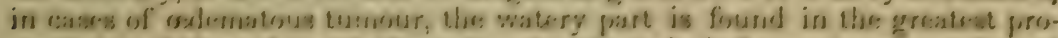

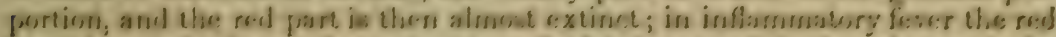

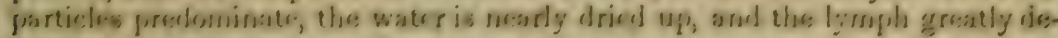
creaseres.

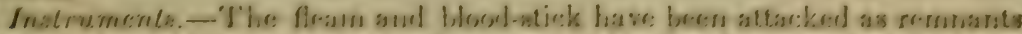

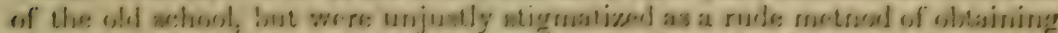

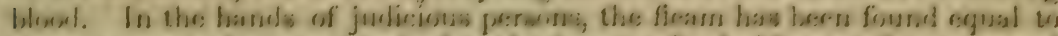

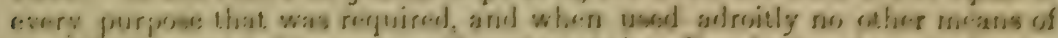

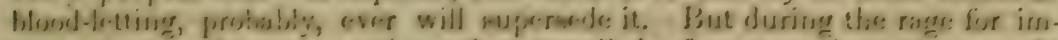

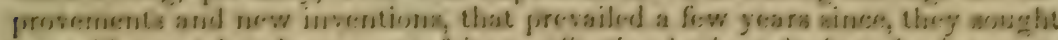

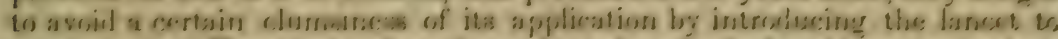

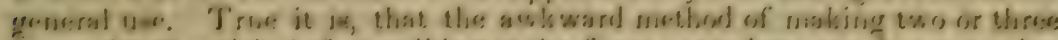

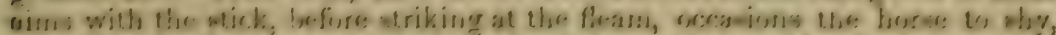

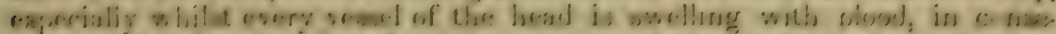

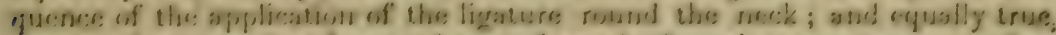

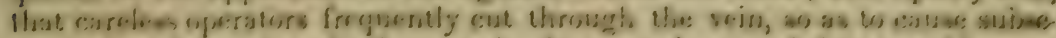

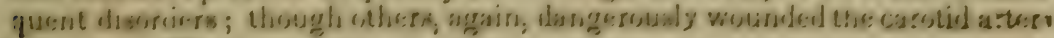


that passes under the vein; yot are there insurmountable obstacles to the go. neral use of the laneet, that ean nover be overeome.

()f those, I need mention lnt one oljection, viz. the time ocenpied in makung the opening-soldem less than four or live seconds, which causes the animal (o) more its head, amd thus to defeat the intention of making a sufficient orifie, wherehy the alipose muscle of fleshy animals is allowed to interpuse,

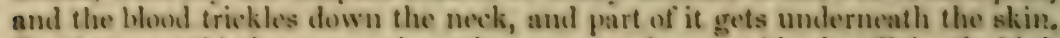
By the way, this happens when the operator does not beed sufliciently high nj the neck, the skin and muscle heing moch thicker lower down. Upon carre animals, likewise, the lamet is wholly incompetent to its purpose, owing b) the very thick teguments it has fo pass ihrough, leaving entirely out of eonsilleration the substance of the rein itseif. To remedy these otjections, the spring tham is more adviscelly comployed by less practiscil hands, and is found to combine the alvautages assumed for the lancet, whilst it secures the reyuisite oritice punctured by the flemm.

Blecting is mow pertioned without previunsly applying a ligature, as it he. came apparent that the hloud which was thus detained in both reins, disteme. ed also the capillary vessels in the heal, which pressed upen the bmin. Heme it fequently happened that vertigo came over the animal, filling it with the apprelwensun of danger. Sometimes it fell down throngh compression of the brain, and plunged; whereupon the diseonecrted opentor was known to give it up fior a bail joh, at the noment it lecame more than ever necessary, charging the lault to acount of the horse's restiveness, with an expressed intention of resuming the attempt at some more favourable opprontunity. But this was a promise he was schlom able to rederem cleverly; the alarm excited by striking the fleam arain and angin scarecty ever sulsiding, fir the fension of the vein would but increase with the continuance of the ligature, and caused it to slip asile more certainly. Apophlexy amd ileath has ensued from the same cause, namely, the application of a ligature, and the consequent hursting of the fine blool-vessels of the brain.

A large rein is more desirable to take blond from, as an evacuation that is to relieve the whole system, than a small one, and the jugular or useck vein,

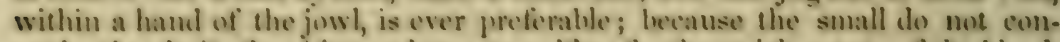
veniently almit of making solarge an urifice, for the quick escape of the blemel, upon which so moch benetit dopends; nor for the same reason allow of drawing a suthicient yuantity at one time, to cflect any grond upen the spasmerlic tendency or irritability of the vessels.

Lecal beccling, in the plate win for example, for a bresise in that region, dess not enter exactly into my present view of the subject of blond-lething; though as much service to the part aftected may be derived from drawing off from the circulation at the neck vein, as spraying a vein immediately at the seat of the evil. Blecding in the font is the only exception I should make: andess the practice of incising the bars of the month when the animal will mot take his sorn, be another, or at least not of importanee sufficient to be mentoned at all, even as nu exception.

The jugu?ar roin being sought for where it is largest and nearest the surface, this will be fiomd upen pressing it with the finger, a hambls breadeh from the setting on of the head, a very litte helow the place where a branch comes from the lower jaw, and joins another firm the upper part. The Frenchman mstructs ins marchal ihus pithily on this tophe, at on several others- "Do not hloed your horso in the heal, hut as mear to it as pussible." Its sifuation being thus finumb take the flewm hetween the fore-finger and thumb of the weft hand, amd pressing aently upon the vein below with the ofher fingers, she sin will rise; then strike, with stick or spring as the case may lw, and connumue the pressure ustil the proper quantity of blexd is dratwin oft. If this 


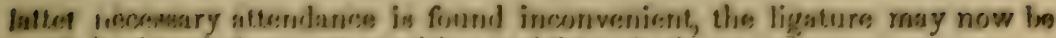
applisel without daneger, but with no additional advantages.

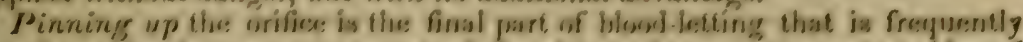
overdone; that is as way, wo much of the skin is drawn up ower the orifice of

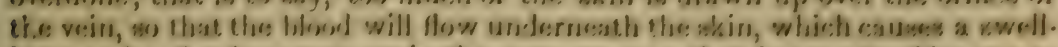

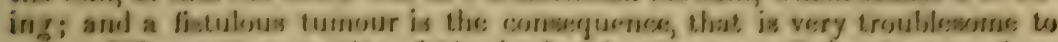
sure. Where the quartity of blowel taken has bren armall, leaving a reclun.

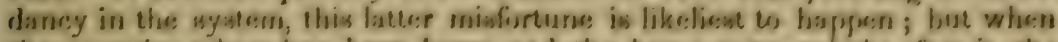
the yuantity taken has been larges, and the heone restes questly affer it, the pinnuge up anay be dispensed with, for the Bend cesasing to flow of itself, the parts heing lorought begether will ashere alnom naturally, by holding the finger

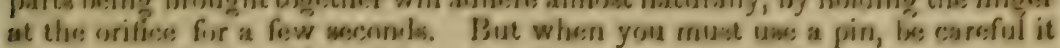
does not prick the orifiese of the vein.

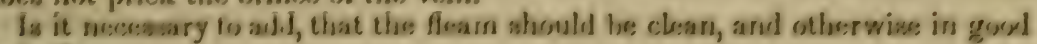
orilor?

Rrulen. 1. Alwaga give purging pliysics after letling blocel. 2. Never

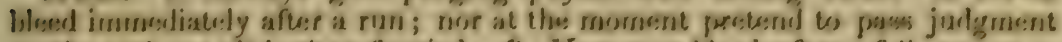
on the pulse, as it is then flucried. 3. You may besed after a fall, or a cens. tuasel wosurel; though the pulese be not quick, it will then lese irrogular : inciased wounds do not reguire bleseding, sincs: enough escaposes at the wound. 4. If the blosed in the mesasure he vory hard, with buff at the tops, the animal may be blesl again : it indicatess high fever. 5. If the blosed scarcely coagulatese the peor creature ouglit not to have bexen blexplesl at all.

\section{ON ACU'TE FOUNDER.}

Foumber, as a general sulject, is one of geseat importance; and when it is

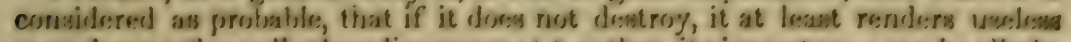
more horses than all exher discases put togecther, its importince can harilly bes rated tor high. To a proper consideration of it, however, it muat lee reggardos] as connisting of two kinds, and these ensentially differing from eareh other. The one is asi arcute attack, depesudent on diffused inflammotion or fower, like the inflammations of any other important organas: the other, a chronie, occal siomed by local inflammation, sometimes dependent on conmtitutional liability,

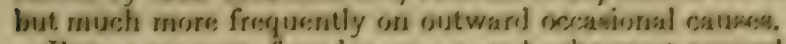

But as an acute founder apposese to be the mom genseral disoase in this country, I shall ronfirue myelf entimig to a conviseration of $i t$.

A cure Forsora apprars to have 2 wo origins, in one case being a true me. tantavis of primary fever, of translation of diesase from one part to another;

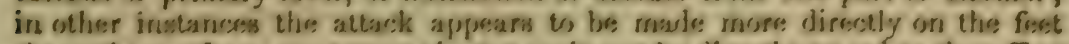
themedves. In a great many instancess it can be direcetly traced to the effecet of ofutrucket? perepiration; or at least of the sadelen alternations of temperature, operating in the production of general febrile affections, whome tranela.

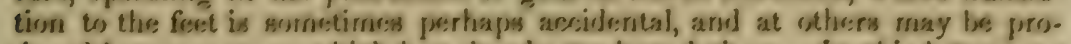
duced by some causes which hass alrealy weakened thern. In this latter way it offen occurs after very severe exertions; as very hard riding or driving, with

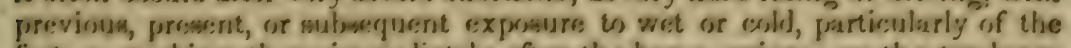

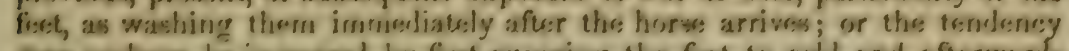

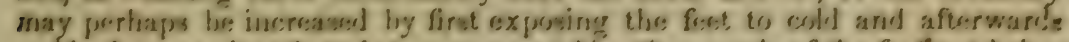

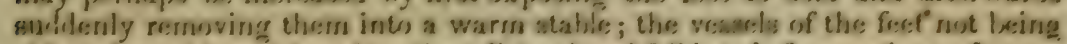
able wo bear this sudden alteration, disterud and fall into inflammation It may in unany of these casess oreur prior to greneral frever, which will then bes symp.

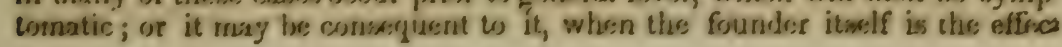


of transhatum; and both are frequently ecoasioned, as before stated, by ro peated and long comtinued exertions with subsquent expesure to cold, espo cially by the custom of washing the fiet and leors when hot.

Foumiler very frequendy proceeds from cold too sublenty applied to the bods foun a current of cold air acting upen it when in an over-beated state, or from drinking focky of cold sater. The symptems are at lirst these: when the horse hegins to cool, he appears very still and fieble in his foro quarters, and, when foreed to move forwards, he collects his body, as it were, into a heap, and lrings his hind fect as fir torward under him as he can, in order to remove the pressure of the weight of his boly from the fore legs a d fect; at the same time he sets his fore fect to the groumb with great pain; his fore parts are extremely hot, and sometimes his lers are considerably swollen, and evidenty painful to the animal when touched.

As som as the complaint has risen to any lwight, the feet will be found inintensely hot, and the pastern arteries pulsating wery strongly; there is sometimes some little tumefiction round the ferbelse, and when one fient is held up fior examination, it grves so mueh pain to the other that the horse is in danger of falling. 'The poor beast groans and breaks out into profuse sweats at one fime, and at oflers is cold; his eyes are moist and rol, and his whole appearame betokens that he is labouring under a mest painful intlammatory afleclivn.

In thes state, the complaint shows itself the tirst three or four days, after which its eflects are varions. In excessively bad cases, when the symptoms stated have raged a lew days, a slight separation of the hoof at the coronet may be observed, from which a small quantity of thin matter may be pressed; the sensible lamina of the font, now hesing their connexion with the insensible lamine by the elliets of the intlammation, the hoofs gradually separate, and at last drip off. At other times the eflects are not quite so violent : still however the termination is sulliciently unfortunate; for covarublele lymph is thrown out, which equally forees off the heofis; but not uneil the parts underneath inave actuired some solidity, nor till the germ of a new hoof appears, which if suthered to grow never proves perfect; on the contrary, the horse usually remains permanenty lame. In other cases the lamine, losing their elasticity and power, vield to the weight of the cotlin-bone, which becomes pushed hackwards, and in its passige draws with it the front of the hoof, which falls in; the pressure also of the eothin-home destroys the concavity of the horny sole, which hecomes convex, or pumiect, learing a large space hollow towaris the toe, which very frequently turns up.

But when the aftack is not commenced with that riolence which has been detailed, or when an early and judicious plan of treatment is adopted, the termination will be more fortunate; the horse will stand longer upon his feet, tho pulse, which at the onset of the disease is very high, will gradually fall, theso fivourable appearamees will increase daily, and in tho end the animal will recover the use of his feet.

As soon as the disease is disenvered, talie away blood from the neck to the amount of four, five, or six quarts as circumstances may require, or size and comlition will permit; back-ralie and throw up clysters, but unless there be much costiveness present, do not give strong purgative medicine, as the high state of irritative fever which is generally present, forbids such practice Mild laxatives should be given twice or three times a day until the bowels are molerately opened, thecther with the fever ball, recommented some bages further back, twice a day, until the intammatory symptoms have sub. sicherl.

'he feet should he atended to after the aeneral blecting, se. In the first puace iet tire shoes be taliein oft; and the soles pared a little; the hoof should 
lo: rasped as thin as is prudent, which will greatly relieve the internal senstble parts, which are tender and swollen, by removing the pressure of the sole and hoof from them; let the feet be inmersed in warm water or apply proulticess to them, or if preferred wet cloths may bo kept round them; if the general febrile symptoms still continue repeat the bleceling and the medicine. As soon as amendinent becomes apparent, feed millly, and allow the horse to rest; do not jroceed to exercise until the feet have gained some strength, nor must it be forgotten that feet once foundered, require great caution in their future managernent, as they are very liable to become again affected on any considerable exertion. 



\section{N D E X.}

A.

Abscess and tumours, how engendered, 110.

critical, treatment of, 113.

Drawing poultice, 114.

deep-seated, danger of, 115 .

Acute founder, origin and treatment of, 209.

Age of horses, how to estimate the, 202.

Air, effects of, on the blond, 39.

-, confined or noxious, a cause of inflammation, 60.

-, the importance of keeping out a draught or current of, in stabrea, 78

, cells, controversy concerning, 82.

Anatomy of the foot, 169.

Animal system, general ubservations on the, 54 . definition of the term, 54 .

, how deranged, 55.

Anticor, prevalence of, in France, 142.

Anticor, prevalence of, in France, symptoms, and method of curing, 142.

Alterative ball, 143.

Arabs, practice of the, in cases of lameness, 170, 177.

Arteries and veins, their office, 41.

B.

Back, strain of the, cause and symptoms of, 197.

, effects of, and remedies for, 198.

Back-raking, in cases of costiveness, method of, 69.

Bile, excess and deficiency of, 50.

Bishoping, how to detect, 204.

Bladder, construction of the, 53.

- diseases of the, 54, 104.

inflammation of the, cause of, 105.

cases of stone found in the, 108 .

Bleeding, copious, in certain cases recommended, 74, 198.

- - dangerous, after continuance of inflammation, 74.

- of the employment of the fleam and blood-stick in, 207.

-, objections to the lancet, 208.

-

_. modern method of, 208.

- on pinning up the orifice after the operation of, 209.

Diles to be observed in, 209.

Blind-gut, its uses, 46.

Blistering, to divert inflammation, considered, 75. 
Blood, circulation of the, 38 .

- effects of air on the, 39.

- how cleansed, 40.

- fluidity of the, 42 .

$\longrightarrow$ effusion of the, 42 .

_-, the, how made, 48.

- healthy proportion of the component parts of s pound, 207.

Blood-letting, remarks on, 206.

- use of a graduated measure recommended in, 207.

Blood-vessels of the foot, 168.

Bone spavin-See Spavin.

Bones and integuments of the foot and leg, description of the, 169.

Bowels, inflammation of the, symptoms of, 88.

Breeders, advice to, 18.

Broken wind, 82. See Organs of Respiration 35.

Brood-mares, treatment of 18.

\section{C}

Calculus, or stone in the bladder, cause of, 107.

its resemblance to colic, 109.

Canine madness, causes of, 159.

Canker, causes, symptoms, and method of curing, 190.

L treatment in cases of, 190.

- how prevented, 191.

Cat-hams, how contracted, 13.

Circulation of the blood, 36 .

Cline, Mr., his opinion regarding hereditary roaring, 85.

Coffin-joint, strain of the, how caused, 194.

Cold, progress of $a, 33$. , symptoms and cure of, 195.

mistreatment of $a, 35$.

Cold or Catarrh, causes of a, 76 .

- symptoms of $\mathrm{a}, 77$.

remedies in cases of, 78.

Colic, a prolific source of inflammation, 88.

-, spasmodic or flatulent, symptoms of, 90,96 .

- definition and re-production of, 94.

- causes and progress of, 95 .

$$
\begin{aligned}
& \text { Drench, No. 1, } 98 . \\
& \text { Sedative ball, } 98 .
\end{aligned}
$$

Colts, consequence of mounting too early, 19.

Concretions, cause of, 107 -the coecum, 46 ; kilneys, 51 ; bladder, 69

Consumption, definition of the term, 82.

Contraction caused by paring the sole inconsiderately, 185

Corns, how caused, 193.

-, symptoms and mode of curing, 193.

Costiveness, causes of, 68 .

$\longrightarrow$ symptoms of, 68

remedy in cases of, $68,92$.

restoratives, 69.

laxative drench, 69.

tonic ball, No. 1, 69 .

- No. 2, 70 
Cough rémedies for, 79 .

cooling decoction, 70 .

expectorant ball, No. 1, 80.

a laxative ball, 81 , No. 2, 80 .

a diuretic ball, 81 .

- drench, No. 1, 81.
, No. 2, 81.

- diet and regimen in cases of, 81 .

Cough, chronic, descrilsed, 36.

- symptoms of, 86.

plethoric, liow brought on, 86 . remedy in cases of, 86 . jurgative ball, 86 .

periodical, treatment of, 87.

mild purgative ball, 87

- constitutional, 88.

alterative ball, 87 .

$$
\text { drench, } 88 .
$$

Curb, description of, and how cured 174.

\section{D.}

Dead suljects, duty of examining, 2 .

Defectiveness, constitutional, 110.

Diabetes, cause and symptoms of, 106.

- remedies for, 106.

Diet and regimen in cases of cough, 81 .

Digestion, the process of, 43.

Diseases of tho lungs, review of, 35 .

$\longrightarrow$, origin of constitutional, 48.

Disorders, inflammatory, 59.

Dissection, how to proceed with, 2.

Docking, introduction of the practice of, 56 .

_ effects of, 157.

Dung, an indication of the state of the body, 65 .

E.

Eirs, the, by their movements, indicate the passions, $5 \%$.

Eclipse, the race-horse, 5, 10.

, weight of the heart of, 37.

Englishman's lescription of a good horse, 202.

Eruptions, scurvical, treatment of, 176.

Exercise, effects of, 42.

Eye, appearance of the, a criterion by which to judge of the constit

F.

Farcy and poll-evil, connexion of, 121.

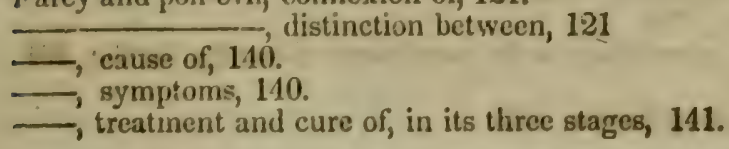


Farcy, morcury, a specifin in, 142.

Farcy buds, the free application of the actual cautery recommended purgative ball, 141. alterative ball, 141 . mercurial ball, No. 1, 142.

Fever, predisposition to, 59 . No. 2, 143.

- and inflammation, slight distinction between, 60 .

-nomedies recommended in cases of, 61.

high, iudications of, 62.

_ simple, symptoms and treatment of, 63 .

- danger of relapse, in cases of, 65.

low, cause of, 66 .

- symptoms of, 66.

remedy and restoratives in cases of, 67.

_- typhus or putrid, causes and symptoms of, 70.

- epidemic, cause of, 71 .

Fever in the feet, $15,178$.

purgative ball, 63 .

-, clyster, 64 .

fever powder, No. 1, 65.

fever drink, 65. No. 265.

laxative draught, 67.

Figg. See Corns.

diuretic ball, 67 .

Firing, barbarity of the operation of, 56 .

- in cases of strains, when proper, 179.

Fistula in the withers, cause of, 122.

,


operations necessary in, 123.
cold lotion, 124.

Fleam, the spring, advantages of, $20 \%$.

Fluidity of the blood, 43.

Fomentations, great service of, in strains, 198.

Food of the horse, 43.

Foot, constitutional defects in the form of the, 7 .

- cutting away the horny part of the sole, reprobated, 56.

a section of the, 166.

structure and physiology of the, 164, 168.

- mode of severing $a, 167$.

blood vessels of the, 168 .

- ligaments and tendons of the, 168.

- anatomy of the, 169 .

- and leg, description of the bones and integuments of the, 169.

- olservations on the disorders of the, 170 .

.. - remarks on the diseases of the, 188 .

France, prevalence of anticor in, 142.

French method of cleaning sores, 124.

- , notions of strains, 176 .

, military service, instructions to the purchasers of cavalry for the, 20 i

Fiounder, causes of, 198.

$$
\text { , in young horses, } 199 .
$$


Founder, symptoms attending, 199.

- distinction between acute and chronic, 20\%

remedies in cases of, 200.

- the effect of inflammatory fever, 200

Frash. See Tlerush.

\section{G.}

Genitals, how nourished, 57.

Glanders, how generated, 33.

-, observations on, 129.

, predisposition to, 129.

_- symptoms of the tiue, 134.

_- controversy as to, communicable, 135.

of three soris-two contagious, 136.

_, cause of, 129, 136.

-, symptoms, $13 \%$.

_, tests of true, 138.

-, legal restraints regarding, 139.

Glands, on the functions and diseases of the, 29, 129.

Grease, causes of, 143.

- white feet liable to, 144 .

_ symptoms of, 144.

- preventives and remedies, 144.

_- regimen recrmmended, 146. alum wash, No. 1, 145.

strong alum wash, No. 2, 145.

strongest, or mercurial wash, No. $3,145$.

diuretic alterative fo'w er, 146.

purging ball, 146.

alterative balls, 146, $14 \%$.

diaphoretic ball, 146.

ointment, $14 \%$.

_, molten, physiolugy of, 93.

- treatment of, 94.

sedative clyster, 94.

Great gut, course of the, 46 .

Gripes and inflammation of the lowels, distinguishing symptoms between, the

_, distinguishing symptoms of, 96.

, treatment in cases of, $9 \%$.

Head, motions of the, indications of pleasure and pain, 14.

--, a large, a sign of sluggishness, 17.

Heart, structure and functions of the, 3.

- organization of the, 37 .

- slape of the, 40 .

weight of Eclipse's, 37.

Hide bound, caused by internal tumoure, 149.

__ symptoms, 150. 
Hide bound, method of curing, 150 . alterative laxative, 150. tonic, No. 1, 150. - No. 2, 151. alterative balls, 151 .

Hip-joint, treatment in cases of strains of the, $\mathbf{1 9 7 .}$ Hoof, shape and make of the, 11 .

_- , duty of studying deformities of the, 164 .

_, internal structure of the, $\mathbf{i} 66$.

- component parts of the, 166.

_ brittle, a cause of sand-crack, 192.

Horse, external structure of the, 5 .
- evils resulting from bad make and shape of the, 6
_- length of body of the, 15.
__ hollow back, 16 .
-, food of the, 43 .
__ of the leg and foot of the, 164.
_- impolicy of working the, too early, 19, 170.
_- advice to purchasers of $a, 201$.
__, Englishmau's description of a good, 202.
Hydrophobia, an incurable malady, 159.
$\longrightarrow$, causes of, $15 \%$.
symptoms of, in the $\log , 160$. , in the horse, 160.
-, water no true test of, 161 , regimen recommended in, 161 .
- writers on, $162,163$. Purgative ball, 162.

\section{1 and $\mathbf{J}$.}

Indigrestion, diseases of, 45.

Inllammation of the stomach, 44, 88.

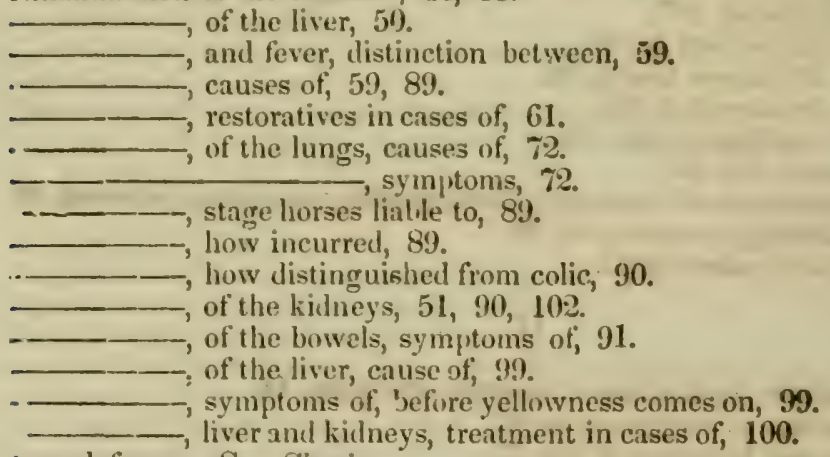

Iron defence. See Shoeing.

Instructions, French military, for the purchase of horses, 201. Intestines, construction and disenses of the, 44, 88 .

Jeundice, or yellows, cause of, 101.

, symptoms of, 101. 


\section{INDEX}

K.

Kulneys, functions and äiseases of the, 51 .

-, influence of inflamed, 91.

inflammation of the, 102.

- inflammation of the, 102.

Mild purgative ball, 104. symplums, 103.

Embrocation, 104.

L.

I acrtes, Mr. Maberly's, a capital leaper, 9.

Laineness, test for ascertaining, 171, 895 .

-, remarks on, 171, 105.

, rest indispensable in cases of, 170 .

Lainpers, or lampas, description, symptoms, and method of curing, 128

Lancet, objections to the, in blood-letting, 208.

Lawler, Denis, anecdote of, 196.

Leg and foot, on the disorders of the, 170.

Legs, mechanical explanation of the form of the, 6 .

Ligaments and tendons of the fout, 168.

Liver, situation of the, 49.

- functions and diseases of the, 49, 99.

- inflamination of the, $50,99$.

- - ulcers and tumours on the, 102.

- complaints, and kidneys, discriminative symptoms of, 102

Lncked jaw, symptoms, 157.

_

Lungs, description of the, 31 .

- experiments on the, 32.

-

-, ulcer on the, frequently mistaken for worms, 39.

- causes of inflammation of the, 72 .

- symptoms, 72.

_-, restoratives iu cases of inflamed, 75.

Lvinphatics, importance of stimulating the, 30 .

\section{M.}

Marlness, canine, causes of, 159

$$
\text { , treatment of, } 161 \text {. }
$$

Mallesders and sallenders, cause and cure of, 176.

Marge, cure for the, 148. See Surfeit.

Ointment, 149.

Alterative for the mange, No. 1, 142.

Megrims, characteristics of, 156.

$$
\text { No. 2. } 149 .
$$

- remedies, 156.

Membranes, construction of the, 27.

Mercury, a specific in farcy 141. 
Mercury, green food improper under a course of, 112 Midriff, its uses, 26,34 .

Millers' horses most liable to stone in bladder, and why, 102 Molten grease. See Grease.

Muscles, their construction, shape, and uses, 28.

N.

Nailing, impurtance of the operation of, 186.

- risks attending the old method, 186.

- improved modern mode of, $18 \%$.

Nerves, construction and uses of the, 30 .

o.

Organs, large and small, description of, 21.

- of respiration, liable to several kinds of disease, 35.

-, urinary, diseases of the, 105.

P.

Pcgged, how to ascertain whether a horse has been, 206.

Perspiration, 23.

Phenomena, the trotting mare, 6, 9 .

Physiology of the stomach, 43.

Pinning up the orifice, after bleeding, cautions relative to, 202

Pleurisy, 77.

Poll-evil, causes of, 115.

, symptoms of, 116.

-, cure for, by dispersion, 116 ; by suppuration, 117 .

- form of bandage for, 118 .

, method of operating, in cases of, 118.

- the seton, how applied in, 118.

—, general remarks on, 121.

_ and farcy, connexion of, 121.

embrocation, 116.

, distinction between, 121.

alterative ball, 117 .

irritating mixture, 119.

digestive ointment, No. 1, 119.

scalding mixture, No. 1, 120.

$\longrightarrow$ No. 2, 120.

digestive ointme, No. 3. 120.

I'ulmonary patients, treatment of, 72.

Pulse, observations on the state of the, 62, 206.

-, a register of the state of the, recommended to be kept, 62

Purchasers of horses, advice to, 201.

Q.

Quittor, how caused, 125.

_- method of curing, 125.

- mild treatment of, recommended, 1272 
first alterative ball, 126.

second - 126.

R.

Rabies, incurable, 159.

-, means of discriminating the true from the false, $\mathbf{1 6 0}$.

- progress of symptoms in, 160 .

- nostrums recommended in, 162

Regimen and diet in cases of cold, 81 .

Relapse, danger of, in cases of strains, 179.

Respiration, its close counexion with the formation of blood, 31.

the organs of, liable to several kinds of diseases, 35 .

and exercise, effects of, 42.

Ringbone, causes, symptoms, and remedies, 172 .

Roarers, hereditary, Mr. Cline's opinion respecting, 85.

Rules to be observed in bleeding, 209.

S.

Sadlle galls, how caused, and remedy for, 124

Sand-crack, cause of, 192 .

$\longrightarrow$, symptoms of, 192.

-, treatment in cases of, 192.

, remedies for, 192 .

Secretions, uses of, redundant and defective, 22

Shoe, shape of the, English, 181.

, French, 181

an improved form of described, 182.

- the patent, remarks on, $180,184$.

- the jointed, 183; Bracy Clark's, 183; Goldfinch's jointed, 183; Colo man's frog shoe, 184; Teast's, 188.

- ruinous consequences of trying on the, hot, 185.

- importance of the operation of nailing the, 186.

Shoes, various, for diseased feet, 188.

-, cast iron, objection to the use of, 188.

Shoeing, remarks on, 179, 185.

, of preparing the hoof for, 184.

, French method of, $18 \%$.

Shoulder, conformation of the, 10.

Sitfasts, how to remove, 125.

Skeleton, explanation and practical use of the, 4.

Sole, danger of paring the, too much, $180,185$.

Sores, French method of cleaning, 124.

Spavin, varieties of, 173.

, bone causes of, 173.

Splents, cause and symptoms of, 175 .

, remedies for, 175.

_- in some instances, occasioned by shoeing, 175.

Liquid blister, 175.

Stathles, close, prejudicial to health, 39.

- the necessity of ventilation in, 74.

Staggers, origin of, 155156. 
Staggers, varieties of, 156.

$\longrightarrow$ romedies for, 156 .

$\longrightarrow$ mad, a case of, 71 .

Staling, excessive, or diabetes, 106.

Stallions, on the choice of, 18.

Stille. Seo Strains.

Siomach, physiology of the, 43.

- intlammation of the, 44,88 .

Stone, cases of, found in the bladder, 109.

Strains, remarks on, 176.

$\longrightarrow$, of the back sinew and ligaments, cause of, 177.

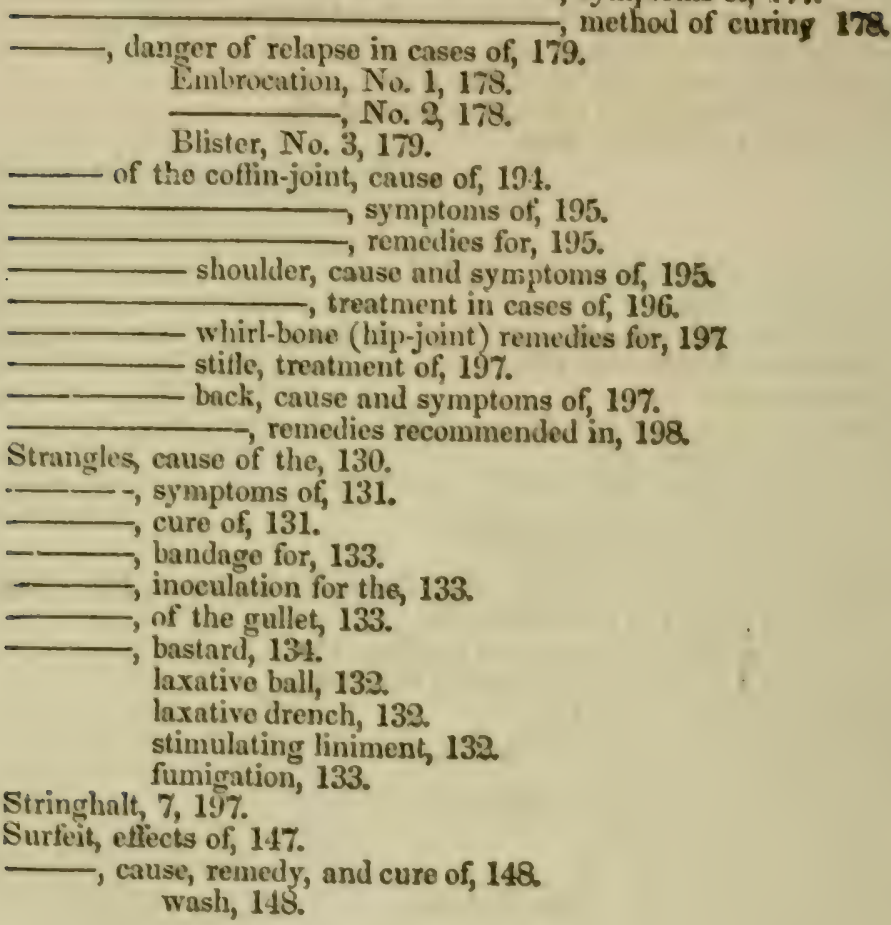

\section{$\mathbf{T}$}

Teeth, description of the, 203 .

Tenidons and ligaments of the foot, 168.

Thoroughpin, cause of, and remedies for, 173

Throat, sore, remedies in cases of, 78 .

- method of bandaging for, 79.

Thrush or "frush," cause and symptoms of, 102

Tongue, state of the, a health-guage, 56 .

T'onics requisite after inllammatory diseases, 69

Tumours, internal and extersal, 12 
Tumisus, on the her, 99.

- definition of, 111. how engendered, 111.

- distirctums between the single and the varied, 112.

- the kind of hores mont liaslo to, 112.

, on the joints, 113.

- and absces, gerseral observations on, 112.

\section{U.}

Ulewe on the lungs, frequusmtly mistaken for worma, 39.

Urinary organs, cliseases of the, 105.

Urime, secretion of the, 52.

- chemical analysis of, 53

- a gorod indication of the stace of the body, 65.

-. suppression of the, 103.

- hails, evil effects of, 104.

- incontinence of, 105.

-_, blondy, cause of, and treatrnent recommended, 102.

\section{V.}

Veins and arteries, their co-construction, 41.

Ventilation of stables, the impronce of, 74.

Veterinary knowledge, the advantages of, 1.

Vives, description, cause, and syruptoms of, 126, 127.

- its connexion with farcy and glanders, $12 \%$.

cure for, 127.

- false, method of removing, 128. lotion, 127.

W.

Warbles. See Saddle-galls, and Sitfasts.

Water, no true test of rabies, 161.

Whirl-bone, strain of the, remedies for, 197.

Wind, broken, how acquired, 82.

- varieties of, 82.

-, causes of, 83.

_ tonic ball, 81.

ball, 81 .

Windgalls, causes of, 173.

-, temporary cure of, 173 .

Windpipe, construction of the, 32 .

Withers, fistula in the, 122.

Worms, general remarks on, 151.

— C causes of, 152.

— distinguishing symptoms of, 152.

- regimen recommented in cases of, 15 s

- cure for, $15 \%$.

No. 1, mercurial bolus, 153.

No. 2, purgative ball, 154.

No. 3, laxative alterative balls, 154. 
laxative powder, No. 1, 155. balls, 155 . powder, No. \& 155.

8.

rollows, See Jaundica 


\section{S U P PLEM E N T \\ To \\ M A S O N A N D H I N D'S}

POPULAR SYSIEM OF

\section{F A R R I E R Y: \\ COMPRISING}

AN ESSAY ON DOMESTIC ANIMALS,

ESPECIALLY THE HORSE;

WI'TI!

REMARKS ON TREATMENT AND BREEDING:

TOGETHER WITH

TROTTING AND RACING TABLES.

SHOWING

THE BEST TIME ON RECORD, AT ONE, TWO, TH AND FOUR MLLE HEATS:

PEDIGREES OF WINNING HOISES, SINCE 1839;

AND OF THE MOST

CELEBRATED STALLIONS AND MARES; พITH

USEFUI, CALVINO ANI) LAMIBNG TABI,KB, ETC., ETC.

\section{B Y J. S. S K I N NER,}

Ldiwr now of the Farners' Luturary, Now York; Founder of the Amorican Farmer, in 1820 and of the Turf Register und Sporting Magazins, in 1829: beeng the first Agncul-

taral and the first Sporting Periodicals estublishod in the Cnated Stales.

P'H I LA DEL P H I A

E. CLAXTON \& COMPANY, 930 M A RET STREET.

I 883 . 
Entered acending to Aet of congress, in the your 1 ssis, by E. CLAXTON \& CO,

In the ottice of the Librarian of congress, at Washington. 


\section{E D I C A T I O N.}

Wrruour going through the formality of asking leave to say " by his gracious permission," which, if sought, might have been withheld, this Supplement to Mason and Hind's Popular Systems of Farriery is respectfully dedicated to Col. Balie Peyton.

It is not that a contribution so inconsiderable is deemed worthy of him, or the subject so interesting; but that the Author would fain embrace any fair occasion to manifest to hirn, and through him to their common friends at New Orleans, his grateful remembrance of their kindness when among them.

There would be, moreover, an essential propriety in dedicating to Col. P. a more adequate offering of this sort; as he is known to be a breeder and warm amateus of the high-bred horse; and, in his own spirit and cha racter, exemplary of what is best bred and most excel lent among men.

$$
\text { J. S. S. }
$$

New Yran's Dax, 1848.

For the nonce at Annapolis, $\mathrm{Nd}$ 



\section{PREFACE.}

ThưGH, 'under ever fluctuating but sometimes pro pitious circumstances, the very climax of equestrian power may have been reached in a few cases in the United States, as in the country from which we derived our skill and material, is it not still worthy of all consideration how we may contrive to belay, as the sailors say, what we have gained in that important branch of Rural Industry - not only as a means of individual enjoyment, but as a prolific, indispensable source of National power and wealth?

However serious and apparently insurmountable may be the difficulties that stand in the way of farther improvement of domestic animals, and especially the Horse -either in the general absence of the necessary means and appliances, and of adequate encouragement for the care and expense attendant on the production of Horses of high qualities, there ought, surely, among well-informed men, to be no obstacle arising from ignorance of the art of breeding. Hence it is that in sending forth the Ninth Edition of this popular work on Farriery, while nothing seemed to be needed in the way of description or treatment of the diseases of domestic animals, and while the author of this Supplement was only called on to extend the stud-book in a manner to embrace the pedigrees to which breeders and dealers might have occasion to refer, he could not forego the opportunity 
to offer some such additional matter as, to him at least, seems to be of sufficient value to render it acceptable and useful.

In the introductory remarks on the relations existing between Man and the animals destined for his use and amusement, and the obligations these relations impose, the writer has but expressed the sentiments he has ever entertained, of duty on our part to respect the feelings and comfort of the humblest among them; and has endeavoured to encourage continued exertions for their melioration by showing how successful and progressive such efforts have been, even up to the present time.

To these observations of his own are appended those of writers of acknowledged judgment and authority accompanied by such notes as appeared to be apposite and well-founded; and to these, again, have been superadded a few tables and other items which might not elsewhere be conveniently met with. His undertaking, kind reader, "hath this extent, no more." All, then, that the author of the "Supplement to Mason's FarRier" has to ask of you is that you will bear in mind that there has been no engagement to write anything-much less a Book on Farriery: for that there was no call or necessity. With this intimation, the reader will please accept for what it is worth and with all due allowances, the little that has been volunteered-by one who may claim to have been all his life an amateur if not a connoisseur of the Horse.

J. S. S.

Edit. Farmers' Library 


\section{CONTENTS.}

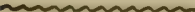

In the relations between Man and the Domestic Animals, especially the Horse, and the obligations they impose, Paga 9

On the Form of Aninals ..................... 18

The Chest ............................ 19

The Pelvis ................................. 20

The Head ............................... 20

The Muscles................................ 21

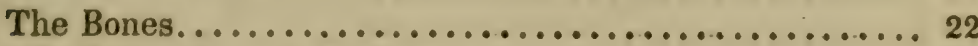

On the Improvement of Form. . . . . . . . . . . . . 22

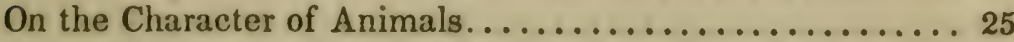

Examples of the good and bad effects of crossing the breeds 26

On the importance of more attention to the Principles of

Breeding-the Stallion and the Brood Mare........... 31

An Essay on the Condition of a Stallion.............41

Tables-Weights and Measures................ 49

List of Medicines ......................... 50

Apparatus for Compounding Medicines.............. 56

Instruments........................... $5 c$

Calving Table............................. 51

Lambing Table ........................... 51

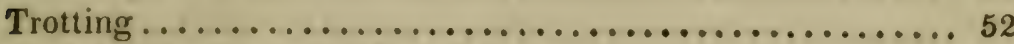

Best Trotting Time, at Mile Heats................ 53

At Two Mile Heats........................ 53

At Three Mile Heats....................... 53

At Four Mile Heats....................... 53

Racing-Best Time on Record at Mile Heats........... 54

At Two Mile Heats...................... 54

At Three Mile Heats....................... 56

At Four Mile Heats...................... 57

The St. Leger......................... 58

Average Speed for the Doncaster St. Leger ............ 59

Pedigrees of Winning Horses, since $1839 \ldots \ldots \ldots \ldots \ldots 60$

Celebrated Stallions and Brood Mares............... 89 



\section{S U P P L E M E N T, ETC.}

ON THE RELATIONS BETWEEN MAN AND THE DO. MESTIC ANIMALS - ESPECIALLY THE HORSE - ANL THE OBLIGATIONS THEY IMPOSE.

"La connaissance de la conformation exterieure du cheval est beau. cıup moins répandu qu'on ne le pense vulgairement: elle repose sur des etudes d'anatomie de physiologie, de mecanique, et d' histoire naturelle dont peu de personnes se font une juste idée."

If animals were classified by naturalists in the order of their intelligence, docility and usefulness, the Horse and the Dog would occupy, in relation to Man, the juxtaposition they have assigned-on the ground of physical structure-to the impracticable baboon and the grotesque and chattering monkey; and in lieu of groping in the darkness of antiquity for the period when they are supposed to have been entrapped or subdued, by fraud or violence, we should the rather conclude that Nature placed all the domestic animals where we have ever found them - in close association with Man, administering to his pleasures and wants; lightening his toils and sharing his dangere, and constantly advancing, like Man himself, under the improving influence of civilization and the arts that belong to it.

In contemplating the whole animal kingdom, does not Man-standing preeminently at the head of it, surrounded iv the domestic races - present everywhere the most 
lustr ous spot on the varied map of living creation? From the everlasting snows of the north to the burning sands of tropical deserts, his faithful dog follows at his foot; the horse is at his side - submissive to his will ; - the patient $0 \mathbf{x}$ bows his neck to the yoke; and the sheep and the hog are present to supply his clothing and his food. Far otherwise is it with untameable and predatory birds and beasts. Restricted to particular regions by an allwise Providence, the absence of food and climate congenial to their nature forbids them to roam beyond limits comparatively circumscribed. And do not these arrangements for our benefit, and which give us "dominion over all the earth and every creeping thing that creepeth upon the earth," enjoin on us the duty of studying their habits, their economy, and all the laws of their existence - with a view to their improvement for our advantage, in every way consistent with kindness to them and with gratitude to Hm,

"Who in his sovereign wislom made them all ""

And while these considerations teach us to be merciful ourselves, do they not convey the admonition

"Ye therefore who love mercy, teach your sons

To love it too!"

The very fact that to them has been denied the power of speech, and the necessity of uncomplaining submission under every hardship, ought to put us constantly on our guard against practising, or permitting to be practised, iny, the smallest measure of abuse or ill treatment. Thus every man of common humanity will study their comfort in all things, consistently with the purposes for which they were designed, and will nerer even mount his faithful horse without seeing that whatever is needed has been done to give an easy set to his saddle-and, still more, tnat all is right about his feet ! 
Doctur Rush, in a beautiful and benevolent eulogy op the Horse, in one of his lectures, related a touching anecdote of a highly intelligent and successful Pennsylvania farmer, who, stricken down suddenly with apoplexy in his barn-yard, expired on the instant-with this last direction to his herdsman on his lips: "Take care of the creatures!" And the biographer of an eminent English Chancellor relates, as from himself, how his beloved son had preferred to him, in his very last moments, a petition in favour of his faithful terrier; "And Father, you'll take cure of poor Pilcher, won't you?" Nevertheless, after all the care that can be taken, we should probably be amazed if we could know the amount of pain unwittingly inflicted on animals dedicated to our service, and some of whose bodies are at last consumed to afford usas some would contend-superfluous nourishment, refer ring back as they do to that golden age when

"Man walked with beast-joint tenant of the shade;

The same his table and the same his bed-

No murder clothed him, and no murder fed."

Even all unnecessary harshness of reproof should be avoided-for it is well known that some animals are even more susceptible of painful and violent emotions, from various causes, than some men, whose hardened nature and familiarity with vice, render them as insensible to the reproaches of others as to the stings of their own conscience. Those, for instance, who have studied the character and affections of the horse-with a view to his diseases and moral susceptibilities-need not be told that while sharp and threatening words will so disturb him as to quicken his pulse some ten beats or more in a minute,

* The natural constitution of different varieties of the same class of
animals is worthy of close attention. In small and thorough-bred horses,
:or instance, the pulsations of the heart are about 40 to 42 -while in
the larger, cold-blooded cart-horse, they do not amount to more than 36 ,
But when ill-treated, as before suggested, their pulsations are increased. 
ne has in very memorable cases been known to fall dead under the excitement of the sexual and other passions. 'That he is sometimes aniunated by the strongest spirit of rivalry, and a noble ambition to excel, has been occasionally evinced by violent attacks on his passing rivals on the turf-and very recently the case occurred with a noble animal which fell dead at the very winning-post, in vainly struggling for victory, on the Pharsalia course at Natchez. The contest which had this melancholy issue was between Col. Minor's Jenny Lind and Col. Bingaman's Black Dick :

“Dick was the farourite at odds. Some even bets were made that he would win at three heats-and some, if the heats were broken, would not win. Jenny drew the track, and after some little manœvring, they got off together, but Dick outfooted her and took the track on the turn; at the half-mile post she had got her head to his hips, and they ran locked round the upper turn; at the head of the front stretch she began to draw clear of him, and spurs were applied. 'Then burst his mighty heart,' for he soon was seen to reel, but he still struggled on; his jockey Mat, leaped unharmed from his back, and the noble animal fell dead within ten feet of the winningpost, which he had left not two minutes before in perfect health and the finest condition. No shout of triumph hailed the winner: all was sympathy and regret. Two

say, ten in a minute. The natural circulation of the sheep is about 70 per minute. The average pulse of a full-grown ox, in a state of health, in England, is about 40-but this increases in a climate of higher tem. perature. Doctor James Smith (Journal of Agriculture, vol. ii. p. 92, ) finds that in the climate of Iovisiana the pulse of the $o x$, in its natural state, is from 68 to 75 -rising on the slightest excitement to 80 . Every ono knows how destructive is the moral influence of fright to a flock of sheep-when, for instance, they have been badly scared by dogs. It often happens that they never recover from its effects.

For all farrners wh, nave occasion to fatten animals, we must take room fo: three words-warmth, cleanliness, and quictude. They aro the veni-vidi-vici, in their fields of action. 
of our most talented medical gentlernen immediately made a post-mortem examination, and carne to the conclusion that the death of the horse was produced by apoplexy, caused by congestion of the heart, brought on by over-excitement and violent excrtion."

The annals of domestic animals abound in cases tn show how liable they are to acute affections and suffering, far beyond the apprehension of the most considerate and humane.

Thus much, good reader, have we gladly seized the opportunity, and even gone a little beyond the requirements of our publishers, to say in the way of appeal in behalf of speechless creatures, as alive to pain as to a sense of gratitude for generous treatment; and having already adverted to the obligation we are under to study the laws of their existence, and the means of their melioration, it may now, even be insisted that in the whole range of the occupations and interests of breeders of their own stock, there are few things that demand more consideration and skill than does this very branch of rural industry.

The study and the pride of every one should be, not merely to maintain them at a point of excellence already acquired, but to have them progressively improving in whatever constitutes economy and value; for why shoula any man indolently conclude that his stock has already actained the ne plus ultra in the way of ameliorations however superior it may be? Such is not the fact, nor, it may safely be affirmed, would it be consonant with the orders of Providence, or even with our own interests, that it should be so. To man has been given dominion over the beasts of the field-that, like the earth itself, he should cultivate and improve them; and for that, among other purposes, was he endowed with the great, distinguishing, and godlike power to prosecute intellectuas 
investigations into every department of nature and industry. Doubtless our ancestors, more than a century ago, were ready to believe-what indolence is ever ready to whisper - that the several races of domestic animals most immediately under their care, had then already been carried up to the maximum of improvability; yet which of them has not been vastly bettered in the meantime, in all their valuable points-and that, too, not by any sudden or accidental accession of one or more good qualities, but constantly and progressively; by a closer study and a better knowledge of the laws of animal and vegetable physiology, and by the application of other appropriate sciences. In the plain English of the motto chosen for these reflections what is there said of the Horse may apply to other animals:

"The knowledge of the external conformation of the horse is much less extended than is generally supposed. It reposes on the study of anatomy, of physiology, of mechanics, and of natural history, in a manner of which few persons have a just conception."

In 1710, by the estimate of Dr. Davenant, - a writer of unquestioned candour and authority, - the weight of "black cattle" (so called, because, at that day, most cattle were of that colour) averaged but 370 pounds; the weight of the calf was estimated at 50 pounds; and the average of sheep and lambs, taken promiscuously in the London market, was only 28 pounds. After the lapse of 120 years, - with far less of science applied to the subject than at this time,-M'Culloch, in his dictionary, so highly characterized by the accuracy of its statements, puts the average of cattle at 556 ; sheep and lambs at 50 ; and calves at 105. But the late accomplished Professor Youatt, in his able work on cattle: estimates the average weight now at Smithfield at 656 ; that of sheep and lambs at 90 ; and calves at 144 ; - the weight of 
each having doubled in 130 years; and that, as before said, not by any accidental importation from abroad, or fortunate cross at home, but by a course of careful, systematic, and sagacious attention to the laws and principles of breeding and feeding. The horse, standing at the head of the list,--sharing and supporting man in all his most pleasurable as well as toilsome and dangerous enterprises,-naturally engaged his earliest attention and most assiduous care, to cherish and improve to the high. est pitch, his noble faculties of strength, speed, and endurance; and thus may have been already brought to the zenith of his capabilities, if indeed he has not passed the culninating point; but see what must have been achieved by the stimulus of the turf, and art in the breeding-stud, to raise the bred horse of England to a height of perfection, even above the wonderful capacity of his south-eastern ancestry, - the very "drinkers of the wind" themselves! - for we have the high authority of Nimrod, the crack writer of England on all fieldsports, for saying that, on the best Indian authorities, " the best Arab, on his own ground, has not a shadow of a chance against an imported English racer, in anything like a good form." "The celebrated race on the Calcutta Course, between Pyramus and Recruit, - the former the best Arab of his year; the latter a secondrate English race-horse, by Whalebone, the property of the Marquis of Exeter,-settled this point, inasmuch as allowance was made for the comparatively diminutive size of the Arab, - it being what is termed a give-and take match, or weight for inches; in which Recruit carred 10 stone 12 (152) pounds; and Pyramus only 8 stone 3 (115) pounds, an extra allowance of 7 pounds having been given to him as an Arab.

Pyramus, says the reporter of this race. is as goni 
an Arab (he had previously beaten all the best Arabs in Calcutta for the gold cup) as has appeared for many years. His condition was undeniable; the distance was all in his favour, and he was ridden with superior judgmentso that the result of his match with Recruit may be considered to have established this an axiom : that no allowance of weight, within the bounds of moderation, can bring the best Arab-eren in a climate most congenial to him-upon a par with an English thorough-bred horse of moderate goodness. In addition to all these circumstances in favour of Pyramus, it must be remembered that Recruit only landed on the 28th May, (the race was run in January), after a voyage of five months."

In England, where the progress of improvement was greatly accelerated by a seasonable infusion of Arabian and barbaric blood, the bred-horse-standing, in respect of the equîne race, as the capital on the Corinthian pillar-has reached a point of perfection that, if it can be kept up, we can hardly dare hope will ever be excelled In that country, four-mile races are nearly abolished, and it has been said with every show of reason, that early training, light weights and short distances, are impairing the stoutness of tise English race-horse and hunter, and their capacities to stand up and go the pace as in the palmy days of the English turf. In our own country, the annals of the course show, that our climate is highly congenial to the constitution and physical development of the horse - and that whenever the sport has been fashionable and the rewards adequate, he has ever been ready to meet all reasonable expectations-rather advancing tran falling oack.

When Floretta won her race in Washington-winning the $2 \mathrm{~d}$ heat in 7.52, against such nags as Oscar, Topgallant and First Consul, it was deemed a mar.ellous 
perform ance ;* and sportsmen thought that the arme of speed and bottom had been reached in our country in the days of Sir Charles and Eclipse, yet have not their best achievements been eclipsed by two illustrious and yet living rivals of each other - Boston and Fashion? But what have we not to apprehend should what seems to be threatened come soon to pass, and the turf - the only sure test of speed and stoutness, be allowed to go down? We remember once at a dinner-party at the British Minister's in Washington, to have inquired of the late John Randolph of Roancke, whether the Old Dominion maintained, unimpaired, her claim to a superior race of horses? "No, Sir; no, Sir," was his shrill-toned prompt reply; "Since we gave up horse-racing and foxhunting, and turned up the whites of our eyes, our hor zes as well as our men have sadly degenerated."

Finally-justice, truth, and a sense of obligation fcr the assistance derived from his labours, in the small contribution we are here making to the breeders and amateurs of the Horse, demand of us to say, at the least, that if the American Turf should decline, it will not be for want

* This was one of the most memorable contests that ever came off on the Washington Course. Horses were horses, and men were men, in those days. Fair-top boots, powdered heads, and golden "guineas" were all the go-and for fairness and honour, a "stain was felt like a wound."

The horses were thus placed :

Dr. Edelin's c. m. Floretta, by Spread Eagle, 6 years old, 5 1 1

Gen. Riagely's b. h. Oscar, by Gabriel, 6 yrs. old, 222

J. B. Bond's b. h. First Consul, by Flag of Truce, aged 433

Col. 'Tayloe's b. h. Top-gallant, by old Diomed, 6 yrs. old, 144

M. Brown's b. m. Nancy, by Spread Eagle, 6 years old. 3 dr.

In this race Floretta was closely run by Oscar and First Consul ach heat was run under 8 minutes, and the second in 7.52. Each horse made play from the score, and the time was better than had been made In that Course even up to 1829. Has such a field of men and horses come to that post since?

In another pace-the trot-it was deemed marvellous that " old Top" chould go his mile with 150 pounds weight in 2.45. But Lady Sulfolk - well dashed with the old Messenger blood - has done hers in $2.28 \frac{1}{2}$, and is yet in full if not improving vigour. 
of an able, industrious, and tasteful advocate and illus. trator of its advantages and uses, as long as W. T. PokTER shall continue to animate and guide the "SPIRIT of rhe Times." Extensive acquaintance and coëxtensive popularity-the just fruits of accomplished manners and an obliging temper-have made him the focus of a most varied and recherché correspondence: while his own tact, scholarship and nice appreciation of what is good in the literary and the sporting world, enable him to turn all his nich resources to the best account, for the enjoyment of his numerous and refined readers-for the most part, gentlemen of blood and mettle.

\section{ON THE FORM OF ANIMALS,}

BY HENRY CLINE, ESQ. SURGEON.

WITH NOTES BY J.S. SKINNER.

The form of domestic animals has been greatly improved by selecting with much care, the best formed for breeding-but the theory of improvement has not been so well understood, that rules could be laid down for directing the practice. There is one point particularly, respecting which the opinions of breeders have much varied, which is, whether crossing the breed be essential to improvement.

It is the intention of this communication to ascertain in what instances crossing is proper, and in what prejudicial; and the principles upon which the propriety of it depends.

It has been generally supposed that the breed of animals is improved by the largest males. This opinion has done considerable mischief, and would have done more injury had it not been counteracted by the ciesire of selecting animals of the best form and proportions, which are rarely to be met with, in those of the largest size 
Experience has proved that crossing has only succeeded in an eminent degree, in those instances in which the females were larger than in the usual proportion of females to males; and that it has generally failed when the males are disproportionally large.

The external form of domestic animals has been much studied, and the proportions are well ascertained. But the external form is an indication only of internal structure. The principles of improving it must therefore be founded on the knowledge of the structure and use of internal parts.

The lungs are of the first importance. It is on their size and soundness that the health of an animal principally depends. The power of converting food into nourishment, is in proportion to their size. An animal with large lungs, is capable of converting a given quantity of food into more nourishment than one with smaller lungs, and therefore has a greater aptitude to fatten.*

\section{The Chest.}

The external indication of the size of the lungs is the form and size of the chest; the form of which should

* [In farther explanation of this principle, it may be added, from an author who had evidently read and relied on this able Essay of Surgeon Cline, that muscular exertion facilitates the return of vewous blood to the right side of the heart, and in long continued and violent exertion, the respiration being quickened, the lungs-if small_-are unable to urterialize and get rid of the blood as fast as it is pumped into them; consequently, if there is not room for the blood, congestion takes place, and the horse becomes what is termed "blown"-the lungs being gorged pith blood, and sometimes the animal is destroyed by it. In England it is said to be "well understood that a majority of horses that perish under a hard press 'across the country,' are narrow-chestea!" Tho conical form, not of the body, but of the chest, as laid down in the next paragraph, is very observable in the best paintings of Fashion. Thero, and in her quarters and hocks, appear to us to lie the great sources of fer yet in this country unequalled speed and stoutness. - I. S. S.7 
have the figure of a cone, baving its apex situated between the shoulders, and its base towards the loins.

The capacity of the chest depends upon its form more than on the extent of the circumference; for, where the girth is equal in two animals, one may have much larger lungs than the other. A deep chest therefore is not capacious unless it is proportionally broad.

\section{The Pelvis.}

The pelvis is the cavity formed by the junction of the haunch bones with the bones of the rump. It is essential that this carity should be large in the female, that she may be enabled to bring forth her young with less diff:culty. Wren this carity is small, the life of the mother and of her offspring is endangered.

The size of the pelvis is chiefly indicated by the width of the hips and the breadth of the twist, which is the space between the thighs.

The breadth of the loins is always in proportion to that of the chest and pelvis.

\section{The Head.}

The head should be small, by which the birth is facilitated. Its smallness affords other advantages, and generally indicates that the animal is of a good breed.

Horns are useless to domestic animals. It is not difficult to breed animals without them. The breeders of horned cattle and horned sheep, sustain a loss more extensive than they may conceive ; for it is not the horns alone, but also much more bone in the skulls of such anımals to support their horns; besides there is an additional quantity of ligament and muscle in the neck which is of small value.

The skull of a ram with its horns, weighed five times more than another skull which was hornless. Both these skulls were taken from sheep of the same aç, each be ng 
four years old. The great difference in weight depended chiefly on the horns; for the lower jaws were nearly equal, one weighing seven ounces, and the other six ounces and three quarters; which proves that the natural size of the head was nearly the same in both, independent of the horns and the thickness of the bone which supports them.*

In a horned animal, the skull is extremely thick. In a hornless aninal it is much thinner; especially in that part where the horns usually grow.

To those who have not reflected on the subject, it may appear of little consequence whether sheep and cattle have horns-but on a very moderate calculation it will be found, that the loss in farming stock, and also in the diminution of animal food, is very considerable, from the production of horns and their appendages. A mode of breeding which would prevent the production of these, would afford a considerable profit in an increase of meat and wool, and other valuable parts.

The length of the neck should be proportioned to the height of the animal, that it may collect its food with ease.

\section{The Muscles.}

The muscles and tendons, which are their appendages, should be large; by which an animal is enabled to travel with greater facility.

* [ It is matter of surprise that among the varieties of cattle imported, no one should bring the celebrated Suffoll polled or hornless cattle. Besides the advantage here enumerated, valuable animals are sometimes killed by leing gored. In respect of this breed, Youatt speaks very highly. He says they sometimes give 32 quarts of millk, and 21 is not uncommon, in a day-and adds:- "There are few short-horn cows ; although far superior in size to the Suffolks, and consuming nearly dubble the quantity of ford; that will yicld more milk than is usuallo obtained from the smaller prolled lireml." Formerly the suffolk pollen cattle were generally of a dun colour, and thence commonly called Suf. olk duns, but that colour has of late been repudiated.-J. S. S.] 


\section{The Bones.}

The strength of an animal does not depend upon the size of the bones, but on that of the muscles-Many animals with large bones are weak, their muscles being small. Animals that were imperfectly nourished d iring growth, have their bones disproportionately large. If such deficiency of nourishment originated from a constitutional defect, which is the most frequent cause, they remain weak during life. Large bones, therefore, generally indicate an imperfection in the organs of nutrition.

\section{On the improvement of Form.}

To obtain the most approved form, two modes of breeding have been practised-one, by the selection of individuals of the same family-called breeding in-andin. The other by selecting males and females from different varieties of the same species; which is called crossing the breed.

When a particular variety approaches perfection in form, breeding in-and-in may be the better practiceespecially for those not well acquainted with the principles on which improvement depends. *

* [Professor Youatt says, on this subject [breeding in-and-in]: "It is tho fact, however some may deny it, that strict confinement to one breed, however valuable or perfect, produces deterioration." By what he afterward says, as will be seen, he must have meant confinement to one family or strain of the same breed. The rule should be this: that valuable qualities being once established, which it is desirable to keep up, should thereafter be preserved by occasional crosses with the best animal to be had of the same breed, but of a different family, This is the secret which has maintained the bred Horse in his great superiorityfor although, as Nimrod avers, the immediate descendants of eastern horses have, almost without an exception, proved so deficient of lato years that breeders will no more have recourse to them than the farmer would go for immediate improvement to the natural or original oat; yei the breecier is glad to cross his stock with one of another strain or family of the same blood, taking care never to depart from the blood of the sou th. eastern courser which flows in the heart of all families of Horses of th. highest capabilities. 
When the male is much larger than the ferna'e, the olfspring is generally of an imperfect form. If the female be proportionally larger, the offspring is of an improved form. For instance, if a well-formed large rain be put to ewes proportionally smaller, the lambs will not be so well shaped as their parents; but if a small ram be put to larger ewes, the lambs will be of an improved form.

It is here wortly of remark that Nicholas Hankey Smith, who resided a long time among the Arabs, in a work entitled "Observations on Brecling for the Turf," gives as his opinion that colts bred in-and-in show more blood in their heads, are of better form, and fit to start with fewer sweats than the English turf-horse; but when the incestuous intercourse has continued a few generations, he says, the animal degenerates.

This plan of breeding in-and-in, says Youatt farther, when speaking of cattle: "has many advantages to a cerlain exlent. It may be pursued antil the excellent form and qualities of the breed are developed and established. It was the source whence sprung the cattle and the sheep of Bakewell, and the superior cattle of Colling-and to it must be traced the speedy degeneracy, the ahsolute disappearance, of the new Leicester or Bakewell cattle; and in the hands of many an agriculturist, the impairment of constitution and decreased value of the new Leicester sheep and the Short-Horn beasts. It has therefore become a kind of principle with the agriculturist to effect sorne change in his stock every second or chird year-and that change is most conveniently effected by introducing a new bull or ram. These should be as nearly as possible of the same 6ort coming from a similar pasturage and climate, but possessing no relationship, or at most a very distant one, to the stock to which he is introduced" - and these remarks "apply to all descriptions of live-stock," says Professor Johnston, author of the Farmer's Cyclopedia.

This is the secret wherely Mr. Grongr: Patrinsos, of Maryland, has not only kept up but improved the size ard beauty of his North Devons. Every "two or three years," a new hull the best to be had in England, is introduced to his cows. The neglect of this precaution, and breeding in-ind-in too closely, are the true reasons why we so rarely seo the descendants of imported stock in this country equal to the originals. Too close breeding tells in Man as well as in beast; hence the famous lines of Lord Byron when speaking of the nobility :

" They breed in-and-in as might be known,

"Marrying their cousins, nay, their aunts and nicees,

"Which always spoils the breed, if it increases."

But, after all, we must look closely to the form of the parents as well in Horses as cattle_for, let the world dispute as it may, whether "blood is everything," or "blood is nothing,"- - be the blood what it may, who has ever seen, as Apperley asks, an instance of a misshajen horse aral ill-formed mare producing winners? - J. S. S.] 
The proper method of improving the form of animals, consists in selecting a well-formed female, proportionally larger than the male. The improvement depends on this principle, that the power of the female to supply he: offspring with nourishment is in proportion to her size, and to the power of nourishing herself from the excellence of her constitution.

The size of the fotus is generally in proportion to that of the male parent; and therefore, when the female parent is disproportionately small, the quantity of nourishment is deficient, and her offspring has all the disproportions of a starveling. But when the female, from her size and good constitution, is more than adequate to the nourishment of a fœtus of a smaller male than herself, the growth must be proportionately greater. The larger female has also a greater quantity of milk, and her offspring is more abundantly supplied with nourishment after birth.

To produce the most perfect formed animal, aoundant nourishment is necessary from the earliest period of its existence, until its growth is complete.

It has been observed, in the beginning of this paper, that the power to prepare the greatest quantity of nourishment, from a given quantity of food, depends principally upon the magnitude of the lungs, to which the organs of digestion are subservient.

To obtain animals with large lungs, crossing is the most expeditious method; because well-formed females may be selected from a variety of a large size, to be put to a well-formed male of a variety that is rather smaller.

By such a method of crossing; the lungs and heart become proportionately larger, in consequence of a peculiarity in the circulation of the fotus, which causes a larger proportion of the blood, under such circumstances, to be uistributed to the lungs than to the other parts of 
the body; and as the shape and size of the chesi denenti upon that of the lungs, hence arises the remarkably largi chest, which is produced by crossing with females thas are larger than the males.

The practice according to this principle of improve. ment, however, ought to be limited ; for, it may be carried to such an extent, that the bulk of the body might be so disproportioned to the size of the limbs as to prevent the animal from moving with sufficient facility.

In animals where activity is required, this practice should not be extended so far as in those which are required for the food of man.

\section{On the Character of Animals.}

By character in animals is here meant, those external cppearances by which the varieties of the same species are distinguished.

The characters of both parents are observed in their offspring; but that of the male more frequently predominates.

* To the contrary of this, as to Horess, T. B. Johnson, author of the Shooter's Companion, and a writer of high authority, says : "although it is a maxim universally admitted, that an equal degree of precaution should be used in respect to the Horse, it is doubly and trebly necessary with the mare-because strict observation has demonstrated that nearly or full two out of every three foals, display in their appearance more of the dam than the sire; and that there are more fillies than colts fallen every year will not admit of a doubt."

'This positively asserted predominance of females over males, may be accounted for on the principle established by very numerous experiments in France with sheep, if not with other animals-on the results of which the experimenter, whose name is not remembered, based and confidently asserted his theory, that the sex of the offspring, in all cases, depends much on the comparative vigour of the parents. By putting old ewes to young rams in the prime of life, he never failed to get a large proportion of ram lambs; and, vice versa, when young ewes in their prime were put to a ram lamb, which had not yet attained his full growth anci development, or to old ones far gone in the down-hill of life, then a very large proportion were females. $\Lambda$ great number of experiments were given corroborative of the doctrine. Is it not reasonable to suppose that an influence sufficient to control the sex, would have an effect on exte?- 
This naly be illustrated in the breeding of horned aximals; among which there are many varieties of sheep, and some of cattle, that are hornless.

If a hornless ram be put to a horned ewe, almost all the lambs will be hornless; partaking of the character of the male rather than of the female parent.

In some countries, as Norfolk, Wiltshire, Dorsetshire, most of the sheep have horns. In Norfolk the horns may be got rid of by crossing with the Ryeland rams; which would also inprove the form of the chest and the quality of the wool. In Wiltshire and Dorsetshire, the same improvements might be made by crossing the sheep with South Down rams.

An offspring without horns might be obtained from the Devonshire cattle, by crossing with hornless bulls of the Galloway breed; which would also improve the form of the chest, in which, the Devonshire cattle are often deficient.

Examples of the good effects of crossing the breeds.

The great improvement of the breed of horses in England arose from crossing with those diminutive Stallions, Barbs, and Arabians; and the introduction of Flanders mares into this country was the source of improvement in the breed of cart-horses.

The form of the swine has also been greatly improved, by crossing with the small Chinese boar.

Examples of the bad effects of crossing the breeds.

When it became the fashion in London to drive large bay horses, the farmers in Yorkshire put their mares to

nal form and colour? It may be a reason why some of our very popular sralions, heing overtakked, have had so few of their get to rival them in power and fame. Every reader may cast ahout for himself, for instances, to see tow far and to what other animals the principle applies. After all, in an economicu-ayricultural view, it is much more important that the stallion should be all right because it is his bleyd that is to be dillused far and wide.-J. S. S.] 
nuuch larger stallions than usual, and thus, did infinite mischief to their breed, by producing a race of smald chested, long legged, large boned worthless animals.*

A similar project was adopted in Normandy, to enlarge the breed of Horses there by the use of stallions from Holstein; and, in consequence, the best breed of Horses in France would have been spoiled, had not the farmers discovered their mistake in time, by observing the offspring much inferior in form, to that of the native stallions.

Some graziers in the Island of Sheppey, concerved that they could improve their sheep by large Lincolnshire rams, the produce of which, however, was much inferior in the shape of the carcase, and the quality of the wool ; and their flocks were greatly injured by this attempt to improve them.

Attempts to improve the native animals of a country, by any plan of crossing, should be made with the greatest caution; for, by a mistaken practice extensively pursued, irreparable injury may be done.

* [This was the effect experienced in Maryland, by the use of Exile, a Cleveland bay, of the highest breeding of his sort in England, imported by the late Robert Patterson about the year 1820. At three years old, he was advertised for sale, and stated to be then upward of 16 hands high.

They may do very well, with their long legs, long backs and long tails, for the heavy, lumbering slow coaches of millionaires, to drive to church, and occasionally to make a swell in town, but they are not fitted for the country - and especially not for this country. True, for the coach-horse we want substance, but we want that substance well placed, deep, well-proportioned body, rising in the withers, and slanting shoulders, short back well ribbed home, and broad loins; sound, fiat, short legs, with plenty of bone under the knee; and sound, open, tough feet. "In fact, coach-horses should be nothing more than large hackneys, rarying in height from 15 hands 1 inch to 16 hands 1 inch." Such lıorses, of good colour, and well matched, will always commard a high figure from the swelled heads in our large cities-men who bavp grou. rich as the conduits of exchange, between the producer and tne cas rumer of Agriculture and Manufactures. — I. S. S.] 
In any country where a particular race of animals nas contmued for centuries, it may be presumed that their constitution is adapted to the food and climate.

The pliancy of the animal economy is such, as that an animal will gradually accommodate itself to great vicissitudes in climate and alterations in food; and by degrees undergo great changes in constitution; but these changes can be affected only by degrees, and may often require a greater number of successive generations for their accomplishment.

It may be proper to improve the form of a native race, nut at the same time it may be very injudicious to attempt to enlarge their size.

The size of animals is commonly adapted to the soil which they i-habit; where produce is nutritive and abundant, the animals are large, having grown proportionally to the quantity of food which for generations they have been accustomed to obtain. Where the produce is scanty, the animals are small, being proportioned to the quantity of food which they were able to procure. Of these contrasts the sheep of Lincolnshire and of Wales are examples. The sheep of Lincolnshire would starve on the mountains of Wales.

Crossing the breed of animals may be attended with bad effects in various ways; and that, even when adopted In the beginning on a good principle; for instance, suppose some larger ewes than those of the native breed were taken to the mountains of Wale's and put to the rams of that country; if these foreign ewes were fed in proportion to their size, their lambs would be of an improved form and larger in size than the native animals; but the males produced by this cross, though of a grood form, would be disproportionate in size to the native ewes; and therefore, if permitted to mix with them, would be productive of a standing ill-formed prugeny 
Thus a cross which, at first, was an inprovement, would, by giving occasion to a contrary cross, ultimately prejudice the breed.

The general mistake in crossing has arisen from an attempt to increase the size of a native race of animals ; being a fruitless effort to counteract the laws of nature.

The Arabian Horses are, in general, the most perfect in the world; which probably has arisen from great care in selection, and also from being unmixed with any variety of the same species, the males have therefore never been disproportioned in size to the females.

The native Horses of India are small, but well proportioned, and good of their kind. With the intention of increasing their size, the India company have adopted a plan of sending large stallions to India. If these stallions should be extensively used, a disproportioned race must be the result, and a valuable breed of Horses be irretrievably spoiled.

From theory, from practice, and from extensive observation, whicn is more to be depended upon than either, it is reasonable to form this conclusion, that it is wrong to enlarge a native breed of animals; for in proportion to their increase of size, they become worse in form, less hardy, and more liable to disease.*

* [For this plain reason, our farmers should have recourse to well-formed bulls of a smaller or middling size, rather than to those of a larger breed than the average size of their own cattle, and also why it is far better to employ compact, short-backed, well-formed, thorough-bred stallions, than cold-blooded stallions of larger size.

Essential difference has been found, by analysis in France, between the blood of the ordinary Horse and that of the aristocratic race descended from the south-eastern courser. It is stated to be less serous than that of the common Horse. One cannot but admire the ardour with which, in France, they are now applying the sciences to enlighten all branches of agriculture, as it has been so much more and more successfully applied to other industries. A society of the first men of that country is devoted to the meliorution of the Horse, and they under take to predict the time nut distant when "la science du cheval," the 
seience of the anatomy and physiology of the Horse-wilh be as well understood and agreed upon as any principles in Geometry.

The reason that, in our country, agriculture has benefited so much less by the application of the sciences, is that the policy of the government has a tendency to disperse them, while it concentrates other classes Instead of compelling the consumer - the shoemaker, the tailor, the wheelwright, and all manufacturing consumers to come from abroad as well as at home, and settle down nearest to them, the agriculturisto foster a policy which compels them-over bad roads-to expend half tho produce in carrying it to the fashioner and consumer._- J. S. 3.] 
1) N THE IMPORTANCE OF MORE ATTENTION TO THE. PRINCIPLES OF BREEDING-THE STALLION AND THE BROOD MARE.

To every lover of the Horse, possessed of a knowledge of his fine points and capabilities, it must be lamentable to perceive how miserably ignorant and careless the mass of breeders of that noble animal appear to be, as to all the precautions which are indispensable to maintain him at the point of excellence which is known to be attainable -much less by well-digested and rational systems of breeding and rearing throughout the country, to meliorate his form and invigorate his constitution; and on no one point is there, seemingly, more pernicious indifference displayed than in regard to the condition of the stallions they employ, as set forth in the Essay which these remarks are intended to introduce.

Well has it been said, in the introduction to the " $A n$ nales des Haras et de l'Agriculture," that if the importance of a question is to be measured by the number of those who are occupied with it, that of the multiplicat: and of the amelioration of the Horse ought to hold the first rank in Political and Rural economy. The traditions of antiquity-those of nations, whether barbarous or snlightened-writings the most ancient as well as the zost modern-prove to us i.le estimation which Man, m all times, has attached to this his most noble conquest, to use the expression of Buffos. The Horse, as there alleged, is in truth the most fruitful scurce of the riches of States, by his indispensable instrumentality in the cultivation of the soil. $\mathrm{He}$ is one of the most direct ugents of their power by the use that is made of him in armies, whether in peace or in war; and has contributed much more than is generally considered, to the civiliza 
tron of communities, by facilitating intercourse betwees. them and the individuals of whom they are composed.

It is not, then, astonishing that in the abstract, so much importance should be attached to the multiplication and improvement of an animal so useful; but is it not amazing that this universal admission of his value, and the general interest of society in cultivating his finest qualities, should give rise to no association or system in our country, based on reason, and guided by scientific principles? On the contrary, everything is left to chance, to ignorance, and to narrow and sordid calculations of economy. True, we have societies that group the Horse with every other animal and thing, and offer petty pre miums for the mere exhibition of the best that may happen to be convenient to, or purchased for the show: but should not an object so important be made the sub ject of special associations, and of legislative encouragement, directed to a thorough investigation of the princ ples to be followed in all enlarged and judicious plans for the melioration of the whole race? Look at the amount of capital involved in the whole Union-4,365,669 horses. Value these at an average of $\$ 50$, and we have a capital of $\$ 218,283,450$, which, with anything like judgment or system, might be brought to an average improrement of at least twenty. per cent. in a few years. What is the number lost by exposure to sudden ricissitudes of weather - to lad shoeing - in short, to ill treatment and ignorar:e of the management and the remedies prescribed in this work, no one can renture to estımate. Youat sets down the loss of cattle by disease annually in England at $\$ 50,000,000$ !- and the loss of sheep at one-tenth of the whole number; and though there the veterinary art is taught as a science in the endowed colleges, and regrular professors practise it throughour tre kingdom, he says it is difficult to say 
wl It is is the greater source of this immense loss to th agriculture of the country- " the ignorance and obstinacy of the servant and the cow-leech, or the ignorance and supineness of the owner." The Horse, in a state of nature, even the colt-until subjected to ignorant handling and cruel management, is much healthier than after he comes under the hands of him who ought to be his kindest friend.

If such be the immense mortality in England, what nust it be among Horses in this country, where not one farmer in a hundred knows how to tell the colic from the botts, or the thrush from the scratches - ignorant alike of symptoms and of treatment?

Properly appreciating the importance of a constant supply of Horses for their cavalry, as one of the most efficient arms of her military power-the French Government takes it upon itself to supply its thirty-six thousand communes with stallions, whose services are put at the lowest rate, the average being set down at 5 or 10 francs, (one or two dollars,) and these stallions are required to be not under a certain age-four at the least-nor under a certain standard of height, according as they are thorough-bred, half-bred, or slow draft: $1 \mathrm{~m} .49$ centimes, or a fraction over 14.2 for thorough-bred; $1 \mathrm{~m} .55 \mathrm{c}$. for half-bred; and $1 \mathrm{~m} .55 \mathrm{c}$. for heavy draft stallionsand undergo every year rigid inspection, to guard not only against palpable deformity of shape, but against any latent or transmissible diseases. Opposed as is the genius of our political institutions to regulations, too minute, of individual industry and concerns, yet it is hard to say why a planter's tobacco or his butter should be subjected to rigid inspection, and condemned and taken from him for bad quality or short weight, and yet that any fat, lazy, lounging rapscallion should be allowed to set up a public stallion without spirit or action, anu 
bo often tainted with some hereditary disorder or defec: of body or temper-to deform and poison everything he ss allowed to touch. The Arabians, after having brought their breed of Horses to the highest degree of perfection of which they consider them capable, are said to have preserved their splendid qualities of great endurance. with highly organized matter and natural soundness of limb, by prohibiting the use of stallions until approved by a public inspector. "Breeders of all kinds of Horses," says Nimrod, "but of the race-horse above all others, scarcely require to be cautioned against purchasing or breeding from mares, or putting them to stallions, constitutionally inferior. By constitutionally inferior is chiefly implied, having a tendency to fail in the legs and feet during their training, which too many of our present racing breed are given to-although the severity of training is not equal to what it was some years back. It would be invidious to particularize individual sorts ; but, says he, we could name stallions and mares from which the greatest expectations were raised, whose progeny have sacrificed thousands of their owners' money, entirely from this cause." After instancing numerous cases to show the heritableness of diseases-glanders among others - of horses, sheep, and cattle, " these conside1ations," continues an eminent French writer, Professor Dupuy, on the Veterinary art, "are to us of the greatest moment, since we have it in our power by coupling and crossing well-known breeds, to lessen the number of animals predisposed to these diseases. Acting up to these ideas, our line of conduct is marked out. We must banish from our establishments, designed to improve the breed, such animals as show any signs of tuberculous disease or any analogous affection."

Thus much have we felt called upon to say, introductory of the following able dissertation on the cordition 
of the stallion - anonymously written by some gentleman who has evidently observed the precaution tow often neglected; to understand his subject, before he vegan to speak upon it. It is taken from the "FARMrRs' Library," for which it was written, and where, it may be needless to say, such writers will always be truly ..elcome. As against the assertion of Surgeon Cline, with whom the author of this Essay agrees as to the predominant influence of the male in characterizing the progeny, we have, in another place, arrayed the opinion of Mr. Johnson, it is but fair here to adduce, in support of the affirmative side of the proposition, the all-powerrul testimony of Mr. Apperly, who says: "Virgil, in his excellent remarks on breeding Horses, tells those of his readers who wish to gain prizes to look at the dam; and until of very late years, it was the prevailing opinion of Englishmen that in breeding a racer the mare is more essential than the Horse, in the production of him in his highest form; and we know it to have been the notion entertained by the late Earl of Grosvenor-the most extensive though not perhaps the most successful breeder of thorough-bred stock that England ever saw. The truth of this supposition, however, has not been confirmed by the experience of the last half century, and much more dependence is now placed on the stallion than on the mare. The racing calendar, indeed, clearly proves the fact.

"Notwithstanding the prodigious number of very highly bred and equally good mares that are every year put to the horse, it is from such as are put to our very best stallions that the great winners are produced. This can in no other way be accounted for than by such horses having the faculty of imparting to their progeny th: peculiar external and internal formation absolutely essensial to the first-rate race-horse ; or, if the term 'blooa' 
be insisted on, that certain innate but not preternatura virtue peculiarly lelonging to some horses, but not to others, which, when it meets with no opposition from the mare-or, in the language of the stable, where 6 the cross nicks' by the mare admit of a junction of good shapesseldom fails in producing a race-horse in his very best form."

After all, when the reader shall have carefully perused the following disquisition, he will, we think, be apt to concur with us in the belief that incalculable loss and deterioration ensue from an almost universal want of attention to the condition of the stallion, and from ignorance in what true condition consists. The maxim of the feeder of the ox may be embraced in the words warmth, cleanliness and quiet. Not so with the grazier of stock-cattle-for they may be kept too warm; nor with the owner of a Stallion; yet too generally they manage him as if he had nothing to do but to eat, drink, and sleep-except when suddenly aroused to go through violent agitation to the opposite extreme.

-On the subject of the comparative agency of the male and female parent in the modification of the progeny in form and character, as sir Roger expressed it " much may be said on both sides." There needs no citation of instances to show the influence of the male progenitor in modifying the exterior form and colour, of the off spring, and may we not infer it in regard to its internal structure, its temper and character? Neither can we deny the share of the female parent in the same influences --see how often the calf, in its marks, exhibits an exact copy of its dam. But there are cases of what is called superfœtation, which go to show some extraordinary power of the male in transmitting his influence even tc the second and third generation on the furits of subsequent conceptions from sexual intercourse between the 
same dam and other males. No fact in Natural History need to be better proved; and circumstances lead us ty believe, though we are not aware that the question has occurred to naturalists, that this always occurs with the first or virgin conception; and if so, it admonishes the breeder to be especially particular in the selection of the male to which is granted the high privilege of the first access. Out of many cases that might be referred to, the reader's memory may be here refreshed as to two that are somewhat familiar.

Twenty-six years ago, in the London Farmer's Journal was recorded the ease which had then lately appeared in the Philosophical Transactions, on the authority of Eari Moreton, stating that his lordship possessed a male animal called Quagga by the Hottentots - in whose mountains they abound. It closely resembles the Zebra, but of a smaller size. He determined on obtaining a foal by this animal, from a chestnut-coloured mare of seven-eighths blood, which had never been bred from. This gross prostitution - as we should call it - took place, and accordingly a female hybrid progeny was produced, which bore, in form and colour, decided indications of mixed blood, but proved incapable of breeding-as is almost universally the case with mules; but not quite, as the writer has proved in his edition of Youatt on the Horse, (Lea \& Blanchard,) on the most unquestionable testimony.

This mare of seren-cighth Arabian blood was soon after sold to Sir Gore Ousley, who afterward bred from her, by a very fine black Arabian stallion, two colts. These Lord Moreton went to see and examine,-the one a two-year old filly; the other a yearling colt-both of which were as strongly characterized by Arabian bloos as might be expecterl where there was fiftern-sixteenth of it present-but both in their colour ard hair of their manes, they showed a striking resemblance to the mogga 
The whole statement was fully verifie to the Society by Doctor Woolaston, a member of it, who examined both the filly and colt, and who was " distinguished for his very extensive knowledge."

Following the cornmunication of Lord Moreton in the Transactions, is one from Dr. Woolaston, relating the case of a black and white sow, of Mr. Western's celebrated breed of hogs (she being the property of a $\mathrm{Mr}$. Giles) which was put to a wild boar, of a deep chestnut colour, that was soon after by accident drowned. The pigs produced, which were the sow's first litter-partook in appearance of both boar and sow, but in some the chestnut colour of the boar strongly prevailed. This sow was afterward put to a boar of Mr. Western's breed. The pigs produced were some of them stained and clearly marked with the chestnut colour which had prevailed in the former litter. Her next litter, by a boar of Mr. Western's spotted, black and white breed, were also stair.ed with marks of the wild boar - although in no other instance, with any other sow, had the least tinge of the chestnut colour been observed.

Another very striking instance of the transmissible influence which survives the $f$ st and impresses itself on subsequent conceptions, occ red under the observation of the writer of this, and wa it is believed, related in a small volume scribbled and : sblished under the title of "The Sportsman and his Dug." The case was that of a beautiful coach-dog bitch, Annette, presented to him by that earnest and efficient promoter of agricultural improvement, Gorham Parsons of Massachusetts, along with her full brother, Lubin. Though closely watched for the first signs of sexual appetite, with a view to a litter of the genuine breed for the great pleasure of giving them to friends to whom they were promised, a stray dog, of large size, of white colour, except his black ears 
contrived in steal the first access to the bitch, and in all subsequent litters, ly Lublin, one pup always appeared to attest the indelible impression made in the enthusiasin of a first cmbrace. It may gratify curiosity to note such facts, and may serve, beyond all dispute, to show how cautious every breeder should be in the choice of the male-especially the one first employed.

But how vain to endearour to account for these things! Nature invites us to study her ways, and science is most efficiently applied to every art and every industry, when it most closely conforms to her laws: but she has certain arcana of her own, which she keeps in reserve, and which defy the scrutiny of the most curious and importunate inquirer. We see enough to know that her laws are enacted by an All-Wise and Overruling Power; and can never be too grateful for the faculties that enable us, so much above other created beings, to study and understand them, and yet more for that hopeful thirst for knowledge which is leading us on from one discovery to another, until, in view of what science is revealing from year to year, who shall say how near we may be permitted to approach the Supreme Intelligence? Ols that our love of peace and of each other, may keep way wisth our progress in knowledge!-for of those to whom much is given, much shall be required-else, has it been wein esked,

\footnotetext{
" why was Man thus emisuntly raised Amid the vast creation? Why empowered, Through life and death, to cast his watchful eye With thought beyond the limits or his frameBut that the Omnipotent might send him forth In sight of angels and approving worlds : Might send him forth the sovereign good to learn, 'To chase each meaner passion from his hreast, And through the storms of passion and of sense To hold straight on, with constant heart, and eye Still fixed upon Man's cverlasting palm, 'The approving smilo of Heaven."
} 
There is, as elsewhere intimated, if we consult Nature, always acting for the best, - reason to conclude it was intended, with domestic animals, that the male should exert the greater influence over the form and qualities of the progeny. Were it not so, how slow and ineffectual would be all attempts at amelioration, for it is through one male that blood and form and qualities are imparted to great numbers-while, with the female, but a solitary effect or result can be accomplished during a whole period of gestation. In herds of wild Horses, Nature allows troops of mares to be engrossed by the stallion of most courage and strength, thus guarding against the inevitable degeneracy of promiscuous intercourse-and he again, after a season or two, is supplanted by some rebellious young rival, stronger if not braver than he, before time enough has elapsed to stamp the whole race by that degeneracy which follows incest tous intercourse long continued. Here again we are irvited to follow, and, as art may always do, inprove upon, if we do follow, the laws of Nature. But, alas, of breeders of animals it may be said, "s they have sought out many inventions" that violate her laws, and the consequence is, a miserable race of ill-formed, decrepit garrans, fit neither for harness nor saddle, for the road or the chase, for peace nor for war, nox tos anvthing but-dog's meat. 


\section{AN ESSAY ON THE CONDITION OF A STALLION}

The word condition is used by horsemen in a differeni sense from that in which it is understood as applied to cattle by the mass of farmers. By condition the farmer often means a high state of fatness; the horseman, on the contrary, makes use of the word to indicate the greatest health and strength produced by reducing all superfluous fat, bringing the mere flesh into clean, hard and powerful muscle, and invigorating the lungs and other internal organs, so that they may promptly discharge their respective functions, and suffer no damage from uncommon stress-the whole in order to the animal's performing labours and sustaining a continuance of action to which he would not be adequate without such especial preparation.

By the Condition of a Stallion is meant the state of the system in which the male horse should be kept, in order to deriving from him the greatest excellence in the progeny.

Too many persons are content to breed their mares to a horse whose figure suits them, without regard to his condition. The mention of one prominent instance alone will be sufficient to show that good condition is essential to the production of a valuable progeny. A remarkable case occurred in England some years since, in so high a quarter as to attract public attention, and consequently th 2 fact of the account's obtaining currency without contradiction is a fair evidence of its correctness. The Prince of Wales, who afterwards became George the Fourth, owned, and was in the habit of riding as a hunter, an entire horse of unequalled excellence. In consequence of this horse's superior qualities, His Royal Highness caused a few of his own mares to be bred $t$ 
nim in the spring, after he had been kept in the highesi condition as a hunter throughout the winter, and the produce, on growing up, proved every way worthy of their sire. When His Royal Highness, as Prince Regent, became seriously engaged in the cares of Government, and therefore relinquished the pleasures of the chase, being desirous to perpetuate the fine qualities of this stock, he ordered the horse to be kept at Windsor for public covering, prorided the mares should be of the first quality; and in order to insure a sufficient number of these, directed the head groom to keep him exclusively for such, and to make no charge, with the exception of the customary groom's-fee of half a guinea each. The groom, anxious to pocket as many half guineas as possible, published His Royal Highness's liberality, and vaunted the qualities of the horse, in order .o persuade all he could to avail themselves of the benefit. The result was, the horse being kept without his accustomed exercise and in a state of repletion, and serving upward of a hundred mares yearly, that the stock, although tolerably promising in their early age, shot ur into lank, weakly, awkward, leggy, good-for-nothing creatures, to the entire ruin of the horse's character as a sire-until some gentleman, aware of the cause, took pains to explain it, proving the correctness of their statements by reference to the first of the horse's get, produced under a proper system of breeding, and which were then in their prime, and among the best horses in England.

Almost every observing farmer in this country has lemarked that whenever, within his knowledge, an ordinary work-horse has, by chance, covered a tolerably good mare, the foal thus produced has, at maturity, almost invariably become a better animal than it was expected to be, and in many cases proved quite superior to the get of the high-priced and highly pampered stal- 
lions of the neighbourhood. What was the cause of this? Condition. The work-horse, by coustant aud severe exercise, was brought into health and strength, and his stock partook of the state of his system at the time or copulation. Why is it that many experienced farmers, after having tried the best stallion within theit knowledge, frequently resort to the keeping of one of their own colts or farm-horses entire, for the service of their mares, and actually obtain as large and as good and saleable stock from such a one, as that from the public stallions of far superior size, form, blood, and all other qualities, except this indispensable condition?

It may be stated that, generally, whenever the get of a stallion has proved, at maturity, to be of remarkable excellence comparatively with the sire, such horse has been, at and previously to the time of getting such valuable stock, kept without pampering, without excessive sexual service, and with a good share of exercise or labour.

To show the effect of a peculiar state of the system in the parents at the time of copulation, instances may be cited from various sources. We will content ourselves with two-and first take a lamentable case in the human species as given in the raluable work on "The Constitution of Man," by George Combe:

"In the summer of $18: 27$, the practitioner alluded to was called upon to visit professionally a young woman in the immediate neighbourhood, who was safely delivered of a male child. As the parties appeared to be respectable, he made some inquiries regarding the absence of the child's father, when the old woman told him that her daughter was still unmarried; that the child's father belonged to a regiment in Ireland; that last autumn ne had obtained leave of absence to visit his friends in this part of the country, and that, on the eve of his de. 
parture to join his regiment, an entertainment was giren, at which her daughter attended. During the whole evening she and the soldier clanced and sang togrether; when heated by the toddy and the dance, they left the cottage and after the lapse of an hour were found together in a glen, in a state of utter insensibility, from the effects of their former festivity; and the consequence of this interview was the birth of an idiot. He is now nearly six years of age, and his mother does not believe that he is able to recognise either herself or any other udividual. He is quite incapable of making signs whereby his wants can be made known, with th. is exception, that when hungry he gives a wild shriek. This is a case upon which it would be painful to dwell, and I shall only remark that the parents are both intelligent, and that the fatal result cannot otherwise be accounted for than by the almost total prostration or eclipse of the intellect of both parties from intoxication."

For another instance of a peculiar constitution derivec from a parent at the time of copulation, and owing to a temporary excitement of the animal, a respectable farmer related to the writer of this Essay that he witnessed the effect of pain and nerrous agitation on a stallinn just before the moment of covering, in the production of a wild, timid, violent and worthless colt. 'The sire was in repute as one of the best horses ever kept in the dis trict; and his stock afterward justified the opinion. The groom became angry and beat him in his stall in a cruel manner, and then led him out and allowed him to cover the mare, which was one of a perfectly quiet and ordorly temper. The consequence was the production of an animal totally valueless, as above mentioned.

That the doctrine here held is no " new thing under the sun" is evident from many venerated authors. Plutarch says " The advice which I am now about to give, 
is indeed no other than what hath been given by those who have undertaken this argument before me. You will ask me what is that? 'Tis this, that no man keep company with his wife for issue sake, but when he is sober-as not having before either drunk any wine, or, at least, not tc such a quantity as to distemper him; for they usually prove wine-bibbers and drunkards whose parents begot them when they were drunk; wherefore, Diogenes said to a stripling somewhat crack-brained and half-witted, 'Surely, young man, thy father begot thee when he was drunk?"

Shakspeare intimates the same belief in making a hero insult his enemies with the taunt

\section{"For ye were got in fear."}

On no other known priıciple than this condition, or a peculiar state of the system at and before the time of copulation, can be explained the important fact which forms at once a criterion of skill in the scientific breeder, and a stumbling-block to the ignorant and unreasonable one, who would expect success without giving himself the trouble of investigating the natural laws which govern the subject of his operation: such a person is too apt to argue within himself that because the same parents at different times produce offspring of opposite characteristics, there can be no certain rules by which to create determinate qualities in the progeny: such a one would maintain that, because all the children of one married couple are usually somewhat different in characteristics from each other, there can be no means of predicting, with an approach to certainty, the qualities to be produced in the offspring by a particular sexual intercourse. Now this law of condition accounts for the difference bctween individuals produced at several births from the same parents. The case of twins, in the human species, serves to strengthen this argument, inasmuch as the two 
persons produced at one birth usually beas a close resem ilance to each other, in all respects.

It is known that ideal impressions on the femal parent, subsequent to conception, frequently take permanent effect on the offspring. That such causes do not usually give the leading characteristics to the progeny, is evident from these considerations:

1st. The consequences of such impressions on the female, are usually somewhat of an unnatural or monstrous order, being different from the traits of either parent, and from the common nature of the variety to which the animals belong.

$2 \mathrm{~d}$. It is a settled point with breeders that the pro geny is more strongly characterized by the traits of the male, than by those of the female parent. This fact is well known; and indeed it can hardly be expected otherwise than that the sex which bears so much the stronge. impress of character, should impart the more visible re. semblance to the offspring.

$3 \mathrm{~d}$. It is an ascertained law of Nature, that peculiarities of climate, food, occupation and most other circurn stances affecting the well-being of an animal, produce in its constitution a change such as is necessary for the welfare of the species; and that this proceeds throughout many generations, until the animal becomes completely adapted to the circumstances of its existence. [The same thing occurs in the regetable kingdom.]

This last consideration, of the gradually aliered state of an animal through successive generations, is a strong instance of the effect of condition; and it is by a regard to this invariabie law of Nature, of self-adaptation to circumstances, that the cultivation or improvement of any oreed is to be effected. "Hence the most acid and worthless grape is by skilful culture rendered sweet and uscious, flowers without attraction are gradually nurtured 
into beauty and fragrance; the cat may be made to present all the rich colours of the tortoise-shell, and the pigeon may be "bred to a feather.'"

Let us now endeavour to deduce a useful, practical conclusion from the foregoing arguments. If our doctrine be correct, the horse-breeder will depend upon the condition of the stallion, in order to the producing of valuable stock from him, as well as upon his other qualities of pedigree, speed, action, bottom, wind, temper, spirit, form, style, size, colour, \&c.

The next practical question is, how this condition is to be attained, and how the animal is to be kept at the required standard in this respect. The requisite condition is only to be attained by training for health and strength in a great measure according to the system of training for races: supplying an abundant nourishment of the best quality, allowing sufficient periods of repose for $\mathrm{d}_{\mathrm{l}}$ gestion, and giving regular and strong exercise, the whole with such variations as only experience and close observation, under constant practice, can dictate.

'The aptitude of an animal to benefit by training is often inherited, like other qualities, from its parentage; and judicious breeding alone can insure a continuance of the desirable quality, or create a propensity for it by proper crossing, when it does not exist in the parents.

The age at which the horse is best adapted to undergo a course of training, is just at the close of his most rapid period of growth, while the system is in its greatest freshness and vigour. 'This period is at abo' five years old. 'The powers of a horse will augment by suitable treatment in this respect until about the age of nine years: and, in order to obtaining the most valuabie stock, a stallion should not be put to service before attaining a full deselopment of his powers, nor kept at it after his form or energies appear to be affected for the 
worse. He should be, then, between five and fifteen years of age, if of an ordinary constitution; but if of remarkable energy and endurance, and exhibiting no symptom of debility, may be continued until past twenty.

Trainers find their endeavours to produce the highest state of strength, in an animal, greatly impeded by any excitement of the sexual appetite. It is then the more necessary to keep the horse in a state of training throughout the year, impressing most forcibly a tone of health and strength upon his system at the time when his nerves are liable to the least distraction; and continuing the course carefully thoroughout the season of copulation; never allowing such excess of service, or of the excitement of sexual appetite, as to induce a disturbance of spirit or temper, or a relapse from the most thoroughly strong, healthy and regular tone of the system.

G, B. 


\section{T' A B I E S.}

Tura following 'Tables may be so often useful to the classes of persons for whom this work is intended, that it has been thought expredient to give them a place.

The list of medicines embraces such as ought to be kept constantly on hand, not only in every training and livery stable, but by every farmer and breeder who aspires to good management, and to deserve the praise of all men who happen to visit his establishment, and who know, as the French say, what is comme il faut. Some other medicines might well be added, but it is thought best not $t w$ leave any excuse to the indolent and improvident to say that too much is required-but we will begin with

\section{WEIGH'TS AND MEASURES.}

A pothecaries' or 'Troy weight is most usually employed in modi cino. In this, a pound contains twelve ounces:

$1 \mathrm{lb}$ is.................... 5760 Troy grains.

$9 \mathrm{oz}$. or three-quarters of a $\mathrm{lb} . \ldots 4320$ " "

6 " "a half lb............2880 "

3 " " one-fourth of a $\mathrm{lb} . \ldots .1440$ "

1 " " 8 drachms ........... 480 " *

7 drachms.............. 420 " a

6 " $6 \ldots \ldots \ldots \ldots \ldots \ldots .360$ "

5 " $5 . \ldots \ldots \ldots \ldots \ldots .300$ " "

4 " or a half oz........ 240 " u

3 " $3 \ldots \ldots \ldots \ldots \ldots \ldots .180$ "

2 " $2 \ldots \ldots \ldots \ldots \ldots \ldots \ldots 120$ "

1 " $1 . \ldots \ldots \ldots \ldots \ldots .60 .60$ " 6

1 scruple ............... 20 "

APOTHECARIR' WXIGHT.

Twenty grains ................ one scruple

Three scruples................. one drachn

Eight drachms ................. one ounce.

Twelve ounces ................ one pound.

MEASURE OR FLUIDS.

Sixty drops ................ one fluid drachm.

Eight fluid drachms .......... one fluid ounco.

Four fluid ounces ........... a measure or nagg?k

Sixteen fluid ounces .......... one fluid pint.

Eight fluic pints.............. one gallon. 


\section{LIST OF MEDICINES,}

And other articles which ought to be at hand about every training and livery stable, and every Fariner's and Breeder's estaolishment:

MEDICINES.

Alues, Barbadoes,

Aluni,

Arrow Root,

Bas:icon, yellow,

Camphor,

Castile Soap,

Goulard's Extract

Honey,

Hog's Lard,

Linseed Meal,

Nitre,

Oil of Caraway,

Oil, Castor,

Oil of Cloves,

Dil of Olives,

Hartshorn,
Resin,

Spanish Flies,

Sweet Spirit of Nitro

Spirit of Turpentine,

Salt, common,

Soft Soap,

Tar,

Tartar Emetic,

Tincture of Myrrh,

Venus Turpentine,

Vinegar,

Vitriol, Blue,

Verdigris,

Wax,

White Lead.

Apparatus for Compounding Medicines.

A box of small weights and scales, for the weighing of medicines in small portions, as from a grain to two drachns - the weights marked with English characters.

One pair of two-ounce scales; one pair of pound scales, one pound of brass box-weights.

A graduaterl glass for the measure of fluids, marked with English tharacters.

One large and one small pestle and mortar.

One marble slab, a foot and a half square, for mixing ointments.

One large and one small ladle.

One large and one small pallet knife-to mix and spread plasters

Articles necessary to be kept for admonustering and applying Medicines.

Improved Ball Iron.

Drenching horn.

Flannel-for the app.ying of fornentations and poultices.

Woollen and linen bandages.

Tow, and broad coarse tape.

\section{Instruments.}

Stomach-pump,

Elasti: tube,

Fleam and blood stick,

Abscess lancet,

Tooth rasp, with a guard,
Seton, and curved needles, Improved casting hobbles, Brushes, curryermbs, \&c., of course. 


\section{CALVING TABLE.}

\begin{tabular}{|c|c|c|c|c|c|c|c|}
\hline Day Bulied. & Will Calve. & (Day Bulled.) & Will Calve. & Day Bulled. & | Will Calve. & Day Bulled. & \\
\hline y 1 & Oct'r 8 & il 1 & & uly 1 & & Oct'r 1 & July 9 \\
\hline & 14 & 7 & & 7 & & 7 & แ 15 \\
\hline 14 & 21 & 14 & 19 & 14 & 20 & 14 & 22 \\
\hline 21 & 28 & 21 & 26 & 21 & " 28 & 21 & " 2 \\
\hline 28 & Nov. 4 & 28 & Feb'y 2 & 28 & May 4 & 28 & Aug. \\
\hline " $: 1$ & & " 30 & $6 \quad 4$ & " 31 & 8 & 31 & \\
\hline Feb'y 1 & & May 1 & & Aug. 1 & 9 & Nov. 1 & \\
\hline & 14 & & 11 & 7 & 15 & 7 & 15 \\
\hline 14 & 21 & 14 & 18 & 14 & 22 & 14 & 21 \\
\hline 21 & " 28 & " 21 & “25 & 21 & 《 $\quad 29$ & 21 & $6 \quad 29$ \\
\hline “ 28 & Dec'r 5 & " 28 & Mar. 4 & 28 & June 5 & 28 & Sept. 5 \\
\hline Mar. 1 & & " 31 & & แ 31 & & " 30 & \\
\hline $\begin{array}{ll}16 & 7\end{array}$ & " 12 & June 1 & 8 & Sept. 1 & & Dec'r 1 & \\
\hline 14 & " 19 & & 14 & $\begin{array}{ll}67 & 7\end{array}$ & 15 & $\begin{array}{ll} & 7\end{array}$ & 21 \\
\hline 21 & “ 26 & 14 & 21 & 14 & 22 & 14 & แ 21 \\
\hline 28 & Jan'y 2 & " 21 & 《 28 & 21 & " 29 & 21 & “ 28 \\
\hline 31 & & " 28 & April 4 & 28 & July 6 & 28 & Oct'r 5 \\
\hline & & 50 & & 30 & & 31 & \\
\hline
\end{tabular}

LAMBING TABLE.

\begin{tabular}{|c|c|c|c|c|c|c|c|}
\hline $\begin{array}{l}\text { When to } \\
\text { Rams. }\end{array}$ & Will Lamb. & $\begin{array}{l}\text { When to } \\
\text { Ram. }\end{array}$ & Will Lamb. & $\begin{array}{l}\text { When to } \\
\text { Ram. }\end{array}$ & Will Lamb. & $\begin{array}{l}\text { When to } \\
\text { Ram. }\end{array}$ & Will Lamb. \\
\hline Jan'y 1 & & April 1 & & July 1 & & Oct'r 1 & \\
\hline " 14 & June 10 & 6 14 & Sept. 8 & (6 14 & Dec'r 9 & 6 14 & Mar. 10 \\
\hline Feb'y 1 & " $\quad 28$ & May 1 & " 22 & Aug. 1 & แ6 26 & Nov. 1 & แ 26 \\
\hline " 14 & July 12 & 6 14 & Oct'r 8 & " 14 & Jan'y 8 & " 14 & April 9 \\
\hline Mar. 1 & แ 26 & Juno 1 & " 25 & Sept. 1 & " 26 & Dec'r 1 & " 25 \\
\hline « 14 & Aug. 8 & "6 14 & Nov. 8 & "6 14 & Feb'y 9 & แ 14 & May 9 \\
\hline
\end{tabular}

\section{TO 'THE PUBLISHERS.}

SaouLd you have anywhere a spare corner, please enter a protest in my name, against the cruel practice recommended, of firing for the lampas; which takes its name from the brutal custom among old farriers, but now alandoned in England, of burning the swe.ling down with a red-hot lamp-iron. In most cases, it will soun oubside of itself, especially if a few mashes be given, aided by a gentle alterative. If need be, a few moderate cuts may be made across the bars with a pen-knife.

Founder may be cured, and the traveller pursue his journey the next day, by giving a table-spoonful of alum! This I got from Dr. P. Thornton, of Montpelier, Rappahannoc county, Virginia, w founded ca his own observation in sevesal cases. 


\section{T R 0 T T I N G.}

Tars is a gait held in high estimation in the northern parts of the Onited States, and in Canada; especially when a horse can go his mile within three minutes. Then, as he falls by seconds, his value rises by guineas. In the south, gentlemen don't "cotton" to such action; though a passion for this sort of equestrian display is travelling towards the land of the magnolia grandiflora, with some other changes less compatible with their ancient high-born chivalry.

On the good old track at Charleston, among gentlemen who have never let the old Huguenot fires go down, you rarely see a snafflebridle, or what is called a "goer!" They have an eye and a hear for a good horse; but choose to retain the power of throwing him on his haunches when occasion may demand it.

It is, we believe, a rule on all courses in the United States, that the jockey's weight, in a trotting race, whether in harness or saddle, must be not under 145 pounds.

In harness, simply signifies a sulky, as light as the owner may choose. They generally weigh from 75 to $125 \mathrm{lbs}$. The weight of a trotting wagon is from 125 to 200 lbs. Hiram Woodruff's weight was about 160 lbs.

An interesting investigation is now going on in Fngland to ascertain whether Tos Teums, the celebrated American trotter, ever performed 20 miles within the hour. Large bets are pending on the result. If he has ever accomplished such a feat, it has not been, within our knowledge, officially recorded. Many of the parties betting on Tom Thumb having performed the above feat, failing so procure satisfactory proof thereof, have paid their bets.

Fanny Jeinks trotted 101 iniles in harness, over the Bull's Head rourse, Albany, in 9 hours, 42 minutes, 57 seconds, on the 5 th of May, 1845.

Fanny Murray trotted 100 miles, in harness, in 9 hours, $41 \mathrm{mi}$ nutes, 26 seconds, on the 15th of May, 1846, over the Bull's Head course, Albany. 


\section{BEST TROTTING TIME, AT MILE HEATS.}

\begin{tabular}{|c|c|c|c|c|}
\hline Name. & $\begin{array}{l}\text { Saddle or } \\
\text { Harness. }\end{array}$ & rime. & Course. & Date. \\
\hline Aggy Down..... & saddle & $\left\{\begin{array}{c}227,292 \frac{1}{3}, 230, \\
230,231,\end{array}\right.$ & Beacon Course, N. J. & Sep. 25, 1845 \\
\hline Beppo.......... & " & $\left\{\begin{array}{c}2.32 \frac{1}{2}, 231 \frac{1}{2}, 233, \\
238,\end{array}\right.$ & Beacon Course, N. J. & Ju re 20̂, 1843 \\
\hline $\begin{array}{l}\text { Confitlence...... } \\
\text { Dutchman ..... }\end{array}$ & harness & $\begin{array}{r}235,237,236 \ldots \\
235,232,235 \ldots\end{array}$ & $\begin{array}{l}\text { Beacon Course, N. J. } \\
\text { Beacon Course, N. J. }\end{array}$ & $\begin{array}{l}\text { June - } 1841 \\
\text { July - } 1839\end{array}$ \\
\hline Dutchman ...... & saddle & $\left\{\begin{array}{cccc}2 & 36,2 & 35,2 & 33, \\
2 & 33 & 2 & 40\end{array}\right\}$ & Trenton, N. J. ..... & Sep. -1836 \\
\hline Edwin Fol rest .. & 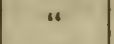 & $231 \frac{1}{2}, 233 \ldots \ldots$ & Centreville, L. I. ... & May - 183-1 \\
\hline Lady Suffolk.... & “ & $\left\{\begin{array}{c}228 \frac{1}{2}, 228,228, \\
229,232,\end{array}\right\}$ & Beacon Course, N. J. & July 4,1843 \\
\hline Lady Suffolk.... & “ & $226 \frac{1}{2}, 227,227$ & Beacon Course, N. J. & July 12, 1843 \\
\hline Norman Leslie.. & “ & $\left\{\begin{array}{c}238,236 \frac{1}{3}, 238, \\
239,238\end{array}\right\}$ & Treuton, N. J. ..... & June - 1836 \\
\hline
\end{tabular}

TWO MILE HEATS.

\begin{tabular}{|c|c|c|c|c|}
\hline $\begin{array}{l}\text { Americus........ } \\
\text { Americus....... } \\
\text { Black Maria.... }\end{array}$ & $\begin{array}{c}\text { harness } \\
\text { " } \\
\text { saddle }\end{array}$ & 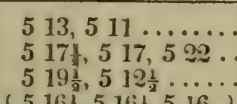 & $\begin{array}{l}\text { Union Course, L. I. } \\
\text { Hunting Park, Pa. } \\
\text { Cambridge Park ... }\end{array}$ & $\begin{array}{l}\text { Oct. } 8,1846 \\
\text { Oct. 17, } 1846 \\
\text { June } 18,1845\end{array}$ \\
\hline Confidence. & harness & $\left\{\begin{array}{c}516 \frac{1}{2}, 516 \frac{1}{2}, 5 \\
518,5 \approx 5\end{array}\right.$ & Centreville, L. I. ... & May - 1841 \\
\hline & saddle & & & $\begin{array}{l}\text { Oct: }-1 \\
\text { April }-1\end{array}$ \\
\hline & harness & & N. J. & Oct. - \\
\hline & addl & & Pa. & May - \\
\hline & arness & $\begin{array}{l}51 \\
52\end{array}$ & $\begin{array}{l}\mathrm{Pa} . \\
\mathrm{Pa} .\end{array}$ & ine $\overline{2}$ \\
\hline & & & L. I. & v. 18 , \\
\hline & & & & Sep. - \\
\hline & ar & & & $M$ \\
\hline & & & & May 21, \\
\hline & “ & & & May - 1 \\
\hline & (1) & & , Pa. . & May - 1842 \\
\hline 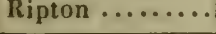 & & & Hunting Park, Pa. & May - 1842 \\
\hline
\end{tabular}

THREE MILE HEATS.

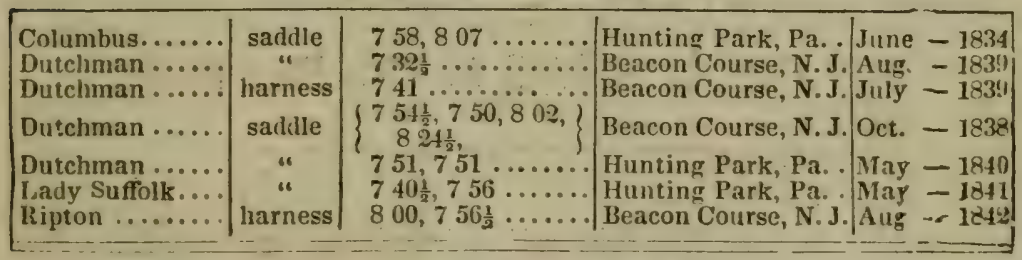

\section{FOUR MILE HEATS,}

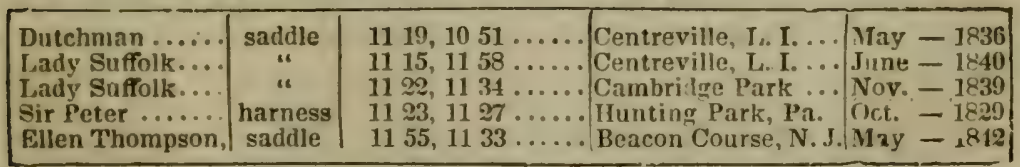




\section{R A C I N G.}

\section{BEST TIME ON RECORD AT MILE HEATS.}

\begin{tabular}{|c|c|c|c|}
\hline Name. & Time. & Course. & Date. \\
\hline Aduella. & $148,150,149 \ldots \ldots \ldots \ldots \ldots$ & New Orleans, La. . & Dec. 25, 1842 \\
\hline Aduelia ... & $150,147,152, \ldots \ldots \ldots \ldots$ & New Orleans, La... & Mar. 19, 1843 \\
\hline Bendigo ... & $150,148,149, \ldots \ldots \ldots \ldots \ldots$ & Lexington, Ky. .... & Sep. 24, 1840 \\
\hline Bendigo ... & $148,150,148,149 \ldots \ldots \ldots$ & New Orleans, La... & Mar. 21, 1841 \\
\hline Beta ....... & $145,145,157,201 \ldots \ldots \ldots$ & Nashville, Tenn.... & May 22, 1841 \\
\hline Big Alick . . & $157,147 \frac{1}{8}, 150,151 \ldots$ & Louisville, Ky. .... & June 4, 1842 \\
\hline Capt. McHea & $149,148,150 \ldots \ldots \ldots$ & Colımbus, Ga. .... & May 4, 1839 \\
\hline $\begin{array}{l}\text { Cassandra ...... } \\
\text { Colt by Levia. }\end{array}$ & $148,149, \ldots \ldots \ldots \ldots$ & Washington, D. C. & June 1,1841 \\
\hline $\begin{array}{l}\text { than, D. F. } \\
\text { Kenner's, }\end{array}$ & $148,147 \frac{3}{4}, 150 \ldots$ & New Orleans, La... & April 1, 1846 \\
\hline Creath ......... & $148,148,146 \ldots$ & New Orleans, La. . & Mar. 27, 1842 \\
\hline Croton ......... & $151,154 \frac{1}{4}, 149 \ldots$ & New Orleans, La... & Dec. 20, $1846^{\circ}$ \\
\hline Croton & $149 \ldots \ldots \ldots$ & New Orleans, La... & Mar. 15, 1846 \\
\hline Dan. Mc & $150,148,151 \ldots \ldots \ldots \ldots \ldots$ & Georgetown, Ky. . & Apr. 28,1842 \\
\hline Fred. K & $150,1 \cdot 18 \frac{1}{2}, 150,153 \frac{1}{2}, 152 \frac{1}{4} !$ & Lou & Oct. 9,1816 \\
\hline Fred & $\left\{\begin{array}{c}152,15 \% \\
157,156 \frac{1}{2},\end{array}\right\} \ldots$ & New Orleans & Dec. 6,1846 \\
\hline Gildersleeve . & $151,149,153,156$. & Versailles, Ky.. & Sep. 18, $1840^{\circ}$ \\
\hline Harden'd Sinner. & $150,148,149 \frac{1}{9} \ldots$ & Jackson, Miss...... & Feb. 17,1844 \\
\hline Houri, (Imp.) ... & $147,153 \ldots \ldots$ & New Orleans, La... & Mar. 18, 1840 \\
\hline Jane Aclams.... & $147 \frac{1}{8}, 152 \ldots \ldots$ & New Orleans, La. . . & Oct. 29,1845 \\
\hline Jim Bell ........ . & $151,146 \ldots \ldots$ & Lexington, $\mathrm{Ky} \mathrm{y}_{\text {...... }}$ & May 21, 1841 \\
\hline John Hampden. . & $49,153 \ldots$ & Orange C. H., Va. . & Sep. 18, 1839 \\
\hline Kitty Harris .... & $148,151,202 \ldots \ldots$ & ore, Md. .... & May 17, 184a \\
\hline Leda & $148,148 \ldots \ldots \ldots \ldots$ & Lexington, Ky..... & May 19, 1841 \\
\hline Little Trick & $148 \ldots$ & E. Feliciana, La... & Apr. 21, 1844 \\
\hline Lucy c. (13ufo & $149,148,151 \ldots$ & Bardstown, Ky..... & Oct. 12, 1839) \\
\hline Mary Brennan .. & $148,149 \ldots \ldots$ & Cincinnati, Ohio... & Oct. 19, 18:39 \\
\hline Minstrel. & $148,148, \ldots \ldots \ldots$ & Louisville, $\mathrm{ky}$..... & June 4, 1839 \\
\hline $\begin{array}{l}\text { Miss Footo. } \\
\text { Music . . . . . }\end{array}$ & $147,149,148,150,150$ & $\mid \begin{array}{l}\text { New Orleans, La... } \\
\text { New Orleans, La. }\end{array}$ & Dec. 12,1841 \\
\hline $\begin{array}{l}\text { Music ........ } \\
\text { Music .... }\end{array}$ & $148 \frac{1}{9}, 146 \frac{1}{1}, \ddot{1} 48 \ldots \ldots$ & New Orleans, La... & Dec. 29,1844 \\
\hline Nathan Rice... & $145,152, \ldots \ldots \ldots$ & Louisville, Ky. .... & Oet. 7,1844 \\
\hline Prospect......... & $150,148,153 \ldots \ldots \ldots$ & Trenton, N. J....... & May 25, 3841 \\
\hline Sailor Boy... & $151,149,148, \ldots \ldots \ldots$ & Cynthiana, Ky..... & Oct. 25, -1839 \\
\hline Serenade........ & $148,155,200 \ldots \ldots$ & Cynthana, Ky.... & Oct. 25, 1839 \\
\hline St. Pierre........ & $147,156,155 \ldots \ldots$ & Orange C. H., Va. . & Sep. 15, 1841 \\
\hline Sunbeam .. & $147,148,146 \frac{1}{9}, 147,147$ & New (Orleans, La. . & Mar. 24, 1814 \\
\hline Susan Hill . . & $155,150,148 \ldots \ldots \ldots \ldots$ & Hatvana $\ldots \ldots \ldots$ & Apr, 30, 1843 \\
\hline The: Duke ..... & $148,155 \frac{1}{2}, 153 \frac{1}{3} \cdots \cdots$ & Trenton, N.J...... & May 31,1839 \\
\hline $\begin{array}{l}\text { Uncas } \ldots \ldots \ldots \\
\text { Victor............ }\end{array}$ & $145,155,148 \ldots \ldots \ldots \ldots \ldots \ldots$ & 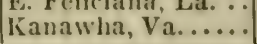 & June 7,1839 \\
\hline
\end{tabular}

\section{BEST TIME ON RECORD AT TWO MILE HEATS.}

\begin{tabular}{|c|c|c|c|}
\hline Namie. & Time. & Course. & Date. \\
\hline & 354 & & Sep. จ6, 18.15 \\
\hline Hay & $343 \frac{1}{2}, 342 \frac{1}{2} \ldots$ & rleans, Lo & Nov. 21,1844 \\
\hline Stu & $350,344,345$. & his, I'Tenn. & Nov, 14, 1843 \\
\hline$\therefore$ & $344 \frac{1}{8}, 349,349$, & ille, Ky. . & June 7,1843 \\
\hline & j, $352 \ldots \ldots$ & inbus, Ga. . & Maty 2, $18: 39$ \\
\hline & 351 & d Rock, Va & Apr. 26,1839 \\
\hline Beek-Wing ..... & 344,3 & New Orle: & Mar. 26, \\
\hline $\begin{array}{l}\text { Betsey Archy, } \\
\text { filly, }\end{array}$ & $353,344 \ldots \ldots \ldots$ & Washington, D. C. & May 31,1841 \\
\hline Rlark-Nose... & $349 \frac{3}{2}$ & & \\
\hline Brown K:tty & $349 \frac{1}{2}, 344,345$. & New Orleans, Ia. & Dec. 1,1840 \\
\hline Gye & $\begin{array}{l}356,340,347 \ldots \\
348,350,340 \text {. }\end{array}$ & New Orleais, La. & $\begin{array}{l}\text { Mar. 18, } 184 \\
\text { Sep. } 27,184\end{array}$ \\
\hline
\end{tabular}




\section{BEST TIME ON RECORD AT TWO MILE HEATS.}

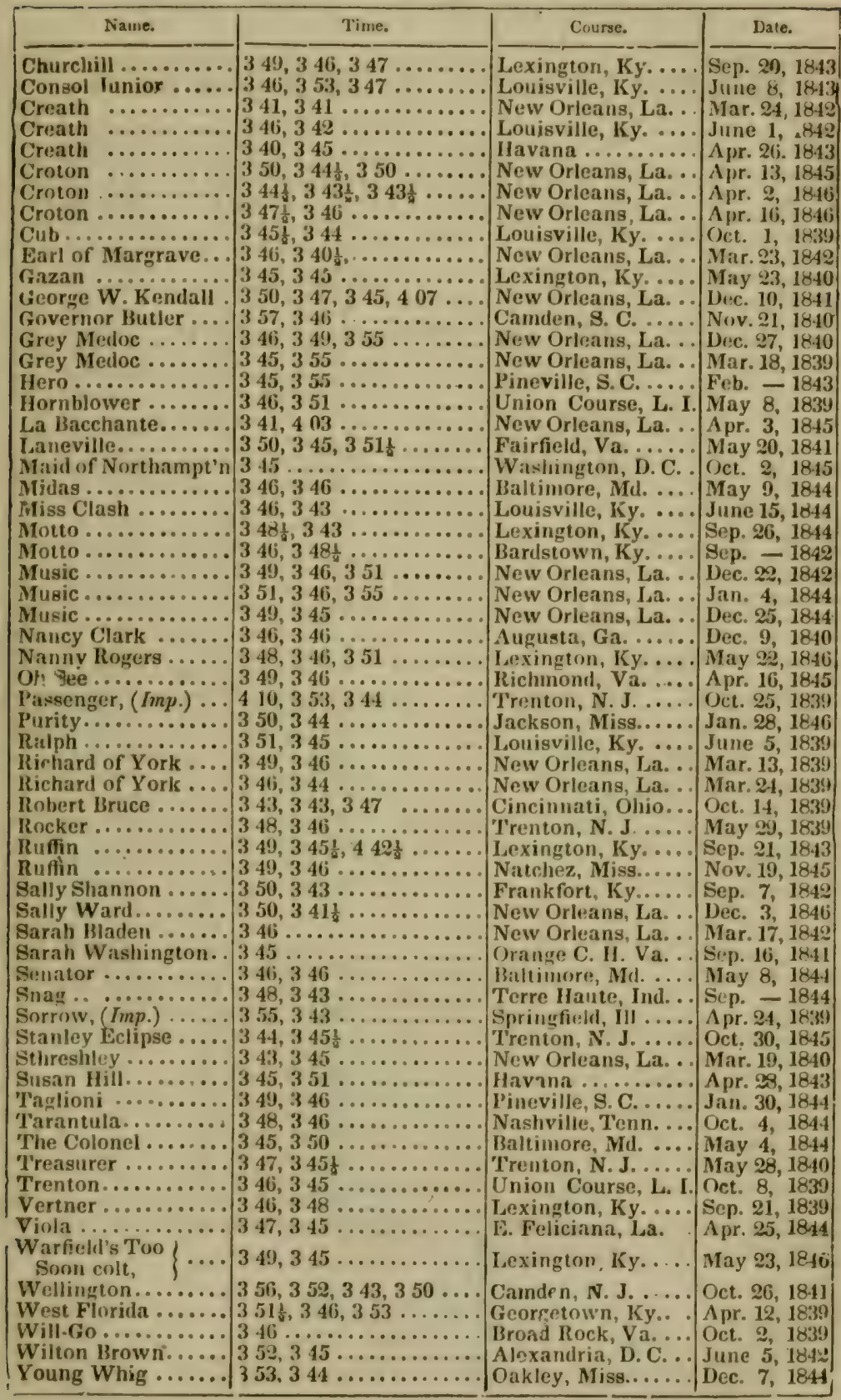




\section{BEST TIME ON RECORD AT THREE MILE HEATS.}

\begin{tabular}{|c|c|c|c|}
\hline Name. & Time. & Course. & Date. \\
\hline rearrins. & $557,546,554 \frac{1}{8}$ & & \\
\hline & & renton, N.J. & Nay 29,1340 \\
\hline entile......... & $542,551 \ldots$ & Louisville, Ky $\ldots$ & June $6,18-14$ \\
\hline & $545,544 \ldots$ & Washington, 1. C. & June 3, 1841 \\
\hline Black-Nose ...... & $548,546$. & Frankfort, Ky... & Sep. 24, 1840 \\
\hline Black-Nose ...... & $545,546 \ldots$ & Lexington, $\mathrm{Ky}$ & Sep. 28,1840 \\
\hline Blue Dick .. & $54,538 \frac{1}{3} \ldots$ & Trenton, N. J. & May 19,1842 \\
\hline ue Dick & $542,539 \frac{1}{2}$. & Alexandria, $\mathbf{D}$. & June 3, 1842 \\
\hline ue Dick & $550,546 \ldots \ldots \ldots$ & Baltimore, Md. & May 6,1844 \\
\hline b Letcher & $552,546,612,551 \ldots$ & Lexington, $k y$. & May $26,1843 \mid$ \\
\hline sto & $546 \ldots \ldots \ldots \ldots \ldots$ & Broad Rock, Va.... & A pr. 27, 18:39 \\
\hline ario & $545 \frac{2}{8}, 557 \ldots \ldots \ldots$ & Union Course, L. I. & Oct. 9,1839 \\
\hline & $557,543 \ldots$ & Louisville, Ky, .... & Oct. 15, 1841 \\
\hline & $544 \frac{1}{8}$ & Orleans, La. & Mar. 28, 1843 \\
\hline Cre: & $544,553$. & & Apr. 99,1843 \\
\hline Calvert & $600 \frac{1}{9}, 559,546 \ldots$ & $\mathrm{n}, \mathbf{N} . \mathbf{J}$. & Oct. 29,1841 \\
\hline & & ore, Md. . & Oct. 16, 1846| \\
\hline Ge & & $\mathbf{N}$ & Mar. 25, 1849 \\
\hline & 549,55 & N & Mar. 17, 1843 \\
\hline & $551 \ldots$. & & pr. 25,1839 \\
\hline Har & 5 & irg, Va. & May 28,1840 \\
\hline & 6 & & Sep. 19, 1843 \\
\hline $\mathbf{J}_{\mathbf{i}}$ & & & 0,1841 \\
\hline & $538 \frac{1}{8}$ & Ne & 7,1844 \\
\hline & 54 & & Nov. 15, 1843 \\
\hline & & s, La. & $\mid$ Dec. $23,1842 \mid$ \\
\hline & & & Oct. 28,1843 \\
\hline & & New & Dec. 4,1846 \\
\hline & & E. & Apr. 26, 1844 \\
\hline & & & May 21,1841 \\
\hline & 5 & & May 16,1834 \\
\hline & & D. C. & May \\
\hline & & & Mar. 10,1842 \\
\hline & & Col & Mav 2, 1839| \\
\hline$Q$ & & & $0 . \quad 17,1839$ \\
\hline & $8,549 \ldots$ & & May $\cong 2,1840$ \\
\hline & & $\mathrm{Be}$ & Oet. 20,1842 \\
\hline & & & Oct. 8, 1840| \\
\hline & 5. & & Sер. 24, 1844 \\
\hline & & Is, $L a$. & Mar. 22, 1844 \\
\hline y Shann $>$ & $541 \frac{1}{8}, 550,557,601$ & & Sep. 21, 1842 \\
\hline & & , S. C. & Feb. 8,1843 \\
\hline 然. & & & Apr. 21,1842 \\
\hline arah Washington. & $540,545 \ldots \ldots \ldots \ldots$ & Baltimnre, IId. & May 19,1842 \\
\hline & & & Sep. I6, 1840 \\
\hline & & & June 2, 1842 \\
\hline & $542,554,556$ & & Nov. 27,1845 \\
\hline & & Union Course, L. I. & June 5, 1840 \\
\hline Trea & $555 \frac{1}{6}, 5$ & Union Course, L. I. & Oct. 5, 1812 \\
\hline & & & June $7,184 ?$ \\
\hline
\end{tabular}




\section{BEST TIME ON RECORD AT FOUR MILE HEATS.}

\begin{tabular}{|c|c|c|c|}
\hline Name. & Time. & Course. & Date. \\
\hline nilrewetta ........ & & Raleigh, N. C. . & Nov. $7,18.39$ \\
\hline Ann Hayes......... & $736 \frac{1}{2}, 742$. & New Orleans, La... & Mar. 23,1844 \\
\hline Bandit ...... & $802,744 \ldots \ldots$ & Baltimore, Md. .... & May 15,1840 \\
\hline Boston ...... & $813,746,758 \frac{1}{9}$ & Union Course, L. I. & May 13,1842 \\
\hline Eutaw ..... & $801,743 \ldots \ldots$ & Waslington, D. C. & Mity 6,1842 \\
\hline Eclipse .... & $737 \frac{1}{9}, 749,824$ & Union Course, L. I. & May 27,1843 \\
\hline Fashion ... & $742,748, \ldots \ldots$ & Camden, N. J. ..... & Oct. 28,1841 \\
\hline Fashion $\ldots$. & $732 \frac{1}{2}, 745 \ldots$ & Union Course, L. I. & May 10,1842 \\
\hline Fashion .... & $738,752 \frac{1}{2}$ & Camden, N. J. ..... & Oct. 29, 1842 \\
\hline Fashion ..... & $736,749 \ldots$ & T'renton, N. J. ..... & Nov, 4, 1842 \\
\hline Fashion .... & $735 \frac{1}{2} \ldots \ldots$ & Baltimore, Md. .... & Oct. 20, 1843 \\
\hline Fashion .... & $743 \frac{1}{9} \ldots \ldots$ & Union Course, L. I. & Oct. 23,1845 \\
\hline Fastion ...... & $36.751 \ldots$ & Baltimore, Md. .... & May 14, 1846 \\
\hline George Martin. & 733,743 & New Orleans, La... & Mar. 29, 1843 \\
\hline Greyhead.... & $745 \frac{1}{2}, 750$ & Lexington, $\mathrm{Ky}$. & Sep. $23,1+43$ \\
\hline Grey Medoc. & $735,819,7$ & New Orleans, & Mar. 20. 1841 \\
\hline 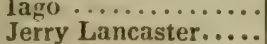 & $745,758 \ldots$ & St. Louis, Mo. .. & June 24,8814 \\
\hline $\begin{array}{l}\text { Jerry Lancaster... . . } \\
\text { Jerry Lancaster.... }\end{array}$ & $\begin{array}{llll}7 & 43,7 & 40 & \cdots \\
7 & 38,8 & 14 & \ldots\end{array}$ & $\begin{array}{l}\text { New Urleans, La... } \\
\text { New Orleans, La. . }\end{array}$ & $\begin{array}{l}\text { Apr, 5, } 1845 \\
\text { Apr. 19, 1845 }\end{array}$ \\
\hline Jerry Lancaster. . & $755,745 \ldots$ & St. Louis, Mo..... & Oct. 21,1846 \\
\hline Jerry Lancaster & $751,743,808$ & New Orleans, La. & Dec. 5,184 . \\
\hline Jim Bell...... & $737,740 \ldots$ & New Orleans, La. & Mar. 19, 1842 \\
\hline Miss Foote... & $802,735 \ldots$ & New Orleans, La. . & Mar. 26, 1842 \\
\hline Miss Foote ... . & $742,740 \ldots \ldots$ & Lexington, $\mathrm{Ky}$. . & Sep. 25, 1842 \\
\hline Miss Foote ... & $736 \frac{1}{9}, 739,751 \frac{1}{8}$ & New Orleans, La. & 1)ec. 24,1842 \\
\hline Onuega ...... & $757,745 \ldots$ & Augusta, Ga. ... & Dec. 11,1840 \\
\hline Peytonit..... & $745,748 \ldots$ & New Orleans, La. . & Jan. 5,1844 \\
\hline Peytona..... & $739 \frac{3}{4}, 745 \frac{1}{4}$ & Union Course, L. I. & May 13,1845 \\
\hline Reel $\ldots \ldots \ldots \ldots$ & $740,743 \ldots$ & New Orleans, La. . . & Dec. 11, 1841 \\
\hline Reel ............. & $743 \frac{2}{2}, 741 \ldots \ldots$ & New Orleans, La... & Mar. 18, 1843 \\
\hline 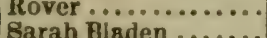 & $739,739 \frac{1}{8}, 751,829$. & New Orleans, La... & Dec. 28, 1844 \\
\hline $\begin{array}{l}\text { Sarah Haden ........ } \\
\text { Vashti ........... }\end{array}$ & $745,740, \ldots \ldots \ldots$ & $\begin{array}{l}\text { New Orleans, La. . } \\
\text { Baltimore, Md. .... }\end{array}$ & Mar. 17, 1841 \\
\hline & & & \\
\hline
\end{tabular}




\section{THE ST. LEGER.}

T're Doncaster St. Leger (in England prono'snce Sellenger,) is the most important stake in Great Britain, amou ing to fron eighteen to twenty-four thousand dollars, and is run for, annually, by three year old colts and fillies: the former carry 19 pounds, the latter 114.

With these tables in view, a comparison of the speed of Englisb and American horses can easily be made, having due regard to weight, age, and the distance run. The St. I eger is a race of one straight heat, and the horse has only to do his ${ }^{\circ}$ est for that single run. J.S. S.

The following table will show the reat , the distan se per second aycraged by horses running at any dista ce:

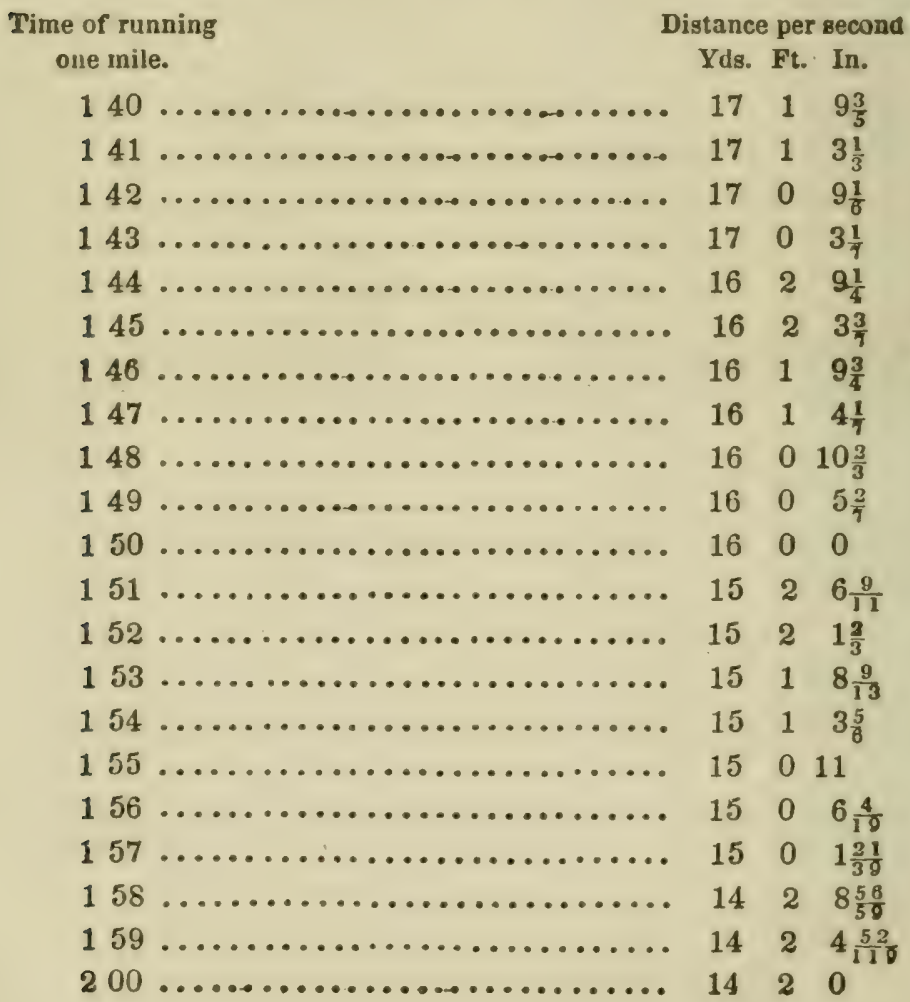




\section{AVERAäe SPEED FOR THE DONCASTER ST. LEGER.}

Distance I mile 6 furlongs 132 yards.

\begin{tabular}{|c|c|c|c|c|}
\hline Year. & Name of Horse. & $\begin{array}{l}\text { Time. } \\
\text { M. } 8 .\end{array}$ & & $\begin{array}{l}\text { Yds. in } 8 \\
\text { minute. }\end{array}$ \\
\hline 1818 & ..... Kっveller ............ & 315 & ...... & 988 \\
\hline 846 & ..... Sir Tatton Sylkes ........... & 316 & ...... & 983 \\
\hline 1838 & ...... Dton John................ & 317 & ...... & 978 \\
\hline 819 & ..... Arronio .................. & 318 & ..... & 973 \\
\hline 842 & . Blur Bonnet............. & 319 & ...... & 968 \\
\hline 1835 & ...... Quown of Trumps.......... & 320 & & 963 \\
\hline 1836 & ..... Elis................... & 320 & ...... & 963 \\
\hline 840 & .. Laurscelot............... & 320 & -.... & 963 \\
\hline 1843 & ..... Nutwith................ & 320 & & 963 \\
\hline 1847 & ap .............. & 320 & ...... & 963 \\
\hline 1834 & ...... Touchstone .............. & 322 & ..... & 954 \\
\hline-841 & tirist ................ & 322 & ... & 954 \\
\hline 1837 & $\ldots \ldots \ldots \ldots \ldots$ & 323 & $\ldots \ldots$ & 949 \\
\hline 1844 & ...... Faugh-a-ballagh ........... & 323 & ...... & 949 \\
\hline 823 & ..... Barefoot ................ & $323 \frac{1}{4}$ & ... & 948 \\
\hline 1825 & mnon................ & $323 \frac{1}{2}$ & ... & 947 \\
\hline 1827 & a................. & 324 & $\ldots \ldots$ & 945 \\
\hline 1826 & ................ & 325 & & 940 \\
\hline i839 & ...... Charles XII............... & 325 & & 940 \\
\hline 1845 & .... The Baron ............... & 325 & ..... & 940 \\
\hline 820 & Patrick............... & 326 & & 935 \\
\hline 1822 & odore................ & 326 & & 935 \\
\hline 1824 & ...... Jerry & 329 & & 922 \\
\hline 810 & .............. & 330 & -.. & 918 \\
\hline 1812 & ...... Otterington............... & 331 & & 913 \\
\hline \multirow[t]{2}{*}{1833} & ..... Rockingham ............ & 338 & & 884 \\
\hline & '1,1, & 324 & & 945 \\
\hline
\end{tabular}




\section{PEDIGREES}

\section{oy \\ W INNING HORSES,}

SINCE 1839.

\section{Being an Appendix to Mason's Farrier}

\section{A.}

AARON, b. h. by Tennessee Citizen, dam by Timoleon. ABBEVILLE, b. h. by Nullifier, dam by Gallatin.

ABNER HUNTER, b. h. by Medoc, dam by Blackburn's Whip.

ACALIA, b. m. by Luckless.

ACHILLES, gr. h. by Boxer.

ADELA, b. m. by The Colonel, dam [Imp.] Variella by Blacklock.

ADELAIDE, b. $m$. by [Imp.] Leviathan, dam by Napoleon.

ADELIA, b. m. by Mons. Tonson, dam by Sir Archy.

ADRIAN, ch. h. by [Imp.] Luzborough, dam Phenomena, by Sir Archy.

ADUELLA, ch. m. by [Imp.] Glencoe, dam Giantess by [Imp.] Le. viathan.

ÆESOP, ch. h. by [Imp.] Priam, dam Trumpetta by Mons. Touson. ETNA, b. m. by Volcano, dam Rebecca by Palafox.

AHIRA, b. h. by Medoc, dam by Tiger.

AILSEY SCROGGINS, ch. m. by Giles Scroggins, dam by Pirate.

AJARRAH HARRISON, ch. m. by Eclipse, dam by Gallatin.

AJAX, gr. h. by [Imp.] Leviathan, dam by Pacolet.

A. J. LAWSON, b. h. by [Imp.] Hedgford, dam Kitty Fisher by Gallatin.

ALAMODE, ch. h. by [Imp.] Margrave, dam by Timoleon.

ALA RIC, b. h. by Mirabeau, dam by [Imp.] Tranby.

Al.ATOONA, b. m. by Argyle, dam Viola by Gallatin.

AJ.BION, [Imp.] bl. h. by Cain or Actæon, dam by Comus or Black lock.

A.LBORAC, b. h. by .Telegraph, dam by Monday.

A LDERMAN, ch. g. by [Imp.] Langford, dam by Sir Clarles.

ALLEGRA, b. m. by Stockholder, dam by Pacolet.

ALL,EN BROWN, ch. h. by Stockholder, dam by [Imp] Eagle. 
ALEXANDER CAMPBELL, b. h. by Collier, dam by Kosciusko.

ALEXANDER CHURCHILL, b. h. by [Imp.] Zinganee, dam by Bertrand.

ALICE, b. m. by Conqueror, dam by Wild Medley.

b. m. by [Imp.] Sarpedon, dam Rowena by Sumpter.

ALICE ANN, gr. m. by Director, dam by Gallatin.

ALMIRA, gr. m. by Eclipse dam by Stockholder.

ALTORF, b. h. by [Imp.] Fylde, dam by Virginian.

ALWILDA, gr. m. by Monmouth Eclipse, dam by John Richards.

AMBASSADOR, ch. h. by Plenipotentiary, dam [Imp.] Jenny Mills by Whisker.

AMELIA, br. m. by Bluster, darn by Messenger.

AMERICA, b. m. by Stockholder, dam by Democrat.

b. m. by [Imp.] Trustee, dam Di Vernon by Florizel.

AMERICAN CITIZEN, b. h. by Marion, dam by Harwood.

EAGLE, gr. h. by Grey Eagle, dam by Waxy.

STAR, ch. h. by Cramp, dam by Pulaski.

AMY THE ORPHAN, ch. m. by [Imp.] Nonplus, dam by Comet.

ANDREWANNA, b. m. by Andrew, dam by Gallatin.

ANDREWETTA, gr. m. by Andrew, dam by Oscar.

ANDREW HAMET, b. h. by Sidi Hamet, dam by Trumpator.

ANN BARROW, b. m. by Cock of the Rock, dam by Virginian.

ANN BELL, ch. m. by Frank, dam Jonquil by Little John.

ANN BLAKE, b. m. by Lance, dam by Blackburn's Whip.

ANN CALENDAR, ch. m. by Eclipse, dam Grand Duchess by [Imp.] Gracchus.

ANN GILLESPIE, br, m. by McCarty's Henry Clay, dam Susan by Sir William.

ANN HARROD, ch. m. by Hickory John, dam by King William.

ANN HAYES, b. m. by [Imp.] Leviathan, dam by Pacific.

A.N INNIS, ch. m. by Eclipse, dam (the dam of Mary Morris) by Sumpter.

ANN KING, b. m. by [Imp.] Sorrow, dam Lady of the Lake by Henry Tonson.

ANN STEVENS, ch. m. by [Imp.] Trustee, dam (an imported mare) by Muley.

ANN STEWART, ch. m. by Eclipse, dam Kitty Hunter by Paragon

ANNE ROYALE, br. m. by Stockholder, dam Alice Lee by Sir Henry Tonson.

ANTOINETTE, ch. m. by [Imp.] Leviathan, dam Multiflora bv Director.

ANTIPATOR, ch. h. by Tychicus, dam Club Foot by Napoleon.

ANVIL, b. h. by [Imp.] Contract, dam by Eclipse.

ARAB, b. h. by Arab, dam by Sir Archy.

ARABELLA, b. $\dot{m}$. by Collier, dam by Gallatin.

ARABIAN MARK, b. h. by [Imp.] Fylde, dam by Sir Charles.

ARGENTILE, b. m. by Bertrand, dam Allegrante by [Imp.] Truffl.

ARGYLE, br. h. by Mons. Tonson, dam Thistle by Ogle's Oscar.

ARII.LA, gr. m. by O'Kelly, dam by Medley.

ARK ALUKA, ch. h. by [Imp.] Leviathan, dam Sally McGehee 
AROOSTOOK, b. h. hy Wheeling Rodolph, darn by Moses.

ARRALINE, ch. m. by [Imp.] Leviathan, dam by Stockholder.

ARRAH NEAL, ch. m. by [Imp.] Leviatlan, dam Ma'riia Wash ington by Sir Charles.

ARSENIC, ch. m. by [Imp.] Leviathan, dam Mary Farmer by Con queror.

ASHLAND, ch. h. by Medoc, dam Lady Jackson by Sumpter.

ASTOR, b. h. by Ivanhoe, dam Tripit by Mars.

ATTAKAPAS, ch. h. by [Imp.] Luzborough, dam by Arab.

ATTILA LECOMTE, b. m. by [Imp.] Glencoe, dam Extant by [Imp.] Leviathan.

ATLANTIC, b. m. by Blood and Turf, dam Old Fly.

AUNT PONTYPOOL, ch.m. by Rertrand Junior, dam Gold Finder

by Virginius.

AUSTER, br. h. by Westwind, dam by [Imp.] Leviathan.

AUTHENTIC, ch. h. by [Imp.] Leviathan, dam Timoura by Timoleon.

\section{B.}

BALD HORNET, ch. g. by Bald Hornet, dam by Bertrand.

BALIE PEYTON, b.h. by Andrew, dam (Master Henry's dam) by Eclipse.

BALTIMORE, b. h. by [Imp.] Iuzzborough, dam by Gohanna.

BAND BOX, gr. m. by O'Kelly, dam Lucy Brooks by Bertrand.

BANDIT, b. h. by [Imp.] Luzborough, dam by Virginian.

BANJO BILL, b. h. by [Imp.] Sarpedon, dam by Darnaby's Diomed. BAND OF MUSIC, ch. m. by O Kelly, dam by Oscar.

BARBARA ALLEN, ch. m. by Collier, dam Lady Jackson by Sumpter.

BASSINGER, bl. h. by [Imp.] Fylde, dam by Randolph's Roanoke. BAYWOOD, b. h. by Editor, dam by Pacolet.

BEACON LIGHT, ch. m. by [Imp.] Glencoe, dam Giantess by [Imp.] Leviathan.

BEATRICE OF FERRARA, m. by Stockholder, dam by Duroc.

EEAU-CATCHER, ch. m. by Leopold, dam Cranberry.

BEE'S-WING, ch. m. by [Imp.] Leviathan, dam Black Sophia by Topgallant.

BELFIELD, b. h. by [Imp.] Priam, dam [Imp.] Bustle by Whalebone.

BELLISSIMA, b. m. by [Imp.] Belshazzar, dam Wingfoot by Rat tler.

BELLE OF WINCHESTER, ch. m. by Stockholder, dam by Sir Archy.

Cado by Sir Archy.

RELLLE TAYLOR, b. m. by Medoc, dam by Sumpter.

BEN BARKLEY, b. h. by Push Pin, dam Miss Wakefield by Sir Hal.

BEN BUSTER; b. $k_{\text {. }}$ by Cherokee, dam by Whip.

BEN FRANKLIN, ch. h. by Flagellator, dam Medoäa by Ecl pse. ch. h. by Woodpecker, dam by Frandliu Reauty 
BEN FRANKLIN, cl. h. by [Imp ] Leviathan, dam by Stockholder BENDIGO gr. h. by Timoleon, dam by Sir Charles. b. h. by Medoc, dam by Sir Archy.

BENGAL, ch. h. by Gobanna, dam Sportsmistress (or Gulnare) by Duroc.

BERENICE, ch. m. by Skylark, dam Kathleen by [Imp.] Leviathan.

BETA, ch. m. by [Imp.] Leviathan, dam by Kosciusko.

BETHESDA, b. m. by Pacific, dam by Sir Henry Tonson.

BETHUNE, br. h. by Sidi Hamet, dam Susette by Aratus.

BETSEY COLEMAN, ch. m. by Goliah, dam Melinda.

BETSEY COODEY, ch.m. by [Imp.] Leviathan, dam by Sir Charles.

BETSEY HUNTER, ch. m. Ly Sir Clinton, . am by Hamiltonian.

BETSEY LAUDERDALE, clr. m. by [Imp.] Leviathan, dam by Sir Richard.

BETSEY MILLER, gr. m. by [Imp.] Leviathan, dam Jane Shore by Oscar.

BETSEY RED, ch. m. by Red Rover, dam Betsey West by [Imp.] Buzzard.

BETSEY SHELTON, b. m. by Jackson, dam Harriet Haxall by Siı Hal.

BETSEY WATSON, br. m. by Jefferson, dam bv Sir Henry Tonson. BETSEY WHITE, ch. $m$. by Goliah, dam by Sir Charles.

BIG ALECK, ch. h. by Medoc, dam by Tiger.

BIG ELLEN, b. m. by Medoc, dam by Old Whip.

BIG JOHN, ch. h. by Bertrand, dam by Hamiltonian.

BIG NANCY, ch. m. by Jackson, dam by Gallatin.

BILLY AYNESWORTH, ch. h. by Traveller, dam Helen by Timoleon.

BILLY BLACK, b. h. by Volcano.

BILLY BOWIE, b. h. by Drone, dam Agility by Sir James.

BILLY GAY, b. h. by [Imp.] Hedgford, dam Mary Francis by Di rector.

BILLY TONSON, gr. h. by Mons. Tonson, dam by Cherokee.

BILLY TOWNES. b. h. by [Imp.] Fylde, dam by Virginian.

BILLY WAJ.KER, ch. h. by [Imp.] Valparaiso, dam by Sir Richa-xh.

BILLET, ch. h. by Mingo, dain by Mambrino.

BILOXE, ch. h. by Dick Chinn, dam Extio by [Imp.] Leviathan.

BLACK BOY, bl. h. by [Imp.] Chateau Margaux, dam by [Imp.] Chance.

by Van Tromp.

bl. h. by [Imp.] Chateau Margaux, dam Lady Mayo

BLACK DICK, bl. h. by [Imp.] Margrave, dam by Pamunky.

BLACK FOOT, cli. h. by Medoc, dam by Blackburn's Whip.

BLACK HAWK, bl. h. by Industry. bl. h. by Mucklejohn.

BLACK JACK, bl, h. by Tom Fletcher, dam by Baronet.

BLACK IJOCUST, bl. h. by [Imp.] Luzborough, dam by Sir Archy.

BLACK NOSE, ch. b. by Medoc, dam Lucy by Orpian.

ELACK PRINCE, bl.h. by [Imp.] Fylde, dam Fantail by Sir Arohy 
BLACK RABBIT, bl.h. by [Imp.] Nonplus, dam (Fair Ellen's dam) by Virginius.

BLACK ROSE, bl. m. by [Imp.] Leviathan, dam by Arab.

BLAZING STAR, b. h. by Henry, dam by Eclipse.

BLOODY NATHAN, gr. h. by [Imp.] Leviathan, dam by Pacolet.

BLOOMFIELD RIDLEY, b. h. by Bell-Air, dam Cedar Snags.

BLOOMSBURY, ch. m. by [Imp.] Fylde, dam by Giles Scroggins.

BLUE BONNET, gr. m. by [Imp.] Hedgford, dam Grey Fanny by Bertrand.

BLUE DICK, gr. h. by [Imp.] Margrave, dam by Lance.

BLUE JIM, ch. h. by Mucklejohn.

BLUE SKIN, h. by Mo mion, dam by Tecumseh.

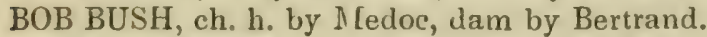

BOB LETCHER, b. h. by Medoc, dam by Rattler.

BOB LOGIC, br. h. by [Imp.] Langford, dam by Mambrino.

BOB RUCKER, ch. h. by Eclipse, dam by Sir Charles.

BOIS D ARC, ch. h. by Eclipse, dam Hortensia by Contention.

BONNY BLACK, bl. m. by [Imp.] Valentine, dam Helen Mar by Rattler.

BORAC, ch. h. by Pacific, dam by Bagdad.

BOSTON, ch. h. by Timoleon, dam (Robin Brown's dam) by Ball's Florizel.

BOSTON FILLY, m. by Boston, dam by [Imp.] Priam.

BOWDARK, b. h. by Anvil, dam by Bagdad.

BOXER, b. h. by Mingo, dam by Eclipse.

BOYD M'NAIRY, ch. h. by [Imp.] Leviathan, dam Morgiana by Pacolet.

BRACELET, ch. m. by Eclipse, dam [Imp.] Trinket.

BREAN, ch. h. by Goliah.

BRILLIANT, b. h. by Sidi Hamet, dam Miss Lancess by Lance.

BRITANNIA, [Imp.] b. m. by Actæon, dam by Scandal.

BROCKLESBY, ch. h. by [Imp.] Luzborough, dam by Roanoke.

BROKER, b. h. by [Imp.] Rowton, dam Jane Bertrand by Bertrand. BROTHER TO HORNBLOWER, b. h. by Monmouth Eclipse, dam

Music by John Richards.

BROTHER TO PEYTONA, ch.h. by [Imp.] Glencoe, dam Giantess by $[\operatorname{Imp}$.$] Leviathan.$

BROTHER TO VICTOR, b. h. by [Imp.] Cetus, dam [Imp.] My Lady by Comus.

BROWN ELK, b. h. by Buck Elk, dam by Whip.

BROWN GAL, br. m. by [Imp.] Leviathan, dam by Virginian.

BROWN KITTY, br. m. by Birmingham, dam by Tiger.

BROWN LOCK, br. h. by Pacific, dam by Sir Hal.

BROWN STOUT, bı ... by [Imp.] Sarpeclon, dam Feathers by Mons. Tonson.

BROWNLOW, br. h. by [Imp.] Merman, dam (Glenare's tamı) by [Inip.]. Leviathan.

BRUCE, ch. h. by [Imp.] Nonplus, dam Lambal'e by Kosciuske

RUBB, $b \mathrm{~m}$. by Bertrand, dam by Whig. 
13UCK-EYE, h. h. by Critic, dam Ann Page by Ogle's Oscar. dian.

b. h. by Lafayette Stockholder, dain Old Squaw by In.

BELLE, ch. m. by Medoc, dam by Sumpter.

LAD, ch. h. by Bertrand, dam by a Son of Spread Ea gle.

BUCK RABBIT, b. h. by [Imp.] Nonplus, dam (Fair Ellen's dam) by Virginius.

BULGER BROWN, b. h. by Lance, dam by Jenkins' Sir William:

BLNKUM, ch. g. by Hyazim, dam by Gallatin.

BURLEIGH, b. h. by Sir Archie Montorio, dam Mary Lee by Con tention.

BUSTAMENTE, ch. h. by Whalebone, dam Sarah Dancy by Timo leon.

BUZ FUZ, gr. h. by Medley, dam by [Imp.] Luzborough.

CADMUS, b. h. by Cadmus.

c.

CALANTHE, b. m. by [Imp.] Leviathan, dam by Jackson.

CALAN'THE, ch. m. by Medoc, dam by Sumpter.

CAMANCHE, ch. h. by Grey Eagle, dam by Rattler.

CAMDEN, br. h. by Shark, dam [Imp.] Invalid by Whisker.

CAMEO, b. m. by [Imp.] Tranby, dam by Buzzard.

CAMEL, ch. h. by Birmingham, dam by Whip or Sumpter.

CAMILLA, br. m. by [Imp.] Hedgford, dam (Picayune's dam) by Sir William of Transport.

CAPTAIN BURTON, br. h. by Cherokee, dam by Green Oak.

CAPTAIN M'HEATH, ch. h. by [Imp.] Leviathan, dam Miss Bailey by $[\operatorname{Imp}$.$] Boaster.$

CAP'TAIN THOMAS HOSKINS, b. h. by [Imp.] Autocrat, dam by Tom Tough.

CAPTAIN (The) b. h. by Sir Archy Montorio, dam Ophelia by Wild Medley.

CAPTAIN WHITE-EYE, bl. h. by Chifney, dam by Sumpter.

CAROLINE MAL_ONE, (Col. Thomas Watson's), ch. m. by [Imp.] Leviathan, dam Proserpine by Oscar. than, dam by Sir Richard.

viathan, dam by Jerry. (Col. J. C. Guild's), b. m. by [Imp.] Levia(Col. Thomas Watson's), b. m. by [IImp.] LA-

CASHIER, ch. h. by Goliah, dam by Sir Charles.

CASKET, b. m. by [Imp.] Priam, dam hy Constitution.

CASETTA CHIEF, ch. h. by Andrew, dam by Wildair.

CASSANDRA, b. m. by [ $\operatorname{lmp}$ ] Priam, dam Flirtilla Jr. by Sir Archy.

EASTIANIRA, ch. m. by [Imp.] Leviathan, dam by Stockholder.

CATALPA, b. m. by Frank, dam by John Richards.

CATARACT, b. h. by Monmouth Eclipse, dam by John Richards.

CATHERINE, b. m. by Bertrand, dam Black-eyed Susan by Tiger.

CATHERINE FENWICK, gr. m. by Mucklejohn, dam by Sૈaxa Weimae 
C.ATHERINE RECTOR, ch, m. hy Pacific, dam Mary Tonson.

CAVALIER SERVAN'T', gr, h. hy Bertrand, dam by Andrew.

CEDRIC, b. h. by [ $\operatorname{lmp}$.] Priam, dam Countess Plater by Virginian.

CELERITY, ch. m. by [ $I m p$. ] Leviathan, dam Patty Puff by Pacolet.

CHAMPAGNE, b. h. by Eclipse, dam by Sir Archy.

CHARLES, b. h. by [Imp.] Rowton, dam Leocadia.

CHARLES ARCHY, ch, h. by Sir Charles, dam by Eclipse.

CHARLES MAI_COLM, ch. h. by Malcolm, dam by Albert Giallatin.

CHARLEY ANDERSON, ch. h. by Medoc, dam by Mercury.

CHARLEY FOX, b. h. by Waxy, dam by Buckner's Leviathan.

CHARI.EY NAYLOR, b. h, by Medoc, dam by Tiger.

CHARI,O'TE BARNES, b. m. by Bertrand, dam hy Sir Archy.

CHARLOTTE CIAAIBORNE, b. m. by Havoc, dam by Conqueror.

CHARLOT'TE HILL, b. m. by Hephestion, dam by Cook's Whip.

CHARITY GIBSON, ch. m. by [ $1 \mathrm{mp}$. $]$ Leviathan, dam by Sir Charles.

CHA'TEAU, [Imp.] b. m. by Chateau Margaux. dam Cuirass by Oiseau.

CHEMISE'TTE, b. m. by [Imp.] Glencoe, dam by Arab.

CHEROKEE MAID, gr. m. by Marmion, dam by Tecumseh.

CHESAPEAKE, b. or br. h. by [ I $m p$. ] Leviathan, dam hy Thaddeus.

CHICOMAH, ch. m. by $\left[\operatorname{Im} p_{0}\right]$ Leviathan, dam White Feather by

Conqueror.

CHICOPA, ch. m. by Tuscahoma, dam Fortuna by Pacolet.

CHIEl"TAIN, b. h. by Godolphin, dam Young Lottery by Sir Archy.

CHO'TAUK, br. h. by Pamunky, dam by Arab.

CHURCHILL, b. h. by [Imp.] Zinganee, dam by Buzzard.

CINDERELLA, b. m. by Pacific, dam Mary Vaughan by Pacolet.

Cl ARA BOARDMAN, b. m. by [Imp.] Consol, dam Sally Bell by Sir Archy.

CLARION, ch. h. by Monmouth Eclipse, dam by Ogle's Oscar.

CLARISSA, ch. m. by Monmouth Eclipse, darn (Clarion's dam) by Ogle's Oscar.

CLEAR THE TRACK, ch. h. by [Imp.] Luzborough, dam by Stockholder.

CLEUPATRA, b. m. hy [Imp.] Leviathan, dam by Pacolst.

CLEVELAND, gr. h. by [Imp.] Emancipation, dam by [Imp.] Leviathan.

COAL BLACK ROSE, bl. m. hy [ $J_{m p}$.] Leviathan, dam by Arab.

COLUMBLS, Junior, b. h. by Columtius, dam by Bertrand.

COMPROMISE, b. m. by Nullifier, dam by Anti-Tariff.

CONCHITA, ch. m. by [Imp.] Leviathan, dam Miss Bailey by [Imp. Boaster.

('ONSOL, Junior, br. h. by [Imp.] Consol, dam [Imp.] The Nun's Daughter by Filho da Puta.

GORA, [Imp.] ch. m. by Muley Moloch, dam by Champior.

('URA MUNRO, ch. m. by Hugh L. White, dam by Crusher.

VORDFLIA, ch. m. by [Imp.] Leviathan, dam by Sir Archy.

CORK, b. h. by [ $1 \mathrm{mp}$.] Leviathan, dam Caledonia by Jerry.

(')RNELIA, b. m. by Skylark, dam by Arab.

1;ORONATION, ch. h. b.v Laplander, dam by Oscar. 
CO'T'TON Pl.AN'T, gr. m. by Bertrand, dam by Pacolet.

COWBOY, ch. h. by Medoc, dam by Virginian.

URACKAWAY, ch. h. by Marmaduke.

CRACOVIENNE, gr. m. by [Imp.] Glencoe, dana [Imp.] Gallopade by Catton.

CREATH, b. h. by [Imp.] Tranby, dam by Sir Archy Montorio.

CRICHTON, ch. h. by Bertrand, dam by Phenomenon.

CRIPPLE, gr. m. by [Imp.] Philip, dam (Gamma's dam) by Sir Richard.

CROCKETT, b. h. by Crockett, dam by Sir Archy.

CROTON, gr. h. by Chorister, dam by Mucklejohn.

CRUCIFIX, ch. m. by [Imp.] Leviathan, dam Virginia by Sir Archy.

CUB, ch. m. by Medoc, dam by Sumpter.

CUMBERI.AND, b. h. by [Imp.] Leviathan, dam by Sir William.

CURCULIA, ch. m. by Medoc, dain by Sumpter.

CZARINA, gr. m. by [Imp.] Autocrat, dam Aurora by Arab.

\section{D.}

UANDRIDGE, b. h. by Garrison's Zinganee, dam by Walnut or Lafayette.

DAN MARBLE, ch. h. by Woodpecker, dam (a sister to West Florida's dam) by Potomac.

D.N M'INTYRE, ch. h. by Medoc, dam by Sumpter.

DAN TUCKER, ch. h. by [Imp.] Belshazzar, dam by Pulaski.

DANIEL BUCK, ch. h. by Collier, dam by Pacolet.

DARIUS, b. h. by Orphan Boy, dam bv Sumberland.

UARKNESS, bl. m. by Wagner, das Sally Shannon's dam) liv Sir Richard.

DARNLEY, ch. h. by John Richards, dam Lady Gray by Sir Richard.

DAR'T, b. h. hy [Iinp.] Doncaster, dam Jane Gray by Orphan Boy.

DAVE PATTON, ch. h. by Sumpter, dam by Hamiltonian.

D) A VID FYLDE, b. h. by [Imp.] Fylue, dam by Clay's Sir William.

DAY DREAM, br. m. by [Imp.] Luzborough, dam by Sir Archy.

DA Y TON, ch. h. by Tormentor, dam by 'Tuckahoe.

DECATUR, ch. h. by Henry, dam Ostrich by Eclipse.

DECEPTION, b. h. by Stockholder, dam by [Imp.] Leviathan.

DE LAT'TRE, br. h. by [ Imp.] Consol, dam [ Imp.] Design by Tramp.

DEL.A WA RE, b. h. hy Mingo, dam by John Richards.

DEI,PHINE, ch. m. by Sumpter.

DEMCCRA'T', ch. h. by [Imp.] Iuzborough, dam by Eagle.

1)ENMARK, br. h. by [Imp.] Hedgford, dam Betsey Harrison by Aratus.

UENIZEN, [Imp.] b. h. by Actæon, dam Design by Tramp.

UEVIL JACK, ch. h. by [Imp.] Leviathan, dam Lady Burton by T'imoleon.

I)[ANA CROW, bl. m. by Mark Antony, dam by Botts' Lafayctte. UIANA SYNTAX, br. $m$. by Doctor Syntax, dam [Imp.] Diana br Calton.

DICK COLLIER, ch. h. hy Collier, dam by Whip.

DCK MENIFEE, br. h. hy Iance, dam by Sir William of Transpo-1 
DOC'I'OR DUDLEY, b. h. by Bertrand, dam by Robin Ciray.

DOCTOR DUNCAN, ch. h. by Cadmus, dam by Old Court.

DOCTOR FRANKLIN, ch. h. by Frank, dam Althea by Big Areliy.

DOC'TOR WILSON, ch. h. by John Bascombe, dam Bolivia by Bo livar.

DOLLY DIXON, b. m. by [Imp.] Tranby, dam Sally House by Vir. ginian.

DOLLY MILAM, b. m. by [Imp.] Sarpedon, dam by Eclipse.

DONCAS'TER, [ $\operatorname{Imp}$.$] bl. h. by Longwaist, dam by Muley.$

DONNA VIOLA, b. m. by [Imp.] Luzborough, uam (Jack Downing's dam) by Mons. Tonson.

DUANNA, gr. m. by [Imp.] Sarpedon, dam Goodloe Washington ly Washington.

DUBLIN, gr. h. by [Imp.] Lueviathan, dam by Jerry.

DUCKIE, b. m. by [Imp.] Sarpedon, dam Mary Jones by Kosciusko.

DUKE SUMNER, gr. h. by Pacific, dam by Grey Archy.

DUNGANNON, b. h. by Mingo, dam by John Stanley.

DUNVEGAN, b. h. by [Imp.] Trustee, dam Jemima by Rattler.

E.

EARL OF MARGRAVE, b. h. by [Imp.] Sarpedon, dam Duchess of Marlborough by Sir Archy.

ECLIPTIC, ch. h. by Eclipse, dam (Podolph's dam) by Moses.

EDISTA, b. h. by [Imp.] Rowton, dam Empress.

EDWARD EAGLE, ch. h. by Grey Eagle, dam by Director.

EFFIE, b. m. by [Imp.] Leviathan, dam by Stockholder.

EL BOLERO, br. h. by Stockholder, dam by [Imp.] Leviathan.

EL FURIOSO, b. h. by [Imp.] Hedgford, dam Rattlesnalse by Bertrand.

ELIAS RECTOR, b. h. by [Imp.] Luzborough, dam Kate Blair.

ELI ODOM, br. h. by [Imp.] Leviathan, dam Chuckfahila by Ber. trand.

ELIZA CULVERT (or Calvert), ch. m. by Cymon, dam Lacly Surn ner by Shawnee.

ELIZA HUGHES, b. m. by Marmion, dam by Whip.

ELIZA JANE, b. m. by [Imp.] Monarch, dam Big Jinny by Kattler.

ELIZA ROSS, b. m. by Marmion, dam by Tiger or Whip (or 'ligor Whip).

ELIZABETH GREATHOUSE, b. m. by Masaniello, dam by Waxy.

ELIZABETH JONES, $m$. by Pacific, dam by Mons. Tonson.

ELLA, ch. m. by Young Virginian, dam by Harwood.

ELLEN HUTCHINSON, ch. m. by [Intp.] Leviathan, dam by Ber trarid.

ELLEN CARNELL, ch. m. by [Imp.] Belrhazzar, dam by [Imp., Leviathan.

ELLEN JORDAN, b. m. by ( $I m p$.) Jordar, dam Ellen Tiee by Henry.

ELLEN PERCY, ch. m. by Godolphin, dam by (Imp.) Bedford. ch. $m$. by Godolphin, dam by Financier.

ELLEN WALKER, b. m. by (Imp.) Consol, dam (Imp.) Plenty u. Emilıus.

ELLISIS, b. m. by Platoff, dam by Mucklejohrs. 
EILIPTIC, ch. h. hy Monmouth Eclipse, dam Amanda by Revenge F.L(ISE, ch. m. by (Imp.) Luzborough, dam Mary Wasp by Dos Quixotte.

ELVIRA, ch. m. by Red Gauntlet, dam by Rob Roy.

E.IERALD, b. m. by (Imp.) Leviathan, dam (Imp.) Eliza by Ru bens.

EMIGRANT, gr. h. by Cadet, dam by (Imp.) Contract.

I.IIILY, ch. m. by Medoc, dam Spider by Almanzar.

- br, m. by (Imp.) Priam, dam by Tom Tough.

- - (Imp.) b. m. by Emilius, dam Elizabeth by Rainbow.

F.MILY SPEED, ch. m. by (Imp.) Leviathan, dam by Pacolet.

EMMET, b. h. by Bertrand, dam by Gallatin.

LSMERALDA, b. m. by Pressure, dam by Murat.

LSPER SYKES, (Imp.) br. h. by Belshazzar, dam Capsicum by Emilius.

ESTA, gr. m. by Bolivar, dam by (Imp.) Barefoot.

ESTHER WAKE, gr. m. by (Inp.) Luzborough, dam by Stock. holder.

ETHIOPIA, bl. m. by Dashall, dam by (Imp.) Expedition.

EUDORA, br. $m$. by Jefferson, dam by Oscar.

EUCLID, br. h. by (Imp.) Luzborough, dam by Sir Archy.

EUTAW, b. h. by (Imp.) Chateau Margaux, dam by Sir Charles.

EVERGREEN, ch. m. by Wild Bill, dam by Sir Charles.

EX'TIO, b. m. by (Imp.) Leviathan, dam (Imp.) Refugee by Wan. derer.

\section{F.}

FANCY, br. m. by (Imp.) Fylde, dam by Sir Archy.

FANDANGO, gr. m. by (Imp.) Leviathan, dam (Imp.) Gallopade by Catton.

FANNY, ch. m. by Eclipse, dam Maria West by Marion.

- (J. Guildersleeve's), bl. m. by Sidi Hamet, dam by Sumpter. Trumpator.

FANNY BAILEY, ch. m. by Andrew, dam by Bertrand.

FANNY FORESTER, b. m. by (Imp.) Emancipation, dam by In. dustry.

FANNY GREEN, b. m. by (Imp.) Trustee, dam Betsey Archy by Sir Archy.

FANNY KING, b. m. by (Imp.) Glencoe, dam Mary Smith by Sir Richard.

FANNY LIGHTFOOT, b. m. by Stockholder, dam by Sumpter.

FANNY ROBERTSON, b. m. by (Imp.) Priam, dam Arietta by Vir ginian.

F ANNY STRONG, ch. m. by (Imp.) Leviathan, dam Sally Bell ly Sir Archy.

FANNY WYATT, ch. m. by Sir Charles, dam by Sir Hal.

FAN'TAIL, ch. m. hy Waxy, dam by Sumpter.

FAIRLY FAIR, ch. m. by (Imp.) Luzborough, dam by Peter Teazlo.

FAI'TH, b. m. by (Imp.) Tranby, dam Lady Painter by Lance

EASHION, ch. m. Ly (Imp.) Trustee, dam Bonnets O' Blue by tis Charles. 
FFATHLRS, ch. m. by (Imp.) Leviathan, dam (George Kendall's (laun) by Stocliholder.

FE.TIVITY, b. h. by (Imp.) Leviathan, dain Magnolia by Mons T'onson.

FIAT, b. m. by (Imp.) Hedgford, dam Lady Tompkins by Eclipst. FIFF.R, b. h. by Monmouth Eclipse, dam Music by John Richards.

FILE-LEADER, ch. h. by (Imp.) Barefoot, dam Saluda by Timo leon.

FINANCE, b. m. by Davy Crocket, dam by Sir Henry Tonson.

FLASH, b. m. by (Imp.) Leviathan, dam by Conqueror.

FLAXINELLA, gr. $m$. by (Imp.) Leviathan, dam by Virginian.

FLEE'TFOO'T, gr. m. by (Imp.) Barefoot, dam Dove by Duroc.

FLETA (James L. French's) br. m. by (Imp.) Sarpedon, dam by Rasselas.

- (G. B. Williams's), ch. h. by (Imp.) Leviathan, dam by Clay's Sir William.

fiLIGHT, ch. m. by (Imp.) Leviathan, dam by Sir Charles.

FLORA HUNTER, gr. m. by Sir Charles, dam by Duroc.

FORDHAMI, ch. h. by Eclipse, dam Janette by Sir Archy.

FORTUNATUS, ch. h. by Carolinian, dam by Sir Charles.

FORTUNE, b. m. by (Imp.) Tranby, dam by Maryland Eclipse.

FRANCES AMANDA, ch. m. by Pennoyer, dam Sally McGrath.

FRANCES TYRREL, b. $m$. by Bertrand, dam by Rockinglam.

L'RED KAYE, b. h. by Grey Eagle, dain by Moses.

FRESHET, ch. m. by Tom Fletclıer, dam Caroline (or Catherine) by Pacific.

FliEE JACK, br. h. by (Imp.) Luzborough, dam (Imp.) Tinsel by Napoleon.

FROS'TY, ch. h. by Eclipse, dam Martha Holloway by Rattler.

FURY, bl. m. by Terror, dam by Smith's Bedford.

- (Col. Wade Hampton's), ch. m. by (Imp.) Priam, dam (Imp.) sister to Ainderby by Velocipede.

G.

GABRIEL, ch. h. by Napoleon, dam Harpalyce by Collier.

GAI_ANTHA, b. m. by (Imp.) Leviathan, dam by Jackson.

GAMMA, gr. m. by Pacific, dam (Melzare's dam) by Sir Richard.

GANO, b. h. by Eclipse, dam Betsey Richards by Sir Archy.

GARRICK, gr. h. by (Imp.) Shakspeare, dam by Eaton's Columbus GAR'TER, b. m. by (Imp.) Glencoe, dain by Trumpator.

GAS-LIGHT, br. h. by (Imp.) Merman, dam by Mercury.

rAZAN, b. h. by Sir Leslie, dam Directress by Director.

GENERAL DEBUYS, ch. h. by (Imp.) Leviathan, dam (I $m_{1}$ ?

Nanny Killam by Voltaire.

GENERAL RESULT, b. h. by (Imp.) Consol, dam by Timoleon.

GENEVA, ch. $m$. by Medoc, dam by Arab.

'iEORGE BURBRIDGE, b. h. by (Inip.) Chateau Margaux, dam hy Mons. Tonson.

1.EORGE ELLIOT'T, br. h. by (Imp.) Leviathan, dam by Lawrence LiEORGE LIGHTFOOT, b. b. by Eclipse Lightufnot, dans Maiy Logan by Arab. 
GEORGF MARTIN, b. h. by Garrison's Zinganee, dam Gabriella by Sir Archy.

GEOliGE: W. KENDALL, ch. h. by Medoc, dam Jenny Devers by Stockliolder.

GEROW, ch. h. by Henry, dam Vixen by Eclipse.

GERTRUDE, b. m. by (Imp.) Leviathan, dam Parasol by Napoleon GIFT, ch. m. by Dick Chinn, dam Milch Cow.

GIPSEY, b. m. by Nullifier, dam by Anti-Tariff.

GLENARA, b. h. by (Imp.) Rowton, dam Nell Gwynne by Tramp. ..._- (Davis \&: Riagland's,) ch. m. by (Imp.) Glencoe, dam Kitty Clover by Sir Charles.

(Dr. Thos. Payne's,) b. m. by (Imp.) Leviathan, dam Jane Shore by Sir Archy.

GLIDER, ch. h. by (Imp.) Valparaiso, dam by Clifton.

GLIMPSE, b. h. by MIedoc, dam by Tiger.

GLORVINA, ch. m. by Industry, dam by Bay Richmond.

GI.OVER ANN, gr. in. by (Imp.) Autocrat, dam by Bolivar.

G?LI) EAGLE, ch. h. by Grey Eagle, dam Eliza Jenkins by Sir William.

GOLD) FRINGE, ch. h. by (Imp.) Glencoe, dam (Imp.) Gold Wire.

GONE AWAY, b. h. by (Imp.) Leviathan, dam by Virginian.

GOSPORT, br. h. by (Imp.) Margrave, dam Miss Valentine by (Imp.) Valentine.

GOVERNOR BARBOUR, b. h. by (Imp.) Trufle, dam by Holmes' Vampire.

GOVERNOR BUTLER, ch. h. by Argyle, dam Mary Frances by Director.

GOVERNOR CLARK, ch. h. by Medoc, dam by Old Court.

GOVERNOR POINDEXTER, ch. h. by (Imp.) Leviathan, dam Eliza Clay (the dam of Giantess,) by Mons. Tonson.

GRACE DARLING, ch. m. by (Imp.) Trustee, dam Celeste by Henry.

GRAMPUS, b. h. by (Imp.) Whale, dam by Timoleon. br. h. by Shark, dam by Mons. Tonson.

GRATTAN, b. h. by (Imp.) Chateau Margaux, dam Flora by Maryland Eclipse.

GREY ELLA, (A. G. Reed,) gr. m. by Big Archy, dam by Bertrand. - (A. G. Reed, gr. m. by Collier, dam by Gallatin

GREY FRANK, gr. h. by Frank, dam by Buzzard.

GREY-HEAD, (J. L. Bradley's,) b. h. by Chorister, dam by Sumpter john.

GREY MARY, gr. m. by Ben. Sutton, dam by Hamiltonian.

GREY MEDOC, gr. h. by Medoc, dam Grey Fanny by Bertrand.

GREY MOMUS, gr. h. by Hard Luck, dam by Mons. Tonson.

GT'INEA-COCK, br. h. by Merlin, dam by Grey-tail Florizel.

GULNARE, b. m. by (Imp.) Sarpedon, dam by Sir William of 'Transport.

GUSTA VUs, b. h. by Sussex, dam by Thornton's Rattler

GUY OF WAFWICK, ch. h. by Frank, dam hy Hamiltonian. 


\section{H.}

HANNAH HARRIS, b. m. by Bertrand, dam Grey Goose oy Pacoles HANNIBAL, b. h. by O Kelly, dam Roxana by Sir Charles. HA'-PENNY, b. m. by Birmingham, dam Picayune by Medoc. HARDENED SINNER, b. h. by (Imp.) Philip, dam by (Imp.) Bluster.

HARD CIDER, b. h. by (Imp.) Tranby, dam by Sir Charles.

HARK-AWAY, ch. h. by Enilius, dam (Imp.) Trapes.

HARPALYCE, ch. m. by Collier, dam by Sea-Serpent.

HARRIET, ch. m. by Eclipse, dam by Shylock.

HARRY BLUFF, bl. h. by (Imp.) Autocrat, dam by Pakenham.

HARRY CARGILL, ch. h. by (Imp.) Leviathan, dam (Imp.) Florentine by Whisker.

HARRY HILL, b. h. by (Imp.) Chateau Margaur, dam (Imp.) Anna Maria by Truffle.

HARRY WHITEMAN, ch. h. by Orphan Boy, dam by Sir Archy.

HAWK-EYE, ch. l. by Sir Lovell, dam Eliza Jenkins by Sir Wil. liam.

HEAD 'EM, b. h. by (Imp.) Trustee, dam Itasca by Eclipse.

HEALER, ch. m. Dy Monmouth Eclipse, dam by Sir Archy of Transport.

HEBE, ch. $m$. by Collier, dam by. Bertrand.

HECTOR BELL, gr. h. by Drone, dain Mary Randolph by Gohanna. HEIRESS, (THE) ch. m. by (Imp.) Trustee, dam by Henry.

HELEN, (Imp.) b. m. by (Imp.) Priam, dam Malibran by Rubens.

HENRY A. WISE, br. h. by Dashall, dam by Hickory.

IIENRY CLAY, br. l. by Cock of the Rock, dam by Virginian.

HENRY CROWELL, b. h. by Bertrand Junior, dam sister to Muckle. john Junior.

HERALD, ch. h. by Plenipotentiary, dam (Imp.) Delphine by Whisker.

HERMIONE, ch. m. by (Imp.) Non Plus, dam Leocadia by Virginian. HERO, ch. h. by Bertrand Junior, dam (Imp.) Mania by Figaro.

HIT-OR-MISS, b. m. by (Imp.) Somonocodrom, dam (Imp.) Bayadere. [These horses are owned in Canada.]

HOOSIER-GIRL, ch. m. by (Imp.) Langford.

HOPE, ch. h. by the Ace of Diamonds, dam (The Captain's dam,) by Oscar.

HORNBLOWER, br. h. by Monmouth Eclipse, dam Music by Johu Richards.

HOURI, (Imp.) ch. m. by Langar, dam Annot Lyle by Ashton.

HUGUENOT, ch. h. by Convention, dam (Imp.) Marigold.

HUMMING-BIRD, br. m. by Industry, dam Virginia by Thornton's Rattle.

HUNTSMAN, gr. h. by (Imp.) Leviathan, dam by Pacolet.

HYNE PARK, ch. h. by (Imp.) Barefoot, dam Saluda by Tímolec

I.

IAG(), bl. h. by Othello, dam (Sartin's dam,) by Timolcon. CEI.AND, ch. h. by Medoc, dam Lady Jackson by Sumpier ILLINNIS, b. h. by Medoc, dam by Bertrand. 
IOWA, ch. h. by (IInp.) Barefoot, dam (Imp.) Woodbine.

IRENE, ro. m. by Printer, dam McKinney's Roan.

ISEE TURNER, ch. m. by (Imp.) Leviathan, dam by Stockholde?

ISIDORA, b. m. by (Imp.) Blacklock.

ISOLA, ch. m. by Bertrand, dam Susette.

\section{J.}

JACK DOWNING, b. h. by Pacific, dam by Mons. Tonson.

JACK PENDLE'ION, ch. h. by Goliah, dim (Philip's dam,) by 'Tre falgar.

JACK IVALKER, ch. h. by Cymon, dam by (Imp.) Luzborough.

JAMES ALLEN, ch. h. by (Imp.) Leviathan, dam Donna Maria by Sir Hal.

JAMES CROWELL, br. h. by Bertrand, dam by Sir Charles.

JAMES JACKSON, ch. h. by (Imp.) Leviathan, dam Parasol by Tiger.

JAMES F. ROBINSON, ch. h. by Medoc, dam by Potomac.

JAMES K. POLK, b. h. by (Imp.) Luzborough, dam Oleana by Tele graph.

b. h. by Telegraph, dam by Buzzard. ch. h. by Buck-eye, dam by Medoc.

JANE ADAMS, b. m. by (Imp.) Tranby.

JANE FRANCIS, b. m. by Granby, dam by Tecumseh.

JANE MITCHELI, ch. m. by (Imp.) Leviathan, dam by Conqueror. JANE ROGERS, ch. m. by (Imp.) Leviathan, dam by Sir Charles.

JANE SMITH, b. m. by John Dawson, dam by Pacolet.

JANE SPLANE, gr. m. by (Inp.) Autocrat, dam Helen McGregor by Mercury.

JEANET'TE BERKELEY, ch. m. by Bertrand jr., dam Carolina by Young Buzzard.

JEANNETTON, ch. m. by (Imp.) Leviathan, dam by Stockholder.

JENNY-ARE-YOU-THERE, ro. m. by Sir Archy Montorio, dam by Potomac.

JENNY RICHMOND, ch. m. by Medoc, dam by Hamiltonian.

JENNY ROBERTSON, b. m. by (Imp.) Luzborough, dam by Marcus.

JEROME, b. h. by (Imp.) Luzborough, dam by Sir Charles.

JERRY, gr. h. by Jerry, dam by Blackburn's Sir William.

JERRY LANCASTER, ch. g. by Mark Moore, dam Maid of Warsan by Gohanna.

JIM BELL, b. h. by Frank, dam Jonquil by Little John.

JIM ROCK, ch. h. by Young Eclipse, dam by Potomac.

JOB, h. h. by Eclipse, dam Jemima by Rattler.

JOE, ch. h. by Medoc, dam by Sir Archy Montorio.

JOE ALLEN, ch. h. by Goliah, dam by Sir Charles.

JOE CHALMERS, ch. h. by (Imp.) Consol, dam (Imp.) Rachel by Partisan (or Whalebone).

JOE DAVIS, b. h. by Eclipse, dam Virginia Washington by Saxa Weimar.

JOE GATES, ch. h. by Marlborough, dam by Eclipse.

JOE MIURRAY, br. h. by Waxy, dam by Hamiltonian.

'OE STURGES, ch. h. by John Bascombe, dam by Thomas $\mathrm{s}$ ฟ: Andrew.

JOE WVINFIELD, b. h. by John Dawson, dam Sally Dillard. 
IOIIN ANDERSON, b. h. by (Imp.) I,uzborough, dam by Bagdad. by $(\operatorname{Imp}$.) Eagle. ch. h. by Cadmus, dam (Kate Anderson's dam,)

JOIJN ARCIIY, ch. h. by John Richards, dam by Old Whip.

JOHN BEI,L, b. h. by Shark, dam Kate Kearney.

JOHN BENTON, gr. h. by (Imp.) Leviathan.

JOIIN BLEVINS, ch. h. by 'The Colonel, dam (Imp.) Trinket.

JOIIN B. JONES, b. h. by Bertrand, dam by Director.

JOHN BLUNT, b. h. by Marion, dam (Mary Blunt's dam,) by Alfred.

JOHN CAUSIN, b. h. by (Imp.) Zinganee, dam Attaway by Sir James.

JOHN C. S'TEVENS, ch. h. by Medoc, dam by Sumpter.

JOHN DUNIKIN, b. h. by Mucklejohn, dam Coquette.

JOHN FRANCIS, ch. h. by Francis Marion, dam Mary Doubleday by

Sir Henry.

JOIIN HAMPDEN, ch. h. by Goliah, dam by Dircetor.

JOHN HIN'IER, b. h. by Shark, dam Coquette by Sir Archy.

'OHN KIRLMAN, ch. h. by Birmingham, dam by Sir Henry Tonson.

JOHN LEMON, ch. h. by Uncas, dam by Oscar.

JOHN MALONE, ch. h. by (Imp.) Leviathan, dam Proserpine by Tenriessee Oscar.

JOHN MARSHALL, b. h. by (Imp.) Luzborough, dam Lady Bass by Conqueror.

JOIIN R. GRY MES, gr. h. by (Imp.) Leviathan, dam Alice Grey by Pacolet.

than, dam Fanny Jarman by Mercury.

JOHN ROSS, bl. h. by Waxy, dam by Topgallant. ch. h. by (Imp.) Leviathan, dam by Oscar.

JOIN VAIIANT, bl. h. by Valiant, dam by King's Archer.

JoHN YOUNG, b. h. by Jisn Richards, dam by Trumpator.

JOHNS(ON, br. h. by Star, dam Vanity hy Grigsby's Potomac.

JOSIIUA BELI, ch. h. by Frank, dam Junguil by Little John.

J ) Y ('E AILLEN, b. m. by (Imp.) Fmancipation, dam Leannah by Seagull.

JULIA, b. m. by (Imp.) Rowton, dam by Roscius.

JUI.IA BUR'ION, ch. m. by Gohinna, dam by Tom Tough.

JULIA DAVIE, ch.m. by (Imp.) Rowton, dam by Kosciusko.

JUISI FISHER, ro. m. by (Imp.) Luzborough, dam Polly Bellew by 'I'imoleon.

JULIUS, ch. h. by (Imp.) Luzbornugh, dam by Jackson.

JUMPER, ch. h. by 'I'imoleon, dam Diana Vernon by Herod.

\section{K.}

KANAWA, ch. h. by Medoc, dam by Rattler.

KATE, b. f. by Monmouth Eclipse, dam Shepherdess by Apollo.

KA'T'E ANDERSON, b. m. by Columbus, dam Eaglet by (Imp.) Filugle.

KATE AUBREY, gr. m. by Eslipse, dam Grey Fanny by Ie:trand.

KA'TF, CUNVERSE, b. m. by (Imp.) Non Plus, dam 1)aisy by Kiesciustro.

A A'TE COY, b. m. by Critic, dan Nancy Bone by Sussex.

KATE HAUN, br. m. by Stockhulder, dam by Timoleon. 
¿ATE LCCKET'T, b. m. by Monmouth Eclipse, dam Shepherdess by A pollo.

KATE NICKLEBY, br. m. by (Imp.) Trustee, dam by Teniers. than. b. in. by (Imp.) Glencoe, dam by (Imp.) Levia

KA'TE SEYTON, br. m. by Argyle, dam Pocahontas by Sir Archy.

KA'TE SIIELBY, ch.m. by (Imp.) Leviathan, dam Maria Shelby by Stockholder.

KAVANAGH, b. or ch. h. by Bertrand, dam by Director.

KEWANNA, b. m. by (Imp.) Cetus, dam (Imp.) My Lady by Comus KI'T'TY HARRIS, gr. m. by (Imp.) Priam, dam Ninon de l'Linclos by Rattler.

KI'T'TY THOMPSON, gr. m. by (Imp.) Margrave, dam Ninon de l'Enclos by Rattler.

L.

LA BACCHANTE, ch. $m$. by (Im $r$.) Glencoe, dam by Bertrand.

LA BELLA COMBS, ch. m. by Andrew, dam by Director.

LADY CANTON, gr. m. by (Imp.) Tranby, dam Mary Randolph $\mathrm{b}$. Gohanna.

LAI)Y CAVA, ch. m. by Bertrand, dam Betsey Echols by Archy Montorio.

LADY FRANCIS, b. m. by Trumpator, dam (Pressure's grandam.)

LADY FRANKLIN, b. m. by (Imp.) Luzborough, dam Sting by Con queror.

LADY HARRISON, b. m. by Sir Henry, dam by Mucklejohn.

LADY JACKSON, - m. by Sumpter.

LADY JANE, gr. m. by (Imp.) Leviathan, dam Lady Grey by Orphan Boy.

LADY PLAQUEMINE, ch. m. by Little Red, dam by (Imp.) Eagle.

LADY PLYMOUTH, b. m. by Flagellator, dam Black Sophia by Eclipse.

LADY SKIPETH, $m$. by (Imp.) Leviathan, dam by Truxton.

LADY SLIPPER, ch. m. by (Imp.) Leviathan.

LADY STOCK, ch. m. by Stockholder, dam by Potomac.

LADY SUSAN, b. m. by Cramp, dam by Pantaloon.

LAFIT'TE, gr. h. by O'Kelly, dam Caroline Wilson by Timoleon.

I.ANDSCAPE, b. h. by (Imp.) Margrave, dam by Sir Archy.

LANGHAM, ch. h. by Medoc, dam by Cumberland.

LANEVILLE, ch. h. by Eclipse, dam by Arab.

LASSO, b. m. by Mucklejohn, dam by Gallatin.

LAURA, b. m. by Medoc, dam by Moses.

LAURA LECONITE, b. m. by 'Tarquin, dam Sarah by (Imp.) Sar. pedon.

I,AURE'I'TE, ch. m. by Jerseyman, dam Maria Harrison.

LAVINIA PIPER, ch. m. by (Imp.) Leviathan, dam by Murphy s Pacolet.

LAVUL'TA, b. m. by Medoc, dam by Blackburne's Buzzard.

LAWYER MCCAMPBELL, b. h. by Lord Byron, dam Warping Bars by Rattle the Cash.

LEUA, ch. $m$. by 'Tiger, dam by Sumpter.

LEESBURG, ch. h. by Red Rover, dam by Tuckahoe.

LLG-B.IIL, ch. h. by Jackson, dain by Miarshal Ney.

LEG.TREASURER, ch. h. by Medoc, dam by Cumberland. 
I.EHIGH, ch. h. by (Imp.) Skylark, dam Nelly Webb by Industry.

LEN NOX, b. h. by (Imp.) 'I'rustec, dam (Imp.) Rosalind by Pawlowitz

LESLIE, ch. h. by (Imp.) Leviathan, dam by Stockholder.

I.F'T'TY FLOYD, ch. m. by (Imp.) Rowton, dam Palmetto by Rab Roy

LEVI, -. h. by Star, dam by Walnut.

LEVITHA, ch. m. by (Imp.) Leviathan.

LEXPIHILI, ch. m. by Hugh L. White, dam by Pacolet.

LIATUNAH, ch. m. by (Imp.) Ainderby, dam (Imp.) Jenny Mills sy Whisker.

I.IBERALITY, ch. h. by Maryland Eclipse, dam by Sir Alfred.

LIBERTAS, ch. h. by Eclipse, dam by Director.

LIEUTENANT BASSI VGER, br. h. by (Imp.) Fylde, dam by Roanoke.

LIKENESS, (Imp.) ch. m. by Sir Peter Lely, dam Worthless by Walnut.

LILY, gr. m. by Tychicus, dam Laura by Rob Roy.

LIMBER JOHN, ch. h. by Kosciusko, dam by Moses.

LINWOOD, ch. h. by Wild Bill, dam by Pacolet.

LITTLE BAR'TON, b. h. by Bertrand, dim by Hamiltonian.

LITTLE BLIIE, gr. h. by Marmion, dam by 'Tecumseh.

LITTLE MISERY, b. m. by Anvil, dam (Imp.) Anna Maria by Truffle.

LITTLE PRINCE, gr. h. by John Bascombe, dam Bolivia by Bclivar.

LITTLE RED, ch. h. by Medoc, dam by Sumpter.

LITTLE TRICK, b. h. by (Imp.) Tranby, dam (Occident's dam,) by Florizel.

LIVE OAK, b. h. by (Imp.) Luzborough, dam by Pacific.

LIVINGS'TON, gr. h. by Medley, dam by Van 'Tromp.

L. h. by (Imp.) I'rustee, dam by Henry.

LIZ LONG, br. m. by (Imp.) Merman, dam by Alpheus.

LIZ TILLETT, ch. m. by Frank, dam by Medoc.

LIZZY HEWITT, b. m. by Ivanhoe, dam Princess Ann by Mons Tonson.

LOG.CABIN, ch. h. by Frank, dam by Hamiltonian.

LONG TOM, ch. h. by Pacific, dam by Jerry.

LORD OF LORN, br. h. by Argyle, dam Maria by Virginian.

br. h. by Argyle, dam Duck Filly by Virginius

LORD OF THE ISLES, gr. li. by Pacific, dam by Jerry.

LORENZO, b. h. by Bertrand, dam by Whip.

LORINDA, ch. m. by Havoc, dam by Conqueror.

LOUISA JORDAN, ch. m. by (Imp.) Jordan, dam Betsey Marshal by John Richards.

LOUISA WINSTON, b. m. by Waxy.

LUCRETIA NOLAND, br. in. by (Imp.) Hedgford, dam Frances Ann by Frank.

LUCY A. MEYER, b. m. by Pacific, dam by Sir Richard.

LUCY BENTON, br. m. by Hugh L. White, dam by Moloch.

LUCYY DASHWOOD, gr. m. by (Imp.) Leviathan, dam Miss Bailey by (Imp.) Buaster.

I.UCY FUT,LER, ch. m. by Eclipse, dam by Pakenham.

LLCY LONG, m. by John Richards, dam by Diomed.

LIJCY WEIBB, ch. m. by Medoc, dam by Sumpter. 
LUDA, b. m. by Medoc, dam Duchess of Marlbornugh by Sir Archy LUNA DOE, ch. m. by (Imp.) Leviathan, dam Telie Doe by Pucifie LYNUIIURS'l, ch. h. by $(\operatorname{limp}$.) Leviathan, dam by Wonder. LYNEDOCH, ch. h. by (Imp.) Leviathan, dam by Wonder.

\section{I.}

MABEL WYNNE, b. m. by (Imp.) Rowton, dam by Sir Archy.

MADAME ARRALINE, ch. in. by Medoc, dam by Cadmus.

MAFFIT, b. h. by Frank, dam by Aratus.

MAGNATE, ch. h. by Eclipse, dam Cherry Elliott by Sumpter

MAID OF A'THENS, b. In. by (Imp.) Priam, dam by Arab.

MAID OF NOR'TIAMPTON, gr. m. by (Imp.) Autocrat, dem bj Rattler.

MAJOR BOOTS, br. h. by (Imp.) Merlin, dam by Alborak.

MANALOPAN, gr. h. by Medley, dam by John Richards.

MANGO, (Imp.) ch. m. by Taurus, dam Pickle by Emilius.

MARCHIONESS, ch. m. by (Imp.) Rowton, dam (Fancy's da.ns) by Sir Archy.

MARCO, b. h. by Sir Leslie, dam by Lance.

MARGARE'T CARTER, b. m. by Medoc, dam Lady Whip by Sis Archy.

MARGARET BLUNT, b. m. by Eclipse, dam by Contention.

MARGARET WOOD, b. m. by (Imp.) Priam, dam Maria West hy Marion.

MARIA, ch. m. by (Imp.) Jordan, dam Polly Powell by Virginian.

MARIA BLACK, (Imp.) br. m. by Filho da Puta, dam by Smolensko.

MARIA BROWN, br. m. by (Imp.) Luzborough, dam Brunette by Sir IIal.

MARIA COLLIER, br. m. by Collicr, dam by Gallatin.

MARIA MILLER, br. $m$. by Stockholder, dam by Madison.

MARIA PEYTON, ch. m. by Balie Peyton, dam by Tariff.

MARIA SHELTON, ch. m. by Andrew, dam (Ajurrah Harrison's (am) by Gallutin.

MARIA SPEED, ch. m. by (Imp.) ILeviathan, dam by Pacific.

MARIA IVILLIAMS, ch. m. by (Imp.) Leviathan, dam by Napoleon

MARINER, bl. h. by Sharik, dam Bonnet's o' Blue by Sir Charles.

MARION, b. m. by (Imp.) Autocrat, dam by Rob Roy.

MAR'THA BICKLR'OON, b. m. by Pamunlsy, dam by Tariff.

MARTHA CARTER, ch. m. by Bertrand, dam Sally Naylor by Gal. latin.

MARTHA CALVIN, h. m. by Agrippa, dam by IValnut.

M.ARTHA MALONE, b. m. by (Imp.) Leviathan, dam Tatchecana by Bertrand.

MAR'THA RANEY, b. m. by (Imp.) Luzborough, dam by Sumpte1.

MAR'THA ROW'TON, ch. m. by (Imp.) Rowton, dam Martha (sriffin by Phenomenon.

MARTHAVILLE, b. m. by Dick Singleton, dain Black. Eyed Stisan

IA'TCHEM, ch. h. by (Imp.) Luzborough, dam by Pl:nd Jackson.

MAR'TIN'S JLDY, br. m. by Young's Mercury, dam by Eclipse.

MARTIN VAN BJREN, b. h. by Lafayette Stockholder, dam by In uiar

MARY, gr. m. by Old Saul, dam by Free Mulutto. 
MARY, gr. m. by (Imp.) Consol, dam Sally Bell by Sir Archy.

MARY INN FURMAN, br. m. by (Imp.) Sarpedon, dam by Eor. trand.

MARY BEECHLAND, b. m. by Sir Leslie, dam by Potomac.

MARY BELL, b. m. by Seagull, dam (Vidocq's dam) by Stockholder

MARY BRENNAN, b. m. by Richard Singleton, dam by Hamiltonian.

MARY BURNHAM, b. m. by Archy Montorio, dam by Stockholder.

MARY CHASE, b. m. by (Imp.) Felt, dam by Sir Archy.

MARY CHURCHILL, b. m. by (Imp.) Barefoot.

MARY DOUGLAS, gr. m. by Jerry, dam by Stockholder.

MARY ELIZABETH, ch. m. by Andrew, dam by Gallatin.

MARY ELLEN, b. m. by Woodpecker, dam by Sumpter.

MARY HEDGFORD, br. m. by (Imp.) Hedgford, dam Mary Franci by Director.

MARY JONES, ch. m. by (Imp.) Barefoot, dam by Eclipse.

MARY LEWIS, ch. m. by (Imp.) Leviathan, darn Proserpine by $\mathrm{Cs}$ car.

MARY LONG, b. m. by (Imp.) Tranby, dam Lady Pest by Carolinian.

MARY LUCKET'T, ch. m. by Marion, dam (Charles Archy's dam) by Eclipse.

MARY MASON, br. m. by Pirate, dam by (Imp.) Consol.

MAR.Y MEADOWS, ch. in. by Stockholder, dam by Timoleon.

MARY MILLER, ch. m. by Arab, dam by Peacemaker.

MARY MORRIS, b. m. by Medoc, dam Miss Obstinate by Sumpter.

MARY OUSLEY, br. m. by King's Bertrand, dam by Pacolet.

MARY PORTER, ch. m. by Mucklejohn, dam by Printer.

MARY REED, br. m. by Industry, dam by Rattler.

MARY RODGERS, b. m. by (Imp.) Hibiscus, dam Ten Brueck's dam.

MARY SCOTT, b. m. by Bertrand, dam by Blackburn's Whip.

MARY SHERWOOD, b. m. by Stockholder, dam by (Imp.) Levia. than.

MARY STEWART, b. m. by (Imp.) Valentine, dam by Henry.

MARY THOMAS, b. m. by (Imp.) Consol, dam Parrot by Roanoke.

MARY TRIFLE, ch. m. by Nedoc, dam by Hamiltonian.

MARY VAUGHAN, b. m. by IVaxy, dam by (Imp.) Bluster.

MARY WALTON, ch. m. by (Imp.) Leviathan, dam Miss Bailey by (Imp.) Boaster.

MARY IVATSON, gr. m. by Robin Hood, dam Bolivia by Bolivar.

MARY IVELLER, ch. m. by Sterling, dam Discord by (Imp.) I,uzborough.

MARY WICKJIFFE, b. m. by Medoc.

MARY WYNNE, b. m. by Eclipse, dam Flirtilla Jr. by Sir Arciny.

MASTER HENRY, b. h. by Heury, dam (Balie Peyton's dam) by Eclipse.

MAT. MLRPHY, ch. h. by Pete Whetstone, dam by Rattler.

MEDINA, b. m. by (Imp.) Barefoot, dam by Director.

MEDOCA, ch. m. by Medoc, dam by Doublehead.

MEDORA WINSTON, b. m. by Telegraph, dam by Pacolet.

MELISSE BYRON, b. m. by Cherolsee, dam by Barnett's Uiomed.

MLELODY, ch. m. by Medoc, dam (Randolph's dam) by Haxall's Moses

MERCER cn. h. by Woodpecker, dam by Hamiltonian 
MERIDIAN, ch. h. by (Imp.) Barefoot, dam by Eclipsc.

METARIE, ch. m. by Frank, dam (Musedora's dam) by Kosciusko.

ME'TEOR, ch. h. by (Imp.) Priam, dam (Baltimure's darn) by Go. hanna.

MrINTYRE, ch. h. by Medoc, dam by Sumpter.

MIDNIGHT, bl. m. by Shark, dam Meg Dods, by Sir Archy.

MIDAS, b. h. by (Imp.) Rowton, dam by Roanoke.

MILTON HARRISON, b. h. by Orange Boy, dam by Quicksilver.

MINERVA ANDERSON, ch. m. by (Imp.) Luzborough, dam by Sir Charles.

MINERVA PROFFIT, ch. m. by (Imp.) Luzborough, dam Sophia Bess.

MINISTER, b. h. by Medoc, dam by Alexander.

MINSTREL, b. m. by Medoc, dum by Bedford's Alexander.

MINT JULEP, br. h. by Godolphin, dam Isora by Dockon.

MiRABEAU, b. h. by Medoc, dam Ann Merry by Sumpter.

MIRIAM, b. m. by (Imp.) Autocrat, dam Laura by Rob Ruy.

MIRTH, b. m. by Medoc, dam (Minstrel's dam) by Bedford's Alexan. der.

MISKWA, ch. m. by Dick Chinn, dam Linnet by (Imp.) Leviathan.

MISSISSIPPI, b. h. by John Dawson, dam by Partnership.

MISSOURI, ch. m. by Eclipse, dam by Director.

MISTAKE, b. m. by Eclipse, dam by Timoleon.

MISS ACCIDENT, (Imp.) b. m. by Tramp, dam Florestine by Whis ker.

MISS ANDREW, ch. m. by Andrew, dam by Gallatin.

MISS BELL, b. m. by (Imp.) Censol, dam (Imp.) Amanda by Moriseo.

MISS CHESTER, b. m. by (Imp.) Sarpedon, dam Delilah by Tiger.

MISS CLARK, ch. m. by Birmingham, dam by Cumberland.

MISS CLASH, ch. m. by Birmingham, dam by Stockholder.

MISS CLINKER, (Imp.) b. m. by Humphrey Clinker, dam Mania by Maniac.

MISS FOOTE, b. m. by (Imp.) Consol, dam (Imp.) Gabriella by Oscar (or Oiseau).

HISS JACKSON, sh. m. by Oakland, dam by Diomed.

IIISS LETTY, b. m. by (Imp.) Priam, dam Patty Burton by Marion.

MISS MACARTY, b. m. by Waxy.

MISS RIDDLE, ch. m. by (Imp.) Riddlesworth, dam Lady Jackson by Sumpter.

MISS WILLS, gr. m. by (Imp.) Zinganee, dam Sorrow by Rob Roy.

MOBILE, b. h. by (Imp.) Consol, dam (Imp.) Sessions by Whalebone.

MOLLY LONG, ch. m. by Tom Fletcher, dam by (Imp.) Janus.

MOLLY WARD, b. m. by (Imp.) Hedgford, dam by Bertrand.

MOLOCH, (Imp.) b. h. by Muley Moloch, dam Sister to Puss by Te niers.

MONARCH, (Imp.) b.h. by Priam, dam Delphine by Wlisker.

MONGRELIA, ch. m. by Medoc, dam Brownlock by Tiger.

MUNKEY DICK, b. h. by Dick Singleton, dam b; Sumpte:

MORDAC, ch. h. by Eclipse, dam by Whip.

MORGAN, ch. h. by John Bascombc, dam A:ny Hamilton.

MORGIANA, eh. in. by Red Gauntlet, dam by Joe Kent.

MORTIMER, ch. h. by Monmouth Eclipse, dam by Ogle's Osear 
MOSELLE (Colonel Gavan's), b. m. by Tulegraph, dum (Imp.) Jano şhore.

MOSELLE (E. P. Dave's), b. m. by (Imp.) Luzborough, dara (Imp.) Jane Shore.

MOTH, ch. m. by (Imp.) Glencoe, dam (Imp.) Jessica by Velocıpede. MO'T'TO, ch. m. by (Imp.) Barefoot, dam Lady Tompkins by Eclipse,

MOUNTAINEER, ch. h. by Yorkshire, dam by Rattler.

MOUNTJOY, b. h. by (Imp.) Tranby, dam by Sir Charles.

MUD, gr. h. by (Imp.) Leviathan, dam by Pacolet.

MUSEDORA, ch. m. by Medoc, dam by Kosciusko.

MUSE SANDFORD, b. h. by Hickory, dam by (Imp.) Contract.

MUSIC, gr. h. by (Imp.) Philip, dam Piano by Bertrand.

\section{N.}

NANCY BUFORD, ch. m. by Medoc, dam by Thornton's Rattler.

NANCY CLARK, b. m. by Bertrand, dam Morocco Slipper by Time leon.

NANCY DAWSON, ch. m. by Frank, dam by Voltaire.

NANCY O., ch. m. by Flagg, dam Milly 'Tonson by Mons. Tonson.

NANCY ROWLAND, b. m. by (Imp.) Rowton, dam by Rob Roy.

NANNY, b. m. by (Imp.) Trustee, dam Miss Mattie by Sir Archy.

NARCISSA PARISH, ch. m. by Stockholder, dam by (Imp.) Eagle.

NARINE, ch. m. by (Imp.) Jordan, dam Louisianaise.

NAT BRADFORD, gr. l. by Bertrand, dam Moroceo Slipper by Ti moleon.

NATHAN RICE, br. h. by Birmingham, dam by Whipster.

NED WELLS, b. h. by O'Connell, dam by Stockholder.

NEPTUNE, ch. m. by (Imp.) Jordan, dan I,ouisianaise.

NIAGARA, ch. h. by (Imp.) Trustee, dam Gipsey by Eclipse.

NICK BIDDLE, b. h. by Score Double, dam Highland Mary.

NICK DAVIS, ch. h. by (Imp.) Glencoe.

NICON, ch. h. by Pacific, dam by Jackson.

NOBLEMAN, ch. h. by (Imp.) Cetus, dam (Imp.) My Lady by Comus.

NORFOLK, br. h. by (Imp.) Fylde, dam Polly Peachem by Julın Richards.

NORMA, ch. m. by Longwaist, dam (Imp.) Novelty by Blacklock.

NORTH S'TAR, ch. h. by Emilius, dam Polly Hopkins by Virginıan.

\section{O.}

UCTAVE, b. m. by (Imp.) Emancipation, dam Polly Kennedy.

OGLENA H, ch. h. by Medoc, dam Maria by Hamiltonian.

OII SEE, ch. h. by (Imp.) Foreigner, dam by Mons. Tonson.

UI,D DOMINION, ch. h. by Eclipse, dim Isabella by Sir Archy.

(1LD MISTRESS, ch. m. by Count Badger, dam Timoura by Timn lcon.

(ILEAN, ch. m. by (Imp.) Leviathan, dam by 'Truxton.

()LEANUER, ch. m. by (Imp.) Glencoe, dam Aranetta by Bertrand OLIVIA WAKEFIELD, gr.m. by Patrick Henry.

OLYMPUS, ch. h. by Eclipse, dan Flirtilla Junior, by Sir Archy.

DMEGA, gr. m. by Timoleon, dam Daisy Cropper by Ogle's Oscar.

OMOHONDRO, ch. h. by Robin Brown, dam by Mason's Rattler.

OREGON b. \& by (Imp.) Philip, dam by (Imp.) Luzborough.

ORIAN $\Lambda$, br m. by (Imp.) Longwaist, dam (Imp.) Orleana by Bu* uned 
ORIFLAMME, ch. h. by Mons. Tonson, dam by Sir Hul.

GRIOLE, b. m. by (Imp) Leviathan, dam Object by Marshal Ney.

ORI.EANS, ch. h. by Cock of the Ruck, dam by T'imoleon.

ORSON, ch. h. by (Imp.) Valentire, dam Ethelinda by Marshal Ber trand.

DSTRICH, ch. h. by Collier, dam by Shakspeare.

OSCAR, (Josiah Chambers's), ch. h. by Ulysses, dam by Bertrand.

OSCEOLA, b. h. by Pacific, dam by Oliver H. Perry.

ch. h. by Wild Bill, dam by Timoleon.

ch. h. by Collier, dam by Sumpter.

OTHELLO, ch. h. by Waxy, dam by Hickory.

(NUR MARY, br. m. by (Imp.) Langford, dam Ostrich by Eclipse.

\section{P.}

P.IIXHAN, b. h. by ( $\operatorname{Imp}$ ) Felt, dam Mary Hutton.

PAL.MERSTON, b. h. by (Imp.) Merman, dam (Imp.) by Cadmus.

PANIC, ch. h. by Eclipse, dam Aggy-up by Timoleon.

PARIS, bl. h. by (Imp.) Priam, dam Water-Witch.

PARTNER, ch. h. by Medoc, dam by Doublehead.

PASSENGER, (Imp.) b. h. by Langar, dam My Lady by Comus.

b. h. by Balie Peyton, dam by Pamun's.

PASSAIC, (Imp.) ch. h. by Reveller, dam Rachel by Moses.

PATRICK H. GALIVEY, ch. h. by (Imp.) Jordar, dam Duchess of Ashland by Shakspeare.

PATSEY ANTHONY, b. m. by (Imp.) Priam, dam (Josephus's dam) by Virginian.

PATSEY BUFORD, b. m. by Mazeppa, dam by Pattler.

PATSEY CROWDER, gr. m. by Pairick Henry, dam Hillon by Antelope.

PA'TSEY DAVIS, ch. m. by Count Padgur, dam Timoura by Tima leon.

PATSEY STUART, b. m. by Bertrand, dan by Redgauntlet.

PEDLAR, ch. h. by (Imp.) Leviathan, d.ara by Pizarro.

PEGGY IIALE, ch. m. by (Imp.) Skylark, dam by Sir Charles.

PENELOPE, (Imp.) ch. m. by Fleripo, dain Brazil by Ivanhoe.

PENSEE, gr. m. by Lauderdale, dam by Lightning.

PEORIA, ch. m. by Medoc, dam by Whip.

PETER PINDAR, ch. h. by (Imp.) Daghee, dam by (Imp.) Barefoot.

PETER SPYKE, ch. h. by Eclipes, dam by (Imp.) Jack Andrews.

PETWAY, b. h. by (Imp.) Glercoe, dam Kitty Clover by Sir Charlea. br. h. by (Imp.) Glencoe, dam by Sir Archy.

PETIVORTH, b. h. by (Inro.) Philip, dam (Kinlock's dam) by Shaw. nee.

PEYTONA, ch.m. by (Im $\left.\aleph_{*}\right)$ Glencoe, dam Giantess by (Imp.) Levia. than.

PHANTOM, b. h. by (Imp.) Contract, dam by Potomac.

PHIL. BROWN, (Imp.) ch. h. by Glaucus, dam Bustle by Whalebone.

PICKWICK, b. h. by Pacific, dam by Pacolet.

PICOLO, br. h. by Lord Byron, dam Highland Mary iNick Biddle's dam).

PILO'T, b. h. by Wild Bill, dam by Oscar.

PLENIPO, (Imp.) b. h. by Plenipo, dam Polly Hopkins by Vırgun:an

POKEROOT, gr. h. by William Tell, dam by Citizen 
POLLARD BROWN, b. h. by Wild Biil, dam Hippy by Pacolet. POLLY ELLIS, m. by (Imp.) Trustec, dam Rosalind by Ogle's Oscas POLLY GREEN, br. m. by Sir Charles, dam Polly Peachem by John Richards.

POLLY HUNTER, ch. m. by Andrew, dam by Crusader.

POLLY MILAM, b. m. by (Imp.) Sarpedon, dam by Escape.

POLLY PILLOW, b. m. by (Imp.) Leviathan, dam by Sir Archy. POLLY PIPER, ch. m. by Count Piper, dam by Consul or Sumptes PONEY, ch. h. by (Imp.) Leviathan, dam by Stockholder. PONOLA, ch. h. by Hannibal, dam by Sir Archy.

PORTSHOUTH, br. h. by (Imp.) Luzborough, dam Polly Peachem by John Richards.

POSTMASTER, (The) b. h. by (Imp.) Consol, dam Country Maid by Pacific.

POWELL, ch. h. by Medoc, dam by Alexander or Virginian. PRENTISS, (S. S.) b. h. by (Imp.) Fylde, dam by Washington. PRESTON, br. h. by Telegraph, dam (Olivia's dam).

- b. h. by (Imp.) Leviathan, dam Parrot by Roanoke.

PRIMA DONNA, b. m. by (Imp.) Priam, dam Lady Rowland by Ts riff.

PRINCE ALBER'T, ch. h. by (Imp.) Margrave, dam (Eutaw's dam, by Sir Charles.

PRINCESS, ch. m. by (Imp.) Priam, dam Sally Hope by Sir Archy.

PRINCESS ANN, b. m. by (Imp.) Leviathan, dam by Stockholder.

PRISCILLA MAR'TIN, ch. m. by (Imp.) Leviathan, dam by Arab.

PROMISE, ch. $m$. by Wagner, dam by Lance.

PROSPEC'T, ch. h. by Monmouth Eclipse, dam by (Imp.) Expedition. Stockholder.

PRYOR, b. h. by (Imp.) Priam, dam Queen of Clubs by Virginian.

PURITY, b. m. by (Imp.) Ainderby, dam Betty Martin by Giles Scroggins.

PUSS, b. m. by (Imp.) Priam, dam by Virginian.

\section{Q.}

QUEEN ANNE, (Imp.) bl. m. by Cam-l, dam by Langar.

QUEEN ELIZABE'TH, br. m. by ( $I m_{\alpha_{0}}$ ) Leviathan, dam by Sir Archy QUEEN MARY, ch. m. by Bertrand, dam by Brimmer.

QUININE, ch. m. by Red Tom, d₹sm by Bertrand.

R.

RAGLAND, ch. h. by ( $\operatorname{lmp}$; Leviathan, dam by Stockholder. RALPH, b. h. by Woodpesker, dam Brown Mary by Sumpier. RANCOPUS, ch. $\mathrm{m}$. by rlagellator, dam Molly Longlegs.

RAN PEYTON, ch. K. by ( $I m p$.) Leviathan, dam by Stockhclder. RAPIDES, ch. h. by (Imp.) Skylark, dam Margaret May by Pacific. RASP, gr. h. by (Imp.) Fylde, dam by Director.

REBECCA KENNER, b. m. by (Imp.) Skylark, dam Lady Halstor by Bertrand.

REBEIL, ch. h. by Gohanna, dam (Ohio's dam).

PEU BILI, ch. h. by Medoc, dam Brown Mary by Sumpter.

RED BREAS'T, ch. h. by (Imp.) Priam, dam Fanny Wyutt by Sis Charles. 
RED BUCK, ch. h. by (Imp.) Rowton, ditm Lady Deerpond.

RED EAGLE, br. h. by Grey Eagle, dam by Moses.

RED FOX, ch.h. by (Imp.) Luzborough.

RED GAUNTLET', ch. h. by (Imp.) 'Trustee, dam (Imp.) Vaga.

RED HAIVK, ch. h. by Mcdoc, dam by Sumpter.

RED HEAD, b. h. by Woodpecker, dam by Whipster.

RED MOROCCO, ch. m. by Medoc, dam Brownlock by Tiger.

RED ROSE, br.m. by (Imp.) Leviathin, dain by (Imp.) Bagdad.

RED TOM, ch. h. by Bertrand, dam Duchess of Marlborough by sis Archy.

REEL, gr. m. by (Imp.) Glencoe, dam (Imp.) Gallopade by Catton.

REGEN'I', b. h. by (Imp.) Priam, Jam Fantail by Sir Archy.

REGISTER, gr. h. by (Imp.) Priam, dam Maria Louisa by Mons. Tonson.

RELIANCE, b. h. by (Imp.) Autocrat, dam Lady Culpeper by Caroli. nian.

RESCUE, br.h. by (Tinp.) Emancipation, dam Louisa Lee by Medley.

REVEILLE, b. m. by Bertrand, dam Sally Melville by Virginian.

b. or br. h. by Young Virginian, dam by Harwood.

REVERIE, b. or br. m. by (Imp.) Ainderty, dam by Giles Scroggins.

RHYNODINO, gr. h. by Pacific, dam by Hamiltonian.

RICHARD OF YORK, b. h. by Star, dam by Shylock.

RICHARD ROWTON, b. h. by (Imp.) Rowton, dam by Falstaff.

RIENZI, b. h. by (Imp.) Autocrat, dam by Sir Charles. phax (or Diomed).

RINGDOVE, b. m. by (Imp.) Merman.

RIPPLE, b. m. by Medoc, dam Belle Anderson by Sir William.

ROANNA, ro. m. by Archy Montorio, dam by Potomac.

ROBERT BRUCE, b. h. by Clinton, dam by Sir Archy.

ROBIN COBB, ch. h. by (Imp.) Felt, dam Polly Cobb.

ROCKER, b. h. by Eclipse, dain by Virginian.

ROCKE'T'T, b. h. by Sir Leslie, dam Miss Lancess by Lance.

RODERICK DHU, gr. h. by Merlin, dam by (Imp.) Bagdad.

RODNEY, br. h. by (Imp.) Priam, dam Medora.

ROSABELLA, b. m. by (Imp.) Shakspeare, dam by Timoleon.

ROSA VERTNER, b. m. by Sir Leslie, dam Directress by Director.

ROSCOE, b. h. by Pacific, dain by Grey Archy.

ROTHSCHILD, b. h. by (Imp.) Zinganee, dam by Tiger.

ROVER, b. h. by Woodpecker, dam Sally Miller by Cherokee.

ROW'I'ONELLA, ch. m. by (Imp.) Rowton, dam Sally Hopkins by Kosciusko.

RUBY, b. m. by (Imp.) Rowton, dam Bay Maria by Eclipse. ch. m. by Duke of Wellington, dam Lively by Eclipse

RUFFIN, b. h. by (Imp.) Hedgford, dam Duchess of Marlborough by Sir Archy.

S.

SAILOR BOY, b. h. by Jim Cropper, dam by Marshal.

DALADIN; h. h. by John Richards, dam by Henry.

SALKAHATCHIE, b. m. by Vertumnun, dam Sally Richardson by Kosciusko.

SAL S'TRICKLAND, ch. m. by (Imp.) Leviathan, dam bv Pacolet 
SALLY BARTON, ch. m. by Jackson, dam by Gallatin.

SALLY BROWN, b. m. by Jackson, dum by Gillatin.

SALLY CARR, b. m. by Stockholder, dam by

SALLY CRESSOP, ch. m. by Eclipse, dam by Arab.

SALLY DILLIARD (or HILLIARD), gr. m. by O'Kelly, dam by Shawnee.

SALI.Y HARDIN, b. m. by Bertrand, dam Peggy Stewart by Whip

SALLY HART, m. by (Imp.) Luzborough, dam Clear-the-Kitchen by Shakspeare.

\$ALLY McGHEE, ch. m. by Gascoigne, dam Thisbe.

SALLY MORGAN, b. m. by (Imp.) Emancipation, dam Lady Mor gan by John Richards.

SALLY SHANNON, b. m. by Woodpecker, dam (Darnley's dain,) by Sir Richard.

SALLY WARD, m. by John R. Grymes, dam by

SAMBO, ch. h. by Equinox, dam by Aratus.

SAM HOUSTON, b. h. by (Imp.) Autocrat, dam by (Imp.) Major.

SANDY YOUNG, b. h. by Medoc, dam Natchez Bell by Seagull.

SANTA ANNA, ch. h. by Bertrand Junior, dam Daisy by Kosciusko.

SANTEE, ch. h. by Wild Bill, dam Sally McGhee by Timoleon.

SARAH BLADEN, ch. m. by (Imp.) Leviathan, dam Morgiana by Pacolet.

SARAH BURTON, m. by Pacific, dam by Timoleon.

SARAH CHANCE, ch. m. by Lafayette, dain by Sir Archy.

SARAH JACKSON, JUNIOR, b. m. by Piamingo, dam by Arab.

SARAH MORTON, b. m. by Sidi Hamet, dam Rowena by Sumpter.

SARAH WASHINGTON, b. m. by Garrison's Zinganee, dam by Contention.

SARTIN, br. h. by (Imp.) Luzborough, dam Julia Fisher by Timo. leon.

SCARLET, ch. h. by Uncas, dam by Pacolet.

SENATOR, ch. h. by (Imp.) Priam, dam Ariadne by Gohanna.

SFRENADE, b. h. by Woodpecker, dam by Cook's Whip.

SEVEN-UP, b. m. by (Imp.) Chateau Margaux, dam by Arab.

SHAMROCK, (Imp.) ch. h. by St. Patrick, dam Delight by Ro veller.

SHARATOCK, ch. h. by Medoc, dam by Trumpator.

SHEPHERDESS, ch. m. by Lance, dam Amanda by Revenge.

SIGNAL, bl. h. by (Imp.) Margrave, dam by Mons. Tonson.

SIMON BENTON, ch. h. by Medoc, dam by Rattler.

SIMON GURTY, ch. h. by Mark Moore, dain by Tiger.

SIMON KENTON, ch. h. by Eclipse, dam by Rattler.

SIR ARISS, g. h. by Trumpator, dain Ophelia by Wild Medley.

SIR ELI.IOTT, b. h. by (Imp.) Leviathan, dam Lady Frolic by Six Charles.

SIR JOSEPH BANKS, b. h. by (Imp.) Luzborough, dam by Sir Archy.

SIR WILLIAM, b. h. by Sir William, dam by Rattler.

SISSY, b. m. by (Imp.) Leviathan, dam (Imp.) Gutty by Whalebone.

SISTER TO 'THORNHIJ,L, ch, m. by (Imp.) Glencoe, dam (Imp-;

Pickle by Emilius.

SLEFPER, gr. h. by (Imp.) Sarpedon, dam Flora by Grand Seignor. 
SLE HPER (TIIE), gr. h. by (Imp.) Surpedon, dam by C. . is Mes senger.

SLEEPY JOHN, b. h. by John Dawson, dam Sally Dilliasd by Vir. ginian, (or Phenomena).

SMOKE, ch. h. by (Imp.) Trustee, dam Bianca by Medley.

SNAG, ch. h. by Medoc, dam by Rattler.

SNCIVBIRD, gr.h. by (Imp.) Chateau Margaux, dam Forsaken Filly by Jerry.

SOPHIA LOVELL, b. m. by Sir Lovell, dam Eliza Jenkins by Sir William.

SORROW, (Imp.) ch. h. by Defence, dam Tears by Woful.

SPLINT, ch. $m$. by Hualpa, dam by Phenomenon.

STACKPOLE, ch. h. by (Imp.) Leviathan, dam by Stockholder.

STAGE-DRIVER, b. h. by Lance, dam by Bertrand.

STANHOPE, ch. h. by Eclipse, dam Helen Mar by Rattler.

S'l'ANLEY, clı. h. by (Imp.) Leviathan, dam Aronetta by Bertrand. ch. h. by Eclipse, dam by Busiris.

ECLIPSE, ch. h. by Busiris, dam by John Stanley.

STAR, h. h. by (Imp.) Skylark, dam Betsey Epps by Timoleon.

S'IAR OF THE WEST, b. m. by Bertrand, dam by Whip.

trand.

STEEL, b. h. by (Imp.) Fylde, dam Dimont by Constitution.

STHRESHLEY, ch. h. by Medoc, dam by Paragon.

STRANGER, b. h. by Lance, dam by Whip.

STOCKBOROUGH, ch. h. by (Imp.) Luzborough, dam by Stockholder.

ST. CHARLES, ch. h by (Imp.) Jordan, dam by Mercury.

ST. CLOUD, ch. h. by (Imp.) Belshazzar, dam by Old Partner.

ST. LOUIS, gr. h. by Altorf, dain Fleta by Jackson's (or Johnsun's) Medley.

ST. PIERRE, bl. h. by Pamunky, dam by Lafayette.

SUFFERER, b. lis by Eclipse, dam Meg Dods by Sir Archy.

SUFFOLK, b. h. by Andrew, dam Ostrich by Eclipse.

SUN BEAM, ch. m. by ( $1 \mathrm{mp}$.) Leviathan, dam Alice Grey by Mercury. ch. h. by (Imp.) Langford, dam Gipsey, (sister to Medoc).

SUS.AN HILL, ch. m. by (Imp.) Glencoe, dam Susan Hill by Timo. leon.

SUSAN TYLER, b. m. by (Imp.) Sarpedon.

SUSAN VANCE, ch. m. by Sialadin, dam by Sir William.

SIV ALLOW, b. m. by (Imp.) Leviathan, dam Object by Marshal Ney

SWEET HOME, ch. m. by Medoc, dam by Hamiltonian.

SWISS BOY, br. h. by (Imp.) Swiss, dam by Stuckholder.

SYLPHIDE, (Imp.) b. m. by Emilius, dam Polly Hopkins by Virgı. nian.

SYMLETRY, b. m. by (Imp.) Priam, dam Phenomena by Sir Archy

T.

TABITHA, ch. m. by Hualpa, dam by Phenumenon.

TAGLIONI, ch. m. by (Imp.) Priam, dam by Sir Charles.

TALLEY, ch. h. by Talleyrand, dam by Bertrand.

TALLULAH, ch. m. by Hyazim, dam by Gallatin.

TAMERLANE, ch. h. by Cowper, dam by Directur. 
TAMMANY, b. h. by (Imp.) Trustee, dam Camilla by Henry.

TARANTULA, ch.m. by (Imp.) Belshazzar, dam Mary Jane Davis by Stockholder.

TARLTON, b. h. by Woodpecker, dam by Robin Grey.

TARQUIN, b. h. by (Imp.) Consol, dam Jeannie Deans by Powhattar,

TATTERSALL, ch. l. by (Imp.) Emancipation, dam (Volney's dam, by Sir Archy.

TAYLOE, b. h. by (Imp.) Autocrat, dam Peggy White.

TAZEWELL, b. h. by (Imp.) Fylde, dam by Gallatin.

TEARAWAY, b.h. by (Imp.) Trustee, dam Jemima by Thornton's Rattler.

TELAMON, ch. h. by Medoc, dam Cherry Elliott by Sumpter.

TELIE DOE, b. m. by Pacific, dam Matilda by Greytail.

TELLULA, ch. m. by Eclipse, dam by Whip.

TE.MPEST, ch. h. by (Imp.) Trustee, dam Jeanette by Sir Archy.

TEMPLAR, b. h. by (Imp.) Sarpedon, dam by Timoleon.

TEN BROECK, ch. h. by Eclipse, dam by Bertrand.

TENNESSEE, b. m. by (Imp.) Felt, dain Berenice by Archy Junior.

TEXANA, b. m. by (Imp.) Hedgford, dam Goodlee Washington by Washington.

TEXAS, b. h. by (Imp.) Fylde, dam by Potomac.

THE COLONEL, ch. h. by (Imp.) Priam, dam (Imp.) My Lady by Comus.

THE COLONEL'S DAUGHTER, b. m. by The Colonel, dam (Imp.) Variella by Blacklock.

THE DUKE, ch. h. by Monmouth Eclipse, dam by (Imp.) Expedition.

THE MAJOR, b. h. by Othello, dam by Citizen.

THE IERCER COLT, br. h. by (Imp.) Mercer, dam Miss Mattio by Sir Archy.

THE PONEY, ch. h. by (Imp.) Leviathan, dam by Stockholder.

THE POSTMASTER, b. h. by ( $I m p$.) Consol, dam Country Maid by Pacific.

THE QUEEN, (Imp.) cl. m. by Priam, dam Delphine by Whisker.

THOMAS HOSLíINS, b. h. by (Imp.) Autocrat, dam Minerva by Tom Tough.

THOMAS R. ROOTS, b. h. by (Imp.) Tranby, dam Eliza Jenkins by Sir. William of 'Transport.

THORNHILL, ch. h. by (Imp.) Glencoe, dam (Imp.) Pickle by Emilius. TIBERIAS, b. h. by (Imp.) Priam, dam Fanny Wright by Silverheels. TIPPECANOE, ch. h. by Eclipse, dam by Rattler.

TISHANNA, b. m. by Benbow, dam Fidget by Eclipse.

TISHIMINGO, b. h. by (Imp.) Leviathan, dam Maria Shepherd bv Sir Archy.

TOBY, b. h. by Bertrand, dam by Eagle.

'TOM AND JERRY, ch. h. by Heart of Oak, dam by Lafayette,

TOM BENTON, b. h. by Wild Bill, dam by Pacolet.

TOM BUCK, ro. h. by (Imp.) Glencoe, dam Lady Sykes by Timoleon.

Tr,M CHILTON, ch. h. by (Imp.) Leviathan, dam by Childers.

TOM CORWIN, b. h. by (Imp.) Emancipation, dam by Lottery.

TOM CRINGLE, ch. h. by Carolinian.

TOM DAY, b. h. by Bertrand, dam Sally Melville by Virginan.

TOM MARSHAL, (Col. Bingamun's.) gr. h. by (lmp.) Leviathan, dam Fanny Jarman by Mercury. 


\section{WINNING HORSES SINCE 1839.}

T(TM MABSHAL, (Col. Buford's.) b. h. by Mecloc, dam by Simnpter. TOM PAINE, bl. h. by (Imp.) Margrare, dan (Emily Thomas's dam) by Tom 'Tough.

TOM THURMAN, ๖. h. by (Imp.) Fylde, dam by Citizen.

TOM WALKER, ch. h, by Marylander, dain by Rattler.

TOMMY WAKEFIELD, ch. b. by Drone, dam by Eclipse.

TORCH-LIGH'T, ch. m. by (Imp.) Glencoe, dam Wax-light by (Imp. Leviathan.

TORNADO, ch. h. by Eclipse, dam Polly Hopkins by Virginian.

TRANBYANNA, m. by (Imp.) Tranby dam Lady Tompkins by Eclipse.

TRANSI'T, b. h. by (Imp.) Hedgford, dam (Molly Ward's dam) by Bertrand.

TREASURE.R, b. h. by (Imp.) Roman, dam Dove by Duroc.

'TRENTON, o. h. by Eclipse Lightfoot, dam by Tuckahoe.

TROUBADOUR, bl. h. by (Imp.) Luzborough, dam by Stockholder.

TRUXTON, b. h. by (Imp.) Barefoot, dam Princess by Defiance.

TUSKENA, b. h. by Mons. Tonson, dam Creeping Kate.

TYLER, b. h. by (Imp.) Trustee, dam Kate Kearney by Sir Archy,

UNCAS, ch. h. by Diomed.

\section{U.}

- b. h. by (Imp.) Jordan, dam by Pacific.

UNITY, ch. f. by Genito, dam Lady Pest by Carolinian.

\section{V.}

VAGABOND, ch. h. by (Imp.) Ainderby, dam (Imp.) Vaga.

VAGRANT, ch. h. by (Imp.) Trustee, dam (Imp.) Vaga.

VANITY, b. m. by Traveller.

VAN TROMP, h. by Van Tromp, dam by Mucklejohn.

VASHTI, b. m. by (Imp.) Leviatlıan-Slazy by Bullock's Mucklejohn.

VELASCU, b. h. by Sliark, dam by Virginian.

VELOCITY, ch. m. by (Imp.) Leviathan, dam Patty Puff by Pacolet. VERTNER, ch. h. by Medoc, dam Lady Adams by Whipster.

VETU, ch. h. by Eclipse, dam by Diomed.

—_ h. by (Imp.) Luzborough, dam Lady Washington by Wash. ington.

VICTOR, br. h. by (Imp.) Cetus, dam (Imp.) My Lady by Comus.

VICTORIA, gr. m. by Sir Kirkland, dam by Tippoo Saib.

b. m. by (Imp.) Luzborough, dam by Timoleon.

- ROWTON, ch. m. by (Imp.) Rowton, dam by Phenu

menon.

VICTRESS, b. m. by Grey Eagle, dam by Royal Charley.

VIDOCQ, br. h. by Medoc, dam by Stockholder.

VICLA, ch. m. by (Imp.) Leviathan, dam Mary Longfit by Pacific. VIRGINIA, ch. m. by (Imp.) Leviathan, dam by Sir Rich'd Tonson. I IRGINIA ROBINSON, b. m. by (Imp.) Lnzborough, dam Becky by Marquis (or Marcus).

V()LTAIRE, ch. h. by (Imp.) Leviathan, dam by Bertrand.

W.

WACOUSTA, ch. h. by Jerseyman, dam Lady Vixen.

WADDY THOMPSON, ch. h. by (Imp.) Emannipation, dum by Tra falgar. 
WA FNER, ch. h. by Sir Charles, dam Maria West by Marion. WALK-IN-THE-WATER, b. h. by Collier, dam by Bertrand. WALTER L., b. h. by (Imp.) Fylde, dam by Sir Charles. WAITON WILL, b. h. by Brunswick, dam by Prince Edward. WARSAW, ch. h. by Eclipse, dam by Arab.

WARWICK, ch. h. by Stockholder, dam by (Imp.) Leviathan:

WASHENANGO, ch. h. by (Imp.) Sorrow, dam by (Imp.) Leviathan

W A TKINS, ro. h. by John Richards, dam by Whip.

WA XETTA, br. m. by Waxy, dam by Kennedy's Diomed.

WEBS'TER, b. h. by (Imp.) Priam, dam Fairy.

W'ELLINGTON, b. h. by (Imp.) Sarpedon, dam (Volney's dam) hy Sir Archy.

WESLEY MALONE, b. h. by ( $\operatorname{Imp}$.) Leviathan, dam by Sir Richard WEST FLORIDA, b. m. by Bertram, dam by Potomac.

WEST.WIND, br. h. by (Imp.) Chateau Margaux, dam Mambrina by Bertrand.

WHALEBONE, b. h. by (Imp.) Cetus, dam by Gohanna.

WHISKER, b. h. by (Imp.) Einancipation, dam by Walnut.

WILL-GO, b. or br. h. by (Imp.) Luzborough, dam by Eclipse.

WILLIAM R., b. h. by Goliah, dam by Sir Alfred.

WILD BURK, ch. h. by Medoc, dam by (Imp.) Bluster.

WILLIS, ch. h. by Sir Charles, dam by (Imp.) Merryfield.

WILLIS P. MANGUM, b. h. by Shark, dam Aggy Down.

WILTON BROWN, gr. h. by (Imp.) Priam, dam Ninon de l'Enclos by Rattler.

WINCHESTER, ch. h. by Clifton, dam by Contention.

WINFIELD (or WINFIELD SCOTT), ch. h. by Andrew, dam by Eclipse.

WONDER, b. h. by Tychicus, dam Nancy Marlborough by Rob Roy.

WOODCOC'K, b. h. by (Imp.) Emancipation, dam by Shylock.

WORKMAN, ch. h. by (Imp.) Luzborough, dam by Timoleon.

\section{$\mathbf{X}$}

YAZOO TRAPPER, ch. h. by Sir William.

YELLOW ROSE, ch. $m$. by Andrew, dam Tuberose by Arab.

YORKSHIRE, b. h. by St. Nicholas, dam Moss Rose by Tramp.

YOUNG DOVE, gr. m. by (Imp.) Trustee, dam Dove by Duroc.

YOUNG FRAXINELLA, gr. m. by (Imp.) Autocrat, dam by Virginian.

YOUNG MEDOC, ch. h. by Medoc.

\section{Z.}

ZAMPA, ch. h. by (Imp.) Priam, dam Celeste by Henry.

ZEBA, ro. m. by Eclipse, dam Miss Walton by Mendoza.

ZEMMA (or ZAMOUR), ch. h. by Ulysses, dam by Stockholder

ZENITH, b. h. by Ecliuse, dam Belle Anderson by Sir William of Transpor:

7.ENOBIA, c.. m. by (Imp.) Roman, dam Dove by Duroc.

ZOF, ch. m. by (Imp.) Kowton, dain (Little Venus's dam,) by Sis William.

LORAIDA, b m. by Virginius, dam by Comet. 


\section{CELEBRATED STALLIONS AND BROOD MARES.}

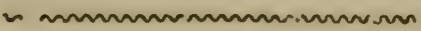

A.

ABDALI.AH, b. h. hy Mambrino, dam Amazonia.

ABJER, [Imp.] got by Olil Trufle, lam Briscis by Beningbrough, gr. dam Lar?y Jane hy sir l'erer Teazle - Paulina by Florizeh \&c.-foaled 1817, dicd 1S:S.-Alabama. James Jackson.

ADMIRAL, [Imp.] b. l. got l,y i'lorizel, dam the Spectator mare, (who was also bic ciun of Old imp. Diomed)-foaled 1779.New York.

J. Delancy.

AFRICAN, bl. h. by [Imp.] Valentine, dam by Marshal Bertrand.

ALLEN BROWN, ch. h. by Stockholder, dam by [Imp.] Eagle.

ALL FOURS, [Inp.] got by All Fours, son of Regulus-BlankBolton Starling-Miss Meynell by Partror-Greyhound-Cur. win's Bay Barb, \&c. imp. into Massachusetts or Connecticut.

ALONZO, ch. h. by Eclipse, dam by Sir Archy.

AINDERBY, [Imp.] ch. h. by Velocipede, dam Kate by Catton.

ALTORF, b. h. by [Imp.] Fylde, clam Countess Plater by Virginian.

AMBASSADOR, [Imp.] b. h. by Emilius, dam [Imp.] Trapes by Tramp.

AMERICUS, [Imp.] b. h. got by Babraham-Creeping Molly by Se cond-General Evans' Arabian Cartouch-foaled 1775.

William Macklin.

ANDREW, ch. h. by Sir Charles, dam by Herod.

ANDREW JACKSON, b. h. by Timoleon, dam by [Imp.] Whip.

ANN PAGE, m. by Maryland Eclipse, dam by Tuckahoe.

ARAMINTA, b. m. by May-Day, dam Tripit by Mars.

ARGYLE, br. h. by Mons. Tonson, dam Thistle by Ogle's Oscar.

AUTOCRAT, [Imp.] gr. c. got by Grand Duke, dam Olivetta by Sir

Oliver-Scotiua by Delphi-Scota by Eclipse-foaled 1822. New York.

William Jackson.

\section{B.}

BABRAHAM, [Imp.] b. h. got by Ola Fearnought (son of Godolphin Ar.) - Silver - imported into Virginia by William Evans of Surrey county, and got by the Belsize Arabian in England, and foaled 1759.-Va. 1765. William and George Evans.

[Imp.] b. h. got by Wildair-Babraham-Sloe-Bart lett's Childers - Counsellor - Suake, \&c. - foaled 1775. - Va 1783. 
BAI.IE PEYTON, b. b. by Andrew, dam Pocaliontas by Felipse BAY MIDDT.FTON, b. h. by [Imp.] Fylle, dam by Potomac. BELLE ANDERSON, in. by William of Transport, dam Butterfly BELSHAZZAR, [Imp.] ch. by Blacklock, dain Manuella by Dicd Andrews.

BERNER'S COMUS, [Imp.] b. h. by Comus, dam Rotterdanı by Juniper.

BERTRAND Junior, ch. h. by Bertrand, dam Transport by Virgi. nius.

BETSEY MAJ,ONE, m. by Stockholder, dam by Potomac.

BIANCA, m. by Medley, dam Puwancey by Sir Alfred.

BIG JOHN, ch. h. by Bertrand, dam by Hamiltonian.

BILL AUSTIN, b. h. by Bertrand, dam by Timoleon.

BIRMINGHAM, br. h. by Stockiolder, dam Black Sophia by Top gallant.

BLACK ARABIAN, [Imp.]-Presented by the Emperor of Morocco to the United States' Government.

BLACK PRINCE, b. h. by [Imp.] Fylde, dam Fantail by Sir Archy. [Imp.] bl. h. got by Babraham - Riot by Regulus -Blaze-Fox, \&c.-foaled 1760.-New York. A. Ramsay.

BLOODY NATHAN, ch. h. by [Imp.] Valentine, dam Daphne by Duroc.

BOHEMOTH, Junior, b. h. by Old Bohemoth.

BONNYFACE, [Imp.] (also called Master Stephen) dk. b. h. got by a son of Regulus out of the Fen mare, got by Hutton's Royal colt-Blunderbuss, \&c.-foaled 1768.-Va.

French.

BOSTON, ch. 1. by 'Timoleon, dam (Robin Brown's dam) by Ball's Florizel.

BRITANNIA, [Imp.] m. by Milley, dam Nancy by Dick Andrews.

BUFF COA T, [Imp.] dun h. got by Godolphin Arabian - Silver Locks by the Bald Galloway-Ancaster Turli-Leeds A rabian, \&c.-foaled 1742.-Va. 1761.

Joseph Wells.

BULLE ROCK, [Imp.] got by the Darley Arabian - Byerly Turk, out of a natural Arabian mare, \&c.-foaled 1718._-Virginia, 1735-6.

Samuel Patton.

BUSIRIS, ch. h. by Eclipse, dam Grand Duchess by [Imp.] Grac. chus.

BUSSORAH ARABIAN - Imported by Abraham Oyden, Esq., of New York.

BUTTERFLY, m. by Surpter, dain by [Imp.] Buzzard.

¿.

CALMUS, ch. h. by Eclipse, dam Di Vernon by Ball's Florizel

C.AMDFN, b. h. by [Imp.] Sarpedon, dam by Old Cherokee.

EAMILLA, m. by [Imp.] Philip, dam Roxana by Timoleon.

CANNON, [Imp.] br. h. got by Dungannon-Miss Spindleshanks by Omar-Staring, \&c.-foaled 1789.-Boston. Gen. Lyman.

CAROLET, ch. m. by [Inıp.] Leviathan, dam Peg Caruthers by Arab.

¿aROLINE, m. by Eclipse, dam Miss Mattie. 
CARVFR, [Imp.] b. h. got by Young Snap - Blank - BabrahamAlrcaster Starling - Grasshopper, \&c. - foaled 1770.- Norfolk county, Va.

Dr. Charles Mayle.

CETA, m. by [Imp.] Cetus, dam Harriet Heth by Mons. Tonson.

CETUS, [Inip.] b. h. by Whalebone, dam Lamea by Gohanna.

CHARLEY NAILOR, b. h. by Medoc, dam by Tiger.

CHARLOTTE PAGE, m. by Sir Archy, dam by [Imp.] Restless.

CHATEAU MARGAUX, [Imp.] dk. br. h. got by Whalebone, (best son of Waxy,) dam Wasp by Gohanna - Highflyer - Eclipse, \&c.-foaled 1822.-Va. 1835.

J. J. A very \& Co.

CHFROKEE, h. by Sir Archy, dam Roxana by Hephestion.

CHESTERFIELT, b. h. by Pacific, dam by Wilkes' Madison.

CHIFNEY, ch. h. by Sir Charles, dam by Sir Archy.

CHILTON, b. h. by Seagull, dam by Hazard.

CINDERELLA, b. m. by Saladin, dam by Aratus.

CIPPUS, bl. h. by Industry, dam by Randolph's Mark Antony.

CIVIL JOHN, gr. h. by T'ariff, dam by Pakenham.

CLARET, [ Imp.] got by Chateau Margaux, dam by Partisan-Silver Tail by Gohanna-Orville, \&c.-foaled 1830.-N. Carolina.

Wyatt Cardwell.

CLARINET, ch. m. by Kentucky Sir Charles, dam Mary Grindle by Eclipse.

CLARION, ch. h. by Monmouth Eclipse, dam by Ogle's Oscar.

COCK OF THE ROCK, b. h. by Duroc, dam by Romp.

COLORADO, h. by Eclipse, dam by Sir Archy.

COMMENCEMENT, $m$. by Arab, dam by Francisco.

COMMODORE, b. h. by Mambrino, dam by True American.

CORONET, [Imp.] b. h. by Catton, dam by Paynator.

CORTES, h. by Old Rattler, dam by Jack Andrews.

COUNT BADGER, ch. h. by Eclipse, dam Arabella by Hickory.

COUNT ZALDIVAR, ch. h. by Andrew, dam by Timoleon.

COUNTESS BERTRAND, $m$. by Bertrand, dam Nancy Dawson by

Platt's Alexander.

CRIPPLE, b. h. by Medoc, dam Grecian Princess by Whip.

CRITIC, ch. h. by Eclipse, dam by Eclipse Herod.

CUSSETA CHIEF, ch. h. by Andrew, dam Virago by Wildair of Wonder.

CYMON, ch. h. by Marion, dam Fair Forester by [Imp.] Chance.

\section{D.}

DAGHEE, [Imp.] b. h. by Muley, dam by Arabian Sheik.

DAMASCUS, h. by [Imp.] Zilcadi, dam Dido by [Imp.] Expedition,

DANCING MASTER, [Imp.] b. h. got by Woodpecker-Madcap by Snap-Miss Meredith by Cade, \&c.-foaled 1788.-S. Carolına.

DANIEL O'CONNELL, gr. h. by Sir Henry Tonson, dam by [Imp.] Sir Harry.

DAVY CROCKETT, h. by Constitution, dam by Suttor's Whip

DEBASH, [Imp.] b. h. got by King Fergus-Hightlyer-Madcap by Snap-Miss Meredith by Cade, \&c.-foaled 17')2. Im [.orted into Massachusetts. Junes. 
DECATUR, ch h. by Henry, dam Ostrich by Eclipse.

DERBY, [Imp.] dr. b. h. got by Peter Lely out of Urganda. former? Lady Eleauor, she by Milo, dam by Sorcerer sut of Twins, \&c -foaled 1831.

R. D. Shepherd.

DIANA, m. by Mons. Tonson, dam by Conqueror.

DIANA, [Imp.] m. by Catton, dam Trulla by Sorcerer.

DIANA, m. by Mercury, dam Rarity.

DUNCASIER, [Imp.] b. h. by Longwaist, dam by Muley, grandam Lady Ern by Stamford.

DON QUIXOTE, [Imp.] ch. h. by O'Kelly's Eclipse-Grecian Princess by Forester - Coalition colt - Bustard, \&c.- foaled 1784. Imported into $\mathrm{Va}$.

DORMOUSE, [Imp.] dk. b. h. got by Old Dormouse, dam by Whitefoot - Silverlocks by Bald Galloway, \&c. - foaled 1753.-Va. 1759.

DOSORIS, ch. h. by Henry, dam (Goliah's dam) by Mendoza.

DRONE, [Imp.] b. h. got by King Herod-Lily by Blank-Peggy by Cade-Croft's Partner-Bloody Buttocks, \&c.-foaled 1777.Duchess county, New York.

ch. h. by Mons. Tonson, dam Isabella by Sir Archy.

DUANE, lr. h. by [Imp.] Hedgford, dam Goodloe Washington by Waslington.

DUCHESS, b. m. by [Imp.] Coronet, dam by Tariff.

DUCHESS OF YORK, [Imp.] ch. m. got by Catton, dam by Sancuo -Coriander-Highflyer, \&c.-foaled 1821.-Va.

R. D. Shepherd.

DUKE SUMNER, gr. h. by Pacific, dam by Grey Archy.

DUNGANNON, ch. h. by Sumpter, dam by Duke of Bedford.

E.

ECLIPSE, (American,) ch. h. by Duroc, dam Miller's Damsel by [Imp.] Messenger.

ECLIPSE THE SECOND, b. h. by Eclipse, dam Lady Nimble by Sir William.

ELIZA A RMSTRONG, m. by Flying Childers, dam Gipsey by Florizel.

ELIZA MILLER, m. by Miller's Bertrand, dam Lucy Forester by Marshal Ney.

ELLEN GRANVILLE, b. m. by [Imp.] Tranby, dam by Contention.

EMANCIPATION, [Imp.] br. l. by Whisker, dam by Arirossan.

ENGLISHMAN, (Imp. by Mr. Walter Bell of Va., in his datn,) by

Eagle (also imported)-PotSos-Pegasus_Small Bories by Jus. tice, \&c.-foaled 1812.

ENTERPRISE, h. by John Richards, dain by Don Quixote.

EUGENIUS, [Imp.] ch. h. by Chrysolite, dam Mixbury by Regulus

-Little Bowes by a brother to Mixbury-Hutton's Barb, \&c.foaled 1770 .

S.XILE. h. lyy [Imp.] Leviathan, dam [Imp.] Refugee by Wanderer 
F.

PAIRF P.X ROANE, [Imp.] (alias Strawberry Roan) ro. h. got by Adolphus, dam by Sinith's 'Tartar (a son of Croft's Partner) g. dam by Midge (son of Snalie) - Hip, \&c. - foaled 1764-Va. -Fairfax.

FANNY WRIGHT, in. by Silverheels, dam Aurora by Governo Wright's Vingtun.

FFLT, [Imp.] b. h. by Langar, dam Steam by Waxy Pope.

FESTIVAL, ch. h. by Eclipse, dam by Timoleon.

FIFER, b. h. by Monmouth Eclipse, dam Music by John Richards.

FLATTERER, [Imp.] b. h. by Muley, dam Clari by Marmion.

FLORANTHE, m. by John Richards, dam Fanny Wright.

FOP, [Imp.] gr. h. by Stumps, dam by Fitz James.

FRANCIS MARION, ch. h. by Marion, dam Malvina by $S_{\perp}$ Archy FRANK, ch. h. by Sir Charles, dam Betsey Archy by Sir Archy.

G.

GANDER, gr. h. by Wild Bill, dam Grey Goose by Pacolet. GANO, b. h. by Eclipse, dam Betsey Richards by Sir Archy.

GENERAL MABRY, h. by [Imp.] Leviathan, dam Galen by Pacific. GEROW, ch. h. by Henry: dam Vixen by Eclipse.

GIFT, [Imp.] b. h. got by Cadormus, dam by Old Crab - Second Starling, \&c.-foaled 1768.-New Kent county, Va.

Colonel Dangerfield.

GILES SCROGGINS, b. h. by Sir Archy, dam Lady Bedford by [Imp.] Bedford.

GLENCOE, [Imp.] ch. h. by Sultan, dam Trampoline by Tramp.

GLOSTER, b. h. by Sir Clıarles, dam by Alfred.

GOHANNA, h. by Sir Archy, dam Merino Ewe by [Imp.] Bedford. GOLD BOY, b. h. by Industry, dam (Buck Eye's dam) by Medoc.

GOLDWIRE, [Imp.] br. m. by Whalebone, dam Young Amazon by Gohanna.

GOVERNOR HAMILTON, gr. h. by Sir Andrew, dam by Bonaparte.

GRANBY, [Imp.] b. h. got by Blank-Old Crab-Cyprus Ar.-Conmoner-Makeless - Brimmer, \&c.-foaled 1759. - Powhatan county, Va.

Samuel Watkins.

GRECIAN PRINCESS, m. l,y Virginian, dam Calypso by Bell-Ai» -Dare Devil-Old Wildas - Piccadilla by Fearnought - Godolphin-Hob or Nob, \&c.

GREY EAGLE, gr. h. by Woodpecker, danı Ophelia by Wild Med ley.

GREY MEDOC, gr. h. by Medoc, dam Grey Fauny by Bertrand. GROUSE, br. h. by Eclipse, dam by Erie.

GUM ELASTIC, b. h. by Waxy, dam by Read's Spread Eagle

H.

HALO, h. by Sir Archy Montorio, lam Semiramis.

HARD LUCK, gr. L. by Randolph's Ruanoke, dann Lady Washin ton. 
HAYWOOD, h. by [Imp.] Leviathan, dam Black Sophia by Topga! lant.

HECTOR, [Inp.] bl. h. got by Lath - Childers-Basto - Curwin's Bay Barb, \&c.-foaled 1745. Colonel Marshall.

HEDGFORD, [Imp.] br. h. by Filho da Puta, dam Miss Craigie by Orville.

gle.

(Young) h. by [Imp.] Hedgford, dam by [Inp.] Ea

HERCULES - a grey draft horse, imported into Louisville, Ky.

HERO, [Imp.] b. h. got by Blank-Godolphin Ar. \&c.-foaled 1747. - Va.

John S. Wilson.

HIAZIM, ch. h. by Sir Archy, dam Janey by [Imp.] Archduke. HIBISCUS, [Imp.] b. h. by Sultan, dain Duchess of York by Waxy.

HICKORY JOHN, ch. h. by John Richards, dam Kitty Hickory by Hickory.

HIGHLAND HENRY, ch. h. by Henry, dam Highland Mary by Eclipse.

HORNBLOWER, br. h. by Monmouth Eclipse, dam Music by John Richards.

HUGH LUPUS, [Imp.] b. h. by [Imp.] Priam, dam Her Highnese by Moses.

\section{I.}

IBARRA, b. h. by [Imp.] Hedgford, dam by Virginian.

[BRAHIM PACHA, [Imp.]-a pure Bedouin Arabian-imported by Captain James Riley.

J.

JACK OF DIAMONDS, [Imp.] dk. b. h. by Cullen's Arabian-Darley Ar. - Byerly Turk, \&c. - Va. 1763. Imported by Colonel Syottswood.

JACK PENDLETON, ch. h. by Goliah, dam by Trafalgar.

JANF. GRAY, m. by Orphan Boy, dam Rosalind by Ogle's Oscar.

JEROME, br. h. by [Imp.] Luzborough, dam by Sir Charles.

JESSICA, [Imp.] ch. m. by Velocipede, dam by Sancho.

JIM JACKSON, ch. h. by [Imp.] Leviatlan, dam by Conqueror.

JOB, b. h. by Eclipse, dam Jemima by Thornton's Rattler.

JOHN BASCOMBE, ch. h. by Bertrand, dam Grey Goose by Pacolet

JOHN BULL, [Imp.] b. h. by Chateau Margaux, dam by Woful.

JOHN DAWSON, b. h. by Pacific, dam by Grey Archy.

JOHN GASCOIGNE, h. by Randolph's Gascoigne, dam by Virgi nian.

JOHN RICHARDS, b. h. by Sir Archy, dam by Rattler, gr. dam by [Imp.] Medley.

JORDAN, [Imp.] ch. h. by Langar, dam Matilda by Comus.

'UNIUS, [Imp.] bl. h. got by Old Starling - Old Crab - MonkeyCurwin's Bay Barb-Spot, \&c.-foaled 1754.-Va. 1759.

IIJSTICE, [Imp.] b. h. got by Blank, dam Aura by Stamford Turk, g1. dain by a b'other to Conqueror-Cliilders, \&c.-Va. 1780. 
;USTICE, [ [mp.] got by Olil Jilitice (son of King Heroul) - Old Squirt mare - Mogul - Canilla by Bay Bciton, \&c. - foaled 1782.-S. Carolina.

Major Butler.

\section{K}

KANGAROO, ch, h. by Uncas, dam by (Irphan.

KATE NICKLEBY, $m$. by [Imp.] Trustee, dam Lady Mostyn by Teniers.

KING WILLIAM, [ Imp.] red sor. h. got by Florizel, dam Milliner by Matchem -Cassandria by Blank, \&c.-foaled 1781.-Chester county, $\mathrm{Pa}$.

Dr. Norriss. [Imp.] b. h. by King Herod, dam Madcap by Snap - Miss Meredith by Old Cade, \&c.-foaled 1777. - Connecticut.

Skinner.

KITTY BRIM, b. m. by Old Conqueror, dam by Gallatin; gr. dam by Hightlyer.

L.

LADY CLIFDEN, m. by Sussex, dam Betsey Wilson.

LADY CULPEPER, m. by Carolinian, dam Flora by Ball's Florizel.

LADY MORGAN, m. by John Richards, dam Matchless by [Imp.] Expedition.

LADY MOSTY N, [Imp.] m. by Teniers, dam Invalid by Whisker. LADY NIMBLE, m. by Eclipse, dam 'Transport by Kosciusko.

LADY SCOTT, [Imp.] br. m. got by Ardrosson, dam Dido by Viscount-Brilliant by Whiskey, \&c.

R. D. Shepherd.

LADY WHIP, m. by Whip, dam by Alonzo, gr. dam by [Imp.] Buzzard.

LAFAYETTE, b. h. by Conqueror, dam Julia by Sir Arthur.

LANGFORD, [Imp.] br. h. got by Starch, out of Peri by Wanderer, her dam Thalistris by Alexander, out of Rival by Sir PeterHorne by Drone-Manilla by Goldfinder-foaled 1833.

F. P. Corbin.

LAPLANDER, ch. or br. h. by Flagellator, dam Medora.

LEOPARDESS, m. by Medoc, dam by Haxall's Moses.

LEVIATHAN, [Imp.] ch. h. by Muley, dam hy Windle.

Diomed.

LILY, $m$. by Eclipse, dam Garland by Duroc.

LIMBER JOHN, ch. h. by Kosciusko, dam by Moses.

IJOF'TY, [Imp.] b. h. by Godolphin Arabian-Croft's Partner-Bloody Buttocks-Greyhound, \&c.-foaled 1753.-Virginia, Chesterfield county. 'Thomas Goode.

LOUISA, ch. m. by [Imp.] Bluster, dam by Hamiltonian.

LIJRCHER, [Imp.] gr. h by Grey Leg, dam Harpalyce by (rohanna LUZBOROUGH, [Imp.] br. h. by Williamson's Ditto, dam by Dick Andrews. ter. Junior, b. h. by [Imp.] Luzborough, dam by Sump

LYCURGUS, [Imp.] ch. h. by Blank-Suip-lath, \&ce.-foaled $176^{*}$ -Va. 1776

Gco. H. Harrison 
LYNEDOCH, ch. h. by [Imp: Leviathan, dam Kosetta by Wilkea Wonder.

II.

MAGNUM BONUM, [Imp.] ro. h. by Matchem-Swift-RegulusDairy Maid by Bloody Buttocks, \&c. - foaled 1774. - Hartiord, Conn.

F. Kilborne.

MANALOPAN, gr. h. by Medley, dam by John Richards.

MARIA DAVIESS, ch. m. by Sir Charles, dam Mary Grindle Iy Eclipse.

M ARIA VAUGHAN, m. by Pacific, dam Mary Vaughan by Pacolet.

MARION, b. h. by Sir A rchy, dam by [ $1 m p$. $]$ Citizen.

MARGRAVE, [ $I m p$.$] ch. h. by Muley, dam by Election.$

MARK MOORE, ch. h. by Eclipse, dam Lalla Rookh by Gabriel Oscar.

MARMION, br. h. by [ $\operatorname{Imp} p$.$] Merman, dam by Crusader.$

MARPLOT, [Imp.] by Highflyer-Omar-Godolphin Arabian, \&cc.

MAR'THA BICKERTON, b. m. by Pamunky, dam by Tariff.

MARSHAL NEY, h. by Pacolet, dam Virginia by Dare Devil.

MARY BIDDLE, $\mathrm{m}$. by [ Imp.] Priam, dam Flora by Mons. Tonson.

MARY VAUGHAN, gr. m. by Old Pacolet, dam by Old Chanticleer.

MAS'TER ROBERT, [ Imp.] ch. h. by Star, dam a young Marske mare-foaled 1793 .

MASTER SOLOMON, b. h. by Reveller, dam by Lord Berners.

MATCHEM, [Imp.] b. h. by Matchem-Lady by Sweepstakes-Pa. triot_Old Crab, \&c.-foaled 1773.-S. Carolina. Gibbs.

MATCHLESS, [Imp.] b. h. by Godolphin Arabian - Soreheel Makeless, \&c.-S. Carolina.

MATILDA, gr. m. by Greytail Florizel, dam by [ $\operatorname{lmp}$.] Jonah.

MAXIMUS, b. h. by Bertrand, dam Miss Dance by [Imp.] Eagle.

MAYZOUBE - a gr. horse imported from Arabia by Captain James Riley.

MELZARE, br. h, by Bertrand, dam by Sir Richard.

MENDOZA, [Imp.] b. h. by Javelin - Paymaster — Pamona by King Herod.

MERMAN, [Imp.] hr. h. by Whalebone, dam by Orville.

MERRY PINTLE, [ $\operatorname{Imp}$.$] gr. h. by Old England, dam by Old Merry$ Pintle-Skipjack, \&c.-foaled J752.-Va. $1775 . \quad$ J. Strong.

MERRY TOM, [ Imp.] b. h. by Regulus - Locust - a son of Flying Childers_Croft's Old Partner, \&c.-foaled 1758.

MFRCER, [ $\operatorname{Imp}$.$] b. h. by Emilus, dam Young Mouse by Godolphin.$

MERWICK BALL, [Imp.] ch, h. by Regulus-dam a Traveller mare - Hartley's blind horse-foaled 1762 .

MINOR, b. h. by Mons. Tonson, dam by 'Topgallant.

MISS ANDREWS, [Imp.] b. rn. hy Catton, dam by Dick Andrews.

MISS MA'TTIE, m. by Sir Archy, dam Black Ghost by Pantaloon.

MISS ROSE, [Imp.] h. m. hy 'Tramp, dam by sancho, gr. dam by Coriander, \&c.-foaled 1826 .

MISS VAIENTINE, m. by [ $I m p$.] Valerstine, dam by John Richards. MU'NAR(:H, [Impi, b. h. hy Priam, dum Delphine hy Whisker.

M (IN MOUTH, b. h. by John Richards, dam by Duroc. 
MONMOUTH ECLIPSE, ch. h. by Eclipse, dam Honesty by [Imp.] Expedition.

MONS. TONSON, gr. h. by Pacolet, dam Madame Touson by Topgallant.

MORDECAI, [Imp.] b. h. by Lottery, dam by Welbeck.

MORVEN, [Imp.] ch. h. by Rowton, dam Nanine by Selim.

MOSES MARE (Chas. Buford's) by Haxall's Moses, dam by Cook's or Blackburn's Whip.

N.

NANCY THATCHER, $m$. by Medoc, dam by Archy of Transport.

NELL GWYNNE, [Imp.] m. hy Tramp, dam by Beningbrough.

NE'TTY, $[$ Imp. $]$ ch. $m$. by Velocipede, dam Miss Rose.

NICHOLAS, [Imp.] h. by St. Nicholas, dam Miss Rose.

NIMROD, [Imp.] b. h. by King Fergus - O'Kelly's Eclipse - Old Marske, \&c.-Philadelphia, 1788.

NON PLUS, [Imp.] b. h. by Catton, dam Miss Garforth by WaltonHyacinthus, \&c.--foaled 1824.-S. Carolina. R'd. Singleton.

NORTH BRITAIN, [Imp.] b. h. by Alcock's Arabian-Northumber. land Arabian-Hartley's blind horse._-Philad. 1768. Crow.

NOVELTY, $[I m p.] \mathrm{m}$. by Blacklock, dam Washerwoman by Walton.

o.

O'KELLY, ch. h. by Eclipse, dam by Oscar.

OLIVER, h. by May-Day, dam Young Betsey Richards by John Richards.

ONUS, [1mp.] br. h. by Camel, dam The Eiching by Rubens.

ORLEANA, [Imp.] m. by Bustard, dam Laureola by Orville.

OROUNOKO, [Imp.] bl. h. by Old Crab, dam Miss Slammerkin by

Young True Blue-Bloody Shouldered Arabian, \&c.-_foaled 1745

-S. Carolina.

J. Mathews.

OTHELLO, br. h. by [Imp.] Leviathan, dam by Sir Archy.

$\mathbf{P}$.

PACIFIC, b. h. by Sir Archy, dam Eliza by [Imp.] Bedford.

PACOLET, [Imp.] h. hy Sparke, dam Queen Mab-Hampton Court Childers-Harrison's Arabian, \&c.-Va. 1791. Thos. Goode.

PACTOLUS, ch. h. by Pacific, dam Mary Vaughan by Pacolet.

PAMUNKY, b. h. by Eclipse, dam Bellnna by Sir Harry.

PAUL CLIFFORD, h. by Eclipse, dam Betsey Richards by John Ri chards.

PETE WHETSTONE, b. h. by [Imp.] Leviathan, dam by Stock holder.

PIIARAOH, [Imp.] b. h. by Moses, dam by Godolphin Arabian Smockface by Old Snail, \&c. - foaled 1753.-S. Carolina.

PHILIP, [ $\operatorname{lmp}$.] hr. h. by Filho da Puta, dam Treasure by Camillus Trafalgar.

PICTON, br. h. by [Imp.] Luzborough, dam Isabella by Sir Archy.

PLATOFF, b. h. by Kosciusko, dam hy Hephestion. 
PONEY, (The) ch. h. by [ $1 \mathrm{mp}$.] Leviathan, dam by Stockholder.

PORTLAND, [Imp.] ch. h. by Recovery, dam by Walton.

PORT'SMOUTH, br. h. by [ Imp. Luzborough, dam Polly Peache by John Richards.

POST BOY, ch. h. by Fenry, dam Garland by Duroc.

POWHAT'AN, b. h. by Arab, dam by Whip.

PRESTO, b. h. by [Imp.] Leviathan, dam by Stockholder.

PRIAM, [Imp.] b. h. by Emilius, dam Cressida by Whisker.

- Junior, h. by [Imp.] Leviathan, dam by Sir Archy.

PRINCE, [Imp.] b. h. by Herod, dam Helen by Blank-Crab, \&c.foaled 1773.-S. Carolina.

PRINCE FERDINAND, [Imp.] by Herod, dam by Matchem - gr dam the Squirt mare, \&c.

PRUNELLA, [Imp.] m. by Comus, dam by Partisan.

PUZZLE, [Imp.] b. h. by Reveller, dam by Juniper.

\section{Q.}

QUEEN OF THE WEST, br, m. by Shark, out of Lady Mostyn by Teniers, gr. dam Invalid by Whisker.

R.

RATTLER, ch. h. by Sir Archy, dam by [Imp.] Robin Red Breast.

RED BILL, b. h. by Medoc, dam Brown Mary by Sumpter.

RED BUCK, b. h. by [Imp.] Leviathan, dam Sally Bell by Contration.

RED TOM, ch. h. by Bertrand, dam Duchess of Marlborough by Sir Archy.

REINDEER, ch. h. by Henry, dam Sportsmistress by. Hickory. ch. h. by Sussex, dam by Oscar.

REPITBLICAN, [Imp.] ch. h. by Wentworth's Ancaster - Old Royal Changeling-Bethel's Arabian, \&c.-Va. 1797.

Charles Young.

RICHARD SINGLETON, b. h. by Bertrand, dam Black-Eyed Susan by Tiger.

RIDDLESW ORTH, [Imp.] ch. h. by Emilius, dam Filagree by Sooth. sayer.

ROANOKE, b. h. by Sir Archy, dam by Cœur de Lion.

ROBIN BROWN, ch. h. by Mons. Tonson, dam (Boston's dam) by Ball's Flurizel.

RODOLPH, b. h. by Archy of Transport, dam by Haxall's Moses.

RODERICK DHU, [ $[\mathrm{m} p$.] by Sir Peter Teazle, dam by Young Marske - Matchem-Targuin, \&c. Imported into New York.

ROSALBA, m. by Old Trafalgar, dam Rosalba by Spread Eagle.

ROSIN THE BOW, b. h. by Bertrand, dam Lady Grey by Robin Grey

RUBY, [Imp.] b. h. by Emilius, dam Eliza by Rubens.

RUSHLIGHT, ch. m. by Sir Archy, dam Pigeon by Pacolet.

S.

SALLY BARBOUR, $m$. hy [ $7 m p$.] Truffe, dam by Ball's Florizel.

BALLY HYDE, m. by Sumner's Grey Archy, dam by Mealley. 
SAM HOUSTON, ch. h. by Barney O'Lynn, dam Judy Bakewell by Eagle.

SAN'TEE, b. h. by Roh Roy, dam Betty by [Imp.] Buzzard.

SARACEN, b. h. by Eclipse, dam sally Slouch by Virginian.

SARPEDON, [Imp.] br. h. by Emilius, dam Icaria by The Flyer-

Parma by Dick Andrews, \&c.

SCIPIO, b. h. by [Imp.] Leviathan, dam Kitty Clover by Sir Charles.

SCOUT, [Imp.] br. h. by St. Nicholas, dam by Blacklock.

SEAGULL, b. h. by Sir Archy, dam Nancy Air by [Imp.] Bedford.

SHADOW, bl. h. by Eclipse Lightfoot, dam Sally Slouch by Virginian.

SHADOW, [Imp.] b. h. got by Babraham-Bolton Starling-Cough ing Polly by Bartlett's Childers, \&c.-foaled 1759.-Va. $17 \% 1$.

T. Burwell.

SHAKSPEARE, [Imp.] br. h. by Smolensko, dam Charming Molly by Rubens.

SHARK, bl. h. by Eclipse, dam Lady Lightfoot by Sir Archy.

SHAMROCK, [Imıp.] ch. h. St. Patrick, dam Delight by Reveller.

SHEPHERDESS, [Imp.] b. m. by Young Blacklock, dam Spermaceti by Sligo Waxy.

SHERIFF PACHA, b. h. Nedji bred_imported by Com. Elliott.

SHOCK, [Imp.] got by Shock-Partner-Makeless-Brimmer, \&c.Va. Caroline county.

SIDI HAME'T, b. h. by Eclipse, dam Princess by Defiance.

SIDNEY, b. h. by Sir Char!es, dam Virginia by 'Thornton's Rattler.

SIR CHARLES, ch. h. by Saladin, dam by Cultivator.

SIR JOSEPH, br. h. by (Imp.) Luzborough, dam Sally Maclin by Sir Archy.

SIR LESLIE, b. h. by Sir William, dam by (Imp.) Buzzard.

SIR MEDLEY, ch. h. by Medley, dam by Sir Charles.

SIR PETER TEAZLE, (Imp.) ro.h. got by Sir Peter Teazle-Mercury-Cythera by King Herod-Blank, \&c.-foaled 1802.-\$. Carolina.

Gen. Jno. McPherson.

SIR ROBERT, (Imp.) b. h. by Bobadil, dam Fidalma by Waxy Pope.

SIR WILLIAM, h. by Sir William, dam by Tiger.

SKYLARK, (Imp.) br. h. by Waxy Pope, dam Skylark by Musician. SLOUCH, (Imp.) ch. h. by Cade, dam the little Hartley mare by Bartlett's Childers - Flying Whig by Woodstock, \&c.-foaled 1747. - S. Carolina.

SOURKROUT, (Imp.) b. c. by Highflyer, dam Juwel by Squirrel, Sophia by Blank, \&c.-foaled 1786.

SOVEREIGN, (Imp.) b. h. by Emilius, dam Fleur de Lis by Bourbon.

STARLING, (Imp.) by Young Starling-Regulus-.-Snalse, Partnes \&c.-foaled 1756.-Va. 1762.

STANHOPE, ch. h. by Eclipse, dam Helen Mar by Rattler.

ST EEL, b. h. by (Imp.) Fylde, dam Diamond by Constitution.

STOCKHOLDER, b. h. by Sir Archy, dam by (Imp.) Citizen

ST. LEGER, gr. h. by Eclipse, dam (Ariel's dam,) by Finansies. 
ST. PAUL, (Imp.) sor. h. by Old Saltram, dam Purity by Matchem,

Pratt's famous Squirt mare, \&c.-foaled 1789.-Va. 1804.

STRAWBERRY ROAN, (see Fairfax Roan).

\section{Wm. Lightfoot.}

SWISS, (Imp.) b. h. by Whisker, dam by Shuttle.

SYMMETRY, ch. m. by (Imp.) Ainderby, dam Ellen Douglass br Bertrand.

T.

T\&RGET, ch. h. by (Imp.) Luzborough, dam Becky by Marquis.

T A. RLTON, b. h. by Woodpecker, dam by Robin Gray.

TARQUIN, br. h. by Henry, dam Ostrich by Eclipse.

- - h. by (Imp.) Luzborough, dam Hackabout by Timoleon. - (Imp.) h. by the Hampton-Court Chesnut Ar. our of Fair Rosamond by Cade-Traveller, \&c.-foaled 1720.

TELIE DOE, $m$. by Pacific, dam Matilda by Grey-tail Florizel.

TENNESSEE CITIZEN, ch. h. by Stockholder, dam Patty Puff by Pacolet.

THOMAS H. BENTON, br. h. by Waxy, dam Virginia by Matapone. TITRY, (Imp.) ch. m. by Langar, dam Zephyrina by Middlethorpe. TOBACCONIST, b. h. by Gohanna. dam Yankee Maid by Ball's Florizel.

TOM MOORE, h. by Contention, dam Pocahontas by Virginian. IORNADO, ch. h. by Eclipse, dam Polly Hopkins by Virginian.

TRANBY, (Imp.) br. h. by Blacklock, dam by Orville-Miss Grim. stone by Weazle-Ancaster, \&c.-foaled 1826.-Va. 1835.

TRIPIT, br. m. by Mars, dam by Post Boy.

J. J. Avery \& Co.

TRUFFLE, (Imp.) b. h. by Truffe, dam Helen by Whiskey.

TRUSTEE, (Imp.) ch. h. by Catton, dam Emma by Whisker.

v.

VALPARAISO, (Imp.) ch. h. by Velocipede, dam Julianna by Ge hanna.

VERTNER, ch. h. by Medoc, dam Lady Adams by Whipster

VERTUMNUS, b. h. by Eclipse, dam Princess by Defiance.

VICEROY, ch. h. by Eclipse, dam Saluda by 'Timoleon.

VOLCANO, b. h. by Stockholder, dam Forest Maid by Ratray.

VOLNEY, b. h. by Mons. Tonson, dam by Sir Archy. Phantom. (Imp.) b. h. by Velocipede, dam (Voltaire's dam,) by

\section{W.}

WACOUSTA, ch. h. by (Imp.) Leviathan, dam Lady Lightfoot by Oscar.

WARNER, ch. h. by Sir Charles, dam Maria West by Marion.

WASHENANGO, ch. h. by Timoleon, dam Arialne by (Imp.) Citizen.

WHALE, (Imp.) by Whalebone, (who was by Waxy,) dain Rectory hy Octavius-Catharine by Woodpecker.-N. Carolina.

Edward Townes.

WHALFBI)NE b. h. by Sir Archy, dam by Pacolet. 
CELEBRATED STALLIONS AND BROOD MARCs. 101

WILD BILL, b. h. by Sir Archy, dam Maria by Gallatin.

WILLLAM H. HARRISON, gr. h. by 'Trumpator, dam by Double head.

WILLIS, ch. h. by Sir Charles, daın by (Imp.) Merryfield.

WANDER, ch. h. by Monmouth Eclipse, dam Powancey by Alfred. WOODPECKER, b. h. by Bertrand, dam by (Im ə.) Buzzard.

\section{Y.}

ORKSHIRE, (Imp.) got by St. Nicholas, dam Miss Rose.

YOUNG GOHANNA, h. by Gohanna, dam by Pacolet.

R. D. Shepherd.

YOUNG MEDLEY, h. by Potomac, dam by Medley.

YOUNG TRAMP, (Imp.) h. by Barefoot, dam Isabella by Comus. YOUNG WONDER, h. by Cock of the Rock, dam Nell Sanders.

Z.

ZINGANEE, (Imp.) b. h. by Tramp, dam Folly by Young Drone. Chance.

\section{(Garrison's, ) b. h. by Sir Archy, dam Atalanta by (Imp.)}


WEC 8 iü 


LIBRARY OF CONGRESS

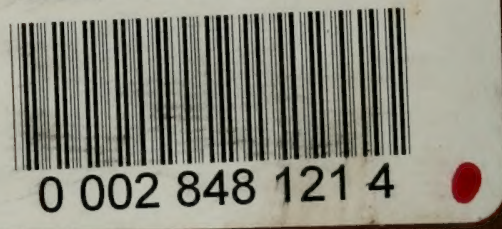

